Cochrane Database of Systematic Reviews

\title{
Paying for performance to improve the delivery of health interventions in low- and middle-income countries (Review)
}

Diaconu K, Falconer J, Verbel Facuseh AV, Fretheim A, Witter S

Diaconu K, Falconer J, Verbel Facuseh AV, Fretheim A, Witter S.

Paying for performance to improve the delivery of health interventions in low- and middle-income countries.

Cochrane Database of Systematic Reviews 2020, Issue 12. Art. No.: CD007899.

DOI: 10.1002/14651858.CD007899.pub3.

www.cochranelibrary.com

Paying for performance to improve the delivery of health interventions in low- and middle-income countries (Review) 
TABLE OF CONTENTS

HEADER 1

ABSTRACT

PLAIN LANGUAGE SUMMARY

SUMMARY OF FINDINGS

BACKGROUND

OBJECTIVES

METHODS

RESULTS

Figure 1.

Figure 2.

Figure 3.

DISCUSSION

AUTHORS' CONCLUSIONS

ACKNOWLEDGEMENTS

REFERENCES

CHARACTERISTICS OF STUDIES

ADDITIONAL TABLES

APPENDICES

FEEDBACK

WHAT'S NEW

HISTORY

CONTRIBUTIONS OF AUTHORS

DECLARATIONS OF INTEREST

SOURCES OF SUPPORT

DIFFERENCES BETWEEN PROTOCOL AND REVIEW 
[Intervention Review]

\section{Paying for performance to improve the delivery of health interventions in low- and middle-income countries}

Karin Diaconu ${ }^{1}$, Jennifer Falconer ${ }^{1}$, Adrian V Verbel Facuseh ${ }^{2}$, Atle Fretheim ${ }^{3,4}$, Sophie Witter ${ }^{1}$

1Institute for Global Health and Development, Queen Margaret University, Edinburgh, UK. 2Evidence-based Insurance Medicine, University Hospital Basel, Basel, Switzerland. ${ }^{3}$ Institute of Health and Society, University of Oslo, Oslo, Norway. ${ }^{4}$ Norwegian Institute of Public Health, Oslo, Norway

Contact address: Karin Diaconu, kdiaconu@qmu.ac.uk.

Editorial group: Cochrane Effective Practice and Organisation of Care Group.

Publication status and date: New search for studies and content updated (conclusions changed), published in Issue 12, 2020.

Citation: Diaconu K, Falconer J, Verbel Facuseh AV, Fretheim A, Witter S. Paying for performance to improve the delivery of health interventions in low- and middle-income countries. Cochrane Database of Systematic Reviews 2020, Issue 12. Art. No.: CD007899. DOI: 10.1002/14651858.CD007899.pub3.

Copyright @ 2020 The Cochrane Collaboration. Published by John Wiley \& Sons, Ltd.

\section{A B S T R A C T}

\section{Background}

There is a growing interest in paying for performance as a means to align the incentives of health workers and health providers with public health goals. While the volume of schemes implementing paying for performance has increased over the last decade, rigorous evidence on the effectiveness of these strategies in improving health care and health, particularly in low- and middle-income countries is lacking. This is an update on the 2012 review on this topic, which had identified a limited evidence base from which to draw conclusions.

\section{Objectives}

To summarise the current evidence for the effects of paying for performance on the provision of health care and health outcomes in lowand middle-income settings.

\section{Search methods}

We searched more than 15 databases in 2018, including the Cochrane Central Register of Controlled Trials (CENTRAL) (2018, Issue 3), the Cochrane Effective Practice and Organisation of Care (EPOC) Group Specialised Register (10 April 2018), MEDLINE, Ovid (1946 to Present) (searched 10 April 2018), EMBASE, Ovid (10 April 2018), WHOLIS, VHL (April 2018), CINAHL, EBSCOhost (1981 to present) (April 2018), Global Health, Ovid (27 April 2018), The Grey Literature Report (June 2018) and OpenGrey (June 2018). We also searched the websites and online resources of numerous international agencies, organisations and universities to find relevant grey literature and contacted experts in the field. Relevant studies identified from rerunning the strategies in 2020 are placed under Studies awaiting classification.

\section{Selection criteria}

We included randomised or quasi-randomized trials, controlled before-after studies or interrupted time series studies conducted in lowor middle-income countries (as defined by the World Bank in 2018). Pay for performance refers to the transfer of money or material goods conditional on taking a measurable action or achieving a predetermined performance target. To be included, a study had to report at least one of the following outcomes: changes in targeted measures of provider performance, such as the delivery or utilisation of healthcare services, or patient outcomes, unintended effects and/or changes in resource use.

\section{Data collection and analysis}

We extracted data as per original review protocol and narratively synthesised findings. We used standard methodological procedures expected by Cochrane. Given diversity and variability in intervention types, patient populations and analyses and outcome reporting, 
meta-analysis was deemed inappropriate. Within the review, we note the range of effects associated with P4P against each outcome of interest.

\section{Main results}

We included 59 studies in this update. Evaluations were predominantly controlled before and after studies or quasi randomized trials, however we also identified cluster randomized trials and interrupted time-series studies.

Studies focused on a wide range of paying for performance (P4P) interventions, including target payments and payment for outputs as modified by quality (or quality and equity assessments). Only one study assessed results-based aid. The majority of assessed schemes were funded by the World Bank. Targeted services varied, however most of the interventions focused on indicators related to reproductive, maternal and child health. Participants were predominantly located in public or in a mix of public, non-governmental and faith-based facilities. The assessment of P4P was predominantly at health facility level, though districts and other levels were also involved.

The majority of studies assessed the effects of paying for performance (P4P) against a status quo control (49 studies); however, some studies focused on assessing effects against comparator interventions (predominantly enhanced financing intended to match P4P funds, based on 17 studies). Four studies reported on intervention effects against both comparator and status quo.

In relation to utilization and service delivery outcomes, we identify inconsistent effects overall.

P4P may have slight positive impacts on the majority of health outcomes appraised against a pure control or standard care; however, when compared against other interventions such as enhanced financing, limited to no impacts were identifiable. P4P probably increases quality of care overall, particularly when directly targeted by scheme designs, and may have positive impacts on the availability of medicines, equipment and infrastructure. However, we found limited to uncertain effects on general quality of care indicators such as providers conducting background or physical assessments, or counselling patients. P4P probably has limited to no negative distorting unintended effects, however these were assessed in a minority of studies.

For secondary effects, we note mixed effects on health worker variables, such as motivation. The evidence suggests the intervention may increase managerial autonomy, but have limited effects on quality of management or governance in general. Equity effects are also uncertain: when assessed against a pure control, P4P appears may have largely beneficial redistributive effects, but when assessed against a comparator the evidence appears mixed. Effects on user fees are also unclear.

\section{Findings of sub-group analyses:}

Based on intervention descriptions provided in reviewed documents, we classified the various designs schemes used and explored variation in effect by scheme design. Performance based contracting and results-based aid appeared to yield the greatest positive effects upon outcomes overall. However, we note that these scheme designs were used in a minority of schemes and studies, so the effects observed may be spurious.

Overall, schemes adjusting both for quality of service as well as rewarding equitable delivery of services appeared to perform best, particularly in relation to service utilization outcomes. Similarly, schemes employing payments per output with a quality adjustment, or combining a payment per output and target payment, appeared to outperform the payment per output and target payment designs.

\section{Authors' conclusions}

The evidence base on the impacts of P4P schemes has grown considerably, with study quality gradually increasing. We have identified mixed effects of P4P schemes on outcomes of interest and further noted high heterogeneity in the types of schemes implemented as well as evaluations conducted. Performance based funding is not a uniform intervention, but rather a range of approaches. Its effects depend on the interaction of several variables, including the design of the intervention (e.g. who receives payments, the magnitude of the incentives, the targets and how they are measured), the amount of additional funding, other ancillary components such as technical support, and contextual factors, including the organisational context in which it is implemented.

\section{PLAIN LANGUAGE SUMMARY}

\section{Paying for performance to improve the delivery of health interventions in low- and middle-income countries}

Researchers in the Cochrane Collaboration conducted a review of the effects of paying for performance on the delivery of healthcare services in low- and middle-income countries.

After searching for all relevant studies, they found 59 studies that met their requirements. The findings of this review are summarised below.

What is pay for performance? In a 'pay for performance' approach, people are given money or other rewards if they carry out a particular task or accomplish a particular target. This approach is usually directed at health workers or healthcare organisations. Health workers and healthcare organisations may be rewarded if they offer particular services, if they deliver care that is of a certain quality, or if their patients make use of particular services and achieve better health as a result. 


\section{What happens when health workers and healthcare organisations are paid for performance?}

The review authors searched literature up to 2018 and identified 59 studies which answer this research question. The studies originated from a wide range of countries, however the majority were from Sub-Saharan Africa and Asia. The pay for performance schemes which were reviewed were predominantly funded by the World Bank. Overall, the majority of studies included were of low to moderate quality. 49 studies compared the effects of paying for performance against doing business as usual (a so-called status quo) and 17 compared effects against a different type of intervention (usually providing matched funding to facilities not implementing pay for performance); these figures include the four studies for which both a status quo comparison and alternate intervention comparison where reported. The pay for performance scheme designs varied greatly, however the majority involved paying health facilities for providing a service and for the quality of service. Overall, the review notes that paying health workers and healthcare organizations for performance is likely to have some positive effects: it may lead to increased uptake of some health services, better structural quality of care, and strengthen the availability of resources and of management autonomy in healthcare organizations. Effects on health, equity, provider satisfaction, facility governance, procedural aspects of quality of care and financial access for users are uncertain. 


\section{S U M MARY OF FINDINGS}

\section{Summary of findings 1. Comparison 1: Summary of findings on effects of paying for performance against standard} care

$\begin{array}{lll}\text { Outcome Summary of impacts } & \begin{array}{l}\text { Certainty of the evi- } \\ \text { dence (GRADE)* }\end{array}\end{array}$

\section{Review primary outcomes}

Utilization and delivery of health services
Evidence on the effects of P4P on the utilization and delivery of services is largely inconsistent: the intervention may improve some utilization and delivery indicators but may lead to poorer results for other indicators.

When targeted:

- Proportion of persons receiving HIV testing (range 6-600\%) and delivery of PMTCT (range 3.8 to $21 \%$ ) may be affected positively; proportion of persons receiving ART and children (up to $120 \%$ decline) and households protected with bednets may decline (up to $7.3 \%$ );

- effects on tuberculosis adherence are uncertain given very low certainty evidence;

- effects on family planning outreach may be positive (moderate certainty evidence, increase up to $300 \%)$

- Evidence on mother and child immunizations and antenatal care utilization is mixed.

Effects on indicators when they are not targeted are largely uncertain or neutral.
The effects of the intervention on procedural quality of care are largely uncertain. Overall, effects on quality of care indicators appear to be sustained only when indicators are targeted.

Indicators for which moderate certainty evidence was found include:

- P4P probably improves quality of care scores (range 5 to $300 \%$ relative increases);

- P4P probably improves the quality scores of available medicine and equipment, effects ranged from $2.7 \%$ to $220 \%$;

- Overall quality of service by specific departmental area/service: P4P probably improves the average quality of service scores in specific targeted areas (effects ranged from $39 \%$ to 15 -fold increase in scores).

P4P may make little or no difference to staff knowledge and skills (low certainty evidence), and its effects on staff responsiveness (as observed by researchers/P4P scheme verifiers) are uncertain overall (very low certainty evidence.)

\footnotetext{
Health outcomes When targeted:

- P4P may reduce child mortality (range: $0.2-6.5 \%$ );

- P4P may lead to a modest reduction of $2-3 \%$ in the proportion of children with reported anaemia;

- P4P may increase the likelihood of tuberculosis treatment success (range: $12-20 \%$ improvement in treatment success).

- Evidence neonatal mortality is inconsistent: P4P may have desirable effects and ensure reduction in neonatal mortality in implementing clinics by up to $22 \%$ in one study, however, another study identified increases in region of $6.5 \%$ across catchment areas of P4P incentivized providers.
} 
Changes in resource use
Overall certainty in evidence across indicators is low, for those where moderate certainty observed:

- P4P probably has a positive effect on human resource availability (range: $19-44 \%$, moderate certainty evidence).

- P4P probably affects infrastructure functionality and medicine availability positively.

\section{Review secondary outcomes}

Provider motivation, satisfaction, absenteeism and acceptability
P4P probably makes little or no difference to provider absenteeism (range: $0.7-2 \%$, low certainty evidence). Effects on overall motivation scores and satisfaction are largely neutral (low certainty evidence).

Where these outcomes were not directly targeted, the intervention may have desirable effects.

\section{Patient satisfaction} and acceptability
P4P may have desirable effects on targeted outcomes, with only two outcomes noting limited to no effect in relation to the intervention (satisfaction with care quality and provider communication). When not targeted, effects may be largely positive, except for satisfaction with provider-patient contact time and facility opening hours.

\section{Impacts on manage- ment or information systems (if not a tar- geted measure of performance)}

P4P may positively affect facility managerial autonomy (low certainty evidence), $\quad \oplus \oplus \ominus \ominus \quad$ Low probably makes little to no difference to management quality or facility governance.
Equity considerations: evidence of differential impacts on different parts of the population

\section{When targeted: P4P may increase the proportion of poor persons utilizing child im-} munization services, however the intervention may potentially decrease the proportion of poor persons utilizing antenatal care. P4P may make little to no difference to the utilization of institutional deliveries by poorest groups.

If not explicitly targeted, effects are mixed.

* GRADE ratings here refer to summative judgments of the authors across multiple outcomes. Please see Table 1 for a detailed account of all outcomes and relevant evidence ratings.

\section{Summary of findings 2. Comparison 2: Summary of findings on effects of paying for performance against comparator interventions}

\begin{tabular}{|c|c|c|}
\hline Outcome & Summary of impacts & $\begin{array}{l}\text { Certainty of the evi- } \\
\text { dence (GRADE)* }\end{array}$ \\
\hline
\end{tabular}

\section{Review primary outcomes}

Utilization and delivery of health services
P4P may positively affect the probability of persons utilizing care (range: 2 to $10 \%$, however, evidence on immunization utilization is indicative of little to no effect or uncertain.

P4P may have little to no important effect on the utilization of any family planning services or the overall rates of antenatal care utilization; however, P4P may positively affect the timeliness of ANC care-seeking (range: 1 to 10\% women accessing care earlier).

Evidence on the effects of P4P on \% women utilizing institutional deliveries is uncertain (range between $-9 \%$ and $23 \%$ ). 
P4P may have negative effects on postnatal care utilization.

Evidence on effects on non-targeted utilization outcomes is sparse.

\begin{tabular}{|c|c|c|c|}
\hline Quality of care & $\begin{array}{l}\text { P4P probably leads to improved quality of care in relation to family planning or an- } \\
\text { tenatal care (moderate certainty evidence, range). } \\
\text { P4P may also increase procedural care quality, e.g. increasing the proportion of staff } \\
\text { conducting appropriate patient background and physical assessments during con- } \\
\text { sultations. }\end{array}$ & $\oplus \oplus \ominus \ominus$ & Low \\
\hline Health outcomes & $\begin{array}{l}\text { P4P may have little to no effect on health outcomes, both when targeted and when } \\
\text { not targeted. }\end{array}$ & $\oplus \oplus \ominus \ominus$ & Low \\
\hline $\begin{array}{l}\text { Changes in resource } \\
\text { use }\end{array}$ & $\begin{array}{l}\text { P4P may increase equipment availability by } 75 \% \text {, however medicine availability } \\
\text { may be reduced by up to } 160 \% \text {. }\end{array}$ & $\oplus \oplus \ominus \ominus$ & Low \\
\hline
\end{tabular}

\section{Review secondary outcomes}

\begin{tabular}{|c|c|c|c|}
\hline $\begin{array}{l}\text { Provider motivation, } \\
\text { satisfaction, absen- } \\
\text { teeism and accept- } \\
\text { ability }\end{array}$ & $\begin{array}{l}\text { We did not identify studies assessing directly targeted indicators for this outcome. } \\
\text { Available evidence suggests that paying for performance may make little to no dif- } \\
\text { ference to these outcomes. }\end{array}$ & $\oplus \oplus \ominus \ominus$ & Low \\
\hline $\begin{array}{l}\text { Patient satisfaction } \\
\text { and acceptability }\end{array}$ & $\begin{array}{l}\text { We did not identify studies assessing directly targeted indicators for this outcome. } \\
\text { Available evidence suggests desirable effects on cleanliness, waiting and contact } \\
\text { time indicators, but the intervention may make little to no different to overall pa- } \\
\text { tient satisfaction scores. }\end{array}$ & $\oplus \oplus \ominus \ominus$ & Low \\
\hline $\begin{array}{l}\text { Impacts on manage- } \\
\text { ment or information } \\
\text { systems (if not a tar- } \\
\text { geted measure of } \\
\text { performance) }\end{array}$ & $\begin{array}{l}\text { Where indicators have been targeted, paying for performance may have desirable } \\
\text { effects. For untargeted outcomes, effects are uncertain due to very low certainty ev- } \\
\text { idence. }\end{array}$ & $\oplus \oplus \ominus \ominus$ & Low \\
\hline $\begin{array}{l}\text { Equity considera- } \\
\text { tions: evidence of dif- } \\
\text { ferential impacts on } \\
\text { different parts of the } \\
\text { population }\end{array}$ & $\begin{array}{l}\text { The intervention may have little or no effect on equity or may worsen equity, for ex- } \\
\text { ample, paying for performance may lead to increased utilization of family planning } \\
\text { services and institutional deliveries among wealthier population groups. }\end{array}$ & $\oplus \oplus \ominus \ominus$ & Low \\
\hline
\end{tabular}

* GRADE ratings here refer to summative judgments of the authors across multiple outcomes. Please see Table 2 for a detailed account of all outcomes and relevant evidence ratings. 


\section{B A C K G R O U N D}

\section{Description of the condition}

Improving the performance of healthcare delivery systems is an important objective, both in high-income settings and, even more critically, in low- and middle-income country (LMIC) settings, where resources for health are much more constrained. Performancebased payment (P4P) has for more than a decade now received increased attention as a strategy for improving the performance of healthcare providers, organisations and governments. It is also promoted as an important tool for wider health system reforms (Meessen 2011, Soucat 2017). However, the last Cochrane Review found limited rigorous evidence on its effectiveness (Witter 2012) and while there has been a growth in studies of P4P since that review, there is a gap in relation to synthesised evidence of its effectiveness in different contexts and for different services in LMICs .

\section{Description of the intervention}

Pay for performance refers to the transfer of money or material goods conditional on taking a measurable action or achieving a predetermined performance target (Eichler 2006). Paying for performance is also sometimes referred to as results-based financing (RBF), performance-based funding (PBF) and outputbased aid (OBA). While paying for performance is a relatively simple concept, it includes a wide range of interventions that vary with respect to the level at which the incentives are targeted (recipients of health care, individual providers of health care, healthcare facilities, private sector organisations, public sector organisations and national or sub-national levels) and the type of reward (payment based on fee-for-service, other monetary payments and non-monetary rewards) (Musgrove 2011). Paying for performance interventions can also reward a wide range of measurable actions, including health outcomes, delivery of effective interventions (for instance, immunisation), utilisation of services (such as prenatal visits or births at an accredited facility) and quality of care. Paying for performance interventions typically also include ancillary components such as increasing the availability of resources to health care, education, supplies, technical support or training, monitoring and feedback, increasing health worker pay, construction of new facilities, improvements in planning and management or information systems etc (Oxman 2008).

While it is conceivable that pay increases designed to increase motivation and retention of staff might fall within this definition, in this review we focus on reforms which are explicitly linked to changing patterns of activity, output or outcome indicators (thus excluding routine changes to pay or public funding flows, or user fee regimes). Another systematic review has addressed the use of conditional cash transfers for service users (demandside paying for performance) for improving the uptake of health interventions in LMICs (Lagarde 2011, currently being updated). This review therefore focuses on updating the evidence originally appraised by Witter and colleagues in 2012 of the impacts of supplyside paying for performance aimed at improving the delivery of health interventions (New Reference). In this review, paying for performance includes both paying for performance schemes (including ancillary components) and paying for performance per se (where any ancillary components are controlled for).

\section{How the intervention might work}

Paying for performance by individuals is not new - it has taken the form of user fees, and in many low- and middle-income countries it remains one of the main forms of health financing. However, public funding for health has commonly taken the form of budget flows, which are linked to indicators such as staffing levels or bed numbers (for facilities), inputs (such as estimated drug needs), population numbers (for regions and districts, in some cases) and also historical trends in expenditure (all modified by overall budget constraints).

These bureaucratic mechanisms offer the advantage of stability and predictability, and rely on local clinical judgement as to how and what services to offer. The disadvantage, however, is that health systems based on budget funding and salaried staff can lack incentives to improve quality, to increase outputs and to improve outcomes. Paying for performance aims to reintroduce those incentives by linking pay (at individual or facility level) to desired activities and/or outcome indicators. It may in addition increase resources (by providing supplementary funding) or may be an alternative mechanism for channelling existing funding resources (substituting for existing funds).

In Organisation for Economic Co-operation and Development (OECD) countries, paying for performance is generally described as a tool for improving performance and accountability (Christianson 2007, Cashin 2014). In LMICs, however, it can has wider objectives (Witter 2009; Witter 2013). These include

- to increase the allocative efficiency of health services (by encouraging the provision of high-priority and cost-effective services);

- to increase the technical efficiency (by making better use of existing resources such as health staff);

- to improve equity of outcomes (for example, by encouraging expansion of services to hard-to-reach groups).

Others emphasise the potential of paying for performance to transform health sectors, introducing client-oriented public finance models inspired by the new public management mode (Meessen 2011). A review of the potential mechanisms of change for P4P emphasises their complexity, the lack of consensus on how P4P might work, and the importance of local norms and values in how P4P will function (Renmans 2016).

Paying providers for performance is clearly premised on the assumption that a change in behaviour on the provider side is required for allocative and technical efficiency and equity of outcomes to change. However, if substantive demand-side barriers exist (such as low affordability of services), then paying for performance for providers alone will not be effective.

Paying providers for performance in LMICs can operate at a number of levels. It can be offered directly to community health workers or to professional health workers (in public, private or private notfor-profit sectors) or to facilities. It can be used to set budgets or supplement budgets at higher organisational units, such as health districts or regions. It can also be used at national level, in particular by donor organisations negotiating aid to a national health sector. Clearly, incentives would be expected to operate differently at these different levels: incentives to individuals are likely to be 
more directly motivating (incentives to organisations only affect behaviour indirectly, if passed on in some way to individuals), but may undermine cooperation (unlike organisational incentives, which might be expected to reinforce co-operation).

It seems intuitive that paying more money for the delivery of effective services will improve health care, but health care does not operate like a classic free market. Human behaviour is complex and there are many theories that attempt to explain both health behaviour and professional behaviour. Principal-agent theory addresses relationships where one individual (the patient) cannot directly observe or know the level of skill or effort expended by the other individual (the professional) doing the contracted work. Patients do not have perfect knowledge of their medical condition, their need for care, or the expected outcome of healthcare services. They therefore are willing to have healthcare professionals act as their agents in providing information and services and patient demand for health care may be unresponsive to technical quality. One theoretical advantage of performance pay is that explicit financial incentives are provided even when patient demand for health care is unresponsive to quality. In other words, professional effort in providing high quality is rewarded, regardless of whether patients recognise it. This theoretical advantage relies, however, on a host of assumptions, including the ability to assess quality, the linkage of paying for performance systems with quality measures, and the absence of adverse consequences. Moreover, as indicated above, in LMICs in particular, paying for performance is being deployed for a wide range of reasons other than improving quality. It is envisaged more ambitiously as a tool to increase the responsiveness of staff and the health system generally to priority areas, and in some settings is the main funding mechanism for primary care (Witter 2019).

It is also important to note that although financial incentives and healthcare payment systems are likely to have an important influence on professional behaviour, this influence is far from exclusive. In economic terms, professionals are viewed as maximising their utility function (i.e. their well-being). Important factors in their utility function, besides income, include professional and social status (or self-image), altruism (doing what they perceive to be best for their patients), the burden of efforts to change their behaviour, and their uncertainty about the benefits of changing their behaviour. Moreover, there may be other barriers to changing professional behaviour, even when professionals are motivated, including patient factors, lack of time, lack of technical skills, lack of resources and organisational constraints.

It is generally accepted that professionals are motivated by the satisfaction of doing their jobs well (intrinsic motivation). Indeed, it is doubtful whether some valued-but-difficult-to-observe dimensions of quality (such as empathy or listening in the medical encounter) would be provided at all if physicians were solely interested in income. Health professionals therefore have both monetary and non-monetary incentives, all of which affect their performance. It is possible that financial incentives may dilute professionals' intrinsic motivation and this is the subject of widespread debate around public sector motivation in higherincome countries (Marquand 2004). Psychological studies also highlight the risks to intrinsic motivation of extrinsic rewards (Deci 1999). The risk of coercion for patients - for example, when specific family planning methods are incentivised - is also highlighted by some studies (for example, Blacklock 2016). On the other hand, where health workers' pay is low in absolute terms, incentives may be an important channel to improve motivation through increasing their income levels. There is a small but growing literature on the effects of pay for performance (P4P) on provider motivation, the results of which are so far ambiguous (for example, Dale 2014), highlighting the importance of understanding different contexts and models.

The timescale of evaluation is another important consideration. Financial incentives might be effective in the short run for simple and distinct, well-defined behavioural goals, but these are not necessarily sustained in the longer run. Some studies have now focused on the period after the end of P4P programmes, giving a longer-term perspective on their effects (Huillery 2014). Paying for performance schemes are often accompanied by ancillary features, such as training initiatives and enhanced supervision arrangements. When paying for performance schemes including these features are compared to no intervention, it may be impossible to disentangle the impact of paying for performance per se from the impact of these ancillary components. It is also important to capture systemic effects, where possible: P4P is increasingly recognised to be a complex package of measures, influenced by and potentially influencing the wider health system (Witter 2013).

\section{Why it is important to do this review}

The first systematic review of the impacts of supply-side paying for performance in LMICs was published in 2012, and found the evidence base to be weak. Since then the number of $\mathrm{P} 4 \mathrm{P}$ programmes in LMICs has expanded considerably, as have the number of studies examining different aspects of these programmes. In particular, the World Bank-managed Health Results Innovation Trust Fund has spent 307.1 million USD on programs in 28 countries and supported 24 impact evaluations alongside these programs (RBF Health 2020). With this growth in interest, funding and potentially robust studies, it is timely to review the evidence base.

While reviews of schemes in high-income countries can help to inform decisions in LMICs, there are several reasons for undertaking a review of the impacts of paying for performance in LMICs specifically. The potential benefits, harms and costs of paying for performance may be greater in LMICs, where there are fewer resources than in high-income countries, weak health systems, inadequate supplies, facilities and human resources, and greater inequities, and where paying for performance schemes are often introduced by donors and include ancillary components, such as increased resources and technical support.

Paying for performance is a complex intervention with uncertain benefits and potential harms. It may, for example, lead to the concentration of resources in areas where targets are easier to meet (which typically are better served areas), thus increasing inequity of provision, or lead to neglect of unincentivised services. The extent to which benefits attributed to paying for performance in LMICs are attributable to conditionality (versus ancillary components of paying for performance schemes in LMICs, such as increased resources and technical support) is also uncertain. Paying for performance may not be a good use of resources, even when it is effective, due to potentially small effects and high costs. For these reasons an updated systematic review of evaluations of the impacts of paying for performance is needed to inform decisions about 
whether and when to use paying for performance, how to design these schemes, and how to monitor and evaluate them in LMICs.

\section{O B JE C T IVES}

To assess the effects of paying for performance on the provision of health care and health outcomes in low- and middle-income countries.

\section{METHODS}

\section{Criteria for considering studies for this review Types of studies}

A brief outline of inclusion and exclusion criteria follows; a full list of exclusion reasons is available in Appendix 1.

\section{Types of studies}

The review includes:

- Randomised trials

- Non-randomised trials (experimental studies in which people are allocated to different interventions using methods that are not random)

- Controlled before-after (CBA) studies where:

- at least two clusters are included in each comparison group;

- pre and post intervention periods for study and control groups are the same;

- choice of the control site is appropriate: i.e. sites have similar socio-economic characteristics and/or there are no major differences evident in the baseline groups.

- Interrupted time series (ITS) studies with at least three measurements before and after introducing the intervention

Well-designed cluster-randomised trials protect against selection bias and are likely to provide the most rigorous estimates of the impacts of paying for performance schemes. However, cluster randomised trials may not be practical for evaluating some paying for performance schemes (e.g. when there is simultaneous systemwide implementation). Although CBA studies are often at high risk of bias, we believe it is important, at least at this time, to include these studies. ITS studies may be problematic due to changes in information systems and the reliability of information systems used in paying for performance schemes in LMICs. However, they potentially have a lower risk of bias than CBA studies. Other study designs may provide useful information about acceptability, potential effects or explanations for observed effects of paying for performance, but are unlikely to provide useful estimates of the impact of paying for performance on the main outcomes of this review.

\section{Types of participants}

Participants in P4P schemes include providers of healthcare services (health workers and facilities), sub-national organisations (health administrations, non-governmental organisations or local governments), national governments and combinations of these.
All sectors (public, private and private not-for-profit) have been included in the review.

\section{Types of interventions}

Paying for performance takes three main forms.

- Conditional cash payment

- Conditional provision of material goods

- Target payments (payments for reaching a certain level of coverage, which can be defined in absolute terms or relative to a starting point)

We have included evaluations of paying for performance schemes (including ancillary components), compared to any alternative (including non-conditional financial incentives and different levels of conditional financial incentives). We have included comparisons with alternatives where there may be differences in ancillary components, such as increased resources, as well as differences in paying for performance.

We have excluded studies in which:

- The primary focus of the financing scheme is the demandside of healthcare (e.g. conditional cash transfers targeted at specific population groups) or where demand-side interventions are purposefully run concurrently with a P4P intervention but effects of the latter cannot be untangled.

- Payment to health workers or facilities not explicitly linked to changing patterns of performance (e.g. for coming to work; salary increases; routine increases in activity-based payments such as Diagnosis-Related Groups (DRGs) or fees for service; or changes to budget flows which are routine or intended to motivate, but without being conditional on specific activity or output measures)

Studies for which full-texts could not be obtained have been identified as such under Studies awaiting assessment.

\section{Types of outcome measures}

\section{Primary outcomes}

To be included, a study must report at least one of the following outcomes:

- Patient health outcomes (for example mortality rates, treatment success);

- Changes in targeted measures of provider performance, such as the utilization, delivery or quality of healthcare services;

- Unintended effects, including motivating unintended behaviours, distortions (ignoring important tasks that are not rewarded with incentives), cherry-picking/cream-skimming (prioritising patients that are most profitable over those who release fewer financial rewards), gaming (improving or cheating on reporting rather than improving performance), increased inequities and dependency on financial incentives

- Changes in resource use, including for incentives, administration and services 


\section{Secondary outcomes}

The following outcomes are included if reported in included studies or in publications or reports ancillary to the main impact evaluation:

- Impacts on provider motivation, satisfaction, absenteeism and acceptability

- Impacts on patient satisfaction and acceptability (such as satisfaction scores)

- Impacts on overall financing or resource allocation

- Impacts on management or information systems (if not a targeted measure of performance)

- Equity-consideration: evidence of differential impact on different parts of the population

Given the focus on effectiveness, the results of qualitative studies conducted alongside impact evaluations have not been included. However, we have included estimates of health economic evaluations conducted alongside impact evaluations as they report on changes in resource use linked to P4P schemes.

\section{Search methods for identification of studies}

\section{Electronic searches}

Searches for all studies were carried out in 2018 and then updated in 2020. Studies from the initial 2018 search are incorporated in this review. Studies identified in subsequent search updates have been marked as relevant and are listed under Studies awaiting classification.

We searched the following electronic databases:

- The Cochrane Central Register of Controlled Trials (CENTRAL) 2018, Issue 3, part of the Cochrane Library (www.thecochranelibrary.com) including the Cochrane Effective Practice and Organisation of Care (EPOC) Group Specialised Register (searched 10 April 2018)

- MEDLINE, Ovid Epub Ahead of Print, In-Process \& Other NonIndexed Citations, MEDLINE Daily and MEDLINE, Ovid (1946 to Present) (searched 10 April 2018)

- EMBASE, Ovid (1974 to 2018 April 09) (searched 10 April 2018)

- PsycINFO, Ovid (1806 to April Week 12018 )

- EconLit, EBSCOhost (1886 to present) (searched 27 April 2018)

- LILACS, VHL (searched 10 April 2018)

- WHOLIS, VHL (searched 10 April 2018, not updated as no results retrieved in previous search)

We revised the original review protocol to expand the number of databases searched. For this review update, we also searched:

- CINAHL, EBSCOhost (1981 to present) (searched 10 April 2018)

- 3ie Database of Impact Evaluations (searched 7 June 2018)

- BLDS British Library for Development Studies (searched 18 June 2018)

- Global Health, Ovid (1973 to 2018 Week 15) (searched 27 April 2018)
Two grey literature databases (The Grey Literature Report, and OpenGrey) and two clinical trials databases (ICTRP (WHO) and ClinicalTrials.gov) were searched in June 2018.

We did not search International Pharmaceutical Abstracts, so it is possible that studies relating to pharmaceuticals were missed. However, the general searches, including in websites focused on this topic, did not suggest that we had missed any relevant studies.

We developed strategies that incorporated the methodological component of the EPOC search strategy combined with selected index terms and free-text terms. The updated search strategy incorporated new terms recently cited in the literature to describe pay for performance interventions. We placed no language or date restrictions on the search strategy. We translated the MEDLINE search strategy into the other databases using the appropriate controlled vocabulary; filters related to study design and setting (low- and middle-income countries) were applied.

The full search strategies for all databases are included in Appendix 2.

\section{Searching other resources}

We contacted international experts in the field, including the authors of relevant articles that were retrieved. We asked them to identify additional websites, experts, academic (or other) institutions active in this field, as well as additional relevant studies.

In addition, the websites of organisations likely to be active in the field were searched in May and June 2018 (and checked for update in November-December 2020), including: the World Bank and RBFHEALTH, the African Development Bank, the Inter-American Development Bank, U.S. Agency for International Development (USAID), Cordaid, Management Sciences for Health (MSH), Centre for Global Development, World Health Organization (WHO), Swiss Tropical and Public Health Institute (Swiss TPH), Deutsche Gesellschaft für Technische Zusammenarbeit (GTZ), KfW Entwicklungsbank, Department for International Development (DFID), The Global Alliance for Vaccines and Immunization (GAVI), The Global Fund to Fight AIDS, Tuberculosis and Malaria, Asian Development Bank and Pan American Health Organization (PAHO).

In 2018 (and for the 2020 update), we additionally searched the websites of academic institutions active in this field, such as the London School of Hygiene and Tropical Medicine, the Harvard School of Public Health, University of Cape Town, Institute of Policy Studies of Sri Lanka (IPS), the Kenya Institute of Policy Analysis and Research (IPAR) and Institute of Tropical Medicine, Belgium. Given the sparse results obtained from these sources, we revised the list of websites to be searched for updates in December 2019. Updated searches included websites of the University of Heidelberg, University of Bergen and University of Rotterdam.

We additionally conducted a Web of Science citation search for the studies included in the review and checked references from included studies and other relevant articles, to identify other relevant studies that met the inclusion criteria.

\section{Data collection and analysis}

\section{Selection of studies}

Two authors independently screened abstracts in order to identify studies which met the inclusion criteria. We then retrieved studies

Paying for performance to improve the delivery of health interventions in low- and middle-income countries (Review) 
which were selected as meeting or possibly meeting the criteria in full and two authors again checked them independently in order to produce a final list of included studies.

\section{Data extraction and management}

Data extraction was carried out by one author using a modified version of the Cochrane EPOC Group data collection checklist; a second reviewer independently verified all extractions. Disagreements were settled by discussion.

A data extraction template is available in Appendix 3. Among others, we extracted data on: the performance based financing scheme (including P4P scheme type, targeted sectors and levels, scope and funding source of the scheme, relative and absolute magnitude of incentives, verification mechanisms and ancillary components), study design and setting, study participants, study methods (including units of allocation and analysis, data sources, power calculations, analytic methods), outcome measures (as prespecified above) and associated results, and comments by authors on interpretation of findings.

\section{Assessment of risk of bias in included studies}

Two authors independently used criteria recommended by the Cochrane EPOC Group to assess the risk of bias for each main outcome in all studies included in the review (EPOC 2017a).

\section{Measures of treatment effect}

For randomised and non-randomised trials and CBA studies, we recorded the effect estimates reported by investigators. Most commonly reported were the relative effects of the intervention obtained from difference in difference regression models adjusting for multiple covariates and confounders. These relative effects were reported in the form of regression betas, however measures of precision (confidence intervals, standard errors or deviations) were frequently not reported. For all such betas, we opted to re-calculate a more easily interpretable relative effect measure denoting the attributable \% change in an outcome indicator due to the intervention in comparison to the control group baseline mean: i.e. we divide the effect estimate beta by control group mean and multiply by 100 to obtain a \% change in outcome attributable to the intervention. Throughout, we therefore report this relative effect measure, rather than absolute percentage point differences.

If papers with CBA design did not provide an appropriate analysis or reporting of results, but presented the data for each district/ region in the intervention and control groups respectively, we reanalysed the data using a difference-in-difference design. We created a dataset with the same number of events and non-events per district/region pre- and post-intervention as reported in the paper. We estimated the post intervention relative risk for the event (intervention relative to control), adjusted for the difference in risk between intervention and control pre-intervention, and pre-versus post intervention (underlying trend). In line with the above, we estimated the relative effect of the intervention as pr above.

For ITS studies we recorded changes in level and in slope. If papers with ITS design did not provide an appropriate analysis or reporting of results, but presented the data points in a graph or in a table that could be scanned or file as supplied by authors, we reanalysed the data using methods described in the Cochrane EPOC group guidance (EPOC 2017b). Specifically, we used piecewise linear regression and estimated post-interruption changes in level and slope using the ITSA add-on command for STATA 15. For multiple group designs, we adjusted as per Linden 2015. For all models fitted, we conducted robustness checks to assess whether autocorrelation considerably affected findings; if this was the case, we report adjusted values of the ITS analyses. All analyses were carried out in STATA 15 and results of analyses were included in summary of findings as relevant. All calculations use raw data as presented in reviewed studies.

\section{Unit of analysis issues}

For cluster-randomised trials and CBA studies we appraised whether an appropriate analysis had been done that adjusted for clustering in calculating confidence intervals or $P$ values. If an analysis had not done this, we considered whether the effect estimate was likely to be affected by such issues and appropriately noted this as a potential source of bias relating to the outcome in question.

\section{Dealing with missing data}

We have contacted the authors of included studies where substantive concerns over missing data were noted. Authors were given two weeks to reply and supply data for re-analysis; if we did not hear back from authors, we attempted to contact them a second time. If this was also unsuccessful, we did not include data provided by the study in our Summary of Findings, however otherwise include the study in the review and describe the study and intervention in principal descriptive tables.

\section{Assessment of heterogeneity}

Upon completion of data extraction, the author group considered the diversity in intervention designs and also the clinical and methodological diversity across studies as per the Cochrane Handbook (Chapter 10.10.1). We noted high levels of diversity (see Description of Included studies) and also considered limitations in how data is reported (effect estimates not being accompanied by measures of precision) and decided against conducting a statistical assessment of heterogeneity or meta-analysis.

\section{Assessment of reporting biases}

Selective outcome reporting is a risk for pay for performance studies, where information on many indicators was recorded in the intervention, but not all indicators are reported in studies. We assessed risks qualitatively: for each study we considered the outcomes incentivised by P4P schemes, noted which outcomes were captured by the evaluations and identified outcomes that were not reported on. We additionally compared the stated aims of each evaluation with the outcomes reported on. If we suspected reporting bias, we logged this as appropriate in our assessment.

We also assessed publication bias qualitatively for each outcome and indicator reviewed, based on the results and characteristics of the included studies, including the extent to which only effects in favour of the intervention are reported, the extent to which funders or investigators are advocates of paying for performance or have a vested interest in the results, and the extent to which the authors' interpretations of the results are supported by the actual results. 


\section{Data synthesis}

Studies of paying for performance are heterogeneous in relation to context, study design, characteristics of the participants and the interventions, follow-up time periods and the outcome measures. We therefore judged it to be uninformative to calculate average effects across studies. We additionally note substantive gaps in data reported by study authors, principally relating to precision measures (standard errors, standard deviation and confidence intervals), thus precluding any potential for data pooling o metaanalysis. We therefore decided to use narrative synthesis and report on this as per SWiM guidelines (Campbell 2019).

\section{Grouping of studies for main comparison}

We aimed to review the evidence on P4P against the primary and secondary outcomes as formulated, however upon initial review of included studies noted two sources of diversity that had not been pre-specified in the study protocol and which required us to deviate from initially specified analyses approaches.

\section{Identifying main comparisons}

First, some studies assessed intervention effects against either a standard care or status quo control group, whereas others assessed effects against a comparator intervention (usually enhanced financing). Other studies assessed effects against both a control and comparator. We therefore chose to report on P4P effects against control and P4P effects against comparator interventions, drawing on the information and effect data reported by studies against each comparison as relevant.

\section{Defining level of synthesis}

Second, effects of the intervention are reported at more granular level than anticipated. For example, we aimed to consider effects on delivery and utilization of care services, however numerous individual indicators relating to this outcome were reported on, including: utilization of one or more antenatal care visits, delivery of HIV-testing and delivery of modern family services among others.

We therefore extracted data on each of these more granular indicators and established that when synthesising and presenting evidence, we would do so at different hierarchical levels.

Specifically, we aimed to present the effects of $\mathrm{P} 4 \mathrm{P}$ against a control or comparator at:

- indicator level: i.e. summarising range of effects for each indicator which was formulated and assessed in a comparable manner across studies (see Criteria used to prioritise results for synthesis);

- clinical area level: i.e. grouping clinically similar indicators together to summarise the effects of the intervention on a clinical area, e.g. reviewing and grouping individual vaccination indicators for BCG, DTP and tetanus and narratively summarising evidence against the area of vaccinations;

- outcome level: i.e. reviewing effects across the different individual indicators and emerging patterns by clinical areas, summarising how the intervention affects the macro-level outcomes as formulated in our initial study protocol.

\section{Distinguishing between targeted and untargeted effects}

At any of the above levels, and as per our original review protocol, we aimed to distinguish between effects of the intervention on targeted vs. untargeted indicators. The need to distinguish between such effects relates to debates around the broader theory of change for the intervention. On one hand, should P4P schemes directly incentivise an indicator, i.e. by making payments conditional upon achieving a specified target or otherwise, we would expect health professionals to change their practice and performance around this indicator to respond favourably. On the other hand, depending on design, overall budgets involved and wider inclusion of quality of carer indicators, P4P schemes are likely to contribute to broader health system strengthening, thus creating an environment where other indicators - even not targeted - respond positively.

Given the above, we additionally therefore decided to summarise intervention effects across targeted and untargeted indicators separately. The former specifically relate to indicators which P4P schemes include in their designs; i.e. payments made to facilities and health workers are conditional based on performance for these specific indicators. We define an indicator to be targeted if it is directly included among indicators specified by the scheme design, or indirectly targeted; e.g. if a scheme rewards four or more antenatal consultations, we consider that the first three antenatal consultations are also targeted.

Indicators that are not targeted are those that are assessed by the evaluation and defined by authors of reviewed studies as not targeted or identified by the review team as not relating to targeted indicators.

For details on how we grouped studies and synthesised information for sub-group and sensitivity analyses, please see relevant headings.

\section{Standardised metric}

At any of the above levels, we do not generate pooled estimates, given limited reporting of precision estimates, but instead report the range of relative effects noted across reviewed studies. See Measures of Treatment Effect for further details.

\section{Criteria used to prioritise results for synthesis}

Given the volume of data retrieved and need to systematically and meaningfully compare effects, we restricted our synthesis only to those indicators that were comparable and reported in 2 or more studies. To be deemed comparable, indicators needed to be similarly specified (in terms of measurement instruments and timepoints) and appraised via similar means (in terms of data collection mechanisms).

\section{Synthesis method and presentation of findings}

For each comparison (P4P against control or comparator), for each indicator, we reviewed the effect sizes noted to identify the range of relative effects of the intervention, noting at the same time whether these are predominantly suggestive of desirable, neutral, undesirable or uncertain effects. We present this detailed information by indicator and clinical area specific Summary of Findings tables in Appendix 4 and Appendix 5

For each indicator, we deemed effects predominantly suggestive of benefits of introducing the intervention as desirable. This meant reviewing all the effects contributing to a comparison against a

Paying for performance to improve the delivery of health interventions in low- and middle-income countries (Review) 
specific indicator and judging whether effects were consistently positive, or in cases where negative effects were also noted, whether these were small (under 5\%) and present in a minority of cases only. We judged undesirable effects as those where studies predominantly suggest the intervention may imply more harms than benefits: this meant that effects were predominantly negative and positive effects relatively small (under $5 \%$ ). In order to judge effects as suggestive of neutral, we applied a contextualized judgment dependent on outcome, however generally considered effects under $5 \%$ to be of this nature. For some indicators, where both the range of effects identified were suggestive of both potential benefit and harm, and were beyond $5 \%$, we classified the overarching effect of the intervention as uncertain.

To prepare summaries of findings across main outcomes as presented in the main Summary of Findings tables, we first created Meta-Summary graphics, summarising desirable, undesirable or neutral effects and certainty of evidence against each indicator. We further summarise information narratively across all indicators associated with a specific outcome, offering a general overview of effects, commenting on whether these change based on whether indicators are targeted or not. We reached an overarching judgment on the certainty of evidence against each outcome by considering the relative distribution of certainty ratings across an outcome.

\section{Subgroup analysis and investigation of heterogeneity}

For both comparisons of P4P effects against control and those against comparator interventions, we stated that we would explore the extent to which the magnitude of incentives and/or ancillary components might explain differences in the impacts of paying for performance, along with the level at which they were paid (Witter 2012). However, studies did not consistently report the magnitude of incentives and the presence of ancillary components. It was therefore not possible to conduct sub-group analyses based on magnitude of incentives.

We did however conduct a sub-group analysis by level at which performance is assessed and paid, which links to the P4P scheme design and mechanism. We classified all studies according to their broad scheme design - distinguishing, for example, between performance related pay, payment per output, and target payments. For each of the indicators assessed (whether targeted or untargeted), we then set a minimum certainty threshold - i.e. we restrict sub-group analyses to indicators for certainty in evidence is at minimum low across both targeted and untargeted outcomes. We then assessed whether the range of effects reported in the reviewed studies varied by classification of the P4P scheme. Against each indicator, we thus assessed whether any pattern was evident in relation to the scheme designs contributing information to the comparison. We noted indicators for which no pattern was evident and for those indicators where a pattern was distinguishable, we assigned the best performing scheme (schemes securing positive relatively high magnitude of effect) a rank of 1 - and second-best performing scheme a rank 2 and so forth. We thus reached a qualitative judgment on relative performance of diverse schemes types in comparison to one another. To comment on broader patterns across outcomes of the review, we then calculated a median rank for each scheme design, across the indicators associated with each outcome, in order to establish an overarching relative rank for each type of P4P scheme design. We further review the ranking patterns across schemes and comment on these.

\section{Sensitivity analysis}

For all indicators, we present summaries across the whole body of evidence and separately summarise the evidence from RCT studies in the comments section and additional tables in order to probe whether results differ if less robust studies are excluded.

\section{Summary of findings and assessment of the certainty of the evidence}

We summarize the effects of P4P for each indicator and against each of the above comparators (control and comparator) in summary of findings tables, distinguishing principally between whether indicators were targeted or not, and further summarize interpretation of results against review outcomes in meta-summary tables and the overarching Summary of Findings tables. We provide the range of effects corresponding to intervention impacts noted across studies against each indicator, however do not calculate a single effect estimate of the intervention against either control or comparators.

We assessed the certainty of the evidence (high, moderate, low, and very low) using the five GRADE considerations (risk of bias, inconsistency of results, imprecision, indirectness, and publication bias) as per Section 77.6 and Chapter 14 of the Cochrane Handbook for Systematic Reviews of interventions (Higgins 2019), and the EPOC worksheets (EPOC 2017c). Given the absence of metaestimates, our GRADE assessment corresponds to an assessment of certainty in the overall direction of effect of the intervention. We present the range of effects noted by study authors across the reviewed literature and used the approach noted by Murad 2017 to consider methodological limitations of studies, issues of indirectness, imprecision, inconsistency, likelihood of publication bias and appropriateness of raising certainty ratings. Alongside summary of findings tables, we provide justification for decisions to down- or upgrade the ratings using notes in the table and make comments to aid readers' understanding of the review where necessary.

As per ongoing research and recommendations (Hultcrantz 2017), we assess certainty in whether the intervention has a desirable (positive), neutral, undesirable (negative) or uncertain effect (see Data Synthesis), and further refer readers to the identified range of effect sizes for interpretation (Hultcrantz 2017). To reach a judgment on certainty we proceeded stepwise. First, we considered all evidence to be of high quality (4-point GRADE rating). Second, we systematically appraised the evidence collated against each outcome in light of the five GRADE criteria, down-grading evidence as appropriate (EPOC 2017c; Higgins 2019). In relation to risk of bias criteria specifically and as per Murad 2017, this implied downgrading evidence by 2 points for indicators where the majority of evidence was from controlled before and after studies. In addition to the criteria listed, we further down-graded evidence provided by one study only (downgraded by 1 point). Third, we proceeded to upgrade evidence by 1 point if the magnitude of effect was particularly large (i.e. corresponding to a relative risk of 2 or above) (as per section 5.3.1 in Schünemann 2013). Fourth, we consistently reviewed judgments made on effects (whether they are desirable, undesirable, neutral or uncertain) in light of GRADE ratings. For all indicators where certainty in evidence was deemed very low, we revised our assessment and noted effects as uncertain.

Paying for performance to improve the delivery of health interventions in low- and middle-income countries (Review) 
Given the diversity of study designs, we further reviewed the evidence across RCT studies only (see sensitivity analyses) and applied GRADE again as per the above principles.

All GRADE assessments were done independently by two authors, with disagreements being resolved by discussion and in consultation with a third author.

\section{RES U LTS}

\section{Description of studies}

\section{Results of the search}

Searches in the specified databases and websites yielded 11,529 unique references, which two researchers examined independently (See Figure 1). We retrieved 912 complete articles which were independently assessed by two researchers. We included 59 studies in the review. 


\section{Figure 1. PRISMA Flowchart}

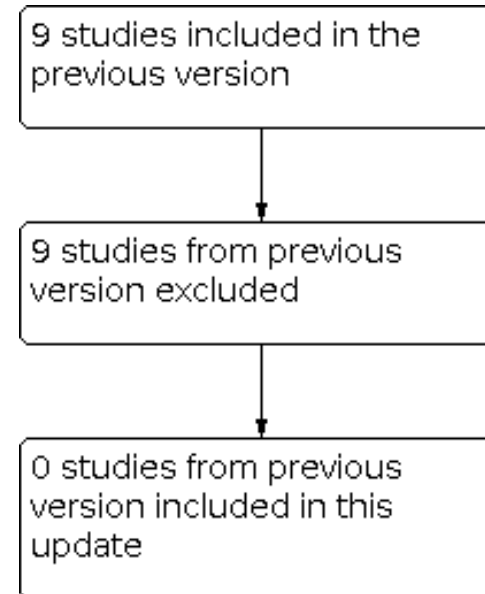

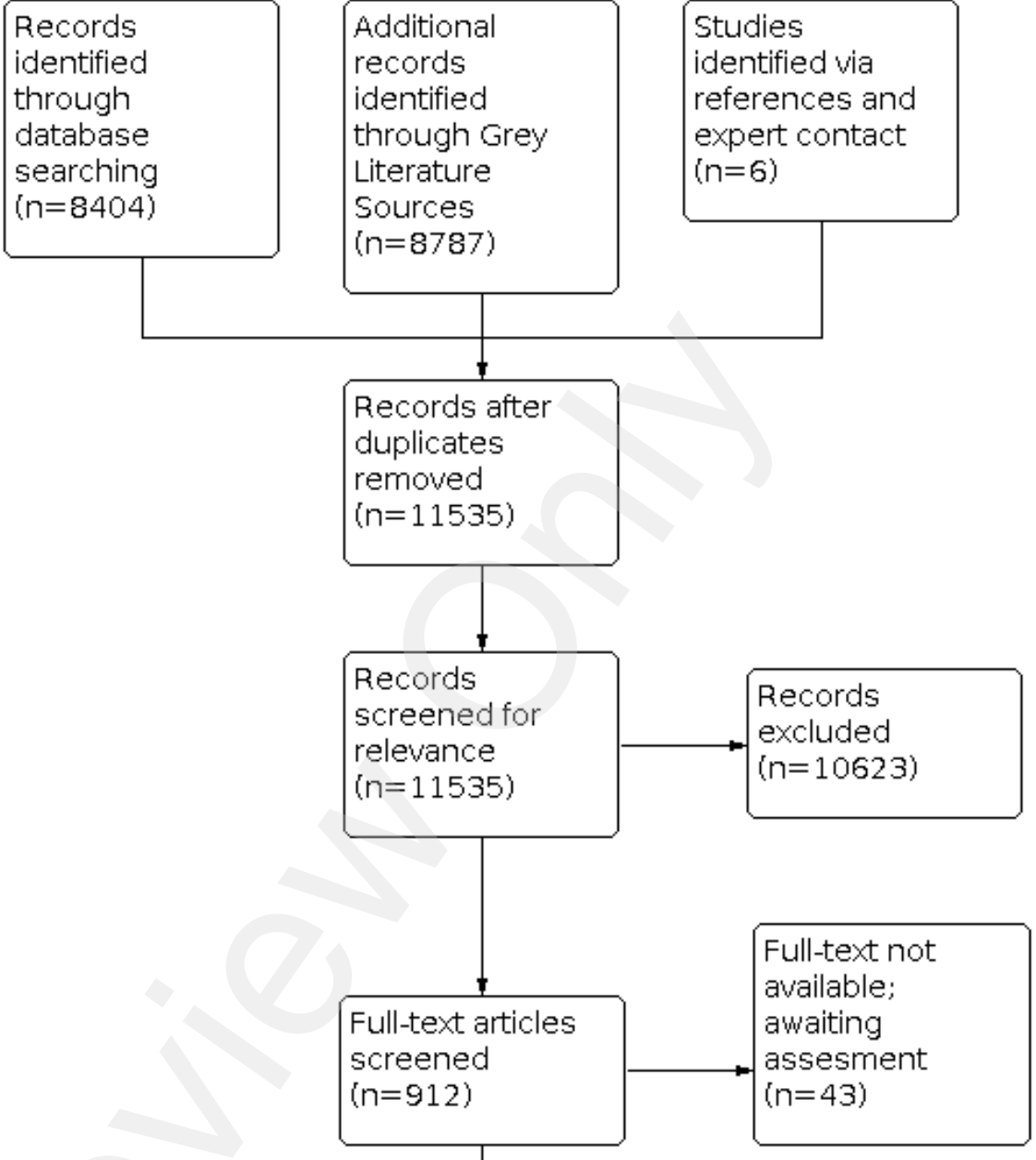

Full-text articles excluded, with reasons $(n=807)$ :

Study type not appropriate

(402);

Duplicate (151);

Study focused on demand side of health care only (141): Study not an impact evaluation of P4P scheme compared to an alternative (52); Study population or 
Figure 1. (Continued)

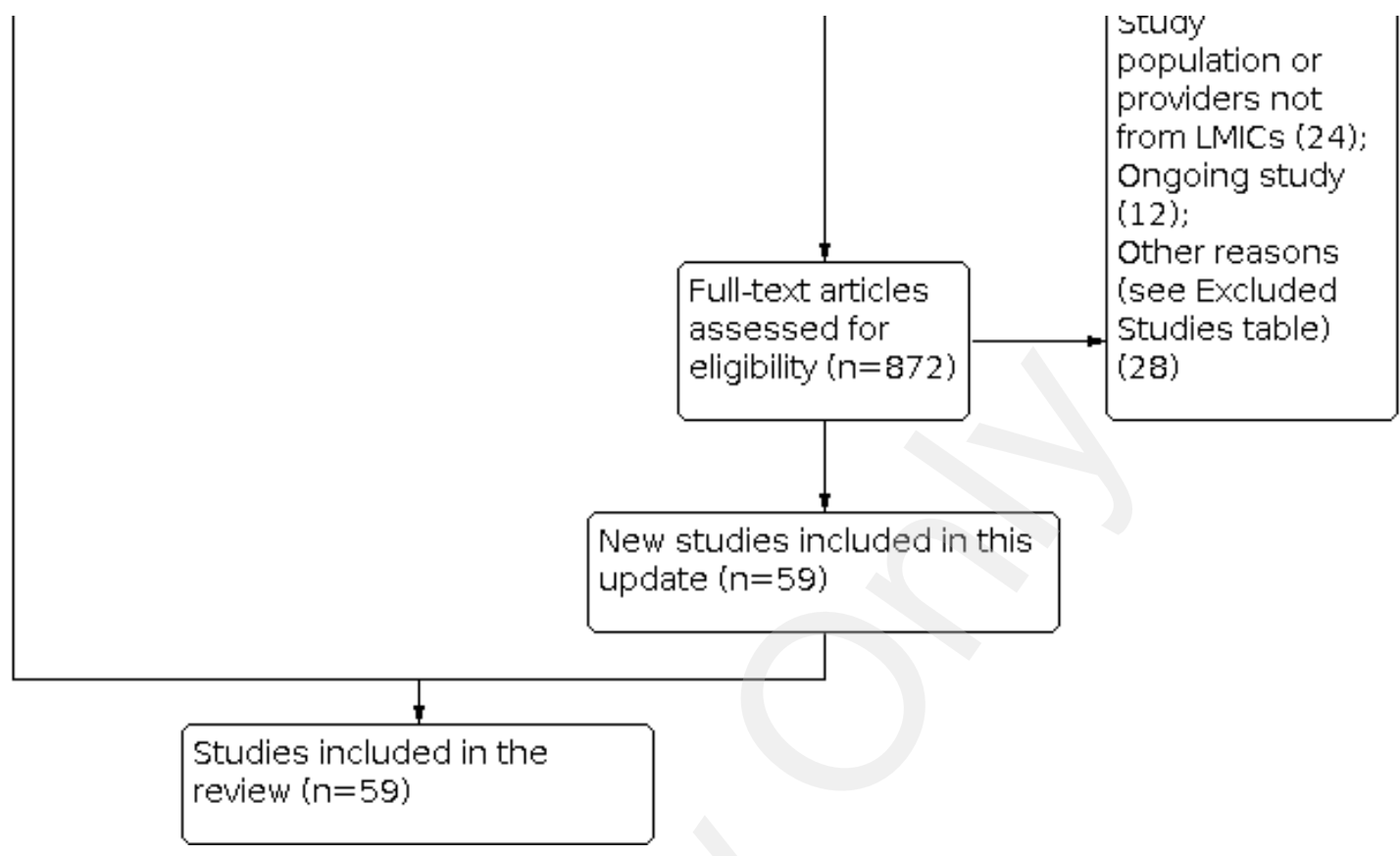

Upon updating searches, we identified additional studies for which full texts need to be reviewed in the next review update and have listed these under Studies awaiting classification.

\section{Included studies}

59 studies were included (see Characteristics of included studies Table 3 and Table 4). The majority are studies assessing the effects of P4P against a control group. 24\% $(n=14)$ of studies were randomized control trials, $27 \%(n=16)$ non-randomized trials, a further $32 \%(n=19)$ controlled before-and after studies. $15 \%$ $(n=9)$ were interrupted time series studies, with one further study including both an interrupted time series and controlled beforeafter analysis. Most studies followed up and assessed the effects of P4P schemes 3 years post initiation, however this varied considerably across the reviewed literature, with some evaluations being conducted as soon as one-year post scheme start and others following up trends as long as 17 years post initial implementation.

\section{Intervention characteristics}

\section{Geography, context and location of care}

Interventions were implemented across 25 countries overall (see Characteristics of interventions Table 5 and Table 6); however, the majority of studies were impact evaluations focused on the P4P schemes implemented in Rwanda $(17 \%, n=10)$, China $(12 \%, n=7)$ and Tanzania $(8.4 \%, \mathrm{n}=5)$.

Studies predominantly studied interventions implemented across both urban and rural locations $(29 \%, n=18)$, however two focused specifically only on urban environments (Brock 2018; Wu 2014). A substantive proportion of studies $(37 \%, \mathrm{n}=24)$ did not offer a precise description of locations.

Over half of the reviewed studies described P4P schemes focused on reproductive, maternal and child health services only; eight schemes were more focused in relation to clinical area (e.g. as in Kliner 2015 and Yao 2008 where the focus was on tuberculosis.)
$61 \%(n=36)$ of studies reported on schemes operating at both inand out-patient levels with a further $15 \%$ focused on outpatient care $(n=9)$ or inpatient care $(n=9)$ respectively. Two studies focused on community-based care exclusively (Kliner 2015; Witvorapong 2016).

\section{Participants}

91\% ( $n=54$ ) of studies reported on P4P schemes involving public or not for profit facilities (usually faith-based). Few studies included a mix of public, private and not-for-profit (Brock 2018; Huillery 2017) and only one study focused on private health providers exclusively (Mohanan 2017).

\section{Scheme funders}

Overall, studies noted a high proportion of schemes funded by national governments and Ministries (37\%, $n=23) ; 33 \%(n=20)$ were funded by external agencies $(33 \%, n=23)$. As per Table 6 , none of the schemes were funded without some level of national support support; no schemes were funded only by sub-national or local funds. Three further $(5 \%)$ studies noted that schemes were cofinanced by national governments and external donors or nongovernmental organizations, and across 13 studies (22\%) no clear details on scheme funders were provided. Across schemes funded by external agencies, the World Bank and Government of Norway were the main funders, having supported $11(19 \%)$ and $5(7 \%)$ schemes respectively. The latter two actors are also the main funders of the impact evaluations included in the review, having contributed to the financing of roughly $17(29 \%)$ and $5(10 \%)$ respectively of the studies included in this review. Four studies (7\%) were further funded by the US National Institute of Health and the remainder by a varied mix of funders, including the Bill and Melinda Gates Foundation, Cordaid and the European Union.

\section{Scale of intervention}

The scale of implementation differed by country. The majority of studies $(42 \%, n=26)$ focused on studying intervention effects

Paying for performance to improve the delivery of health interventions in low- and middle-income countries (Review) 
across a range of districts (e.g. as de Walque 2017 in Cameroon). Other studies focused on studying effects across one particular province $(20 \%, n=12$, e.g. as Yip 2014) or a particular facility (13\%, n=8, e.g. as Wu 2014); others studied national level rollout and implementation of P4P ( $21 \%, n=13$, e.g. as Gertler 2012). For the majority of P4P schemes described across studies (76\%, $\mathrm{n}=45$ ), purchasing arrangements were integrated into the national purchasing functions of the relevant Ministry of Health.

\section{Target setting and incentive payments}

Schemes targeted a wide range of indicators, which varied in number among schemes. Very few schemes focused on one indicator only (e.g. Celhay 2015, Argentina) while others noted that schemes had used as many as 42 indicators (e.g. as in the case of Burundi as reported by Falisse 2015). On average, schemes targeted approximately 8-12 core indicators, which related to the delivery or utilization of services.

Over half of included studies $(57 \%, n=34)$ did not include details on why and how indicators were chosen and set. Studies which included details on these processes suggest that consultative processes between national Ministry of Health actors, nongovernmental and aid organizations were employed to set targets based on emerging priorities or in line with best locally or internationally available evidence.

\section{Magnitude of incentives}

The absolute magnitude of incentives appears to range between 0.5 to $10 \mathrm{US} \$$ /per indicator. However, for some indicators which require repeat contact with the health service, or imply specialist skills, capita costs were used. These were consistently priced at higher rates: e.g. correct tuberculosis patient management and skilled birth attendance were incentivized at 20US\$/patient (e.g. in Bonfrer 2014a) and at 35.63US\$ (e.g. in Engineer 2016) respectively.

$54 \%(n=32)$ of included studies report on the relative magnitude of incentives. Of these, 10 studies note the relative magnitude of incentives in relation to facility funding; the majority of studies estimate that P4P incentives equate to $14-50 \%$ of funds available to facilities overall. 14 studies further note the relative magnitude of incentives in relation to health worker salaries; incentives are estimated to equate to anything between $1-78 \%$ of health worker salaries, however the majority of studies report on incentives equal to approximately $10 \%$ of overall annual pay.

\section{Measurement and verification of performance}

$61 \%(n=38)$ of studies reported that performance against incentivized indicators was assessed using data routinely reported by health facilities. $16 \%(n=10)$ of studies similarly noted using data captured by the national health management information systems or equivalent electronic health record systems as the basis for performance measurement. 32 of these studies additionally described verification procedures, which included assessments by district level management teams, study teams active in assessing the effectiveness of P4P schemes or by teams including community and purchaser representatives.

$6.4 \%(n=4)$ of these studies described verification via national level statistics or via bespoke community and household surveys.

In $16 \%(n=10)$ of studies it was unclear how performance was measured and verified.

\section{Assessment and purchasing arrangements}

Across schemes, the focus of scheme assessment and payment was largely at health facility level $(n=33,55 \%)$. Seven studies reported on schemes where P4P performance was assessed at both district and health facility levels; a further 6 studies noted performance being assessed at health worker level directly.

The majority of studies $(85 \%, \mathrm{n}=50)$ reported that $\mathrm{P} 4 \mathrm{P}$ payments were additional to normal wages or funding received. Only 2 studies conducted in China, both focused on containment of unnecessary health related services and expenditures, reported on schemes whereby health facilities or health workers may be penalized (i.e. fines would need to be paid if outcomes were not achieved) as a result of $\mathrm{P} 4 \mathrm{P}$ schemes.

Predominantly payments appear to be made to health facilities directly; the latter then cascade payments to health care workers as agreed in the setup of the P4P scheme. This may be at the discretion of the facility (e.g. as in Zeng 2013 in Haiti) or may be according to an agreed principle whereby a proportion of the overall bonus is shared with staff and the rest is reinvested (e.g. as in Steenland 2017 in Burkina Faso).

\section{Intervention classification}

Schemes operated according to an assortment of designs (see Intervention Classification Table 7 and Table 8). The majority of schemes focused on assessing performance at facility level and on providing a payment per incentivized indicator. However even within this group, some schemes focused on incentivizing both the volume and quality of outputs, while others focused on incentivizing outputs only. Other schemes operated on a payment to target principle; while in the majority of cases this meant that bonuses were released upon targets being met, one scheme applied penalties if targets were not achieved and consequently withheld income (Wu 2014). A minority of studies focused on schemes which included assessments of performance at district or national levels. Only one study focused on assessing the effects of results-based aid (Bernal 2018).

\section{Ancillary components}

A third of all studies reported that P4P schemes had no ancillary outcomes. However, the majority of schemes included multiple ancillary components. Among these, quality improvement strategies, training, enhanced supervision activities and technical support were noted most commonly. Other components, such as receiving additional funding or in-kind support (e.g. supplies), or putting in place strategies for consultation with other stakeholders in order to enhance the efficacy of processes needed to support $\mathrm{P} 4 \mathrm{P}$, were mentioned infrequently.

\section{Comparator characteristics}

44 studies focused on assessing P4P against a control, usually described as standard care within the respective country and health facilities. Other studies reported against comparator interventions predominantly focused on providing facilities with enhanced financing: i.e. funding matched to what facilities in the $\mathrm{P} 4 \mathrm{P}$ arm were due to receive was disbursed to comparator facilities in order to isolate the effect of incentivization and performance assessment (e.g. as in Friedman 2016a). In other cases, comparators included an existing P4P scheme (e.g. as in Celhay 2015 or Shapira 2017) or provision of in-kind support (e.g. as in Soeters 2011). 


\section{Outcomes reported}

Schemes may target an indicator both directly, such as utilization of four or more antenatal care visits, as well as indirectly (e.g. by incentivizing four or more antenatal care visits, the area of antenatal care and care quality in general may in practice be incentivized). Studies therefore predominantly reported on a range of both directly and indirectly targeted indicators to assess the effects of P4P. Some studies (e.g. Binyaruka 2015) additionally focused on assessing the effects of P4P on explicitly untargeted indicators. Overall, studies report on a range of indicators; some report specifically on one primary indicator (e.g. as Celhay 2015), while others include data on up to 386 indicators (e.g. as in Friedman 2016a).

\section{Sources of heterogeneity and diversity}

We did not formally assess statistical heterogeneity, however as per the above sections note substantial sources of diversity in relation to study designs, clinical areas and patient groups studied and also intervention designs and outcomes assessed.

\section{Excluded studies}

A list of all excluded studies can be obtained from the authors upon request. The majority of studies were excluded due to study design issues ( $n=402$ ). Full references of the 36 studies excluded due to other reasons are included under Excluded studies.

\section{Risk of bias in included studies}

Drawing on assessments outlined in Appendix 6, we present a summary of the risk of bias assessment in the Risk of Bias Graphic (Figure 2) and and in the Risk of Bias Summary (Figure 3). While multiple studies may have reported on the same scheme, studies themselves frequently included diverse populations and we therefore assessed the risk of bias for each study. As expected, CBAs were recorded to be at higher risk of bias than other study designs, particularly due to lacking randomization and allocation concealment. However, some RCT studies were also downgraded on specific risk of bias criteria, predominantly due to differences in the baseline characteristics of P4P implementing areas versus control sites. ITS studies were noted to provide insufficient information (or attempt to control for) other concurrent changes going on in the countries or sites where P4P was implemented.

\section{Figure 2.}

Random sequence generation (selection bias)

Allocation concealment (selection bias)

Blinding (performance bias and detection bias): All outcomes Incomplete outcome data (attrition bias): All outcomes Selective reporting (reporting bias)

Other bias

Baseline outcome measurement: All outcomes

Matched characteristics for control study sites

Protection against contamination (intervention and controls)

Intervention independent (ITS)?

Shape of effect pre-specified (ITS)?

Unlikely to affect data collection (ITS)?

Incomplete outcome data addressed (ITS)?

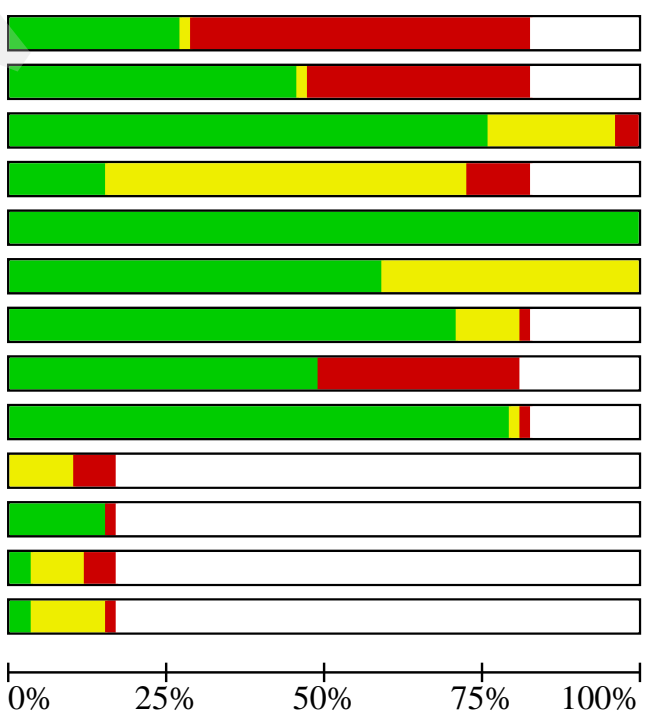

$\square$ Low risk of bias $\square$ Unclear risk of bias $\square$ High risk of bias


Figure 3. Risk of bias summary by study

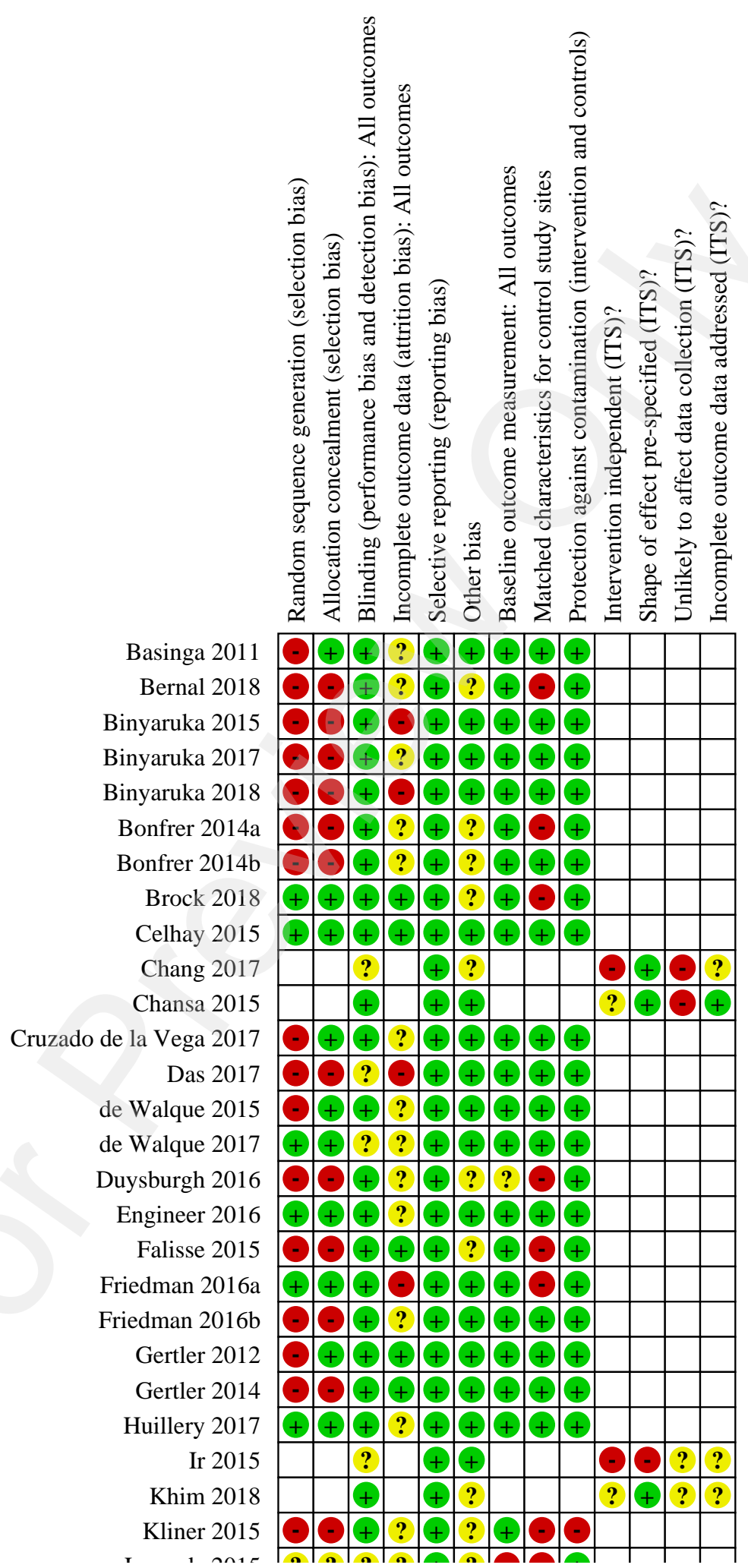


Figure 3. (Continued)

\begin{tabular}{|c|c|c|c|c|c|c|c|c|c|c|c|c|c|}
\hline Kliner 2015 & & & + & $?$ & + & $?$ & + & & $\odot$ & & & & \\
\hline Lagarde 2015 & $?$ & $?$ & $?$ & $?$ & + & $?$ & - & - & + & & & & \\
\hline Lannes 2015 & $\odot$ & + & + & $?$ & + & + & $?$ & E & + & & & & \\
\hline Lannes 2016 & 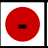 & + & + & $?$ & + & + & + & + & + & & & & \\
\hline Liu 2005 & & & + & & + & + & & & & - & + & + & + \\
\hline Matsuoka 2014 & & & $?$ & & + & $?$ & & & & $?$ & + & $?$ & $?$ \\
\hline Mayumana 2017 & & - & $?$ & E & + & + & + & + & + & & & & \\
\hline McMahon 2016 & & & $?$ & & + & + & & & & $?$ & + & & \\
\hline Menya 2015 & + & + & + & $?$ & + & + & $?$ & - & + & & & & \\
\hline Mohanan 2017 & + & + & + & $?$ & + & + & $?$ & + & $?$ & & & & \\
\hline Peabody 2011 & + & + & + & $?$ & + & + & + & - & + & & & & \\
\hline Peabody 2014 & + & + & + & $?$ & + & $?$ & + & + & + & & & & \\
\hline Powell-Jackson 2014 & 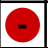 & + & $?$ & $?$ & + & $?$ & + & + & + & & & 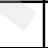 & \\
\hline Priedeman Skiles 2013 & - & + & + & $?$ & + & $?$ & + & + & + & & & & \\
\hline Priedeman Skiles 2015 & 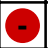 & + & + & $?$ & + & $?$ & + & + & + & & & & \\
\hline Quimbo 2016 & + & + & + & $?$ & + & + & + & & + & & & & \\
\hline Rudasingwa 2014 & & $\Theta$ & $?$ & + & + & $?$ & + & ? & $(4$ & & & & \\
\hline Rusa 2009 & & & $?$ & & + & + & & & & 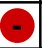 & + & $?$ & $?$ \\
\hline Shapira 2017 & + & + & E & + & + & + & + & + & + & & & & \\
\hline Shen 2017 & + & + & - & $?$ & + & + & + & 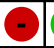 & + & & & & \\
\hline Sherry 2017 & & + & + & $?$ & + & $?$ & + & + & + & & & & \\
\hline Soeters 2011 & & 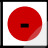 & \pm & $?$ & + & + & + & - & + & & & & \\
\hline Steenland 2017 & & 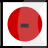 & + & + & + & $?$ & + & - & + & & & & \\
\hline Sun 2016 & 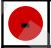 & + & + & $?$ & + & $?$ & + & + & + & & & & \\
\hline Van de Poel 2016 & & 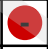 & + & $?$ & + & $?$ & + & + & + & & & & \\
\hline Viñuela 2015 & & & + & & + & $?$ & & & & $?$ & + & $?$ & $?$ \\
\hline Wagner 2018 & + & + & + & + & + & + & + & + & + & & & & \\
\hline Witvorapong 2016 & + & + & + & E & + & $?$ & $?$ & - & + & & & & \\
\hline Wu 2014 & & & + & & + & $?$ & & & & $?$ & + & + & $?$ \\
\hline Yao 2008 & & & + & $?$ & + & + & $?$ & E & + & & & & \\
\hline Yip 2014 & + & + & + & $?$ & + & + & + & + & + & & & & \\
\hline Zang 2015 & & & $?$ & $?$ & + & + & + & + & + & & & & \\
\hline Zeng 2013 & & & + & $?$ & + & $?$ & + & 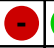 & + & & & & \\
\hline Zeng 2018a & & & + & $?$ & + & + & + & - & + & & & & \\
\hline
\end{tabular}

Overall, we note that selective outcome reporting was assessed as low: study authors consistently reported on the effects of P4P on the outcomes identified at the outset of their impact evaluations. However, the majority of authors fail to provide clear reports on how missing or incomplete data was handled during their studies or analyses.

\section{Other potential sources of bias}

We considered the potential bias introduced by unit of analysis issues, more specifically the absence of clustering or clustering at level different to allocation (e.g. clustering by region when allocation was at facility level). The majority of reviewed studies reported on facility level clustered difference in difference regression models, thus appropriately accounting for unit of analysis issues, however for few studies we noted potential high risk of bias due to clustering at different levels (See Appendix 6 for detailed judgments on risk of bias assessments).

\section{Effects of interventions}

See: Summary of findings 1 Comparison 1: Summary of findings on effects of paying for performance against standard care; Summary of findings 2 Comparison 2: Summary of findings on effects of paying for performance against comparator interventions

Within the 59 studies included in this review update, 42 reported on the effects of P4P against a standard care or status quo control group, 13 reported on the effects against an enhanced financing control or alternative financing intervention and 4 reported on effects against both a control and matched or otherwise enhanced financing comparator. Of the 59 studies which were included in

Paying for performance to improve the delivery of health interventions in low- and middle-income countries (Review) 
the review, 41 studies noted that P4P schemes were accompanied by a diverse range of ancillary components. Predominantly these components focused on training and supervision initiatives and in some cases, increases in overall resources allocated to facilities to assist with the roll-out of P4P schemes. Interpretation of the estimates of the impact of paying for performance therefore has to bear this in mind. We have highlighted differences in context, intervention design, resourcing and ancillary components in the Discussion.

\section{Comparison 1: Effects of P4P against standard care Overarching trends}

A meta-summary of the effects of P4P on individual indicators assessed against standard care, grouped by each of the primary outcomes of the review, is presented in Meta-Summary: Effects of P4P against control (Table 1) and Summary of findings 1 . All individual summary of findings tables, by outcome, are available in Appendix 4. We extracted effects on indicators directly targeted by P4P schemes (see Appendix 4 Tables 1-23) and indicators not explicitly targeted (see Appendix 4 tables 24-45).

\section{Comparison 1a: Effects on targeted outcomes}

Summary of findings tables 1-24 in Appendix 4 present the evidence collated for each of the primary and secondary outcomes.

\section{1. Targeted measures of provider performance}

\section{1. 1. Delivery and utilization of services}

Evidence on the effects of P4P on the utilization and delivery of services (see Table 1 and Appendix 4, Tables 1-8) is largely inconsistent across the indicators reviewed: the intervention may improve some utilization and delivery indicators but may lead to poorer results for other indicators (overall certainty of the evidence is low).

Effects on HIV/AIDS, malaria and TB services are overall mixed (low certainty evidence, Table 1): HIV testing and PMTCT delivery may be positively affected, however ART delivery may decline. P4P may have negative effects on the proportion of children and households protected by bednets (low certainty evidence), and effects on tuberculosis treatment adherence are uncertain (very low certainty evidence).

Moderate certainty evidence for improvements in indicators was found for the delivery of family planning services by health providers. P4P probably improves the number of outreach activities on family planning services offered by health providers and probably increases the likelihood of providers supplying contraception to clients (effects ranging between 10-300\%, see Table 4).

Undesirable effects were noted for a minority of utilization and delivery indicators (low certainty evidence).

Findings are inconsistent overall for two of the areas of service delivery and utilization most commonly targeted by P4P schemes: mother and child immunizations (see Table 2) and antenatal care (see Table 5) (low certainty evidence).

\section{1. 2. Quality of care}

Overall, the evidence suggests that quality of care indicators may improve where P4P is implemented (see Table 1 and Appendix 4, Tables 9-12). Across the indicators for which evidence was available, improvements were noted for the majority and only one indicator suggested that quality of care may decrease (this was in relation to waiting times). Generally the evidence for this outcome was of low certainty. Further, the methods for quality of care assessment were inconsistent across studies, however data is sourced predominantly from direct observation by scheme supervision teams or data collectors. In some cases, e.g. quality of child health care or quality of service by specific service area, data from structured patient exit interviews have also been used.

Indicators for which moderate certainty evidence was found include:

- quality of child health care: P4P probably improves quality of care scores (moderate certainty evidence; effects ranged from 5 to $300 \%$ relative increases) (see Table 12 );

- quality of medicine and equipment: P4P probably improves the quality scores of available medicine and equipment, effects ranged from $2.7 \%$ to $220 \%$ (moderate certainty evidence) (see Table 12);

- overall quality of service by specific departmental area/service: P4P probably improves the average quality of service scores in specific targeted areas (moderate certainty evidence; effects ranged from $39 \%$ to 15 -fold increase in scores (Table 12)).

In general, the effects of P4P schemes on a range of procedural quality of care indicators is uncertain, including the likelihood of providers carrying out background and physical assessments, managing patients correctly or counselling patients appropriately (very low certainty evidence - see Table 9). However, P4P may improve specific aspects of the quality of antenatal care, particularly the likelihood of receiving immunizations or being prescribed iron or folic acid in pregnancy (low certainty evidence).

The intervention may make little or no difference to staff knowledge and skills (see Table 10, low certainty evidence), and its effects on staff responsiveness (as observed by researchers/P4P scheme verifiers) are uncertain overall (very low certainty evidence; range: $-2 \%$ to $49 \%$ change in responsiveness).

\section{2. Health outcomes}

The available evidence suggests that overall P4P may improve some health outcomes (see Table 1 and Appendix 4, Tables 13-17).

- child mortality: P4P may reduce child mortality (range: 0.2-6.5\%, low certainty evidence; Table 14);

- anaemia in children: P4P may lead to a modest reduction of $2-3 \%$ in the proportion of children with reported anemia (low certainty evidence; Table 15).

- the likelihood of tuberculosis treatment success (low certainty evidence; range: $12-20 \%$ improvement in treatment success, Table 16).

Evidence neonatal mortality is inconsistent: P4P may have desirable effects and ensure reduction in neonatal mortality in implementing clinics by up to $22 \%$ in one study, however, another study identified increases in region of $6.5 \%$ across catchment areas of P4P incentivized providers (low certainty evidence, Table 14). 
The effects of the intervention on outcomes such as unwanted pregnancies are uncertain because the certainty of the evidence is very low (Table 11).

\section{3. Resource use}

In relation to resource use (see Table 1 and Appendix 4, Tables 17-18), the intervention seems to predominantly affect indicators positively. P4P probably has a positive effect on human resource availability (range: 19-44\%, moderate certainty evidence, Table 17). Effects on curative visits logged per health care professional are uncertain (very low certainty evidence, Table 17). P4P probably affects infrastructure functionality and medicine availability positively (moderate certainty evidence, Table 18).

\section{4. Secondary outcomes}

P4P may have neutral or positive effects on secondary outcomes (low certainty evidence, see Table 1 and Appendix 4, Tables 19-23).

P4P probably makes little or no difference to provider absenteeism (range: $0.7-2 \%$, low certainty evidence, Table 19). Effects on overall motivation scores and satisfaction are largely neutral (low certainty evidence, Table 19).

Overarachingly, P4P may have little to no or positive impacts on measures of patient satisfaction (low certainty evidence, Table 20).

In relation to impacts on financing, limited evidence is available and all is sourced from one study exploring the impacts of a P4P scheme where income may be withheld if targets are not achieved (Table 21). Patient expenditure on medicine and equipment may increase for insured patients (estimate $2.5 \%$ ), but may decrease for the uninsured (estimate $0.9 \%$ ), suggesting small positive redistributive effects (low certainty evidence).

P4P may positively affect facility managerial autonomy (low certainty evidence, see Table 22). However, the intervention probably makes little to no difference to management quality or facility governance, using the number of staff meetings held in the last 3 months as a proxy (low certainty evidence).

Effects on indicators focused on assessing care equity are predominantly neutral (see Table 23). P4P may increase the proportion of poor persons utilizing child immunization services (low certainty evidence), however the intervention may potentially decrease the proportion of poor persons utilizing antenatal care (low certainty evidence). P4P may make little to no difference to the utilization of institutional deliveries by poorest groups (low certainty evidence).

\section{Comparison 1b: Effects on untargeted outcomes}

Evidence on the effects of P4P on untargeted outcomes is presented in Tables 24-45 in Appendix 4 and also summarized in the MetaSummary Graphic: Effects of P4P against control (Table 1).

\section{5. Changes in untargeted measures of provider performance}

\section{5. 1. Untargeted delivery and utilization}

In relation to service utilization (see Table 1 and Appendix 4, Tables 24-30), P4P may improve the rate of HIV testing (low certainty evidence), however probably has no important effect on bednet use (moderate certainty evidence) (see Table 25). The former finding is inconsistent with when the same indicator is targeted; in the latter case, P4P had negative effects.

We further note that P4P:

- may make little to no difference to the probability of services being utilized and frequency of visits by elderly populations in particular (low certainty evidence);

- has uncertain effects on the frequency of outpatient consultations overall (low certainty evidence, see Table 25);

- probably makes little or no difference to utilization of modern family planning methods (moderate certainty evidence), but may increase the rate of family planning outreach delivery by up to $10 \%$ (low certainty evidence) (see Table 26 );

- may have little to no effect on utilization of antenatal care (up to $5 \%$, low certainty evidence), with most other effects on antenatal care being uncertain (see Table 27);

- may have little to no effect on institutional deliveries (low certainty evidence); effects on the delivery of C-sections are uncertain (very low certainty evidence) (see Table 28);

- has overarchingly inconsistent effects on postnatal care: P4P may improve the delivery and coverage of postnatal care (low certainty evidence), however probably slightly decreases the overall utilization of such services (moderate certainty evidence) and may have desirable effects on the timeliness of postnatal care utilization (low certainty evidence) (see Table 29).

\subsection{Untargeted quality of care}

Overall, estimates presented on quality of care (see Table 1 and Appendix 4, Tables 31-35) indicate P4P may have neutral or uncertain impacts, suggesting that quality of care indicators must be explicitly targeted for outcomes to be achieved (overarching low certainty evidence). Effects on total care quality scores are uncertain in relation to maternity care, outpatient services and medicine and equipment quality, however P4P probably has negative effects on general quality of care scores when such indicators are not explicitly targeted (moderate certainty evidence).

\section{6. Untargeted health outcomes}

The effects of P4P on health outcomes are largely consistent with those reported when indicators are targeted (moderate certainty evidence, see Table 1 and Appendix 4, Tables 36-37). Moderate certainty evidence suggests that P4P probably:

- reduces child mortality by up to $1 \%$ (moderate certainty evidence, Table 36)

- reduces the proportion of children with anaemia (approximately 5\%, moderate certainty evidence, Table 37)

- reduces the proportion of children with wasting (range 5.9-9.25\%, moderate certainty evidence, Table 37).

P4P probably has no important effect on the incidence of neonatal mortality or pregnancies recorded (effects under $1 \%$, moderate certainty evidence, Tables 36-37).

\section{7. Unintended effects}

P4P may have little to no distorting unintended effects (see Table 1 and Appendix 4, Table 38), with studies suggesting that free riding 
and unwanted task shifting were slightly lowered (low certainty evidence).

\section{8. Untargeted resource use}

Effects of P4P on non-targeted resource use indicators appear largely uncertain (very low certainty evidence, see Table 1 and Appendix 4, Tables 39-40).

\section{9. Untargeted secondary outcomes}

Effects on the majority of secondary untargeted indicators are largely inconsistent (see Table 1 and Appendix 4, Tables 41-45). However, P4P may positively affect patient satisfaction scores on quality of care and provider communication, despite indicators not being directly targeted (low certainty evidence). P4P probably has little to no impact on expenditure related to medicines and equipment (moderate certainty evidence), however impacts on out of pocket payments are inconsistent across service areas (Table 43, low certainty evidence). In relation to impacts on facility governance and equity promoting distributive effects (Tables 44-45), evidence is overarchingly inconsistent (low certainty evidence).

\section{Comparison 2: Effects of P4P against comparator interventions}

\section{Overarching trends}

The Meta-Summary: Effects of P4P against comparator (Table 2) and Summary of findings 2 outline the effects of P4P on individual indicators assessed against comparator interventions. Individual Summary of Findings tables by indicator are available in Appendix 5. Comparator interventions predominantly consisted of enhanced financing interventions within which comparator health facilities received funding matched to $\mathrm{P} 4 \mathrm{P}$ groups.

\section{Comparison 2a: Effects on targeted outcomes}

\section{1. Targeted measures of provider performance}

\section{1. 1. Delivery and utilization}

In contrast to the findings on the effects of P4P against a pure control, P4P has largely neutral or desirable effects on utilization and delivery indicators (see Table 2 and Appendix 5, Tables 46-51).

P4P may positively affect the probability of persons utilizing care (range: 2 to 10\%, low certainty evidence, see Table 50), however, evidence on immunization utilization is indicative of little to no effect or uncertain (Table 46).

Evidence on family planning is largely consistent with that presented on the effects of P4P against standard care (Table 47): $\mathrm{P} 4 \mathrm{P}$ may have little to no important effect on the utilization of any family planning services (low certainty evidence).

Effects on the overall rates of antenatal care utilization are indicative of little to no important effect (Table 48), however, P4P may positively affect the timeliness of ANC care-seeking (range: 1 to $10 \%$ women accessing care earlier, low certainty evidence).

Evidence on the effects of P4P on \% women utilizing institutional deliveries is uncertain (range between $-9 \%$ and $23 \%$, low certainty evidence, Table 49). However, P4P may have negative effects on postnatal care utilization (low certainty evidence, Table 49).

\section{1. 2. Quality of care}

Evidence on the effects of P4P on quality of care indicators is largely positive for specific clinical areas and overall quality (see Table 2 and Appendix 5, Tables 51-54). P4P probably leads to improved quality of care in relation to family planning or antenatal care (moderate certainty evidence, see Table 53). $\mathrm{P} 4 \mathrm{P}$ may also have positive effects on care processes, such as leading to increases in the proportion of staff conducting appropriate patient background and physical assessments during consultations, however effects on quality of counselling during consultations are uncertain (low certainty evidence, see Table 51). P4P may slightly increase the quality of care of immunizations as well as staff knowledge and skills, however impacts on patient knowledge outcomes are uncertain (low certainty evidence, Table 52).

\section{2. Health outcomes}

Effects on health outcomes are suggestive of little or no impact (see Table 2 and Appendix 5, Table 54). P4P may have little to no impact on the proportion of breastfeeding among mothers seeking care in $\mathrm{P} 4 \mathrm{P}$ implementing facilities versus comparator facilities (low certainty evidence).

\section{3. Resource use}

In relation to resource use indicators, the evidence is mixed (see Table 2 and Appendix 5, Table 55, low certainty evidence). While P4P may increase equipment availability by $75 \%$, medicine availability may be reduced by up to $160 \%$. The latter effect is likely due to scheme design, as the Zambia scheme offered supplies as an ancillary component of the intervention but not medication.

\section{4. Secondary outcomes}

P4P seems to have mixed effects on secondary outcome indicators (see Table 2 and Appendix 5, Tables 56-58). Similar to the effects of P4P against a pure control, P4P may positively affect facility autonomy (low certainty evidence, Table 56); however impacts on patient satisfaction and acceptability are uncertain (very low certainty evidence, see table 57). P4P may have little to no effect on the equitable utilisation of curative and antenatal care visits (low certainty evidence), however may have negative redistributive effects in relation to institutional delivery utilisation (i.e. utilization appears to increase in least poor groups) and family planning (see Table 58, low certainty effect).

\section{Comparison 2b: Effects on untargeted outcomes}

\section{5. Untargeted measures of provider performance}

\section{5. 1. Untargeted delivery and utilization}

Evidence on the effects of P4P on untargeted utilization is only available for two indicators (Table 2 and Appendix 5, Tables 59-60). For both, the evidence suggests P4P may make little to no difference (low certainty evidence).

\section{5. 2. Quality of care}

Effects of P4P on untargeted quality of care appear uncertain due to very low certainty in evidence (Appendix 5, Table 61).

\section{6. Untargeted health outcomes}

In relation to untargeted health outcomes (Table 2 and Appendix 5 , Table 62), P4P may have little to no effect on the proportion of women breastfeeding (low certainty evidence). P4P may positively

Paying for performance to improve the delivery of health interventions in low- and middle-income countries (Review) 
affect the incidence of reported illness in children (range -5 to $10.5 \%$, low certainty evidence).

\section{7. Unintended effects}

No evidence on distorting unintended effects is available.

\section{8. Untargeted resource use}

In relation to both equipment and medicine availability, certainty in evidence is very low and effects are therefore uncertain (Table 2 and Appendix 5, Table 63).

\section{9. Untargeted secondary outcomes}

In relation to secondary outcomes (Table 2 and Appendix 5, Tables 64-66), limited evidence is available. Effects of P4P on facility and managerial autonomy are uncertain (very low certainty in evidence, Table 64). P4P may have largely positive effects on patient satisfaction and acceptability even when indicators are not explicitly targeted (low certainty evidence, see Table 65). However, there may be little to no effect on staff motivation or satisfaction when not targeted (low certainty evidence, see Table 66).

\section{Sensitivity analyses}

Across Summary of Findings Tables 1-66, we include comments on the range of the intervention's effects on each of the reviewed indicators based on RCT studies only; where relevant, these findings have been GRADEd separately.

For a more complete overview, the Sensitivity Analyses Summary tables (Table 9 and Table 10) illustrate the effects recorded in RCTs. Overall, the certainty of evidence reviewed is assessed as low to moderate. Concerns over the risk of bias in individual studies and the limited availability of studies, with the majority of indicators being reported on in only one study, are the primary reason for downgrading evidence to 'low'.

Table 9 illustrates and comments on effects of P4P against a status quo control. Overall, effects are largely consistent, however some deviations are notable when appraising the effects of P4P against a control (see Table 9) in relation to utilization and quality of care indicators. In particular, effects on specific immunization and quality of care indicators are now more clearly distinguishable (and appear largely positive). However, in relation to antenatal care, the evidence from RCTs seems to indicate that P4P may have negative effects on utilization of such services. Only one study appraised a health outcome indicator, and here we note that P4P may have a very slight effect only. Further, RCT evidence suggests P4P may have only limited $(<5 \%)$ effects on secondary outcomes such as provider motivation and patient satisfaction.

In relation to the effects of P4P as assessed against comparator interventions (see Table 10), relatively limited evidence was available, the majority of which has been assessed as low certainty. In relation to service utilization and delivery a mixed picture emerges. Evidence suggests effects on immunization are overall inconsistent, effects on utilization overall appear neutral, however effects on institutional delivery and postnatal care utilization seem negative. In relation to quality of care, mixed effects are also notable.

\section{Sub-group analyses}

Upon reviewing the Characteristics of Interventions in detail, we further classified the P4P schemes according to the design reported in reviewed documents (see Table 7 and Table 8; Please note that to ensure consistency, we have chosen to classify all studies based on descriptions provided in the reviewed documents). We reviewed findings presented in Tables 1-66 and sought to identify patterns which would explain variation in effect given the P4P scheme classification. The results of this exercise are presented in the Subgroup analyses findings tables (Table 11 and Table 12)

Similar patterns emerged across both the studies assessing the effects of P4P against control as well as those assessing effects against a comparator (Table 11). Performance based contracting and results-based aid appeared to yield the greatest effects upon outcomes overall. However, we note that these scheme designs were used only in a minority of studies, so the effects observed may be spurious.

Payment per output designs were most commonly implemented, however, and clear patterns in relation to the relative effects of such schemes emerged. Overall, schemes adjusting both for quality of service as well as rewarding equitable delivery of that service appeared to perform best, particularly in relation to service utilization outcomes. Similarly, schemes employing payments per output with a quality adjustment, or combining a payment per output and target payment, appeared to outperform the payment per output and target payment designs.

Differential effects by outcome were evident however (see Table 12): health outcome indicators, for example, appeared to respond best to target payment, and payment per output designs where adjustments for quality scoring took place. However, we caution that health outcome indicators were appraised in a minority of reviewed studies, therefore patterns observed here may be due to chance.

\section{DISCUSSION}

In recent years, the literature on the theory, effects and implementation of P4P programmes has expanded dramatically. Our search strategies retrieved over 11 thousand results, of which $10 \%$ were of potential relevance to this review.

Increasingly, P4P is being framed not as one intervention, but as a class of interventions using a collection of mechanisms (Renmans 2016). Our Intervention Classification illustrates that a wide range of scheme designs are used with the fundamental idea to align the incentives of providers with those of the commissioners of care. However, our typology is necessarily simplified and the details and mechanisms by which results are achieved (or not) will vary. The effects and impacts of P4P likely depend on a range of factors, including how and why schemes are designed, the degree of participation in setting targets, what targets are used, how they are measured, the level of rewards they attract and by the context in which the schemes take place, including the efficiency of implementation systems and underlying factors such as starting levels of pay and funding. For that reason, this review has presented considerable detail on the design and implementation of the P4P schemes, as these factors are key to interpreting results. Considering the intervention Complexity Assessment Tool 
for Systematic Reviews (Lewin 2017), P4P scores highly in every domain.

We note that while many details of schemes (e.g. funders, verification processes among others) are consistently reported on, some critical reporting gaps in relation to scheme design exist. For example, only $40 \%$ of studies describe the location of care provision and a minority of studies report on scheme costs. Further, explicit theories of change or programme theories detailing how and why schemes are designed, and how they are fit for specific contexts are often not provided. To illustrate this point, it is often unclear how schemes set their targets or choose indicators, including why some schemes would incorporate over 200 quality of care markers for assessment, while others include under 100. Similarly, it is not always clear what aspects of schemes are core mechanisms versus additional features, e.g. it is often unclear whether auditing processes and procedures are designed for verification only, as opposed to wider initiatives intended to strengthen managerial capacity and oversight. Setting of 'prices' of indicators is another area lacking clarity in relation to how these were calculated, and based on what rationale (e.g. to replace user fee revenues, or based on an understanding of facility cost structures, to give just two possible examples).

\section{Summary of main results}

This review included 59 studies for which evidence has been assessed to be of low to moderate certainty. Increasingly however, more robust study designs are being used to assess the effects of $\mathrm{P} 4 \mathrm{P}$, including, for example, controlled ITS and cluster-RCTs.

Findings identify some evidence of scheme success as well as evidence on some areas and indicators which appear to be less responsive to P4P. However, findings additionally indicate that the choice of comparator intervention (whether control or a different comparator intervention) and scheme design are critical in interpreting results.

In relation to utilization and service delivery outcomes, we identify inconsistent effects overall. P4P may have differential desirable as well as undesirable effects: e.g. while indicators relating to HIV testing, family planning, and postnatal care appear to be positively impacted, evidence on the effects of P4P on indicators such as ART, antenatal care or immunization utilization is mixed. These findings are surprising as antenatal care and immunization are frequently targeted by P4P schemes, however we note that in the case of the latter indicator, findings may be due to broader circumstances surrounding vaccine availability. Overall, we noted that performance-based contracting, results-based aid and P4P designs including both payment per output and quality and equity adjustments performed best in relation to securing increased service delivery and utilization.

While health outcomes were appraised in a minority of studies, we note interesting effects in relation to these. Whether targeted or not, P4P may have slight positive impacts on health outcomes appraised against a pure control or standard care; however, when compared against other interventions such as enhanced financing, limited to no impacts were identifiable.

P4P probably increases quality of care overall, especially when directly targeted. However, indicators which are clinical-area specific (e.g. quality of ANC consultations) or which are broadly related to medicine and equipment quality appear to respond best. We have noted limited to uncertain effects on general quality of care indicators such as providers conducting background or physical assessments, or counselling patients.

Further, P4P schemes may have positive impacts overall on the availability (and as relevant functionality) of medicines, equipment and infrastructure and probably have limited to no negative distorting unintended effects.

In relation to secondary outcomes, we have identified surprising results. P4P's effects on provider satisfaction and motivation are overall mixed, however the evidence suggests the intervention may increase managerial autonomy, but have limited effects on quality of management or governance in general. Equity effects are also uncertain: when assessed against a pure control, P4P appears may have largely beneficial redistributive effects, but when assessed against a comparator the evidence appears mixed. We identified little to no effect or uncertain effects on user fees are found, which is disappointing as this is an important intended mechanism of change for P4P schemes.

\section{Sub-group analyses}

Sub-group analyses suggest that different scheme designs may be more effective than others in securing effects against assessed outcomes. Among promising scheme designs, we note payment per output with quality and/or equity adjustment, performance based contracting and results-based aid. We caution however that the latter designs were implemented and studied in a small range of contexts, therefore effects observed may be due to contextual differences and drivers rather than scheme design.

We had expected to conduct sub-group analyses by magnitude of incentive (either absolute or relative) and also to attempt to isolate the effects of ancillary components (such as supervision). However, given limited reporting on these characteristics, we were unable to conduct such analyses.

\section{Overall completeness and applicability of evidence}

This study is an update of the original review on the effects of P4P in low- and middle-income countries and therefore capitalises on the additional research carried out over the last 7 years. As noted previously, this research area has seen an exponential increase in interest and the evidence base overall has been strengthened.

In comparison to the original review, which included 9 studies, 6 times as many studies have been included in this update $(n=59)$. While the predominant focus of evaluations is still on the schemes from Rwanda, Tanzania and China, a broader range of country settings are represented, including increasingly studies from Latin America. Most studies continue to focus on schemes targeted at strengthening reproductive, maternal and child health services, but increasingly evidence on schemes focused on other areas, such as HIV and TB, is becoming available.

Overall, we note a clear focus on evidence reflecting the effects of $\mathrm{P} 4 \mathrm{P}$ implementation in the public sector; only one of the reviewed studies focused on the private sector only. However, we note a more heterogeneous picture emerging in terms of the types of P4P schemes being assessed (although only one eligible study on the effects of results-based aid was located), as well as the study types, comparators and time-frames of assessment. While 
these developments are encouraging, and suggestive of a broader interest in P4P effects, both in the short- and long-term and on targeted and not-targeted outcomes, they imply added complexity for the synthesis of evidence and interpretation of effects. Further, both the proliferation and heterogeneity of evidence available makes it difficult to detect publication bias. Given that most studies report on over 10 core outcomes each, from schemes which may target even more indicators (as illustrated in Josephson 2017), within varying population groups or clinical areas, it is difficult to assess whether reporting is purposefully restricted to positive effects or pragmatically restricted to indicators where data is available and analysable.

During searches we identified health economic evaluations estimating costs of P4P schemes in Tanzania (Borghi 2015), the Philippines (Peabody 2017) and Zambia (Zeng 2018b). Alongside information presented in Gertler 2014, these studies estimate the approximate expenditure per capita of the P4P programme to be 7-10\$US; total costs per program vary widely between approximately 2,6 million \$US(2012) in Tanzania to 20,45 million \$US in Argentina. We note that P4P appears to incur slightly higher costs in implementing facilities compared to those implementing enhanced financing interventions. The increment ranges from 0.57 \$USD extra for consumables to $10 \%$ higher expenditure in the PBF groups (Lagarde 2015, Zeng 2018b). The only two studies (Borghi 2015 , Peabody 2017) providing a comprehensive breakdown of implementation expenditure within the PBF scheme indicate that $22 \%$ and $52 \%$ of scheme costs were spent on bonus payments in Tanzania and the Philippines respectively. In Tanzania specifically, $37 \%$ of costs were spent on data generation, and $28 \%$ on management of the scheme, highlighting potentially high health system costs for implementation. Gertler 2014 and Peabody 2017 additionally respectively estimate the cost-utility of programs at 814 \$US (ranging from 442-5086)/DALY averted and 1.58 DALY/ \$US spent, further highlighting potentially high variability in costutility of schemes.

Similar to other research on the cost-effectiveness of P4P schemes (Turcotte-Tremblay 2016), we conclude evidence on costs and health economic impacts of P4P schemes to be relatively scarce; this is something that other evaluators and future review updates should carefully consider. Similarly, evidence on health outcomes is also sparse.

\section{Certainty of the evidence}

The certainty of reviewed evidence differed by indicator; however, across the majority of indicators, evidence was down-graded due to concerns related to risk of bias, indirectness or imprecision. In relation to risk of bias, we note that the majority of available studies are still of a controlled before and after or quasi-randomized design. Across this body of evidence, lack of randomization and allocation concealment were the primary reasons for downgrading the quality of evidence. However, the increased availability of RCT and ITS designs meant the certainty of evidence could be judged as moderate for a greater number of indicators in comparison to the original 2012 review.

\section{Potential biases in the review process}

We identify two biases in the review process. First, given the volume of studies and indicators evaluated, we had to restrict the focus of the review and only report on those indicators which were comparable and assessed across two or more studies. Comparability of indicators is a subjective judgment, and while two reviewers conducted this process and submitted all materials for review by the wider group, researcher bias may be present. We further note that this will remain a potentially problematic area unless there is harmonization in reported indicators.

Second, we restrict reporting to relative effects and acknowledge a major limitation in being unable to supplement this with information on absolute effects. The majority of reviewed studies restricted their reporting to beta coefficients obtained from clustered regression, accounting for multiple covariates associated with both intervention and population characteristics. Given the clustered nature of the data and lack of reporting on cluster characteristics overall (e.g. coefficients of variation of cluster sizes and intra-cluster correlation coefficients) we could not re-do analyses and instead have opted to use the relative effect measures (as provided by study authors themselves, or re-calculated).

Several other external limitations apply. First, we note substantive lack of harmonization across schemes - e.g. several child immunization indicators were reported on, however utilization rates referred to different age-groups, making synthesis difficult. Second, the assessment of effects on health outcomes is a clear gap area: it is unclear why such outcomes were assessed across a minority of studies, when data should have been more generally available given the wide range of indicators targeted. Third, we were unable to produce a meta-estimate on the effects of P4P against each of the assessed indicators as we judged this uninformative given the aforementioned comparability issues. While similar analyses techniques were used across studies (principally difference in difference analyses), the effect estimates derived from equations adjusting for multiple covariates could not be meaningfully synthesised. Additionally, studies did not consistently report on measures of precision, thus precluding the possibility of comprehensively attempting pooling of estimates.

Fourth, we note two further areas which demand exploration via analyses which account for the inherent complexity of P4P scheme design. One area concerns itself with how P4P may have interacted with other ongoing interventions (e.g. the expansion of health insurance coverage); another relates to accounting for the implementation of ancillary components alongside the main P4P scheme. To adequately assess the impacts of both of these on P4P effects, as well as impact of diverse contexts and scheme designs, complexity science methods may be required. Further, we have restricted this review to evidence collated in quantitative impact evaluations only; qualitative and health economic studies conducted alongside these evaluations would need to be consulted to appropriately investigate variations in scheme design, roll-outs and further implementation as well as explore how schemes have been received by health and allied professionals at different system levels. Last, we note that it was difficult to conduct a comprehensive sub-group analysis given the data volume available and multitude of scheme designs implemented. We urge readers to consider our attempt here cautiously.

\section{Agreements and disagreements with other studies or reviews}

Several findings are of particular interest when compared with the original 2012 review on this topic (New Reference) and to other available evidence on the effects of P4P. First, in relation to the 
original 2012 review, we note that available evidence has multiplied and also somewhat improved in quality.

Our findings differ across several of the outcomes assessed. In the original review, evidence on quality of care was mixed, however we currently assess that P4P may have positive impacts on this outcome. This is particularly interesting as the general debate in the P4P community has focused on how to shift from volume to effective quality measures (Josephson 2017). A priori, we would therefore have expected the opposite patterns from the findings of this review, with utilisation indicators responding more than quality ones. While the quality of care indicators assessed were numerous and diverse (Josephson 2017), and included both structural and process quality measures, we generally noted findings similar to those of Das, Gopalan and Chandramohan in their 2016 review on the topic (Das 2016).

Our findings suggest that P4P may have positive effects on health outcomes (relative to pure controls, if not matched comparators) and also on some utilization indicators, such as those related to modern family planning (Blacklock 2016) and postnatal care, which were previously noted to be unresponsive. In relation to the effects of P4P on the more commonly targeted utilization outcomes such as antenatal care and institutional deliveries, our findings are largely consistent with the 2012 review.

In relation to motivation and satisfaction, we note findings similar to those of Dale 2014. However, we acknowledge particular methodological challenges surrounding the appraisal of this evidence: certainty in our findings may be compromised by indirectness in particular. As Dale (2014) points out, motivation is often assessed and measured using different scales. Indeed, in our review, we have attempted to synthesise information across a range of different outcomes and measurement.

\section{AUTHORS' CONCLUSIONS}

\section{Implications for practice}

The evidence around P4P has grown considerably since the last review (Witter 2012), with researchers and practitioners gradually focused on unpacking the wider health system effects and impacts of P4P schemes. Study quality has gradually improved, with more RCT designs being used, however the overarching evidence base to date is still dominated by CBAs. This, alongside the heterogeneity of schemes implemented and reviewed here, makes any conclusions and implications tentative.

Overall, this review suggests that in comparison to a status quo control P4P may have some positive effects on service utilization and delivery, for example in relation to family planning; however, impacts on other service areas (e.g. antenatal care, immunization, institutional delivery) may be difficult to secure. P4P may also have positive effects on health outcomes when compared to a status quo control, however limited evidence on health outcomes is available from comparisons of $\mathrm{P} 4 \mathrm{P}$ against other interventions such as matched financing. We further note that technical inputs (e.g. infrastructure functionality, equipment and medicine availability) may be positively affected by the introduction of P4P schemes; facility autonomy may be fostered as well, although effects on procedural care and governance are uncertain.
Few studies focused on assessing P4P impacts against a comparator intervention, however our findings to date tentatively suggest that some indicators react to the influx of funding itself and not the performance-related conditionality of payment. Subgroup analyses additionally suggest that specific scheme designs may perform better at achieving targeted outcomes. For example, target payments were noted to outperform other scheme designs in relation to health outcomes in particular (e.g. payments being conditional on tuberculosis success rates), whereas utilization and delivery outcomes seemed to increase most in schemes adjusting for both service quality and equity.

\section{Implications for research}

As noted above, we acknowledge the exponential growth in studies focused on assessing and exploring the impacts of P4P schemes since the publication of the last review (Witter 2012). Conclusions presented here are limited as we have focused on quantitative impact evaluations only, however these are presented as complementary to the work of other groups focused, for example, on conducting realist syntheses of P4P schemes (Borghi 2018).

The evidence base has expanded to consider a greater range of P4P scheme designs and modalities, covering diverse scales of magnitude, levels of implementation within the health system, types of services and providers, comparator groups as well as contexts. Increasingly, cluster RCTs are used to assess the effects of P4P schemes: this is a welcome development; however, we caution that such studies must be complemented by thorough theory-based evaluations so as to understand how the schemes were designed (and by whom) and their ex ante theory of change, compared with the mechanisms which were triggered ex post. It is also important to document the interaction of P4P with the wider health system (Witter 2013) how it affects components such as supervision, referrals and health information systems, and is affected by them in turn.

Multi-arm or stepped wedge RCT designs, as well as controlled ITS, may be needed to additionally unpack the effects of diverse $\mathrm{P} 4 \mathrm{P}$ implementation pathways or alternative scheme designs going forward. This implies a shift in focus from research assessing whether P4P may or may not work, to research focused on both establishing P4P effects and identifying, understanding and unpacking the contextualized pathways to scheme impact, using dynamic approaches.

Longer-time frames of inquiry and diverse and alternative comparator groups would also be of particular interest. The evidence base on impacts of P4P is still dominated by studies assessing impacts after approximately 3 years, however little is known on how schemes change once they are embedded in systems, how they are affected by their coherence (or lack of it) with wider health financing policies, and on whether they are sustainable and maintain impacts long term.

Few studies to date explored the equity effects of schemes and heterogeneity of P4P results for different provider types, areas and populations sub-groups; when this was done, studies noted challenges in relation to study design and power as restricting their conclusions (e.g. as in Binyaruka 2018). 
Further, few studies to date purposefully assessed effects against a realistic enhanced financing comparator (such as direct facility financing embedded in routine planning and reporting systems) or demand-side interventions; given the drive to expand universal health coverage, these types of studies - when robustly designed and allowing for the isolation of P4P effects - are greatly needed.

Another important area for future research is that of the costeffectiveness of P4P schemes. We have identified a small number of studies focused on this, which we have not been able to review, however a comprehensive search for such evidence will be warranted in future. Similarly, the sustainability of schemes, as well as cost and budgetary implications, remains an under-researched topic.

To fully explore the impacts of P4P schemes, evaluations should continue to adopt rigorous research designs and take a broad perspective in considering wider intended or unintended system effects; the focus for research going forward should be on identifying for whom, under what conditions, via what mechanism, at what cost and compared to what other interventions, does P4P work?

\section{ACKNOWLEDGEMENTS}

We gratefully acknowledge the help of Marit Johansen and Lara Christianson in developing and implementing the search strategies, of Nicole Vidal for assisting with data extraction and of Stefan Lhachimi for his inputs in the initial phases of the review. We also acknowledge the helpfulness of the original study authors in providing additional data and information. We further extend our gratitude to the Institute for Global Health and Development at Queen Margaret University for funding the staff time necessary to complete this review and also to the Norwegian EPOC satellite for funding meetings between review authors.

The Norwegian Satellite of the EPOC Group receives funding from the Norwegian Agency for Development Cooperation (Norad), via the Norwegian Institute of Public Health to support review authors in the production of their reviews. 


\section{R E F E R E N C E S}

\section{References to studies included in this review}

\section{Basinga 2011 \{published data only\}}

Basinga P, Gertler PJ, Binagwaho A, Soucat AL, Sturdy J, Vermeersch CM. Effect on maternal and child health services in Rwanda of payment to primary health-care providers for performance: an impact evaluation. Lancet 2011;377(9775):1421-8.

\section{Bernal 2018 \{published data only\}}

Bernal P, Celhay P, Martinez S. Is results-based aid more effective than conventional aid? Evidence from the health sector in El Salvador. IDB Working Paper Series No. IDB-WP-859 2018.

\section{Binyaruka 2015 \{published data only\}}

Binyaruka P, Patouillard E, Powell-Jackson T, Greco G, Maestad O, Borghi J. Effect of paying for performance on utilisation, quality, and user costs of health services in Tanzania: a controlled before and after study. PLOS One 2015;10(8):e0135013.

\section{Binyaruka 2017 \{published data only\}}

Binyaruka P, Borghi J. Improving quality of care through payment for performance: examining effects on the availability and stock-out of essential medical commodities in Tanzania. Tropical Medicine and International Health 2017;22(1):92-102.

\section{Binyaruka 2018 \{published data only\}}

Binyaruka P, Robberstad B, Torsvik G, Borghi J. Who benefits from increased service utilisation? Examining the distributional effects of payment for performance in Tanzania. International Journal for Equity in Health 2018;17:14.

Bonfrer 2014a \{published data only\}

Bonfrer I, Soeters R, Van de Poel E, Basenya O, Longin G, van de Looij $F$, et al. Introduction of performance-based financing in Burundi was associated with improvements in care and quality. Health Affairs 2014;33(12):2179-87.

\section{Bonfrer 2014b \{published data only\}}

Bonfrer I, Van de Poel E, Van Doorslaer E. The effects of performance incentives on the utilization and quality of maternal and child care in Burundi. Social Science and Medicine 2014;123:96-104.

\section{Brock 2018 \{published data only\}}

Brock JM, Lange A, Leonard KL. Giving and promising gifts: experimental evidence on reciprocity from the field. Journal of Health Economics 2018;58:188-201.

\section{Celhay 2015 \{published data only\}}

Celhay P, Gertler P, Giovagnoli P, Vermeersch C. Long-run effects of temporary incentives on medical care productivity. National Bureau of Economic Research: NBER Working Paper Series. Working Paper No. 21361. 2015.

\section{Chang 2017 \{published data only\}}

Chang F, Xi Y, Zhao J, Zhang X, Lu Y. A time series analysis of the effects of financial incentives and mandatory clinical applications as interventions to improve spontaneous adverse drug reaction reporting by hospital medical staff in China. Journal of Evaluation in Clinical Practice 2017;23(6):1316-21.

\section{Chansa 2015 \{published data only\}}

Chansa C, Das A, Qamruddin JN, Friedman J, Mkandawire A, Vledder M. Linking results to performance: evidence from a results based financing pre-pilot project in Katete District, Zambia. Washington, D.C.: World Bank Group. Health, Nutrition and Population Discussion Paper No. 98265. 2015.

\section{Cruzado de la Vega 2017 \{published data only\}}

Cruzado de la Vega V. Payment by performance to improve the nutritional status of children: Impact of budget support agreements in three Peruvian regions with a high prevalence of chronic malnutrition in children in 2010-2014 [Pagos por desempeño para mejorar el estado nutricional infantil: impacto de los convenios de apoyo presupuestario en tres regiones peruanas con alta prevalencia de desnutrición crónica infantil, 2010-2014]. Revista Peruana de Medicina Experimental y Salud Publica 2017;34(3):365-76.

\section{Das 2017 \{published data only\}}

Das A. Effect of pay for performance on the quality of antenatal care in Zimbabwe: a controlled before-after study [Doctor of Philosophy thesis]. London: London School of Hygiene and Tropical Medicine, 2017.

\section{de Walque 2015 \{published data only\}}

de Walque D, Gertler PJ, Bautista-Arredondo S, Kwan A, Vermeersch C, de Dieu Bizimana J, et al. Using provider performance incentives to increase HIV testing and counseling services in Rwanda. Journal of Health Economics 2015;40:1-9.

\section{de Walque 2017 \{published data only\}}

de Walque, Robyn PJ, Saidou H, Sorgho G, Steenland M. Looking into the performance-based financing black box: evidence from an impact evaluation in the health sector in Cameroon. Washington, D.C.: World Bank Group. Policy Research Working Paper No. WPS8162. 2017

\section{Duysburgh 2016 \{published data only\}}

Duysburgh E, Temmerman M, Yé M, Williams A, Massawe S, Williams J, et al. Quality of antenatal and childbirth care in rural health facilities in Burkina Faso, Ghana and Tanzania: an intervention study. Tropical Medicine and International Health 2016;21(1):70-83

\section{Engineer 2016 \{published data only\}}

Engineer CY, Dale E, Agarwal A, Agarwal A, Alonge O, Edward A, et al. Effectiveness of a pay-for-performance intervention to improve maternal and child health services in Afghanistan: a cluster-randomized trial. International Journal of Epidemiology 2016;45(2):451-9. 


\section{Falisse 2015 \{published data only\}}

Falisse JB, Ndayishimiye J, Kamenyero V, Bossuyt M. Performance-based financing in the context of selective free health-care: an evaluation of its effects on the use of primary health-care services in Burundi using routine data. Health Policy and Planning 2015;30(10):1251-60.

\section{Friedman 2016a \{published data only\}}

Friedman J, Qamruddin J, Chansa C, Das AK. Impact evaluation of Zambia's health results-based financing pilot project. Washington, D.C.: World Bank Group. Working Paper No. 120723. 2016.

\section{Friedman 2016b \{published data only\}}

Friedman J, Das A, Mutasa R. Rewarding provider performance to improve quality and coverage of maternal and child health outcomes. Zimbabwe results-based financing pilot program: evidence to inform policy and management decisions. Washington, D.C.: The International Bank for Reconstruction and Development/ The World Bank. Report No. 106518-ZW. 2016.

\section{Gertler 2012 \{published data only\}}

Gertler P, Vermeersch C. Using performance incentives to improve health outcomes. Washington, D.C.: World Bank. Policy Research Working Paper No. WPS 6100. 2012.

\section{Gertler 2014 \{published data only\}}

Gertler P, Giovagnoli P, Martinez S. Rewarding provider performance to enable a healthy start to life: evidence from Argentina's Plan Nacer. Washington DC: World Bank Group. Policy Research Working Paper No. WPS 6884. 2014.

\section{Huillery 2017 \{published data only\}}

Huillery E, Seban J. Money for nothing? The effect of financial incentives on efforts and performances in the health sector. 2017. [PDF: econ.sciences-po.fr/sites/default/files/file/elise/ paper_DRC_July2016.pdf]

\section{Ir 2015 \{published data only\}}

Ir P, Korachais C, Chheng K, Horemans D, Van Damme W, Meessen B. Boosting facility deliveries with results-based financing: a mixed-methods evaluation of the government midwifery incentive scheme in Cambodia. BMC Pregnancy and Childbirth 2015;15:170.

\section{Khim 2018 \{published data only\}}

Khim K, Jayasuriya R, Annear PL. Administrative reform and pay-for-performance methods of primary health service delivery: a comparison of 3 health districts in Cambodia, 2006-2012. International Journal of Health Planning and Management 2018;33(2):e569-85.

\section{Kliner 2015 \{published data only\}}

Kliner M, Canaan M, Ndwandwe S, Busulwa F, Welfare W, Richardson $\mathrm{M}$, et al. Effects of financial incentives for treatment supporters on tuberculosis treatment outcomes in Swaziland: a pragmatic interventional study. Infectious Diseases of Poverty 2015;4:29.

\section{Lagarde 2015 \{published data only\}}

Lagarde M, Burn S, Lawin L, Bello K, Dossou J-P, Makoutode P, et al. Exploring the impact of performance-based financing on health workers' performance in Benin. RBF Health 2015. [PDF: www.rbfhealth.org/sites/rbf/files/Benin\%20RBFHRH $\% 20$ report.pdf]

\section{Lannes 2015 \{published data only\}}

Lannes L. Improving health worker performance: the patientperspective from a PBF program in Rwanda. Social Science and Medicine 2015;138:1-11.

\section{Lannes 2016 \{published data only\}}

Lannes L, Meessen B, Soucat A, Basinga P. Can performancebased financing help reaching the poor with maternal and child health services? The experience of rural Rwanda. International Journal of Health Planning and Management 2016;31(3):309-48.

Liu 2005 \{published data only\}

Liu X, Mills A. The effect of performance-related pay of hospital doctors on hospital behaviour: a case study from Shandong, China. Human Resources for Health 2005;3:11.

\section{Matsuoka 2014 \{published data only\}}

Matsuoka S, Obara H, Nagai M, Murakami H, Chan Lon R. Performance-based financing with GAVI health system strengthening funding in rural Cambodia: a brief assessment of the impact. Health Policy and Planning 2014;29(4):456-65.

\section{Mayumana 2017 \{published data only\}}

Mayumana I, Borghi J, Anselmi L, Mamdani M, Lange S. Effects of payment for performance on accountability mechanisms: evidence from Pwani, Tanzania. Social Science and Medicine 2017;179:61-73.

\section{McMahon 2016 \{published data only\}}

McMahon S, De Allegri M. Final results of the SSDI-PBI process and impact evaluation. 2016. [PDF: heidelberg.de/fileadmin/ inst_public_health/Dokumente/SSDI_final_report.pdf]

\section{Menya 2015 \{published data only\}}

Menya D, Platt A, Manji I, Sang E, Wafula R, Ren J, et al. Using pay for performance incentives (P4P) to improve management of suspected malaria fevers in rural Kenya: a cluster randomized controlled trial. BMC Medicine 2015;13:268.

\section{Mohanan 2017 \{published data only\}}

Mohanan M, Miller G, Donato K, Truskinovsky Y, VeraHernández M. Different strokes for different folks: experimental evidence on the effectiveness of input and output incentive contracts for health care providers with different levels of skills. Washington DC: Centre for Global Development. Working Paper No. 464. 2017.

\section{Peabody 2011 \{published data only\}}

Peabody J, Shimkhada R, Quimbo S, Florentino J, Bacate M, McCulloch CE, et al. Financial incentives and measurement improved physicians' quality of care in the Philippines. Health Affairs 2011;30(4):773-81. 
Peabody 2014 \{published data only\}

Peabody JW, Shimkhada R, Quimbo S, Solon O, Javier X, McCulloch $C$. The impact of performance incentives on child health outcomes: results from a cluster randomized controlled trial in the Philippines. Health Policy and Planning 2014;29(5):615-21.

\section{Powell-Jackson 2014 \{published data only\}}

Powell-Jackson T, Yip WC, Han W. Realigning demand and supply side incentives to improve primary health care seeking in rural China. Health Economics 2014;24(6):755-72.

\section{Priedeman Skiles 2013 \{published data only\}}

Priedeman Skiles M, Curtis S, Basinga P, Angeles G. An equity analysis of performance-based financing in Rwanda: are services reaching the poorest women? Health Policy and Planning 2013;28(8):825-37.

\section{Priedeman Skiles 2015 \{published data only\}}

Priedeman Skiles M, Curtis SL, Basinga P, Angeles G, Thirumurthy $\mathrm{H}$. The effect of performance-based financing on illness, care-seeking and treatment among children: an impact evaluation in Rwanda. BMC Health Services Research 2015;15:375

\section{Quimbo 2016 \{published data only\}}

Quimbo S, Wagner N, Florentino J, Solon O, Peabody J. Do health reforms to improve quality have long-term effects? Results of a follow-up on a randomized policy experiment in the Philippines. Health Economics 2016;25(2):165-77.

\section{Rudasingwa 2014 \{published data only\}}

Rudasingwa M, Soeters R, Bossuyt M. The effect of performancebased financial incentives on improving health care provision in Burundi: a controlled cohort study. Global Journal of Health Science 2014;7(3):15-29.

\section{Rusa 2009 \{published data only\}}

Rusa L, Ngirabega J de D, Janssen W, Van Bastelaere S, Porignon D, Vandenbulcke W. Performance-based financing for better quality of services in Rwandan health centres: 3year experience. Tropical Medicine and International Health 2009;14(7):830-7.

\section{Shapira 2017 \{published data only\}}

Shapira G, Kalisa I, Condo J, Humuza J, Mugeni C, Nkunda D, et al. Effects of performance incentives for community health worker cooperatives in Rwanda. Washington, D.C.: World Bank Group. Policy Research Working Paper No. WPS 8059. 2017.

\section{Shen 2017 \{published data only\}}

Shen GC, Nguyen HT, Das A, Sachingongu N, Chansa C, Qamruddin J, et al. Incentives to change: effects of performance-based financing on health workers in Zambia. Human Resources for Health 2017;15(1):20.

\section{Sherry 2017 \{published data only\}}

Sherry TB, Bauhoff S, Mohanan M. Multitasking and heterogeneous treatment effects in pay-for-performance in health care: evidence from Rwanda. American Journal of Health Economics 2017;3(2):192-226.
Soeters 2011 \{published data only\}

Soeters R, Peerenboom PB, Mushagalusa P, Kimanuka C. Performance-based financing experiment improved health care in the Democratic Republic of Congo. Health Affairs 2011;30(8):1518-27.

\section{Steenland 2017 \{published data only\}}

Steenland M, Robyn PJ, Compaore P, Kabore M, Tapsoba B, Zongo $A$, et al. Performance-based financing to increase utilization of maternal health services: evidence from Burkina Faso. SSM - Population Health 2017;3:179-84.

Sun 2016 \{published data only\}

Sun X, Liu X, Sun Q, Yip W, Wagstaff A, Meng Q. The impact of a pay-for-performance scheme on prescription quality in rural China. Health Economics 2016;25(6):706-22.

Van de Poel 2016 \{published data only\}

Van de Poel E, Flores G, Ir P, O'Donnell O. Impact of performance-based financing in a low-resource setting: a decade of experience in Cambodia. Health Economics 2016;25(6):668-705.

Viñuela 2015 \{published data only\}

Viñuela L, Zoratto L. Do performance agreements help improve service delivery? the experience of Brazilian states. Washington DC: World Bank Group. Policy Research Working Paper No. WPS 7375. 2015.

\section{Wagner 2018 \{published data only\}}

Wagner N, Quimbo S, Shimkhada R, Peabody J. Does health insurance coverage or improved quality protect better against out-of-pocket payments? Experimental evidence from the Philippines. Social Science and Medicine 2018;204:51-8.

\section{Witvorapong 2016 \{published data only\}}

Witvorapong N, Foshanji Al. The impact of a conditional cash transfer program on the utilization of non-targeted services: evidence from Afghanistan. Social Science and Medicine 2016;152:87-95.

\section{Wu 2014 \{published data only\}}

Wu B. Mismeasurement in pay-for-performance: evidence from an intervention to reduce health care spending in China. New Jersey: Rutgers University, Department of Economics. Departmental Working Papers 201409. 2014.

\section{Yao 2008 \{published data only\}}

Yao H, Wei X, Liu J, Zhao J, Hu D, Walley JD. Evaluating the effects of providing financial incentives to tuberculosis patients and health providers in China. International Journal of Tuberculosis and Lung Disease 2008;12(10):1166-72.

\section{Yip 2014 \{published data only\}}

Yip W, Powell-Jackson T, Chen W, Fe E, Hu M, Jian W, et al. Capitation combined with pay-for-performance improves antibiotic prescribing practices in rural China. Health Affairs 2014;33(3):502-10.

Paying for performance to improve the delivery of health interventions in low- and middle-income countries (Review) 
Zang 2015 \{published data only\}

Zang O, Djienouassi S, Sorgho G, Taptue JC. Impact of performance-based financing on health-care quality and utilization in urban areas of Cameroon. 2015

\section{Zeng 2013 \{published data only\}}

Zeng W, Cros M, Wright KD, Shepard DS. Impact of performancebased financing on primary health care services in Haiti. Health Policy and Planning 2013;28(6):596-605.

\section{Zeng 2018a \{published data only\}}

Zeng W, Shepard DS, Rusatira JD, Blaakman AP, Nsitou BM. Evaluation of results-based financing in the Republic of the Congo: a comparison group pre-post study. Health Policy and Planning 2018;33(3):392-400.

\section{References to studies excluded from this review}

\section{Aninanya 2016 \{published data only\}}

Aninanya GA, Howard N, Williams JE, Apam B, Prytherch H, Loukanova $\mathrm{S}$, et al. Can performance-based incentives improve motivation of nurses and midwives in primary facilities in northern Ghana? A quasi-experimental study. Global Health Action 2016;9:32404.

\section{Anselmi 2017 \{published data only\}}

Anselmi L, Binyaruka P, Borghi J. Understanding causal pathways within health systems policy evaluation through mediation analysis: an application to payment for performance (P4P) in Tanzania. Implementation Science 2017;12:10.

\section{Aung 2015 \{published data only\}}

Aung T, White C, Montagu D, McFarland W, Hlaing T, Khin HS, et al. Improving uptake and use of malaria rapid diagnostic tests in the context of artemisinin drug resistance containment in eastern Myanmar: an evaluation of incentive schemes among informal private healthcare providers. Malaria Journal 2015;14:105

\section{Banerjee 2008 \{published data only\}}

Banerjee AV, Duflo E, Glennerster R. Putting a band-aid on a corpse: incentives for nurses in the Indian public health care system. Journal of the European Economic Association 2008;6(2-3):487-500.

\section{Basinga 2010 \{published data only\}}

Basinga P, Gertler PJ, Binagwaho A, Soucat ALB, Sturdy JR, Vermeersch CMJ. Paying primary health care centers for performance in Rwanda. Washington, D.C.: World Bank Group. Policy Research Working Paper WPS5190 2010.

\section{Biai 2012 \{published data only\}}

Biai S, Rodrigues A, Gomes M, Ribeiro I, Sodemann M, Alves F, et al. Reduced in-hospital mortality after improved management of children under 5 years admitted to hospital with malaria: randomised trial. BMJ 2012;335:862.

\section{Borghi 2015 \{published data only\}}

Borghi J, Little R, Binyaruka P, Patouillard E, Kuwawenaruwa A. In Tanzania, the many costs of pay-for-performance leave open to debate whether the strategy is cost-effective. Health Affairs 2015;34(3):406-14.

Canavan 2008 \{published data only\}

Canavan A, Swai G. Payment for Performance (P4P) Evaluation: Tanzania Country Report for Cordaid.

\section{Department for International Development 2017 \{published} data only\}

Department for International Development. Evaluation of results based financing programme for Northern Uganda. Department for International Development 2017. [URL: www.gov.uk/government/publications/evaluation-of-resultsbased-financing-programme-for-northern-uganda]

\section{Kumar 2016 \{published data only\}}

Kumar M, Lehmann JT, Rucogoza A, Kayobotsi C, Das AK, Schneidman M. East Africa - Public health laboratory networking project: evaluation of performance-based financing for public health laboratories in Rwanda (English) [2016]. Washington, D.C.: World Bank Group. Health, Nutrition, and Population Discussion Paper 105015.

Liu 2003 \{published data only\}

Liu X, Mills A. The influence of bonus payments to doctors on hospital revenue: results of a quasi-experimental study. Applied Health Economics \& Health Policy 2003;2:91-8.

\section{Morisky 1985 \{published data only\}}

Morisky DE. Evaluating the effectiveness of utilizing traditional birth attendants for maternal and child health/family planning programs in the rural Philippines. International Quarterly of Community Health Education 1985;6(2):131-43.

Ngo 2017 \{published data only\} Ngo DKL, Sherry TB, Bauhoff S. Health system changes under pay-for-performance: the effects of Rwanda's national programme on facility inputs. Health Policy and Planning 2017;32(1):11-20.

\section{Nguyen 2015 \{published data only\}}

Nguyen HTH, Gopalan S, Mutasa R, Friedman J, Das AK, Sisimayi $C$, et al. Impact of results-based financing on health worker satisfaction and motivation in Zimbabwe. RBF Health 2015. [URL: www.rbfhealth.org/resource/impact-resultsbased-financing-health-worker-satisfaction-and-motivationzimbabwe]

\section{Not reported 1962 \{published data only\}}

Not reported. Report on the incentive payment system for the workers employed in the Indian undertakings of the public sector. Not reported 1962

\section{Olken 2012 \{published data only\}}

Olken BA, Onishi J, Wong S. Should aid reward performance? Evidence from a field experiment on health and education in Indonesia. National Bureau of Economic Research, Working Paper 17892. 2012.

Paying for performance to improve the delivery of health interventions in low- and middle-income countries (Review) 
Peabody 2010 \{unpublished data only\}

Peabody J, Shimkhada R, Quimbo S, Solon O, Javier X, McCulloch C. Linkage between measurement and incentive payments and health outcomes: experimental data froma policy experiment in the Philippines..

\section{Peabody 2017 \{published data only\}}

Peabody JW, Quimbo S, Florentino J, Shimkhada R, Javier X, Paculdo $D$, et al. Comparative effectiveness of two disparate policies on child health: experimental evidence from the Philippines. Health Policy and Planning 2017;32(4):563-71.

\section{Phillips 1975 \{published data only\}}

Phillips JF, Silayan Go A, Pal Montano A. An experiment with payment, quota, and clinic affiliation schemes for lay motivators in the Philippines. Studies in Family Planning 1975;6(9):326-34.

\section{Prakarsh 2017 \{published data only\}}

Prakarsh S, Sandip M. Incentives, information and malnutrition: evidence from an experiment in India. European Economic Review 2017;93:24-46.

\section{Quy 2003 \{unpublished data only\}}

Quy H, Lan N, Lonnroth K, Buu T, Dieu T, Hai T. Public- private mix for improved TB control in Ho Chi Minh City, Vietnam: an assessment of its impact on case detection. International Journal for Tuberculosis and Lung Disease 2003;7(464-71).

Rahman 2017 \{published data only\}

Rahman S, Choudhury AA, Khanam R, Moin SMI, Ahmed S, Begum N, Shoma NN, Quaiyum MA, Baqui AH. Effect of a package of integrated demand- and supply-side interventions on facility delivery rates in rural Bangladesh: Implications for large-scale programs. PLOS One 2017;12(10):e0186182.

\section{RBF Health 2017 \{published data only\}}

RBF Health. The Gambia's community-based RBF scheme: contracting communities to boost demand. RBF Health 2017. [URL: www.rbfhealth.org/resource/gambia\%E2\%80\%99scommunity-based-rbf-scheme-contracting-communities-boostdemand]

\section{Rusa 2009b \{published data only\}}

Rusa L, Schneidman M, Fritsche G, Musango L. Chapter 10. Rwanda: performance-based financing in the public sector. In: Performance Incentives for Global Health: Potential and Pitfalls. Washington, D.C.: Center for Global Development, 2009:189-214. [URL: www.cgdev.org/ sites/default/files/9781933286297-Levine-performanceincentives.pdf]

\section{Shen 2015 \{published data only\}}

Shen G, Nguyen HTH, Das AK, Sachingongu N, Chans C, Friedman J, Qamruddin J. Results-based financing's impact on human resources for health in Zambia. RBF Health 2015. [URL: www.rbfhealth.org/sites/rbf/files/Zambia\%20RBFHRH \%20report.pdf]
Singh 2015 \{published data only\}

Singh P. Performance pay and information: reducing child undernutrition in India. Journal of Economic Behavior and Organization 2015;112:141-63.

\section{Soeters 2005 \{unpublished data only\}}

Soeters R, Musango L, Meessen B. Comparison of two output based schemes in Butare and Cyangugu provinces with two control provinces in Rwanda.. GBPOA, World Bank, Ministry of Health Rwanda 2005.

\section{Soeters 2008 \{unpublished data only\}}

Soeters R, Kimakuka C. Résultats de l'enquête ménage, l'enquête qualité, et l'enquête infirmiers titulaires. Pour le Programme Achat de Performance dans les Zones de Santé du District Sanitaire Nord du Sud Kivu. 2008.

Soeters 2009 \{unpublished data only\}

Soeters R, Kiwanuka C. Rapport de l'Etude d'Evaluation du programme Achat de Performance dans les Provinces Bubanza et Cankuzo, basé sur les résultats des enquêtes ménages, qualité et infirmiers titulaires réalisées en 2006 et 2008. 2008.

Sylvia 2015 \{published data only\}

Sylvia SY. Managerial Incentives in Public Service Delivery: Evidence from School-Based Nutrition Programs in Rural China [Thesis]. Maryland, USA: University of Maryland, 2015. [URL: hdl.handle.net/1903/15457]

\section{Valadez 2015 \{published data only\}}

Valadez JJ, Jeffery C, Brant T, Vargas W, Pagano M. Final impact assessment of the results-based financing programme for Northern Uganda. Department for International Development 2015. [URL: www.gov.uk/government/uploads/system/uploads/ attachment data/file/607579/Evaluation-of-Results-BasedFinancing-Programme-for-Northern-Uganda.pdf]

\section{Vergeer 2008 \{unpublished data only\}}

Vergeer P, Chansa C. Payment for Performance (P4P) Evaluation: Zambia Country Report for Cordaid.. 2008.

\section{World Bank 2015 \{published data only\}}

India - Impact evaluation of results-based payments for hospital care for the poor in Karnataka state (English). Washington, D.C.: World Bank Group. Health, Nutrition, and Population Global Practice Discussion Paper 97519. 2015.

\section{Zeng 2018b \{published data only\}}

Zeng W, Shepard DS, Nguyen H, Chansa C, Das AK, Qamruddin J, et al. Cost-effectiveness of results-based financing, Zambia: a cluster randomized trial.. Bulletin of the World Health Organisation 2018;96(11):760-71.

\section{Zhang 2017 \{published data only\}}

Zhang W, Luo H, Ma Y, Guo Y, Fang Q, Yang Z, et al. Monetary incentives for provision of syphilis screening, Yunnan, China. Bulletin of the World Health Organization 2017;95(9):657-62.

\section{Zhao 2013 \{published data only\}}

Zhao Y, Huo Z, Wu J, Xie S, Zhang L, Feng Z. Impact on the performance of health workers adopted performance-related 
contracts in the provision of basic public health service at village and township levels. Iranian Journal of Public Health, 42(4): 358-67 2013;42(4):358-67.

\section{References to studies awaiting assessment}

Ababe 2019 \{published data only\}

Ababe Tamirat Deressa, Getachew Zeru. Work motivation and its effects on organizational performance: the case of nurses in Hawassa public and private hospitals: mixed method study approach.. 2019;12(213).

\section{Afolabi 2018 \{published data only\}}

Afolabi A, Fernando S, Bottiglieri T. The effect of organisational factors in motivating healthcare employees: a systematic review. British Journal of Healthcare Management 2018;24(12):603-10.

\section{Agarwal 2019 \{published data only\}}

Agarwal S, Anaba U, Abuya T, Kintu R, Casseus A, Hossain S, Obadha M, Warren C E. Understanding incentive preferences of community health workers using discrete choice experiments: a multicountry protocol for Kenya, Uganda, Bangladesh and Haiti. 2019;9(12):e033601.

\section{Aghajani \{published data only\}}

Aghajani M H, Manavi S, Maher A, Rafiei S, Ayoubian A, Shahrami A, Ronasiyan R, Maziar P. Pay for performance in hospital management: A case study.

\section{Ahmed 2019 \{published data only\}}

Ahmed T, Arur A, De Walque D, Shapira G. Incentivizing quantity and quality of care: evidence from an impact evaluation of performance-based financing in the health sector in Tajikistan. 2019.

\section{Alonge 2017 \{published data only\}}

Alonge O, Lin S, Igusa T, Peters D H. Improving health systems performance in low- and middle-income countries: a system dynamics model of the pay-for-performance initiative in Afghanistan. 2017;32(10):1417-1426.

\section{Angell 2019 \{published data only\}}

Angell B, Dodd R, Palagyi A, Gadsden T, Abimbola S, Prinja S, Jan S, Peiris D. Primary health care financing interventions: a systematic review and stakeholder-driven research agenda for the Asia-Pacific region. 2019;4.

\section{Anjana 2019 \{published data only\}}

Anjana Das, Bitra George, Virupax Ranebennur, Parthasarathy M R, Shreenivas G S, Priyamvada Todankar, Amit Shrivastav, Reddy A K, Akolo C, Cassell M, Sandeep Mane, Deepak Tripathi, Jiban Baishya. Getting to the first 90: incentivized peer mobilizers promote HIV testing services to men who have sex with men using social media in Mumbai, India.. 2019;7(3):469-477.

\section{Anselmi 2020 \{published data only\}}

Anselmi L, Borghi J, Brown G W, Fichera E, Hanson K, Kadungure A, Kovacs R, Kristensen S R, Singh N S, Sutton M.
Pay for Performance: A Reflection on How a Global Perspective Could Enhance Policy and Research. 2020;9(9):365-369.

Bai 2019 \{published data only\}

Bai J, Bundorf K, Bai F, Tang H, Xue D. Relationship between physician financial incentives and clinical pathway compliance: a cross-sectional study of 18 public hospitals in China. BMJ Open 2019;9(5):e027540.

Ballard 2017 \{published data only\}

Ballard M, Montgomery P. Systematic review of interventions for improving the performance of community health workers in low-income and middle-income countries.. 2017;7(10):e014216.

Baral 2018 \{published data only\}

Baral S, Subedi HN, Paudel P, Chand PB, Shrestha MP, McCullough A, et al. Implementation research to assess a health workers performance-based management system in Nepal. Acta Paediatrica 2018;107(Suppl 471):24-34.

Barreto 2015 \{published data only\}

Barreto Jorge Otávio Maia. Pagamento por desempenho em sistemas e serviços de saúde: uma revisão das melhores evidências disponíveis. 2015;20(5):1497-1514.

Barreto 2016 \{published data only\}

Barreto Jorge Otávio Maia, Dias Raphael. Opções para a implementação do pagamento por desempenho na saúde: um overview de revisões sistemáticas. 2016;27(2):119-128.

Basinga 2011a \{published data only\}

Basinga P, Mayaka S, Condo J. Performance-based financing: the need for more research. 2011;89(9):698-699.

Beibei 2017 \{published data only\} Beibei Yuan, Li H E, Qingyue Meng, Liying J I A. Effectiveness evaluation of pay-for-performance for outpatients care services. 2017:8-21.

\section{Bernal 2018a \{published data only\}}

Bernal P, Martinez S. In-kind Incentives and Health Worker Performance: Experimental Evidence from. IDB Working Paper Series No IDB-WP-974 2018///.

\section{Bernal 2018b \{published data only\}}

Bernal Pedro, Celhay Pablo, Martinez Sebastian. Is ResultsBased Aid More Effective than Conventional Aid? Inter-American Development Bank 2018///;(January).

\section{Bernal 2020 \{published data only\}}

Bernal P, Martinez S. In-kind incentives and health worker performance: Experimental evidence from El Salvador. 2020;70:102267.

\section{Bertone 2018 \{published data only\}}

Bertone MP, Falisse JB, Russo G, Witter S. Context matters (but how and why?) A hypothesis-led literature review of performance based financing in fragile and conflict-affected health systems. PLOS ONE 2018:1-27. 


\section{Bertone 2018a \{published data only\}}

Bertone MP, Jacobs E, Toonen J, Akwataghibe N, Witter S. Performance-based financing in three humanitarian settings: principles and pragmatism. Conflict and Health 2018;12:28.

\section{Bertone 2019 \{published data only\}}

Bertone M P, Jowett M, Dale E, Witter S. Health financing in fragile and conflict-affected settings: What do we know, seven years on?2019;232:209-219.

\section{Bettampadi 2019 \{published data only\}}

Bettampadi D. Socioeconomic Inequalities in Childhood Vaccination in India: Pathways and Interventions [Doctor of Philosophy Thesis]. University of Michigan: Ann Arbor, 2019.

\section{Binyaruka 2018a \{published data only\}}

Binyaruka P, Robberstad B, Torsvik G, Borghi J. Does payment for performance increase performance inequalities across health providers? A case study of Tanzania. Health Policy and Planning 2018;33(9):1026-36.

\section{Binyaruka 2020 \{published data only\}}

Binyaruka P, Lohmann J, De Allegri M. Evaluating performancebased financing in low-income and middle-income countries: the need to look beyond average effect. 2020;5(8).

\section{Binyaruka 2020a \{published data only\}}

Binyaruka P, Anselmi L. Understanding efficiency and the effect of pay-for-performance across health facilities in Tanzania. 2020;5(5).

\section{Binyaruka 2020b \{published data only\}}

Binyaruka Peter, Lohmann Julia, De Allegri Manuela. Evaluating performance-based financing in low-income and middleincome countries: The need to look beyond average effect. BMJ Global Health 2020///;5(8):1-3.

\section{Borghi 2018 \{published data only\}}

Borghi J, Singh NS, Brown G, Anselmi L, Kristensen S. Understanding for whom, why and in what circumstances payment for performance works in low and middle income countries: protocol for a realist review. BMJ Global Health 2018;3(3):e000695.

\section{Bowser 2013 \{published data only\}}

Bowser D M, Figueroa R, Natiq L, Okunogbe A. A preliminary assessment of financial stability, efficiency, health systems and health outcomes using performance-based contracts in Belize. 2013;8(9):1063-1074.

\section{Brenner 2018 \{published data only\}}

Brenner S, Mazalale J, Wilhelm D, Nesbitt RC, Lohela TJ, Chinkhumba J, et al. Impact of results-based financing on effective obstetric care coverage: evidence from a quasiexperimental study in Malawi. BMC Health Services Research 2018;18:791.

\section{Brenner 2020 \{published data only\}}

Brenner S, Chase R P, McMahon S A, Lohmann J, Makwero C J, Muula A S, De Allegri M. Effect Heterogeneity in Responding to Performance-Based Incentives: A Quasi-Experimental
Comparison of Impacts on Health Service Indicators Between Hospitals and Health Centers in Malawi. 2020;6(1):e1745580.

Brenner 2020a \{published data only\}

Brenner Stephan, Chase Rachel P, McMahon Shannon A, Lohmann Julia, Makwero Christopher J, Muula Adamson S, De Allegri Manuela. Effect Heterogeneity in Responding to Performance-Based Incentives: A Quasi-Experimental Comparison of Impacts on Health Service Indicators Between Hospitals and Health Centers in Malawi. Health Systems and Reform 2020///;6(1).

Bright 2017 \{published data only\}

Bright T, Felix L, Kuper H, Polack S. A systematic review of strategies to increase access to health services among children in low and middle income countries. 2017;17.

\section{Bunda 2019 \{published data only\}}

Bunda BA, Bassett IV. Reaching the second 90: the strategies for linkage to care and antiretroviral therapy initiation. Current Opinion in HIV and AIDS 2019;14(6):494-502.

\section{Carmichael 2019 \{published data only\}}

Carmichael SL, Mehta K, Raheel H, Srikantiah S, Chaudhuri I, Trehan S, et al. Effects of team-based goals and non-monetary incentives on front-line health worker performance and maternal health behaviours: a cluster randomised controlled trial in Bihar, India. BMJ Global Health 2019;4(4):e001146.

\section{Carvalho 2019 \{published data only\}}

Carvalho N, Rokicki S. The impact of India's Janani Suraksha Yojana conditional cash transfer programme: a replication study. Journal of Development Studies 2019;55(5):989-1006.

\section{Celhay 2019 \{published data only\}}

Celhay PA, Gertler PJ, Giovagnoli P, Vermeersch C. Longrun effects of temporary incentives on medical care productivity. American Economic Journal: Applied Economics 2019;11(3):92-127.

\section{Chansa 2019 \{published data only\}}

Chansa Collins, Matsebula Thulani, Piatti Moritz, Mudenda Dale, Chama-Chiliba Chitalu Miriam, Chitah Bona, Kaonga Oliver, Mphuka Chris. Zambia Health Sector Public Expenditure Tracking and Quantitative Service Delivery Survey. Zambia Health Sector Public Expenditure Tracking and Quantitative Service Delivery Survey 2019///;(April).

\section{Chariwala 2020 \{published data only\}}

Chariwala R A, Shukla R, Gajiwala U R, Gilbert C, Pant H, Lewis M G, Murthy G V S. Effectiveness of health education and monetary incentive on uptake of diabetic retinopathy screening at a community health center in South Gujarat, India. 2020;68(Suppl 1):S52-S55.

Chi 2018 \{published data only\}

Chi YL, Gad M, Bauhoff S, Chalkidou K, Megiddo I, Riuz F, et al. Mind the costs, too: towards better cost-effectiveness analyses of PBF programmes. BMJ Global Health 2018;3:e000994.

Paying for performance to improve the delivery of health interventions in low- and middle-income countries (Review) 
Chikovani 2019 \{published data only\}

Chikovani I, Diaconu K, Duric P, Sulaberidze L, Uchaneishvili M, Mohammed N I, Zoidze A, Witter S. Addressing challenges in tuberculosis adherence via performance-based payments for integrated case management: protocol for a cluster randomized controlled trial in Georgia. 2019;20(1):536.

\section{Chimhutu 2015 \{published data only\}}

Chimhutu V, Tjomsland M, Songstad N G, Mrisho M, Moland K M. Introducing payment for performance in the health sector of Tanzania- the policy process. 2015;11.

Chinkhumba 2020 \{published data only\}

Chinkhumba J, De Allegri M, Brenner S, Muula A, Robberstad B. The cost-effectiveness of using results-based financing to reduce maternal and perinatal mortality in Malawi. 2020;5(5).

\section{Chukwuma 2017 \{published data only\}}

Chukwuma A, Mbachu C, McConnell M, Bossert T, Cohen J. Do performance-based monetary incentives for referrals by traditional birth attendants increase postnatal care use? Evidence from a Nigerian field experiment. 2017;97(5):283-

\section{Chukwuma 2019 \{published data only\}}

Chukwuma A, Mbachu C, McConnell M, Bossert TJ, Cohen J. The impact of monetary incentives on referrals by traditional birth attendants for postnatal care in Nigeria. BMC Pregnancy and Childbirth 2019;19:150.

\section{Clist 2016 \{published data only\}}

Clist P. Payment by Results in Development Aid: All That Glitters Is Not Gold. 2016;31(2):290-313.

\section{Cole 2019 \{published data only\}}

Cole M S, Boydell V, Hardee K, Bellowsd B. The Extent to Which Performance-Based Financing Programs' Operations Manuals Reflect Rights-Based Principles: Implications for Family Planning Services. 2019;7(2):329-339.

\section{Coulibaly 2020 \{published data only\}}

Coulibaly A, Gautier L, Zitti T, Ridde V. Implementing performance-based financing in peripheral health centres in Mali: what can we learn from it?2020;18(1):54.

\section{Czaicki 2018 \{published data only\}}

Czaicki NL, Dow WH, Njau PF, McCoy SI. Do incentives undermine intrinsic motivation? Increases in intrinsic motivation within an incentive-based intervention for people living with HIV in Tanzania. PLoS ONE 2018;13(6):e0196616.

\section{Dansereau 2019 \{published data only\}}

Dansereau Emily A. Results based aid for universal health coverage in poor and indigenous communities: Impact evaluation of the Salud Mesoamerica initiative. 2019;80(8$B(E))$ :No Pagination Specified-.

\section{Das 2019 \{published data only\}}

Das A, George B, Ranebennur V, Parthasarthy MR, Shreenivas GS, Todankar P, et al. Getting to the first 90: incentivized peer mobilizers promote HIV testing services to men who have sex with men using social media in Mumbai, India. Global Health: Science and Practice 2019;7(3):469-77.

Das 2020 \{published data only\}

Das Maitreyi Bordia, Khan Ibrahim Ali, Tinsley Elaine. ResultsBased Financing Through Social Enterprises. Results-Based Financing Through Social Enterprises 2020///.

\section{De Allegri 2019 \{published data only\}}

De Allegri M, Makwero C, Torbica A. At what cost is performancebased financing implemented? Novel evidence from Malawi. Health Policy and Planning 2019;34(4):282-8.

De Allegri 2019a \{published data only\}

De Allegri M, Chase RP, Lohmann J, Schoeps A, Muula AS, Brenner S, . Effect of results-based financing on facility-based maternal mortality at birth: an interrupted time-series analysis with independent controls in Malawi. 2019;4:e001184.

De Allegri 2019b \{published data only\}

De Allegri M, Lohmann J, Souares A, Hillebrecht M, Hamadou S, Hien $\mathrm{H}$, Haidara O, Robyn P J. Responding to policy makers' evaluation needs: combining experimental and quasi-experimental approaches to estimate the impact of performance based financing in Burkina Faso. 2019;19(1):733.

\section{De Allegri 2019c \{published data only\}}

De Allegri M, Lohmann J, Souares A, Hillebrecht M, Hamadou S, Hien $\mathrm{H}$, Haidara O, Robyn P J. Correction to: Responding to policy makers' evaluation needs: combining experimental and quasi-experimental approaches to estimate the impact of performance based financing in Burkina Faso. 2019;19(1):903.

\section{De Allegri 2019d \{published data only\}}

De Allegri Manuela, Lohmann Julia, Souares Aurélia, Hillebrecht Michael, Hamadou Saidou, Hien Hervé, Haidara Ousmane, Robyn Paul Jacob. Erratum: Correction to: Responding to policy makers' evaluation needs: combining experimental and quasi-experimental approaches to estimate the impact of performance based financing in Burkina Faso (BMC health services research (2019) 191 (733)). BMC health services research 2019///;19(1):903-903.

\section{Deressa 2019 \{published data only\}}

Deressa AT, Zeru G. Work motivation and its effects on organizational performance: the case of nurses in Hawassa public and private hospitals: mixed method study approach. BMC Research Notes 2019;12:213.

\section{De Walque 2018 \{published data only\}}

De Walque D, Robyn PJ, Saidou H, Sorgho G, Steenland M. The impact of performance-based financing on the delivery of HIV testing, prevention of mother to child transmission and antiretroviral delivery in the Cameroon health system [Abstract TUAE0101]. In Special Issue: Oral abstracts of the 22nd International AIDS Conference, 23â€" 27 July 2018, Amsterdam, the Netherlands. Journal of the International AIDS Society 2018;21(Suppl 6):e25148. 


\section{Dizon-Ross 2017 \{published data only\}}

Dizon-Ross Rebecca, Dupas Pascaline, Robinson Jonathan. Governance and the Effectiveness of Public Health Subsidies: Evidence from Ghana, Kenya and Uganda. 2017;156:150-169.

\section{Duchoslav 2019 \{published data only\}}

Duchoslav J, Cecchi F. Do incentives matter when working for god? The impact of performance-based financing on faith-based healthcare in Uganda. World Development 2019;113:309-19.

\section{Egbe 2016 \{published data only\}}

Egbe T O, Atashili J, Talla E, Atanga M B S. Effect of performance based financing home visiting on the use of modern methods of contraception in the kumbo east health district, Cameroon. 2016;1:19.

\section{Eijkenaar 2012 \{published data only\}}

Eijkenaar F. Pay for Performance in Health Care: An International Overview of Initiativess. 2012;69(3):251-276.

\section{El Bcheraou 2018b \{published data only\}}

El Bcheraoui C, Kamath A M, Dansereau E, Palmisano E B, Schaefer A, Hernandez B, Mokdad A H. Results-based aid with lasting effects: Sustainability in the Salud Mesoamerica Initiative 11 Medical and Health Sciences 1117 Public Health and Health Services 16 Studies in Human Society 1605 Policy and Administration. 2018;14 (1) (no pagination)(97).

\section{Fahey 2020 \{published data only\}}

Fahey C A, Njau P F, Katabaro E, Mfaume R S, Ulenga N, Mwenda N, Bradshaw P T, Dow W H, Padian N S, Jewell N P, McCoy S I. Financial incentives to promote retention in care and viral suppression in adults with HIV initiating antiretroviral therapy in Tanzania: a three-arm randomised controlled trial. 2020.

\section{Falisse 2020 \{published data only\}}

Falisse J B, Ntakarutimana L. When information is not power: Community-elected health facility committees and health facility performance indicators. 2020;265:113331.

\section{Federal 2018 \{published data only\}}

Federal Ministry of Health of Nigeria. Impact Evaluation of Nigeria State Health Investment Project. 2018///.

\section{Fillol 2019 \{published data only\}}

Fillol A, Lohmann J, Turcotte-Tremblay AM, Some PA, Ridde V. The importance of leadership and organizational capacity in shaping health workers' motivational reactions to performancebased financing: a multiple case study in Burkina Faso. International Journal of Health Policy and Management 2019;8(5):272-9.

\section{Francetic 2019 \{published data only\}}

Francetic I, Tediosi F, Salari P, de Savigny D. Going operational with health systems governance: supervision and incentives to health workers for increased quality of care in Tanzania. 2019;34(Supplement_2):ii77-ii92.

\section{Freitas 2015 \{published data only\}}

Freitas Paulo Fontoura, Moreira Bianca Carvalho, Manoel Andre Luciano, Botura Ana Clara de Albuquerque. O parecer do Conselho Federal de Medicina, o incentivo à remuneração ao parto e as taxas de cesariana no Brasil. 2015;31(9):1839-1855.

Gang 1996 \{published data only\}

Gang D U, Luxia Gong, Naizhuo X U E, Qingzhu Q I, Weiguang L I. Design of post and performance based hospital compensation. 1996.

\section{Gergen 2017 \{published data only\}}

Gergen J, Josephson E, Coe M, Ski S, Madhavan S, Bauhoff S. Quality of Care in Performance-Based Financing: How It Is Incorporated in 32 Programs Across 28 Countries. 2017;5(1):90-107.

\section{Gergen 2018 \{published data only\}}

Gergen J, Josephson E, Vernon C, Ski S, Riese S, Bauhoff S, et al. Measuring and paying for quality of care in performancebased financing: experience from seven low and middle-income countries (Democratic Republic of Congo, Kyrgyzstan, Malawi, Mozambique, Nigeria, Senegal and Zambia). Journal of Global Health 2018;8(2):21003.

\section{Gergen 2018a \{published data only\}}

Gergen J, Rajkotia Y, Lohmann J, Ravishankar N. Performancebased financing kick-starts motivational "feedback loop": findings from a process evaluation in Mozambique. Human Resources for Health 2018;16:55.

\section{Gergen 2018b \{published data only\}}

Gergen J, Falcao J, Rajkotia Y. Stunted scale-up of a performance-based financing program on HIV and maternalâ €"child health services in Mozambique â€" a policy analysis. African Journal of AIDS Research 2018;17(4):353-61.

\section{Gergen 2018c \{published data only\}}

Gergen J, Rajkotia Y, Lohmann J, Ravishankar N. Performancebased financing kick-starts motivational "feedback loop": findings from a process evaluation in Mozambique. Human Resources for Health 2018///;16.

\section{Glas 2018 \{published data only\}}

Glas AH, Henne FU, Essig M. Missing performance management and measurement aspects in performance-based contracting: a systematic process-based literature analysis of an astonishing research gap. International Journal of Operations \& Production Management 2018;38(11):2062-95.

\section{Grisales 2019 \{published data only\}}

Grisales C M, Salazar L M, Garcia D P. Treatment of synthetic dye baths by Fenton processes: evaluation of their environmental footprint through life cycle assessment. 2019;26(5):4300-4311.

\section{Grover 2019 \{published data only\}}

Grover D, Bauhoff S, Friedman J. Using supervised learning to select audit targets in performance-based financing in health an example from Zambia. PLOS ONE 2019;14(1):e0211262. 


\section{Gupta 2019 \{published data only\}}

Gupta N, Lavallee R, Ayles J. Gendered effects of pay for performance among family physicians for chronic disease care: an economic evaluation in a context of universal health coverage. Human Resources for Health 2019;17:40.

\section{Honda 2013 \{published data only\}}

Honda A. 10 best resources on ... pay for performance in lowand middle-income countries. 2013;28(5):454-457.

\section{Hussain 2019 \{published data only\}}

Hussain H, Mori A T, Khan A J, Khowaja S, Creswel J, Tylleskar T, Robberstad B. The cost-effectiveness of incentive-based active case finding for tuberculosis (TB) control in the private sector Karachi, Pakistan. 2019;19(1).

\section{Ibnat 2019 \{published data only\}}

Ibnat Fabliha, Leonard Kenneth, Bawo Luke, MohammedRoberts Rianna. The Three-Gap Model of Health Worker Performance. World Bank Policy Research Working Paper 2019///;(8782).

\section{ISRCTN14332616 \{published data only\}}

ISRCTN14332616. Impact evaluation of Zambia Health ResultsBased Financing Pilot.

\section{ISRCTN14667607 \{published data only\}}

ISRCTN14667607 Trial group. Impact and cost-effectiveness of integrated care and results-based financing intervention on adherence among pulmonary tuberculosis patients in Georgia.

\section{ISRCTN16392613 \{published data only\}}

ISRCTN16392613 Trial group. Impact evaluation of Zimbabwe?s health results based financing project.

\section{Isrctn 2019 \{published data only\}}

Isrctn. Impact and cost-effectiveness of integrated care and results-based financing intervention on adherence among pulmonary tuberculosis patients in Georgia. 2019.

\section{Jacobs \{published data only\}}

Jacobs E, Bertone M P, Toonen J, Akwataghibe N, Witter S. Performance-Based Financing, Basic Packages of Health Services and User-Fee Exemption Mechanisms: An Analysis of Health-Financing Policy Integration in Three Fragile and Conflict-Affected Settings.

\section{Jalili 2020 \{published data only\}}

Jalili R, Asefzadeh S, Shoghli A, Mohebbi M. The Role of Organizational Justice in Nurses and Midwives' Satisfaction with Performance-Based Payment (Qasedak Project) in Zanjan Educational Hospitals. 2020;9(2):10-17.

\section{James 2020 \{published data only\}}

James N, Lawson K, Acharya Y. Evidence on result-based financing in maternal and child health in low- and middleincome countries: a systematic review. 2020;5(1).

\section{Josephson 2017 \{published data only\}} Josephson E, Gergen J, Coe M, Ski S, Madhavan S, Bauhoff S. How do performance-based financing programmes measure quality of care? A descriptive analysis of 68 quality checklists from 28 low- and middle-income countries. 2017;32(8):1120-1126.

\section{Kanmiki 2018 \{published data only\}}

Kanmiki EW, Bempah BO, Awoonor-Williams JK, Bawah AA, d'Almeida SA, Kassak KM. An assessment of a performancebased management agreement initiative in Ghana's health service. BMC Health Services Research 2018;18:995.

\section{Kantengwa 2010 \{published data only\}}

Kantengwa K, De Naeyer L, Ndizeye C, Uwayitu A, Pollock J, Bryant M. PBF in Rwanda: what happened after the BTC experience?2010;15(1):148-149.

\section{Kazungu 2018 \{published data only\}}

Kazungu JS, Barasa EW, Obadha M, Chuma J. What characteristics of provider payment mechanisms influence health care providers' behaviour? A literature review. International Journal of Health Planning and Management 2018;33(4):e892-905

\section{Khan 2020a \{published data only\}}

Khan Mishal, Roychowdhury Imara, Meghani Ankita, Hashmani Farah, Borghi Josephine, Liverani Marco. Should performance-based incentives be used to motivate health care providers? Views of health sector managers in Cambodia, China and Pakistan. Health Economics, Policy and Law 2020///;15(2):247-260.

\section{Khim 2018a \{published data only\}}

Khim K, Jayasuriya R, Annear P L. Administrative reform and pay-for-performance methods of primary health service delivery: A comparison of 3 health districts in Cambodia, 2006-2012. 2018;33(2):E569-E585.

\section{Kiendrebeogo 2017 \{published data only\}}

Kiendrebeogo J A, Shroff Z C, Berthe A, Yonli L, Bechir M, Meessen B. Why Performance-Based Financing in Chad Failed to Emerge on the National Policy Agenda. 2017;3(2):80-90.

\section{Kitui 2017 \{published data only\}}

Kitui J E, Dutton V, Bester D, Ndirangu R, Wangai S, Ngugi S. Traditional Birth Attendant reorientation and Motherpacks incentive's effect on health facility delivery uptake in Narok County, Kenya: An impact analysis. 2017;17 (1) (no pagination) (125)

\section{Korachais 2020 \{published data only\}}

Korachais C, Nkurunziza S, Nimpagaritse M, Meessen B. Impact of the extension of a performance-based financing scheme to nutrition services in Burundi on malnutrition prevention and management among children below five: A cluster-randomized control trial. 2020;15(9):e0239036.

\section{Kovacs 2020 \{published data only\}}

Kovacs R J, Powell-Jackson T, Kristensen S R, Singh N, Borghi J. How are pay-for-performance schemes in healthcare designed in low- and middle-income countries? Typology and systematic literature review. 2020;20(1).

Paying for performance to improve the delivery of health interventions in low- and middle-income countries (Review) 
Kuunibe 2019 \{published data only\}

Kuunibe N, Lohmann J, Schleicher M, Koulidiati JL, Robyn PJ, Zigani Z, et al. Factors associated with misreporting in performance-based financing in Burkina Faso: implications for risk-based verification. International Journal of Health Planning and Management 2019;34(4):1217-37.

\section{Kuunibe 2020 \{published data only\}}

Kuunibe N, Lohmann J, Hillebrecht M, Nguyen H T, Tougri G, De Allegri M. What happens when performance-based financing meets free healthcare? Evidence from an interrupted timeseries analysis. 2020.

\section{Kuunibe 2020a \{published data only\}}

Kuunibe Naasegnibe, Lohmann Julia, Hillebrecht Michael, Nguyen Hoa Thi, Tougri Gauthier, De Allegri Manuela. What happens when performance-based financing meets free healthcare? Evidence from an interrupted time-series analysis. Health Policy and Planning 2020///;35(8):906-917.

\section{Le 2014 \{published data only\}}

Le Gargasson J B, Mibulumukini B, Gessner B D, Colombini A. Budget process bottlenecks for immunization financing in the Democratic Republic of the Congo (DRC). 2014;32(9):1036-1042.

\section{Leaver 2019 \{published data only\}}

Leaver Clare, Ozier Owen, Serneels Pieter, Zeitlin Andrew. Recruitment, effort, and retention effects of performance contracts for civil servants: Experimental evidence from Rwandan primary schools. World Bank 2019///;(September).

\section{Lisam 2015 \{published data only\}}

Lisam Suchitra, Nandi Sulakshana, Kanungo Kanica, Verma Prem, Mishra Jay Prakash, Mairembam Dilip Singh. Strategies for attraction and retention of health workers in remote and difficult-to-access areas of Chhattisgarh, India: Do they work. 2015.

\section{Lohmann 2018 \{published data only\}}

Lohmann J, Wilhelm D, Kambala C, Brenner S, Muula AS, De Allegri $M$. The money can be a motivator, to me a little, but mostly PBF just helps me to do better in my job.' An exploration of the motivational mechanisms of performance-based financing for health workers in Malawi. Health Policy and Planning 2018;33(2):183-91.

\section{Lohmann 2018a \{published data only\}}

Lohmann J, Muula AS, Houlfort N, De Allegri, M. How does performance-based financing affect health workers' intrinsic motivation? A Self-Determination Theory-based mixedmethods study in Malawi. Social Science and Medicine 2018;208:1-8.

\section{Lohmann 2018c \{published data only\}}

Lohmann J, Wilhelm D, Kambala C, Brenner S, Muula A S, De Allegri M. 'The money can be a motivator, to me a little, but mostly PBF just helps me to do better in my job.' An exploration of the motivational mechanisms of performance-based financing for health workers in Malawi. Health Policy \& Planning 2018///;33(2):183-191.

\section{Lohmann 2020 \{published data only\}}

Lohmann Julia, Koulidiati Jean-Louis, Somda Serge MA, De Allegri Manuela. "It Depends on What They Experience in Each Health Facility. Some Are Satisfied, Others Are Not." A MixedMethods Exploration of Health Workers' Attitudes Towards Performance-Based Financing in Burkina Faso. International Journal of Health Policy and Management 2020///; (x):1-12

\section{Lu 2020 \{published data only\}}

Lu Y, Ni Y, Li X, He X, Huang S, Zhou Y, Dai W, Wu D, Tucker J D, Shen G, Sha Y, Jiang H, Huang L, Tang W. Monetary incentives and peer referral in promoting digital network-based secondary distribution of HIV self-testing among men who have sex with men in China: study protocol for a three-arm randomized controlled trial. 2020;20(1):911.

Mabuchi 2018 \{published data only\}

Mabuchi S, Sesan T, Bennett SC. Pathways to high and low performance: factors differentiating primary care facilities under performance-based financing in Nigeria. Health Policy and Planning 2018;33(1):41-58.

\section{Mabuchi 2019 \{published data only\}}

Mabuchi Shunsuke. Understanding health center management and performance under performance based financing in Nigeria. 2019;80(8-B(E)):No Pagination Specified-.

\section{Magrath 2012 \{published data only\}}

Magrath P, Nichter M. Paying for performance and the social relations of health care provision: An anthropological perspective. 2012;75(10):1778-1785.

\section{Maini 2018 \{published data only\}}

Maini R, Mounier-Jack S, Borghi J. Performance-based financing versus improving salary payments to workers: insights from the Democratic Republic of Congo. BMJ Global Health 2018;3:e000958.

\section{Maini 2019 \{published data only\}}

Maini Rishma, Lohmann Julia, Hotchkiss David R, MounierJack Sandra, Borghi Josephine. What happens when donors pull out? Examining differences in motivation between health workers who recently had performance-based financing (PBF) withdrawn with workers who never received PBF in the democratic republic of Congo. International Journal of Health Policy and Management 2019///;8(11):646-661.

\section{Manga 2018 \{published data only\}}

Manga LJ, Fouda AA, Mbida L, Mvogo CE. Performance based financing and job satisfaction in a semiurban health district in Cameroon. Journal of Public Health in Africa 2018;9(1):760.

\section{Ma-Nitu 2018 \{published data only\}}

Ma-Nitu SM, Tembey L, Bigirimana E, Dossouvi CY, Basenya O, Mago $E$, et al. Towards constructive rethinking of PBF: perspectives of implementers in sub-Saharan Africa. BMJ Global Health 2018;3:e001036. 
Manjang 2018 \{published data only\}

Manjang B, Hemming K, Bradley C, Ensink J, Martin JT, Sowe J, et al. Promoting hygienic weaning food handling practices through a community-based programme: intervention implementation and baseline characteristics for a cluster randomised controlled trial in rural Gambia. BMJ Open 2018;8(8):e017573.

\section{Manongi 2014 \{published data only\}}

Manongi R, Mushi D, Kessy J, Salome S, Njau B. Does training on performance based financing make a difference in performance and quality of health care delivery? Health care provider's perspective in Rungwe Tanzania. 2014;14.

\section{Masoud 2014 \{published data only\}}

Masoud Abolhallaje, Seyyed Meysam Mousavi, Mehdi Jafari. Implementation of performance-based budgeting in the health system: luxury or necessity?2014;43(11):1593-1594.

\section{Mattos 2002 \{published data only\}}

Mattos Ruben Araújo de. O incentivo ao Programa de Saúde da Família e seu impacto sobre as grandes cidades. 2002;12(1):77-108.

\section{Mclsaac 2018 \{published data only\}}

Mclsaac M, Kutzin J, Dale E, Soucat A. Results-based financing in health: from evidence to implementation. Bulletin of the World Health Organization 2018;96:730-730A.

\section{Mckay 2016 \{published data only\}}

Mckay Gillian, Parker Melissa. LSHTM Research Online Epidemics. ResearchOnline 2016///;38(1):81-95.

\section{McMahon 2018 \{published data only\}}

McMahon SA, Muula AS, De Allegri M. "I wanted a skeleton ... they brought a prince": A qualitative investigation of factors mediating the implementation of a Performance Based Incentive program in Malawi. SSM - Population Health 2018;5:64-72.

\section{Mokdad 2018 \{published data only\}}

Mokdad AH, Palmisano EB, Zuniga-Brenes P, Rios-Zertuche D, Johanns CK, Schaefer A, et al. Supply-side interventions to improve health: findings from the Salud Mesoamerica Initiative. PLOS ONE 2018;13(4):e0195292.

\section{Montagu 2011 \{published data only\}}

Montagu D, Yamey G. Pay-for-performance and the Millennium Development Goals. 2011;377(9775):1383-1385.

\section{Morgan 2013 \{published data only\}}

Morgan L, Stanton M E, Higgs E S, Balster R L, Bellows B W, Brandes N, Comfort A B, Eichler R, Glassman A, Hatt L E, Conlon $C M$, Koblinsky M. Financial Incentives and Maternal Health: Where Do We Go from Here?2013;31(4):8-22.

\section{Mukwenha 2020 \{published data only\}}

Mukwenha Solomon, Dzinamarira Tafadzwa, Mugurungi Owen, Musuka Godfrey. Maintaining robust HIV and tuberculosis services in the COVID-19 era: A public health dilemma in
Zimbabwe. International Journal of Infectious Diseases 2020///;100:394-395

Mwase 2020 \{published data only\}

Mwase T, Lohmann J, Hamadou S, Brenner S, Somda S M A, Hien H, Hillebrecht M, De Allegri M. Can Combining Performance-Based Financing With Equity Measures Result in Greater Equity in Utilization of Maternal Care Services? Evidence From Burkina Faso. 2020.

NCT03890653 \{published data only\}

NCT03890653. Impact evaluation of the Nigeria result-based financing project.

\section{Nct 2016 \{published data only\}}

Nct. Measuring and Understanding the Effects of a Performance Based Financing Scheme Applied to Nutrition Services in Burundi. 2016.

Nct 2017 \{published data only\}

Nct. Financial Incentives to Increase Pediatric HIV Testing. 2017.

Nct 2019 \{published data only\}

Nct. Impact Evaluation of the Nigeria Result-Based Financing Project. 2019.

\section{Neeru 2019 \{published data only\}}

Neeru Gupta, Lavallee R, Ayles J. Gendered effects of pay for performance among family physicians for chronic disease care: an economic evaluation in a context of universal health coverage.. 2019;17(40).

\section{Nguyen 2017 \{published data only\}}

Nguyen H T, Bales S, Wagstaff A, Dao H. Getting Incentives Right? The Impact of Hospital Capitation Payment in Vietnam. 2017;26(2):263-272.

\section{Nigel 2015 \{published data only\}}

Nigel G Bruce Kristin Aunan Eva A Rehfuess. Materials on Development Financing. 2015///;(8):44-44.

\section{Patel 2018 \{published data only\}}

Patel S. Structural, institutional and organizational factors associated with successful pay for performance programmes in improving quality of maternal and child health care in lowand middle-income countries: a systematic literature review. Journal of Global Health 2018;8(2):21001.

Paul \{published data only\}

Paul E, Brown G W, Ensor T, Ooms G, van de Pas R, Ridde V. We shouldn't count chickens before they hatch: results-based financing and the challenges of cost-effectiveness analysis.

\section{Paul 2018 \{published data only\}}

Paul E, Renmans D. Performance-based financing in the heath sector in low- and middle-income countries: is there anything whereof it may be said, see, this is new? International Journal of Health Planning and Management 2018;33(1):51-66. 
Paul 2018a \{published data only\}

Paul E, Drame ML, Kashala JP, Ndema AE, Kounnou M, Aissan JC, et al. Performance-based financing to strengthen the health system in Benin: challenging the mainstream approach. International Journal of Health Policy and Management 2018;7(1):35-47.

\section{Peabody 2011a \{published data only\}}

Peabody. Financial Incentives And Measurement Improved Physicians' Quality Of Care In The Philippines (vol 30, pg 773, 2011). 2011;30(6).

\section{Petross 2020 \{published data only\}}

Petross C, McMahon S, Lohmann J, Chase R P, Muula A S, De Allegri M. Intended and unintended effects: community perspectives on a performance-based financing programme in Malawi. 2020;5(4):e001894.

\section{Petross 2020a \{published data only\}}

Petross Chisomo, McMahon Shannon, Lohmann Julia, Chase Rachel P, Muula Adamson S, De Allegri Manuela. Intended and unintended effects: Community perspectives on a performancebased financing programme in Malawi. BMJ Global Health 2020///;5(4):1-12.

\section{Rajkotia 2017 \{published data only\}}

Rajkotia Y, Zang O, Nguimkeu P, Gergen J, Djurovic I, Vaz P, Mbofana $F$, Jobarteh $\mathrm{K}$. The effect of a performance-based financing program on HIV and maternal/child health services in Mozambique-an impact evaluation. 2017;32(10):1386-1396.

\section{Ridde 2018 \{published data only\}}

Ridde V, Gautier L, Turcotte-Tremblay AM, Sieleunou I, Paul E. Performance-based financing in Africa: time to test measures for equity. International Journal of Health Services 2018;48(3):549-61.

\section{Ridde 2018a \{published data only\}}

Ridde V, Yaogo M, Zongo S, Some PA, Turcotte-Tremblay AM. Twelve months of implementation of health care performancebased financing in Burkina Faso: a qualitative multiple case study. International Journal of Health Planning and Management 2018;33(1):e153-67.

\section{Rowe 2018 \{published data only}

Rowe AK, Rowe SY, Peters DH, Holloway KA, Chalker J, RossDegnan D. Effectiveness of strategies to improve health-care provider practices in low-income and middle-income countries: a systematic review. Lancet Global Health 2018;6(11):e1163-75.

Rudasingwa 2015 \{published data only\}

Rudasingwa M, Soeters R, Bossuyt $M$. The effect of performancebased financial incentives on improving health care provision in Burundi: a controlled cohort study. 2015;7(3):15-29.

\section{Rudasingwa 2017 \{published data only\}}

Rudasingwa M, Uwizeye M R. Physicians' and nurses' attitudes towards performance-based financial incentives in Burundi: a qualitative study in the province of Gitega. 2017;10:1-15.
Rudasingwa 2017a \{published data only\}

Rudasingwa M, Soeters R, Basenya 0 . The effect of performance-based financing on maternal healthcare use in Burundi: a two-wave pooled cross-sectional analysis. 2017;10(1):1327241.

\section{Salehi 2020 \{published data only\}}

Salehi A S, Borghi J, Blanchet K, Vassall A. The cost-effectiveness of using performance-based financing to deliver the basic package of health services in Afghanistan. 2020;5(9).

\section{Saran 2020 \{published data only\}}

Saran Indrani, Winn Laura, Kipkoech Kirui Joseph, Menya Diana, Prudhomme O'Meara Wendy. The relative importance of material and non-material incentives for community health workers: Evidence from a discrete choice experiment in Western Kenya. 2020;246:N.PAG-N.PAG.

\section{Sato 2020 \{published data only\}}

Sato R, Belel A. Effect of performance-based financing on health service delivery: a case study from Adamawa state, Nigeria. 2020.

\section{Sato 2020a \{published data only\}}

Sato R, Belel A. The effect of performance-based financing on child vaccinations in northern Nigeria. 2020;38(9):2209-2215.

\section{Schuster 2018 \{published data only\}}

Schuster RC, de Sousa O, Reme AK, Vopelak C, Pelletier DL, Johnson LM, et al. Performance-based financing empowers health workers delivering prevention of vertical transmission of HIV services and decreases desire to leave in Mozambique. International Journal of Health Policy and Management 2018;7(7):630-44.

\section{Selviaridis 2015 \{published data only\}}

Selviaridis K, Wynstra F. Performance-based contracting: a literature review and future research directions. 2015;53(12):3505-3540.

\section{Shapira 2018 \{published data only\}}

Shapira G, Kalisa I, Condo J, Humuza J, Mugeni C, Nkunda D, et al. Going beyond incentivizing formal health providers: evidence from the Rwanda Community Performance-Based Financing program. Health Economics 2018;27(12):2087-106.

\section{Sherry 2017a \{published data only\}}

Sherry T B, Bauhoff S, Mohanan M. MULTITASKING AND HETEROGENEOUS TREATMENT EFFECTS IN PAY-FORPERFORMANCE IN HEALTH CARE. 2017;3(2):192-226.

\section{Shimkhada 2008 \{published data only\}}

Shimkhada R, Peabody J W, Quimbo S A, Solon O. The Quality Improvement Demonstration Study: An example of evidencebased policy-making in practice. 2008;6 (no pagination).

\section{Shroff 2017 \{published data only\}}

Shroff Z C, Tran N, Meessen B, Bigdeli M, Ghaffar A. Taking Results-Based Financing from Scheme to System. 2017;3(2):69-73. 
Shu 2015 \{published data only\}

Shu Jiang, Chuan Y A N, Girault Anne, Ferrua Marie, Fourcade Aude, Loirat Philippe, Minvielle Etienne. International experiences on pay-for-performance programs and implications for China. 2015:27-35.

\section{Sieleunou 2017 \{published data only\}}

Sieleunou I, Turcotte-Tremblay A M, Yumo H A, Kouokam E, Fotso J C T, Tamga D M, Ridde V. Transferring the Purchasing Role from International to National Organizations During the Scale-Up Phase of Performance-Based Financing in Cameroon. 2017;3(2):91-104.

\section{Sieleunou 2017a $\{$ published data only\}}

Sieleunou I, Turcotte-Tremblay A M, Fotso J C T, Tamga D M, Yumo H A, Kouokam E, Ridde V. Setting performancebased financing in the health sector agenda: A case study in Cameroon. 2017;13(1).

\section{Sieleunou 2019 \{published data only\}}

Sieleunou I, Turcotte-Tremblay A M, De Allegri M, Taptue Fotso J C, Azinyui Yumo H, Magne Tamga D, Ridde V. How does performance-based financing affect the availability of essential medicines in Cameroon? A qualitative study. 2019;34(Supplement_3):iii4-iii19.

\section{Sieleunou 2020 \{published data only\}}

Sieleunou I, De Allegri M, Roland Enok Bonong P, Ouedraogo S, Ridde V. Does performance-based financing curb stock-outs of essential medicines? Results from a randomised controlled trial in Cameroon. 2020;25(8):944-961.

\section{Singh 2019 \{published data only\}}

Singh S, Kumar Y, Arrawatia R. Can disincentives bring accountability in governance? Experiences of Right to Public Services Guarantee Act in Madhya Pradesh State of India. 2019;19(4).

\section{Singh 2020 \{published data only\}}

Singh P, Masters W A. Performance bonuses in the public sector: Winner-take-all prizes versus proportional payments to reduce child malnutrition in India. 2020;146:102295.

\section{Smith 2019 \{published data only\}}

Smith M K, Shen H, Huang S, Zheng H, Yang B, Wiesen C, Wang $C$. Detection-based monetary incentives to improve syphilis screening uptake: results of a pilot intervention in a high transmission setting in southern China. 2019.

\section{Smith 2020 \{published data only\}}

Smith M K, Shen H, Huang S, Zheng H, Yang B, Wiesen C, Wang C. Detection-Based Monetary Incentives to Improve Syphilis Screening Uptake: Results of a Pilot Intervention in a High Transmission Setting in Southern China. 2020;47(3):187-191.

\section{Soucat 2017 \{published data only\}}

Soucat A, Dale E, Mathauer I, Kutzin J. Pay-for-Performance Debate: Not Seeing the Forest for the Trees. 2017;3(2):74-79.

\section{Sutherland 2008 \{published data only\}}

Sutherland K, Christianson J B, Leatherman S. Impact of Targeted Financial Incentives on Personal Health Behavior. 2008;65(6_suppl):36S-78S.

Tabrizi 2017 \{published data only\}

Tabrizi J S, JafarAbadi M A, Farahbakhsh M, Ahari A M, lezadi S. RESULTS AND DESIGNS OF P4P IN PRIMARY HEALTHCARE: A SCOPING REVIEW. 2017;2(3):573-585.

Tan 2019 \{published data only\}

Tan S Y, Melendez-Torres G J, Pang T. Implementation of provider payment system reforms in the age of universal health coverage: a realist review of evidence from Asian developing countries. 2019;24(4):279-287.

Tawfiq 2018 \{published data only\}

Tawfiq E, Desai J, Hyslop D. Effects of results-based financing of maternal and child health services on patient satisfaction in Afghanistan. 2018.

\section{Tawfiq 2019 \{published data only\}}

Tawfiq E, Desai J, Hyslop D. Effects of results-based financing of maternal and child health services on patient satisfaction in Afghanistan. Journal of Health Services and Research Policy 2019;24(1):4-10.

\section{Thi 2018 \{published data only\}}

Thi Ha, Nguyen Hong. Improving grassroots service delivery using results based financing in Viet. 2018///.

\section{Thirumurthy 2018 \{published data only\}}

Thirumurthy H, Emperador D, Ndyabakira A, Kwarisiima D, Camlin CS, Kamya MR, et al. Randomized controlled trial of financial incentives for achieving viral suppression [CROI Abstract 95]. In Special Issue: Abstracts From the 2018 Conference on Retroviruses and Opportunistic Infections. Topics in Antiviral Medicine 2018;26(Suppl 1):40s.

\section{Triyana 2017 \{published data only\}}

Triyana M, Shankar A H. The effects of a household conditional cash transfer programme on coverage and quality of antenatal care: A secondary analysis of Indonesia's pilot programme. 2017;7(10)

\section{Turcotte-Tremblay 2018 \{published data only\}}

Turcotte-Tremblay AM, De Allegri M, Gali-Gali IA, Ridde V. The unintended consequences of combining equity measures with performance-based financing in Burkina Faso. International Journal for Equity in Health 2018;17:109.

\section{Turcotte-Tremblay 2020 \{published data only\}}

Turcotte-Tremblay A M, Gali Gali I A, Ridde V. An Exploration of the Unintended Consequences of Performance-Based Financing in 6 Primary Healthcare Facilities in Burkina Faso. 2020.

\section{Visconti 2020 \{published data only\}}

Visconti Roberto Moro, Morea Donato. Healthcare digitalization and pay-for-performance incentives in smart hospital project financing. International Journal of Environmental Research and Public Health 2020///;17(7). 
Vokes 2018 \{published data only\}

Vokes RA, Bearman G, Bazzoli GJ. Hospital-acquired infections under pay-for-performance systems: an administrative perspective on management and change. Current Infectious Disease Reports 2018;20:35.

\section{Witter 2012 \{published data only\}}

Witter S, Fretheim A, Kessy F L, Lindahl A K. Paying for performance to improve the delivery of health interventions in low- and middle-income countries. 2012;(2).

\section{Witter 2019 \{published data only\}}

Witter S, Bertone MP, Namakula J, Chandiwana P, Chirwa Y, Ssennyonjo A, et al. (How) does RBF strengthen strategic purchasing of health care? Comparing the experience of Uganda, Zimbabwe and the Democratic Republic of the Congo. Global Health Research and Policy 2019;4:3.

\section{Witter 2019b \{published data only\}}

Witter S, Chirwa Y, Chandiwana P, Munyati S, Pepukai M, Bertone M P. The political economy of results-based financing: the experience of the health system in Zimbabwe. 2019;4(1).

\section{Witter 2020 \{published data only\}}

Witter S, Chirwa Y, Chandiwana P, Munyati S, Pepukai M, Bertone M P, Banda S. Results-based financing as a strategic purchasing intervention: some progress but much further to go in Zimbabwe?2020;20(1):180.

\section{Witter 2020a \{published data only\}}

Witter Sophie, Chirwa Yotamu, Chandiwana Pamela, Munyati Shungu, Pepukai Mildred, Bertone Maria Paola, Banda Steve. Results-based financing as a strategic purchasing intervention: Some progress but much further to go in Zimbabwe? BMC Health Services Research 2020///;20(1):1-18.

\section{World Bank Group \{published data only\}}

World Bank Group. Invitations and incentives for primary care screenings in Armenia.

\section{Wright 2018 \{published data only\}}

Wright J, Eichler R. A Review of Initiatives that Link Provider Payment with Quality Measurement of Maternal Health Services in Low- and Middle-Income Countries. Health Systems and Reform 2018;4(2):77-92.

\section{Wu 2018 \{published data only\}}

Wu Zeng, Shepard Donald S, Ha Nguyen, Chansa Collins, Das Ashis Kumar, Qamruddin Jumana, Friedman Jed. Cost-effectiveness of results-based financing, Zambia: a cluster randomized trial. 2018;96(11):760-771.

\section{Ye 2016 \{published data only\}}

Ye M, Diboulo E, Kagone M, Sie A, Sauerborn R, Loukanova S. Health worker preferences for performance-based payment schemes in a rural health district in Burkina Faso. 2016;9:1-12.

\section{Yingxia 2017 \{published data only\}}

Yingxia Zhou, Jiajun Yuan, Luo L U, Bin Dong, Liebin Zhao. The effectiveness of a pay for performance incentive program on the comprehensive management in patients with type 2 diabetes. 2017:1017-1023.

\section{Zeng 2018 \{published data only\}}

Zeng W, Sun DX, Nair D, Nam JE, Gheorghe A. Strengthening performance-based financing as a health system approach for quality improvement. Journal of Global Health 2018;8(2):20305.

\section{Zeng 2018c \{published data only\}}

Zeng Wu, Lannes Laurence, Mutasa Ronald. Utilization of health care and burden of out-of-pocket health expenditure in Zimbabwe: Results from a national household survey. Health Systems and Reform 2018///;4(4):300-312.

\section{Zeng 2018d \{published data only\}}

Zeng Wu, Lannes Laurence, Mutasa Ronald. Utilization of health care and burden of out-of-pocket health expenditure in Zimbabwe: Results from a national household survey. Health Systems and Reform 2018///;4(4):300-312.

\section{Zhang 2019 \{published data only\}}

Zhang H, van Doorslaer E, Xu L, Zhang Y, van de Klundert J. Can a results-based bottom-up reform improve health system performance? Evidence from the rural health project in China. 2019;28(10):1204-1219.

\section{Zheng 2019 \{published data only\}}

Zheng CY, Musominali S, Chaw GF, Paccione G. A performancebased incentives system for village health workers in Kisoro, Uganda. Annals of Global Health 2019;85(1):46.

\section{Zitti 2019 \{published data only\}}

Zitti T, Gautier L, Coulibaly A, Ridde V. Stakeholder Perceptions and Context of the Implementation of Performance-Based Financing in District Hospitals in Mali. 2019;8(10):583-592.

\section{Zizien 2019 \{published data only\}}

Zizien ZR, Korachais C, Compaore P, Ridde V, De Brouwere V. Contribution of the results-based financing strategy to improving maternal and child health indicators in Burkina Faso. International Journal of Health Planning and Management 2019;34(1):111-29.

\section{Zombre 2020 \{published data only\}}

Zombre D, De Allegri M, Ridde V. No effects of pilot performancebased intervention implementation and withdrawal on the coverage of maternal and child health services in the Koulikoro region, Mali: an interrupted time series analysis. 2020;35(4):379-387.

\section{References to ongoing studies}

\section{Burkina Faso \{published data only\}}

RBF Health. Burkina Faso impact evaluation. www.rbfhealth.org/impact-evaluation/burkina-faso-impactevaluation (accessed prior to 24 January 2020). 
Burundi \{published data only\}

RBF Health. Burundi impact evaluation. www.rbfhealth.org/ impact-evaluation/burundi-impact-evaluation (accessed prior to 24 January 2020).

\section{Ethiopia \{published data only\}}

CORDAID. Equitable health care through RBF in Ethiopia. www.cordaid.org/en/publications/equitable-health-carethrough-pbf-in-ethiopia (accessed prior to 24 January 2020).

\section{Ghana \{published data only\}}

RBF Health. Ghana impact evaluation. www.rbfhealth.org/ impact-evaluation/ghana-impact-evaluation (accessed prior to 24 January 2020).

\section{Haiti \{published data only\}}

RBF Health. Haiti Impact Evaluation. www.rbfhealth.org/ impact-evaluation/haiti-impact-evaluation (accessed prior to 24 January 2020).

\section{Kyrgyz Republic \{published data only\}}

RBF Health. Kyrgyz Republic impact evaluation. www.rbfhealth.org/impact-evaluation/kyrgyz-republic-impactevaluation (accessed prior to 24 January 2020).

\section{Lesotho \{published data only\}}

RBF Health. Lesotho impact evaluation. www.rbfhealth.org/ impact-evaluation/lesotho-impact-evaluation (accessed prior to 24 January 2020).

\section{Nigeria \{published data only\}}

RBF Health. Nigeria impact evaluation. www.rbfhealth.org/ impact-evaluation/nigeria-impact-evaluation (accessed prior to 24 January 2020).

\section{Tajikistan A \{published data only\}}

RBF Health. Tajikistan impact evaluation. www.rbfhealth.org/ impact-evaluation/tajikistan-impact-evaluation (accessed prior to 24 January 2020)

\section{Tajikistan B \{published data only\}}

RBF Health. Baseline study for the impact evaluation of a performance based financing (PBF) pilot in Tajikistan. documents.worldbank.org/curated/en/992471492590596793/ pdf/114374-WP-TajikistanPBFIEBaselinereportFinal-PUBLIC.pdf (accessed prior to 24 January 2020).

The Gambia \{published data only\}

RBF Health. The Gambia maternal and child nutrition and health results project baseline survey report. www.rbfhealth.org/sites/rbf/files/documents/Gambia\%20IE \%20baseline\%20report.pdf (accessed prior to 24 January 2020).

\section{Uganda \{published data only\}}

CORDAID. Improving health service delivery through PBF. www.cordaid.org/en/publications/improving-health-servicedelivery-through-pbf (accessed prior to 24 January 2020).

\section{Additional references}

\section{Binyaruka 2018}

Binyaruka, P, Robberstad, B, Torsvik, $G$ et al. Who benefits from increased service utilisation? Examining the distributional effects of payment for performance in Tanzania. Int J Equity Health 2018;17(14).

\section{Blacklock 2016}

Blacklock C, MacPepple E, Kunutsor S, Witter S. Paying for performance to improve the delivery and uptake of family planning in low and middle income countries: a systematic review. Studies in Family Planning 2016;47(4):309-24.

\section{Borghi 2015}

Borghi J, Little R, Binyaruka P, Patouillard E, Kuwawenaruwa A. In Tanzania, the many costs of pay-for-performance leave open to debate whether the strategy is cost-effective. Health Affairs 2015;34(3):406-14

\section{Campbell 2019}

Mhairi Campbell, Joanne E McKenzie, Amanda Sowden, Srinivasa Vittal Katikireddi, Sue E Brennan, Simon Ellis, Jamie Hartmann-Boyce, Rebecca Ryan, Sasha Shepperd, James Thomas, Vivian Welch, Hilary Thomson. Synthesis without meta-analysis (SWiM) in systematic reviews: reporting guideline. British Medical Journal 2020;368(I6890).

\section{Cashin 2014}

Cheryl Cashin, Y-Ling Chi, Peter C Smith, Michael Borowitz and Sarah Thomson. https://dx.doi.org/10.1787/9789264224568-en. New York: World Health Organization, 2014.

\section{Christianson 2007}

Christianson J, Leatherman S, Sutherland K. Financial Incentives, Health Care Providers and Quality Improvements: A Review of the Evidence. London: The Health Foundation, 2007.

\section{Dale 2014}

Dale EM. Performance-Based Payments, Provider Motivation and Quality of Care in Afghanistan [Doctor of Philosophy thesis]. Baltimore, Maryland (USA): Johns Hopkins University, 2014.

\section{Das 2016}

Das A, Gopalan SS, Chandramohan D. Effect of pay for performance to improve quality of maternal and child care in low- and middle-income countries: a systematic review. BMC Public Health 2016;16:321.

\section{Deci 1999}

Deci E, Ryan R, Koestner R. A meta-analytic review of experiments examining the effects of extrinsic rewards on intrinsic motivation. Psychological Bulletin 1999;125(6):627-8.

\section{Eichler 2006}

Eichler R. Can "Pay for Performance" increase utilization by the poor and improve the quality of health services? Center for Global Development. Discussion paper for the first meeting of the Working Group on Performance-Based Incentives. 2006. 


\section{Eldridge 2009}

Eldridge C, Palmer N. Performance-based payment: some reflections on the discourse, evidence and unanswered questions. Health Policy and Planning 2009;24(3):160-6.

\section{EPOC 2017a}

Cochrane Effective Practice and Organisation of Care (EPOC). Suggested Risk of Bias Criteria for EPOC Reviews. EPOC Resources for Review Authors, 2017. epoc.cochrane.org/ resources/epoc-resources-review-authors (accessed prior to 24 January 2020). 2017.

\section{EPOC 2017b}

Cochrane Effective Practice and Organisation of Care (EPOC). Interrupted Time Series (ITS) Analyses. EPOC Resources for Review Authors, 2017. epoc.cochrane.org/resources/epocresources-review-authors (accessed prior to 24 January 2020). 2017.

\section{EPOC 2017C}

Cochrane Effective Practice and Organisation of Care (EPOC). EPOC Worksheets for Preparing a Summary of Findings (SoF) Table using GRADE. EPOC Resources for Review Authors, 2017. epoc.cochrane.org/resources/epoc-resources-review-authors (accessed 24 January 2020). 2017.

\section{Higgins 2019}

Higgins JP, Thomas J, Chandler J, Cumpston M, Li T, Page MJ, et al. Cochrane Handbook for Systematic Reviews of Interventions version 6.0 (updated July 2019). Cochrane, 2019.

\section{Huillery 2014}

Huillery E, Seban J. Performance-based financing, motivation and final output in the health sector: experimental evidence from the Democratic Republic of Congo. No 2014-12, Sciences Po Economics Discussion Papers, Sciences Po Department of Economics. 2014.

\section{Hultcrantz 2017}

Hultcrantz M, Rind D, Akl EA, Treweek S, Mustafa RA, lorio A, et al. The GRADE Working Group clarifies the construct of certainty of evidence. Journal of Clinical Epidemiology 2017;87:4-13.

\section{Josephson 2017}

Josephson E, Gergen J, Coe M, Ski S, Madhavan S, Bauhoff S. How do performance-based financing programmes measure quality of care? A descriptive analysis of 68 quality checklists from 28 low- and middle-income countries. Health Policy and Planning 2017;32(8):1120-6.

\section{Lagarde 2011}

Lagarde M, Palmer N. The impact of user fees on access to health services in low- and middle-income countries. Cochrane Database of Systematic Reviews 2011, Issue 4.

\section{Lewin 2017}

Lewin S, Hendry M, Chandler J, Oxman AD, Michie S, Shepperd S, et al. Assessing the complexity of interventions within systematic reviews: development, content and use of a new tool (iCAT_SR). BMC Medical Research Methodology 2017;17:76

\section{Linden 2015}

Linden A. Conducting interrupted time-series analysis for single- and multiple-group comparisons. The Stata Journal 2015;15(2):480-500.

\section{Marquand 2004}

Marquand D. Decline of the Public. The Hollowing Out of Citizenship. Cambridge: Polity Press, 2004.

\section{Meessen 2011}

Meessen B, Soucat A, Sekabaraga C. Performance-based financing: just a donor fad or a catalyst towards comprehensive health-care reform? Bulletin of the World Health Organization 2011;89:153-6.

\section{Murad 2017}

Murad MH, Mustafa RA, Schünemann HJ, Sultan S, Santesso N. Rating the certainty in evidence in the absence of a single estimate of effect. BMJ Evidence-Based Medicine 2017;22:85-7.

\section{Musgrove 2011}

Musgrove P. Financial and Other Rewards for Good Performance or Results: A Guided Tour of Concepts and Terms and a Short Glossary. Available at https://www.rbfhealth.org/sites/rbf/files/ RBFglossarylongrevised_0.pdf (accessed prior to 24 January 2020). 2011.

\section{Oxman 2008}

Oxman AD, Fretheim A. An overview of research on the effects of results-based financing. Report Nr 16-2008. Oslo: Nasjonalt kunnskapssenter for helsetjenesten. 2008.

\section{Peabody 2017}

Peabody JW, Quimbo S, Florentino J, Shimkhada R, Javier X, Paculdo D, et al. Comparative effectiveness of two disparate policies on child health: experimental evidence from the Philippines. Health Policy and Planning 2017;32(4):563-71.

\section{RBF Health 2020}

RBF Health. Projects. https://www.rbfhealth.org/projects (accessed prior to 24 January 2020).

\section{Renmans 2016}

Renmans D, Holvoet N, Orach CG, Criel B. Opening the 'black box' of performance-based financing in low- and lower middleincome countries: a review of the literature. Health Policy and Planning 2016;31(9):1297-309.

\section{Schünemann 2013}

Schünemann H, BrożekJ, Guyatt G, Oxman A, (editors). Handbook for Grading the Quality of Evidence and the Strength of Recommendations using the GRADE Approach (updated October 2013). GRADE Working Group, 2013. Available from gdt.guidelinedevelopment.org/app/handbook/handbook.html 2013.

\section{Soucat 2017}

Agnès Soucat, Elina Dale, Inke Mathauer \& Joseph Kutzin. Payfor-Performance Debate: Not Seeing the Forest for the Trees, Health Systems \& Reform 2017;3(2):74-79. 


\section{Turcotte-Tremblay 2016}

Turcotte-Tremblay AM, Spagnolo J, De Allegri M, Ridde V. Does performance-based financing increase value for money in lowand middle- income countries? A systematic review. Health Economics Review 2016;6(1):30.

\section{Witter 2009}

Witter S, Kessy FL, Fretheim A, Lindahl AK. Paying for performance to improve the delivery of health interventions in low and middle-income countries. Cochrane Database of Systematic Reviews 2009, Issue 3.

\section{Witter 2013}

Witter S, Toonen J, Meessen B, Kagubare J, Fritsche G, Vaughan K. Performance-based financing as a health system reform: mapping the key dimensions for monitoring and evaluation. BMC Health Services Research 2013;13:367.

\section{CHARACTERISTICS OF STUDIES}

Characteristics of included studies [ordered by study ID]

Basinga 2011

\section{Study characteristics}

\section{Witter 2019}

Witter S, Chirwa Y, Chandiwana P, Munyati S, Pepukai M, Bertone MP. The political economy of results-based financing: the experience of the health system in Zimbabwe. Global Health Research and Policy 2019;4:20.

\section{Zeng 2018b}

Zeng W, Shepard DS, Nguyen H, Chansa C, Das AK, Qamruddin J, et al. Cost-effectiveness of results-based financing, Zambia: a cluster randomized trial.. Bulletin of the World Health Organisation 2018;96(11):760-71.

\section{References to other published versions of this review Witter 2012}

Witter S, Fretheim A, Kessy FL, Lindahl AK. Paying for performance to improve the delivery of health interventions in low- and middle-income countries. Cochrane Database of Systematic Reviews 2012, Issue 2.

Methods

Participants

Interventions

Outcomes

Notes

\section{Risk of bias}

\begin{tabular}{lll}
\hline Bias & Authors' judgement & Support for judgement \\
\hline $\begin{array}{l}\text { Random sequence genera- } \\
\text { tion (selection bias) }\end{array}$ & High risk & Randomization compromised \\
\hline $\begin{array}{l}\text { Allocation concealment } \\
\text { (selection bias) }\end{array}$ & Low risk & Assignment by province/district/cluster \\
\hline $\begin{array}{l}\text { Blinding (performance } \\
\text { bias and detection bias) } \\
\text { All outcomes }\end{array}$ & Low risk & Blinded assessments \\
\hline $\begin{array}{l}\text { Incomplete outcome data } \\
\text { (attrition bias) }\end{array}$ & Unclear risk & Not specified \\
All outcomes & & \\
\hline
\end{tabular}

Selective reporting (reporting bias) 
Basinga 2011 (Continued)

Other bias

Low risk

$\begin{aligned} & \text { Baseline outcome mea- Low risk } \\ & \text { surement }\end{aligned}$ Analyses methods adjust for differences
Alloutcomes

All outcomes

\begin{tabular}{lll}
\hline $\begin{array}{l}\text { Matched characteristics } \\
\text { for control study sites }\end{array}$ & Low risk & Comparable \\
\hline $\begin{array}{l}\text { Protection against cont- } \\
\begin{array}{l}\text { amination (intervention } \\
\text { and controls) }\end{array}\end{array}$ & Low risk & Assignment by province/district/cluster \\
\hline
\end{tabular}

Bernal 2018

\section{Study characteristics}

\section{Methods}

\section{Participants}

Interventions

\section{Outcomes}

\section{Notes}

\section{Risk of bias}

\begin{tabular}{|c|c|c|}
\hline Bias & Authors' judgement & Support for judgement \\
\hline $\begin{array}{l}\text { Random sequence genera- } \\
\text { tion (selection bias) }\end{array}$ & High risk & As per guidance \\
\hline $\begin{array}{l}\text { Allocation concealment } \\
\text { (selection bias) }\end{array}$ & High risk & As per guidance \\
\hline $\begin{array}{l}\text { Blinding (performance } \\
\text { bias and detection bias) } \\
\text { All outcomes }\end{array}$ & Low risk & $\begin{array}{l}\text { Bernal } 2018 \text { Section } 6 \text { outlines sensitivity analyses and details quality checks } \\
\text { on data }\end{array}$ \\
\hline $\begin{array}{l}\text { Incomplete outcome data } \\
\text { (attrition bias) } \\
\text { All outcomes }\end{array}$ & Unclear risk & Not specified \\
\hline $\begin{array}{l}\text { Selective reporting (re- } \\
\text { porting bias) }\end{array}$ & Low risk & \\
\hline Other bias & Unclear risk & Reforms were taking place at the same time \\
\hline $\begin{array}{l}\text { Baseline outcome mea- } \\
\text { surement } \\
\text { All outcomes }\end{array}$ & Low risk & Analyses methods adjust for differences \\
\hline
\end{tabular}


Bernal 2018 (Continued)

$\begin{array}{lll}\begin{array}{l}\text { Matched characteristics } \\ \text { for control study sites }\end{array} & \text { High risk } & \begin{array}{l}\text { Bernal } 2018 \text { Table } 2 \text { and page } 9 \text { highlight the differences between results } \\ \text { based aid provinces and those with national funding }\end{array}\end{array}$

Protection against cont- Low risk Assignment by province/district/cluster

amination (intervention

Assignment by province/district/cluster

and controls)

Binyaruka 2015

\section{Study characteristics}

Methods

\section{Participants}

Interventions

Outcomes

\section{Notes}

\section{Risk of bias}

\begin{tabular}{|c|c|c|}
\hline Bias & Authors' judgement & Support for judgement \\
\hline $\begin{array}{l}\text { Random sequence genera- } \\
\text { tion (selection bias) }\end{array}$ & High risk & As per guidance \\
\hline $\begin{array}{l}\text { Allocation concealment } \\
\text { (selection bias) }\end{array}$ & High risk & As per guidance \\
\hline $\begin{array}{l}\text { Blinding (performance } \\
\text { bias and detection bias) } \\
\text { All outcomes }\end{array}$ & Low risk & Unlikely outcome assessment affected by allocation knowledge \\
\hline $\begin{array}{l}\text { Incomplete outcome data } \\
\text { (attrition bias) } \\
\text { All outcomes }\end{array}$ & High risk & Authors note that this may have biased results \\
\hline $\begin{array}{l}\text { Selective reporting (re- } \\
\text { porting bias) }\end{array}$ & Low risk & \\
\hline Other bias & Low risk & \\
\hline $\begin{array}{l}\text { Baseline outcome mea- } \\
\text { surement } \\
\text { All outcomes }\end{array}$ & Low risk & Analyses methods adjust for differences \\
\hline $\begin{array}{l}\text { Matched characteristics } \\
\text { for control study sites }\end{array}$ & Low risk & $\begin{array}{l}\text { Low except for: ANC visits and IPT during ANC, outpatient visits per month un- } \\
\text { der/over 5, patient assessments of staff kindness, probability of payment for } \\
\text { delivery care, satisfaction with interpersonal care }\end{array}$ \\
\hline $\begin{array}{l}\text { Protection against cont- } \\
\text { amination (intervention } \\
\text { and controls) }\end{array}$ & Low risk & Assignment by province/district/cluster \\
\hline
\end{tabular}

Paying for performance to improve the delivery of health interventions in low- and middle-income countries (Review) 
Binyaruka 2017

\section{Study characteristics}

\section{Methods}

\section{Participants}

Interventions

\section{Outcomes}

\section{Notes}

\section{Risk of bias}

\begin{tabular}{|c|c|c|}
\hline Bias & Authors' judgement & Support for judgement \\
\hline $\begin{array}{l}\text { Random sequence genera- } \\
\text { tion (selection bias) }\end{array}$ & High risk & As per guidance \\
\hline $\begin{array}{l}\text { Allocation concealment } \\
\text { (selection bias) }\end{array}$ & High risk & As per guidance \\
\hline $\begin{array}{l}\text { Blinding (performance } \\
\text { bias and detection bias) } \\
\text { All outcomes }\end{array}$ & Low risk & Unlikely outcome assessment affected by allocation knowledge \\
\hline $\begin{array}{l}\text { Incomplete outcome data } \\
\text { (attrition bias) } \\
\text { All outcomes }\end{array}$ & Unclear risk & Not specified \\
\hline $\begin{array}{l}\text { Selective reporting (re- } \\
\text { porting bias) }\end{array}$ & Low risk & \\
\hline Other bias & Low risk & \\
\hline $\begin{array}{l}\text { Baseline outcome mea- } \\
\text { surement } \\
\text { All outcomes }\end{array}$ & Low risk & Analyses methods adjust for differences \\
\hline $\begin{array}{l}\text { Matched characteristics } \\
\text { for control study sites }\end{array}$ & Low risk & Low except for: availability and stockouts of medicines and medical supplies \\
\hline $\begin{array}{l}\text { Protection against cont- } \\
\text { amination (intervention } \\
\text { and controls) }\end{array}$ & Low risk & Assignment by province/district/cluster \\
\hline
\end{tabular}

\section{Binyaruka 2018}

\section{Study characteristics}

\section{Methods}

\section{Participants}


Binyaruka 2018 (Continued)

Interventions

\section{Outcomes}

Notes

\section{Risk of bias}

\begin{tabular}{|c|c|c|}
\hline Bias & Authors' judgement & Support for judgement \\
\hline $\begin{array}{l}\text { Random sequence genera- } \\
\text { tion (selection bias) }\end{array}$ & High risk & As per guidance \\
\hline $\begin{array}{l}\text { Allocation concealment } \\
\text { (selection bias) }\end{array}$ & High risk & As per guidance \\
\hline $\begin{array}{l}\text { Blinding (performance } \\
\text { bias and detection bias) } \\
\text { All outcomes }\end{array}$ & Low risk & Unlikely outcome assessment affected by allocation knowledge \\
\hline $\begin{array}{l}\text { Incomplete outcome data } \\
\text { (attrition bias) } \\
\text { All outcomes }\end{array}$ & High risk & Authors note that this may have biased results \\
\hline $\begin{array}{l}\text { Selective reporting (re- } \\
\text { porting bias) }\end{array}$ & Low risk & \\
\hline Other bias & Low risk & \\
\hline $\begin{array}{l}\text { Baseline outcome mea- } \\
\text { surement } \\
\text { All outcomes }\end{array}$ & Low risk & Analyses methods adjust for differences \\
\hline $\begin{array}{l}\text { Matched characteristics } \\
\text { for control study sites }\end{array}$ & Low risk & $\begin{array}{l}\text { Low except for: ANC visits and IPT during ANC, outpatient visits per month un- } \\
\text { der/over 5, patient assessments of staff kindness, probability of payment for } \\
\text { delivery care, satisfaction with interpersonal care }\end{array}$ \\
\hline $\begin{array}{l}\text { Protection against cont- } \\
\text { amination (intervention } \\
\text { and controls) }\end{array}$ & Low risk & Assignment by province/district/cluster \\
\hline
\end{tabular}

Bonfrer 2014a

\section{Study characteristics}

Methods

\section{Participants}

Interventions

\section{Outcomes}

\section{Notes}


Bonfrer 2014a (Continued)

Risk of bias

\begin{tabular}{|c|c|c|}
\hline Bias & Authors' judgement & Support for judgement \\
\hline $\begin{array}{l}\text { Random sequence genera- } \\
\text { tion (selection bias) }\end{array}$ & High risk & As per guidance \\
\hline $\begin{array}{l}\text { Allocation concealment } \\
\text { (selection bias) }\end{array}$ & High risk & As per guidance \\
\hline $\begin{array}{l}\text { Blinding (performance } \\
\text { bias and detection bias) } \\
\text { All outcomes }\end{array}$ & Low risk & Unlikely outcome assessment affected by allocation knowledge \\
\hline $\begin{array}{l}\text { Incomplete outcome data } \\
\text { (attrition bias) } \\
\text { All outcomes }\end{array}$ & Unclear risk & Not specified \\
\hline $\begin{array}{l}\text { Selective reporting (re- } \\
\text { porting bias) }\end{array}$ & Low risk & \\
\hline Other bias & Unclear risk & Authors recognize they only assess impacts of 6 out of 23 targeted services \\
\hline $\begin{array}{l}\text { Baseline outcome mea- } \\
\text { surement } \\
\text { All outcomes }\end{array}$ & Low risk & Analyses methods adjust for differences \\
\hline $\begin{array}{l}\text { Matched characteristics } \\
\text { for control study sites }\end{array}$ & High risk & $\begin{array}{l}\text { Bonfrer 2014a Appendix Table } 6 \text { suggests differences exist between the differ- } \\
\text { ent districts, e.g. popuation characteristics (poverty) varies between } 28.7 \% \\
\text { and } 82.3 \%\end{array}$ \\
\hline $\begin{array}{l}\text { Protection against cont- } \\
\text { amination (intervention } \\
\text { and controls) }\end{array}$ & Low risk & Assignment by province/district/cluster \\
\hline
\end{tabular}

Bonfrer 2014b

\section{Study characteristics}

Methods

Participants

Interventions

Outcomes

$$
\text { Notes }
$$

\section{Risk of bias}

\begin{tabular}{lll}
\hline Bias & Authors' judgement & Support for judgement \\
\hline $\begin{array}{l}\text { Random sequence genera- } \\
\text { tion (selection bias) }\end{array}$ & High risk & As per guidance \\
\hline \hline
\end{tabular}


Bonfrer 2014b (Continued)

\begin{tabular}{lll}
$\begin{array}{l}\text { Allocation concealment } \\
\text { (selection bias) }\end{array}$ & High risk & As per guidance \\
\hline $\begin{array}{l}\text { Blinding (performance } \\
\text { bias and detection bias) }\end{array}$ & Low risk & Blinded assessments \\
All outcomes & &
\end{tabular}

Incomplete outcome data Unclear risk $\quad$ Not specified
(attrition bias)
All outcomes
Selective reporting (re- Low risk porting bias)

\begin{tabular}{|c|c|c|}
\hline Other bias & Unclear risk & Authors recognize they only assess impacts of 6 out of 23 targeted services \\
\hline $\begin{array}{l}\text { Baseline outcome mea- } \\
\text { surement } \\
\text { All outcomes }\end{array}$ & Low risk & Analyses methods adjust for differences \\
\hline $\begin{array}{l}\text { Matched characteristics } \\
\text { for control study sites }\end{array}$ & Low risk & Comparable \\
\hline $\begin{array}{l}\text { Protection against cont- } \\
\text { amination (intervention } \\
\text { and controls) }\end{array}$ & Low risk & Assignment by province/district/cluster \\
\hline
\end{tabular}

Brock 2018

\section{Study characteristics}

\begin{tabular}{|c|c|c|}
\hline \multicolumn{3}{|l|}{ Methods } \\
\hline \multicolumn{3}{|l|}{ Participants } \\
\hline \multicolumn{3}{|l|}{ Interventions } \\
\hline \multicolumn{3}{|l|}{ Outcomes } \\
\hline \multicolumn{3}{|l|}{ Notes } \\
\hline \multicolumn{3}{|l|}{ Risk of bias } \\
\hline Bias & Authors' judgement & Support for judgement \\
\hline $\begin{array}{l}\text { Random sequence genera- } \\
\text { tion (selection bias) }\end{array}$ & Low risk & Sequence described in enough detail \\
\hline $\begin{array}{l}\text { Allocation concealment } \\
\text { (selection bias) }\end{array}$ & Low risk & Assignment by health care professional, done post baseline assessment \\
\hline $\begin{array}{l}\text { Blinding (performance } \\
\text { bias and detection bias) } \\
\text { All outcomes }\end{array}$ & Low risk & Blinded assessments \\
\hline
\end{tabular}


Brock 2018 (Continued)
Incomplete outcome data
Low risk
Drop-out pre-assignment $12 \%$, but post only $3 \%$
(attrition bias)
All outcomes
Selective reporting (re- Low risk porting bias)

\begin{tabular}{|c|c|c|}
\hline Other bias & Unclear risk & $\begin{array}{l}\text { The initial design was changed given few clinicians saw sufficiently high num- } \\
\text { ber of patients to be of relevance. Initial provider pool covenience sample }\end{array}$ \\
\hline
\end{tabular}

\begin{tabular}{lll}
\hline $\begin{array}{l}\text { Baseline outcome mea- } \\
\text { surement } \\
\text { All outcomes }\end{array}$ & Low risk & Comparable \\
\hline $\begin{array}{l}\text { Matched characteristics } \\
\text { for control study sites }\end{array}$ & High risk & $\begin{array}{l}\text { Brock 2018 Tables 2 and 3 suggest some differences between providers and } \\
\text { patients }\end{array}$ \\
\hline
\end{tabular}

Protection against cont- Low risk Assignment by health care professional
$\begin{aligned} & \text { amination (intervention } \\ & \text { and controls) }\end{aligned}$

\section{Celhay 2015}

\section{Study characteristics}

\section{Methods}

\section{Participants}

$$
\text { Interventions }
$$

\section{Outcomes}

$$
\text { Notes }
$$

\begin{tabular}{|c|c|c|}
\hline Bias & Authors' judgement & Support for judgement \\
\hline $\begin{array}{l}\text { Random sequence genera- } \\
\text { tion (selection bias) }\end{array}$ & Low risk & Sequence described in enough detail \\
\hline $\begin{array}{l}\text { Allocation concealment } \\
\text { (selection bias) }\end{array}$ & Low risk & Assignment by province/district/cluster \\
\hline $\begin{array}{l}\text { Blinding (performance } \\
\text { bias and detection bias) } \\
\text { All outcomes }\end{array}$ & Low risk & Unlikely outcome assessment affected by allocation knowledge \\
\hline $\begin{array}{l}\text { Incomplete outcome data } \\
\text { (attrition bias) } \\
\text { All outcomes }\end{array}$ & Low risk & Authors use routine data and perform robustness analyses \\
\hline
\end{tabular}

\section{Risk of bias}

\footnotetext{
Selective reporting (re- Low risk porting bias)
} 
Celhay 2015 (Continued)

\begin{tabular}{lll} 
Other bias & Low risk & \\
\hline $\begin{array}{l}\text { Baseline outcome mea- } \\
\text { surement } \\
\text { All outcomes }\end{array}$ & Low risk & Comparable \\
\hline $\begin{array}{l}\text { Matched characteristics } \\
\text { for control study sites }\end{array}$ & Low risk & Comparable \\
\hline $\begin{array}{l}\text { Protection against cont- } \\
\text { amination (intervention } \\
\text { and controls) }\end{array}$ & Low risk & Assignment by province/district/cluster \\
\hline
\end{tabular}

\section{Chang 2017}

\section{Study characteristics}

\section{Methods}

\section{Participants}

Interventions

\section{Outcomes}

\section{Notes}

\section{Risk of bias}

\begin{tabular}{|c|c|c|}
\hline Bias & Authors' judgement & Support for judgement \\
\hline $\begin{array}{l}\text { Blinding (performance } \\
\text { bias and detection bias) } \\
\text { All outcomes }\end{array}$ & Unclear risk & Not specified \\
\hline $\begin{array}{l}\text { Selective reporting (re- } \\
\text { porting bias) }\end{array}$ & Low risk & \\
\hline Other bias & Unclear risk & Three PBF schemes were implemented, only one assessed \\
\hline $\begin{array}{l}\text { Intervention independent } \\
\text { (ITS)? }\end{array}$ & High risk & $\begin{array}{l}\text { Other interventions concurrent (including further PBF + introduction of data- } \\
\text { base) }\end{array}$ \\
\hline $\begin{array}{l}\text { Shape of effect pre-speci- } \\
\text { fied (ITS)? }\end{array}$ & Low risk & Specified as per guidance \\
\hline $\begin{array}{l}\text { Unlikely to affect data col- } \\
\text { lection (ITS)? }\end{array}$ & High risk & Intervention introduced alongside an HMIS intervention \\
\hline $\begin{array}{l}\text { Incomplete outcome data } \\
\text { addressed (ITS)? }\end{array}$ & Unclear risk & Not specified \\
\hline
\end{tabular}


Chansa 2015

\section{Study characteristics}

\section{Methods}

\section{Participants}

Interventions

\section{Outcomes}

\section{Notes}

\section{Risk of bias}

\begin{tabular}{lll}
\hline Bias & Authors' judgement & Support for judgement \\
\hline $\begin{array}{l}\text { Blinding (performance } \\
\text { bias and detection bias) }\end{array}$ & Low risk & Unlikely allocation affects data collection \\
All outcomes & & \\
\hline
\end{tabular}

Selective reporting (re- Low risk porting bias)

\begin{tabular}{lll}
\hline Other bias & Low risk & \\
\hline $\begin{array}{l}\text { Intervention independent } \\
\text { (ITS)? }\end{array}$ & Unclear risk & Not specified \\
\hline $\begin{array}{l}\text { Shape of effect pre-speci- } \\
\text { fied (ITS)? }\end{array}$ & Low risk & Specified as per guidance \\
\hline $\begin{array}{l}\text { Unlikely to affect data col- } \\
\text { lection (ITS)? }\end{array}$ & High risk & Intervention introduced alongside audits \\
\hline $\begin{array}{l}\text { Incomplete outcome data } \\
\text { addressed (ITS)? }\end{array}$ & Low risk & HMIS data \\
\hline
\end{tabular}

\section{Cruzado de la Vega 2017}

\section{Study characteristics}

\section{Methods}

\section{Participants}

Interventions

\section{Outcomes}

\section{Notes}

\section{Risk of bias}


Cruzado de la Vega 2017 (Continued)

\begin{tabular}{lll}
$\begin{array}{l}\text { Random sequence genera- } \\
\text { tion (selection bias) }\end{array}$ & High risk & No randomization \\
\hline $\begin{array}{l}\text { Allocation concealment } \\
\text { (selection bias) }\end{array}$ & Low risk & Assignment by province/district/cluster \\
\hline
\end{tabular}

(selection bias)

Blinding (performance $\quad$ Low risk Unlikely outcome assessment affected by allocation knowledge
bias and detection bias)

All outcomes

\begin{tabular}{l}
\hline Incomplete outcome data Unclear risk Not specified \\
(attrition bias) \\
All outcomes
\end{tabular}

Selective reporting (re- Low risk
porting bias)

\begin{tabular}{|c|c|c|}
\hline Other bias & Low risk & \\
\hline $\begin{array}{l}\text { Baseline outcome mea- } \\
\text { surement } \\
\text { All outcomes }\end{array}$ & Low risk & Analyses methods adjust for differences \\
\hline $\begin{array}{l}\text { Matched characteristics } \\
\text { for control study sites }\end{array}$ & Low risk & Comparable \\
\hline $\begin{array}{l}\text { Protection against cont- } \\
\text { amination (intervention } \\
\text { and controls) }\end{array}$ & Low risk & Assignment by province/district/cluster \\
\hline
\end{tabular}

\section{Das 2017}

\section{Study characteristics}

\section{Methods}

\section{Participants}

$$
\text { Interventions }
$$

\section{Outcomes}

\section{Notes}

\section{Risk of bias}

\begin{tabular}{lll}
\hline Bias & Authors' judgement & Support for judgement \\
\hline $\begin{array}{l}\text { Random sequence genera- } \\
\text { tion (selection bias) }\end{array}$ & High risk & As per guidance \\
\hline $\begin{array}{l}\text { Allocation concealment } \\
\text { (selection bias) }\end{array}$ & High risk & As per guidance \\
\hline
\end{tabular}


Das 2017 (Continued)
Blinding (performance
Unclear risk
Not specified
bias and detection bias)
All outcomes

Incomplete outcome data High risk Sub-set analyses with particularly small samples
(attrition bias)

Selective reporting (re- Low risk
porting bias)

\begin{tabular}{|c|c|c|}
\hline Other bias & Low risk & \\
\hline $\begin{array}{l}\text { Baseline outcome mea- } \\
\text { surement } \\
\text { All outcomes }\end{array}$ & Low risk & Analyses methods adjust for differences \\
\hline $\begin{array}{l}\text { Matched characteristics } \\
\text { for control study sites }\end{array}$ & Low risk & Comparable \\
\hline $\begin{array}{l}\text { Protection against cont- } \\
\text { amination (intervention } \\
\text { and controls) }\end{array}$ & Low risk & Assignment by province/district/cluster \\
\hline
\end{tabular}

de Walque 2015

\section{Study characteristics}

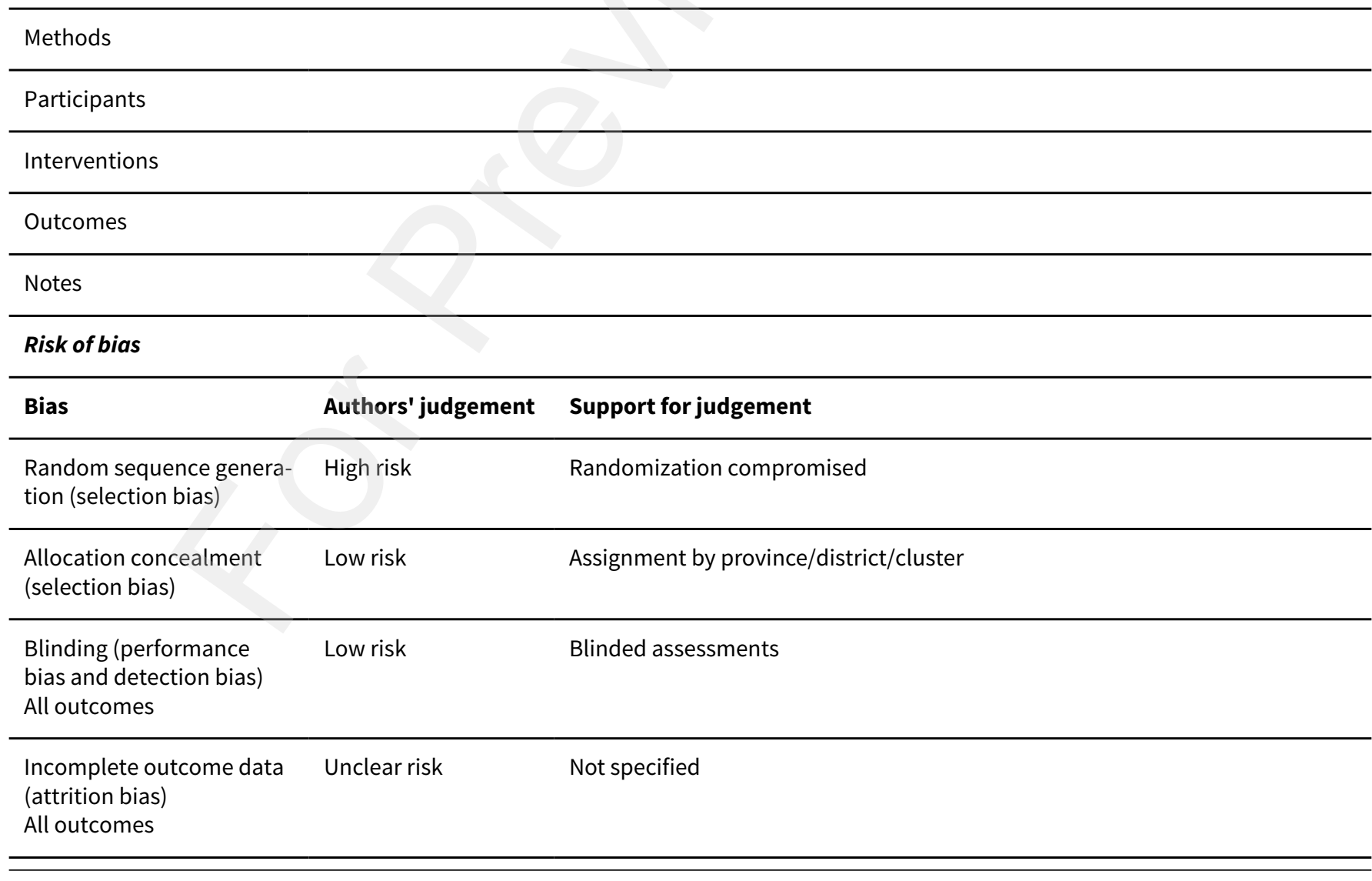


de Walque 2015 (Continued)

Selective reporting (re- Low risk
porting bias)

Other bias Low risk

Baseline outcome mea- Low risk Analyses methods adjust for differences

surement

All outcomes

\begin{tabular}{lll}
\hline $\begin{array}{l}\text { Matched characteristics } \\
\text { for control study sites }\end{array}$ & Low risk & Comparable \\
\hline $\begin{array}{l}\text { Protection against cont- } \\
\begin{array}{l}\text { amination (intervention } \\
\text { and controls) }\end{array}\end{array}$ & Low risk & Assignment by province/district/cluster \\
\hline
\end{tabular}

\section{de Walque 2017}

\section{Study characteristics}

Methods

\section{Participants}

Interventions

\section{Outcomes}

Notes

\section{Risk of bias}

\begin{tabular}{|c|c|c|}
\hline Bias & Authors' judgement & Support for judgement \\
\hline $\begin{array}{l}\text { Random sequence genera- } \\
\text { tion (selection bias) }\end{array}$ & Low risk & Sequence described in enough detail \\
\hline $\begin{array}{l}\text { Allocation concealment } \\
\text { (selection bias) }\end{array}$ & Low risk & Assignment by province/district/cluster \\
\hline $\begin{array}{l}\text { Blinding (performance } \\
\text { bias and detection bias) } \\
\text { All outcomes }\end{array}$ & Unclear risk & Not specified \\
\hline $\begin{array}{l}\text { Incomplete outcome data } \\
\text { (attrition bias) } \\
\text { All outcomes }\end{array}$ & Unclear risk & Not specified \\
\hline $\begin{array}{l}\text { Selective reporting (re- } \\
\text { porting bias) }\end{array}$ & Low risk & \\
\hline Other bias & Low risk & \\
\hline $\begin{array}{l}\text { Baseline outcome mea- } \\
\text { surement }\end{array}$ & Low risk & Analyses methods adjust for differences \\
\hline
\end{tabular}


de Walque 2017 (Continued)

All outcomes

Matched characteristics
for control study sites

\begin{tabular}{ll}
\hline $\begin{array}{l}\text { Protection against cont- } \\
\text { amination (intervention }\end{array}$ & Low risk
\end{tabular}

and controls)

\section{Duysburgh 2016}

\section{Study characteristics}

\section{Methods}

\section{Participants}

Interventions

\section{Outcomes}

\section{Notes}

\section{Risk of bias}

\begin{tabular}{|c|c|c|}
\hline Bias & Authors' judgement & Support for judgement \\
\hline $\begin{array}{l}\text { Random sequence genera- } \\
\text { tion (selection bias) }\end{array}$ & High risk & As per guidance \\
\hline $\begin{array}{l}\text { Allocation concealment } \\
\text { (selection bias) }\end{array}$ & High risk & As per guidance \\
\hline $\begin{array}{l}\text { Blinding (performance } \\
\text { bias and detection bias) } \\
\text { All outcomes }\end{array}$ & Low risk & $\begin{array}{l}\text { Indicators assessed objectively by trained health workers not working in as- } \\
\text { sessed facilities }\end{array}$ \\
\hline $\begin{array}{l}\text { Incomplete outcome data } \\
\text { (attrition bias) } \\
\text { All outcomes }\end{array}$ & Unclear risk & Not specified \\
\hline $\begin{array}{l}\text { Selective reporting (re- } \\
\text { porting bias) }\end{array}$ & Low risk & \\
\hline Other bias & Unclear risk & $\begin{array}{l}\text { This was re-analysed because initial analyses were inappropriate. And did not } \\
\text { account for baseline differences }\end{array}$ \\
\hline $\begin{array}{l}\text { Baseline outcome mea- } \\
\text { surement } \\
\text { All outcomes }\end{array}$ & Unclear risk & $\begin{array}{l}\text { Paper re-analysed; re-analysed results noted as low (analyses methods adjust } \\
\text { for differences) }\end{array}$ \\
\hline $\begin{array}{l}\text { Matched characteristics } \\
\text { for control study sites }\end{array}$ & High risk & $\begin{array}{l}\text { Duysburgh } 2016 \text { Appendix Table S1 suggests differences between intervention } \\
\text { and control sites but unclear what effect this would have on outcomes }\end{array}$ \\
\hline
\end{tabular}


Duysburgh 2016 (Continued)

Protection against cont- Low risk Assignment by province/district/cluster amination (intervention and controls)

\section{Engineer 2016}

\section{Study characteristics}

\section{Methods}

\section{Participants}

Interventions

\section{Outcomes}

\section{Notes}

\section{Risk of bias}

\begin{tabular}{|c|c|c|}
\hline Bias & Authors' judgement & Support for judgement \\
\hline $\begin{array}{l}\text { Random sequence genera- } \\
\text { tion (selection bias) }\end{array}$ & Low risk & Sequence described in enough detail \\
\hline $\begin{array}{l}\text { Allocation concealment } \\
\text { (selection bias) }\end{array}$ & Low risk & Assignment by province/district/cluster \\
\hline $\begin{array}{l}\text { Blinding (performance } \\
\text { bias and detection bias) } \\
\text { All outcomes }\end{array}$ & Low risk & Blinded assessments \\
\hline $\begin{array}{l}\text { Incomplete outcome data } \\
\text { (attrition bias) } \\
\text { All outcomes }\end{array}$ & Unclear risk & Not specified \\
\hline $\begin{array}{l}\text { Selective reporting (re- } \\
\text { porting bias) }\end{array}$ & Low risk & \\
\hline Other bias & Low risk & \\
\hline $\begin{array}{l}\text { Baseline outcome mea- } \\
\text { surement } \\
\text { All outcomes }\end{array}$ & Low risk & Analyses methods adjust for differences \\
\hline $\begin{array}{l}\text { Matched characteristics } \\
\text { for control study sites }\end{array}$ & Low risk & Comparable \\
\hline $\begin{array}{l}\text { Protection against cont- } \\
\text { amination (intervention } \\
\text { and controls) }\end{array}$ & Low risk & Assignment by province/district/cluster \\
\hline
\end{tabular}


Falisse 2015

\section{Study characteristics}

\section{Methods}

\section{Participants}

Interventions

\section{Outcomes}

\section{Notes}

\section{Risk of bias}

\begin{tabular}{|c|c|c|}
\hline Bias & Authors' judgement & Support for judgement \\
\hline $\begin{array}{l}\text { Random sequence genera- } \\
\text { tion (selection bias) }\end{array}$ & High risk & As per guidance \\
\hline $\begin{array}{l}\text { Allocation concealment } \\
\text { (selection bias) }\end{array}$ & High risk & As per guidance \\
\hline $\begin{array}{l}\text { Blinding (performance } \\
\text { bias and detection bias) } \\
\text { All outcomes }\end{array}$ & Low risk & Blinded assessments \\
\hline $\begin{array}{l}\text { Incomplete outcome data } \\
\text { (attrition bias) } \\
\text { All outcomes }\end{array}$ & Low risk & $\begin{array}{l}\text { Authors note outcomes to focus on chosen based on completeness and sensi- } \\
\text { tivity analyses conducted }\end{array}$ \\
\hline $\begin{array}{l}\text { Selective reporting (re- } \\
\text { porting bias) }\end{array}$ & Low risk & \\
\hline Other bias & Unclear risk & Authors chose which indicators to report on based on data availability \\
\hline $\begin{array}{l}\text { Baseline outcome mea- } \\
\text { surement } \\
\text { All outcomes }\end{array}$ & Low risk & Analyses methods adjust for differences \\
\hline $\begin{array}{l}\text { Matched characteristics } \\
\text { for control study sites }\end{array}$ & High risk & Data not presented \\
\hline $\begin{array}{l}\text { Protection against cont- } \\
\text { amination (intervention } \\
\text { and controls) }\end{array}$ & Low risk & Assignment by province/district/cluster \\
\hline
\end{tabular}

\section{Friedman 2016a}

\section{Study characteristics}

\section{Methods}

\section{Participants}

\section{Interventions}

Paying for performance to improve the delivery of health interventions in low- and middle-income countries (Review) 
Friedman 2016a (Continued)

Outcomes

\section{Notes}

\section{Risk of bias}

\begin{tabular}{|c|c|c|}
\hline Bias & Authors' judgement & Support for judgement \\
\hline $\begin{array}{l}\text { Random sequence genera- } \\
\text { tion (selection bias) }\end{array}$ & Low risk & Sequence described in enough detail \\
\hline $\begin{array}{l}\text { Allocation concealment } \\
\text { (selection bias) }\end{array}$ & Low risk & Assignment by province/district/cluster \\
\hline $\begin{array}{l}\text { Blinding (performance } \\
\text { bias and detection bias) } \\
\text { All outcomes }\end{array}$ & Low risk & Unlikely outcome assessment affected by allocation knowledge \\
\hline $\begin{array}{l}\text { Incomplete outcome data } \\
\text { (attrition bias) } \\
\text { All outcomes }\end{array}$ & High risk & $\begin{array}{l}\text { Authors note that high data collection costs meant that population based data } \\
\text { was only included in } 18 / 30 \text { study districts }\end{array}$ \\
\hline $\begin{array}{l}\text { Selective reporting (re- } \\
\text { porting bias) }\end{array}$ & Low risk & \\
\hline Other bias & Low risk & \\
\hline $\begin{array}{l}\text { Baseline outcome mea- } \\
\text { surement } \\
\text { All outcomes }\end{array}$ & Low risk & Analyses methods adjust for differences \\
\hline $\begin{array}{l}\text { Matched characteristics } \\
\text { for control study sites }\end{array}$ & High risk & Not specified \\
\hline $\begin{array}{l}\text { Protection against cont- } \\
\text { amination (intervention } \\
\text { and controls) }\end{array}$ & Low risk & Assignment by province/district/cluster \\
\hline
\end{tabular}

Friedman 2016b

\section{Study characteristics}

\section{Methods}

\section{Participants}

Interventions

\section{Outcomes}

\section{Notes}

\section{Risk of bias}


Friedman 2016b (Continued)

Random sequence genera- High risk No randomization, though stratification and matching tion (selection bias)

\begin{tabular}{lll}
\hline $\begin{array}{l}\text { Allocation concealment } \\
\text { (selection bias) }\end{array}$ & High risk & Allocation was done by MoH via matching
\end{tabular}

\begin{tabular}{lll}
\hline $\begin{array}{l}\text { Blinding (performance } \\
\text { bias and detection bias) } \\
\text { All outcomes }\end{array}$ & Low risk & Unlikely outcome assessment affected by allocation knowledge \\
\hline $\begin{array}{l}\text { Incomplete outcome data } \\
\text { (attrition bias) }\end{array}$ & Unclear risk & $\begin{array}{l}\text { Not specified (authors note that for household expenditure data there was } \\
\text { All outcomes }\end{array}$
\end{tabular}

All outcomes

Not specified (authors note that for household expenditure data there was

missingness)

Selective reporting (re- Low risk
porting bias)

\begin{tabular}{lll}
\hline Other bias & Low risk & \\
\hline $\begin{array}{l}\text { Baseline outcome mea- } \\
\text { surement } \\
\text { All outcomes }\end{array}$ & Low risk & Analyses methods adjust for differences \\
\hline $\begin{array}{l}\text { Matched characteristics } \\
\text { for control study sites }\end{array}$ & Low risk & $\begin{array}{l}\text { Comparable. (Friedman 2016b Appendix 3 tests parallel trends, though base- } \\
\text { line characteristics are dissimilar at times) }\end{array}$ \\
\hline $\begin{array}{l}\text { Protection against cont- } \\
\text { amination (intervention } \\
\text { and controls) }\end{array}$ & Low risk & Assignment by province/district/cluster \\
\hline
\end{tabular}

\section{Gertler 2012}

\section{Study characteristics}

\section{Methods}

\section{Participants}

\section{Interventions}

\section{Outcomes}

\section{Notes}

\section{Risk of bias}

\begin{tabular}{lll}
\hline Bias & Authors' judgement & Support for judgement \\
\hline $\begin{array}{l}\text { Random sequence genera- } \\
\text { tion (selection bias) }\end{array}$ & High risk & Randomization compromised \\
\hline $\begin{array}{l}\text { Allocation concealment } \\
\text { (selection bias) }\end{array}$ & Low risk & Assignment by province/district/cluster \\
\hline
\end{tabular}


Gertler 2012 (Continued)
Blinding (performance
Low risk
Unlikely outcome assessment affected by allocation knowledge
bias and detection bias)
All outcomes

\begin{tabular}{lll}
\hline $\begin{array}{l}\text { Incomplete outcome data } \\
\text { (attrition bias) } \\
\text { All outcomes }\end{array}$ & Low risk & Authors note similar levels of attrition \\
\hline $\begin{array}{l}\text { Selective reporting (re- } \\
\text { porting bias) }\end{array}$ & Low risk & \\
\hline Other bias & Low risk & Analyses methods adjust for differences \\
\hline $\begin{array}{l}\text { Baseline outcome mea- } \\
\text { surement } \\
\text { All outcomes }\end{array}$ & Low risk & \\
\hline $\begin{array}{l}\text { Matched characteristics } \\
\text { for control study sites }\end{array}$ & Low risk & Comparable \\
\hline $\begin{array}{l}\text { Protection against cont- } \\
\text { amination (intervention } \\
\text { and controls) }\end{array}$ & Low risk & Assignment by province/district/cluster \\
\hline
\end{tabular}

\section{Gertler 2014}

\section{Study characteristics}

\begin{tabular}{|c|c|c|}
\hline \multicolumn{3}{|l|}{ Methods } \\
\hline \multicolumn{3}{|l|}{ Participants } \\
\hline \multicolumn{3}{|l|}{ Interventions } \\
\hline \multicolumn{3}{|l|}{ Outcomes } \\
\hline \multicolumn{3}{|l|}{ Notes } \\
\hline \multicolumn{3}{|l|}{ Risk of bias } \\
\hline Bias & Authors' judgement & Support for judgement \\
\hline $\begin{array}{l}\text { Random sequence genera- } \\
\text { tion (selection bias) }\end{array}$ & High risk & As per guidance \\
\hline $\begin{array}{l}\text { Allocation concealment } \\
\text { (selection bias) }\end{array}$ & High risk & As per guidance \\
\hline $\begin{array}{l}\text { Blinding (performance } \\
\text { bias and detection bias) } \\
\text { All outcomes }\end{array}$ & Low risk & Indicators assessed objectively \\
\hline $\begin{array}{l}\text { Incomplete outcome data } \\
\text { (attrition bias) } \\
\text { All outcomes }\end{array}$ & Low risk & $\begin{array}{l}\text { Paper mentions missingness of } 3 \% \text {, similar across groups. Complete case } \\
\text { analyses are conducted which may compromise results but no reporting of } \\
\text { missingness by outcome }\end{array}$ \\
\hline
\end{tabular}

Paying for performance to improve the delivery of health interventions in low- and middle-income countries (Review) 
Gertler 2014 (Continued)

Selective reporting (re- Low risk
porting bias)

Other bias Low risk

Baseline outcome mea- Low risk Analyses methods adjust for differences

surement

All outcomes

\begin{tabular}{lll}
\hline $\begin{array}{l}\text { Matched characteristics } \\
\text { for control study sites }\end{array}$ & Low risk & $\begin{array}{l}\text { Low except high for neonatal mortality (noted imbalance only for this out- } \\
\text { come). }\end{array}$ \\
\hline $\begin{array}{l}\text { Protection against cont- } \\
\text { amination (intervention } \\
\text { and controls) }\end{array}$ & Low risk & Assignment by province/district/cluster \\
\hline
\end{tabular}

Huillery 2017

\section{Study characteristics}

\begin{tabular}{l} 
Methods \\
\hline Participants
\end{tabular}

Interventions

\section{Outcomes}

Notes

\section{Risk of bias}

\begin{tabular}{|c|c|c|}
\hline Bias & Authors' judgement & Support for judgement \\
\hline $\begin{array}{l}\text { Random sequence genera- } \\
\text { tion (selection bias) }\end{array}$ & Low risk & Sequence described in enough detail \\
\hline $\begin{array}{l}\text { Allocation concealment } \\
\text { (selection bias) }\end{array}$ & Low risk & Assignment by province/district/cluster \\
\hline $\begin{array}{l}\text { Blinding (performance } \\
\text { bias and detection bias) } \\
\text { All outcomes }\end{array}$ & Low risk & Unlikely outcome assessment affected by allocation knowledge \\
\hline $\begin{array}{l}\text { Incomplete outcome data } \\
\text { (attrition bias) } \\
\text { All outcomes }\end{array}$ & Unclear risk & Not specified \\
\hline $\begin{array}{l}\text { Selective reporting (re- } \\
\text { porting bias) }\end{array}$ & Low risk & \\
\hline Other bias & Low risk & \\
\hline $\begin{array}{l}\text { Baseline outcome mea- } \\
\text { surement }\end{array}$ & Low risk & Comparable (see Huillery 2017 Appendix) \\
\hline
\end{tabular}


Huillery 2017 (Continued)

All outcomes

$\begin{aligned} & \text { Matched characteristics } \\ & \text { for control study sites }\end{aligned}$
Low risk Comparable (see Huillery 2017 Appendix)

Protection against cont- Low risk Assignment by province/district/cluster

amination (intervention

and controls)

\section{Ir 2015}

\section{Study characteristics}

\section{Methods}

\section{Participants}

Interventions

\section{Outcomes}

\section{Notes}

\section{Risk of bias}

\begin{tabular}{|c|c|c|}
\hline Bias & Authors' judgement & Support for judgement \\
\hline $\begin{array}{l}\text { Blinding (performance } \\
\text { bias and detection bias) } \\
\text { All outcomes }\end{array}$ & Unclear risk & Health workers themselves appear to be reporting \\
\hline $\begin{array}{l}\text { Selective reporting (re- } \\
\text { porting bias) }\end{array}$ & Low risk & \\
\hline Other bias & Low risk & \\
\hline $\begin{array}{l}\text { Intervention independent } \\
\text { (ITS)? }\end{array}$ & High risk & $\begin{array}{l}\text { Multiple PBF reforms introduced alongside voucker schemes, changes to } \\
\text { health service delivery (more trained professionals) also occurred }\end{array}$ \\
\hline $\begin{array}{l}\text { Shape of effect pre-speci- } \\
\text { fied (ITS)? }\end{array}$ & High risk & As per guidance, effect shape not specified \\
\hline $\begin{array}{l}\text { Unlikely to affect data col- } \\
\text { lection (ITS)? }\end{array}$ & Unclear risk & $\begin{array}{l}\text { lintervention may have affected data collected as same source was used for } \\
\text { payments and for outcome assessment. }\end{array}$ \\
\hline $\begin{array}{l}\text { Incomplete outcome data } \\
\text { addressed (ITS)? }\end{array}$ & Unclear risk & Not specified \\
\hline
\end{tabular}

Khim 2018

\section{Study characteristics}

\section{Methods}

Paying for performance to improve the delivery of health interventions in low- and middle-income countries (Review) 
Khim 2018 (Continued)

Participants

Interventions

Outcomes

Notes

\section{Risk of bias}

\begin{tabular}{|c|c|c|}
\hline Bias & Authors' judgement & Support for judgement \\
\hline $\begin{array}{l}\text { Blinding (performance } \\
\text { bias and detection bias) } \\
\text { All outcomes }\end{array}$ & Low risk & Unlikely allocation affects data collection \\
\hline $\begin{array}{l}\text { Selective reporting (re- } \\
\text { porting bias) }\end{array}$ & Low risk & \\
\hline Other bias & Unclear risk & $\begin{array}{l}\text { Several other schemes were implemented at the same time and high variabili- } \\
\text { ty in implementation of this scheme noted }\end{array}$ \\
\hline $\begin{array}{l}\text { Intervention independent } \\
\text { (ITS)? }\end{array}$ & Unclear risk & Not specified \\
\hline $\begin{array}{l}\text { Shape of effect pre-speci- } \\
\text { fied (ITS)? }\end{array}$ & Low risk & Specified as per guidance \\
\hline $\begin{array}{l}\text { Unlikely to affect data col- } \\
\text { lection (ITS)? }\end{array}$ & Unclear risk & Intervention may have affected data collection \\
\hline $\begin{array}{l}\text { Incomplete outcome data } \\
\text { addressed (ITS)? }\end{array}$ & Unclear risk & Not specified \\
\hline
\end{tabular}

Kliner 2015

\section{Study characteristics}

\section{Methods}

Participants

Interventions

Outcomes

Notes

\section{Risk of bias}

\section{Bias}

Random sequence generation (selection bias)

\section{Authors' judgement Support for judgement}

High risk

No randomization 
Kliner 2015 (Continued)

\begin{tabular}{lll}
$\begin{array}{l}\text { Allocation concealment } \\
\text { (selection bias) }\end{array}$ & High risk & Allocation was pragmatic \\
\hline $\begin{array}{l}\text { Blinding (performance } \\
\text { bias and detection bias) } \\
\text { All outcomes }\end{array}$ & Low risk & Unlikely outcome assessment affected by allocation knowledge
\end{tabular}

Incomplete outcome data $\quad$ Unclear risk $\quad$ Not specified
(attrition bias)
All outcomes

Selective reporting (re- Low risk
porting bias)

\begin{tabular}{ll}
\hline Other bias & We are unclear if this is a CBA or a quasi-non randomized trial (the authors \\
themselves describe both as randomized and then as 'randomization not pos- \\
sible) + this is not going to be generalizable, given it was in one main hospital \\
population
\end{tabular}

\begin{tabular}{lll}
\hline $\begin{array}{l}\text { Baseline outcome mea- } \\
\text { surement } \\
\text { All outcomes }\end{array}$ & Low risk & Analyses methods adjust for differences \\
\hline $\begin{array}{l}\text { Matched characteristics } \\
\text { for control study sites }\end{array}$ & High risk & Kliner 2015 Table 2 suggests differences in populations and outcomes exist \\
\hline $\begin{array}{l}\text { Protection against cont- } \\
\begin{array}{l}\text { amination (intervention } \\
\text { and controls) }\end{array}\end{array}$ & High risk & $\begin{array}{l}\text { Allocation was pragmatic and unclear how patients moving would have been } \\
\text { dealt with }\end{array}$ \\
\hline
\end{tabular}

\section{Lagarde 2015}

\section{Study characteristics}

\section{Methods}

\section{Participants}

$$
\text { Interventions }
$$

\section{Outcomes}

\section{Notes \\ Risk of bias}

\begin{tabular}{lll}
\hline Bias & Authors' judgement & Support for judgement \\
\hline $\begin{array}{l}\text { Random sequence genera- } \\
\text { tion (selection bias) }\end{array}$ & Unclear risk & Not specified \\
\hline $\begin{array}{l}\text { Allocation concealment } \\
\text { (selection bias) }\end{array}$ & Unclear risk & Not specified \\
\hline
\end{tabular}


Lagarde 2015 (Continued)
Blinding (performance
Unclear risk
Not specified
bias and detection bias)

All outcomes

Incomplete outcome data Unclear risk Not specified
(attrition bias)
All outcomes

\begin{tabular}{lll}
\hline $\begin{array}{l}\text { Selective reporting (re- } \\
\text { porting bias) }\end{array}$ & Low risk \\
\hline Other bias & Unclear risk & Authors specify ceiling effects for some outcomes \\
\hline $\begin{array}{l}\text { Baseline outcome mea- } \\
\text { surement } \\
\text { All outcomes }\end{array}$ & High risk & $\begin{array}{l}\text { Analyses methods do not adjust for baseline differences in outcomes, but do } \\
\text { adjust for facility and health worker differences }\end{array}$ \\
\hline $\begin{array}{l}\text { Matched characteristics } \\
\text { for control study sites }\end{array}$ & High risk & $\begin{array}{l}\text { Lagarde 2015 Appendix Table } 6 \text { suggests differences exist between the differ- } \\
\text { ent districts, e.g. popuation characteristics (poverty) varies between 28.7\% } \\
\text { and 82.3\%. }\end{array}$ \\
\hline $\begin{array}{l}\text { Protection against cont- } \\
\text { amination (intervention } \\
\text { and controls) }\end{array}$ & Low risk & Assignment by province/district/cluster \\
\hline
\end{tabular}

Lannes 2015

\section{Study characteristics}

\section{Methods}

\section{Participants}

Interventions

\section{Outcomes}

\section{Notes}

\section{Risk of bias}

\begin{tabular}{lll}
\hline Bias & Authors' judgement & Support for judgement \\
\hline $\begin{array}{l}\text { Random sequence genera- } \\
\text { tion (selection bias) }\end{array}$ & High risk & Randomization compromised \\
\hline $\begin{array}{l}\text { Allocation concealment } \\
\text { (selection bias) }\end{array}$ & Low risk & Assignment by province/district/cluster \\
\hline $\begin{array}{l}\text { Blinding (performance } \\
\text { bias and detection bias) } \\
\text { All outcomes }\end{array}$ & Low risk & Blinded assessments \\
\hline
\end{tabular}

$\begin{aligned} & \text { Incomplete outcome data } \\ & \text { (attrition bias) }\end{aligned}$
Unclear risk $\quad$ Not specified, using data from Basinga 2011


Lannes 2015 (Continued)

All outcomes

\section{Selective reporting (re- Low risk} porting bias)

\begin{tabular}{lll}
\hline Other bias & Low risk & \\
\hline $\begin{array}{l}\text { Baseline outcome mea- } \\
\text { surement }\end{array}$ & Unclear risk & Not specified \\
All outcomes & &
\end{tabular}

\begin{tabular}{lll}
\hline $\begin{array}{l}\text { Matched characteristics } \\
\text { for control study sites }\end{array}$ & High risk & Not specified \\
\hline $\begin{array}{l}\text { Protection against cont- } \\
\begin{array}{l}\text { amination (intervention } \\
\text { and controls) }\end{array}\end{array}$ & Low risk & Assignment by province/district/cluster \\
\hline
\end{tabular}

Lannes 2016

\section{Study characteristics}

\section{Methods}

\section{Participants}

Interventions

\section{Outcomes}

\section{Notes}

\section{Risk of bias}

\begin{tabular}{lll}
\hline Bias & Authors' judgement & Support for judgement \\
\hline $\begin{array}{l}\text { Random sequence genera- } \\
\text { tion (selection bias) }\end{array}$ & High risk & Randomization compromised \\
\hline $\begin{array}{l}\text { Allocation concealment } \\
\text { (selection bias) }\end{array}$ & Low risk & Assignment by province/district/cluster \\
\hline $\begin{array}{l}\text { Blinding (performance } \\
\text { bias and detection bias) }\end{array}$ & Low risk & Blinded assessments \\
$\begin{array}{l}\text { All outcomes } \\
\text { Incomplete outcome data }\end{array}$ & Unclear risk \\
$\begin{array}{l}\text { (attrition bias) } \\
\text { All outcomes }\end{array}$ & Not specified \\
\hline $\begin{array}{l}\text { Selective reporting (re- } \\
\text { porting bias) }\end{array}$ & Low risk \\
\hline \begin{tabular}{l} 
Other bias \\
\hline
\end{tabular}
\end{tabular}


Lannes 2016 (Continued)

Baseline outcome mea- Low risk $\quad$ Analyses methods adjust for differences
surement

All outcomes

\begin{tabular}{lll}
\hline $\begin{array}{l}\text { Matched characteristics } \\
\text { for control study sites }\end{array}$ & Low risk & Comparable \\
\hline $\begin{array}{l}\text { Protection against cont- } \\
\text { amination (intervention } \\
\text { and controls) }\end{array}$ & Low risk & Assignment by province/district/cluster
\end{tabular}

Liu 2005

\section{Study characteristics}

\section{Methods}

Participants

Interventions

\section{Outcomes}

\section{Notes}

\section{Risk of bias}

\begin{tabular}{|c|c|c|}
\hline Bias & Authors' judgement & Support for judgement \\
\hline $\begin{array}{l}\text { Blinding (performance } \\
\text { bias and detection bias) } \\
\text { All outcomes }\end{array}$ & Low risk & Blinded and random assessments \\
\hline $\begin{array}{l}\text { Selective reporting (re- } \\
\text { porting bias) }\end{array}$ & Low risk & \\
\hline Other bias & Low risk & \\
\hline $\begin{array}{l}\text { Intervention independent } \\
\text { (ITS)? }\end{array}$ & High risk & Other changes in the country likely to affect trends \\
\hline $\begin{array}{l}\text { Shape of effect pre-speci- } \\
\text { fied (ITS)? }\end{array}$ & Low risk & Specified as per guidance \\
\hline $\begin{array}{l}\text { Unlikely to affect data col- } \\
\text { lection (ITS)? }\end{array}$ & Low risk & No effects on data collection \\
\hline $\begin{array}{l}\text { Incomplete outcome data } \\
\text { addressed (ITS)? }\end{array}$ & Low risk & Panel dataset \\
\hline
\end{tabular}


Matsuoka 2014

\section{Study characteristics}

\section{Methods}

\section{Participants}

Interventions

\section{Outcomes}

\section{Notes}

\section{Risk of bias}

\begin{tabular}{lll}
\hline Bias & Authors' judgement & Support for judgement \\
\hline $\begin{array}{l}\text { Blinding (performance } \\
\text { bias and detection bias) }\end{array}$ & Unclear risk & Not specified \\
All outcomes & & \\
\hline
\end{tabular}

Selective reporting (re- Low risk porting bias)

\begin{tabular}{lll}
\hline Other bias & Unclear risk & Note: data re-analysed \\
\hline $\begin{array}{l}\text { Intervention independent } \\
\text { (ITS)? }\end{array}$ & Unclear risk & Not specified \\
\hline $\begin{array}{l}\text { Shape of effect pre-speci- } \\
\text { fied (ITS)? }\end{array}$ & Low risk & Specified as per guidance \\
\hline $\begin{array}{l}\text { Unlikely to affect data col- } \\
\text { lection (ITS)? }\end{array}$ & Unclear risk & Intervention may have affected data collection \\
\hline $\begin{array}{l}\text { Incomplete outcome data } \\
\text { addressed (ITS)? }\end{array}$ & Unclear risk & Not specified \\
\hline
\end{tabular}

Mayumana 2017

\section{Study characteristics}

Methods

\section{Participants}

Interventions

\section{Outcomes}

\section{Notes}

\section{Risk of bias}


Mayumana 2017 (Continued)

\begin{tabular}{lll}
$\begin{array}{l}\text { Random sequence genera- } \\
\text { tion (selection bias) }\end{array}$ & High risk & As per guidance \\
\hline $\begin{array}{l}\text { Allocation concealment } \\
\text { (selection bias) }\end{array}$ & High risk & As per guidance \\
\hline $\begin{array}{l}\text { Blinding (performance } \\
\text { bias and detection bias) } \\
\text { All outcomes }\end{array}$ & Unclear risk & Not specified \\
\hline
\end{tabular}

$\begin{array}{ll}\text { Incomplete outcome data High risk } & \text { Authors note that this may have biased results } \\ \text { (attrition bias) }\end{array}$

(attrition bias)

All outcomes

Selective reporting (re- Low risk
porting bias)

\begin{tabular}{|c|c|c|}
\hline Other bias & Low risk & \\
\hline $\begin{array}{l}\text { Baseline outcome mea- } \\
\text { surement } \\
\text { All outcomes }\end{array}$ & Low risk & Analyses methods adjust for differences \\
\hline $\begin{array}{l}\text { Matched characteristics } \\
\text { for control study sites }\end{array}$ & Low risk & $\begin{array}{l}\text { Low except for: medical supply stockouts, disruptions due to broken equip- } \\
\text { ment, governance outcomes (committee meetings, content of supervision, ex- } \\
\text { istence of community health fund) }\end{array}$ \\
\hline $\begin{array}{l}\text { Protection against cont- } \\
\text { amination (intervention } \\
\text { and controls) }\end{array}$ & Low risk & Assignment by province/district/cluster \\
\hline
\end{tabular}

\section{McMahon 2016 \\ Study characteristics}

\section{Methods}

Participants

\section{Interventions}

\section{Outcomes}

\section{Notes}

\section{Risk of bias}

\begin{tabular}{lll}
\hline Bias & Authors' judgement & Support for judgement \\
\hline $\begin{array}{l}\text { Blinding (performance } \\
\text { bias and detection bias) }\end{array}$ & Unclear risk & Not specified \\
\begin{tabular}{l} 
All outcomes \\
\hline
\end{tabular} & & \\
\hline
\end{tabular}

\footnotetext{
Selective reporting (re- Low risk porting bias)
} 
McMahon 2016 (Continued)

\begin{tabular}{lll} 
Other bias & Low risk & \\
\hline $\begin{array}{l}\text { Intervention independent } \\
\text { (ITS)? }\end{array}$ & Unclear risk & Not specified \\
\hline $\begin{array}{l}\text { Shape of effect pre-speci- } \\
\text { fied (ITS)? }\end{array}$ & Low risk & Specified as per guidance \\
\hline $\begin{array}{l}\text { Unlikely to affect data col- } \\
\text { lection (ITS)? }\end{array}$ & High risk & Intervention directly targets improvements in data \\
\hline $\begin{array}{l}\text { Incomplete outcome data } \\
\text { addressed (ITS)? }\end{array}$ & High risk & Several indicators excluded due to missingness \\
\hline
\end{tabular}
addressed (ITS)?

\section{Menya 2015}

\section{Study characteristics}

\section{Methods}

\section{Participants}

Interventions

\section{Outcomes}

\section{Notes}

\section{Risk of bias}

\begin{tabular}{|c|c|c|}
\hline Bias & Authors' judgement & Support for judgement \\
\hline $\begin{array}{l}\text { Random sequence genera- } \\
\text { tion (selection bias) }\end{array}$ & Low risk & Sequence described in enough detail \\
\hline $\begin{array}{l}\text { Allocation concealment } \\
\text { (selection bias) }\end{array}$ & Low risk & Assignment by province/district/cluster \\
\hline $\begin{array}{l}\text { Blinding (performance } \\
\text { bias and detection bias) } \\
\text { All outcomes }\end{array}$ & Low risk & Unlikely outcome assessment affected by allocation knowledge \\
\hline $\begin{array}{l}\text { Incomplete outcome data } \\
\text { (attrition bias) } \\
\text { All outcomes }\end{array}$ & Unclear risk & $\begin{array}{l}\text { One facility excluded due to discontinuation (no laboratory technician avail- } \\
\text { able) }\end{array}$ \\
\hline $\begin{array}{l}\text { Selective reporting (re- } \\
\text { porting bias) }\end{array}$ & Low risk & \\
\hline Other bias & Low risk & \\
\hline $\begin{array}{l}\text { Baseline outcome mea- } \\
\text { surement } \\
\text { All outcomes }\end{array}$ & Unclear risk & Not specified \\
\hline
\end{tabular}


Menya 2015 (Continued)

Matched characteristics for control study sites

Protection against cont-

\section{Mohanan 2017}

\section{Study characteristics}

\section{Methods}

\section{Participants}

\section{Interventions}

Outcomes

\section{Notes}

\section{Risk of bias}

\begin{tabular}{|c|c|c|}
\hline Bias & Authors' judgement & Support for judgement \\
\hline $\begin{array}{l}\text { Random sequence genera- } \\
\text { tion (selection bias) }\end{array}$ & Low risk & Sequence described in enough detail \\
\hline $\begin{array}{l}\text { Allocation concealment } \\
\text { (selection bias) }\end{array}$ & Low risk & Assignment by health care professional \\
\hline $\begin{array}{l}\text { Blinding (performance } \\
\text { bias and detection bias) } \\
\text { All outcomes }\end{array}$ & Low risk & Unlikely outcome assessment affected by allocation knowledge \\
\hline $\begin{array}{l}\text { Incomplete outcome data } \\
\text { (attrition bias) } \\
\text { All outcomes }\end{array}$ & Unclear risk & Not specified \\
\hline $\begin{array}{l}\text { Selective reporting (re- } \\
\text { porting bias) }\end{array}$ & Low risk & \\
\hline Other bias & Low risk & \\
\hline $\begin{array}{l}\text { Baseline outcome mea- } \\
\text { surement } \\
\text { All outcomes }\end{array}$ & Unclear risk & Not specified \\
\hline $\begin{array}{l}\text { Matched characteristics } \\
\text { for control study sites }\end{array}$ & Low risk & Comparable (see Mohanan 2017 Appendix) \\
\hline $\begin{array}{l}\text { Protection against cont- } \\
\text { amination (intervention } \\
\text { and controls) }\end{array}$ & Unclear risk & Contamination could have occurred \\
\hline
\end{tabular}


Peabody 2011

\section{Study characteristics}

Methods

Participants

Interventions

\section{Outcomes}

Notes

\section{Risk of bias}

\begin{tabular}{|c|c|c|}
\hline Bias & Authors' judgement & Support for judgement \\
\hline $\begin{array}{l}\text { Random sequence genera- } \\
\text { tion (selection bias) }\end{array}$ & Low risk & Sequence described in enough detail \\
\hline $\begin{array}{l}\text { Allocation concealment } \\
\text { (selection bias) }\end{array}$ & Low risk & Assignment by province/district/cluster \\
\hline $\begin{array}{l}\text { Blinding (performance } \\
\text { bias and detection bias) } \\
\text { All outcomes }\end{array}$ & Low risk & Blinded assessments \\
\hline $\begin{array}{l}\text { Incomplete outcome data } \\
\text { (attrition bias) } \\
\text { All outcomes }\end{array}$ & Unclear risk & Not specified \\
\hline $\begin{array}{l}\text { Selective reporting (re- } \\
\text { porting bias) }\end{array}$ & Low risk & \\
\hline Other bias & Low risk & \\
\hline $\begin{array}{l}\text { Baseline outcome mea- } \\
\text { surement } \\
\text { All outcomes }\end{array}$ & Low risk & Analyses methods adjust for differences \\
\hline $\begin{array}{l}\text { Matched characteristics } \\
\text { for control study sites }\end{array}$ & High risk & Peabody 2011 Table 1 suggests differences in providers \\
\hline $\begin{array}{l}\text { Protection against cont- } \\
\text { amination (intervention } \\
\text { and controls) }\end{array}$ & Low risk & Assignment by province/district/cluster \\
\hline
\end{tabular}

Peabody 2014

\section{Study characteristics}

\section{Methods}

\section{Participants}


Peabody 2014 (Continued)

Interventions

\section{Outcomes}

Notes

\section{Risk of bias}

\begin{tabular}{|c|c|c|}
\hline Bias & Authors' judgement & Support for judgement \\
\hline $\begin{array}{l}\text { Random sequence genera- } \\
\text { tion (selection bias) }\end{array}$ & Low risk & Sequence described in enough detail \\
\hline $\begin{array}{l}\text { Allocation concealment } \\
\text { (selection bias) }\end{array}$ & Low risk & Assignment by province/district/cluster \\
\hline $\begin{array}{l}\text { Blinding (performance } \\
\text { bias and detection bias) } \\
\text { All outcomes }\end{array}$ & Low risk & Unlikely outcome assessment affected by allocation knowledge \\
\hline $\begin{array}{l}\text { Incomplete outcome data } \\
\text { (attrition bias) } \\
\text { All outcomes }\end{array}$ & Unclear risk & Not specified \\
\hline $\begin{array}{l}\text { Selective reporting (re- } \\
\text { porting bias) }\end{array}$ & Low risk & \\
\hline Other bias & Unclear risk & Outcome specified as 'not wasting' affected by seasonal variations \\
\hline $\begin{array}{l}\text { Baseline outcome mea- } \\
\text { surement } \\
\text { All outcomes }\end{array}$ & Low risk & Analyses methods adjust for differences \\
\hline $\begin{array}{l}\text { Matched characteristics } \\
\text { for control study sites }\end{array}$ & Low risk & Comparable \\
\hline $\begin{array}{l}\text { Protection against cont- } \\
\text { amination (intervention } \\
\text { and controls) }\end{array}$ & Low risk & Assignment by province/district/cluster \\
\hline
\end{tabular}

Powell-Jackson 2014

\section{Study characteristics}

\begin{tabular}{l} 
Methods \\
\hline Participants \\
\hline Interventions \\
\hline Outcomes \\
\hline Notes
\end{tabular}

\section{Risk of bias}

Paying for performance to improve the delivery of health interventions in low- and middle-income countries (Review) 
Powell-Jackson 2014 (Continued)

Bias

Random sequence genera- High risk

tion (selection bias)

\begin{tabular}{l}
$\begin{array}{l}\text { Allocation concealment } \\
\text { (selection bias) }\end{array}$ Low risk Assignment by province/district/cluster \\
\hline
\end{tabular}

Blinding (performance $\quad$ Unclear risk $\quad$ Not specified
bias and detection bias)
All outcomes

Incomplete outcome data Unclear risk Not specified

(attrition bias)

All outcomes

\begin{tabular}{|c|c|c|}
\hline $\begin{array}{l}\text { Selective reporting (re- } \\
\text { porting bias) }\end{array}$ & Low risk & \\
\hline Other bias & Unclear risk & 1 year into scheme so early impacts \\
\hline $\begin{array}{l}\text { Baseline outcome mea- } \\
\text { surement } \\
\text { All outcomes }\end{array}$ & Low risk & Analyses methods adjust for differences \\
\hline $\begin{array}{l}\text { Matched characteristics } \\
\text { for control study sites }\end{array}$ & Low risk & Comparable \\
\hline $\begin{array}{l}\text { Protection against cont- } \\
\text { amination (intervention } \\
\text { and controls) }\end{array}$ & Low risk & Assignment by province/district/cluster \\
\hline
\end{tabular}

\section{Priedeman Skiles 2013}

\section{Study characteristics}

\section{Methods}

\section{Participants}

\section{Interventions}

\section{Outcomes}

\section{Notes}

\section{Risk of bias}

\begin{tabular}{lll}
\hline Bias & Authors' judgement & Support for judgement \\
\hline $\begin{array}{l}\text { Random sequence genera- } \\
\text { tion (selection bias) }\end{array}$ & High risk & Randomization compromised \\
\hline $\begin{array}{l}\text { Allocation concealment } \\
\text { (selection bias) }\end{array}$ & Low risk & Assignment by province/district/cluster \\
\hline \hline
\end{tabular}


Priedeman Skiles 2013 (Continued)
Blinding (performance
Low risk
Unlikely outcome assessment affected by allocation knowledge
bias and detection bias)
All outcomes

Incomplete outcome data $\quad$ Unclear risk $\quad$ Not specified
(attrition bias)
All outcomes

\begin{tabular}{|c|c|c|}
\hline $\begin{array}{l}\text { Selective reporting (re- } \\
\text { porting bias) }\end{array}$ & Low risk & \\
\hline Other bias & Unclear risk & $\begin{array}{l}\text { Rollout of community based health insure may be affecting equity outcomes } \\
\text { in particular }\end{array}$ \\
\hline $\begin{array}{l}\text { Baseline outcome mea- } \\
\text { surement } \\
\text { All outcomes }\end{array}$ & Low risk & Analyses methods adjust for differences \\
\hline $\begin{array}{l}\text { Matched characteristics } \\
\text { for control study sites }\end{array}$ & Low risk & Comparable \\
\hline $\begin{array}{l}\text { Protection against cont- } \\
\text { amination (intervention } \\
\text { and controls) }\end{array}$ & Low risk & Assignment by province/district/cluster \\
\hline
\end{tabular}

\section{Priedeman Skiles 2015}

\section{Study characteristics}

\section{Methods}

\section{Participants}

Interventions

\section{Outcomes}

\section{Notes}

\section{Risk of bias}

\begin{tabular}{lll}
\hline Bias & Authors' judgement & Support for judgement \\
\hline $\begin{array}{l}\text { Random sequence genera- } \\
\text { tion (selection bias) }\end{array}$ & High risk & Randomization compromised \\
\hline $\begin{array}{l}\text { Allocation concealment } \\
\text { (selection bias) }\end{array}$ & Low risk & Assignment by province/district/cluster \\
\hline $\begin{array}{l}\text { Blinding (performance } \\
\text { bias and detection bias) } \\
\text { All outcomes }\end{array}$ & Low risk & Unlikely outcome assessment affected by allocation knowledge \\
\hline $\begin{array}{l}\text { Incomplete outcome data } \\
\text { (attrition bias) }\end{array}$ & Unclear risk & Not specified \\
\hline
\end{tabular}


Priedeman Skiles 2015 (Continued)

All outcomes

Selective reporting (re- Low risk
porting bias)

\begin{tabular}{|c|c|c|}
\hline Other bias & Unclear risk & Assessment time may be too short, seasonal variations also relevant \\
\hline $\begin{array}{l}\text { Baseline outcome mea- } \\
\text { surement } \\
\text { All outcomes }\end{array}$ & Low risk & Analyses methods adjust for differences \\
\hline $\begin{array}{l}\text { Matched characteristics } \\
\text { for control study sites }\end{array}$ & Low risk & Comparable \\
\hline $\begin{array}{l}\text { Protection against cont- } \\
\text { amination (intervention } \\
\text { and controls) }\end{array}$ & Low risk & Assignment by province/district/cluster \\
\hline
\end{tabular}

Quimbo 2016

\section{Study characteristics}

\section{Methods}

\section{Participants}

Interventions

\section{Outcomes}

\section{Notes}

\section{Risk of bias}

\begin{tabular}{lll}
\hline Bias & Authors' judgement & Support for judgement \\
\hline $\begin{array}{l}\text { Random sequence genera- } \\
\text { tion (selection bias) }\end{array}$ & Low risk & Sequence described in enough detail \\
\hline $\begin{array}{l}\text { Allocation concealment } \\
\text { (selection bias) }\end{array}$ & Low risk & Assignment by province/district/cluster \\
\hline $\begin{array}{l}\text { Blinding (performance } \\
\text { bias and detection bias) }\end{array}$ & Low risk & Blinded assessments \\
$\begin{array}{l}\text { All outcomes } \\
\text { Incomplete outcome data }\end{array}$ & Unclear risk \\
$\begin{array}{l}\text { (attrition bias) } \\
\text { All outcomes }\end{array}$ & Not specified \\
\hline $\begin{array}{l}\text { Selective reporting (re- } \\
\text { porting bias) }\end{array}$ & Low risk \\
\hline \begin{tabular}{l} 
Other bias \\
\hline
\end{tabular}
\end{tabular}


Quimbo 2016 (Continued)
Baseline outcome mea-
Low risk
Analyses methods adjust for differences

surement

All outcomes

Protection against cont- Low risk Assignment by province/district/cluster
amination (intervention
and controls)

and controls)

\section{Rudasingwa 2014}

\section{Study characteristics}

\section{Methods}

\section{Participants}

Interventions

\section{Outcomes}

\section{Notes}

\section{Risk of bias}

\begin{tabular}{|c|c|c|}
\hline Bias & Authors' judgement & Support for judgement \\
\hline $\begin{array}{l}\text { Random sequence genera- } \\
\text { tion (selection bias) }\end{array}$ & High risk & As per guidance \\
\hline $\begin{array}{l}\text { Allocation concealment } \\
\text { (selection bias) }\end{array}$ & High risk & As per guidance \\
\hline $\begin{array}{l}\text { Blinding (performance } \\
\text { bias and detection bias) } \\
\text { All outcomes }\end{array}$ & Unclear risk & Not specified \\
\hline $\begin{array}{l}\text { Incomplete outcome data } \\
\text { (attrition bias) } \\
\text { All outcomes }\end{array}$ & Low risk & Authors note outcomes to focus on chosen based on completeness \\
\hline $\begin{array}{l}\text { Selective reporting (re- } \\
\text { porting bias) }\end{array}$ & Low risk & \\
\hline Other bias & Unclear risk & $\begin{array}{l}\text { Authors note small facility sample size, resulting in "a higher probability of } \\
\text { Type II error" (p25). Authors have not considered that results may be influ- } \\
\text { enced by the removal of user fees from certain services at a similar time to } \\
\text { when the PBF programme was introduced. Potential conflict of interest: fund- } \\
\text { ing for data collection by Cordaid, one of the implementing agents of the PBF } \\
\text { scheme. }\end{array}$ \\
\hline $\begin{array}{l}\text { Baseline outcome mea- } \\
\text { surement } \\
\text { All outcomes }\end{array}$ & Low risk & Analyses methods adjust for differences \\
\hline
\end{tabular}


Rudasingwa 2014 (Continued)

\begin{tabular}{lll}
$\begin{array}{l}\text { Matched characteristics } \\
\text { for control study sites }\end{array}$ & High risk & Data not presented \\
\hline $\begin{array}{l}\text { Protection against cont- } \\
\text { amination (intervention } \\
\text { and controls) }\end{array}$ & Low risk & Assignment by province/district/cluster
\end{tabular}

and controls)

\section{Rusa 2009}

\section{Study characteristics}

\section{Methods}

Participants

Interventions

Outcomes

\section{Notes}

\section{Risk of bias}

\begin{tabular}{|c|c|c|}
\hline Bias & Authors' judgement & Support for judgement \\
\hline $\begin{array}{l}\text { Blinding (performance } \\
\text { bias and detection bias) } \\
\text { All outcomes }\end{array}$ & Unclear risk & Not specified \\
\hline $\begin{array}{l}\text { Selective reporting (re- } \\
\text { porting bias) }\end{array}$ & Low risk & \\
\hline Other bias & Low risk & \\
\hline $\begin{array}{l}\text { Intervention independent } \\
\text { (ITS)? }\end{array}$ & High risk & Other changes in the country (user fee removal) likely to affect trends \\
\hline $\begin{array}{l}\text { Shape of effect pre-speci- } \\
\text { fied (ITS)? }\end{array}$ & Low risk & Specified as per guidance \\
\hline $\begin{array}{l}\text { Unlikely to affect data col- } \\
\text { lection (ITS)? }\end{array}$ & Unclear risk & Intervention may have affected data collection \\
\hline $\begin{array}{l}\text { Incomplete outcome data } \\
\text { addressed (ITS)? }\end{array}$ & Unclear risk & Not specified \\
\hline
\end{tabular}

\section{Shapira 2017}

\section{Study characteristics}

Methods 
Shapira 2017 (Continued)

Participants

Interventions

Outcomes

Notes

Risk of bias

\begin{tabular}{|c|c|c|}
\hline Bias & Authors' judgement & Support for judgement \\
\hline $\begin{array}{l}\text { Random sequence genera- } \\
\text { tion (selection bias) }\end{array}$ & Low risk & Sequence described in enough detail \\
\hline $\begin{array}{l}\text { Allocation concealment } \\
\text { (selection bias) }\end{array}$ & Low risk & Assignment by province/district/cluster \\
\hline $\begin{array}{l}\text { Blinding (performance } \\
\text { bias and detection bias) } \\
\text { All outcomes }\end{array}$ & High risk & Outcomes are partly self-assessed \\
\hline $\begin{array}{l}\text { Incomplete outcome data } \\
\text { (attrition bias) } \\
\text { All outcomes }\end{array}$ & Low risk & Unbalanced attrition addressed \\
\hline $\begin{array}{l}\text { Selective reporting (re- } \\
\text { porting bias) }\end{array}$ & Low risk & \\
\hline Other bias & Low risk & \\
\hline $\begin{array}{l}\text { Baseline outcome mea- } \\
\text { surement } \\
\text { All outcomes }\end{array}$ & Low risk & Comparable, except for institutional deliveries and number of pregnancies \\
\hline $\begin{array}{l}\text { Matched characteristics } \\
\text { for control study sites }\end{array}$ & Low risk & Comparable \\
\hline $\begin{array}{l}\text { Protection against cont- } \\
\text { amination (intervention } \\
\text { and controls) }\end{array}$ & Low risk & Assignment by province/district/cluster \\
\hline
\end{tabular}

Shen 2017

\section{Study characteristics}

Methods

Participants

Interventions

\section{Outcomes}

Notes

Paying for performance to improve the delivery of health interventions in low- and middle-income countries (Review)

Copyright $\odot 2020$ The Cochrane Collaboration. Published by John Wiley \& Sons, Ltd. 
Shen 2017 (Continued)

\section{Risk of bias}

\begin{tabular}{|c|c|c|}
\hline Bias & Authors' judgement & Support for judgement \\
\hline $\begin{array}{l}\text { Random sequence genera- } \\
\text { tion (selection bias) }\end{array}$ & Low risk & Sequence described in enough detail \\
\hline $\begin{array}{l}\text { Allocation concealment } \\
\text { (selection bias) }\end{array}$ & Low risk & Assignment by province/district/cluster \\
\hline $\begin{array}{l}\text { Blinding (performance } \\
\text { bias and detection bias) } \\
\text { All outcomes }\end{array}$ & High risk & Outcomes are self-scored \\
\hline $\begin{array}{l}\text { Incomplete outcome data } \\
\text { (attrition bias) } \\
\text { All outcomes }\end{array}$ & Unclear risk & Not specified \\
\hline $\begin{array}{l}\text { Selective reporting (re- } \\
\text { porting bias) }\end{array}$ & Low risk & \\
\hline Other bias & Low risk & \\
\hline $\begin{array}{l}\text { Baseline outcome mea- } \\
\text { surement } \\
\text { All outcomes }\end{array}$ & Low risk & Analyses methods adjust for differences \\
\hline $\begin{array}{l}\text { Matched characteristics } \\
\text { for control study sites }\end{array}$ & High risk & $\begin{array}{l}\text { Shen } 2017 \text { Table } 2 \text { suggestive of differences between facilities and health } \\
\text { worker characteristics }\end{array}$ \\
\hline $\begin{array}{l}\text { Protection against cont- } \\
\text { amination (intervention } \\
\text { and controls) }\end{array}$ & Low risk & Assignment by province/district/cluster \\
\hline
\end{tabular}

Sherry 2017

\section{Study characteristics}

\section{Methods}

\section{Participants}

$$
\text { Interventions }
$$

Outcomes

\section{Notes}

\section{Risk of bias}

\begin{tabular}{lll}
\hline Bias & Authors' judgement & Support for judgement \\
\hline $\begin{array}{l}\text { Random sequence genera- } \\
\text { tion (selection bias) }\end{array}$ & High risk & Randomization compromised \\
\hline
\end{tabular}


Sherry 2017 (Continued)

\begin{tabular}{lll}
$\begin{array}{l}\text { Allocation concealment } \\
\text { (selection bias) }\end{array}$ & Low risk & Assignment by province/district/cluster \\
\hline $\begin{array}{l}\text { Blinding (performance } \\
\text { bias and detection bias) } \\
\text { All outcomes }\end{array}$ & Low risk & Unlikely outcome assessment affected by allocation knowledge \\
\hline
\end{tabular}

Incomplete outcome data Unclear risk $\quad$ Not specified
(attrition bias)
All outcomes
Selective reporting (re- Low risk porting bias)

\begin{tabular}{|c|c|c|}
\hline Other bias & Unclear risk & $\begin{array}{l}\text { Rollout of national immunization campaigns, increased HIV funding coincides } \\
\text { with study periods and may affect results }\end{array}$ \\
\hline
\end{tabular}

\begin{tabular}{lll}
\hline $\begin{array}{l}\text { Baseline outcome mea- } \\
\text { surement } \\
\text { All outcomes }\end{array}$ & Low risk & Analyses methods adjust for differences \\
\hline $\begin{array}{l}\text { Matched characteristics } \\
\text { for control study sites }\end{array}$ & Low risk & Comparable \\
\hline $\begin{array}{l}\text { Protection against cont- } \\
\text { amination (intervention } \\
\text { and controls) }\end{array}$ & Low risk & Assignment by province/district/cluster \\
\hline
\end{tabular}

\section{Soeters 2011}

\section{Study characteristics}

\section{Methods}

\section{Participants}

Interventions

\section{Outcomes}

\section{Notes}

\section{Risk of bias}

\begin{tabular}{lll}
\hline Bias & Authors' judgement & Support for judgement \\
\hline $\begin{array}{l}\text { Random sequence genera- } \\
\text { tion (selection bias) }\end{array}$ & High risk & As per guidance \\
\hline $\begin{array}{l}\text { Allocation concealment } \\
\text { (selection bias) }\end{array}$ & High risk & As per guidance \\
\hline $\begin{array}{l}\text { Blinding (performance } \\
\text { bias and detection bias) } \\
\text { All outcomes }\end{array}$ & Low risk & Low except concerns relating to patient reported outcomes \\
\hline \hline
\end{tabular}


Soeters 2011 (Continued)
Incomplete outcome data
Unclear risk
Not specified
(attrition bias)
All outcomes
Selective reporting (re- Low risk porting bias)

\begin{tabular}{|c|c|c|}
\hline Other bias & Low risk & \\
\hline $\begin{array}{l}\text { Baseline outcome mea- } \\
\text { surement } \\
\text { All outcomes }\end{array}$ & Low risk & Analyses methods adjust for differences \\
\hline $\begin{array}{l}\text { Matched characteristics } \\
\text { for control study sites }\end{array}$ & High risk & Not specified \\
\hline $\begin{array}{l}\text { Protection against cont- } \\
\text { amination (intervention } \\
\text { and controls) }\end{array}$ & Low risk & Assignment by province/district/cluster \\
\hline
\end{tabular}

\section{Steenland 2017}

\section{Study characteristics}

\section{Methods}

\section{Participants}

\section{Interventions}

\section{Outcomes}

\section{Notes}

\section{Risk of bias}

\begin{tabular}{lll}
\hline Bias & Authors' judgement & Support for judgement \\
\hline $\begin{array}{l}\text { Random sequence genera- } \\
\text { tion (selection bias) }\end{array}$ & High risk & As per guidance \\
\hline $\begin{array}{l}\text { Allocation concealment } \\
\text { (selection bias) }\end{array}$ & High risk & As per guidance \\
\hline $\begin{array}{l}\text { Blinding (performance } \\
\text { bias and detection bias) } \\
\text { All outcomes }\end{array}$ & Low risk & HMIS \\
\hline $\begin{array}{l}\text { Incomplete outcome data } \\
\text { (attrition bias) } \\
\text { All outcomes }\end{array}$ & Low risk & See Steenland 2017 Appendix Table 4 \\
\hline $\begin{array}{l}\text { Selective reporting (re- } \\
\text { porting bias) }\end{array}$ & Low risk & \\
\hline
\end{tabular}


Steenland 2017 (Continued)

$\begin{array}{ll}\text { Other bias } & \text { Anclear risk } \\ & \begin{array}{l}\text { Author raises concerns that PBF may have incentivized additional reporting, } \\ \text { therefore data is more available in intervention districts. Potential conflict } \\ \text { of interest: funding for data collection by Cordaid, one of the implementing } \\ \text { agents of the PBF scheme }\end{array}\end{array}$

Baseline outcome mea- Low risk Analyses methods adjust for differences

surement

All outcomes

Matched characteristics High risk
for control study sites

for control study sites

Steenland 2017 Table 1 suggests differences between comparison and intervention exist - e.g. number of health facilities/100,000 people consistently

higher in intervention than in comparator

Protection against cont- Low risk Assignment by province/district/cluster

amination (intervention

and controls)

\section{Sun 2016}

\section{Study characteristics}

\section{Methods}

Participants

Interventions

\section{Outcomes}

\section{Notes}

\section{Risk of bias}

\begin{tabular}{lll}
\hline Bias & Authors' judgement & Support for judgement \\
\hline $\begin{array}{l}\text { Random sequence genera- } \\
\text { tion (selection bias) }\end{array}$ & High risk & Randomization compromised \\
\hline $\begin{array}{l}\text { Allocation concealment } \\
\text { (selection bias) }\end{array}$ & Low risk & Assignment by province/district/cluster \\
\hline $\begin{array}{l}\text { Blinding (performance } \\
\text { bias and detection bias) } \\
\text { All outcomes }\end{array}$ & Low risk & Unlikely outcome assessment affected by allocation knowledge \\
\hline $\begin{array}{l}\text { Incomplete outcome data } \\
\text { (attrition bias) }\end{array}$ & Unclear risk & Not specified \\
All outcomes & & \\
\hline $\begin{array}{l}\text { Selective reporting (re- } \\
\text { porting bias) }\end{array}$ & Low risk & Authors themselves note political interference in process \\
\hline \begin{tabular}{l} 
Other bias \\
\hline
\end{tabular} & Unclear risk & \\
\hline
\end{tabular}


Sun 2016 (Continued)
Baseline outcome mea-
Low risk
Analyses methods adjust for differences
surement

All outcomes

Matched characteristics Low risk Comparable
for control study sites

Protection against cont- Low risk Assignment by province/district/cluster
amination (intervention

and controls)

\section{Van de Poel 2016}

\section{Study characteristics}

\section{Methods}

\section{Participants}

Interventions

\section{Outcomes}

\section{Notes}

\section{Risk of bias}

\begin{tabular}{|c|c|c|}
\hline Bias & Authors' judgement & Support for judgement \\
\hline $\begin{array}{l}\text { Random sequence genera- } \\
\text { tion (selection bias) }\end{array}$ & High risk & As per guidance \\
\hline $\begin{array}{l}\text { Allocation concealment } \\
\text { (selection bias) }\end{array}$ & High risk & As per guidance \\
\hline $\begin{array}{l}\text { Blinding (performance } \\
\text { bias and detection bias) } \\
\text { All outcomes }\end{array}$ & Low risk & Indicators assessed objectively \\
\hline $\begin{array}{l}\text { Incomplete outcome data } \\
\text { (attrition bias) } \\
\text { All outcomes }\end{array}$ & Unclear risk & Not specified \\
\hline $\begin{array}{l}\text { Selective reporting (re- } \\
\text { porting bias) }\end{array}$ & Low risk & \\
\hline Other bias & Unclear risk & $\begin{array}{l}\text { Multiple PBF schemes that overlap and potentially introduced alongside bud- } \\
\text { get increases }\end{array}$ \\
\hline $\begin{array}{l}\text { Baseline outcome mea- } \\
\text { surement } \\
\text { All outcomes }\end{array}$ & Low risk & Analyses methods adjust for differences \\
\hline $\begin{array}{l}\text { Matched characteristics } \\
\text { for control study sites }\end{array}$ & Low risk & Comparable \\
\hline
\end{tabular}


Van de Poel 2016 (Continued)

Protection against cont- Low risk Assignment by province/district/cluster amination (intervention and controls)

\section{Viñuela 2015}

\section{Study characteristics}

\section{Methods}

\section{Participants}

\section{Interventions}

\section{Outcomes}

\section{Notes}

\section{Risk of bias}

\begin{tabular}{|c|c|c|}
\hline Bias & Authors' judgement & Support for judgement \\
\hline $\begin{array}{l}\text { Blinding (performance } \\
\text { bias and detection bias) } \\
\text { All outcomes }\end{array}$ & Low risk & Unlikely allocation affects data collection \\
\hline $\begin{array}{l}\text { Selective reporting (re- } \\
\text { porting bias) }\end{array}$ & Low risk & \\
\hline Other bias & Unclear risk & Data is aggregated at high level - this may impact analyses and findings \\
\hline $\begin{array}{l}\text { Intervention independent } \\
\text { (ITS)? }\end{array}$ & Unclear risk & $\begin{array}{l}\text { Other reforms were happening in the education and justice sectors which } \\
\text { could contribute as well }\end{array}$ \\
\hline $\begin{array}{l}\text { Shape of effect pre-speci- } \\
\text { fied (ITS)? }\end{array}$ & Low risk & Specified as per guidance \\
\hline $\begin{array}{l}\text { Unlikely to affect data col- } \\
\text { lection (ITS)? }\end{array}$ & Unclear risk & Intervention may have affected data collection \\
\hline $\begin{array}{l}\text { Incomplete outcome data } \\
\text { addressed (ITS)? }\end{array}$ & Unclear risk & Not specified \\
\hline
\end{tabular}

\section{Wagner 2018}

\section{Study characteristics}

\section{Methods}

\section{Participants}

\section{Interventions}

Paying for performance to improve the delivery of health interventions in low- and middle-income countries (Review) 
Wagner 2018 (Continued)

Outcomes

\section{Notes}

\section{Risk of bias}

\begin{tabular}{|c|c|c|}
\hline Bias & Authors' judgement & Support for judgement \\
\hline $\begin{array}{l}\text { Random sequence genera- } \\
\text { tion (selection bias) }\end{array}$ & Low risk & Sequence described in enough detail \\
\hline $\begin{array}{l}\text { Allocation concealment } \\
\text { (selection bias) }\end{array}$ & Low risk & Assignment by province/district/cluster \\
\hline $\begin{array}{l}\text { Blinding (performance } \\
\text { bias and detection bias) } \\
\text { All outcomes }\end{array}$ & Low risk & Unlikely outcome assessment affected by allocation knowledge \\
\hline $\begin{array}{l}\text { Incomplete outcome data } \\
\text { (attrition bias) } \\
\text { All outcomes }\end{array}$ & Low risk & $2 \%$ of sample missing only \\
\hline $\begin{array}{l}\text { Selective reporting (re- } \\
\text { porting bias) }\end{array}$ & Low risk & \\
\hline Other bias & Low risk & \\
\hline $\begin{array}{l}\text { Baseline outcome mea- } \\
\text { surement } \\
\text { All outcomes }\end{array}$ & Low risk & Analyses methods adjust for differences \\
\hline $\begin{array}{l}\text { Matched characteristics } \\
\text { for control study sites }\end{array}$ & Low risk & Comparable \\
\hline $\begin{array}{l}\text { Protection against cont- } \\
\text { amination (intervention } \\
\text { and controls) }\end{array}$ & Low risk & Assignment by province/district/cluster \\
\hline
\end{tabular}

Witvorapong 2016

\section{Study characteristics}

\section{Methods}

\section{Participants}

Interventions

\section{Outcomes}

\section{Notes}

\section{Risk of bias}


Witvorapong 2016 (Continued)

\begin{tabular}{lll}
$\begin{array}{l}\text { Random sequence genera- } \\
\text { tion (selection bias) }\end{array}$ & Low risk & Sequence described in enough detail \\
\hline $\begin{array}{l}\text { Allocation concealment } \\
\text { (selection bias) }\end{array}$ & Low risk & Assignment by province/district/cluster
\end{tabular}

(selection bias)

Blinding (performance
bias and detection bias) Low risk Unlikely outcome assessment affected by allocation knowledge

All outcomes

Incomplete outcome data High risk 408 of 7131 observations excluded due to missing data
(attrition bias)
All outcomes

Selective reporting (re- Low risk
porting bias)

\begin{tabular}{lll}
\hline Other bias & Unclear risk & $\begin{array}{l}\text { Potential selection bias and additionally unclear if authors had access to base- } \\
\text { line data }\end{array}$ \\
\hline $\begin{array}{l}\text { Baseline outcome mea- } \\
\text { surement } \\
\text { All outcomes }\end{array}$ & Unclear risk & Baseline measurement not specified \\
\hline $\begin{array}{l}\text { Matched characteristics } \\
\text { for control study sites }\end{array}$ & High risk & Characteristics not specified \\
\hline $\begin{array}{l}\text { Protection against cont- } \\
\text { amination (intervention } \\
\text { and controls) }\end{array}$ & Low risk & Assignment by province/district/cluster \\
\hline
\end{tabular}

\section{Wu 2014}

\begin{tabular}{l}
\hline Study characteristics \\
\hline Methods \\
\hline Participants \\
\hline Interventions \\
\hline Outcomes \\
\hline Notes \\
\hline Risk of bias
\end{tabular}

\footnotetext{
Selective reporting (re- Low risk porting bias)
} 
Wu 2014 (Continued)

\begin{tabular}{lll} 
Other bias & Unclear risk & Not generalizable, study conducted in one setting \\
\hline $\begin{array}{l}\text { Intervention independent } \\
\text { (ITS)? }\end{array}$ & Unclear risk & $\begin{array}{l}\text { Other reforms happening but robustness checks performed to ascertain im- } \\
\text { pacts and effects are consistent }\end{array}$ \\
\hline $\begin{array}{l}\text { Shape of effect pre-speci- } \\
\text { fied (ITS)? }\end{array}$ & Low risk & Specified as per guidance \\
\hline $\begin{array}{l}\text { Unlikely to affect data col- } \\
\text { lection (ITS)? }\end{array}$ & Low risk & No effects on data collection \\
\hline $\begin{array}{l}\text { Incomplete outcome data } \\
\text { addressed (ITS)? }\end{array}$ & Unclear risk & Not specified \\
\hline
\end{tabular}

\section{Yao 2008}

\section{Study characteristics}

Methods

\section{Participants}

Interventions

\section{Outcomes}

\section{Notes}

\section{Risk of bias}

\begin{tabular}{|c|c|c|}
\hline Bias & Authors' judgement & Support for judgement \\
\hline $\begin{array}{l}\text { Random sequence genera- } \\
\text { tion (selection bias) }\end{array}$ & High risk & As per guidance \\
\hline $\begin{array}{l}\text { Allocation concealment } \\
\text { (selection bias) }\end{array}$ & High risk & As per guidance \\
\hline $\begin{array}{l}\text { Blinding (performance } \\
\text { bias and detection bias) } \\
\text { All outcomes }\end{array}$ & Low risk & Blinded assessments \\
\hline $\begin{array}{l}\text { Incomplete outcome data } \\
\text { (attrition bias) } \\
\text { All outcomes }\end{array}$ & Unclear risk & Not specified \\
\hline $\begin{array}{l}\text { Selective reporting (re- } \\
\text { porting bias) }\end{array}$ & Low risk & \\
\hline Other bias & Low risk & (Re-analysis cannot be adjusted for the GDP/country make-up) \\
\hline $\begin{array}{l}\text { Baseline outcome mea- } \\
\text { surement } \\
\text { All outcomes }\end{array}$ & Unclear risk & $\begin{array}{l}\text { Paper re-analysed; re-analysed results noted as low (analyses methods adjust } \\
\text { for differences) }\end{array}$ \\
\hline
\end{tabular}


Yao 2008 (Continued)

$\begin{array}{ll}\begin{array}{l}\text { Matched characteristics } \\ \text { for control study sites }\end{array} & \text { High risk } \\ \end{array}$
for control study sites

Protection against cont- Low risk amination (intervention and controls)

\section{Yip 2014}

\section{Study characteristics}

\begin{tabular}{|c|c|c|}
\hline \multicolumn{3}{|l|}{ Methods } \\
\hline \multicolumn{3}{|l|}{ Participants } \\
\hline \multicolumn{3}{|l|}{ Interventions } \\
\hline \multicolumn{3}{|l|}{ Outcomes } \\
\hline \multicolumn{3}{|l|}{ Notes } \\
\hline \multicolumn{3}{|l|}{ Risk of bias } \\
\hline Bias & Authors' judgement & Support for judgement \\
\hline $\begin{array}{l}\text { Random sequence genera- } \\
\text { tion (selection bias) }\end{array}$ & Low risk & Sequence described in enough detail \\
\hline $\begin{array}{l}\text { Allocation concealment } \\
\text { (selection bias) }\end{array}$ & Low risk & Assignment by province/district/cluster \\
\hline $\begin{array}{l}\text { Blinding (performance } \\
\text { bias and detection bias) } \\
\text { All outcomes }\end{array}$ & Low risk & Unlikely outcome assessment affected by allocation knowledge \\
\hline $\begin{array}{l}\text { Incomplete outcome data } \\
\text { (attrition bias) } \\
\text { All outcomes }\end{array}$ & Unclear risk & Not specified \\
\hline $\begin{array}{l}\text { Selective reporting (re- } \\
\text { porting bias) }\end{array}$ & Low risk & \\
\hline Other bias & Low risk & \\
\hline $\begin{array}{l}\text { Baseline outcome mea- } \\
\text { surement } \\
\text { All outcomes }\end{array}$ & Low risk & Constrained matched randomization \\
\hline $\begin{array}{l}\text { Matched characteristics } \\
\text { for control study sites }\end{array}$ & Low risk & Comparable (see Yip 2014 Appendix) \\
\hline $\begin{array}{l}\text { Protection against cont- } \\
\text { amination (intervention } \\
\text { and controls) }\end{array}$ & Low risk & Assignment by province/district/cluster \\
\hline
\end{tabular}


Zang 2015

\section{Study characteristics}

Methods

Participants

Interventions

\section{Outcomes}

Notes

\section{Risk of bias}

\begin{tabular}{|c|c|c|}
\hline Bias & Authors' judgement & Support for judgement \\
\hline $\begin{array}{l}\text { Random sequence genera- } \\
\text { tion (selection bias) }\end{array}$ & High risk & As per guidance \\
\hline $\begin{array}{l}\text { Allocation concealment } \\
\text { (selection bias) }\end{array}$ & High risk & As per guidance \\
\hline $\begin{array}{l}\text { Blinding (performance } \\
\text { bias and detection bias) } \\
\text { All outcomes }\end{array}$ & Unclear risk & Not specified \\
\hline $\begin{array}{l}\text { Incomplete outcome data } \\
\text { (attrition bias) } \\
\text { All outcomes }\end{array}$ & Unclear risk & Not specified \\
\hline $\begin{array}{l}\text { Selective reporting (re- } \\
\text { porting bias) }\end{array}$ & Low risk & \\
\hline Other bias & Low risk & $\begin{array}{l}\text { (Note: we classify this as CBA, however could be non-randomized trial, but no } \\
\text { allocation mentioned) }\end{array}$ \\
\hline $\begin{array}{l}\text { Baseline outcome mea- } \\
\text { surement } \\
\text { All outcomes }\end{array}$ & Low risk & Analyses methods adjust for differences \\
\hline $\begin{array}{l}\text { Matched characteristics } \\
\text { for control study sites }\end{array}$ & Low risk & Comparable \\
\hline $\begin{array}{l}\text { Protection against cont- } \\
\text { amination (intervention } \\
\text { and controls) }\end{array}$ & Low risk & Assignment by province/district/cluster \\
\hline
\end{tabular}

Zeng 2013

\section{Study characteristics}

Methods 
Zeng 2013 (Continued)

Participants

Interventions

Outcomes

\section{Notes}

\section{Risk of bias}

\begin{tabular}{|c|c|c|}
\hline Bias & Authors' judgement & Support for judgement \\
\hline $\begin{array}{l}\text { Random sequence genera- } \\
\text { tion (selection bias) }\end{array}$ & High risk & As per guidance \\
\hline $\begin{array}{l}\text { Allocation concealment } \\
\text { (selection bias) }\end{array}$ & High risk & As per guidance \\
\hline $\begin{array}{l}\text { Blinding (performance } \\
\text { bias and detection bias) } \\
\text { All outcomes }\end{array}$ & Low risk & Indicators assessed objectively \\
\hline $\begin{array}{l}\text { Incomplete outcome data } \\
\text { (attrition bias) } \\
\text { All outcomes }\end{array}$ & Unclear risk & Not specified \\
\hline $\begin{array}{l}\text { Selective reporting (re- } \\
\text { porting bias) }\end{array}$ & Low risk & \\
\hline Other bias & Unclear risk & NGO facilities may not be a suitable comparator to public facilities \\
\hline $\begin{array}{l}\text { Baseline outcome mea- } \\
\text { surement } \\
\text { All outcomes }\end{array}$ & Low risk & Analyses methods adjust for differences \\
\hline $\begin{array}{l}\text { Matched characteristics } \\
\text { for control study sites }\end{array}$ & High risk & Data not presented \\
\hline $\begin{array}{l}\text { Protection against cont- } \\
\text { amination (intervention } \\
\text { and controls) }\end{array}$ & Low risk & Assignment by province/district/cluster \\
\hline
\end{tabular}

\section{Zeng 2018a}

\section{Study characteristics}

\section{Methods}

\section{Participants}

Interventions

\section{Outcomes}

\section{Notes}


Zeng 2018a (Continued)

Risk of bias

\begin{tabular}{|c|c|c|}
\hline Bias & Authors' judgement & Support for judgement \\
\hline $\begin{array}{l}\text { Random sequence genera- } \\
\text { tion (selection bias) }\end{array}$ & High risk & As per guidance \\
\hline $\begin{array}{l}\text { Allocation concealment } \\
\text { (selection bias) }\end{array}$ & High risk & As per guidance \\
\hline $\begin{array}{l}\text { Blinding (performance } \\
\text { bias and detection bias) } \\
\text { All outcomes }\end{array}$ & Low risk & $\begin{array}{l}\text { Low except concerns relating to patient satisfaction and quality reported out- } \\
\text { comes }\end{array}$ \\
\hline $\begin{array}{l}\text { Incomplete outcome data } \\
\text { (attrition bias) } \\
\text { All outcomes }\end{array}$ & Unclear risk & Not specified \\
\hline $\begin{array}{l}\text { Selective reporting (re- } \\
\text { porting bias) }\end{array}$ & Low risk & \\
\hline Other bias & Low risk & \\
\hline $\begin{array}{l}\text { Baseline outcome mea- } \\
\text { surement } \\
\text { All outcomes }\end{array}$ & Low risk & Analyses methods adjust for differences \\
\hline $\begin{array}{l}\text { Matched characteristics } \\
\text { for control study sites }\end{array}$ & High risk & $\begin{array}{l}\text { Zeng } 2018 \text { a Table } 3 \text { suggests significant differences, e.g. in household size, dai- } \\
\text { ly spending and age of mother }\end{array}$ \\
\hline $\begin{array}{l}\text { Protection against cont- } \\
\text { amination (intervention } \\
\text { and controls) }\end{array}$ & Low risk & Assignment by province/district/cluster \\
\hline
\end{tabular}

Characteristics of excluded studies [ordered by study ID]

\begin{tabular}{ll}
\hline Study & Reason for exclusion \\
\hline Aninanya 2016 & Study does not include major outcomes of interest \\
\hline Anselmi 2017 & Study complementary to, or superseded by, other included study. \\
\hline Aung 2015 & Study does not include major outcomes of interest \\
\hline Banerjee 2008 & Study intervention does not cover relevant payments \\
\hline Basinga 2010 & Study complementary to, or superseded by, other included study \\
\hline Biai 2012 & $\begin{array}{l}\text { Study focussed only on payments which are not explicitly linked to changing patterns of perfor- } \\
\text { mance }\end{array}$ \\
\hline Borghi 2015 & Study is complementary to included evaluations, excluded based on study type \\
\hline Canavan 2008 & Study design is not CBA/RCT/ITS \\
\hline Paying for & \\
\hline
\end{tabular}




\begin{tabular}{|c|c|}
\hline Study & Reason for exclusion \\
\hline $\begin{array}{l}\text { Department for International } \\
\text { Development } 2017\end{array}$ & Study a CBA but choice of control not appropriate \\
\hline Kumar 2016 & Study a CBA but choice of control not appropriate \\
\hline Liu 2003 & Full text not available \\
\hline Morisky 1985 & Study a CBA but only 1 cluster/site in each comparison group \\
\hline Ngo 2017 & Study complementary to, or superseded by, other included study \\
\hline Nguyen 2015 & Study does not include major outcomes of interest \\
\hline Not reported 1962 & Study does not include relevant health care providers \\
\hline Olken 2012 & Study does not include relevant health care providers \\
\hline Peabody 2010 & Study superseded by already included study. \\
\hline Peabody 2017 & Study is complementary to included evaluations, excluded based on study type \\
\hline Phillips 1975 & Study does not include relevant health care providers \\
\hline Prakarsh 2017 & Study does not include relevant health care providers \\
\hline Quy 2003 & Study is an ITS but more time points for assessment needed \\
\hline Rahman 2017 & $\begin{array}{l}\text { Study focussed only on payments which are not explicitly linked to changing patterns of perfor- } \\
\text { mance }\end{array}$ \\
\hline RBF Health 2017 & Study does not include relevant health care providers \\
\hline Rusa 2009b & Study complementary to, or superseded by, other included study \\
\hline Shen 2015 & Study complementary to, or superseded by, other included study \\
\hline Singh 2015 & Study does not include relevant health care providers \\
\hline Soeters 2005 & Study design CBA but insufficient clusters. \\
\hline Soeters 2008 & Study design CBA but insufficient clusters. \\
\hline Soeters 2009 & Study is CBA but has insufficient clusters. \\
\hline Sylvia 2015 & Study does not include relevant health care providers \\
\hline Valadez 2015 & Study a CBA but choice of control not appropriate \\
\hline Vergeer 2008 & Study superseded by other included study. \\
\hline World Bank 2015 & Insufficient information available to determine inclusion \\
\hline Zeng 2018b & Study is complementary to included evaluations, excluded based on study type \\
\hline Zhang 2017 & Study an ITS but not have $\geq 3$ data points before or after the intervention \\
\hline
\end{tabular}




\begin{tabular}{ll}
\hline Study & Reason for exclusion \\
\hline Zhao 2013 & Study a CBA but only 1 cluster/site in each comparison group \\
\hline
\end{tabular}

\section{ADDITIONAL TABLES}

Table 1. Meta-summary: Effects of P4P against control

\begin{tabular}{|c|c|c|c|c|c|}
\hline \multirow[t]{3}{*}{$\begin{array}{l}\text { Out- } \\
\text { come }\end{array}$} & \multirow[t]{3}{*}{ Indicator } & \multicolumn{4}{|c|}{$\begin{array}{l}\text { Direction of relative effect and GRADE as- } \\
\text { sessment for targeted and un-targeted out- } \\
\text { comes }\end{array}$} \\
\hline & & \multicolumn{2}{|c|}{ Targeted outcomes } & \multicolumn{2}{|c|}{$\begin{array}{l}\text { Un-targeted out- } \\
\text { comes }\end{array}$} \\
\hline & & $\begin{array}{l}\text { Direc- } \\
\text { tion of } \\
\text { effect }\end{array}$ & $\begin{array}{l}\text { Certain- } \\
\text { ty of } \\
\text { the evi- } \\
\text { dence }\end{array}$ & $\begin{array}{l}\text { Direc- } \\
\text { tion of } \\
\text { effect }\end{array}$ & $\begin{array}{l}\text { Certain- } \\
\text { ty of } \\
\text { the evi- } \\
\text { dence }\end{array}$ \\
\hline \multirow{17}{*}{$\begin{array}{l}\text { Prima- } \\
\text { ry: Uti- } \\
\text { lization } \\
\text { and de- } \\
\text { livery }\end{array}$} & Provision of HIV testing (\%) & $\boldsymbol{\Delta}$ & $\oplus \oplus \ominus \ominus$ & $\boldsymbol{\Delta}$ & $\oplus \oplus \ominus \ominus$ \\
\hline & Provision of ART services (\%) & $\nabla$ & $\oplus \oplus \ominus \ominus$ & \multicolumn{2}{|c|}{ No evidence } \\
\hline & Provision of PMTCT (\%) & $\boldsymbol{\Delta}$ & $\oplus \oplus \ominus \ominus$ & \multicolumn{2}{|c|}{ No evidence } \\
\hline & Bednet use (\% of children and households using bednets) & $\boldsymbol{\nabla}$ & $\oplus \oplus \ominus \ominus$ & - & $\oplus \oplus \oplus \ominus$ \\
\hline & TB adherence rate & $\square$ & $\oplus \ominus \ominus \ominus$ & \multicolumn{2}{|c|}{ No evidence } \\
\hline & Child immunization: $\%$ at least one vaccine & - & $\oplus \oplus \ominus \ominus$ & \multicolumn{2}{|c|}{ No evidence } \\
\hline & Child immunization: \% fully vaccinate & $\square$ & $\oplus \oplus \ominus \ominus$ & \multicolumn{2}{|c|}{ No evidence } \\
\hline & Child immunization: \% receiving BCG & $\boldsymbol{\Delta}$ & $\oplus \oplus \ominus \ominus$ & \multicolumn{2}{|c|}{ No evidence } \\
\hline & Child immunization: \% receiving DTP & $\boldsymbol{\nabla}$ & $\oplus \oplus \ominus \ominus$ & \multicolumn{2}{|c|}{ No evidence } \\
\hline & Child immunization: \% receiving measles vaccine & $\boldsymbol{\Delta}$ & $\oplus \oplus \ominus \ominus$ & \multicolumn{2}{|c|}{ No evidence } \\
\hline & Child immunization: \% receiving polio vaccine & $\boldsymbol{\Delta}$ & $\oplus \oplus \ominus \ominus$ & \multicolumn{2}{|c|}{ No evidence } \\
\hline & Child immunization: $\%$ receiving pentavalent vaccine & - & $\oplus \oplus \ominus \ominus$ & \multicolumn{2}{|c|}{ No evidence } \\
\hline & Mothers receiving immunizations (\%) & $\boldsymbol{\Delta}$ & $\oplus \oplus \ominus \ominus$ & \multicolumn{2}{|c|}{ No evidence } \\
\hline & Probability of any utilization (\%) & - & $\oplus \oplus \ominus \ominus$ & - & $\oplus \oplus \ominus \ominus$ \\
\hline & Frequency of curative utilization (\%) & $\boldsymbol{\Delta}$ & $\oplus \oplus \ominus \ominus$ & $\square$ & $\oplus \ominus \ominus \ominus$ \\
\hline & Frequency of outpatient utilization (\%) & $\boldsymbol{\Delta}$ & $\oplus \oplus \ominus \ominus$ & - & $\oplus \oplus \ominus \ominus$ \\
\hline & Frequency - all visits (number of visits) & - & $\oplus \oplus \ominus \ominus$ & - & $\oplus \oplus \ominus \ominus$ \\
\hline
\end{tabular}


Table 1. Meta-summary: Effects of P4P against control (Continued)

\begin{tabular}{|c|c|c|c|c|}
\hline \multirow{2}{*}{$\begin{array}{l}\text { Frequency - elderly visits } \\
\text { Antenatal care (\% of women utilizing ANC) }\end{array}$} & \multicolumn{2}{|c|}{ No evidence } & \multirow{2}{*}{-} & \multirow{2}{*}{$\frac{\oplus \oplus \ominus \ominus}{\oplus \oplus \ominus \ominus}$} \\
\hline & $\boldsymbol{\Delta}$ & $\oplus \oplus \ominus \ominus$ & & \\
\hline Total number ANC visits & $\square$ & $\oplus \oplus \ominus \ominus$ & \multicolumn{2}{|c|}{ No evidence } \\
\hline At least one ANC (utilization rates) & $\boldsymbol{\Delta}$ & $\oplus \oplus \ominus \ominus$ & $\square$ & $\oplus \ominus \ominus \ominus$ \\
\hline At least two ANC (utilization rates) & - & $\oplus \oplus \ominus \ominus$ & $\square$ & $\oplus \ominus \ominus \ominus$ \\
\hline At least four ANC (utilization rates) & $\boldsymbol{\Delta}$ & $\oplus \oplus \ominus \ominus$ & $\square$ & $\oplus \ominus \ominus \ominus$ \\
\hline ANC from qualified provider (utilization rate) & - & $\oplus \oplus \ominus \ominus$ & \multicolumn{2}{|c|}{ No evidence } \\
\hline Delivery of iron supplementation during ANC (\% women receiving) & $\boldsymbol{\nabla}$ & $\oplus \oplus \ominus \ominus$ & \multicolumn{2}{|c|}{ No evidence } \\
\hline Women accessing ANC in first trimester (\% women receiving) & $\boldsymbol{\Delta}$ & $\oplus \oplus \ominus \ominus$ & $\boldsymbol{\Delta}$ & $\oplus \oplus \ominus \ominus$ \\
\hline Family planning (\% using of any method) & $\square$ & $\oplus \oplus \ominus \ominus$ & \multicolumn{2}{|c|}{ No evidence } \\
\hline Family planning (\% women utilizing modern methods) & $\square$ & $\oplus \oplus \ominus \ominus$ & - & $\oplus \oplus \oplus \ominus$ \\
\hline Family planning (\% of services delivered) & $\boldsymbol{\Delta}$ & $\oplus \oplus \oplus \ominus$ & $\Delta$ & $\oplus \oplus \ominus \ominus$ \\
\hline Institutional delivery (rates or coverage) & $\square$ & $\oplus \ominus \ominus \ominus$ & - & $\oplus \oplus \ominus \ominus$ \\
\hline Institutional delivery: C section (\%) & $\Delta$ & $\oplus \oplus \ominus \ominus$ & $\square$ & $\oplus \ominus \ominus \ominus$ \\
\hline Institutional delivery: skilled attendance & $\boldsymbol{\Delta}$ & $\oplus \oplus \ominus \ominus$ & \multicolumn{2}{|c|}{ No evidence } \\
\hline Delivery and coverage of postnatal care & $\boldsymbol{\Delta}$ & $\oplus \oplus \ominus \ominus$ & $\mathbf{\Delta}$ & $\oplus \oplus \ominus \ominus$ \\
\hline Postnatal care (overall utilization rate) & $\boldsymbol{\Delta}$ & $\oplus \oplus \ominus \ominus$ & $\nabla$ & $\oplus \oplus \oplus \ominus$ \\
\hline Postnatal care: skilled attendance (\% women receiving) & $\boldsymbol{\Delta}$ & $\oplus \oplus \ominus \ominus$ & \multicolumn{2}{|c|}{ No evidence } \\
\hline Postnatal care: timely access (\%women receiving) & $\boldsymbol{\Delta}$ & $\oplus \oplus \ominus \ominus$ & $\boldsymbol{\Delta}$ & $\oplus \oplus \ominus \ominus$ \\
\hline Utilization rate of consultations in children & $\boldsymbol{\Delta}$ & $\oplus \oplus \ominus \ominus$ & $\square$ & $\oplus \ominus \ominus \ominus$ \\
\hline Utilization rate of curative consultations in children & $\boldsymbol{\nabla}$ & $\oplus \oplus \ominus \ominus$ & \multicolumn{2}{|c|}{ No evidence } \\
\hline Vitamin A supplementation in children (rate) & $\boldsymbol{\Delta}$ & $\oplus \oplus \ominus \ominus$ & \multicolumn{2}{|c|}{ No evidence } \\
\hline Child mortality (per 1000 children born alive) & $\boldsymbol{\Delta}$ & $\oplus \oplus \ominus \ominus$ & $\Delta$ & $\oplus \oplus \oplus \ominus$ \\
\hline Neonatal mortality (rate) & $\square$ & $\oplus \oplus \ominus \ominus$ & - & $\oplus \oplus \oplus \ominus$ \\
\hline Incidence of sickness & \multicolumn{2}{|c|}{ No evidence } & $\boldsymbol{\Delta}$ & $\oplus \oplus \ominus \ominus$ \\
\hline Child wasting (\%) & \multicolumn{2}{|c|}{ No evidence } & $\mathbf{\Delta}$ & $\oplus \oplus \oplus \ominus$ \\
\hline $\begin{array}{l}\text { Unwanted pregnancy rate (targeted); overall pregnancy rate(non-tar- } \\
\text { geted) }\end{array}$ & $\square$ & $\oplus \ominus \ominus \ominus$ & - & $\oplus \oplus \oplus \ominus$ \\
\hline
\end{tabular}


Table 1. Meta-summary: Effects of P4P against control (Continued)

\begin{tabular}{|c|c|c|c|c|c|}
\hline & Reported illness in children: anemia (\%) & $\mathbf{\Delta}$ & $\oplus \oplus \ominus \ominus$ & $\mathbf{\Delta}$ & $\oplus \oplus \oplus \ominus$ \\
\hline & Tuberculosis treatment success rate & $\mathbf{\Delta}$ & $\oplus \oplus \ominus \ominus$ & \multicolumn{2}{|c|}{ No evidence } \\
\hline \multirow{20}{*}{$\begin{array}{l}\text { Prima- } \\
\text { ry: Qual- } \\
\text { ity of } \\
\text { care }\end{array}$} & $\begin{array}{l}\text { Background and physical assessment (scores general, across ANC, PNC, } \\
\text { child care and for other consultations). }\end{array}$ & $\square$ & $\oplus \ominus \ominus \ominus$ & \multicolumn{2}{|c|}{ No evidence } \\
\hline & $\begin{array}{l}\text { Correct patient management by health care providers (scores in rela- } \\
\text { tion to ANC, child care and PNC) }\end{array}$ & $\square$ & $\oplus \ominus \ominus \ominus$ & - & $\oplus \oplus \oplus \ominus$ \\
\hline & Patient counselling (scores on ANC and PNC related counselling) & $\square$ & $\oplus \ominus \ominus \ominus$ & \multicolumn{2}{|c|}{ No evidence } \\
\hline & $\begin{array}{l}\text { Immunizations (score for receiving any tetanus and nr. Of tetanus vacci- } \\
\text { nations) }\end{array}$ & $\boldsymbol{\Delta}$ & $\oplus \oplus \ominus \ominus$ & $\boldsymbol{\Delta}$ & $\oplus \oplus \ominus \ominus$ \\
\hline & Women in ANC given or prescribed folic acid/iron & $\boldsymbol{\Delta}$ & $\oplus \oplus \ominus \ominus$ & \multicolumn{2}{|c|}{ No evidence } \\
\hline & $\begin{array}{l}\text { Prescription quality of care (index score when targeted, \%women re- } \\
\text { ceiving correct prescription in case of illness for non-targeted) }\end{array}$ & $\boldsymbol{\Delta}$ & $\oplus \oplus \ominus \ominus$ & \multicolumn{2}{|c|}{ No evidence } \\
\hline & Staff knowledge and skills (scores) & - & $\oplus \oplus \ominus \ominus$ & - & $\oplus \oplus \ominus \ominus$ \\
\hline & Staff responsiveness (scores) & $\boldsymbol{\Delta}$ & $\oplus \ominus \ominus \ominus$ & \multicolumn{2}{|c|}{ No evidence } \\
\hline & Patient knowledge (score) & $\boldsymbol{\Delta}$ & $\oplus \oplus \ominus \ominus$ & - & $\oplus \oplus \oplus \ominus$ \\
\hline & Contact time (\% change) & - & $\oplus \oplus \ominus \ominus$ & - & $\oplus \oplus \ominus \ominus$ \\
\hline & Waiting time (\% change) & $\boldsymbol{\nabla}$ & $\oplus \oplus \ominus \ominus$ & $\square$ & $\oplus \ominus \ominus \ominus$ \\
\hline & Length of stay (\% change) & \multicolumn{2}{|c|}{ No evidence } & $\nabla$ & $\oplus \oplus \ominus \ominus$ \\
\hline & Overall composite quality of care score & $\boldsymbol{\Delta}$ & $\oplus \oplus \ominus \ominus$ & $\nabla$ & $\oplus \oplus \oplus \ominus$ \\
\hline & Quality family planning (score) & $\boldsymbol{\Delta}$ & $\oplus \oplus \ominus \ominus$ & \multicolumn{2}{|c|}{ No evidence } \\
\hline & Quality of ANC (score) & $\square$ & $\oplus \oplus \ominus \ominus$ & \multicolumn{2}{|c|}{ No evidence } \\
\hline & Quality maternity care (score) & $\boldsymbol{\Delta}$ & $\oplus \oplus \ominus \ominus$ & $\square$ & $\oplus \ominus \ominus \ominus$ \\
\hline & Quality of child health care (score) & $\boldsymbol{\Delta}$ & $\oplus \oplus \oplus \ominus$ & \multicolumn{2}{|c|}{ No evidence } \\
\hline & Quality of outpatient services (score) & $\square$ & $\oplus \ominus \ominus \ominus$ & $\square$ & $\oplus \ominus \ominus \ominus$ \\
\hline & Quality of medicine and equipment (score) & $\boldsymbol{\Delta}$ & $\oplus \oplus \oplus \ominus$ & $\square$ & $\oplus \ominus \ominus \ominus$ \\
\hline & Quality by department and/or service (score) & $\boldsymbol{\Delta}$ & $\oplus \oplus \oplus \ominus$ & \multicolumn{2}{|c|}{ No evidence } \\
\hline $\begin{array}{l}\text { Prima- } \\
\text { ry: Unin- } \\
\text { tended } \\
\text { effects }\end{array}$ & Overall impacts on free riding and task shifting & \multicolumn{2}{|c|}{ No evidence } & - & $\oplus \oplus \ominus \ominus$ \\
\hline \multirow{2}{*}{$\begin{array}{l}\text { Pri- } \\
\text { mary: } \\
\text { Changes } \\
\text { in re- }\end{array}$} & Human resource availability (persons available) & $\boldsymbol{\Delta}$ & $\oplus \oplus \oplus \ominus$ & $\square$ & $\oplus \ominus \ominus \ominus$ \\
\hline & Curative health visits per health care professional & $\square$ & $\oplus \ominus \ominus \ominus$ & $\square$ & $\oplus \ominus \ominus \ominus$ \\
\hline
\end{tabular}


Table 1. Meta-summary: Effects of P4P against control (Continued)

\begin{tabular}{|c|c|c|c|c|c|}
\hline \multirow{8}{*}{$\begin{array}{l}\text { source } \\
\text { use }\end{array}$} & Equipment availability (index) & $\mathbf{\Delta}$ & $\oplus \oplus \ominus \ominus$ & $\square$ & $\oplus \ominus \ominus \ominus$ \\
\hline & Equipment functionality (index) & - & $\oplus \oplus \ominus \ominus$ & $\square$ & $\oplus \ominus \ominus \ominus$ \\
\hline & Infrastructure functionality (index) & $\mathbf{\Delta}$ & $\oplus \oplus \ominus \ominus$ & - & $\oplus \oplus \ominus \ominus$ \\
\hline & Medicine availability (index) & $\mathbf{\Delta}$ & $\oplus \oplus \ominus \ominus$ & $\mathbf{\Delta}$ & $\oplus \oplus \ominus \ominus$ \\
\hline & Vaccine availability (index) & $\square$ & $\oplus \oplus \ominus \ominus$ & $\square$ & $\oplus \ominus \ominus \ominus$ \\
\hline & Stockout of equipment & $\mathbf{\Delta}$ & $\oplus \oplus \ominus \ominus$ & $\square$ & $\oplus \ominus \ominus \ominus$ \\
\hline & Stockout of medicines & \multicolumn{2}{|c|}{ No evidence } & $\square$ & $\oplus \ominus \ominus \ominus$ \\
\hline & Stockout of vaccines & $\boldsymbol{\Delta}$ & $\oplus \oplus \ominus \ominus$ & No & \\
\hline \multirow{3}{*}{$\begin{array}{l}\text { Se- } \\
\text { condary: } \\
\text { Provider } \\
\text { moti- } \\
\text { vation, } \\
\text { satis- } \\
\text { faction, } \\
\text { absen- } \\
\text { teeism } \\
\text { and ac- } \\
\text { cept- } \\
\text { ability }\end{array}$} & Provider absenteeism (\%) & - & $\oplus \oplus \ominus \ominus$ & $\boldsymbol{\Delta}$ & $\oplus \oplus \oplus \ominus$ \\
\hline & Provider motivation (score) & - & $\oplus \oplus \oplus \ominus$ & $\boldsymbol{\Delta}$ & $\oplus \oplus \ominus \ominus$ \\
\hline & Provider satisfaction (score) & - & $\oplus \oplus \oplus \ominus$ & $\square$ & $\oplus \oplus \ominus \ominus$ \\
\hline \multirow{11}{*}{$\begin{array}{l}\text { Se- } \\
\text { condary: } \\
\text { Patient } \\
\text { satisfac- } \\
\text { tion and } \\
\text { accept- } \\
\text { ability } \\
\text { (satis- } \\
\text { faction } \\
\text { scores) }\end{array}$} & Patient satisfaction with facility cleanliness (score) & $\mathbf{\Delta}$ & $\oplus \oplus \ominus \ominus$ & $\square$ & $\oplus \oplus \ominus \ominus$ \\
\hline & Patient satisfaction with contact time (score) & $\square$ & $\oplus \ominus \ominus \ominus$ & $\nabla$ & $\oplus \oplus \ominus \ominus$ \\
\hline & Patient satisfaction with opening hours (score) & $\Delta$ & $\oplus \oplus \ominus \ominus$ & $\nabla$ & $\oplus \oplus \ominus \ominus$ \\
\hline & Patient satisfaction with waiting time (score) & $\square$ & $\oplus \ominus \ominus \ominus$ & $\square$ & $\oplus \oplus \ominus \ominus$ \\
\hline & Patient satisfaction with privacy (score) & $\Delta$ & $\oplus \oplus \ominus \ominus$ & No & \\
\hline & Overall patient satisfaction with quality of care (score) & - & $\oplus \oplus \ominus \ominus$ & $\boldsymbol{\Delta}$ & $\oplus \oplus \ominus \ominus$ \\
\hline & $\begin{array}{l}\text { Overall patient satisfaction with welcome and reception at facility } \\
\text { (score) }\end{array}$ & \multicolumn{2}{|c|}{ No evidence } & $\mathbf{\Delta}$ & $\oplus \oplus \ominus \ominus$ \\
\hline & Patient satisfaction with staff: Communication (score) & - & $\oplus \oplus \ominus \ominus$ & $\boldsymbol{\Delta}$ & $\oplus \oplus \ominus \ominus$ \\
\hline & Patient satisfaction with staff: Trust (score) & \multicolumn{2}{|c|}{ No evidence } & $\boldsymbol{\Delta}$ & $\oplus \oplus \ominus \ominus$ \\
\hline & Patient satisfaction with staff: Attitude (score) & $\mathbf{\Delta}$ & $\oplus \oplus \ominus \ominus$ & $\mathbf{\Delta}$ & $\oplus \oplus \ominus \ominus$ \\
\hline & Overall satisfaction (score) & $\mathbf{\Delta}$ & $\oplus \oplus \ominus \ominus$ & $\mathbf{\Delta}$ & $\oplus \oplus \oplus \ominus$ \\
\hline \multirow{3}{*}{$\begin{array}{l}\text { Se- } \\
\text { condary: } \\
\text { Impacts } \\
\text { on over- } \\
\text { all fi- } \\
\text { nancing }\end{array}$} & Fees & \multicolumn{2}{|c|}{ No evidence } & $\nabla$ & $\oplus \oplus \ominus \ominus$ \\
\hline & Expenditure on medicine and equipment & - & $\oplus \oplus \ominus \ominus$ & - & $\oplus \oplus \oplus \ominus$ \\
\hline & Probability of payment for users & \multicolumn{2}{|c|}{ No evidence } & $\square$ & $\oplus \oplus \ominus \ominus$ \\
\hline
\end{tabular}

Paying for performance to improve the delivery of health interventions in low- and middle-income countries (Review) 
Table 1. Meta-summary: Effects of P4P against control (Continued)

or re-

source

alloca-

tion

\begin{tabular}{|c|c|c|c|c|c|}
\hline \multirow{3}{*}{$\begin{array}{l}\text { Se- } \\
\text { condary: } \\
\text { Impacts } \\
\text { on man- } \\
\text { age- } \\
\text { ment or } \\
\text { infor- } \\
\text { mation } \\
\text { systems } \\
\text { (if not a } \\
\text { target- } \\
\text { ed mea- } \\
\text { sure of } \\
\text { perfor- } \\
\text { mance) }\end{array}$} & Facility or managerial autonomy & $\boldsymbol{\Delta}$ & $\oplus \oplus \ominus \ominus$ & $\boldsymbol{\Delta}$ & $\oplus \oplus \ominus \ominus$ \\
\hline & Facility governance & - & $\oplus \oplus \ominus \ominus$ & $\boldsymbol{\nabla}$ & $\oplus \oplus \ominus \ominus$ \\
\hline & Quality of management & - & $\oplus \oplus \ominus \ominus$ & $\boldsymbol{\nabla}$ & $\oplus \oplus \ominus \ominus$ \\
\hline \multirow{4}{*}{$\begin{array}{l}\text { Se- } \\
\text { condary: } \\
\text { Equi- } \\
\text { ty-con- } \\
\text { sidera- } \\
\text { tion: Ev- } \\
\text { idence } \\
\text { of dif- } \\
\text { ferential } \\
\text { impact } \\
\text { on dif- } \\
\text { ferent } \\
\text { parts of } \\
\text { the pop- } \\
\text { ulation }\end{array}$} & Equity of child immunization delivery (wealth related) & $\boldsymbol{\Delta}$ & $\oplus \oplus \ominus \ominus$ & $\square$ & $\oplus \ominus \ominus \ominus$ \\
\hline & Equity in ANC delivery (wealth related) & $\boldsymbol{\nabla}$ & $\oplus \oplus \ominus \ominus$ & \multicolumn{2}{|c|}{ No evidence } \\
\hline & Equity in institutional delivery (wealth related) & - & $\oplus \oplus \ominus \ominus$ & $\boldsymbol{\nabla}$ & $\oplus \oplus \ominus \ominus$ \\
\hline & Equity in institutional delivery (by educational status of mother) & - & $\oplus \oplus \ominus \ominus$ & $\square$ & $\oplus \ominus \ominus \ominus$ \\
\hline
\end{tabular}

\section{Direction of effect key}

A Desirable

$\boldsymbol{\nabla}$ Non-desirable

- Neutral

$\square \quad$ Uncertain

Certainty in evidence key

$\oplus \oplus \oplus \ominus \quad$ Moderate

$\oplus \oplus \ominus \ominus$ Low

$\oplus \ominus \ominus \ominus \quad$ Very low

Table 2. Meta-summary: Effects of P4P against comparator

\begin{tabular}{|c|c|c|c|c|c|}
\hline \multirow[t]{2}{*}{ Outcome } & \multirow[t]{2}{*}{ Indicator } & \multicolumn{4}{|c|}{$\begin{array}{l}\text { Direction of effect and GRADE rating for } \\
\text { targeted and un-targeted outcomes }\end{array}$} \\
\hline & & $\begin{array}{l}\text { Target- } \\
\text { ed }\end{array}$ & $\begin{array}{l}\text { GRADE } \\
\text { rating }\end{array}$ & $\begin{array}{l}\text { Not-tar- } \\
\text { geted }\end{array}$ & $\begin{array}{l}\text { GRADE } \\
\text { rating }\end{array}$ \\
\hline \multirow{2}{*}{$\begin{array}{l}\text { Primary: Utiliza- } \\
\text { tion and delivery }\end{array}$} & Child immunization (likelihood of being vaccinated) & $\square$ & $\oplus \oplus \ominus \ominus$ & \multicolumn{2}{|c|}{ No evidence } \\
\hline & Child immunization: \% receiving BCG & - & $\oplus \oplus \ominus \ominus$ & \multicolumn{2}{|c|}{ No evidence } \\
\hline
\end{tabular}

Paying for performance to improve the delivery of health interventions in low- and middle-income countries (Review) 
Table 2. Meta-summary: Effects of P4P against comparator (Continued)

\begin{tabular}{|c|c|c|c|c|c|}
\hline & Child immunization: \% receiving DTP & - & $\oplus \oplus \ominus \ominus$ & \multicolumn{2}{|c|}{ No evidence } \\
\hline & Child immunization: \% fully vaccinated & $\square$ & $\oplus \oplus \ominus \ominus$ & \multicolumn{2}{|c|}{ No evidence } \\
\hline & Immunization during ANC - \% receiving tetanus injection & $\boldsymbol{\Delta}$ & $\oplus \oplus \ominus \ominus$ & - & $\oplus \oplus \oplus \ominus$ \\
\hline & Probability of any utilization (generic) & $\Delta$ & $\oplus \oplus \ominus \ominus$ & \multicolumn{2}{|c|}{ No evidence } \\
\hline & Antenatal care: $\%$ receiving at least one ANC & - & $\oplus \oplus \ominus \ominus$ & \multicolumn{2}{|c|}{ No evidence } \\
\hline & Antenatal care: \% receiving four or more ANC & - & $\oplus \oplus \ominus \ominus$ & \multicolumn{2}{|c|}{ No evidence } \\
\hline & Antenatal care: $\%$ receiving ANC in first trimester & $\boldsymbol{\Delta}$ & $\oplus \oplus \ominus \ominus$ & \multicolumn{2}{|c|}{ No evidence } \\
\hline & Child $(<5)$ curative visits (rates) & - & $\oplus \oplus \ominus \ominus$ & \multicolumn{2}{|c|}{ No evidence } \\
\hline & Family planning: \% using any method & - & $\oplus \oplus \ominus \ominus$ & \multicolumn{2}{|c|}{ No evidence } \\
\hline & Family planning: \% using modern methods & - & $\oplus \oplus \ominus \ominus$ & \multicolumn{2}{|c|}{ No evidence } \\
\hline & Institutional delivery (rates and coverage) & $\square$ & $\oplus \oplus \ominus \ominus$ & \multicolumn{2}{|c|}{ No evidence } \\
\hline & Postnatal care (rates and coverage) & $\boldsymbol{\nabla}$ & $\oplus \oplus \ominus \ominus$ & - & $\oplus \oplus \ominus \ominus$ \\
\hline \multirow{2}{*}{$\begin{array}{l}\text { Primary: Changes } \\
\text { in resource use }\end{array}$} & Equipment availability (composite score) & $\Delta$ & $\oplus \oplus \ominus \ominus$ & $\square$ & $\oplus \ominus \ominus \ominus$ \\
\hline & Medicine availability (composite score) & $\nabla$ & $\oplus \oplus \ominus \ominus$ & $\square$ & $\oplus \ominus \ominus \ominus$ \\
\hline \multirow{2}{*}{$\begin{array}{l}\text { Primary: Health } \\
\text { outcomes }\end{array}$} & Proportion of women breastfeeding & - & $\oplus \oplus \ominus \ominus$ & - & $\oplus \oplus \ominus \ominus$ \\
\hline & Reported illness in children (\%) & \multicolumn{2}{|c|}{ No evidence } & $\Delta$ & $\oplus \oplus \ominus \ominus$ \\
\hline \multirow{8}{*}{$\begin{array}{l}\text { Primary: Quality } \\
\text { of care }\end{array}$} & Background and physical assessment (score) & $\Delta$ & $\oplus \oplus \ominus \ominus$ & \multicolumn{2}{|c|}{ No evidence } \\
\hline & Knowledge Outcomes (index) & $\Delta$ & $\oplus \oplus \ominus \ominus$ & \multicolumn{2}{|c|}{ No evidence } \\
\hline & Counselling (score) & $\square$ & $\oplus \oplus \ominus \ominus$ & \multicolumn{2}{|c|}{ No evidence } \\
\hline & Immunizations quality (score) & $\Delta$ & $\oplus \oplus \ominus \ominus$ & \multicolumn{2}{|c|}{ No evidence } \\
\hline & Staff knowledge and skills (score) & $\Delta$ & $\oplus \oplus \ominus \ominus$ & $\square$ & $\oplus \ominus \ominus \ominus$ \\
\hline & Total quality family planning (score) & $\Delta$ & $\oplus \oplus \oplus \ominus$ & \multicolumn{2}{|c|}{ No evidence } \\
\hline & Total quality antenatal care (score) & $\Delta$ & $\oplus \oplus \oplus \ominus$ & \multicolumn{2}{|c|}{ No evidence } \\
\hline & Total quality composite (score) & $\Delta$ & $\oplus \oplus \ominus \ominus$ & \multicolumn{2}{|c|}{ No evidence } \\
\hline \multirow{4}{*}{$\begin{array}{l}\text { Secondary: Equi- } \\
\text { ty-consideration: } \\
\text { Evidence of differ- } \\
\text { ential impact on } \\
\text { different parts of } \\
\text { the population }\end{array}$} & Wealth related: Antenatal care (utilization) & - & $\oplus \oplus \ominus \ominus$ & \multicolumn{2}{|c|}{ No evidence } \\
\hline & Wealth related: Curative visits (utilization) & - & $\oplus \oplus \ominus \ominus$ & \multicolumn{2}{|c|}{ No evidence } \\
\hline & Wealth related: Family planning (utilization) & $\boldsymbol{\nabla}$ & $\oplus \oplus \ominus \ominus$ & \multicolumn{2}{|c|}{ No evidence } \\
\hline & Wealth related: Institutional delivery (utilization) & $\nabla$ & $\oplus \oplus \ominus \ominus$ & \multicolumn{2}{|c|}{ No evidence } \\
\hline
\end{tabular}


Table 2. Meta-summary: Effects of P4P against comparator (Continued)

\begin{tabular}{|c|c|c|c|c|}
\hline $\begin{array}{l}\text { Secondary: Im- } \\
\text { pacts on manage- } \\
\text { ment or informa- } \\
\text { tion systems (if } \\
\text { not a targeted } \\
\text { measure of perfor- } \\
\text { mance) }\end{array}$ & Facility and managerial autonomy (score) & $\oplus \oplus \ominus \ominus$ & $\square$ & $\oplus \ominus \ominus \ominus$ \\
\hline \multirow{4}{*}{$\begin{array}{l}\text { Secondary: Pa- } \\
\text { tient satisfaction } \\
\text { and acceptability }\end{array}$} & Cleanliness & No evidence & $\boldsymbol{\Delta}$ & $\oplus \oplus \ominus \ominus$ \\
\hline & Contact time & No evidence & $\Delta$ & $\oplus \oplus \ominus \ominus$ \\
\hline & Waiting time & $\oplus \ominus \ominus \ominus$ & $\Delta$ & $\oplus \oplus \ominus \ominus$ \\
\hline & Patient satisfaction with staff communication (index) & $\oplus \ominus \ominus \ominus$ & - & $\oplus \oplus \ominus \ominus$ \\
\hline \multirow{2}{*}{$\begin{array}{l}\text { Secondary: } \\
\text { Provider motiva- } \\
\text { tion, satisfaction, } \\
\text { absenteeism and } \\
\text { acceptability }\end{array}$} & Motivation (score) & No evidence & - & $\oplus \oplus \ominus \ominus$ \\
\hline & Satisfaction (score) & No evidence & - & $\oplus \oplus \ominus \ominus$ \\
\hline
\end{tabular}

\section{Direction of effect key}

$\Delta$ Desirable

$\boldsymbol{\nabla}$ Non-desirable

- Neutral

$\square \quad$ Uncertain

Certainty in evidence key

$\oplus \oplus \oplus \ominus \quad$ Moderate

$\oplus \oplus \ominus \ominus$ Low

$\oplus \ominus \ominus \ominus \quad$ Very low 
Table 3. Characteristics of included studies - table A

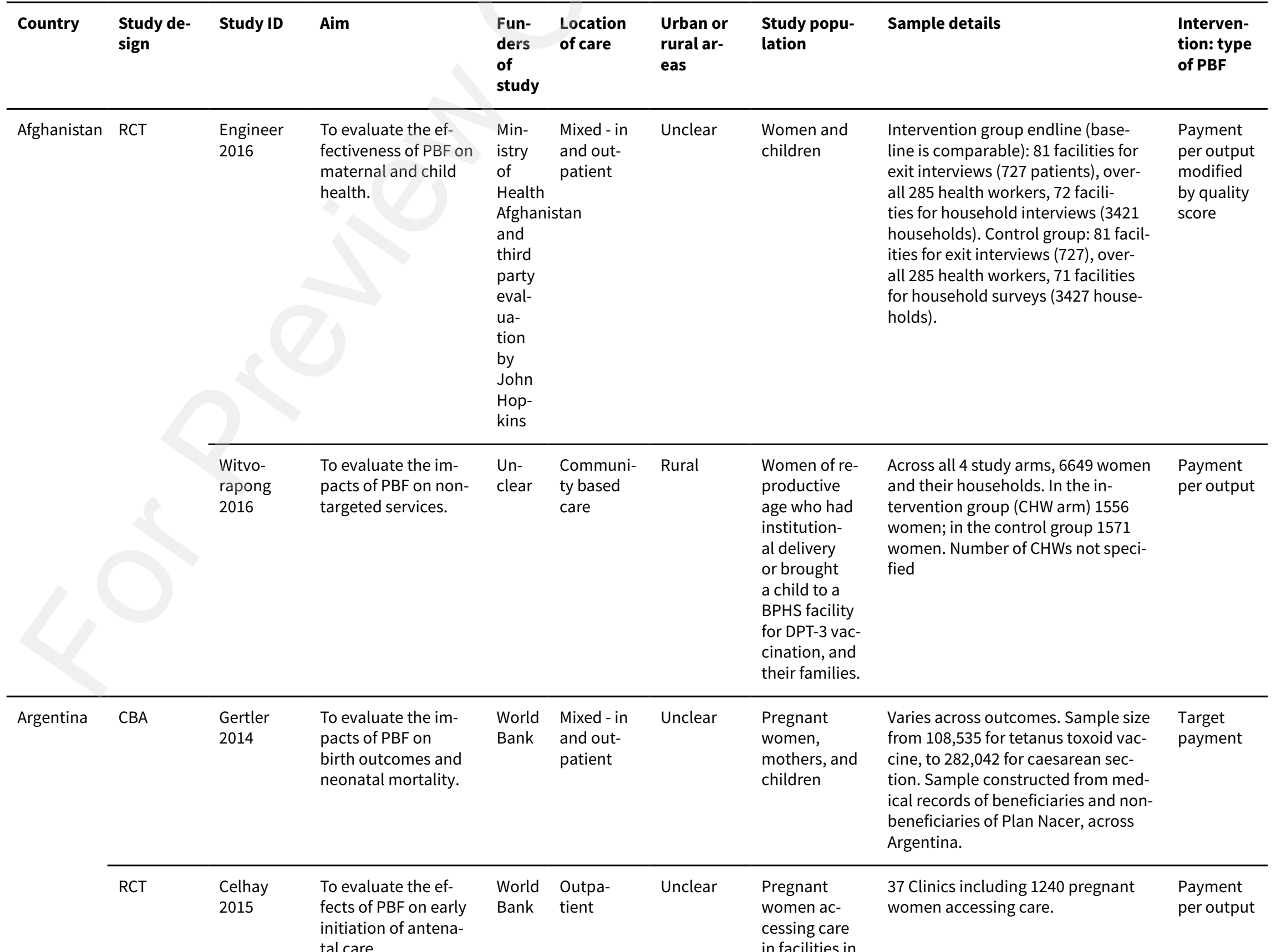




\begin{tabular}{|c|c|c|c|c|c|c|c|c|c|}
\hline & & & & & & & $\begin{array}{l}\text { Misiones, who } \\
\text { were benefi- } \\
\text { ciaries of Plan } \\
\text { Nacer at the } \\
\text { time of their } \\
\text { first visit. }\end{array}$ & & \\
\hline Benin & $\begin{array}{l}\text { Qua- } \\
\text { si/non- } \\
\text { random- } \\
\text { ized trial }\end{array}$ & $\begin{array}{l}\text { Lagarde } \\
2015\end{array}$ & $\begin{array}{l}\text { To identify causal } \\
\text { pathways of how } \\
\text { PBF may work and } \\
\text { evaluate impacts on } \\
\text { range of outcomes. }\end{array}$ & $\begin{array}{l}\text { World } \\
\text { Bank }\end{array}$ & $\begin{array}{l}\text { Mixed - in } \\
\text { and out- } \\
\text { patient }\end{array}$ & $\begin{array}{l}\text { Mixed - ur- } \\
\text { ban and } \\
\text { rural }\end{array}$ & $\begin{array}{l}\text { Patient } \\
\text { groups affect- } \\
\text { ed - appears } \\
\text { to be patients } \\
\text { using RMCH } \\
\text { services and } \\
\text { other curative } \\
\text { services (cu- } \\
\text { rative consul- } \\
\text { tations, HIV } \\
\text { treatment, IST } \\
\text { diagnosis and } \\
\text { treatment, TB } \\
\text { detection and } \\
\text { treatment) }\end{array}$ & $\begin{array}{l}135 \text { Health facilities including } 433 \\
\text { providers and } 3331 \text { patients }\end{array}$ & $\begin{array}{l}\text { Payment } \\
\text { per output } \\
\text { modified } \\
\text { by quality } \\
\text { score }\end{array}$ \\
\hline Brazil & ITS & $\begin{array}{l}\text { Viñuela } \\
2015\end{array}$ & $\begin{array}{l}\text { To explore if any sys- } \\
\text { tematic change in } \\
\text { outcome measures } \\
\text { can be attributed to } \\
\text { PBF }\end{array}$ & $\begin{array}{l}\text { World } \\
\text { Bank }\end{array}$ & Unclear & $\begin{array}{l}\text { Mixed - ur- } \\
\text { ban and } \\
\text { rural }\end{array}$ & Neonates & $\begin{array}{l}27 \text { states plus the federal district. } \\
\text { Other sample details unclear }\end{array}$ & $\begin{array}{l}\text { Perfor- } \\
\text { mance re- } \\
\text { lated pay }\end{array}$ \\
\hline $\begin{array}{l}\text { Burkina } \\
\text { Faso }\end{array}$ & CBA & $\begin{array}{l}\text { Steenland } \\
2017\end{array}$ & $\begin{array}{l}\text { To examine the effect } \\
\text { of PBF pilot } 2011 \text { to } \\
2013 \text { in Burkina Faso. }\end{array}$ & $\begin{array}{l}\text { World } \\
\text { Bank, } \\
\text { through } \\
\text { the } \\
\text { Health } \\
\text { Re- } \\
\text { sults } \\
\text { Inno- } \\
\text { va- } \\
\text { tion } \\
\text { Trust } \\
\text { Fund }\end{array}$ & $\begin{array}{l}\text { Mixed - in } \\
\text { and out- } \\
\text { patient }\end{array}$ & Rural & $\begin{array}{l}\text { Women ac- } \\
\text { cessing an- } \\
\text { tenatal and } \\
\text { postnatal care }\end{array}$ & $\begin{array}{l}186 \text { health providers in the } 3 \text { dis- } \\
\text { tricts, } 8074 \text { women in the analytic } \\
\text { sample }\end{array}$ & $\begin{array}{l}\text { Payment } \\
\text { per output } \\
\text { modified } \\
\text { by quality } \\
\text { and equity } \\
\text { score }\end{array}$ \\
\hline Burundi & CBA & $\begin{array}{l}\text { Bonfrer } \\
2014 a\end{array}$ & $\begin{array}{l}\text { To examine the stag- } \\
\text { gered rollout of PBF } \\
\text { in Burundi. }\end{array}$ & $\begin{array}{l}\text { Un- } \\
\text { clear }\end{array}$ & $\begin{array}{l}\text { Mixed - in } \\
\text { and out- } \\
\text { patient }\end{array}$ & Unclear & $\begin{array}{l}\text { Women, in- } \\
\text { fants and } \\
\text { households; }\end{array}$ & $\begin{array}{l}\text { For studying incentivized outcomes, } \\
\text { the population under study con- } \\
\text { sists: Phase } 1 \text { - } 274 \text { women who de- }\end{array}$ & $\begin{array}{l}\text { Payment } \\
\text { per output } \\
\text { modified }\end{array}$ \\
\hline
\end{tabular}




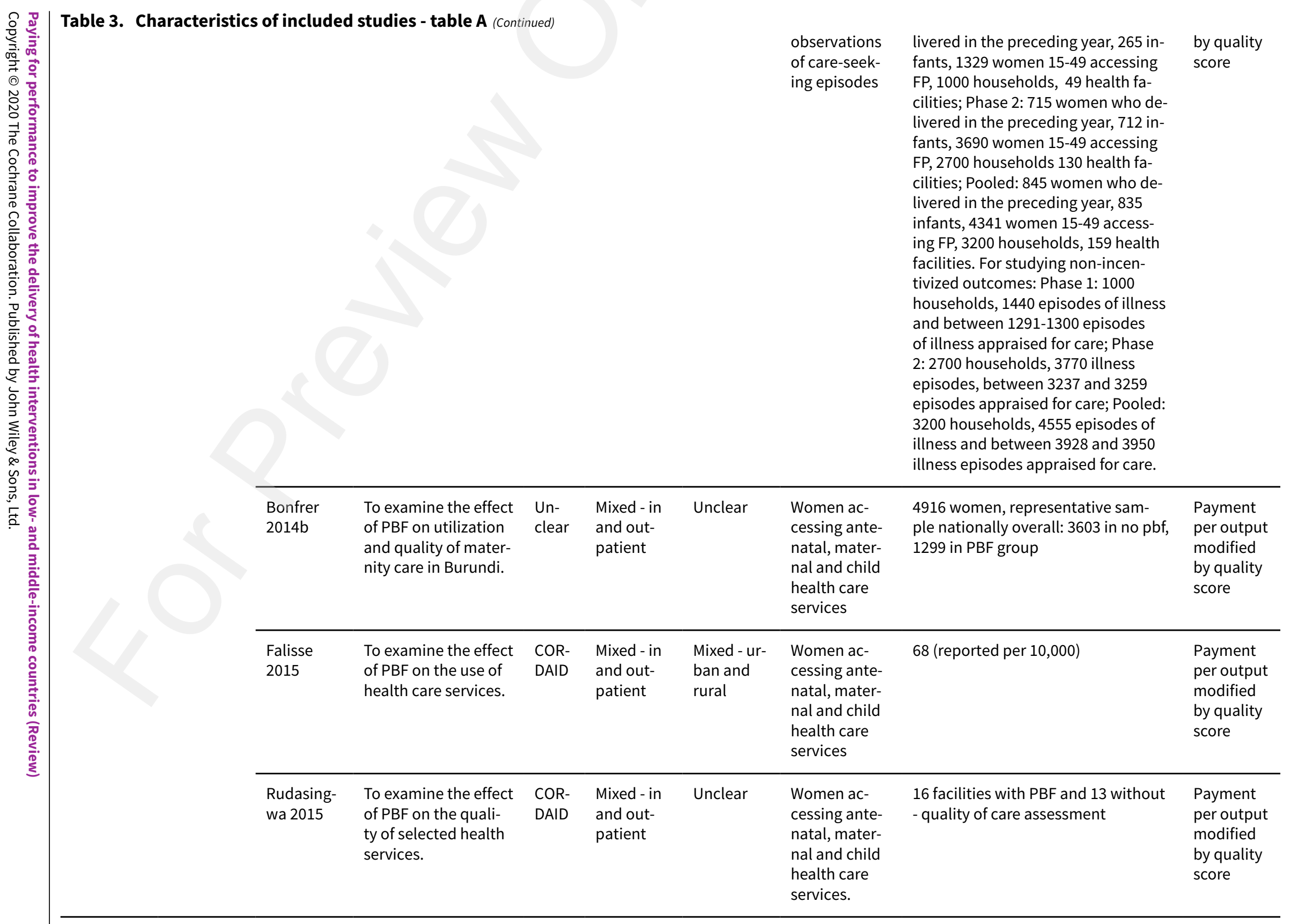




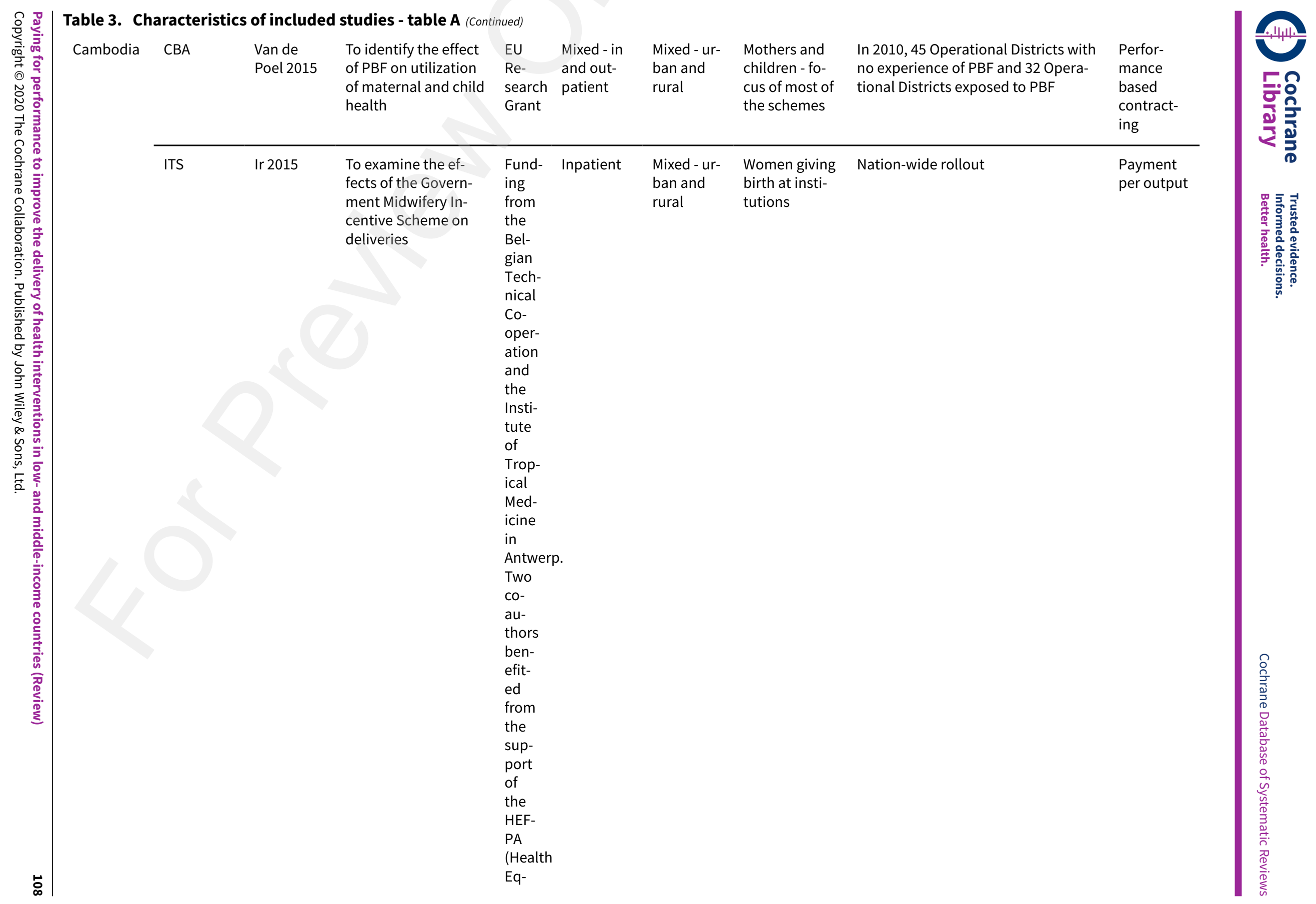




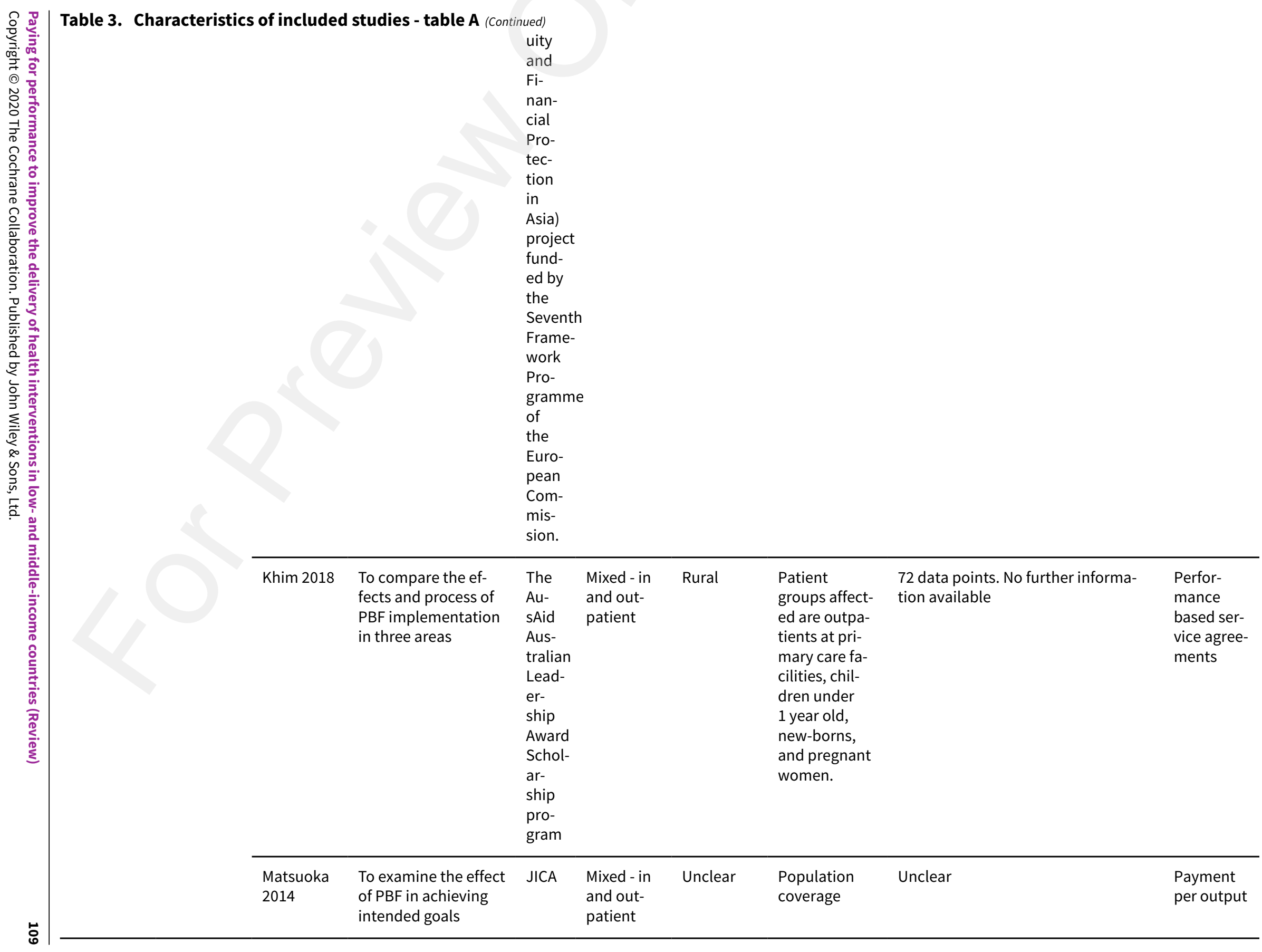




\begin{tabular}{|c|c|c|c|c|c|c|c|c|c|}
\hline Cameroon & $\begin{array}{l}\text { Qua- } \\
\text { si/non- } \\
\text { random- } \\
\text { ized trial }\end{array}$ & $\begin{array}{l}\text { De Walque } \\
2017\end{array}$ & $\begin{array}{l}\text { To estimate impact } \\
\text { of PBF on MCH ser- } \\
\text { vice coverage, quali- } \\
\text { ty of services }\end{array}$ & $\begin{array}{l}\text { World } \\
\text { Bank }\end{array}$ & $\begin{array}{l}\text { Mixed - in } \\
\text { and out- } \\
\text { patient }\end{array}$ & $\begin{array}{l}\text { Mixed - ur- } \\
\text { ban and } \\
\text { rural }\end{array}$ & $\begin{array}{l}\text { Pregnant } \\
\text { women and } \\
\text { mothers, chil- } \\
\text { dren under } 5\end{array}$ & $\begin{array}{l}434 \text { facilities, with } 185 \text { children, } \\
187 \text { caretakers, and } 258 \text { pregnant } \\
\text { women }\end{array}$ & $\begin{array}{l}\text { Payment } \\
\text { per output } \\
\text { modified } \\
\text { by quality } \\
\text { and equity } \\
\text { score }\end{array}$ \\
\hline & CBA & Zang 2015 & $\begin{array}{l}\text { To explore the effects } \\
\text { of the PBF scheme in } \\
\text { Littoral region. }\end{array}$ & $\begin{array}{l}\text { World } \\
\text { Bank }\end{array}$ & $\begin{array}{l}\text { Mixed - in } \\
\text { and out- } \\
\text { patient }\end{array}$ & $\begin{array}{l}\text { Mixed - ur- } \\
\text { ban and } \\
\text { rural }\end{array}$ & $\begin{array}{l}\text { Health facili- } \\
\text { ties and preg- } \\
\text { nant women } \\
\text { and children } \\
\text { under } 5 \text { - un- } \\
\text { clear if further } \\
\text { inclusion/ex- } \\
\text { clusion crite- } \\
\text { ria apply }\end{array}$ & 40 health facilities out of 52. & $\begin{array}{l}\text { Payment } \\
\text { per output } \\
\text { modified } \\
\text { by quality } \\
\text { and equity } \\
\text { score }\end{array}$ \\
\hline China & CBA & Yao 2008 & $\begin{array}{l}\text { To examine the ef- } \\
\text { fects of PBF on TB } \\
\text { case detection and } \\
\text { treatment }\end{array}$ & $\begin{array}{l}\text { COMDIS } \\
\text { - DFID }\end{array}$ & $\begin{array}{l}\text { Outpa- } \\
\text { tient }\end{array}$ & Rural & $\begin{array}{l}\text { Tuberculosis } \\
\text { patients - sus- } \\
\text { pected and di- } \\
\text { agnosed de- } \\
\text { pending on } \\
\text { outcome }\end{array}$ & $\begin{array}{l}\text { Total sample not reported. New } \\
\text { smear-positive cases in intervention } \\
\text { group } 3190 \text { at baseline and } 5449 \text { dur- } \\
\text { ing intervention. In control group, } \\
1864 \text { at baseline, and } 3745 \text { during in- } \\
\text { tervention period. }\end{array}$ & $\begin{array}{l}\text { Payment } \\
\text { per output }\end{array}$ \\
\hline & ITS & $\begin{array}{l}\text { Chang } \\
2017\end{array}$ & $\begin{array}{l}\text { To assess the effects } \\
\text { of PBF on adverse } \\
\text { drug reaction report- } \\
\text { ing }\end{array}$ & $\begin{array}{l}\text { No } \\
\text { fund- } \\
\text { ing }\end{array}$ & Inpatient & Unclear & $\begin{array}{l}\text { All patients } \\
\text { admitted to } \\
\text { First Affiliat- } \\
\text { ed Hospital } \\
\text { of Zhengzhou } \\
\text { Universi- } \\
\text { ty (Henan } \\
\text { Province) }\end{array}$ & $\begin{array}{l}\text { Total patient reports included } \\
2882.128 \text { in pre-intervention peri- } \\
\text { od (2006-2009); } 753 \text { in first interven- } \\
\text { tion }(2009-2011) ; 2001 \text { in second in- } \\
\text { tervention }(2012-2014)\end{array}$ & $\begin{array}{l}\text { Payment } \\
\text { per output }\end{array}$ \\
\hline & & Wu 2014 & $\begin{array}{l}\text { To examine the ef- } \\
\text { fects of PBF (with } \\
\text { mismeasurement) in } \\
\text { China }\end{array}$ & $\begin{array}{l}\text { Un- } \\
\text { clear }\end{array}$ & $\begin{array}{l}\text { Mixed - in } \\
\text { and out- } \\
\text { patient }\end{array}$ & Urban & $\begin{array}{l}\text { Patients at- } \\
\text { tending the } \\
\text { hospital un- } \\
\text { der study }\end{array}$ & $\begin{array}{l}10 \text { wards with } 142 \text { physicians and } \\
5230 \text { patients }\end{array}$ & $\begin{array}{l}\text { Target } \\
\text { payment }\end{array}$ \\
\hline & & $\begin{array}{l}\text { Liu and } \\
\text { Mills } 2005\end{array}$ & $\begin{array}{l}\text { To assess the effects } \\
\text { of PBF on productivi- } \\
\text { ty, cost recovery and } \\
\text { hospital revenue }\end{array}$ & $\begin{array}{l}\text { UNDP/ } \\
\text { WB/ } \\
\text { WHO } \\
\text { Spe- } \\
\text { cial } \\
\text { Pro- }\end{array}$ & Inpatient & Unclear & $\begin{array}{l}\text { Appendicitis } \\
\text { and pneumo- } \\
\text { nia patients }\end{array}$ & $\begin{array}{l}6 \text { hospitals, } 2303 \text { patients ( } 1161 \text { ap- } \\
\text { pendicitis patients and } 1142 \text { pneu- } \\
\text { monia patients) }\end{array}$ & $\begin{array}{l}\text { Payment } \\
\text { per output }\end{array}$ \\
\hline
\end{tabular}




\begin{tabular}{|c|c|c|c|c|c|c|c|c|c|c|}
\hline 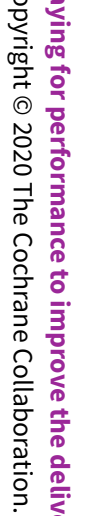 & 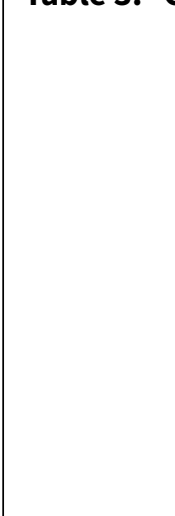 & & & $\sqrt{2}$ & $\begin{array}{l}\text { gramme } \\
\text { for } \\
\text { Re- } \\
\text { search } \\
\text { and } \\
\text { Train- } \\
\text { ing in } \\
\text { Trop- } \\
\text { ical } \\
\text { Dis- } \\
\text { eases } \\
+ \\
\text { DfID }\end{array}$ & & & & & \\
\hline 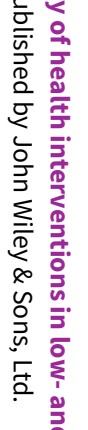 & & $\begin{array}{l}\text { Qua- } \\
\text { si/Non- } \\
\text { random- } \\
\text { ized trial }\end{array}$ & $\begin{array}{l}\text { Pow- } \\
\text { ell-Jack- } \\
\text { son } 2014\end{array}$ & $\begin{array}{l}\text { To assess the im- } \\
\text { pacts of a PBF policy } \\
\text { experiment in Ningx- } \\
\text { ia }\end{array}$ & $\begin{array}{l}\text { Bill } \\
\text { and } \\
\text { Melin- } \\
\text { da } \\
\text { Gates } \\
\text { Foun- } \\
\text { da- } \\
\text { tion } \\
\text { and } \\
\text { EC } \\
\text { grant. }\end{array}$ & $\begin{array}{l}\text { Mixed - in } \\
\text { and out- } \\
\text { patient }\end{array}$ & Rural & $\begin{array}{l}\text { Patients, no } \\
\text { further details }\end{array}$ & $\begin{array}{l}75 \text { towns, } 917 \text { villages, } 357,400 \\
\text { households and } 30,393 \text { individuals } \\
\text { included in surveys }\end{array}$ & $\begin{array}{l}\text { Payment } \\
\text { per out- } \\
\text { put and } \\
\text { for target }\end{array}$ \\
\hline 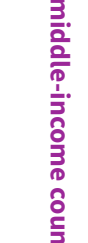 & & & Sun 2014 & $\begin{array}{l}\text { To test alternatives } \\
\text { to fee for service to } \\
\text { inform policy }\end{array}$ & $\begin{array}{l}\text { EU } \\
\text { Re- } \\
\text { search } \\
\text { Grant }\end{array}$ & $\begin{array}{l}\text { Outpa- } \\
\text { tient }\end{array}$ & Rural & $\begin{array}{l}\text { Patients at- } \\
\text { tending vil- } \\
\text { lage clinics } \\
\text { and township } \\
\text { health centres }\end{array}$ & $\begin{array}{l}\text { 29-township health centres (14 in- } \\
\text { tervention, } 15 \text { control); } 3162 \text { pre- } \\
\text { scriptions (Intervention: } 572 \text { town- } \\
\text { ship health centre, and } 1040 \text { village } \\
\text { clinic. Control: } 527 \text { township health } \\
\text { centre, and } 1023 \text { village clinic.) }\end{array}$ & $\begin{array}{l}\text { Capitation } \\
\text { and PBF }\end{array}$ \\
\hline 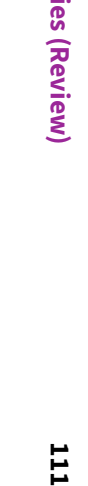 & & $\mathrm{RCT}$ & Yip 2014 & $\begin{array}{l}\text { To assess the effects } \\
\text { of reforming provider } \\
\text { payments from fee } \\
\text { for service to capi- } \\
\text { tation with P4P on } \\
\text { prescribing, health } \\
\text { expenditure, outpa- } \\
\text { tient visits and pa- } \\
\text { tient satisfaction }\end{array}$ & $\begin{array}{l}\text { Bill } \\
\text { and } \\
\text { Melin- } \\
\text { da } \\
\text { Gates } \\
\text { Foun- } \\
\text { da- } \\
\text { tion; } \\
\text { EU } \\
\text { Health- } \\
\text { F2-2009- } \\
\text { HEF- }\end{array}$ & $\begin{array}{l}\text { Mixed - in } \\
\text { and out- } \\
\text { patient } \\
\text {-223166- }\end{array}$ & Rural & $\begin{array}{l}\text { All patients } \\
\text { requiring an- } \\
\text { tibiotic based } \\
\text { care }\end{array}$ & $\begin{array}{l}16866 \text { patients, with } 440473 \\
\text { episodes of care at township health } \\
\text { centres, and } 714661 \text { episodes of care } \\
\text { at village posts }\end{array}$ & $\begin{array}{l}\text { Capitation } \\
\text { and PBF }\end{array}$ \\
\hline
\end{tabular}




\begin{tabular}{|c|c|c|c|c|c|c|c|c|c|}
\hline & & & 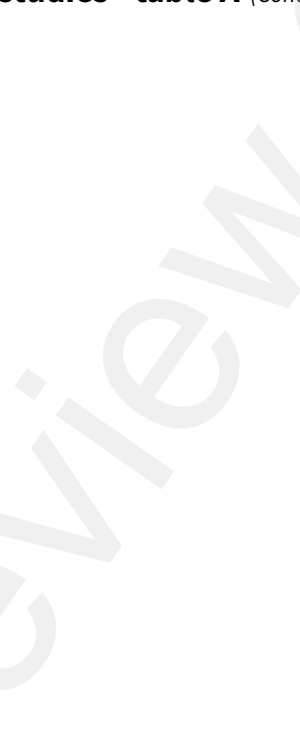 & $\begin{array}{l}\text { PA; } \\
\text { World } \\
\text { Bank } \\
\text { Strate-- } \\
\text { gic } \\
\text { Im- } \\
\text { pact } \\
\text { Eval- } \\
\text { ua- } \\
\text { tion } \\
\text { Fund } \\
\text { pro- } \\
\text { vided } \\
\text { seed } \\
\text { fund- } \\
\text { ing at } \\
\text { plan- } \\
\text { ning } \\
\text { stage }\end{array}$ & & & & & \\
\hline Congo & $\mathrm{CBA}$ & $\begin{array}{l}\text { Zeng } \\
2018 a\end{array}$ & $\begin{array}{l}\text { To evaluate the im- } \\
\text { pacts of PBF on re- } \\
\text { productive, maternal } \\
\text { and child care. }\end{array}$ & $\begin{array}{l}\text { World } \\
\text { Bank }\end{array}$ & $\begin{array}{l}\text { Mixed - in } \\
\text { and out- } \\
\text { patient }\end{array}$ & $\begin{array}{l}\text { Mixed - ur- } \\
\text { ban and } \\
\text { rural }\end{array}$ & $\begin{array}{l}\text { Mothers with } \\
\text { children un- } \\
\text { der } 2 \text { years } \\
\text { old }\end{array}$ & $\begin{array}{l}100 \text { enumeration zones, with } 1325 \\
\text { households, } 1307 \text { mothers and } 1859 \\
\text { children at endline ( } 1349 \text { house- } \\
\text { holds, } 1344 \text { mothers and } 1841 \text { chil- } \\
\text { dren at baseline) }\end{array}$ & $\begin{array}{l}\text { Payment } \\
\text { per output } \\
\text { modified } \\
\text { by quality } \\
\text { score }\end{array}$ \\
\hline \multirow[t]{2}{*}{ DRC } & CBA & $\begin{array}{l}\text { Soeters } \\
2011\end{array}$ & $\begin{array}{l}\text { To explore changes } \\
\text { due to PBF in indica- } \\
\text { tors between } 2005 \\
\text { and } 2008 \text { in the con- } \\
\text { trol and intervention } \\
\text { groups }\end{array}$ & $\begin{array}{l}\text { Un- } \\
\text { clear }\end{array}$ & $\begin{array}{l}\text { Mixed - in } \\
\text { and out- } \\
\text { patient }\end{array}$ & Unclear & $\begin{array}{l}\text { Mothers and } \\
\text { young chil- } \\
\text { dren }\end{array}$ & $\begin{array}{l}240 \text { households in intervention } \\
\text { group and } 200 \text { in control group at } \\
\text { baseline. }\end{array}$ & $\begin{array}{l}\text { Payment } \\
\text { per output } \\
\text { modified } \\
\text { by quality } \\
\text { score }\end{array}$ \\
\hline & $\mathrm{RCT}$ & $\begin{array}{l}\text { Huillery } \\
2017\end{array}$ & $\begin{array}{l}\text { To evaluate impact } \\
\text { of OBF scheme on } \\
\text { utilization, efficiency }\end{array}$ & $\begin{array}{l}\text { Un- } \\
\text { clear }\end{array}$ & $\begin{array}{l}\text { Mixed - in } \\
\text { and out- } \\
\text { patient }\end{array}$ & $\begin{array}{l}\text { Mixed - ur- } \\
\text { ban and } \\
\text { rural }\end{array}$ & $\begin{array}{l}\text { Women and } \\
\text { children }\end{array}$ & $\begin{array}{l}87 \text { health areas, } 123 \text { facilities, } 332 \text { fa- } \\
\text { cility staff, } 1014 \text { patients and } 9234 \\
\text { households }\end{array}$ & $\begin{array}{l}\text { Payment } \\
\text { per output }\end{array}$ \\
\hline $\begin{array}{l}\text { El Sal- } \\
\text { vador }\end{array}$ & $\mathrm{CBA}$ & $\begin{array}{l}\text { Bernal } \\
2018\end{array}$ & $\begin{array}{l}\text { To identify the im- } \\
\text { pacts of results } \\
\text { based aid on delivery } \\
\text { of services and effec- } \\
\text { tiveness }\end{array}$ & IADB & $\begin{array}{l}\text { Mixed - in } \\
\text { and out- } \\
\text { patient }\end{array}$ & Unclear & $\begin{array}{l}\text { Low income } \\
\text { mothers and } \\
\text { children }\end{array}$ & Unclear & $\begin{array}{l}\text { Results } \\
\text { based aid }\end{array}$ \\
\hline
\end{tabular}




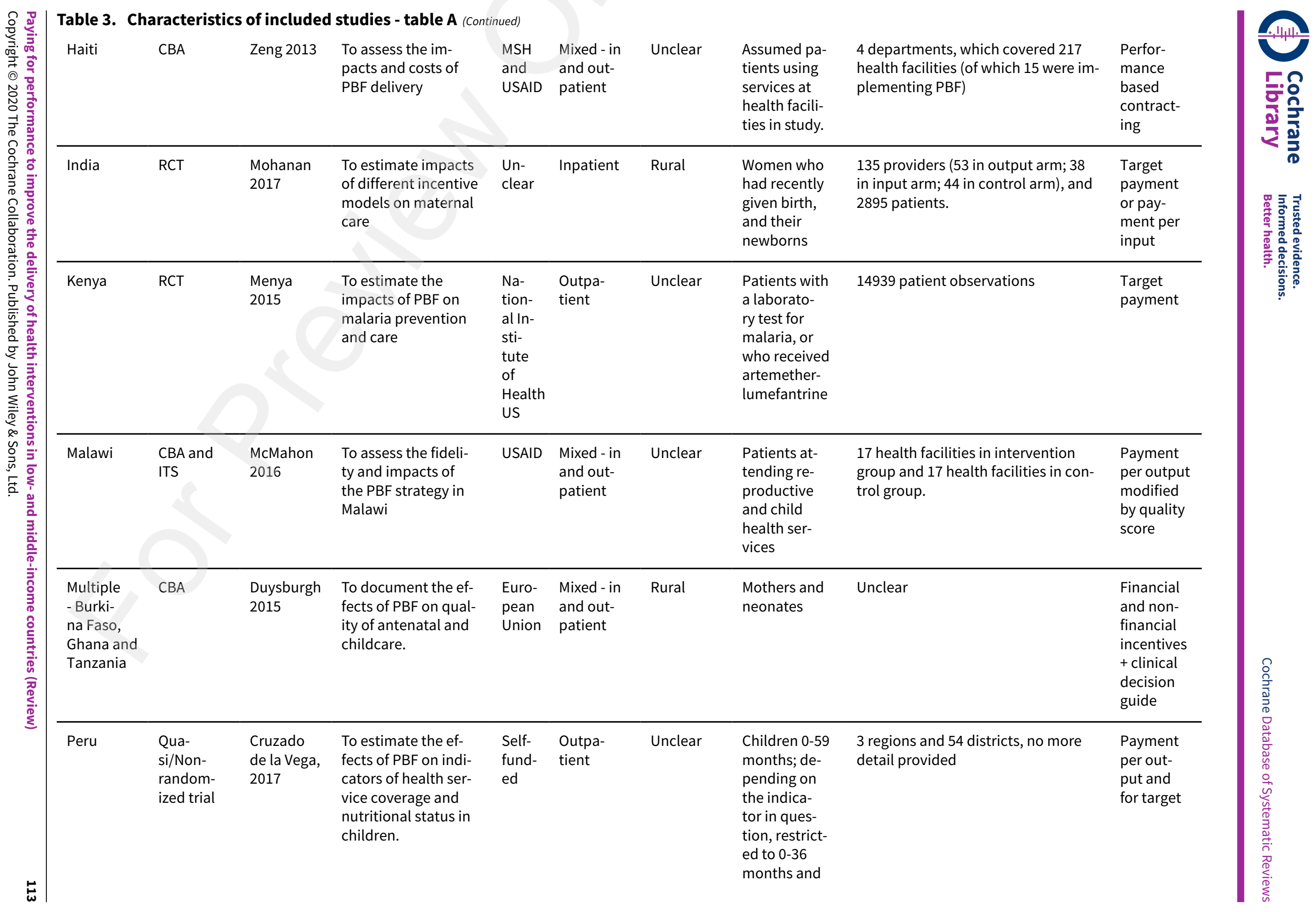




\begin{tabular}{|c|c|c|c|c|c|c|c|c|c|c|}
\hline & & & & & & & $\begin{array}{l}0-24 \text { months, } \\
\text { or preg- } \\
\text { nant women } \\
\text { between } \\
2010-2014\end{array}$ & & & 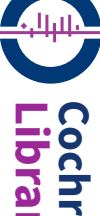 \\
\hline \multirow[t]{3}{*}{$\begin{array}{l}\text { Philip- } \\
\text { pines }\end{array}$} & \multirow[t]{3}{*}{$\mathrm{RCT}$} & $\begin{array}{l}\text { Peabody } \\
2011\end{array}$ & $\begin{array}{l}\text { To examine the effect } \\
\text { of bonus payments } \\
\text { on quality of care. }\end{array}$ & \multicolumn{2}{|c|}{$\begin{array}{l}\text { US Inpatient } \\
\text { Na- } \\
\text { tion- } \\
\text { al In- } \\
\text { sti- } \\
\text { tutes } \\
\text { of } \\
\text { Health } \\
\text { through } \\
\text { an } \\
\text { R01 } \\
\text { grant } \\
\text { (No. } \\
\text { HD042117). }\end{array}$} & Unclear & $\begin{array}{l}\text { Physicians ac- } \\
\text { tive at hospi- } \\
\text { tals in study - } \\
\text { approx. } 3 \text { per } \\
\text { hospital }\end{array}$ & 30 hospitals overall in the study. & $\begin{array}{l}\text { Target } \\
\text { payment }\end{array}$ & 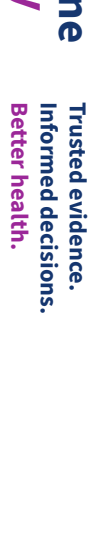 \\
\hline & & $\begin{array}{l}\text { Quimbo } \\
2016\end{array}$ & $\begin{array}{l}\text { To investigate long- } \\
\text { term effects of the } \\
\text { QIDS intervention on } \\
\text { quality of care. }\end{array}$ & $\begin{array}{l}\text { US } \\
\text { Na- } \\
\text { tion- } \\
\text { al In- } \\
\text { sti- } \\
\text { tutes } \\
\text { of } \\
\text { Health } \\
\text { throug } \\
\text { an } \\
\text { R01 } \\
\text { grant } \\
\text { (No. } \\
\text { HD042 }\end{array}$ & $\begin{array}{l}\text { Inpatient } \\
\text { 17). }\end{array}$ & Unclear & $\begin{array}{l}\text { Health } \\
\text { providers en- } \\
\text { gaged in QIDS }\end{array}$ & $\begin{array}{l}81 \text { of the } 89 \text { doctors who previously } \\
\text { participated, including new doctors: } \\
43\end{array}$ & $\begin{array}{l}\text { Target } \\
\text { payment }\end{array}$ & 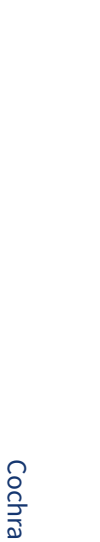 \\
\hline & & $\begin{array}{l}\text { Wagner } \\
2018\end{array}$ & $\begin{array}{l}\text { To estimate effect } \\
\text { of QIDS bonus pay- } \\
\text { ment intervention in } \\
\text { comparison to an in- } \\
\text { creased access inter- } \\
\text { vention and to a con- } \\
\text { trol. }\end{array}$ & $\begin{array}{l}\text { US } \\
\text { Na- } \\
\text { tion- } \\
\text { al In- } \\
\text { sti- } \\
\text { tute } \\
\text { for } \\
\text { Child } \\
\text { Health }\end{array}$ & Inpatient & Unclear & $\begin{array}{l}\text { Children af- } \\
\text { fected by } \\
\text { pneumo- } \\
\text { nia and di- } \\
\text { arrhoea, fol- } \\
\text { lowed-up }\end{array}$ & $\begin{array}{l}3121 \text { children affected treated at one } \\
\text { of the } 30 \text { facilities ( } 10 \text { per interven- } \\
\text { tion and control) within. Study in- } \\
\text { cludes } 479 \text { children in bonus inter- } \\
\text { vention arm, } 447 \text { in expanded inter- } \\
\text { vention and } 467 \text { in control. }\end{array}$ & $\begin{array}{l}\text { Target } \\
\text { payment }\end{array}$ & 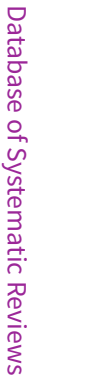 \\
\hline
\end{tabular}




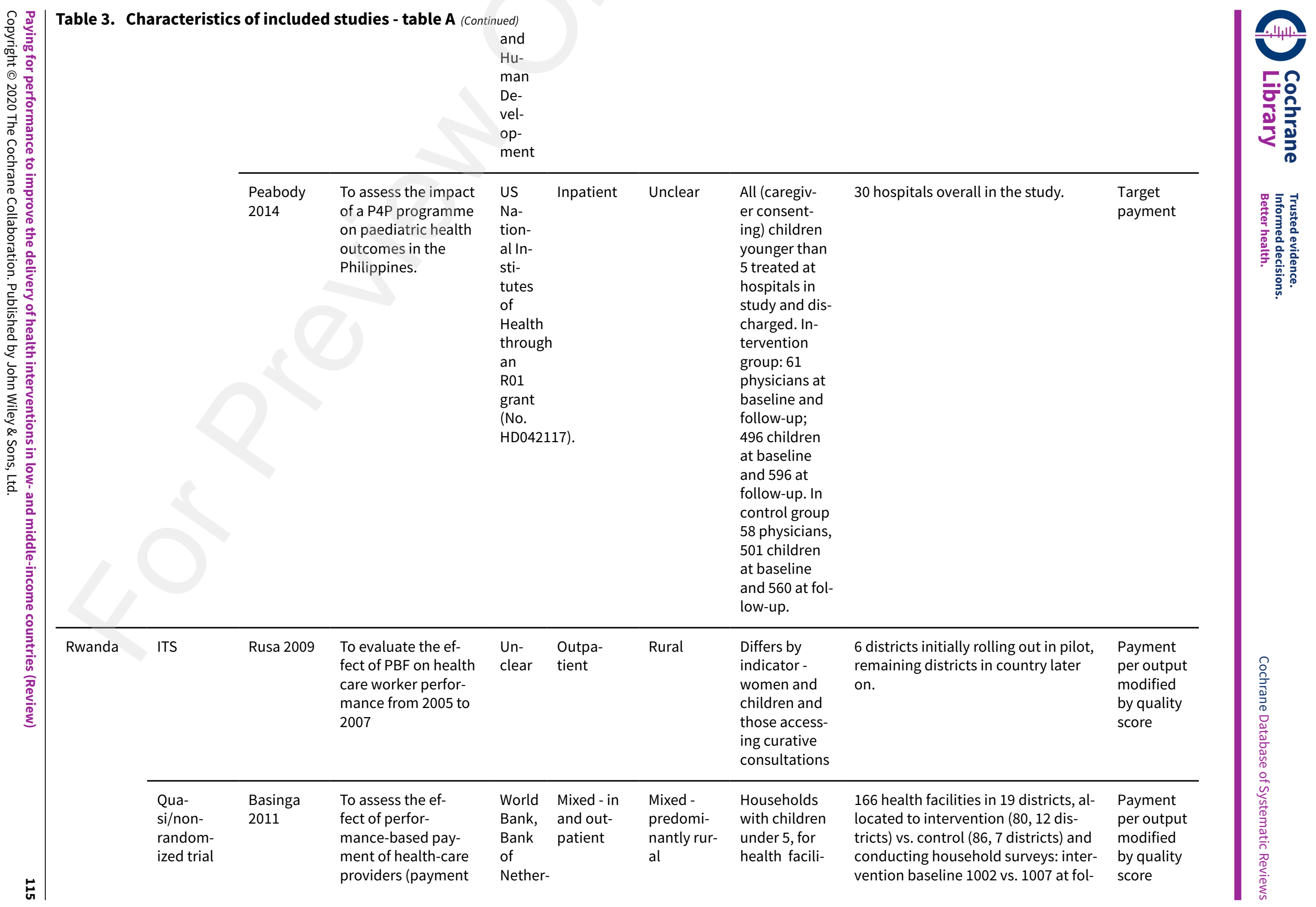


Table 3. Characteristics of included studies - table A (Continued)

for performance; lands

P4P) on use and Part-

ties all $166 \mathrm{fa}$

low-up; for control 1114 at baseline

quality of child and ner-

maternal care ser- ship

vices in health-care Pro-

facilities in Rwanda gram,

the

British

Eco-

nom-

and

So-

cial

Re-

search

Coun-

cil,

the

Gov-

ern-

ment

of

Rwan-

da,

and

the

World

Bank's

Span-

ish

Im-

pact

Eval-

ua-

tion

Fund

\begin{tabular}{|c|c|c|c|c|c|c|c|}
\hline $\begin{array}{l}\text { Lannes } \\
2016\end{array}$ & $\begin{array}{l}\text { To examine distribu- } \\
\text { tional impacts of PBF } \\
\text { in Rwanda. }\end{array}$ & $\begin{array}{l}\text { World } \\
\text { Bank, } \\
\text { Bank } \\
\text { of } \\
\text { Nether- } \\
\text { lands } \\
\text { Part- }\end{array}$ & $\begin{array}{l}\text { Mixed - in } \\
\text { and out- } \\
\text { patient }\end{array}$ & $\begin{array}{l}\text { Mixed - } \\
\text { predomi- } \\
\text { nantly rur- } \\
\text { al }\end{array}$ & $\begin{array}{l}\text { Households } \\
\text { with children } \\
\text { under } 5 \text {, for } \\
\text { health facili- } \\
\text { ties all } 166 \text { fa- } \\
\text { cilities }\end{array}$ & $\begin{array}{l}166 \text { health facilities, } 2145 \text { house- } \\
\text { holds and person observations for } \\
\text { three populations, which feed into } \\
\text { diverse analyses: married women } \\
\text { (15-49) for family planning analysis, } \\
\text { women with pregnancies in last } 2 \\
\text { years for maternal service analysis, }\end{array}$ & $\begin{array}{l}\text { Payment } \\
\text { per output } \\
\text { modified } \\
\text { by quality } \\
\text { score }\end{array}$ \\
\hline
\end{tabular}


Table 3. Characteristics of included studies - table A (Continued)

Fund

\begin{tabular}{lll}
\hline Priede- & To examine the ef- & Un \\
man Skiles & fects of PBF on equi- & clear \\
2013 & ty in maternal health & \\
& service use
\end{tabular}

Mixed - in

$\begin{array}{ll}\text { Mixed - } & \text { Women aged } \\ \text { predomi- } & 18-49 \\ \text { nantly rur- } & \\ & \end{array}$
patient nantly rur-

7899 women 15-49years old - 4477 in intervention and 3422 in control,

across 12 intervention and 7 control districts, clustered into 86 intervention clusters and 64 control clusters.

\begin{tabular}{|c|c|c|c|c|c|c|c|}
\hline $\begin{array}{l}\text { Priede- } \\
\text { man Skiles } \\
2015\end{array}$ & $\begin{array}{l}\text { To estimate the ef- } \\
\text { fects of Rwanda's } \\
\text { PBF program on the } \\
\text { prevalence of child- }\end{array}$ & $\begin{array}{l}\text { Un- } \\
\text { clear }\end{array}$ & $\begin{array}{l}\text { Outpa- } \\
\text { tient }\end{array}$ & $\begin{array}{l}\text { Mixed - } \\
\text { predomi- } \\
\text { nantly rur- } \\
\text { al }\end{array}$ & $\begin{array}{l}\text { Children un- } \\
\text { der } 5\end{array}$ & $\begin{array}{l}5781 \text { children less than } 5 \text { years of age } \\
\text { at the time of each survey who lived } \\
\text { in either an intervention (3307) or } \\
\text { comparison district (2474). }\end{array}$ & $\begin{array}{l}\text { Payment } \\
\text { per output } \\
\text { modified }\end{array}$ \\
\hline
\end{tabular}




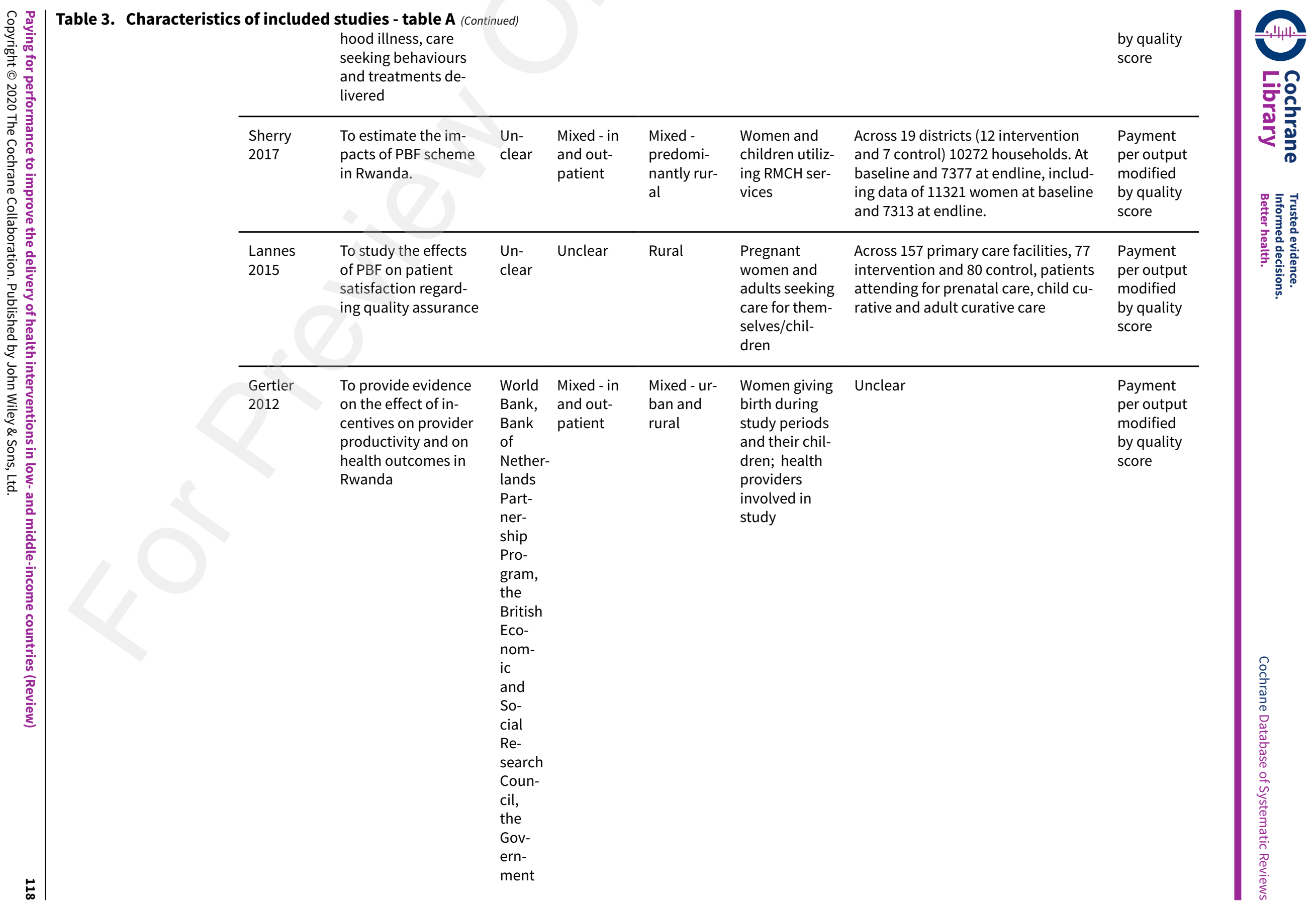




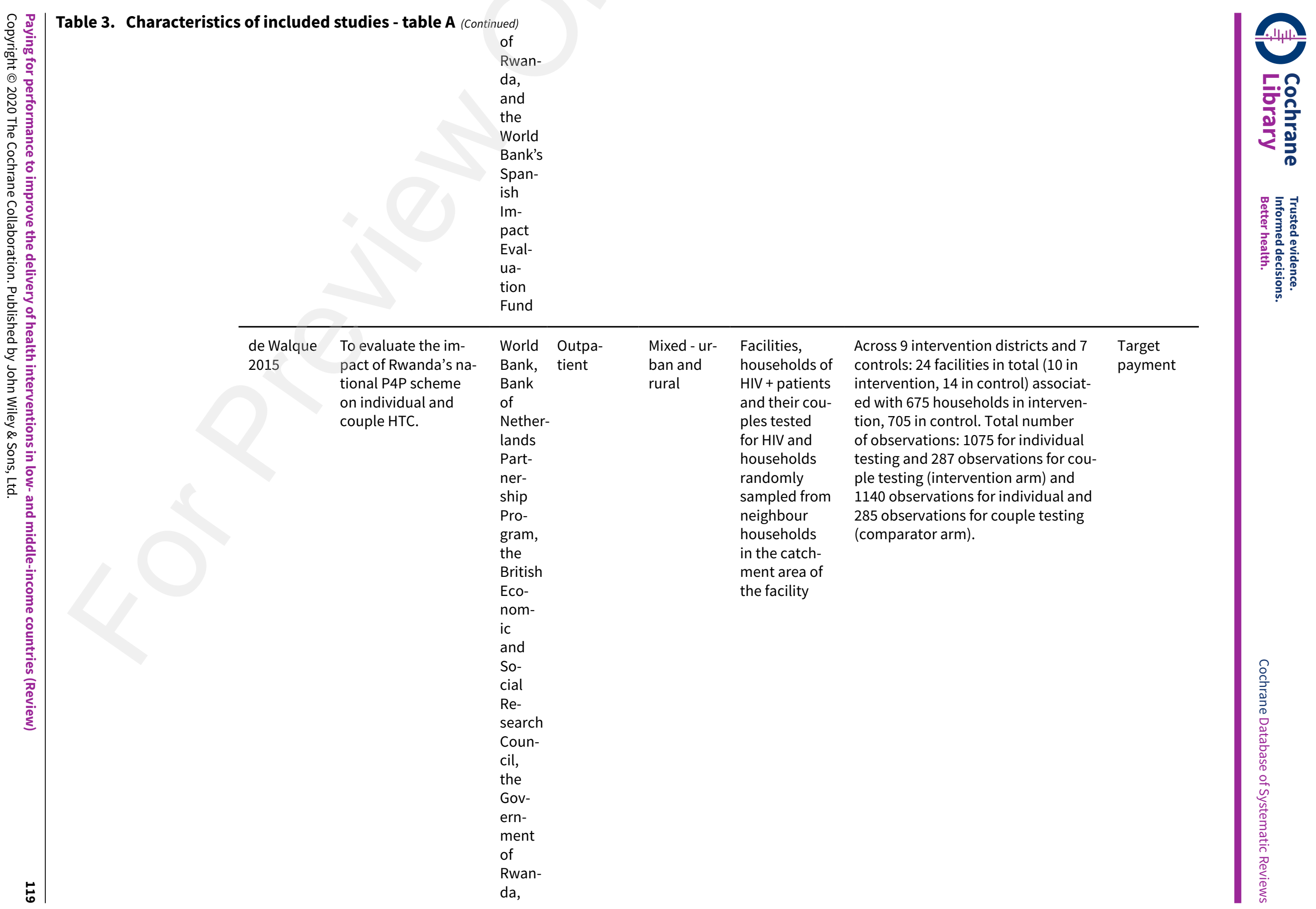




\begin{tabular}{|c|c|c|c|c|c|c|c|c|c|c|}
\hline & & & $\frac{4}{4+5}$ & $\begin{array}{l}\text { and } \\
\text { the } \\
\text { World } \\
\text { Bank's } \\
\text { Span- } \\
\text { ish } \\
\text { Im- } \\
\text { pact } \\
\text { Eval- } \\
\text { ua- } \\
\text { tion } \\
\text { Fund }\end{array}$ & & & & & & 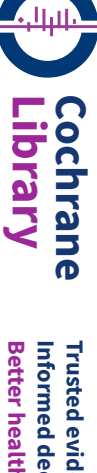 \\
\hline & RCT & $\begin{array}{l}\text { Shapira } \\
2018\end{array}$ & $\begin{array}{l}\text { To evaluate the im- } \\
\text { pact of tying pay- } \\
\text { ments to perfor- } \\
\text { mance }\end{array}$ & $\begin{array}{ll}\text { World } & \mathrm{N} \\
\text { Bank } & \mathrm{c} \\
& \mathrm{n} \\
& \mathrm{h} \\
\mathrm{c} & \end{array}$ & $\begin{array}{l}\text { Mixed - } \\
\text { commu- } \\
\text { nity and } \\
\text { health fa- } \\
\text { cility }\end{array}$ & $\begin{array}{l}\text { Mixed - ur- } \\
\text { ban and } \\
\text { rural }\end{array}$ & $\begin{array}{l}\text { Mothers and } \\
\text { community } \\
\text { health work- } \\
\text { ers }\end{array}$ & $\begin{array}{l}\text { Baseline sample } 2005 \text { community } \\
\text { health workers ( } 84 \% \text { of target). } 2200 \\
\text { CHW at follow-up and } 197 \text { coopera- } \\
\text { tive presidents. Baseline household } \\
\text { sample } 2376 \text {, follow-up sample in- } \\
\text { cluded } 2157 \text { of original sample and } \\
\text { additionally } 2343 \text { of newly sampled } \\
\text { women with recent births or preg- } \\
\text { nancy in the village. }\end{array}$ & $\begin{array}{l}\text { Payment } \\
\text { per output }\end{array}$ & 岁 \\
\hline Swaziland & $\begin{array}{l}\text { Qua- } \\
\text { si/non- } \\
\text { random- } \\
\text { ized trial }\end{array}$ & $\begin{array}{l}\text { Kliner } \\
2015\end{array}$ & $\begin{array}{l}\text { Compare outcomes } \\
\text { for patients with a } \\
\text { treatment support- } \\
\text { ed receiving incen- } \\
\text { tives vs. those pa- } \\
\text { tients with a non-in- } \\
\text { centivised supported }\end{array}$ & $\begin{array}{l}\text { Glob- } \\
\text { al } \\
\text { Fund, } \mathrm{c} \\
\text { COMDIS, } \\
\text { DfID }\end{array}$ & $\begin{array}{l}\text { Communi- } \\
\text { ty based } \\
\text { care }\end{array}$ & Rural & $\begin{array}{l}\text { Tuberculosis } \\
\text { patients }\end{array}$ & $\begin{array}{l}1077 \text { tuberculosis ( } 161 \text { in interven- } \\
\text { tion and } 916 \text { in control) patients di- } \\
\text { agnosed between study dates and } \\
\text { living in the communities of treat- } \\
\text { ment supporters }\end{array}$ & $\begin{array}{l}\text { Payment } \\
\text { per output }\end{array}$ & \\
\hline Tanzania & CBA & $\begin{array}{l}\text { Binyaruka } \\
2015\end{array}$ & $\begin{array}{l}\text { To examine the ef- } \\
\text { fect of a government } \\
\text { P4P scheme on util- } \\
\text { isation, quality, and } \\
\text { user costs of health } \\
\text { services in Tanzania. }\end{array}$ & $\begin{array}{l}\text { Gov- } \\
\text { ern- } \\
\text { ment } \\
\text { of } \\
\text { Nor- } \\
\text { way, } \\
\text { grant } \\
\text { num- } \\
\text { bers: } \\
\text { TAN-3108 } \\
\text { and } \\
\text { TAN } \\
\text { 13/0005. } \\
\text { http:// }\end{array}$ & $\begin{array}{l}\text { Mixed - in } \\
\text { and out- } \\
\text { patient } \\
8\end{array}$ & $\begin{array}{l}\text { Mixed - ur- } \\
\text { ban and } \\
\text { rural }\end{array}$ & $\begin{array}{l}\text { Patients and } \\
\text { households } \\
\text { of women } \\
\text { accessing } \\
\text { care in study } \\
\text { health facili- } \\
\text { ties. }\end{array}$ & $\begin{array}{l}1500 \text { patients and } 3000 \text { households } \\
\text { surveyed across } 11 \text { districts, } 150 \\
\text { health facilities }\end{array}$ & $\begin{array}{l}\text { Target } \\
\text { payment }\end{array}$ & 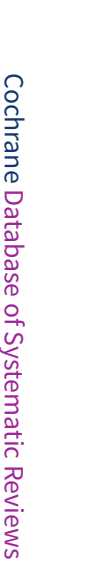 \\
\hline
\end{tabular}




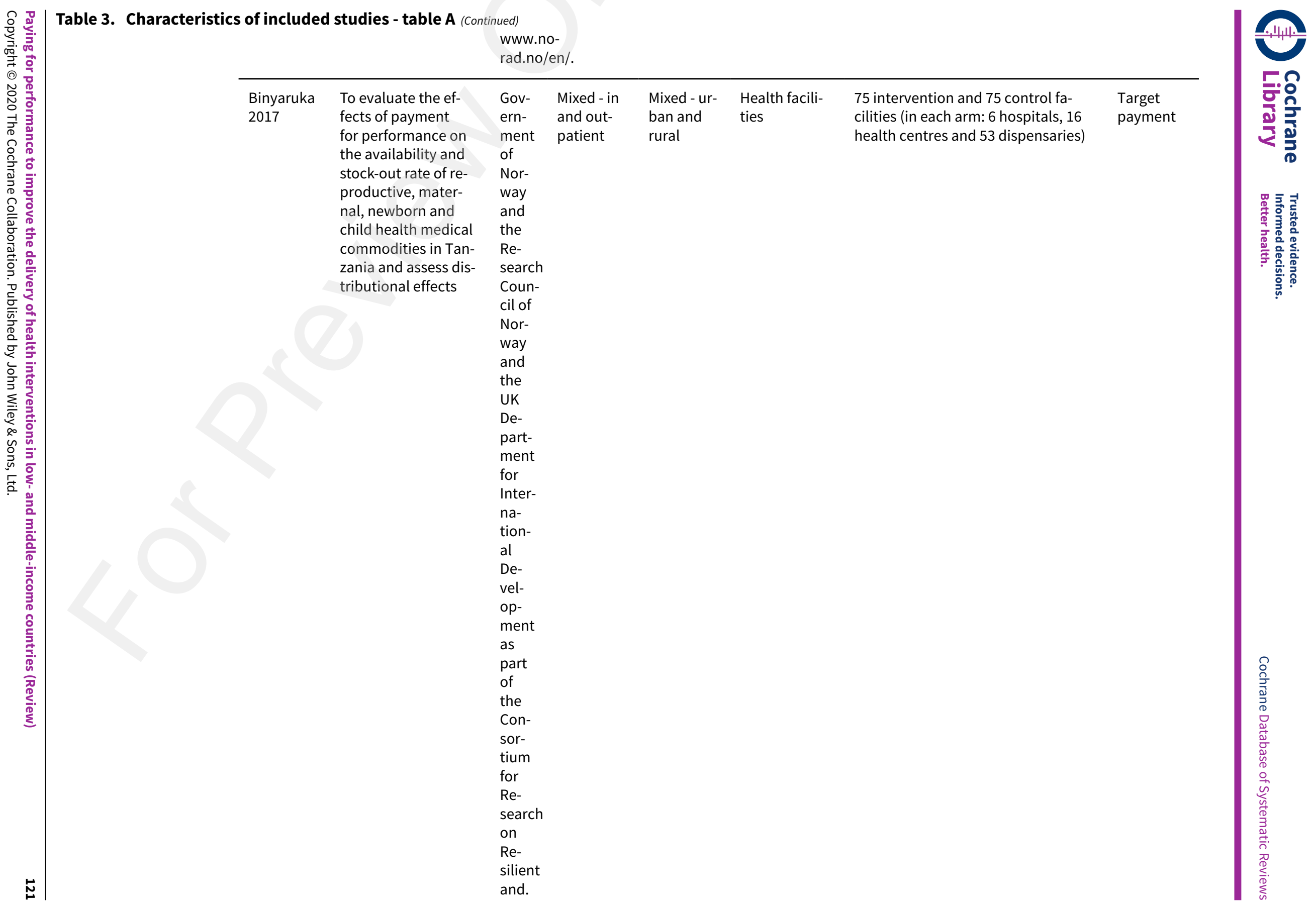




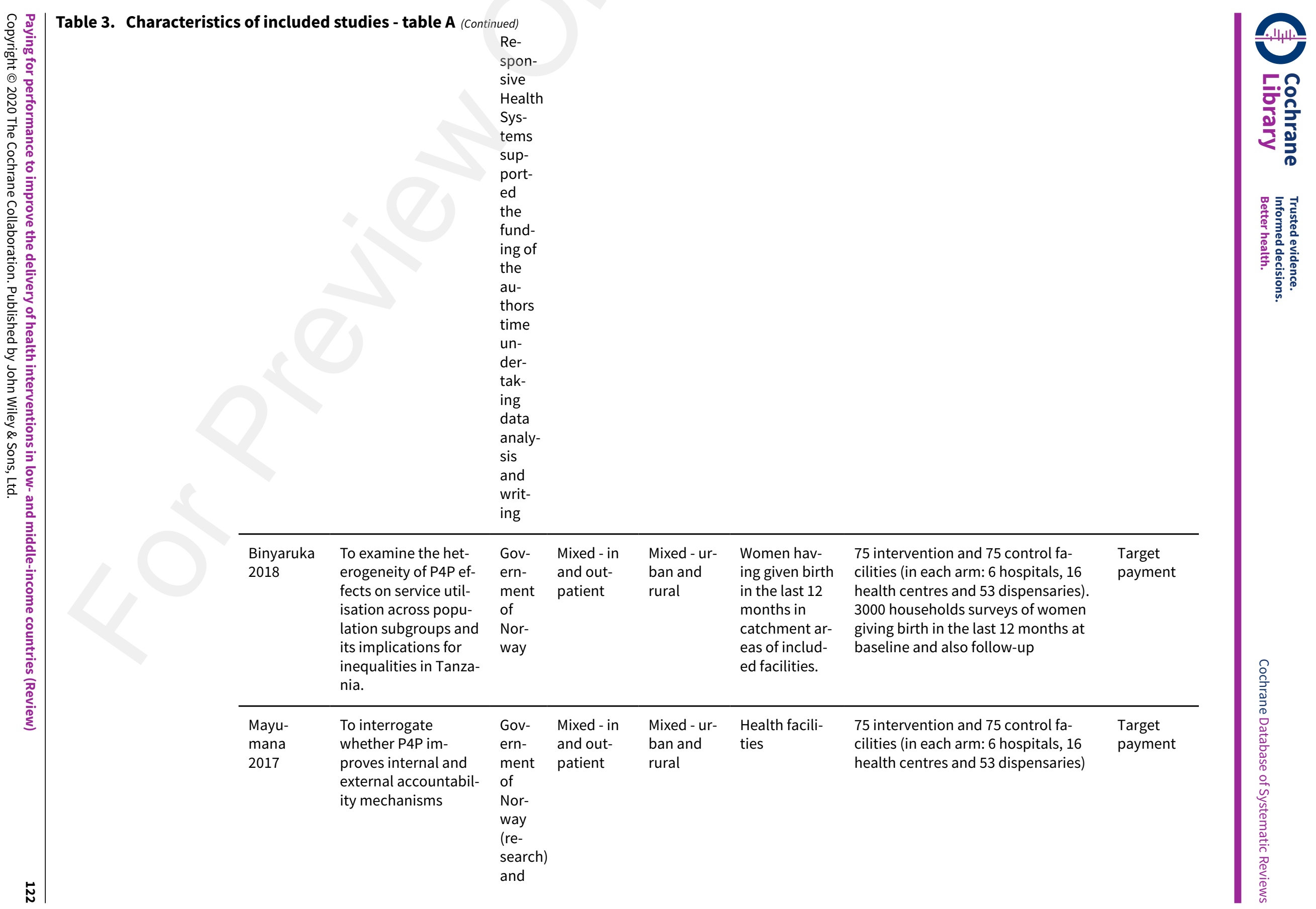


Table 3. Characteristics of included studies - table A (Continued)

tion)

\begin{tabular}{|c|c|c|c|c|c|c|c|c|}
\hline $\begin{array}{l}\text { Qua- } \\
\text { si/non- } \\
\text { random- } \\
\text { ized trial }\end{array}$ & $\begin{array}{l}\text { Brock } \\
2018\end{array}$ & $\begin{array}{l}\text { To compare the val- } \\
\text { ue of non-monetary } \\
\text { gifts (immediate un- } \\
\text { conditional, delayed } \\
\text { unconditional, con- } \\
\text { ditional) as a way } \\
\text { to improve health }\end{array}$ & $\begin{array}{l}\text { Mary- } \\
\text { land } \\
\text { Agri- } \\
\text { cul- } \\
\text { tur- } \\
\text { al ex- } \\
\text { ten- }\end{array}$ & $\begin{array}{l}\text { Outpa- } \\
\text { tient }\end{array}$ & Urban & $\begin{array}{l}\text { Health } \\
\text { providers } \\
\text { engaged in } \\
\text { study and pa- } \\
\text { tients treated }\end{array}$ & $\begin{array}{l}\text { Intervention group: } 21 \text { providers and } \\
940 \text { patients; Unconditional gift } 23 \\
\text { providers, } 1155 \text { patients; Delayed } \\
\text { unconditional gift } 25 \text { providers and } \\
1167 \text { patients; Control } 25 \text { providers } \\
\text { and } 1176 \text { patients. }\end{array}$ & $\begin{array}{l}\text { Condition- } \\
\text { al provi- } \\
\text { sion of } \\
\text { material } \\
\text { goods }\end{array}$ \\
\hline
\end{tabular}

to improve health ten-

worker performance sion

sta-

tion

-

Gov-

ment

of

Nor-

way,

World

Bank

\begin{tabular}{|c|c|c|c|c|c|c|c|c|c|}
\hline \multirow[t]{3}{*}{ Zambia } & ITS & $\begin{array}{l}\text { Chansa } \\
2015\end{array}$ & $\begin{array}{l}\text { To evaluate the ef- } \\
\text { fects of the PBF pre- } \\
\text { pilot in Katete dis- } \\
\text { trict }\end{array}$ & $\begin{array}{l}\text { World } \\
\text { Bank }\end{array}$ & $\begin{array}{l}\text { Mixed - in } \\
\text { and out- } \\
\text { patient }\end{array}$ & $\begin{array}{l}\text { Mixed - ur- } \\
\text { ban and } \\
\text { rural }\end{array}$ & $\begin{array}{l}\text { Women ac- } \\
\text { cessing RM- } \\
\mathrm{NCH} \text { services } \\
\text { and children. }\end{array}$ & $\begin{array}{l}25 \text { health facilities, including } 6 \text { health } \\
\text { posts, } 18 \text { rural health centres and } \\
\text { one urban health centre. }\end{array}$ & $\begin{array}{l}\text { Payment } \\
\text { per output } \\
\text { modified } \\
\text { by quality } \\
\text { score }\end{array}$ \\
\hline & $\mathrm{RCT}$ & $\begin{array}{l}\text { Friedman } \\
2016 a\end{array}$ & $\begin{array}{l}\text { To provide an esti- } \\
\text { mate of PBF impacts } \\
\text { vs. input financing } \\
\text { vs. pure control }\end{array}$ & $\begin{array}{l}\text { World } \\
\text { Bank }\end{array}$ & $\begin{array}{l}\text { Mixed - in } \\
\text { and out- } \\
\text { patient }\end{array}$ & Unclear & $\begin{array}{l}\text { Differs by out- } \\
\text { come - moth- } \\
\text { ers or children }\end{array}$ & $\begin{array}{l}10 \text { PBF intervention districts, } 10 \\
\text { matched financing and equipment } \\
\text { districts, and } 10 \text { control districts }\end{array}$ & $\begin{array}{l}\text { Payment } \\
\text { per output } \\
\text { modified } \\
\text { by quality } \\
\text { score }\end{array}$ \\
\hline & & Shen 2017 & $\begin{array}{l}\text { To estimate effects } \\
\text { of PBF scheme on } \\
\text { health worker moti- }\end{array}$ & $\begin{array}{l}\text { World } \\
\text { Bank }\end{array}$ & Unclear & Unclear & $\begin{array}{l}\text { Three differ- } \\
\text { ent groups } \\
\text { of providers: }\end{array}$ & $\begin{array}{l}186 \text { health centres ( } 86 \text { in PBF group, } \\
49 \text { in enhanced financing group and } \\
51 \text { in pure control group) and } 683\end{array}$ & $\begin{array}{l}\text { Payment } \\
\text { per output } \\
\text { modified }\end{array}$ \\
\hline
\end{tabular}




\begin{tabular}{|c|c|c|c|c|c|c|c|c|c|}
\hline & & & $\begin{array}{l}\text { vation, job satisfac- } \\
\text { tion and staff attri- } \\
\text { tion }\end{array}$ & & & & $\begin{array}{l}\text { those in the } \\
\text { PBF facili- } \\
\text { ties, those in } \\
\text { enhanced fi- } \\
\text { nancing con- } \\
\text { trol and the } \\
\text { pure control. } \\
\text { Patients af- } \\
\text { fected would } \\
\text { be those at- } \\
\text { tending the } \\
\text { participating } \\
\text { facilities. }\end{array}$ & $\begin{array}{l}\text { staff in total (baseline: } 147 \text { in PBF, } 87 \\
\text { in finance control, } 92 \text { in pure control; } \\
\text { endline: } 166 \text { PBF, finance control 92, } \\
\text { pure control 99) }\end{array}$ & $\begin{array}{l}\text { by quality } \\
\text { score }\end{array}$ \\
\hline \multirow[t]{2}{*}{ Zimbabwe } & CBA & Das, 2017 & $\begin{array}{l}\text { To establish impact } \\
\text { of PBF on ANC ser- } \\
\text { vice and process out- } \\
\text { comes }\end{array}$ & $\begin{array}{l}\text { No } \\
\text { fund- } \\
\text { ing }\end{array}$ & $\begin{array}{l}\text { Mixed - in } \\
\text { and out- } \\
\text { patient }\end{array}$ & Rural & $\begin{array}{l}\text { Mothers to be } \\
\text { in facilities se- } \\
\text { lected }\end{array}$ & $\begin{array}{l}705 \text { total facilities ( } 374 \text { intervention: } \\
105 \text { baseline, } 116 \text { follow-up, } 331 \text { con- } \\
\text { trol: } 84 \text { baseline, } 82 \text { follow-up) and } \\
\text { research set } 41 \text { facilities in panel in- } \\
\text { tervention, } 36 \text { facilities in panel con- } \\
\text { trol. } 1011 \text { clients total ( } 565 \text { interven- } \\
\text { tion baseline, } 414 \text { intervention fol- } \\
\text { low-up, } 446 \text { control baseline, } 336 \\
\text { control follow-up) and research set: } \\
\text { intervention } 208 \text { baseline, } 200 \text { fol- } \\
\text { low-up, control } 177 \text { baseline and } 174 \\
\text { follow-up }\end{array}$ & $\begin{array}{l}\text { Payment } \\
\text { per output } \\
\text { modified } \\
\text { by quali- } \\
\text { ty and sat- } \\
\text { isfaction } \\
\text { score }\end{array}$ \\
\hline & $\begin{array}{l}\text { Qua- } \\
\text { si/Non- } \\
\text { random- } \\
\text { ized trial }\end{array}$ & $\begin{array}{l}\text { Friedman } \\
2016 \mathrm{~b}\end{array}$ & $\begin{array}{l}\text { To identify the ef- } \\
\text { fects of the RBF pilot } \\
\text { program on the uti- } \\
\text { lization and quality } \\
\text { of maternal and child } \\
\text { health services as } \\
\text { well as its effects on } \\
\text { health system func- } \\
\text { tioning. }\end{array}$ & $\begin{array}{l}\text { World } \\
\text { Bank }\end{array}$ & $\begin{array}{l}\text { Mixed - in } \\
\text { and out- } \\
\text { patient }\end{array}$ & Unclear & $\begin{array}{l}\text { Households } \\
\text { and patients } \\
\text { seeking RMCH } \\
\text { care }\end{array}$ & $\begin{array}{l}197 \text { health facilities at baseline, } 222 \\
\text { at follow up. } 597 \text { health worker inter- } \\
\text { views at baseline, } 415 \text { at follow up. } \\
\text { Patient exit interviews: for ANC } 1864 \\
\text { at baseline and } 550 \text { at follow-up; for } \\
\text { child health } 1865 \text { at baseline and } 844 \\
\text { at follow-up. } 1610 \text { household sur- } \\
\text { veys at baseline and } 1836 \text { at follow } \\
\text { up. }\end{array}$ & $\begin{array}{l}\text { Payment } \\
\text { per output } \\
\text { modified } \\
\text { by quality } \\
\text { and equity } \\
\text { score }\end{array}$ \\
\hline
\end{tabular}

Table 4. Characteristics of included studies - table B

\begin{tabular}{|c|c|c|c|c|c|c|c|c|}
\hline Country & $\begin{array}{l}\text { Study de- } \\
\text { sign }\end{array}$ & Study ID & $\begin{array}{l}\text { Interven- } \\
\text { tion: type }\end{array}$ & $\begin{array}{l}\text { Con- } \\
\text { trol or }\end{array}$ & $\begin{array}{l}\text { Data } \\
\text { collec- }\end{array}$ & $\begin{array}{l}\text { Time peri- } \\
\text { od }\end{array}$ & Analysis & $\begin{array}{l}\text { Outcomes } \\
\text { reported }\end{array}$ \\
\hline
\end{tabular}




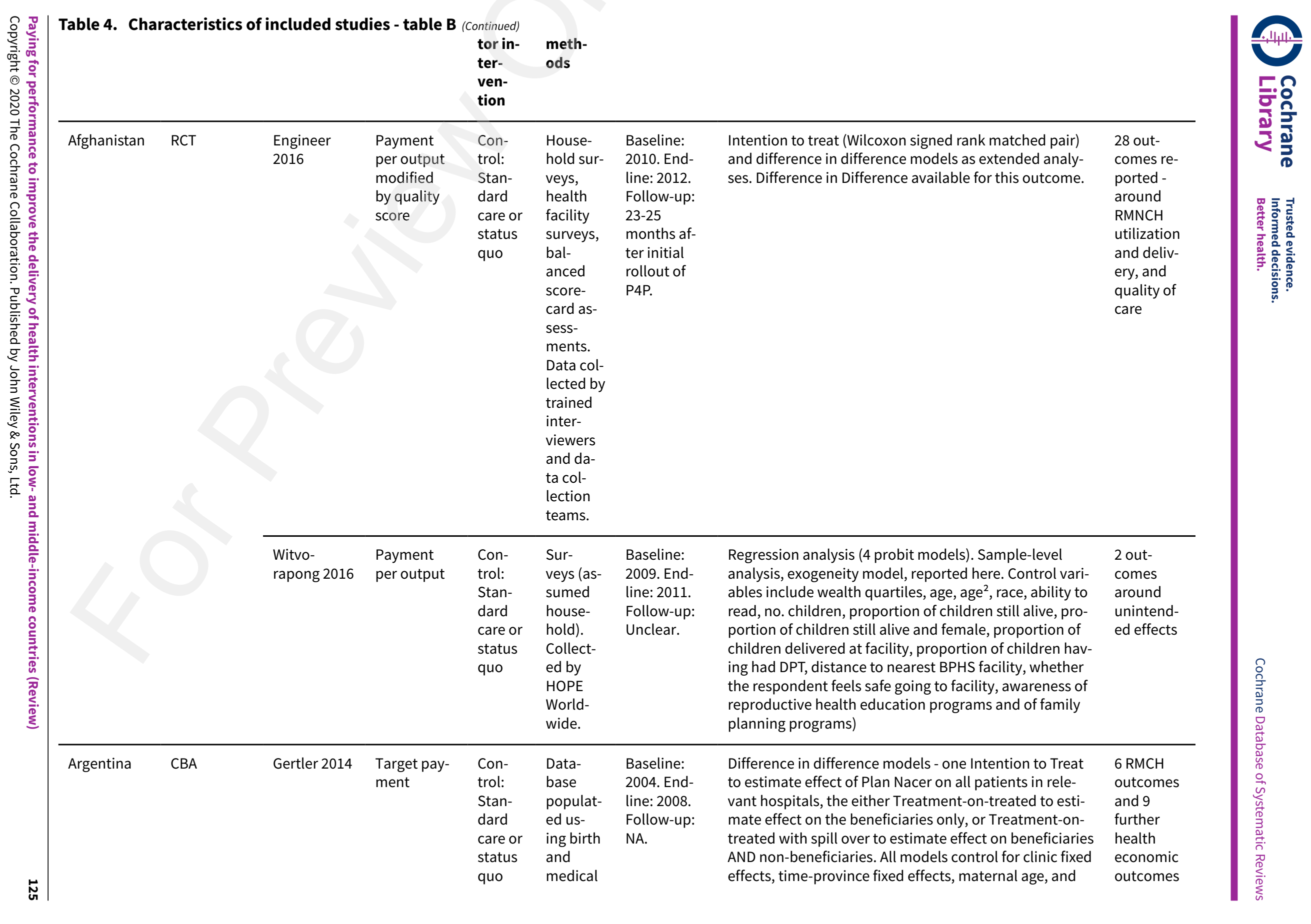


ficiary

status,

pharma-

ceutical

records,

admin-

istrative

records,

popula-

tion cen-

sus.

\begin{tabular}{|c|c|c|c|c|c|c|c|}
\hline RCT & Celhay 2015 & $\begin{array}{l}\text { Payment } \\
\text { per output }\end{array}$ & $\begin{array}{l}\text { Com- } \\
\text { para- } \\
\text { tor: } \\
\text { Stan- } \\
\text { dard } \\
\text { care } \\
\text { under } \\
\text { Plan } \\
\text { Nacer }\end{array}$ & $\begin{array}{l}\text { Patient } \\
\text { records } \\
\text { from } \\
\text { clinics } \\
\text { and hos- } \\
\text { pitals. }\end{array}$ & $\begin{array}{l}\text { Baseline: (i) } \\
\text { a 16-months } \\
\text { pre-inter- } \\
\text { vention pe- } \\
\text { riod from } \\
\text { January } \\
2009 \text { to April } \\
2010 \text {, (ii) an } \\
\text { 8- month in- } \\
\text { tervention } \\
\text { period from } \\
\text { May } 2010 \text { to } \\
\text { December } \\
2010 \text {, (iii) a } \\
15-m o n t h \\
\text { "post-in- } \\
\text { tervention } \\
\text { period I" } \\
\text { from Janu- } \\
\text { ary } 2011 \text { to } \\
\text { March } 2012 \\
\text { and (iv) a } \\
\text { 9-month } \\
\text { "post-inter- } \\
\text { vention pe- } \\
\text { riod II" from } \\
\text { April } 2012 \\
\text { to Decem- } \\
\text { ber } 2012 \text {. } \\
\text { Endline: } 15 \\
\text { months post } \\
\text { inth }\end{array}$ & $\begin{array}{l}\text { Intention to treat but reporting based on local average } \\
\text { treatment. Clustered at the health clinic level. Given } \\
\text { small number of clusters, Wild bootstrap method used, } \\
\text { as a method that is robust to randomized assignment of } \\
\text { treatment among a small number of clusters. }\end{array}$ & $\begin{array}{l}7 \text { out- } \\
\text { comes } \\
\text { around } \\
\text { RMNCH } \\
\text { utiliza- } \\
\text { tion and } \\
\text { delivery, } \\
\text { RMNCH } \\
\text { health } \\
\text { outcomes, } \\
\text { and unin- } \\
\text { tended ef- } \\
\text { fects of in- } \\
\text { centives } \\
\text { on immu- } \\
\text { nizations } \\
\text { and over- } \\
\text { all visits. }\end{array}$ \\
\hline
\end{tabular}




\begin{tabular}{|c|c|c|c|c|c|c|c|c|}
\hline & & & & & & $\begin{array}{l}\text { and further } \\
9 \text { months. } \\
\text { Follow-up: } \\
24 \text { months. }\end{array}$ & & \\
\hline Benin & $\begin{array}{l}\text { Quasi/non- } \\
\text { randomized } \\
\text { trial }\end{array}$ & $\begin{array}{l}\text { Lagarde } \\
2015\end{array}$ & $\begin{array}{l}\text { Payment } \\
\text { per output } \\
\text { modified } \\
\text { by quality } \\
\text { score }\end{array}$ & $\begin{array}{l}\text { Con- } \\
\text { trol } \\
\text { and } \\
\text { Com- } \\
\text { para- } \\
\text { tor. } \\
\text { Con- } \\
\text { trol: } \\
\text { Stan- } \\
\text { dard } \\
\text { care or } \\
\text { status } \\
\text { quo. } \\
\text { Com- } \\
\text { para- } \\
\text { tor: } \\
\text { addi- } \\
\text { tional } \\
\text { fund- } \\
\text { ing } \\
\text { match- } \\
\text { ing } \\
\text { core } \\
\text { ele- } \\
\text { ments } \\
\text { of PBF. }\end{array}$ & $\begin{array}{l}\text { Facility } \\
\text { surveys, } \\
\text { person } \\
\text { ques- } \\
\text { tion- } \\
\text { naires } \\
\text { and ex- } \\
\text { it inter- } \\
\text { views. } \\
\text { Data col- } \\
\text { lected } \\
\text { by study } \\
\text { field- } \\
\text { workers. }\end{array}$ & $\begin{array}{l}\text { Baseline: } \\
\text { 2011. End- } \\
\text { line: } 2015 . \\
\text { Follow-up: } 4 \\
\text { years. }\end{array}$ & $\begin{array}{l}\text { Econometric model. Health worker control variables } \\
\text { covered role, level of experience, primary household in- } \\
\text { come, and household wealth. Facility control variables } \\
\text { covered other nearby facilities, rural or non-rural, quali- } \\
\text { fied staff, facility size and access to electricity. }\end{array}$ & $\begin{array}{l}38 \text { individ- } \\
\text { ual out- } \\
\text { comes as- } \\
\text { sessed } \\
\text { against } \\
\text { control } \\
\text { and } 28 \\
\text { against al- } \\
\text { ternative } \\
\text { compara- } \\
\text { tor; cover- } \\
\text { ing quali- } \\
\text { ty of care, } \\
\text { utilization } \\
\text { and deliv- } \\
\text { ery and } \\
\text { facility } \\
\text { manage- } \\
\text { ment/re- } \\
\text { sources }\end{array}$ \\
\hline Brazil & ITS & $\begin{array}{l}\text { Viñuela } \\
2015\end{array}$ & $\begin{array}{l}\text { Perfor- } \\
\text { mance relat- } \\
\text { ed pay }\end{array}$ & $\begin{array}{l}\text { Over } \\
\text { time: } \\
\text { Com- } \\
\text { par- } \\
\text { ison } \\
\text { over } \\
\text { time. }\end{array}$ & $\begin{array}{l}\text { National } \\
\text { registry } \\
\text { data, ob- } \\
\text { tained } \\
\text { from } \\
\text { routine } \\
\text { sources. }\end{array}$ & $\begin{array}{l}\text { Baseline: } \\
\text { 2002. End- } \\
\text { line: } 2011 . \\
\text { Follow-up: } 9 \\
\text { years. }\end{array}$ & $\begin{array}{l}\text { Regression models. Model without control variables, } \\
\text { and model with control variables: state management re- } \\
\text { forms, sector expenditure per capita, poverty rate and } \\
\text { GDP per capita, GDP per square km, and population } \\
\text { density. }\end{array}$ & $\begin{array}{l}1 \text { health } \\
\text { outcome } \\
\text { reported } \\
\text { on - child } \\
\text { mortality. }\end{array}$ \\
\hline $\begin{array}{l}\text { Burkina Fa- } \\
\text { so }\end{array}$ & CBA & $\begin{array}{l}\text { Steenland } \\
2017\end{array}$ & $\begin{array}{l}\text { Payment } \\
\text { per output } \\
\text { modified by } \\
\text { quality and } \\
\text { equity score }\end{array}$ & $\begin{array}{l}\text { Con- } \\
\text { trol: } \\
\text { Stan- } \\
\text { dard } \\
\text { care or }\end{array}$ & $\begin{array}{l}\text { Data } \\
\text { from } \\
\text { health } \\
\text { manage- } \\
\text { ment in- }\end{array}$ & $\begin{array}{l}\text { Baseline: } \\
\text { Data set } \\
\text { extract- } \\
\text { ed starts } \\
\text { from Jan- }\end{array}$ & $\begin{array}{l}\text { Difference in difference controlling for time trends, sea- } \\
\text { sonal effects and clustering }\end{array}$ & $\begin{array}{l}4 \text { utiliza- } \\
\text { tion and } \\
\text { delivery } \\
\text { outcomes }\end{array}$ \\
\hline
\end{tabular}




\begin{tabular}{|c|c|c|c|c|c|c|c|c|}
\hline & & & -2 & $\begin{array}{l}\text { status } \\
\text { quo }\end{array}$ & $\begin{array}{l}\text { forma- } \\
\text { tion sys- } \\
\text { tem. }\end{array}$ & $\begin{array}{l}\text { uary } 2009 . \\
\text { PBF was } \\
\text { started in } \\
\text { April } 2011 . \\
\text { Endline: } \\
\text { Extracted } \\
\text { data ends } \\
\text { in Decem- } \\
\text { ber 2012. } \\
\text { Follow-up: } \\
\text { April 2011- } \\
\text { December } \\
2012 .\end{array}$ & & $\begin{array}{l}\text { around } \\
\text { RMNCH }\end{array}$ \\
\hline \multirow[t]{3}{*}{ Burundi } & \multirow[t]{3}{*}{ CBA } & $\begin{array}{l}\text { Bonfrer } \\
\text { 2014a }\end{array}$ & $\begin{array}{l}\text { Payment } \\
\text { per output } \\
\text { modified } \\
\text { by quality } \\
\text { score }\end{array}$ & $\begin{array}{l}\text { Con- } \\
\text { trol: } \\
\text { Stan- } \\
\text { dard } \\
\text { care or } \\
\text { status } \\
\text { quo }\end{array}$ & $\begin{array}{l}\text { House- } \\
\text { hold sur- } \\
\text { veys. } \\
\text { Unclear } \\
\text { who col- } \\
\text { lected } \\
\text { the data }\end{array}$ & $\begin{array}{l}\text { Baseline: } \\
\text { 2006. End- } \\
\text { line: } 2010 . \\
\text { Follow-up: } 4 \\
\text { years. }\end{array}$ & $\begin{array}{l}\text { Difference in difference controlling for time trends, sea- } \\
\text { sonal effects and clustering; Bonferroni corrections ap- } \\
\text { plied }\end{array}$ & $\begin{array}{l}15 \text { out- } \\
\text { comes - } \\
\text { utiliza- } \\
\text { tion and } \\
\text { delivery } \\
\text { outcomes } \\
\text { around } \\
\text { RMNCH } \\
\text { and im- } \\
\text { muniza- } \\
\text { tions; } \\
\text { quality of } \\
\text { care out- } \\
\text { comes; } \\
\text { and health } \\
\text { outcomes }\end{array}$ \\
\hline & & $\begin{array}{l}\text { Bonfrer } \\
2014 b\end{array}$ & $\begin{array}{l}\text { Payment } \\
\text { per output } \\
\text { modified } \\
\text { by quality } \\
\text { score }\end{array}$ & $\begin{array}{l}\text { Con- } \\
\text { trol: } \\
\text { Stan- } \\
\text { dard } \\
\text { care or } \\
\text { status } \\
\text { quo }\end{array}$ & $\begin{array}{l}\text { Data } \\
\text { from Bu- } \\
\text { rundi } \\
\text { Demo- } \\
\text { graph- } \\
\text { ic and } \\
\text { Health } \\
\text { Survey } \\
2010 .\end{array}$ & $\begin{array}{l}\text { Baseline: } \\
\text { 2005. End- } \\
\text { line: } 2010 . \\
\text { Follow-up: } 5 \\
\text { years. }\end{array}$ & $\begin{array}{l}\text { Difference-in-differences. Looking at the effect of } \\
\text { whether a province had or did not have PBF when an in- } \\
\text { dividual child was born. Standard errors were adjust- } \\
\text { ed for at the province level. Control variable household } \\
\text { size, wealth quintiles, whether child is first born, moth- } \\
\text { er age at birth, age of household head in year, mother } \\
\text { having primary education, male household head, access } \\
\text { to safe drinking water, household having electricity. Ro- } \\
\text { bustness confirmed using ordinary least squares regres- } \\
\text { sion. }\end{array}$ & $\begin{array}{l}11 \text { out- } \\
\text { comes on } \\
\text { utilization } \\
\text { and deliv- } \\
\text { ery of RM- } \\
\mathrm{NCH} \text {, in- } \\
\text { cluding } \\
\text { RMNCH } \\
\text { immuniza- } \\
\text { tions }\end{array}$ \\
\hline & & Falisse 2015 & $\begin{array}{l}\text { Payment } \\
\text { per output } \\
\text { modified }\end{array}$ & $\begin{array}{l}\text { Con- } \\
\text { trol: } \\
\text { Stan- }\end{array}$ & $\begin{array}{l}\text { Data } \\
\text { from Na- } \\
\text { tional }\end{array}$ & $\begin{array}{l}\text { Baseline: } \\
\text { 2005. End- } \\
\text { line: } 2009 .\end{array}$ & $\begin{array}{l}\text { Difference in difference controlling for province and year } \\
\text { trends, but no controls. A second model includes con- }\end{array}$ & $\begin{array}{l}12 \text { out- } \\
\text { comes, } \\
\text { primari- }\end{array}$ \\
\hline
\end{tabular}


Table 4. Characteristics of included studies - table B (Continued)

by quality

trols, however problematic as $32 \%$ missingness regis-
tered there, so more conservative model reported.

ly around score status mation

System,

and from

Cordaid

and the

EU, who

imple-

ment-

ed PBF

in seven

provinces.

ery of RM-

$\mathrm{NCH}$ and

vaccina-

tions, plus

outpa-

tient and

malaria

visits; one

of these

outcomes

on perina-

tal deaths

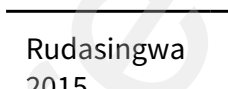

Payment
per output
modified

Con-

Admin-

modified

trol:

istrative

Baseline:

D

through descriptive statistics, paired non-parametric

8 general

quality of

by quality

Stan- data re-

Wilcoxon Signed Ranks test, and difference-in-differ-

care out-

score

care or medical

ence analysis at a significance level of $5 \%$.

comes

status records

years.

quo review,

docu-

ments

and

records

review,

direct

obser-

vation.

Data ob-

tained

from

Cordaid

Nether-

lands.

\begin{tabular}{|c|c|c|c|c|c|c|c|c|}
\hline Cambodia & $\mathrm{CBA}$ & $\begin{array}{l}\text { Van de Poel } \\
2015\end{array}$ & $\begin{array}{l}\text { Perfor- } \\
\text { mance } \\
\text { based con- } \\
\text { tracting }\end{array}$ & $\begin{array}{l}\text { Com- } \\
\text { para- } \\
\text { tor: un- } \\
\text { clear }\end{array}$ & $\begin{array}{l}\text { Cam- } \\
\text { bodian } \\
\text { DHS sur- } \\
\text { veys. Da- } \\
\text { ta col- } \\
\text { lected by } \\
\text { national }\end{array}$ & $\begin{array}{l}\text { Baseline: } \\
\text { 2005/2000. } \\
\text { Endline: } \\
2005 \text { and } \\
\text { 2010. Fol- } \\
\text { low-up: }\end{array}$ & $\begin{array}{l}\text { Difference in difference. Standard error adjusted for } \\
\text { clustering at the OD level (model 1). Extended mod- } \\
\text { el (model } 2 \text { - focussed on in the results) also accounts } \\
\text { for geographic variation in access to public services, } \\
\text { which may constrain extent to which even incentivized } \\
\text { providers can influence utilization rates. Covariates in- } \\
\text { cluded in the model which contain child, mother and }\end{array}$ & $\begin{array}{l}5 \mathrm{RMCH} \\
\text { outcomes }\end{array}$ \\
\hline
\end{tabular}


Table 4. Characteristics of included studies - table B (Continued)

\begin{tabular}{|c|c|c|c|c|c|}
\hline & & & & $\begin{array}{l}\text { authori- } \\
\text { ties. }\end{array}$ & $\begin{array}{l}5 \text { and } 10 \\
\text { years. }\end{array}$ \\
\hline ITS & Ir 2015 & $\begin{array}{l}\text { Payment } \\
\text { per output }\end{array}$ & $\begin{array}{l}\text { Over } \\
\text { time: } \\
\text { Com- } \\
\text { par- } \\
\text { ison } \\
\text { over } \\
\text { time. }\end{array}$ & $\begin{array}{l}\text { Data } \\
\text { from ex- } \\
\text { isting } \\
\text { Nation- } \\
\text { al Health } \\
\text { Infor- } \\
\text { mation } \\
\text { System } \\
\text { data- } \\
\text { base and } \\
\text { DHS da- } \\
\text { ta. }\end{array}$ & $\begin{array}{l}\text { Baseline: } \\
\text { Jan } 2006 . \\
\text { Endline: Dec } \\
\text { 2011. Fol- } \\
\text { low-up: } 4 \\
\text { years and } 3 \\
\text { months. }\end{array}$ \\
\hline
\end{tabular}

household characteristics such as birth interval $<24$

months; mother's age at birth $<20$ years; education lev-

el of mother; and wealth index (see table II for complete list)

Segmented linear regression to identify both level and

1 principal

trend changes, accounting for auto-correlation

outcome

reported

on

\begin{tabular}{|c|c|c|c|c|c|}
\hline Khim 2018 & $\begin{array}{l}\text { Perfor- } \\
\text { mance } \\
\text { based ser- } \\
\text { vice agree- } \\
\text { ments }\end{array}$ & $\begin{array}{l}\text { Over } \\
\text { time: } \\
\text { Com- } \\
\text { par- } \\
\text { ison } \\
\text { over } \\
\text { time. }\end{array}$ & $\begin{array}{l}\text { Data ex- } \\
\text { port- } \\
\text { ed from } \\
\text { Health } \\
\text { Manage- } \\
\text { ment In- } \\
\text { forma- } \\
\text { tion Sys- }\end{array}$ & $\begin{array}{l}\text { Baseline: } \\
\text { 2006. End- } \\
\text { line: } 2012 . \\
\text { Follow-up: } 2 \\
\text { or } 3 \text { years. }\end{array}$ & $\begin{array}{l}\text { Interrupted time series, using segmented linear regres- } \\
\text { sion, which estimated pre intervention trend and level, } \\
\text { and post intervention trend for each indicator. Changes } \\
\text { in level and slope were calculated, controlling for pre-in- } \\
\text { tervention level, trend, and autocorrelation. Autocorre- } \\
\text { lation and serial correlation corrected using Prais-Wis- } \\
\text { ten transformation. }\end{array}$ \\
\hline
\end{tabular}

$4 \mathrm{RMCH}$

outcomes

tems.

\begin{tabular}{llll}
\hline Matsuoka & Payment & Over & Data re- \\
& per output & time: & view of \\
& Com- & existing \\
& par- & records \\
& ison & obtained \\
& over & from \\
& time. & Kroch \\
& & Chh- \\
& mar OD \\
& (health \\
& & adminis \\
& & tration) \\
& & office; \\
& & inter- \\
& & views; \\
& & focus \\
& & groups;
\end{tabular}

Descriptive data analysis. Outcomes compared before

$2 \mathrm{ANC}$ and

Baseline:

January

and after intervention using the chi-square test where

immuniza-

tion indi-

Endline:

appropriate.

cators 


\begin{tabular}{|c|c|c|c|c|c|c|c|c|c|}
\hline & & & & & $\begin{array}{l}\text { health } \\
\text { centre } \\
\text { visits. } \\
\text { Data col- } \\
\text { lected } \\
\text { by study } \\
\text { team. }\end{array}$ & & & & 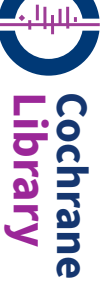 \\
\hline Cameroon & $\begin{array}{l}\text { Quasi/non- } \\
\text { randomized } \\
\text { trial }\end{array}$ & $\begin{array}{l}\text { De Walque } \\
2017\end{array}$ & $\begin{array}{l}\text { Payment } \\
\text { per output } \\
\text { modified by } \\
\text { quality and } \\
\text { equity score }\end{array}$ & $\begin{array}{l}\text { Con- } \\
\text { trol: } \\
\text { Stan- } \\
\text { dard } \\
\text { care or } \\
\text { status } \\
\text { quo }\end{array}$ & $\begin{array}{l}\text { Inter- } \\
\text { views } \\
\text { with } \\
\text { house- } \\
\text { hold } \\
\text { mem- } \\
\text { bers, } \\
\text { facili- } \\
\text { ty-based } \\
\text { sur- } \\
\text { vey, pa- } \\
\text { tient-prov } \\
\text { obser- } \\
\text { vations } \\
\text { and } \\
\text { client ex- } \\
\text { it inter- } \\
\text { views. } \\
\text { Data col- } \\
\text { lected by } \\
\text { Institut } \\
\text { de For- } \\
\text { mation } \\
\text { et de } \\
\text { Recherche } \\
\text { Démo- } \\
\text { graphique } \\
\text { (IFORD) } \\
\text { and re- } \\
\text { search } \\
\text { team. }\end{array}$ & $\begin{array}{l}\text { Baseline: } \\
\text { Unclear } \\
\text { - pre PBF } \\
\text { start. End- } \\
\text { line: } 3 \text { years. } \\
\text { Follow-up: } \\
\text { Unclear. }\end{array}$ & $\begin{array}{l}\text { Difference in difference. Regression models adjusted for } \\
\text { control variables. Facility level controls included type } \\
\text { of health facility (public/religious/private) and location } \\
\text { of health facility (urban/rural). Household level control } \\
\text { variables included number of individuals in the house- } \\
\text { hold, housing type, house ownership, water source, and } \\
\text { type of sanitation. Individual level controls included } \\
\text { age, marital status, education level, religion, ethnicity, } \\
\text { working status and type of work. }\end{array}$ & $\begin{array}{l}102 \text { out- } \\
\text { comes, } \\
\text { around } \\
\text { RMNCH, } \\
\text { vaccina- } \\
\text { tion, HIV, } \\
\text { malaria, } \\
\text { financ- } \\
\text { ing, pa- } \\
\text { tient and } \\
\text { provider } \\
\text { satis- } \\
\text { faction, } \\
\text { equip- } \\
\text { ment and } \\
\text { medicine } \\
\text { availabil- } \\
\text { ity, and } \\
\text { quality of } \\
\text { care. }\end{array}$ & 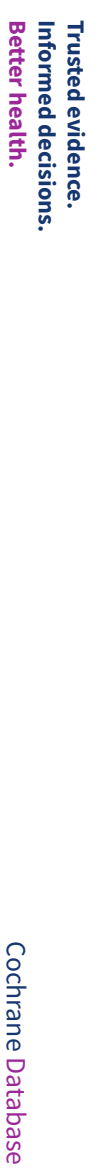 \\
\hline & CBA & Zang 2015 & $\begin{array}{l}\text { Payment } \\
\text { per output } \\
\text { modified by } \\
\text { quality and } \\
\text { equity score }\end{array}$ & $\begin{array}{l}\text { Con- } \\
\text { trol: } \\
\text { Stan- } \\
\text { dard } \\
\text { care or }\end{array}$ & $\begin{array}{l}\text { House- } \\
\text { hold and } \\
\text { facility } \\
\text { surveys. }\end{array}$ & $\begin{array}{l}\text { Baseline: } \\
\text { Jan } 2011 . \\
\text { Endline: Feb } \\
\text { 2013. Fol- }\end{array}$ & $\begin{array}{l}\text { Propensity score matching for (catchment area popu- } \\
\text { lation size, square of catchment area population size, } \\
\text { number of qualified health personnel, square of number } \\
\text { of qualified health personnel and }\end{array}$ & $\begin{array}{l}21 \text { out- } \\
\text { comes. } 9 \\
\text { around } \\
\text { quality } \\
\text { of care; }\end{array}$ & 竞 \\
\hline
\end{tabular}




\begin{tabular}{|c|c|c|c|c|c|c|c|c|}
\hline & & & & $\begin{array}{l}\text { status } \\
\text { quo }\end{array}$ & & $\begin{array}{l}\text { low-up: Un- } \\
\text { clear. }\end{array}$ & $\begin{array}{l}\text { number of qualified health personnel to catchment area } \\
\text { population size) and difference in difference. }\end{array}$ & $\begin{array}{l}4 \text { around } \\
\text { number } \\
\text { of staff; } \\
6 \text { around } \\
\text { RMNCH } \\
\text { utilization } \\
\text { and de- } \\
\text { livery; re- } \\
\text { maining } \\
2 \text { around } \\
\text { utilization } \\
\text { of outpa- } \\
\text { tient con- } \\
\text { sultations, } \\
\text { and drug } \\
\text { availabili- } \\
\text { ty. }\end{array}$ \\
\hline China & CBA & Yao 2008 & $\begin{array}{l}\text { Payment } \\
\text { per output }\end{array}$ & $\begin{array}{l}\text { Con- } \\
\text { trol: } \\
\text { Stan- } \\
\text { dard } \\
\text { care or } \\
\text { status } \\
\text { quo }\end{array}$ & $\begin{array}{l}\text { Data } \\
\text { from } \\
\text { Coun- } \\
\text { ty-based } \\
\text { TB re- } \\
\text { porting } \\
\text { data, } \\
\text { collect- } \\
\text { ed by } \\
\text { health } \\
\text { care } \\
\text { workers. }\end{array}$ & $\begin{array}{l}\text { Baseline: } \\
\text { Janu- } \\
\text { ary-Septem- } \\
\text { ber } 2004 . \\
\text { Endline: } \\
\text { Janu- } \\
\text { ary-Septem- } \\
\text { ber 2005. } \\
\text { Follow-up: } 1 \\
\text { year. }\end{array}$ & $\begin{array}{l}\text { Comparison of proportions and "Descriptive analyses of } \\
\text { independent } t \text {-tests, } \mathrm{X} 2 \text { test and Kruskal-Wallis rank test } \\
\text { were used when appropriate." }\end{array}$ & $\begin{array}{l}2 \text { out- } \\
\text { comes on } \\
\text { treatment } \\
\text { success } \\
\text { and case } \\
\text { notifica- } \\
\text { tion }\end{array}$ \\
\hline & ITS & Chang 2017 & $\begin{array}{l}\text { Payment } \\
\text { per output }\end{array}$ & $\begin{array}{l}\text { Over } \\
\text { time: } \\
\text { Com- } \\
\text { par- } \\
\text { ison } \\
\text { over } \\
\text { time. }\end{array}$ & $\begin{array}{l}\text { Adverse } \\
\text { Drug Re- } \\
\text { action } \\
\text { reports } \\
\text { from } \\
\text { hospital } \\
\text { pharma- } \\
\text { covig- } \\
\text { ilance } \\
\text { pro- } \\
\text { gramme } \\
\text { data- } \\
\text { base, } \\
\text { collect- }\end{array}$ & $\begin{array}{l}\text { Baseline: } \\
\text { 2006. End- } \\
\text { line: } 2014 . \\
\text { Follow-up: } 5 \\
\text { years. }\end{array}$ & $\begin{array}{l}\text { Time series analysis using autoregressive integrated } \\
\text { moving average models }\end{array}$ & $\begin{array}{l}3 \text { out- } \\
\text { comes on } \\
\text { adverse } \\
\text { drug reac- } \\
\text { tions }\end{array}$ \\
\hline
\end{tabular}


Table 4. Characteristics of included studies - table B (Continued)

sions.

\begin{tabular}{|c|c|c|c|c|}
\hline Wu 2014 & $\begin{array}{l}\text { Target pay- } \\
\text { ment }\end{array}$ & $\begin{array}{l}\text { Over } \\
\text { time: } \\
\text { Com- } \\
\text { par- } \\
\text { ison } \\
\text { over } \\
\text { time. }\end{array}$ & $\begin{array}{l}\text { Rou- } \\
\text { tine da- } \\
\text { ta from } \\
\text { tertiary } \\
\text { general } \\
\text { hospital } \\
\text { dataset. }\end{array}$ & $\begin{array}{l}\text { Baseline: } \\
\text { July } 2004 . \\
\text { Endline: } \\
\text { May 2006. } \\
\text { Follow-up: } \\
\text { Approx. } 2 \\
\text { years. }\end{array}$ \\
\hline $\begin{array}{l}\text { Liu and Mills } \\
2005\end{array}$ & $\begin{array}{l}\text { Payment } \\
\text { per output }\end{array}$ & $\begin{array}{l}\text { Over } \\
\text { time: } \\
\text { Com- } \\
\text { par- } \\
\text { ison } \\
\text { over } \\
\text { time. }\end{array}$ & $\begin{array}{l}\text { Inpa- } \\
\text { tient } \\
\text { records } \\
\text { from the } \\
\text { six pan- } \\
\text { el hospi- } \\
\text { tals. Da- } \\
\text { ta col- } \\
\text { lected } \\
\text { by study } \\
\text { team. }\end{array}$ & $\begin{array}{l}\text { Baseline: } \\
\text { 1978. End- } \\
\text { line: } 1997 . \\
\text { Follow-up: } \\
17 \text { years } \\
\text { (First bonus } \\
\text { payment } \\
\text { made 1981). }\end{array}$ \\
\hline
\end{tabular}

Difference in Difference and regression analysis to check 4 outfor trends. All regressions control for patient age, gender, marriage, the number of conditions, a dummy

comes on variable for whether the patient is in severe condition, ture and length of stay, and a set of principal diagnosis fixed ef- length of fects.

Trend analysis, correlation and regression analysis;

4 revenue stepwise regression, with the following indicators enand protered in: "besides indicators of revenue, cost recovery, ductiviunnecessary care and productivity, the year, names of ty related hospitals and bonus type were put into the regression outcomes

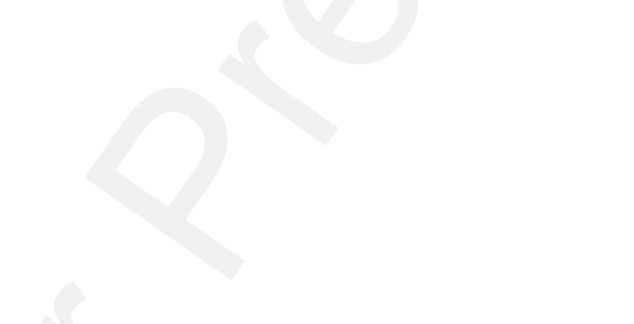

\begin{tabular}{|c|c|c|c|c|c|c|c|}
\hline \multirow[t]{2}{*}{$\begin{array}{l}\text { Quasi/Non- } \\
\text { randomized } \\
\text { trial }\end{array}$} & $\begin{array}{l}\text { Pow- } \\
\text { ell-Jackson } \\
2014\end{array}$ & $\begin{array}{l}\text { Payment } \\
\text { per output } \\
\text { and for tar- } \\
\text { get }\end{array}$ & $\begin{array}{l}\text { Con- } \\
\text { trol: } \\
\text { Stan- } \\
\text { dard } \\
\text { care or } \\
\text { status } \\
\text { quo }\end{array}$ & $\begin{array}{l}2 \text { rounds } \\
\text { of } \\
\text { house- } \\
\text { hold sur- } \\
\text { vey. Da- } \\
\text { ta col- } \\
\text { lected by } \\
\text { research } \\
\text { teams. }\end{array}$ & $\begin{array}{l}\text { Baseline: } \\
\text { Feb } 2009 . \\
\text { Endline: } \\
\text { Early } 2011 . \\
\text { Follow-up: } \\
\text { Approx. } 2 \\
\text { years. }\end{array}$ & $\begin{array}{l}\text { Difference in difference approach - regression with } \\
\text { treatment effects estimated by ordinary least squares, } \\
\text { with clustered nature of data accounted for by cluster- } \\
\text { ing standard errors at village level. Analysis controlled } \\
\text { for individual chronic disease, age, age squared, gen- } \\
\text { der, gender of the household head, household size, as- } \\
\text { set wealth, education, distance from the nearest health } \\
\text { facility of each type, ethnicity, whether the individual is } \\
\text { the household head, and migrant status. }\end{array}$ & $\begin{array}{l}14 \text { out- } \\
\text { comes on } \\
\text { in and out- } \\
\text { patient } \\
\text { care and } \\
\text { processes }\end{array}$ \\
\hline & Sun 2014 & $\begin{array}{l}\text { Capitation } \\
\text { and PBF }\end{array}$ & $\begin{array}{l}\text { Con- } \\
\text { trol: } \\
\text { Status } \\
\text { quo } \\
\text { (glob- } \\
\text { al cap- } \\
\text { itated } \\
\text { bud- } \\
\text { get) }\end{array}$ & $\begin{array}{l}\text { Routine } \\
\text { monitor- } \\
\text { ing and } \\
\text { study } \\
\text { specific } \\
\text { surveys. } \\
\text { Data col- } \\
\text { lected }\end{array}$ & $\begin{array}{l}\text { Baseline: } \\
\text { April 2011. } \\
\text { Endline: } \\
\text { April 2012. } \\
\text { Follow-up: } 1 \\
\text { year. }\end{array}$ & $\begin{array}{l}\text { Difference in Difference, fixed-effects, controlling for sex } \\
\text { and gender }\end{array}$ & $\begin{array}{l}8 \text { prescrip- } \\
\text { tion and } \\
\text { cost out- } \\
\text { comes }\end{array}$ \\
\hline
\end{tabular}




\begin{tabular}{|c|c|c|c|c|c|c|c|c|}
\hline & & & & & $\begin{array}{l}\text { by study } \\
\text { team. }\end{array}$ & & & \\
\hline & $\mathrm{RCT}$ & Yip 2014 & $\begin{array}{l}\text { Capitation } \\
\text { and PBF }\end{array}$ & $\begin{array}{l}\text { Con- } \\
\text { trol: } \\
\text { Stan- } \\
\text { dard } \\
\text { care or } \\
\text { status } \\
\text { quo }\end{array}$ & $\begin{array}{l}\text { Data } \\
\text { from } \\
\text { electron- } \\
\text { ic man- } \\
\text { agement } \\
\text { infor- } \\
\text { mation } \\
\text { system; } \\
\text { house- } \\
\text { hold } \\
\text { survey; } \\
\text { town- } \\
\text { ship } \\
\text { health } \\
\text { centre } \\
\text { and vil- } \\
\text { lage post } \\
\text { survey. }\end{array}$ & $\begin{array}{l}\text { Baseline: } \\
\text { Unclear. } \\
\text { Endline: } \\
\text { January } \\
\text { 30th } 2012 . \\
\text { Follow-up: } \\
\text { Unclear. }\end{array}$ & $\begin{array}{l}\text { Logistic regression and least squares regressions for bi- } \\
\text { nary and continuous outcomes; report unadjusted esti- } \\
\text { mates and those adjusted for sex, age, and dummy vari- } \\
\text { able for cluster-paired fixed effects. SE at town level. } \\
\text { Subgroup analysis by sex. Also for patients with a cold } \\
\text { for antibiotic use }\end{array}$ & $\begin{array}{l}11 \text { pre- } \\
\text { scription. } \\
\text { outcomes } \\
\text { including } \\
\text { expendi- } \\
\text { ture per } \\
\text { visits }\end{array}$ \\
\hline Congo & CBA & Zeng 2018a & $\begin{array}{l}\text { Payment } \\
\text { per output } \\
\text { modified } \\
\text { by quality } \\
\text { score }\end{array}$ & $\begin{array}{l}\text { Con- } \\
\text { trol: } \\
\text { Stan- } \\
\text { dard } \\
\text { care or } \\
\text { status } \\
\text { quo }\end{array}$ & $\begin{array}{l}\text { House- } \\
\text { hold and } \\
\text { health } \\
\text { facility } \\
\text { surveys. } \\
\text { Data col- } \\
\text { lected } \\
\text { by study } \\
\text { teams. }\end{array}$ & $\begin{array}{l}\text { Baseline: } \\
\text { March } 2012 . \\
\text { Endline: } \\
\text { March 2014. } \\
\text { Follow-up: } 2 \\
\text { years. }\end{array}$ & $\begin{array}{l}\text { Difference in difference - multivariate regression model, } \\
\text { which controlled for characteristics which "measured fi- } \\
\text { nancial and physical accessibility of households and re- } \\
\text { spondents' awareness of and education on health care", } \\
\text { which included the location of households, house own- } \\
\text { ership, household size, mother's age, education, status } \\
\text { of living with a partner, status of having a regular job, } \\
\text { and distance of households from health facilities. Mod- } \\
\text { els adjusted for clustering at the village level. Results } \\
\text { from model without village fixed effects. Bonferroni cor- } \\
\text { rection included. }\end{array}$ & $\begin{array}{l}22 \text { vari- } \\
\text { ables } \\
\text { around } \\
\text { utilization } \\
\text { of RMNCH, } \\
\text { immuniza- } \\
\text { tions, and } \\
\text { quality of } \\
\text { care }\end{array}$ \\
\hline DRC & CBA & $\begin{array}{l}\text { Soeters } \\
2011\end{array}$ & $\begin{array}{l}\text { Payment } \\
\text { per output } \\
\text { modified } \\
\text { by quality } \\
\text { score }\end{array}$ & $\begin{array}{l}\text { Com- } \\
\text { para- } \\
\text { tor: in- } \\
\text { kind } \\
\text { med- } \\
\text { icine } \\
\text { and } \\
\text { equip- } \\
\text { ment } \\
\text { dona- } \\
\text { tion, }\end{array}$ & $\begin{array}{l}\text { Strat- } \\
\text { ified } \\
\text { house- } \\
\text { hold } \\
\text { cluster } \\
\text { survey. }\end{array}$ & $\begin{array}{l}\text { Baseline: } \\
\text { Nov } 2005 . \\
\text { Endline: } \\
\text { Feb } 2008 . \\
\text { Follow-up: } \\
2 \text { years } 2 \\
\text { month. }\end{array}$ & $\begin{array}{l}\text { Difference in difference. Logistic regression models; un- } \\
\text { clear whether adjusted. }\end{array}$ & $\begin{array}{l}26 \text { out- } \\
\text { comes - } \\
\text { RMNCH, } \\
\text { quality of } \\
\text { care, pa- } \\
\text { tient satis- } \\
\text { faction, fi- } \\
\text { nancial, }\end{array}$ \\
\hline
\end{tabular}




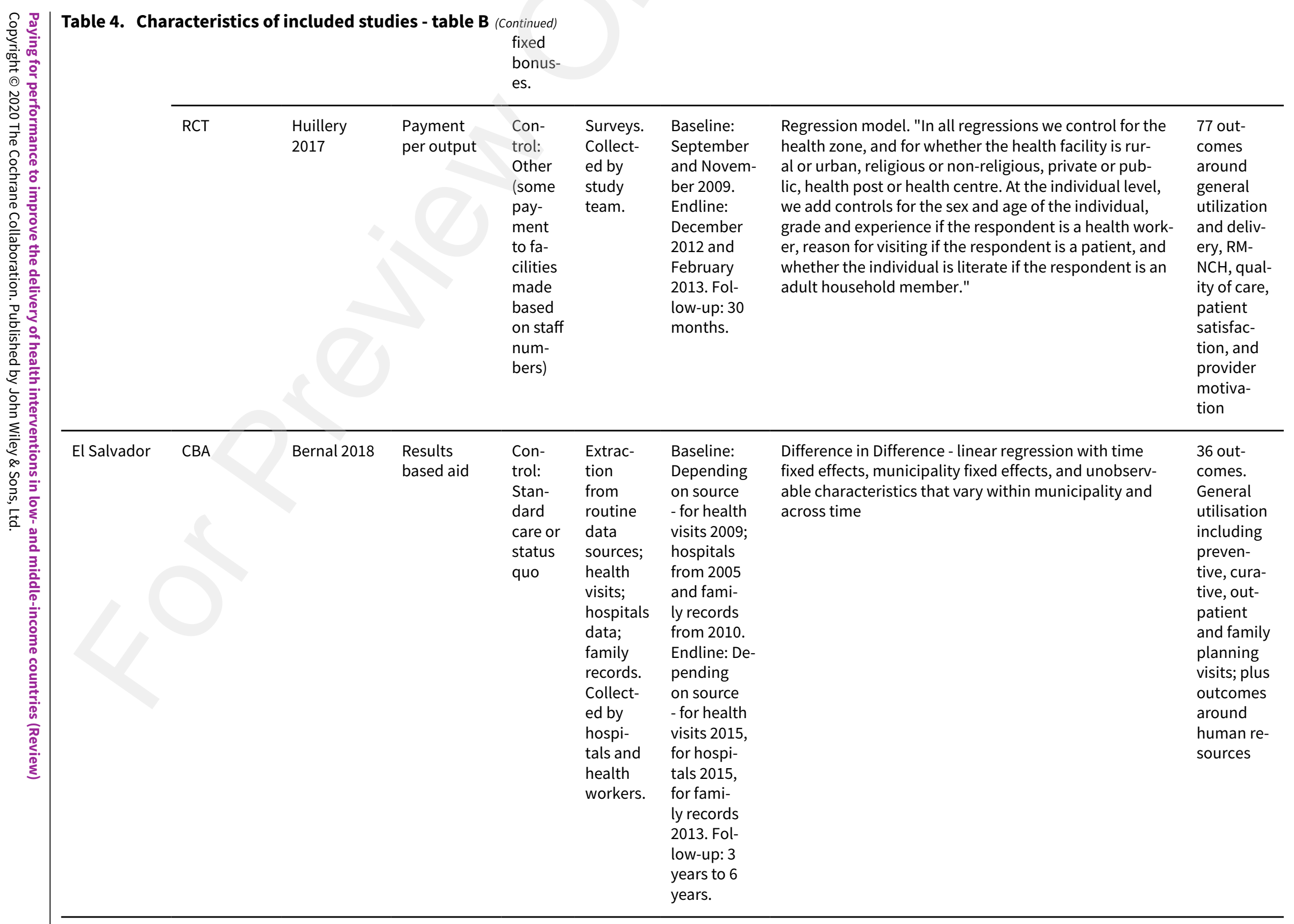




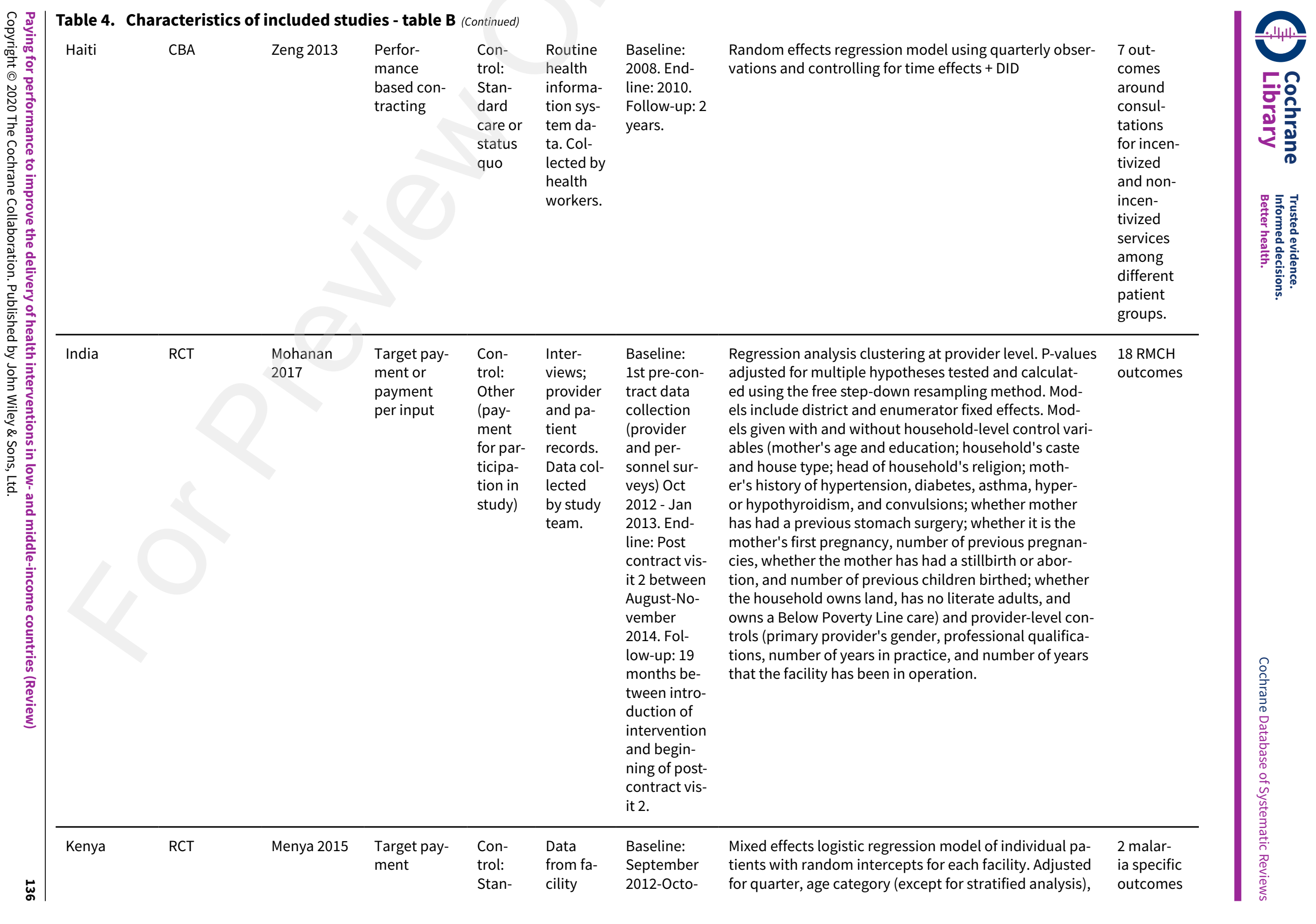




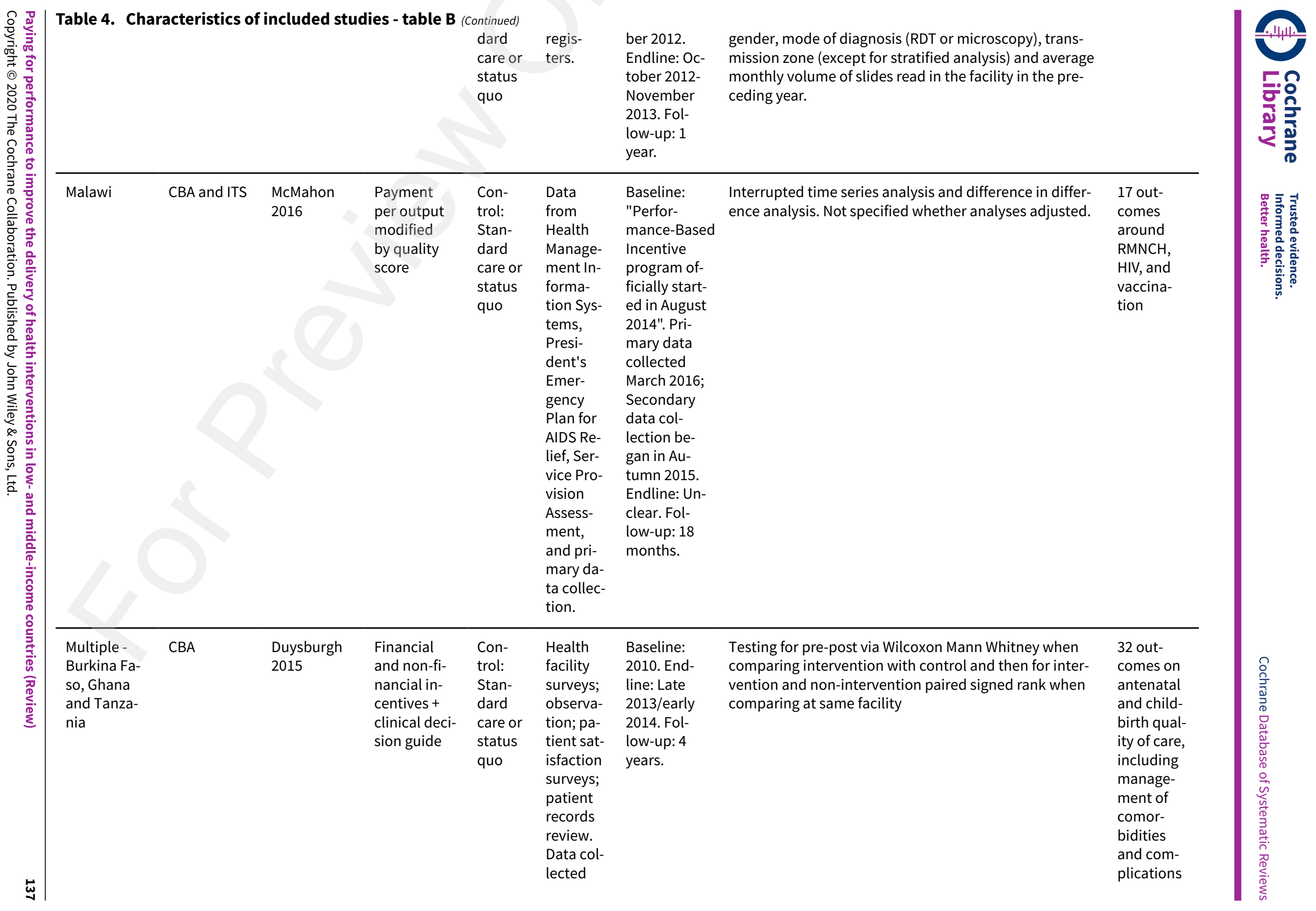




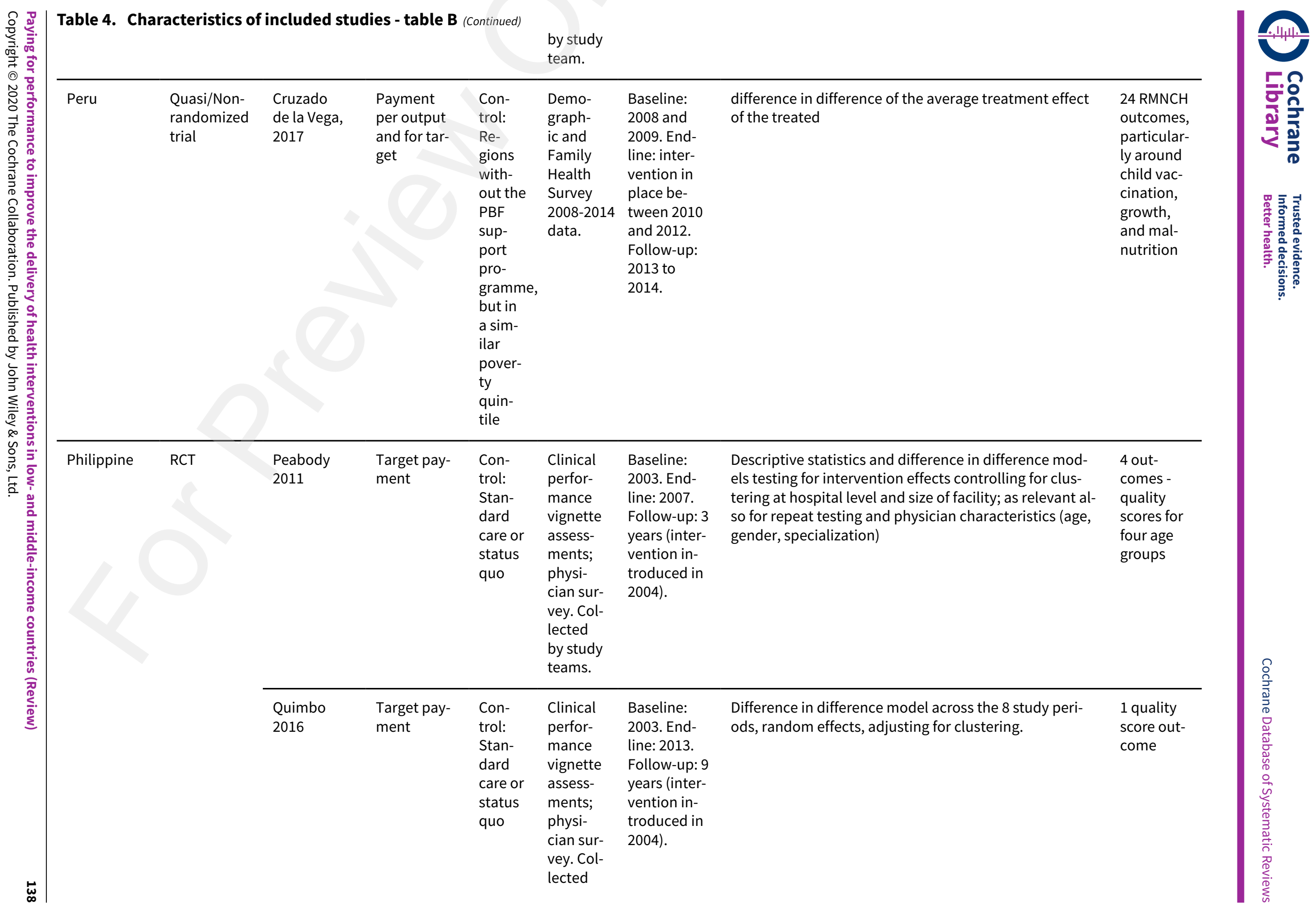


Table 4. Characteristics of included studies - table B (Continued)

\begin{tabular}{lllllll}
\hline Wagner & Target pay- & Con- & Patient & Baseline: & Comparison of means and multivariate models (differ- \\
2018 & ment & trol: & exit sur- & 2003/4. End- & ence in difference), including facility fixed effects and & comes on \\
& & Stan- & vey; fol- & line: $2007 / 8$. & control variables. Include dependents $(0-14$ ratio, and & medical \\
& & dard & low-home & Follow-up: 2 & $65+$ ratio), duration of stay, child having pneumonia/di- & expendi-
\end{tabular}

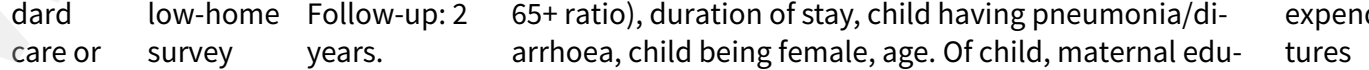
status (4-6) cation, per capita monthly income and household size.

post dis-

charge).

collect-

ed by

QIDS in-

vestiga-

tors.

\begin{tabular}{|c|c|c|c|c|c|c|c|}
\hline & $\begin{array}{l}\text { Peabody } \\
2014\end{array}$ & $\begin{array}{l}\text { Target pay- } \\
\text { ment }\end{array}$ & $\begin{array}{l}\text { Con- } \\
\text { trol: } \\
\text { Stan- } \\
\text { dard } \\
\text { care or } \\
\text { status } \\
\text { quo }\end{array}$ & $\begin{array}{l}\text { House- } \\
\text { hold sur- } \\
\text { veys. Da- } \\
\text { ta col- } \\
\text { lected by } \\
\text { indepen- } \\
\text { dent in- } \\
\text { terview } \\
\text { teams. }\end{array}$ & $\begin{array}{l}\text { Baseline: } \\
\text { 2003. End- } \\
\text { line: } 2007 . \\
\text { Follow-up: } 3 \\
\text { years (inter- } \\
\text { vention in- } \\
\text { troduced in } \\
\text { 2004). }\end{array}$ & $\begin{array}{l}\text { Logistic difference in difference models adjusting for } \\
\text { (1) PhilHealth (insurance) membership, (2) age of child } \\
\text { (months), (3) mother's education (years of schooling), } \\
\text { and (4) household income (PhP), (5) initially visited a } \\
\text { lower-level facility prior to hospitalization and (6) length } \\
\text { of stay in hospital. The individual effects control for indi- } \\
\text { vidual, household and area specific factors that are fixed } \\
\text { over time. Clustering by facility. }\end{array}$ & $\begin{array}{l}4 \text { gener- } \\
\text { al health } \\
\text { outcomes }\end{array}$ \\
\hline ITS & Rusa 2009 & $\begin{array}{l}\text { Payment } \\
\text { per output } \\
\text { modified } \\
\text { by quality } \\
\text { score }\end{array}$ & $\begin{array}{l}\text { Over } \\
\text { time: } \\
\text { Com- } \\
\text { par- } \\
\text { ison } \\
\text { over } \\
\text { time. }\end{array}$ & $\begin{array}{l}\text { Routine } \\
\text { health } \\
\text { facilities } \\
\text { reports } \\
\text { and su- } \\
\text { pervi- } \\
\text { sion } \\
\text { logs. }\end{array}$ & $\begin{array}{l}\text { Base- } \\
\text { line: } 2005 \\
\text { (monthly } \\
\text { basis). End- } \\
\text { line: } 2007 \\
\text { (Decem- } \\
\text { ber). Fol- } \\
\text { low-up: De- } \\
\text { pending on } \\
\text { start - in pi- } \\
\text { lot districts } \\
3 \text { years. }\end{array}$ & $\begin{array}{l}\text { Descriptive - graphic only. Additional data requested, no } \\
\text { data provided. }\end{array}$ & $\begin{array}{l}8 \text { out- } \\
\text { comes } \\
\text { around } \\
\text { RMNCH } \\
\text { and vacci- } \\
\text { nations - } \\
\text { regarding } \\
\text { utilization } \\
\text { and deliv- } \\
\text { ery and } \\
\text { quality of } \\
\text { care }\end{array}$ \\
\hline $\begin{array}{l}\text { Quasi/non- } \\
\text { randomized } \\
\text { trial }\end{array}$ & $\begin{array}{l}\text { Basinga } \\
2011\end{array}$ & $\begin{array}{l}\text { Payment } \\
\text { per output } \\
\text { modified }\end{array}$ & $\begin{array}{l}\text { Com- } \\
\text { para- } \\
\text { tor: } \\
\text { Tradi- }\end{array}$ & $\begin{array}{l}\text { Facility } \\
\text { survey; } \\
\text { house- } \\
\text { hold sur- }\end{array}$ & $\begin{array}{l}\text { Baseline: } \\
\text { Unclear - } \\
\text { P4P start- } \\
\text { ed in } 2006 .\end{array}$ & $\begin{array}{l}\text { Multivariate regression specification of the differ- } \\
\text { ence-in-difference model in which an individual's out- } \\
\text { come is regressed against a dummy variable, indicat- } \\
\text { ing whether the facility received P4P that year, a facility }\end{array}$ & $\begin{array}{l}8 \text { RMNCH } \\
\text { outcomes } \\
-6 \text { relating } \\
\text { to utiliza- }\end{array}$ \\
\hline
\end{tabular}


Table 4. Characteristics of included studies - table B (Continued)

by quality

score

tion-
al in-

vey. Col-

put-based trained

bud-

gets a

enumer-

hired by

ed to external

the fa- firms.

cilities

in the

control

group

wer

in-

creased

by the

aver-

age

amount

of P4P

pay-

ments

that

facili-

ties in

the in-

terven-

tion

group

re-

ceived

every 3

months

during

the 23-

month

assess-

ment

win-

dow.
Endline: 25

months af-

ter baseline

survey. Fol-

low-up: Max

25 months.

Lannes 2016

Payment

per output

Com-

House

hold

survey.

Tradi- Data-

by quality

score

base ob-

\section{Baseline:}

2006. End-

line: 2008.

Follow-up: fixed effect, a year indicator, and a series of individual and household characteristics. Robust standard errors, clustered at the district by year level to correct for corre-

lation of the error terms across facilities within districts.

tion and delivery, and 2 to quality of care.

Clustered T-tests and difference in difference models (linear probability, SURE, robustness checks with fixed effects and clustering) - reporting here on clustered

6 outcomes on equity of $\mathrm{RMNCH}$

services 
Table 4. Characteristics of included studies - table B (Continued)

$$
\text { put-basedfrom months). }
$$

facili-

ties in

the in-

terven-

tion

group

re-

ceived

every 3

months

during

the 23-

month

assess-

ment

win-

dow.

\begin{tabular}{lllll}
\hline Priedeman & Payment & Com- & Survey. & Baseline: \\
Skiles 2013 & per output & para- & DHS da- & 2005. End- \\
& modified & tor: & ta. & line: $2007-8$. \\
& by quality & Tradi- & & Follow-up: \\
& score & tion- & & 18 months. \\
& & al in- & &
\end{tabular}

Bivariate descriptive analyses for outcomes by year/

wealth quintile to capture inequity; difference in dif-

12 out-

munity fixed effects to control for time invariant unob- regard-

served community differences. For ANC visits covari-

regard-

al in-

ates include age, education, marital status, parity, insur- 
dow.

\begin{tabular}{|c|c|c|c|c|c|c|}
\hline $\begin{array}{l}\text { Priedeman } \\
\text { Skiles } 2015\end{array}$ & $\begin{array}{l}\text { Payment } \\
\text { per output } \\
\text { modified } \\
\text { by quality } \\
\text { score }\end{array}$ & $\begin{array}{l}\text { Com- } \\
\text { para- } \\
\text { tor: } \\
\text { Tradi- } \\
\text { tion- } \\
\text { al in- } \\
\text { put-basec }\end{array}$ & $\begin{array}{l}\text { Collation } \\
\text { of sur- } \\
\text { vey da- } \\
\text { ta from } \\
\text { DHS sur- } \\
\text { vey. }\end{array}$ & $\begin{array}{l}\text { Baseline: } \\
\text { 2005. End- } \\
\text { line: } 2008 . \\
\text { Follow-up: } \\
2 \text { or } 1 \text { years } \\
\text { or less (ear- } \\
\text { ly imple- }\end{array}$ & $\begin{array}{l}\text { Difference in difference, fixed effects, and standard er- } \\
\text { rors clustered at district level. Reported illnesses DID } \\
\text { adjusts for: child's age, birth order, gender, and facili- } \\
\text { ty birth; mother's age, education, marital status; house- } \\
\text { hold wealth, toilet facilities, drinking water source, and } \\
\text { bed net use. Facility care seeking and treatment re- } \\
\text { ceived DIDs adjust for child's age, birth order, gender, }\end{array}$ & $\begin{array}{l}10 \text { out- } \\
\text { comes - } \\
\text { RMNCH re- } \\
\text { garding } \\
\text { reporting } \\
\text { of illness, } \\
\text { care seek- }\end{array}$ \\
\hline
\end{tabular}


Table 4. Characteristics of included studies - table B (Continued)

control

group

were

in-

creased

by the

aver-

age

amount

of P4P

pay-

ments

that

facili-

ties in

the in-

terven-

tion

group

re-

ceived

every 3

months

during

the 23

month

assess-

ment

win- mentation

between

Jan 2006-

November

2007) and facility birth; mother's age, education, marital status; household wealth, insurance status, and previous child death. (p7) ing, and

treatment

Sherry 2017 Payment per output

Com-

Routine

Baseline: modified

tor:

DHS da-

by quality

Tradi-

ta.

and July

Difference in difference analysis among intention to

26 outscore

tion-

2005. End-

line: Decem-

treat lines, including adjustment for household and indi-

vidual level control variables and fixed effects (including

comes

around

for birth years), standard errors clustered at district lev-

RMNCH

ber 2007

and vac-

put-based

and April

- health

bud-

2008. Fol- 
Table 4. Characteristics of included studies - table B (Continued)

gets al-

low-up:

18-22

ed to months post

rollout.

utilization

and deliv-

ery out-

the fa-

comes and

quality of

care out-

in the

comes.

group

were

creased

by the

aver-

age

amount

of P4P

pay-

ments

that

facili-

ties in

the in-

terven-

tion

group

re-

ceived

every 3

months

during

the 23-

month

assess-

ment

win-

dow.

Lannes 2015

Payment

Com-

Baseline: per output para- from 2006. End-

Derivation of satisfaction measures using polychoric

12 outmodified tor: original line: 2008. regress satisfaction index on each sample.

score

tion- ga 2011 Varied

al in- dataset. scheme fol-

put-based low-up, max

bud- 23 months.

faction

of care

around cu-

rative, pre-

gets al-

natal, and 
Table 4. Characteristics of included studies - table B (Continued)

cilities

in the

control

group

were

in-

creased

by the

aver-

age

amount

of P4P

pay-

ments

that

facili-

ties in

the in-

terven-

tion

group

re-

ceived

every 3

months

during

the 23-

month

assess-

ment

win-

dow.

Com-

Surveys,

Baseline:

Difference in difference methods including individual

$7 \mathrm{RMNCH}$

per output

para- conduct- 2006. End-

controls and facility fixed effects. We consider two age

outcomes

modified

tor: ed in- line: 23

by quality

Tradi- depen- months

tion- dently later. Fol-

groups: (1) children 0-11 months at endline, and (2) chil-

dren 24-47 months at endline. We estimated 2 versions

around

al in- from the low-up:

of equation (6): one without controls and a second with

growth,

from the low-up:

bud- gram. 18 months.

controls. The controls include the child's age and sex,

quality of

maternal height, mother's age, whether the mother

care, and

Mutuelle (health insurance fund), the total number of 
Table 4. Characteristics of included studies - table B (Continued)

months

during

assess-

ment

win-

dow.

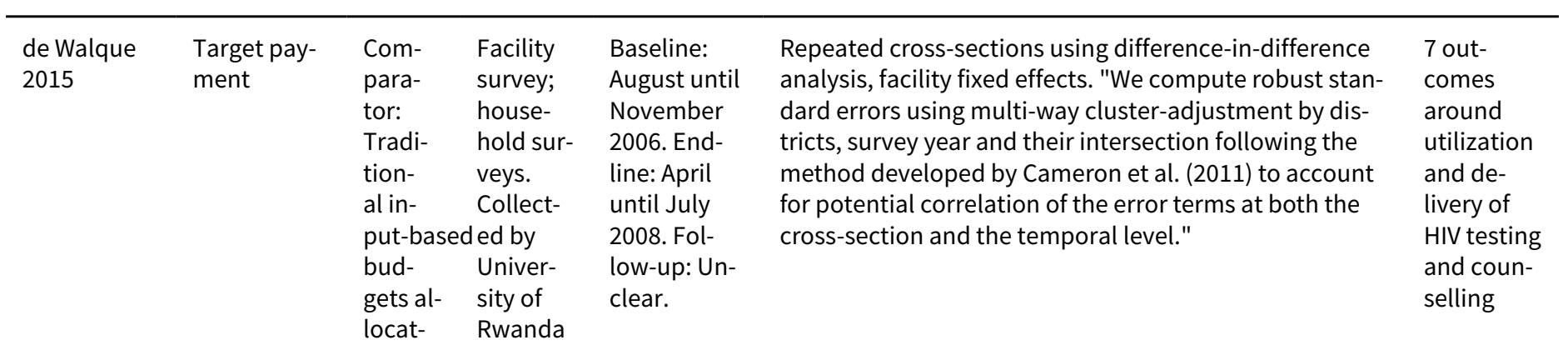

household members, the number of household members under the age of 6 , whether the household owns land, and dummy variables for quartiles of the household asset value.13 The child's age was entered as a series of dummy variables that represent one-month increments." 


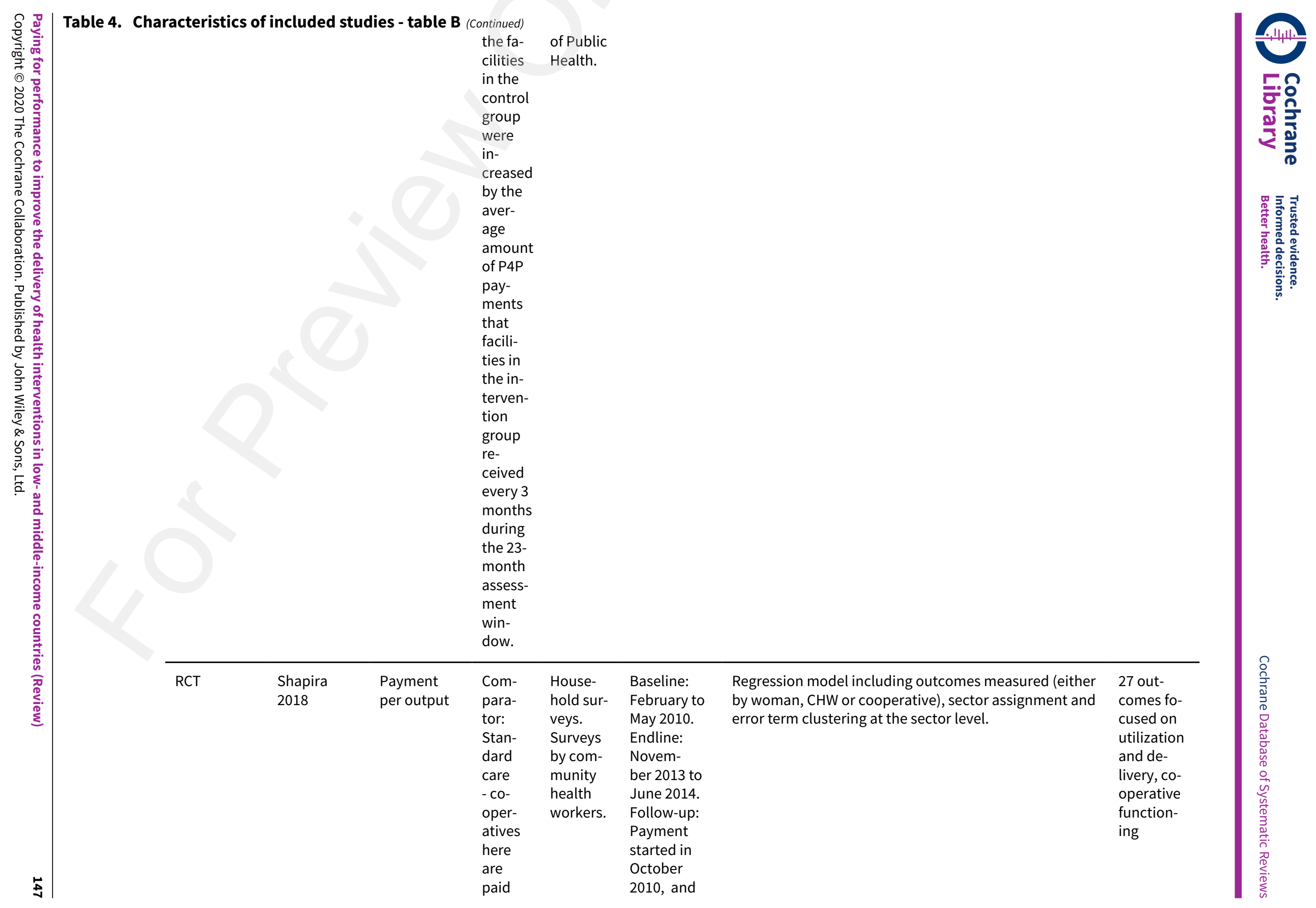


Table 4. Characteristics of included studies - table B (Continued)

for re-

port-

continued

until post

follow-up

ly, this survey, sug-

gesting min.

back-

3.5 years fol-

ground

low-up.

$\mathrm{PBF}$

pro-

gramme.

\begin{tabular}{|c|c|c|c|c|c|c|c|c|}
\hline Swaziland & $\begin{array}{l}\text { Quasi/non- } \\
\text { randomized } \\
\text { trial }\end{array}$ & Kliner 2015 & $\begin{array}{l}\text { Payment } \\
\text { per output }\end{array}$ & $\begin{array}{l}\text { Con- } \\
\text { trol: } \\
\text { Stan- } \\
\text { dard } \\
\text { care or } \\
\text { status } \\
\text { quo }\end{array}$ & $\begin{array}{l}\text { Extrac- } \\
\text { tion } \\
\text { from TB } \\
\text { registry. } \\
\text { Collect- } \\
\text { ed by } \\
\text { study } \\
\text { authors. }\end{array}$ & $\begin{array}{l}\text { Baseline: } \\
\text { 1st January } \\
\text { 2010. End- } \\
\text { line: 30th } \\
\text { September } \\
\text { 2011. Fol- } \\
\text { low-up: } 21 \\
\text { months. }\end{array}$ & $\begin{array}{l}\text { Logistic regression with stepwise selection of covariates } \\
\text { into models (Age (0-14, } 15-24 \text { vs over } 35 \text { reference cat- } \\
\text { egory), TB (any new case or previously treated/TB with } \\
\text { meningitis) with children under } 8 \text { as reference), HIV sta- } \\
\text { tus, being on ART) }\end{array}$ & $\begin{array}{l}8 \text { TB spe- } \\
\text { cific out- } \\
\text { comes }\end{array}$ \\
\hline \multirow[t]{2}{*}{ Tanzania } & CBA & $\begin{array}{l}\text { Binyaruka } \\
2015\end{array}$ & $\begin{array}{l}\text { Target pay- } \\
\text { ment }\end{array}$ & $\begin{array}{l}\text { Con- } \\
\text { trol: } \\
\text { Stan- } \\
\text { dard } \\
\text { care or } \\
\text { status } \\
\text { quo }\end{array}$ & $\begin{array}{l}\text { House- } \\
\text { hold sur- } \\
\text { veys; ex- } \\
\text { it inter- } \\
\text { views; } \\
\text { facility } \\
\text { surveys. } \\
\text { Collec- } \\
\text { tion by } \\
\text { study } \\
\text { authors. }\end{array}$ & $\begin{array}{l}\text { Baseline: } \\
\text { January } \\
2012 \text { (after } \\
\text { P4P train- } \\
\text { ing took } \\
\text { place in sec- } \\
\text { ond half of } \\
\text { 2011). End- } \\
\text { line: March } \\
\text { 2013. Fol- } \\
\text { low-up: } 13 \\
\text { months. }\end{array}$ & $\begin{array}{l}\text { Difference in difference, ordinary least squares, clus- } \\
\text { tered at facility level or facility catchment area. Con- } \\
\text { trolling for individual level characteristics (education, } \\
\text { religion, marital status, occupation, age, number of } \\
\text { pregnancies) and household characteristics (insurance, } \\
\text { number of household members, household head edu- } \\
\text { cation, wealth based on ownership of household assets } \\
\text { and housing particulars) }\end{array}$ & $\begin{array}{l}146 \text { out- } \\
\text { comes } \\
\text { around } \\
\text { medicine } \\
\text { and equip- } \\
\text { ment re- } \\
\text { sources, } \\
\text { cost of } \\
\text { care, pa- } \\
\text { tient sat- } \\
\text { isfaction, } \\
\text { and RM- } \\
\mathrm{NCH} \text { ser- } \\
\text { vices }\end{array}$ \\
\hline & & $\begin{array}{l}\text { Binyaruka } \\
2017\end{array}$ & $\begin{array}{l}\text { Target pay- } \\
\text { ment }\end{array}$ & $\begin{array}{l}\text { Con- } \\
\text { trol: } \\
\text { Stan- } \\
\text { dard } \\
\text { care or } \\
\text { status } \\
\text { quo }\end{array}$ & $\begin{array}{l}\text { Health } \\
\text { facility } \\
\text { surveys; } \\
\text { house- } \\
\text { hold sur- } \\
\text { vey. Un- } \\
\text { clear } \\
\text { who col- } \\
\text { lected }\end{array}$ & $\begin{array}{l}\text { Baseline: } \\
\text { January } \\
\text { 2012. End- } \\
\text { line: March } \\
\text { 2013. Fol- } \\
\text { low-up: } 13 \\
\text { months. }\end{array}$ & $\begin{array}{l}\text { Difference in difference regression models controlling } \\
\text { for time invariant determinants, facility fixed effects. }\end{array}$ & $\begin{array}{l}103 \text { out- } \\
\text { comes } \\
\text { around } \\
\text { medicine } \\
\text { and equip- } \\
\text { ment re- } \\
\text { sources, } \\
\text { includ- } \\
\text { ing equity }\end{array}$ \\
\hline
\end{tabular}




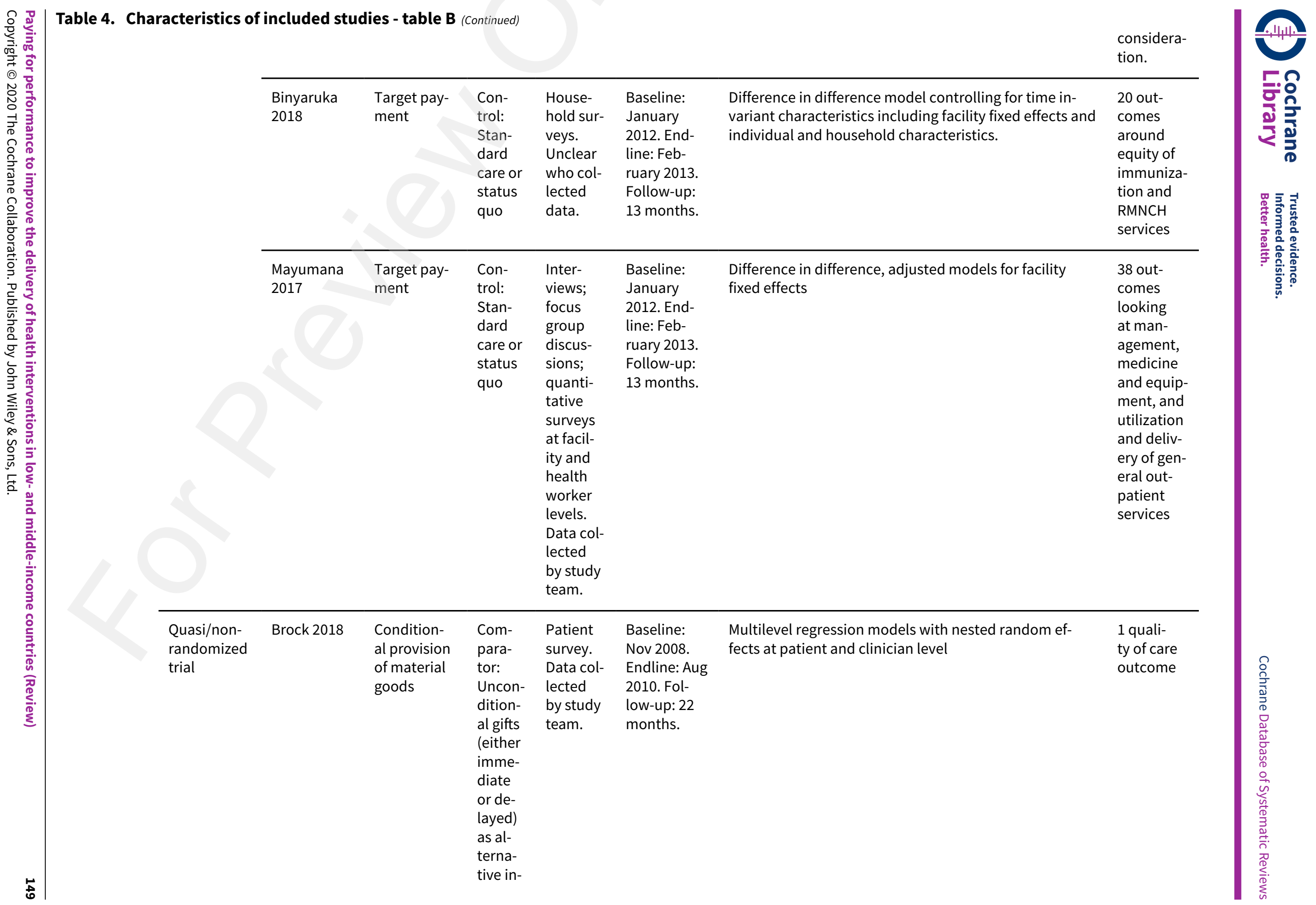




\begin{tabular}{|c|c|c|c|c|c|c|c|c|c|}
\hline & & 2 & 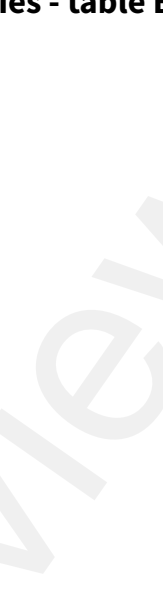 & $\begin{array}{l}\text { terven- } \\
\text { tions } \\
\text { and } \\
\text { control } \\
\text { (all re- } \\
\text { ceive } \\
\text { a stan- } \\
\text { dard } \\
\text { en- } \\
\text { cour- } \\
\text { age- } \\
\text { ment } \\
\text { inter- } \\
\text { ven- } \\
\text { tion) }\end{array}$ & & & & & 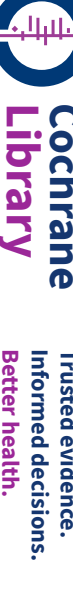 \\
\hline Zambia & ITS & Chansa 2015 & $\begin{array}{l}\text { Payment } \\
\text { per output } \\
\text { modified } \\
\text { by quality } \\
\text { score }\end{array}$ & $\begin{array}{l}\text { Over } \\
\text { time: } \\
\text { Com- } \\
\text { par- } \\
\text { ison } \\
\text { over } \\
\text { time. }\end{array}$ & $\begin{array}{l}\text { HMIS da- } \\
\text { ta export } \\
\text { by study } \\
\text { team. }\end{array}$ & $\begin{array}{l}\text { Baseline: } \\
\text { January } \\
\text { 2006. End- } \\
\text { line: March } \\
\text { 2012. Fol- } \\
\text { low-up: } 14 \\
\text { quarters } \\
\text { (3.5 years). }\end{array}$ & ITS - simulated modelling analysis & $\begin{array}{l}4 \text { out- } \\
\text { comes } \\
\text { looking at } \\
\text { utilization } \\
\text { and deliv- } \\
\text { ery of im- } \\
\text { muniza- } \\
\text { tion, RM- } \\
\mathrm{NCH} \text {, and } \\
\text { outpatient } \\
\text { services }\end{array}$ & \\
\hline & $\mathrm{RCT}$ & $\begin{array}{l}\text { Friedman } \\
2016 a\end{array}$ & $\begin{array}{l}\text { Payment } \\
\text { per output } \\
\text { modified } \\
\text { by quality } \\
\text { score }\end{array}$ & $\begin{array}{l}\text { Con- } \\
\text { trol } \\
\text { and } \\
\text { Com- } \\
\text { para- } \\
\text { tor. } \\
\text { Con- } \\
\text { trol: } \\
\text { Stan- } \\
\text { dard } \\
\text { care or } \\
\text { status } \\
\text { quo. } \\
\text { Com- } \\
\text { para- } \\
\text { tor: } \\
\text { Matched }\end{array}$ & $\begin{array}{l}\text { House- } \\
\text { hold and } \\
\text { health } \\
\text { facility } \\
\text { surveys; } \\
\text { process } \\
\text { evalu- } \\
\text { ation } \\
\text { data; } \\
\text { counter } \\
\text { exter- } \\
\text { nal eval- } \\
\text { uation. } \\
\text { Enumer- } \\
\text { ators } \\
\text { hired as } \\
\text { part of }\end{array}$ & $\begin{array}{l}\text { Baseline: } \\
\text { October-No- } \\
\text { vember } \\
2011 \text {. End- } \\
\text { line: Novem- } \\
\text { ber 2014- } \\
\text { January } \\
\text { 2015. Fol- } \\
\text { low-up: } 3 \\
\text { years. }\end{array}$ & $\begin{array}{l}\text { Difference in difference and regression models - depen- } \\
\text { dent on outcome, controls for district stratification or at } \\
\text { province level, and errors clustered at the Primary Sam- } \\
\text { pling Unit or district level. }\end{array}$ & $\begin{array}{l}386 \text { out- } \\
\text { comes } \\
\text { around } \\
\text { staff sat- } \\
\text { isfaction, } \\
\text { manage- } \\
\text { ment, pa- } \\
\text { tient sat- } \\
\text { isfaction, } \\
\text { quality of } \\
\text { RMNCH } \\
\text { care, uti- } \\
\text { lization of } \\
\text { RMNCH } \\
\text { services, } \\
\text { medicine } \\
\text { and equip- }\end{array}$ & 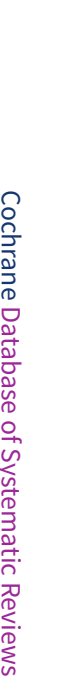 \\
\hline
\end{tabular}




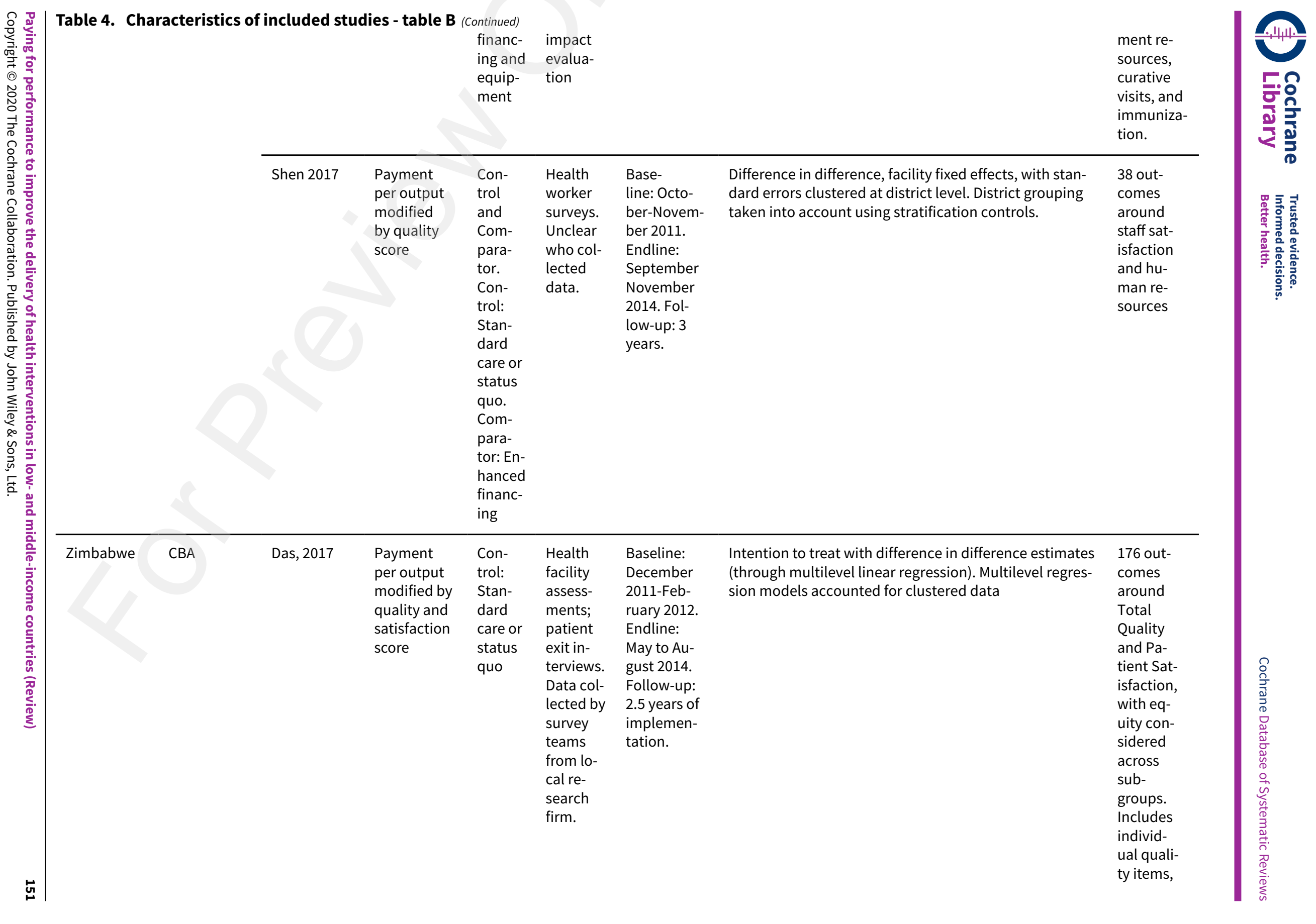


ity type,

provider

cadre,

provider

gender,

patient

character-

istics and

wealth

quintile.

$\begin{array}{llll}\text { Payment } & \text { Con- } & \text { Facili- } & \text { Baseline: } \\ \text { per output } & \text { trol: } & \text { ty and } & \text { Dec 2011- } \\ \text { modified by } & \text { Stan- } & \text { house- } & \text { Feb 2012. } \\ \text { quality and } & \text { dard } & \text { hold sur- } & \text { Endline: } \\ \text { equity score } & \text { care or } & \text { veys; di- } & \text { Midline: } \\ & \text { status } & \text { rect ob- } & \text { May-August } \\ & \text { quo } & \text { serva- } & \text { 2014. Fol- } \\ & & \text { tions. } & \text { low-up: } 2.5\end{array}$

Difference in difference and regression models - depen-

354 out-

Quasi/Non- Friedman

randomized 2016b

trial dent on outcome, controls for district stratification or at

province level, and errors clustered at the district level.

comes in-

cluding

utilization

outcomes,

quality of

care, facil-

ity man-

agement, 


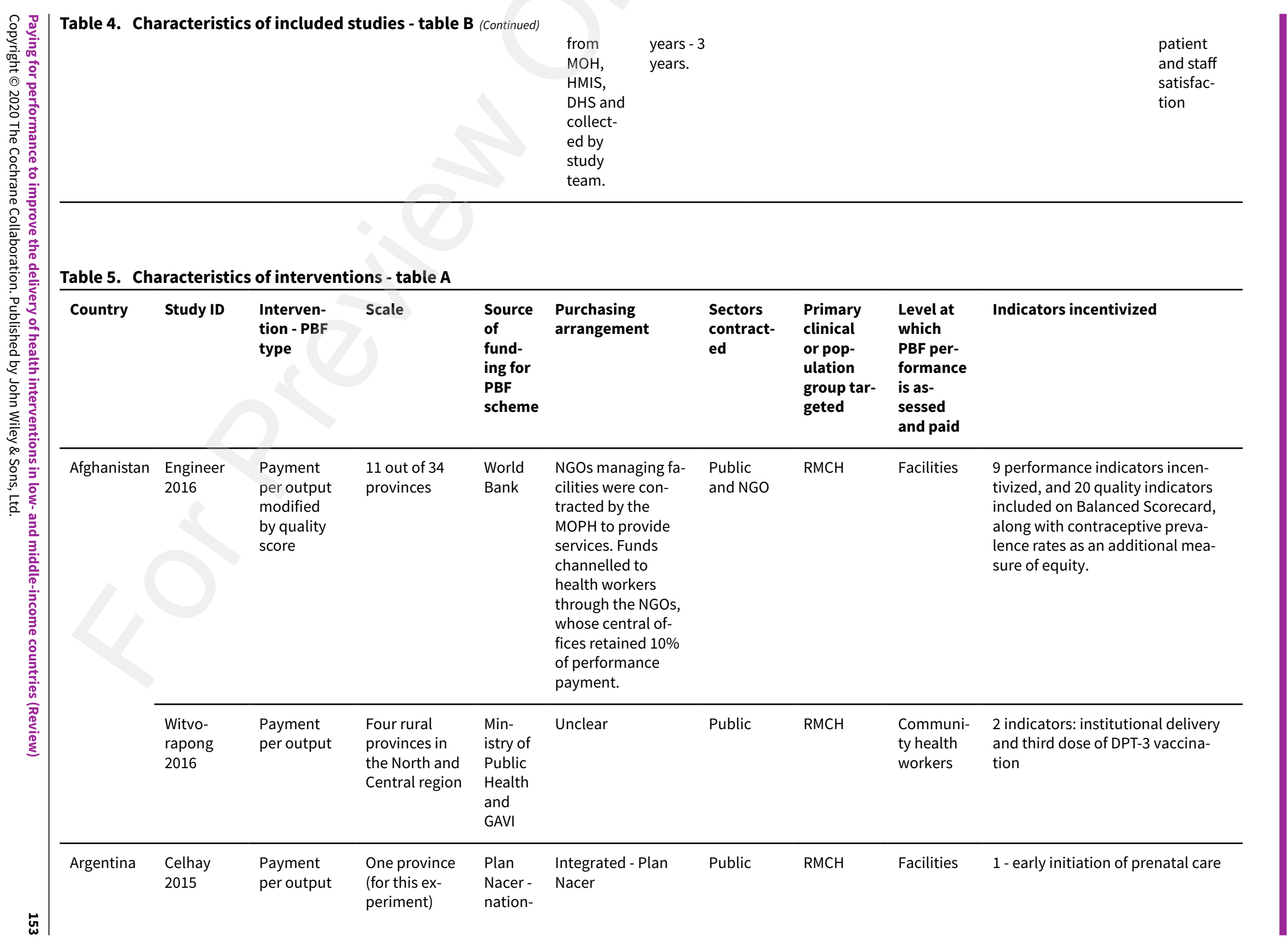




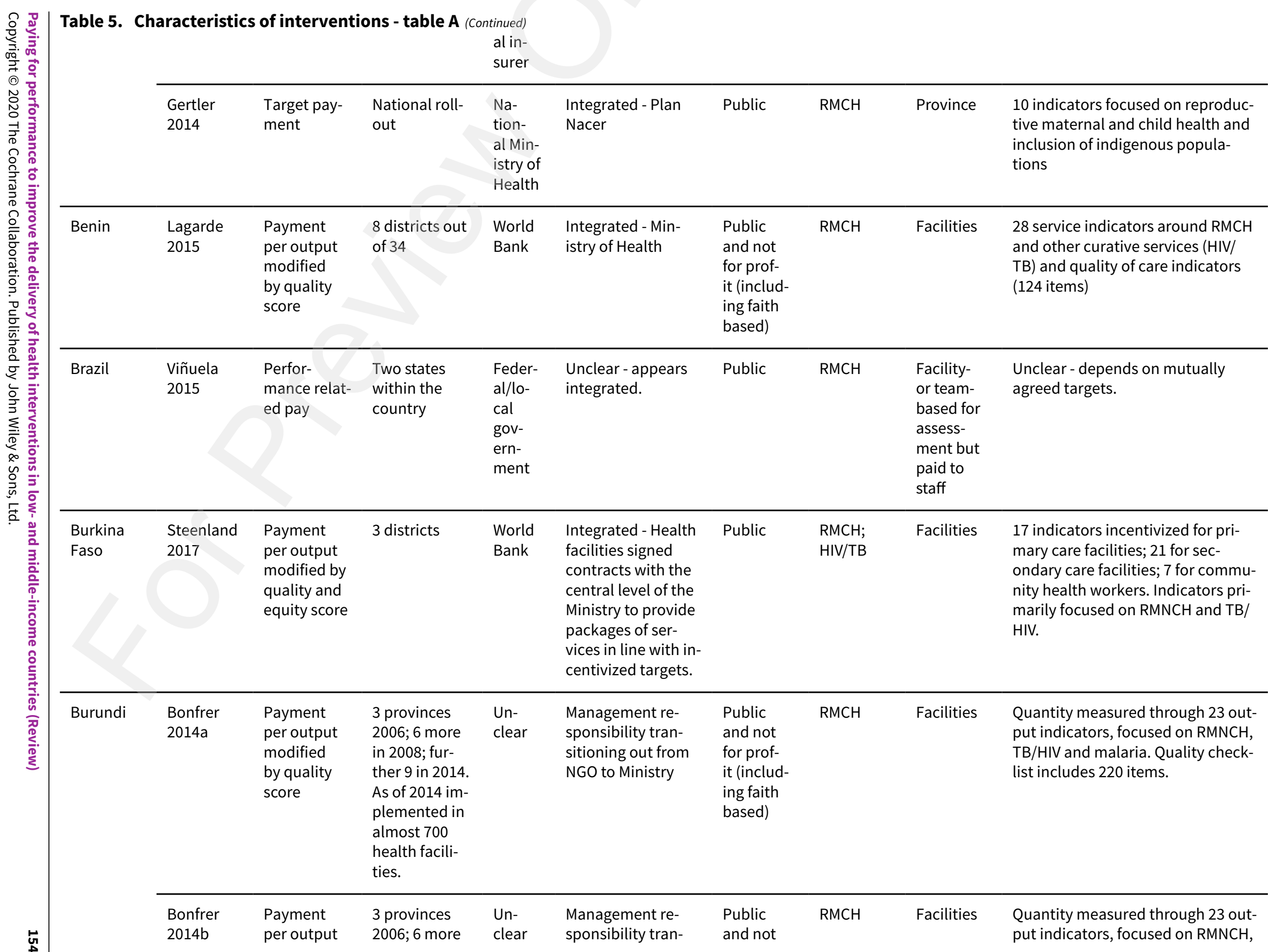




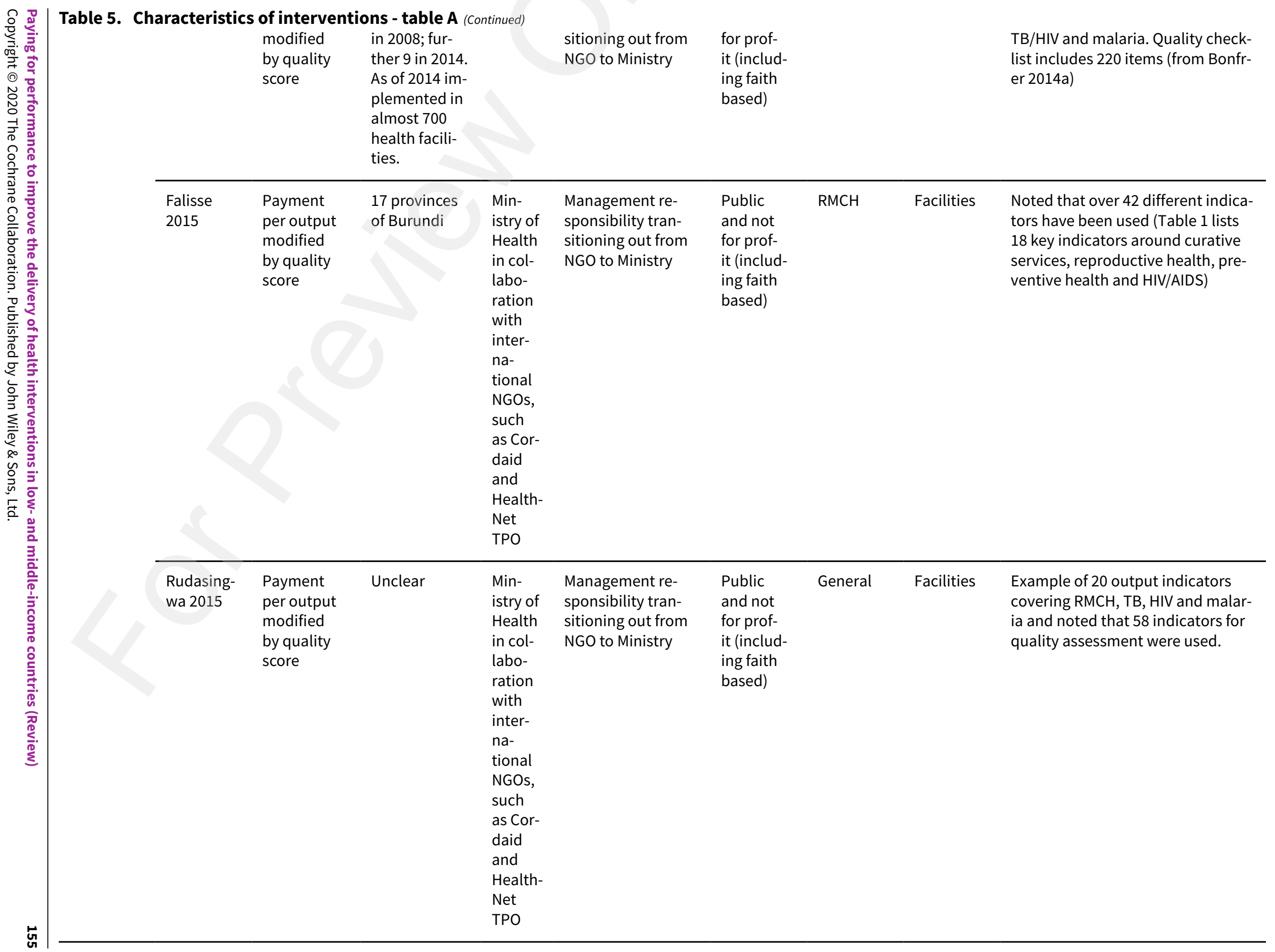




\begin{tabular}{|c|c|c|c|c|c|c|c|c|c|}
\hline Cambodia & Ir 2015 & $\begin{array}{l}\text { Payment } \\
\text { per output }\end{array}$ & $\begin{array}{l}\text { National roll- } \\
\text { out from Oc- } \\
\text { tober } 2007 \text {. }\end{array}$ & $\begin{array}{l}\text { Royal } \\
\text { Gov- } \\
\text { ern- } \\
\text { ment } \\
\text { of } \\
\text { Cam- } \\
\text { bodia }\end{array}$ & $\begin{array}{l}\text { Integrated - Min- } \\
\text { istry of Health }\end{array}$ & Public & $\mathrm{RMCH}$ & $\begin{array}{l}\text { Health } \\
\text { workers }\end{array}$ & $10 \mathrm{RMCH}$ indicators \\
\hline & Khim 2018 & $\begin{array}{l}\text { Perfor- } \\
\text { mance } \\
\text { based ser- } \\
\text { vice agree- } \\
\text { ments }\end{array}$ & $\begin{array}{l}\text { National roll- } \\
\text { out }\end{array}$ & $\begin{array}{l}\text { Un- } \\
\text { clear }\end{array}$ & $\begin{array}{l}\text { External contract- } \\
\text { ing with aid agen- } \\
\text { cies }\end{array}$ & Public & $\begin{array}{l}\text { General; } \\
\mathrm{RMCH}\end{array}$ & Facilities & $4 \mathrm{RMCH}$ indicators \\
\hline & $\begin{array}{l}\text { Matsuoka } \\
2014\end{array}$ & $\begin{array}{l}\text { Payment } \\
\text { per output }\end{array}$ & Ten districts & GAVI & $\begin{array}{l}\text { External contract- } \\
\text { ing with GAVI and } \\
\text { internal purchasing } \\
\text { supplementing }\end{array}$ & Public & $\mathrm{RMCH}$ & Facilities & $2 \mathrm{ANC}$ and immunization indicators \\
\hline & $\begin{array}{l}\text { Van de } \\
\text { Poel } 2015\end{array}$ & $\begin{array}{l}\text { Perfor- } \\
\text { mance } \\
\text { based con- } \\
\text { tracting }\end{array}$ & $\begin{array}{l}\text { Depends on } \\
\text { period of roll- } \\
\text { out - most of } \\
\text { Cambodia }\end{array}$ & $\begin{array}{l}\text { Un- } \\
\text { clear }\end{array}$ & $\begin{array}{l}\text { Management re- } \\
\text { sponsibility tran- } \\
\text { sitioning out from } \\
\text { NGO to Ministry }\end{array}$ & Public & $\mathrm{RMCH}$ & District & $\begin{array}{l}\text { Unclear - different types of targets } \\
\text { noted for the different schemes. }\end{array}$ \\
\hline Cameroon & Zang 2015 & $\begin{array}{l}\text { Payment } \\
\text { per output } \\
\text { modified by } \\
\text { quality and } \\
\text { equity score }\end{array}$ & One region & $\begin{array}{l}\text { World } \\
\text { Bank }\end{array}$ & $\begin{array}{l}\text { Unclear - precur- } \\
\text { sor of program } \\
\text { de Walque as- } \\
\text { sesses, so likely } \\
\text { similar purchas- } \\
\text { ing through au- } \\
\text { tonomous purchas- } \\
\text { ing agencies. }\end{array}$ & Unclear & Unclear & $\begin{array}{l}\text { Health } \\
\text { workers }\end{array}$ & Unclear \\
\hline & $\begin{array}{l}\text { De Walque } \\
2017\end{array}$ & $\begin{array}{l}\text { Payment } \\
\text { per output } \\
\text { modified by } \\
\text { quality and } \\
\text { equity score }\end{array}$ & 26 districts & $\begin{array}{l}\text { World } \\
\text { Bank }\end{array}$ & $\begin{array}{l}\text { Autonomous pur- } \\
\text { chasing agencies } \\
\text { with contractual } \\
\text { agreement to } \mathrm{MoH} \\
\text { and government }\end{array}$ & Public & Unclear & Facilities & $\begin{array}{l}23 \text { indicators; } 7 \text { around curative } \\
\text { care; } 10 \text { around preventive services } \\
\text { - vaccinations, HIV and TB, STIs } \\
\text { etc.; } 6 \text { around reproductive health }\end{array}$ \\
\hline China & $\begin{array}{l}\text { Chang } \\
2017\end{array}$ & $\begin{array}{l}\text { Payment } \\
\text { per output }\end{array}$ & Hospital & $\begin{array}{l}\text { Un- } \\
\text { clear }\end{array}$ & $\begin{array}{l}\text { Integrated - hospi- } \\
\text { tal level }\end{array}$ & Public & General & $\begin{array}{l}\text { Health } \\
\text { workers } \\
\text { and facili- } \\
\text { ties }\end{array}$ & $\begin{array}{l}\text { Reporting of adverse drug reac- } \\
\text { tions }\end{array}$ \\
\hline
\end{tabular}




\begin{tabular}{|c|c|c|c|c|c|c|c|c|c|}
\hline & Yao 2008 & $\begin{array}{l}\text { Payment } \\
\text { per output }\end{array}$ & One province & $\begin{array}{l}\text { Fidelis } \\
\text { project }\end{array}$ & $\begin{array}{l}\text { Integrated - Min- } \\
\text { istry of Health }\end{array}$ & Public & TB & $\begin{array}{l}\text { Health } \\
\text { workers } \\
\text { and village } \\
\text { leaders }\end{array}$ & 2 tuberculosis outcomes \\
\hline & $\begin{array}{l}\text { Pow- } \\
\text { ell-Jack- } \\
\text { son } 2014\end{array}$ & $\begin{array}{l}\text { Payment } \\
\text { per output } \\
\text { and for tar- } \\
\text { get }\end{array}$ & $\begin{array}{l}\text { One region } \\
\text { - Ningxia } \\
\text { province }\end{array}$ & $\begin{array}{l}\text { Un- } \\
\text { clear }\end{array}$ & $\begin{array}{l}\text { Integrated - Min- } \\
\text { istry of Health }\end{array}$ & Public & Unclear & Facilities & $\begin{array}{l}\text { Multiple antibiotic prescription } \\
\text { indicators, patient satisfaction } \\
\text { indicators and process of care } \\
\text { measures for common acute and } \\
\text { chronic conditions. }\end{array}$ \\
\hline & Yip 2014 & $\begin{array}{l}\text { Capitation } \\
\text { and PBF }\end{array}$ & One region & $\begin{array}{l}\text { New } \\
\text { Coop- } \\
\text { erative } \\
\text { Med- } \\
\text { ical } \\
\text { Scheme }\end{array}$ & $\begin{array}{l}\text { Integrated - Min- } \\
\text { istry of Health }\end{array}$ & Public & General & Facilities & Unclear - see Powell Jackson 2014 \\
\hline & Wu 2014 & $\begin{array}{l}\text { Target pay- } \\
\text { ment }\end{array}$ & Hospital & $\begin{array}{l}\text { Un- } \\
\text { clear }\end{array}$ & $\begin{array}{l}\text { Integrated - hospi- } \\
\text { tal level }\end{array}$ & Public & General & $\begin{array}{l}\text { Health } \\
\text { workers }\end{array}$ & $\begin{array}{l}\text { One drug sale ratio to revenue re- } \\
\text { lated indicator }\end{array}$ \\
\hline & $\begin{array}{l}\text { Liu and } \\
\text { Mills } 2005\end{array}$ & $\begin{array}{l}\text { Payment } \\
\text { per output }\end{array}$ & $\begin{array}{l}\text { National roll- } \\
\text { out }\end{array}$ & $\begin{array}{l}\text { Min- } \\
\text { istry of } \\
\text { Health }\end{array}$ & $\begin{array}{l}\text { Integrated - Min- } \\
\text { istry of Health }\end{array}$ & Public & General & $\begin{array}{l}\text { Health } \\
\text { workers }\end{array}$ & $\begin{array}{l}\text { Under flat bonus - no indicators } \\
\text { incentivized. Under quantity-re- } \\
\text { lated bonus } 7 \text { indicator areas } \\
\text { around service provision. Under } \\
\text { revenue-related bonus, bonus for } \\
\text { revenue over a revenue target (rev- } \\
\text { enue from provision of services } \\
\text { and drugs) }\end{array}$ \\
\hline & Sun 2014 & $\begin{array}{l}\text { Capitation } \\
\text { and PBF }\end{array}$ & Two provinces & $\begin{array}{l}\text { New } \\
\text { Coop- } \\
\text { erative } \\
\text { Med- } \\
\text { ical } \\
\text { Scheme }\end{array}$ & $\begin{array}{l}\text { Integrated - Min- } \\
\text { istry of Health }\end{array}$ & Public & General & Facilities & $\begin{array}{l}10 \text { prescription related quality of } \\
\text { care indicators }\end{array}$ \\
\hline Congo & $\begin{array}{l}\text { Zeng } \\
\text { 2018a }\end{array}$ & $\begin{array}{l}\text { Payment } \\
\text { per output } \\
\text { modified } \\
\text { by quality } \\
\text { score }\end{array}$ & Three regions & $\begin{array}{l}\text { World } \\
\text { Bank }\end{array}$ & $\begin{array}{l}\text { External purchaser } \\
\text { - CORDAID }\end{array}$ & Unclear & General & $\begin{array}{l}\text { Facilities } \\
\text { and dis- } \\
\text { trict }\end{array}$ & $\begin{array}{l}25 \text { indicators covering general pop- } \\
\text { ulation services, HIV/AIDS, RMNCH }\end{array}$ \\
\hline
\end{tabular}




\begin{tabular}{|c|c|c|c|c|c|c|c|c|c|}
\hline $\begin{array}{l}\text { Democra- } \\
\text { tic Repub- } \\
\text { lic of the } \\
\text { Congo }\end{array}$ & $\begin{array}{l}\text { Huillery } \\
2017\end{array}$ & $\begin{array}{l}\text { Payment } \\
\text { per output }\end{array}$ & Unclear & $\begin{array}{l}\text { Un- } \\
\text { clear }\end{array}$ & $\begin{array}{l}\text { Integrated - Min- } \\
\text { istry of Health }\end{array}$ & $\begin{array}{l}\text { Mix - pub- } \\
\text { lic, private } \\
\text { and faith } \\
\text { based }\end{array}$ & $\mathrm{RMCH}$ & Facilities & $10 \mathrm{RMCH}$ indicators \\
\hline & $\begin{array}{l}\text { Soeters } \\
2011\end{array}$ & $\begin{array}{l}\text { Payment } \\
\text { per output } \\
\text { modified } \\
\text { by quality } \\
\text { score }\end{array}$ & Two districts & $\begin{array}{l}\text { COR- } \\
\text { DAID }\end{array}$ & Unclear & $\begin{array}{l}\text { Public } \\
\text { and not } \\
\text { for prof- } \\
\text { it (includ- } \\
\text { ing faith } \\
\text { based) }\end{array}$ & $\mathrm{RMCH}$ & Facilities & $\begin{array}{l}\text { Unclear - appears } 9 \text { indicators for } \\
\mathrm{RMCH} \text { and malaria }\end{array}$ \\
\hline $\begin{array}{l}\text { El Sal- } \\
\text { vador }\end{array}$ & $\begin{array}{l}\text { Bernal } \\
2018\end{array}$ & $\begin{array}{l}\text { Results } \\
\text { based aid }\end{array}$ & $\begin{array}{l}14 \text { municipal- } \\
\text { ities }\end{array}$ & $\begin{array}{l}\text { Salud } \\
\text { MesoAme } \\
\text { icana }\end{array}$ & $\begin{array}{l}\text { External purchaser } \\
\text { - Salud Mesoamer- } \\
\text { icana, via MoH } \\
\text { channels }\end{array}$ & Public & $\mathrm{RMCH}$ & $\begin{array}{l}\text { Municipal- } \\
\text { ity }\end{array}$ & $\begin{array}{l}10-11 \text { indicators on delivery of RM- } \\
\mathrm{CH} \text { care and quality }\end{array}$ \\
\hline Haiti & Zeng 2013 & $\begin{array}{l}\text { Perfor- } \\
\text { mance } \\
\text { based con- } \\
\text { tracting }\end{array}$ & $\begin{array}{l}\text { All NGOs sup- } \\
\text { ported by } \\
\text { USAID }\end{array}$ & $\begin{array}{l}\text { USAID } \\
\text { via } \\
\text { MSH }\end{array}$ & $\begin{array}{l}\text { External NGO man- } \\
\text { agement and pur- } \\
\text { chasing }\end{array}$ & NGO & $\begin{array}{l}\mathrm{RMCH} \\
\mathrm{HIV} / \mathrm{TB}\end{array}$ & Facilities & $\begin{array}{l}14 \text { potential indicators covering } \\
\text { RMCH, TB/HIV services and their } \\
\text { quality }\end{array}$ \\
\hline India & $\begin{array}{l}\text { Mohanan } \\
2017\end{array}$ & $\begin{array}{l}\text { Target pay- } \\
\text { ment or } \\
\text { payment } \\
\text { per input }\end{array}$ & $\begin{array}{l}\text { Karnataka } \\
\text { state }\end{array}$ & $\begin{array}{l}\text { Un- } \\
\text { clear }\end{array}$ & $\begin{array}{l}\text { External - study au- } \\
\text { thors }\end{array}$ & Private & $\mathrm{RMCH}$ & $\begin{array}{l}\text { Health } \\
\text { workers }\end{array}$ & $\begin{array}{l}\text { Inputs for offering care or } 4 \text { out- } \\
\text { puts related to minimizing adverse } \\
\text { events during pregnancy/child } \\
\text { birth }\end{array}$ \\
\hline Kenya & $\begin{array}{l}\text { Menya } \\
2015\end{array}$ & $\begin{array}{l}\text { Target pay- } \\
\text { ment }\end{array}$ & $\begin{array}{l}\text { One city and } \\
18 \text { health cen- } \\
\text { tres }\end{array}$ & $\begin{array}{l}\text { Un- } \\
\text { clear }\end{array}$ & $\begin{array}{l}\text { Unclear - presum- } \\
\text { ably via routine } \\
\text { mechanism }\end{array}$ & Public & $\mathrm{RMCH}$ & Facilities & 7 malaria specific indicators \\
\hline Malawi & $\begin{array}{l}\text { McMahon } \\
2016\end{array}$ & $\begin{array}{l}\text { Payment } \\
\text { per output } \\
\text { modified } \\
\text { by quality } \\
\text { score }\end{array}$ & Three districts & $\begin{array}{l}\text { USAID, } \\
\text { with } \\
\text { JPHIEGO } \\
\text { as im- } \\
\text { ple- } \\
\text { menter }\end{array}$ & $\begin{array}{l}\text { Integrated - Min- } \\
\text { istry of Health }\end{array}$ & Public & $\begin{array}{l}\mathrm{RMCH} \\
\mathrm{HIV} / \mathrm{TB}\end{array}$ & Facilities & $\begin{array}{l}13 \mathrm{RMCH} \text { indicators and } 13 \text { quality } \\
\text { dimensions }\end{array}$ \\
\hline $\begin{array}{l}\text { Multiple } \\
\text { - Burki- } \\
\text { na Faso, } \\
\text { Ghana and } \\
\text { Tanzania }\end{array}$ & $\begin{array}{l}\text { Duysburgh } \\
2015\end{array}$ & $\begin{array}{l}\text { Financial } \\
\text { and non-fi- } \\
\text { nancial in- } \\
\text { centives + } \\
\text { clinical deci- } \\
\text { sion guide }\end{array}$ & $\begin{array}{l}6 \text { rural dis- } \\
\text { tricts } 2 \text { per } \\
\text { each of three } \\
\text { countries }\end{array}$ & $\begin{array}{l}\text { Un- } \\
\text { clear }\end{array}$ & Unclear & Unclear & $\mathrm{RMCH}$ & $\begin{array}{l}\text { Book } \\
\text { awards } \\
\text { to health } \\
\text { workers; } \\
\text { health fa- } \\
\text { cilities are }\end{array}$ & Unclear - likely to differ by country \\
\hline
\end{tabular}




\begin{tabular}{|c|c|c|c|c|c|c|c|c|c|}
\hline & & & & & & & & $\begin{array}{l}\text { receiving } \\
\text { money } \\
\text { (Burkina); } \\
\text { others are } \\
\text { not clear }\end{array}$ & \\
\hline Peru & $\begin{array}{l}\text { Cruzado } \\
\text { de la Vega, } \\
2017\end{array}$ & $\begin{array}{l}\text { Payment } \\
\text { per output } \\
\text { and for tar- } \\
\text { get }\end{array}$ & $\begin{array}{l}\text { Sub-nation- } \\
\text { al three re- } \\
\text { gions in Pe- } \\
\text { ru with the } \\
\text { highest rates } \\
\text { of chronic } \\
\text { malnutrition } \\
\text { (CM) in chil- } \\
\text { dren in 2008- } \\
\text { Apurimac, Ay- } \\
\text { acucho, and } \\
\text { Huancavelica }\end{array}$ & $\begin{array}{l}\text { Peru- } \\
\text { vian } \\
\text { gov- } \\
\text { ern- } \\
\text { ment }\end{array}$ & $\begin{array}{l}\text { Integrated nation- } \\
\text { ally - Contracting } \\
\text { with regional gov- } \\
\text { ernments and Min- } \\
\text { istry of Finance }\end{array}$ & Public & $\mathrm{RMCH}$ & $\begin{array}{l}\text { Sub-na- } \\
\text { tional } \\
\text { organi- } \\
\text { sations } \\
\text { (health } \\
\text { adminis- } \\
\text { trations, } \\
\text { NGOs or } \\
\text { local gov- } \\
\text { ernments) }\end{array}$ & $\begin{array}{l}12 \mathrm{RMCH} \text { indicators, focus on child } \\
\text { health }\end{array}$ \\
\hline $\begin{array}{l}\text { Philip- } \\
\text { pines }\end{array}$ & $\begin{array}{l}\text { Peabody } \\
2011\end{array}$ & $\begin{array}{l}\text { Target pay- } \\
\text { ment }\end{array}$ & 10 hospitals & $\begin{array}{l}\text { Phil- } \\
\text { Health }\end{array}$ & $\begin{array}{l}\text { Integrated - Na- } \\
\text { tional Health In- } \\
\text { surance }\end{array}$ & Public & $\mathrm{RMCH}$ & Facilities & $\begin{array}{l}\text { Vignette scores focused on com- } \\
\text { mon childhood conditions }\end{array}$ \\
\hline & $\begin{array}{l}\text { Quimbo } \\
2016\end{array}$ & $\begin{array}{l}\text { Target pay- } \\
\text { ment }\end{array}$ & 10 hospitals & $\begin{array}{l}\text { Phil- } \\
\text { Health }\end{array}$ & $\begin{array}{l}\text { Integrated - Na- } \\
\text { tional Health In- } \\
\text { surance }\end{array}$ & Public & $\mathrm{RMCH}$ & Facilities & $\begin{array}{l}\text { Vignette scores focused on com- } \\
\text { mon childhood conditions }\end{array}$ \\
\hline & $\begin{array}{l}\text { Wagner } \\
2018\end{array}$ & $\begin{array}{l}\text { Target pay- } \\
\text { ment }\end{array}$ & 10 hospitals & $\begin{array}{l}\text { Phil- } \\
\text { Health }\end{array}$ & $\begin{array}{l}\text { Integrated - Na- } \\
\text { tional Health In- } \\
\text { surance }\end{array}$ & Public & $\mathrm{RMCH}$ & Facilities & $\begin{array}{l}\text { Vignette scores focused on com- } \\
\text { mon childhood conditions }\end{array}$ \\
\hline & $\begin{array}{l}\text { Peabody } \\
2014\end{array}$ & $\begin{array}{l}\text { Target pay- } \\
\text { ment }\end{array}$ & 10 hospitals & $\begin{array}{l}\text { Phil- } \\
\text { Health }\end{array}$ & $\begin{array}{l}\text { Integrated - Na- } \\
\text { tional Health In- } \\
\text { surance }\end{array}$ & Public & $\mathrm{RMCH}$ & Facilities & $\begin{array}{l}\text { Vignette scores focused on com- } \\
\text { mon childhood conditions }\end{array}$ \\
\hline Rwanda & $\begin{array}{l}\text { Basinga } \\
2011\end{array}$ & $\begin{array}{l}\text { Payment } \\
\text { per output } \\
\text { modified } \\
\text { by quality } \\
\text { score }\end{array}$ & $\begin{array}{l}\text { National roll- } \\
\text { out (expan- } \\
\text { sion to } 19 \text { dis- } \\
\text { tricts which } \\
\text { did not have } \\
\text { PBF yet) }\end{array}$ & $\begin{array}{l}\text { Gov- } \\
\text { ern- } \\
\text { mental } \\
\text { organi- } \\
\text { sation }\end{array}$ & $\begin{array}{l}\text { Integrated - Min- } \\
\text { istry of Health }\end{array}$ & $\begin{array}{l}\text { Public } \\
\text { and not } \\
\text { for prof- } \\
\text { it (includ- } \\
\text { ing faith } \\
\text { based) }\end{array}$ & $\mathrm{RMCH}$ & Facilities & $\begin{array}{l}7 \text { outreach indicators, } 7 \text { content of } \\
\text { care indicators, } 13 \text { quality domains }\end{array}$ \\
\hline & $\begin{array}{l}\text { Lannes } \\
2016\end{array}$ & $\begin{array}{l}\text { Payment } \\
\text { per output } \\
\text { modified }\end{array}$ & $\begin{array}{l}\text { National roll- } \\
\text { out (expan- } \\
\text { sion to } 19 \text { dis- }\end{array}$ & $\begin{array}{l}\text { Gov- } \\
\text { ern- } \\
\text { mental }\end{array}$ & $\begin{array}{l}\text { Integrated - Min- } \\
\text { istry of Health }\end{array}$ & $\begin{array}{l}\text { Public } \\
\text { and not } \\
\text { for prof- }\end{array}$ & $\mathrm{RMCH}$ & Facilities & $\begin{array}{l}7 \text { outreach indicators, } 7 \text { content of } \\
\text { care indicators, } 13 \text { quality domains }\end{array}$ \\
\hline
\end{tabular}


Table 5. Characteristics of interventions - table $\mathbf{A}$ (Continued)

\begin{tabular}{|c|c|c|c|c|c|c|c|c|}
\hline & $\begin{array}{l}\text { by quality } \\
\text { score }\end{array}$ & $\begin{array}{l}\text { tricts which } \\
\text { did not have } \\
\text { PBF yet) }\end{array}$ & $\begin{array}{l}\text { organi- } \\
\text { sation }\end{array}$ & & $\begin{array}{l}\text { it (includ- } \\
\text { ing faith } \\
\text { based) }\end{array}$ & & & \\
\hline $\begin{array}{l}\text { Priede- } \\
\text { man Skiles } \\
2013\end{array}$ & $\begin{array}{l}\text { Payment } \\
\text { per output } \\
\text { modified } \\
\text { by quality } \\
\text { score }\end{array}$ & $\begin{array}{l}\text { National roll- } \\
\text { out (expan- } \\
\text { sion to } 19 \text { dis- } \\
\text { tricts which } \\
\text { did not have } \\
\text { PBF yet) }\end{array}$ & $\begin{array}{l}\text { Gov- } \\
\text { ern- } \\
\text { mental } \\
\text { organi- } \\
\text { sation }\end{array}$ & $\begin{array}{l}\text { Integrated - Min- } \\
\text { istry of Health }\end{array}$ & $\begin{array}{l}\text { Public } \\
\text { and not } \\
\text { for prof- } \\
\text { it (includ- } \\
\text { ing faith } \\
\text { based) }\end{array}$ & $\mathrm{RMCH}$ & Facilities & $\begin{array}{l}7 \text { outreach indicators, } 7 \text { content of } \\
\text { care indicators, } 13 \text { quality domains }\end{array}$ \\
\hline $\begin{array}{l}\text { Priede- } \\
\text { man Skiles } \\
2015\end{array}$ & $\begin{array}{l}\text { Payment } \\
\text { per output } \\
\text { modified } \\
\text { by quality } \\
\text { score }\end{array}$ & $\begin{array}{l}\text { National roll- } \\
\text { out (expan- } \\
\text { sion to } 19 \text { dis- } \\
\text { tricts which } \\
\text { did not have } \\
\text { PBF yet) }\end{array}$ & $\begin{array}{l}\text { Gov- } \\
\text { ern- } \\
\text { mental } \\
\text { organi- } \\
\text { sation }\end{array}$ & $\begin{array}{l}\text { Integrated - Min- } \\
\text { istry of Health }\end{array}$ & $\begin{array}{l}\text { Public } \\
\text { and not } \\
\text { for prof- } \\
\text { it (includ- } \\
\text { ing faith } \\
\text { based) }\end{array}$ & $\mathrm{RMCH}$ & Facilities & $\begin{array}{l}7 \text { outreach indicators, } 7 \text { content of } \\
\text { care indicators, } 13 \text { quality domains }\end{array}$ \\
\hline $\begin{array}{l}\text { Sherry } \\
2017\end{array}$ & $\begin{array}{l}\text { Payment } \\
\text { per output } \\
\text { modified } \\
\text { by quality } \\
\text { score }\end{array}$ & $\begin{array}{l}\text { National roll- } \\
\text { out (expan- } \\
\text { sion to } 19 \text { dis- } \\
\text { tricts which } \\
\text { did not have } \\
\text { PBF yet) }\end{array}$ & $\begin{array}{l}\text { Gov- } \\
\text { ern- } \\
\text { mental } \\
\text { organi- } \\
\text { sation }\end{array}$ & $\begin{array}{l}\text { Integrated - Min- } \\
\text { istry of Health }\end{array}$ & $\begin{array}{l}\text { Public } \\
\text { and not } \\
\text { for prof- } \\
\text { it (includ- } \\
\text { ing faith } \\
\text { based) }\end{array}$ & $\mathrm{RMCH}$ & Facilities & $\begin{array}{l}7 \text { outreach indicators, } 7 \text { content of } \\
\text { care indicators, } 13 \text { quality domains }\end{array}$ \\
\hline $\begin{array}{l}\text { Lannes } \\
2015\end{array}$ & $\begin{array}{l}\text { Payment } \\
\text { per output } \\
\text { modified } \\
\text { by quality } \\
\text { score }\end{array}$ & $\begin{array}{l}\text { National roll- } \\
\text { out (expan- } \\
\text { sion to } 19 \text { dis- } \\
\text { tricts which } \\
\text { did not have } \\
\text { PBF yet) }\end{array}$ & $\begin{array}{l}\text { Gov- } \\
\text { ern- } \\
\text { mental } \\
\text { organi- } \\
\text { sation }\end{array}$ & $\begin{array}{l}\text { Integrated - Min- } \\
\text { istry of Health }\end{array}$ & $\begin{array}{l}\text { Public } \\
\text { and not } \\
\text { for prof- } \\
\text { it (includ- } \\
\text { ing faith } \\
\text { based) }\end{array}$ & $\mathrm{RMCH}$ & Facilities & $\begin{array}{l}7 \text { outreach indicators, } 7 \text { content of } \\
\text { care indicators, } 13 \text { quality domains }\end{array}$ \\
\hline $\begin{array}{l}\text { Shapira } \\
2018\end{array}$ & $\begin{array}{l}\text { Payment } \\
\text { per output }\end{array}$ & 19 districts & $\begin{array}{l}\text { Min- } \\
\text { istry of } \\
\text { Health }\end{array}$ & $\begin{array}{l}\text { Integrated - Min- } \\
\text { istry of Health }\end{array}$ & $\begin{array}{l}\text { Public } \\
\text { and not } \\
\text { for prof- } \\
\text { it (includ- } \\
\text { ing faith } \\
\text { based) }\end{array}$ & $\mathrm{RMCH}$ & $\begin{array}{l}\text { Coopera- } \\
\text { tives and } \\
\text { communi- } \\
\text { ty health } \\
\text { workers }\end{array}$ & $\begin{array}{l}5 \mathrm{RMCH} \text { indicators as primary fo- } \\
\text { cus of scheme, later supplemented } \\
\text { with HIV/TB indicators }\end{array}$ \\
\hline Rusa 2009 & $\begin{array}{l}\text { Payment } \\
\text { per output } \\
\text { modified } \\
\text { by quality } \\
\text { score }\end{array}$ & $\begin{array}{l}\text { Eventual na- } \\
\text { tional rollout, } \\
\text { reporting here } \\
\text { on pilot in five } \\
\text { rural and one }\end{array}$ & $\begin{array}{l}\text { Min- } \\
\text { istry of } \\
\text { Health } \\
\text { in } \\
\text { Rwan- } \\
\text { da and }\end{array}$ & $\begin{array}{l}\text { External NGO man- } \\
\text { agement and pur- } \\
\text { chasing }\end{array}$ & Public & $\mathrm{RMCH}$ & Facilities & $6 \mathrm{RMCH}$ indicators \\
\hline
\end{tabular}




\begin{tabular}{|c|c|c|c|c|c|c|c|c|c|}
\hline & & & $\begin{array}{l}\text { semi-rural } \\
\text { district }\end{array}$ & $\begin{array}{l}\text { the } \\
\text { Bel- } \\
\text { gian } \\
\text { Tech- } \\
\text { nical } \\
\text { Coop- } \\
\text { eration }\end{array}$ & & & & & \\
\hline & $\begin{array}{l}\text { Gertler } \\
2012\end{array}$ & $\begin{array}{l}\text { Payment } \\
\text { per output } \\
\text { modified } \\
\text { by quality } \\
\text { score }\end{array}$ & $\begin{array}{l}\text { National roll- } \\
\text { out }\end{array}$ & $\begin{array}{l}\text { Min- } \\
\text { istry of } \\
\text { Health }\end{array}$ & $\begin{array}{l}\text { Integrated - Min- } \\
\text { istry of Health }\end{array}$ & Public & $\mathrm{RMCH}$ & Facilities & $\begin{array}{l}7 \text { outreach indicators, } 7 \text { content of } \\
\text { care indicators, } 13 \text { quality domains }\end{array}$ \\
\hline & $\begin{array}{l}\text { de Walque } \\
2015\end{array}$ & $\begin{array}{l}\text { Target pay- } \\
\text { ment }\end{array}$ & $\begin{array}{l}\text { National roll- } \\
\text { out }\end{array}$ & $\begin{array}{l}\text { Min- } \\
\text { istry of } \\
\text { Health }\end{array}$ & $\begin{array}{l}\text { Integrated - Min- } \\
\text { istry of Health }\end{array}$ & $\begin{array}{l}\text { Public } \\
\text { and not } \\
\text { for prof- } \\
\text { it (includ- } \\
\text { ing faith } \\
\text { based) }\end{array}$ & $\begin{array}{l}\text { RMNCH; } \\
\text { HIV/TB }\end{array}$ & Facilities & 10 HIV specific indicators \\
\hline Swaziland & $\begin{array}{l}\text { Kliner } \\
2015\end{array}$ & $\begin{array}{l}\text { Payment } \\
\text { per output }\end{array}$ & Hospital & $\begin{array}{l}\text { Un- } \\
\text { clear }\end{array}$ & $\begin{array}{l}\text { Integrated - Na- } \\
\text { tional TB pro- } \\
\text { gramme }\end{array}$ & Public & TB & $\begin{array}{l}\text { Communi- } \\
\text { ty health } \\
\text { workers }\end{array}$ & $\begin{array}{l}\text { Support of directly observed treat- } \\
\text { ment }\end{array}$ \\
\hline Tanzania & $\begin{array}{l}\text { Brock } \\
2018\end{array}$ & $\begin{array}{l}\text { Condition- } \\
\text { al provision } \\
\text { of material } \\
\text { goods }\end{array}$ & One region & $\begin{array}{l}\text { Un- } \\
\text { clear }\end{array}$ & $\begin{array}{l}\text { External - study au- } \\
\text { thors }\end{array}$ & $\begin{array}{l}\text { Mix - pub- } \\
\text { lic, private } \\
\text { and faith } \\
\text { based }\end{array}$ & General & $\begin{array}{l}\text { Health } \\
\text { workers }\end{array}$ & Adherence to guidelines \\
\hline & $\begin{array}{l}\text { Binyaruka } \\
2015\end{array}$ & $\begin{array}{l}\text { Target pay- } \\
\text { ment }\end{array}$ & One region & $\begin{array}{l}\text { Gov- } \\
\text { ern- } \\
\text { ment } \\
\text { of Nor- } \\
\text { way }\end{array}$ & $\begin{array}{l}\text { Integrated - Min- } \\
\text { istry of Health }\end{array}$ & $\begin{array}{l}\text { Public } \\
\text { and not } \\
\text { for prof- } \\
\text { it (includ- } \\
\text { ing faith } \\
\text { based) }\end{array}$ & $\mathrm{RMCH}$ & $\begin{array}{l}\text { Facilities } \\
\text { and dis- } \\
\text { trict }\end{array}$ & $\begin{array}{l}7 \text { outreach indicators, } 7 \text { content of } \\
\text { care indicators, } 13 \text { quality domains }\end{array}$ \\
\hline & $\begin{array}{l}\text { Binyaruka } \\
2017\end{array}$ & $\begin{array}{l}\text { Target pay- } \\
\text { ment }\end{array}$ & One region & $\begin{array}{l}\text { Gov- } \\
\text { ern- } \\
\text { ment } \\
\text { of Nor- } \\
\text { way }\end{array}$ & $\begin{array}{l}\text { Integrated - Min- } \\
\text { istry of Health }\end{array}$ & $\begin{array}{l}\text { Public } \\
\text { and not } \\
\text { for prof- } \\
\text { it (includ- } \\
\text { ing faith } \\
\text { based) }\end{array}$ & $\mathrm{RMCH}$ & $\begin{array}{l}\text { Facilities } \\
\text { and dis- } \\
\text { trict }\end{array}$ & $\begin{array}{l}7 \text { outreach indicators, } 7 \text { content of } \\
\text { care indicators, } 13 \text { quality domains }\end{array}$ \\
\hline
\end{tabular}




\begin{tabular}{|c|c|c|c|c|c|c|c|c|c|}
\hline & $\begin{array}{l}\text { Binyaruka } \\
2018\end{array}$ & $\begin{array}{l}\text { Target pay- } \\
\text { ment }\end{array}$ & One region & $\begin{array}{l}\text { Gov- } \\
\text { ern- } \\
\text { ment } \\
\text { of Nor- } \\
\text { way }\end{array}$ & $\begin{array}{l}\text { Integrated - Min- } \\
\text { istry of Health }\end{array}$ & $\begin{array}{l}\text { Public } \\
\text { and not } \\
\text { for prof- } \\
\text { it (includ- } \\
\text { ing faith } \\
\text { based) }\end{array}$ & $\mathrm{RMCH}$ & $\begin{array}{l}\text { Facilities } \\
\text { and dis- } \\
\text { trict }\end{array}$ & $\begin{array}{l}7 \text { outreach indicators, } 7 \text { content of } \\
\text { care indicators, } 13 \text { quality domains }\end{array}$ \\
\hline & $\begin{array}{l}\text { Mayu- } \\
\text { mana } \\
2017\end{array}$ & $\begin{array}{l}\text { Target pay- } \\
\text { ment }\end{array}$ & One region & $\begin{array}{l}\text { Gov- } \\
\text { ern- } \\
\text { ment } \\
\text { of Nor- } \\
\text { way }\end{array}$ & $\begin{array}{l}\text { Integrated - Min- } \\
\text { istry of Health }\end{array}$ & $\begin{array}{l}\text { Public } \\
\text { and not } \\
\text { for prof- } \\
\text { it (includ- } \\
\text { ing faith } \\
\text { based) }\end{array}$ & $\mathrm{RMCH}$ & $\begin{array}{l}\text { Facilities } \\
\text { and dis- } \\
\text { trict }\end{array}$ & $\begin{array}{l}7 \text { outreach indicators, } 7 \text { content of } \\
\text { care indicators, } 13 \text { quality domains }\end{array}$ \\
\hline \multirow[t]{3}{*}{ Zambia } & $\begin{array}{l}\text { Friedman, } \\
2016 \mathrm{a}\end{array}$ & $\begin{array}{l}\text { Payment } \\
\text { per output } \\
\text { modified } \\
\text { by quality } \\
\text { score }\end{array}$ & $\begin{array}{l}\text { Pre-pilot in } \\
\text { one district; } \\
\text { following this } \\
\text { PBF expand- } \\
\text { ed to } 10 \text { ad- } \\
\text { ditional dis- } \\
\text { tricts. By end } \\
\text { of project, } 203 \\
\text { health centres } \\
\text { covered. }\end{array}$ & $\begin{array}{l}\text { World } \\
\text { Bank - } \\
\text { Health } \\
\text { Results } \\
\text { Inno- } \\
\text { vation } \\
\text { Trust } \\
\text { Fund }\end{array}$ & $\begin{array}{l}\text { Integrated - Min- } \\
\text { istry of Health }\end{array}$ & Public & $\mathrm{RMCH}$ & $\begin{array}{l}\text { Facilities } \\
\text { and dis- } \\
\text { trict }\end{array}$ & $\begin{array}{l}9 \text { directly incentivized services via } \\
\text { unit payments (RMCH indicators) } \\
\text { and } 10 \text { areas for quality assess- } \\
\text { ment (RMCH care, HIV services, } \\
\text { general management and info sys- } \\
\text { tems, community participation) }\end{array}$ \\
\hline & Shen 2017 & $\begin{array}{l}\text { Payment } \\
\text { per output } \\
\text { modified } \\
\text { by quality } \\
\text { score }\end{array}$ & $\begin{array}{l}\text { Pre-pilot in } \\
\text { one district; } \\
\text { following this } \\
\text { PBF expand- } \\
\text { ed to } 10 \text { ad- } \\
\text { ditional dis- } \\
\text { tricts. By end } \\
\text { of project, } 203 \\
\text { health centres } \\
\text { covered. }\end{array}$ & $\begin{array}{l}\text { World } \\
\text { Bank - } \\
\text { Health } \\
\text { Results } \\
\text { Inno- } \\
\text { vation } \\
\text { Trust } \\
\text { Fund }\end{array}$ & $\begin{array}{l}\text { Integrated - Min- } \\
\text { istry of Health }\end{array}$ & Public & $\mathrm{RMCH}$ & $\begin{array}{l}\text { Facilities } \\
\text { and dis- } \\
\text { trict }\end{array}$ & $\begin{array}{l}9 \text { directly incentivized services via } \\
\text { unit payments (RMCH indicators) } \\
\text { and } 10 \text { areas for quality assess- } \\
\text { ment (RMCH care, HIV services, } \\
\text { general management and info sys- } \\
\text { tems, community participation) }\end{array}$ \\
\hline & $\begin{array}{l}\text { Chansa, } \\
2015\end{array}$ & $\begin{array}{l}\text { Payment } \\
\text { per output } \\
\text { modified } \\
\text { by quality } \\
\text { score }\end{array}$ & $\begin{array}{l}\text { Katete district } \\
\text { pre-pilot }\end{array}$ & $\begin{array}{l}\text { World } \\
\text { Bank } \\
\text { through } \\
\text { the } \\
\text { Health } \\
\text { Results } \\
\text { Inno- } \\
\text { vation }\end{array}$ & $\begin{array}{l}\text { Integrated - Min- } \\
\text { istry of Health }\end{array}$ & Public & $\mathrm{RMCH}$ & Facilities & $\begin{array}{l}9 \text { indicators incentivised around } \\
\mathrm{RMCH} \text {, and } 10 \text { incentivised areas } \\
\text { for quality assessment }\end{array}$ \\
\hline
\end{tabular}




\begin{tabular}{|c|c|c|c|c|c|c|c|c|c|}
\hline & & & & $\begin{array}{l}\text { Trust } \\
\text { Fund. }\end{array}$ & & & & & \\
\hline \multirow[t]{2}{*}{ Zimbabwe } & $\begin{array}{l}\text { Friedman } \\
2016 \mathrm{~b}\end{array}$ & $\begin{array}{l}\text { Payment } \\
\text { per output } \\
\text { modified by } \\
\text { quality and } \\
\text { equity score }\end{array}$ & $\begin{array}{l}\text { Initially in two } \\
\text { districts in } 26 \\
\text { RHCs, then } \\
\text { scaled up to } \\
18 \text { districts }\end{array}$ & $\begin{array}{l}\text { World } \\
\text { Bank } \\
\text { and } \\
\text { co- } \\
\text { fund- } \\
\text { ing } \\
\text { from } \\
\text { the } \\
\text { Min- } \\
\text { istry } \\
\text { of Fi- } \\
\text { nance } \\
\text { and } \\
\text { Eco- } \\
\text { nom- } \\
\text { ic De- } \\
\text { velop- } \\
\text { ment }\end{array}$ & $\begin{array}{l}\text { Integrated into } \\
\text { MoH, with COR- } \\
\text { DAID technical sup- } \\
\text { port }\end{array}$ & $\begin{array}{l}\text { Public } \\
\text { and not } \\
\text { for prof- } \\
\text { it (includ- } \\
\text { ing faith } \\
\text { based) }\end{array}$ & $\mathrm{RMCH}$ & $\begin{array}{l}\text { Facilities } \\
+ \text { district }+ \\
\text { provincial }\end{array}$ & $\begin{array}{l}17 \text { indicators in rural health cen- } \\
\text { tres and } 6 \text { in hospitals, focused on } \\
\text { RMCH; quality scorecard. }\end{array}$ \\
\hline & Das 2017 & $\begin{array}{l}\text { Payment } \\
\text { per output } \\
\text { modified by } \\
\text { quality and } \\
\text { satisfaction } \\
\text { score }\end{array}$ & 18 districts & $\begin{array}{l}\text { World } \\
\text { Bank } \\
\text { and } \\
\text { co- } \\
\text { fund- } \\
\text { ing } \\
\text { from } \\
\text { the } \\
\text { Min- } \\
\text { istry } \\
\text { of Fi- } \\
\text { nance } \\
\text { and } \\
\text { Eco- } \\
\text { nom- } \\
\text { ic De- } \\
\text { velop- } \\
\text { ment }\end{array}$ & $\begin{array}{l}\text { Integrated - Min- } \\
\text { istry of Health }\end{array}$ & $\begin{array}{l}\text { Public } \\
\text { and not } \\
\text { for prof- } \\
\text { it (includ- } \\
\text { ing faith } \\
\text { based) }\end{array}$ & $\mathrm{RMCH}$ & $\begin{array}{l}\text { Facilities } \\
+ \text { district }+ \\
\text { provincial }\end{array}$ & $\begin{array}{l}17 \text { indicators overall for facilities } \\
\text { and } 134 \text { quality indicators. }\end{array}$ \\
\hline
\end{tabular}




\begin{tabular}{|c|c|c|c|c|c|c|c|c|}
\hline Country & Study ID & $\begin{array}{l}\text { Design } \\
\text { of PBF } \\
\text { scheme }\end{array}$ & $\begin{array}{l}\text { How are the PBF incentives used and } \\
\text { cascaded? }\end{array}$ & $\begin{array}{l}\text { Who set the } \\
\text { target and } \\
\text { how were } \\
\text { the targets } \\
\text { set? }\end{array}$ & $\begin{array}{l}\text { Measure- } \\
\text { ment of tar- } \\
\text { gets: how } \\
\text { and where } \\
\text { from? Verifi- } \\
\text { cation proce- } \\
\text { dures }\end{array}$ & $\begin{array}{l}\text { Magnitude of } \\
\text { incentives }\end{array}$ & $\begin{array}{l}\text { Relative } \\
\text { size of in- } \\
\text { centive }\end{array}$ & $\begin{array}{l}\text { Are bonus- } \\
\text { es addition- } \\
\text { al to nor- } \\
\text { mal wages } \\
\text { or funding? }\end{array}$ \\
\hline Afghanistan & $\begin{array}{l}\text { Engineer } \\
2016\end{array}$ & $\begin{array}{l}\text { Payment } \\
\text { per output } \\
\text { modified } \\
\text { by quality } \\
\text { score (pay- } \\
\text { ment per } \\
\text { output, ad- } \\
\text { ditional pay- } \\
\text { ment based } \\
\text { on balanced } \\
\text { scorecard } \\
\text { and con- } \\
\text { traceptive } \\
\text { prevalence } \\
\text { rates, all ad- } \\
\text { justed by } \\
\text { a quality } \\
\text { score - de- } \\
\text { tails of ad- } \\
\text { justment } \\
\text { not provid- } \\
\text { ed) }\end{array}$ & $\begin{array}{l}\text { Bonuses quarterly to health workers, } \\
\text { based on volume of } 9 \text { health services. } \\
\text { Additional annual payments based on } \\
\text { quality, equity, and contraceptive preva- } \\
\text { lence rates. Health workers funds chan- } \\
\text { nelled through NGOs. Total payments } \\
\text { adjusted by quality score. }\end{array}$ & $\begin{array}{l}\text { Unclear } \\
\text { though ne- } \\
\text { gotiation of } \\
\text { targets al- } \\
\text { lowed for } \\
\text { balanced } \\
\text { scorecard. } \\
\text { NGOs and } \\
\text { MOPH ne- } \\
\text { gotiated to } \\
\text { adjust pay- } \\
\text { ments tak- } \\
\text { ing into ac- } \\
\text { count base- } \\
\text { line condi- } \\
\text { tions and } \\
\text { expected } \\
\text { improve- } \\
\text { ments. }\end{array}$ & $\begin{array}{l}\text { Monthly re- } \\
\text { ports from } \\
\text { health facili- } \\
\text { ties verified } \\
\text { quarterly by } \\
\text { independent } \\
\text { monitors, } \\
\text { record-match- } \\
\text { ing, and ran- } \\
\text { dom patient } \\
\text { home visits. }\end{array}$ & $\begin{array}{l}\text { From USD } 1.30 \\
\text { to USD } 10.37 \\
\text { per unit (initial); } \\
\text { from USD } 2.67 \\
\text { to USD } 35.63 \\
\text { per unit (re- } \\
\text { vised) }\end{array}$ & $\begin{array}{l}6-11 \% \\
\text { above salary } \\
\text { (2011), in- } \\
\text { creasing } \\
\text { to } 14-28 \% \\
\text { (cadre de- } \\
\text { pendent) }\end{array}$ & Yes \\
\hline & $\begin{array}{l}\text { Witvo- } \\
\text { rapong } 2016\end{array}$ & $\begin{array}{l}\text { Payment } \\
\text { per output }\end{array}$ & Unclear & Unclear & Unclear & $\begin{array}{l}150 \text { Afghanis } \\
\text { (approx. USD 3) } \\
\text { per referral }\end{array}$ & Unclear & Unclear \\
\hline Argentina & Celhay 2015 & $\begin{array}{l}\text { Payment } \\
\text { per output - } \\
\text { in addition } \\
\text { to Plan Nac- } \\
\text { er, the ex- } \\
\text { periment } \\
\text { pays finan- } \\
\text { cial incen- } \\
\text { tives to clin- } \\
\text { ics at } 200 \%\end{array}$ & $\begin{array}{l}\text { Bonuses to providers set by national } \\
\text { government according to services in } \\
\text { the benefits package. Health facilities } \\
\text { choose how to use revenues - some pay } \\
\text { bonuses to personnel. }\end{array}$ & $\begin{array}{l}\text { National } \\
\text { government } \\
\text { according } \\
\text { to clinical } \\
\text { guidelines } \\
\text { based on in- } \\
\text { ternational } \\
\text { evidence. }\end{array}$ & $\begin{array}{l}\text { Electronic } \\
\text { record man- } \\
\text { agement sys- } \\
\text { tem }\end{array}$ & Unclear & Unclear & Unclear \\
\hline
\end{tabular}




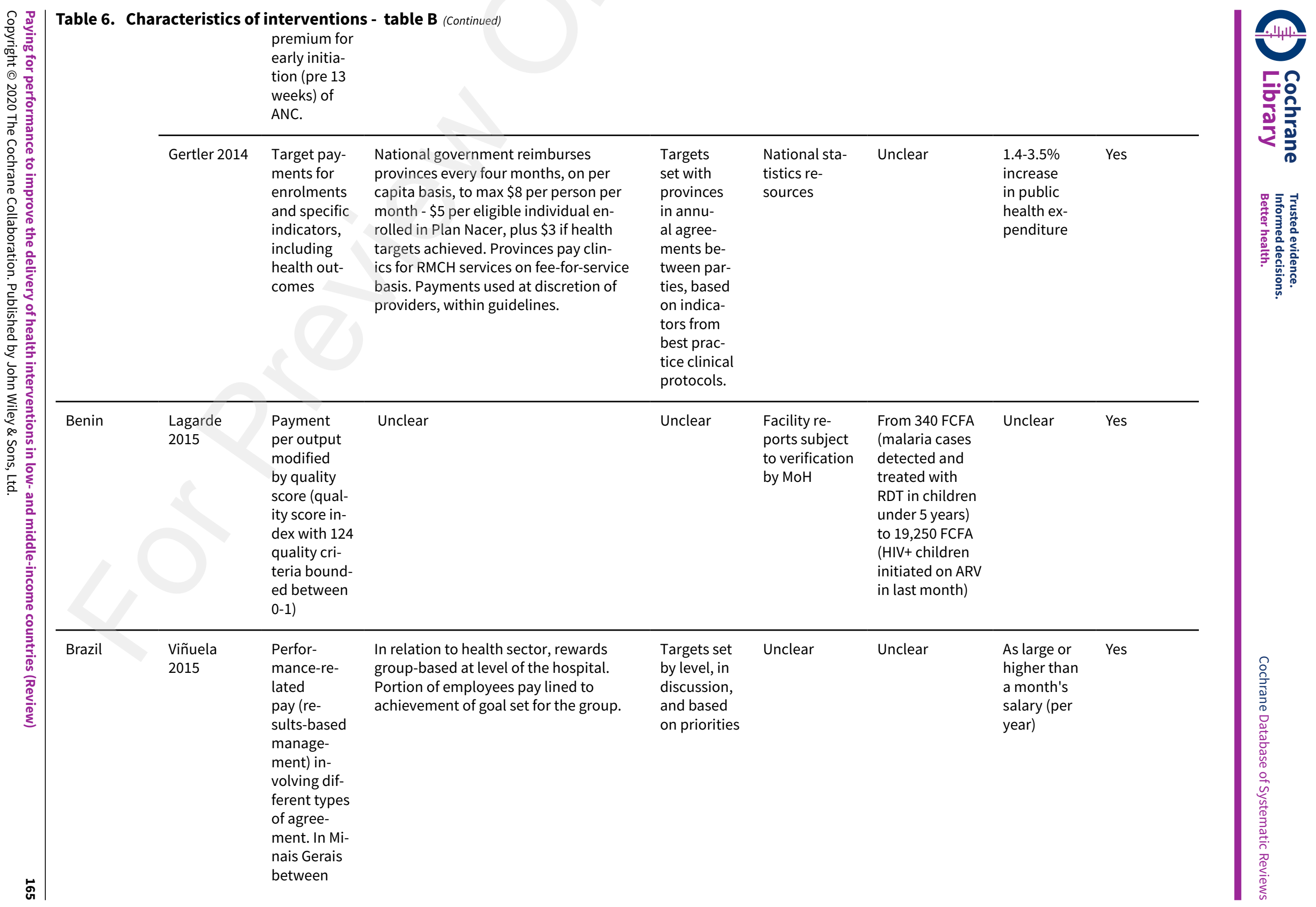




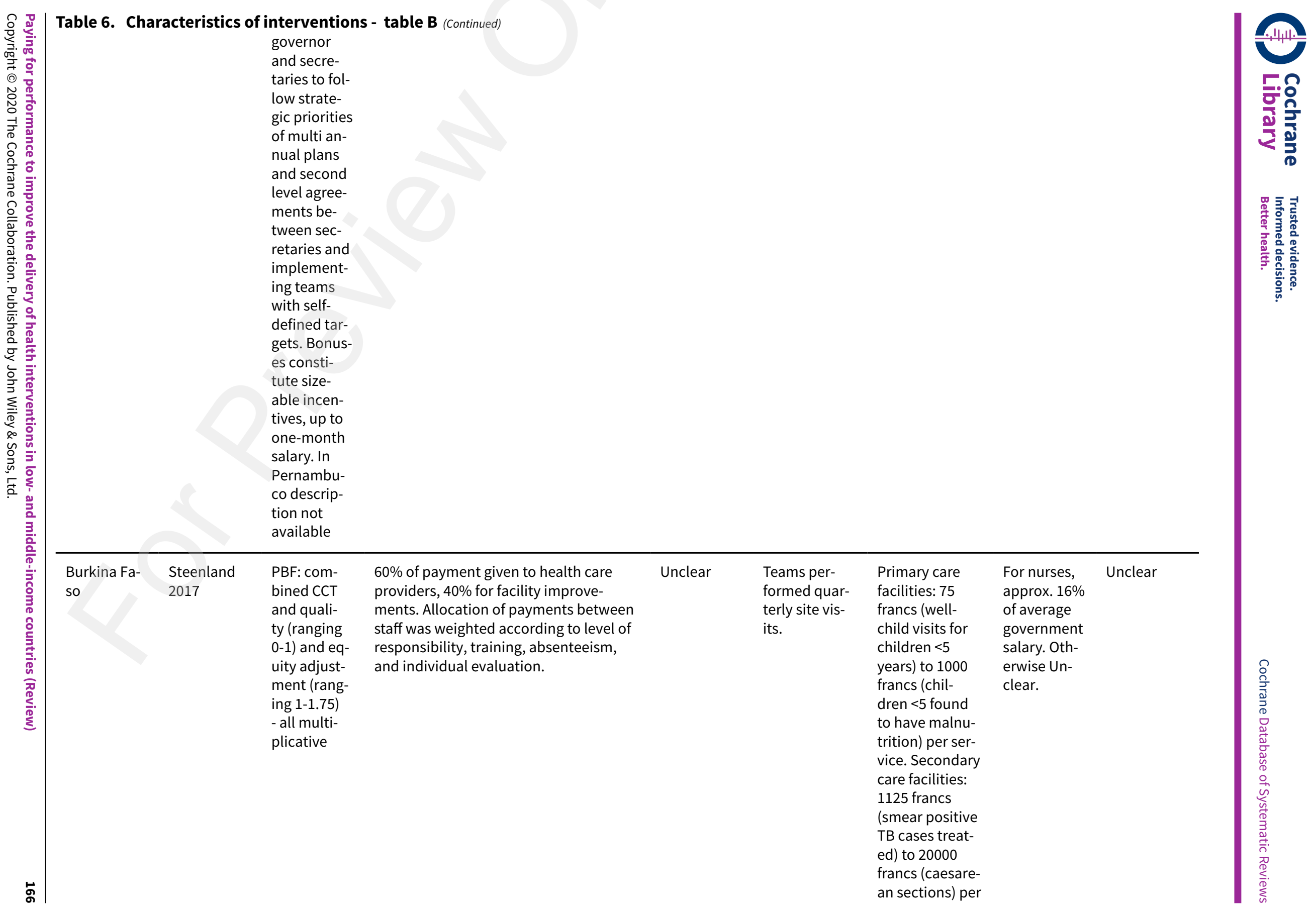




\begin{tabular}{|c|c|c|c|c|c|c|c|c|}
\hline & & & 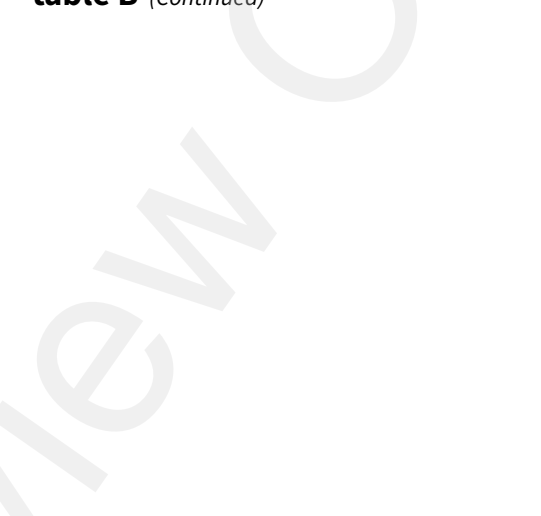 & & & $\begin{array}{l}\text { service. Com- } \\
\text { munity health } \\
\text { workers: - } 50 \\
\text { francs (number } \\
\text { of patients who } \\
\text { did not return } \\
\text { to HF for vacci- } \\
\text { nation) and } 400 \\
\text { francs (number } \\
\text { of patients di- } \\
\text { agnosed with } \\
\text { malaria re- } \\
\text { ferred to CSPS). }\end{array}$ & & \\
\hline \multirow[t]{3}{*}{ Burundi } & $\begin{array}{l}\text { Bonfrer } \\
2014 a\end{array}$ & $\begin{array}{l}\text { Payment } \\
\text { per output } \\
\text { and quality } \\
\text { adjustment } \\
\text { (ranges } 1 \text { - } \\
\text { 1.25) - multi- } \\
\text { plicative }\end{array}$ & Payments made to facilities & Unclear & $\begin{array}{l}\text { Health facil- } \\
\text { ities report } \\
\text { monthly to } \\
\text { MoH. Local } \\
\text { regulatory } \\
\text { authorities } \\
\text { do quarter- } \\
\text { ly checks of } \\
\text { quality on a } \\
\text { random day. }\end{array}$ & $\begin{array}{l}\text { From USD } 0.05 \\
\text { (per child re- } \\
\text { ceiving vit A) to } \\
\text { USD } 20 \text { (per TB } \\
\text { patient correct- } \\
\text { ly treated dur- } \\
\text { ing } 6 \text { months). }\end{array}$ & $\begin{array}{l}\text { Approx. } 40 \% \\
\text { of the total } \\
\text { health facili- } \\
\text { ty budget. }\end{array}$ & Yes \\
\hline & $\begin{array}{l}\text { Bonfrer } \\
\text { 2014b }\end{array}$ & $\begin{array}{l}\text { Payment } \\
\text { per output } \\
\text { and quality } \\
\text { adjustment } \\
\text { (ranges } 1 \text { - } \\
\text { 1.25) - multi- } \\
\text { plicative }\end{array}$ & $\begin{array}{l}\text { Health facilities allocate PBF revenue } \\
\text { between staff remuneration (up to 50\%) } \\
\text { and service quality improvements. }\end{array}$ & $\begin{array}{l}\text { Presumed } \\
\mathrm{MoH}\end{array}$ & $\begin{array}{l}\text { Health facil- } \\
\text { ities report } \\
\text { monthly to } \\
\text { MoH. Local } \\
\text { regulatory } \\
\text { authorities } \\
\text { do quarter- } \\
\text { ly checks of } \\
\text { quality on a } \\
\text { random day. }\end{array}$ & $\begin{array}{l}\text { From USD } 0.05 \\
\text { (per child re- } \\
\text { ceiving vit A) to } \\
\text { USD } 20 \text { (per TB } \\
\text { patient correct- } \\
\text { ly treated dur- } \\
\text { ing } 6 \text { months). }\end{array}$ & $\begin{array}{l}\text { Approx. } 40 \% \\
\text { of the total } \\
\text { health facili- } \\
\text { ty budget }\end{array}$ & Yes \\
\hline & Falisse 2015 & $\begin{array}{l}\text { Payment } \\
\text { per output } \\
\text { and quality } \\
\text { adjustment } \\
\text { (ranges } 1 \text { - } \\
\text { 1.25) - multi- } \\
\text { plicative }\end{array}$ & Unclear & $\begin{array}{l}\text { Appear to } \\
\text { be set by } \\
\text { NGOs or the } \\
\text { MoH. }\end{array}$ & Unclear & Unclear & Unclear & Yes \\
\hline
\end{tabular}




\begin{tabular}{|c|c|c|c|c|c|c|c|c|}
\hline & $\begin{array}{l}\text { Rudasingwa } \\
2015\end{array}$ & $\begin{array}{l}\text { Payment } \\
\text { per output } \\
\text { and quality } \\
\text { adjustment } \\
\text { (ranges } 1 \text { - } \\
1.25 \text { ) - multi- } \\
\text { plicative }\end{array}$ & $\begin{array}{l}\text { Facility managers distributed bonus- } \\
\text { es to staff of facilities included in PBF } \\
\text { scheme, based on profile and perfor- } \\
\text { mance criteria of each staff member - } \\
\text { e.g. qualifications, experience, years of } \\
\text { employment, responsibility, and worked } \\
\text { hours. }\end{array}$ & Unclear & $\begin{array}{l}\text { Quality as- } \\
\text { sessed quar- } \\
\text { terly by eval- } \\
\text { uation team } \\
\text { from district } \\
\text { and provincial } \\
\text { health author- } \\
\text { ities. }\end{array}$ & $\begin{array}{l}\text { From USD } 0.05 \\
\text { (per child re- } \\
\text { ceiving vit A) to } \\
\text { USD } 20 \text { (TB pa- } \\
\text { tient correctly } \\
\text { treated during } 6 \\
\text { months). }\end{array}$ & $\begin{array}{l}\text { Approx. } 20 \% \\
\text { of health fa- } \\
\text { cilities total } \\
\text { revenues }\end{array}$ & Yes \\
\hline Cambodia & Ir 2015 & $\begin{array}{l}\text { Payment } \\
\text { per output }\end{array}$ & $\begin{array}{l}\text { Incentives paid to health facility through } \\
\text { public financial reimbursement chan- } \\
\text { nels, who then distributed to midwives, } \\
\text { physicians, and other trained health per- } \\
\text { sonnel attending deliveries in public } \\
\text { health facilities. Of this up to } 30 \% \text { had to } \\
\text { be shared further with other health per- } \\
\text { sonnel in the facility, and workers such } \\
\text { as traditional birth attendants. }\end{array}$ & $\begin{array}{l}\text { Set by gov- } \\
\text { ernment } \\
\text { (Ministry of } \\
\text { Health) }\end{array}$ & $\begin{array}{l}\text { Monthly re- } \\
\text { ports from } \\
\text { health facility } \\
\text { through rou- } \\
\text { tine health in- } \\
\text { formation sys- } \\
\text { tem. }\end{array}$ & $\begin{array}{l}\text { USD } 15 \text { (per live } \\
\text { birth attended } \\
\text { in health cen- } \\
\text { tre) and USD } 10 \\
\text { (per live birth in } \\
\text { hospitals) }\end{array}$ & Unclear & Yes \\
\hline & Khim 2018 & $\begin{array}{l}\text { PBF (oth- } \\
\text { er) - service } \\
\text { agreement }\end{array}$ & Unclear & $\begin{array}{l}\text { Initially } \\
\text { meant to } \\
\text { be per- } \\
\text { formance } \\
\text { agreements } \\
\text { between } \\
\text { Ministry } \\
\text { of Health } \\
\text { (MOH) and } \\
\text { Provincial } \\
\text { Health De- } \\
\text { partment } \\
\text { (PHD), ser- } \\
\text { vice deliv- } \\
\text { ery agree- } \\
\text { ment be- } \\
\text { tween PHD } \\
\text { and Spe- } \\
\text { cial Oper- } \\
\text { ating Agen- } \\
\text { cies (SOAs), } \\
\text { and agree- } \\
\text { ments be- } \\
\text { tween Direc- } \\
\text { tor of SOA, } \\
\text { heads of fa- }\end{array}$ & Unclear & $\begin{array}{l}\text { USD } 1.18 \text { to } \\
\text { USD } 1.24 \text { (dis- } \\
\text { trict depen- } \\
\text { dent) per capi- } \\
\text { ta Service Deliv- } \\
\text { ery Grant allo- } \\
\text { cation. }\end{array}$ & Unclear & Yes \\
\hline
\end{tabular}




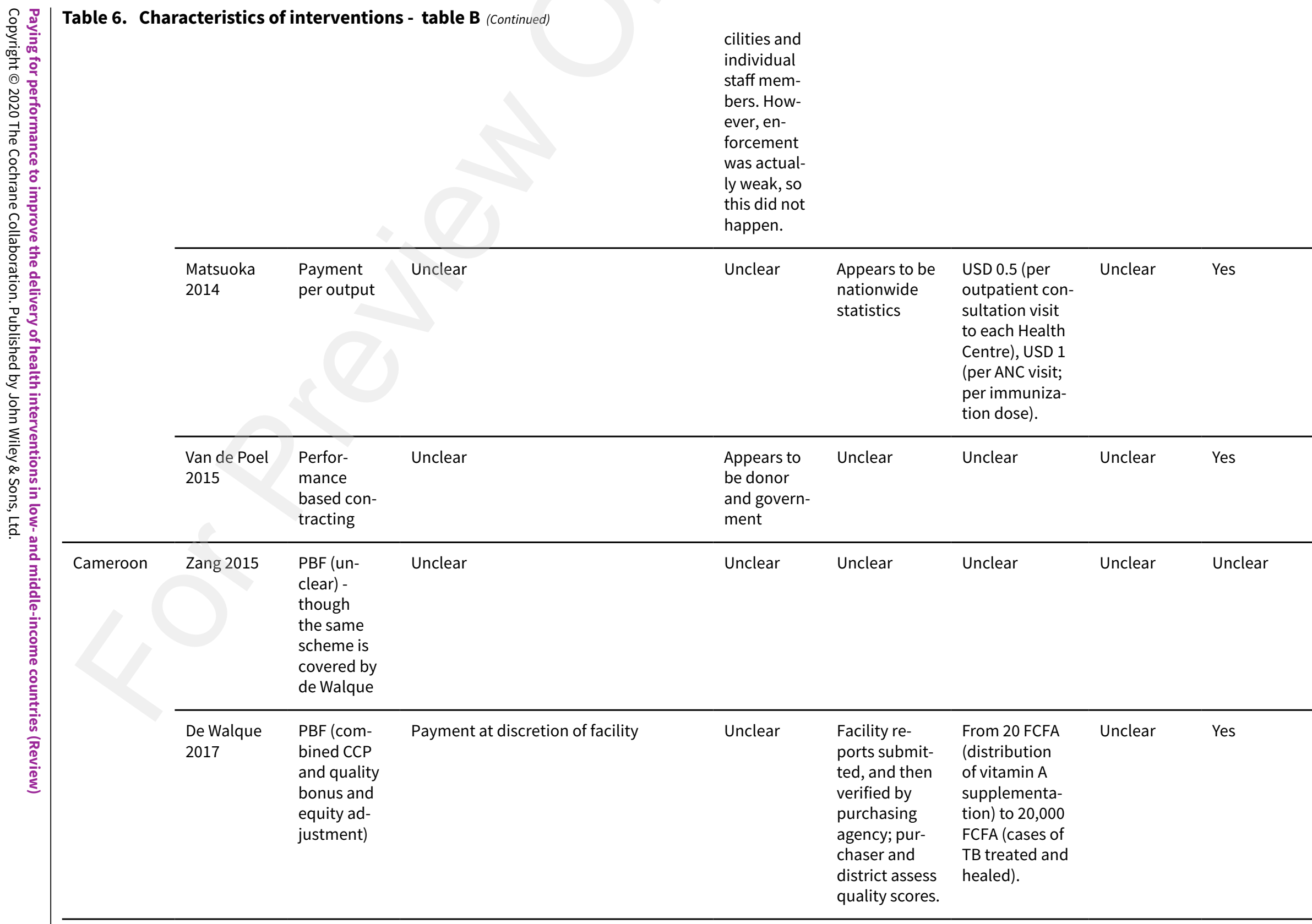




\begin{tabular}{|c|c|c|c|c|c|c|c|c|}
\hline China & Chang 2017 & $\begin{array}{l}\text { Payment } \\
\text { per output } \\
\text { (income } \\
\text { withheld) }\end{array}$ & $\begin{array}{l}\text { Bonuses are paid for reporting of ad- } \\
\text { verse drug reactions, fines if reports } \\
\text { withheld; bonuses apply to both physi- } \\
\text { cians and wards but unclear how distrib- } \\
\text { uted to each. }\end{array}$ & Unclear & $\begin{array}{l}\text { Routine ret- } \\
\text { rospective re- } \\
\text { view of charts } \\
\text { by pharma- } \\
\text { cists }\end{array}$ & $\begin{array}{l}20 \text { RMB for a } \\
\text { spontaneous } \\
\text { Adverse Drug } \\
\text { Reaction re- } \\
\text { port; fine of } \\
\text { 5RMB for a } \\
\text { whitheld report }\end{array}$ & $\begin{array}{l}<1 \% \text { of } \\
\text { physician's } \\
\text { salary }\end{array}$ & Unclear \\
\hline & Yao 2008 & $\begin{array}{l}\text { Payment } \\
\text { per output }\end{array}$ & $\begin{array}{l}\text { Incentives provided to doctors, and to } \\
\text { village leaders for disseminating TB } \\
\text { knowledge - further details not speci- } \\
\text { fied. }\end{array}$ & Unclear & $\begin{array}{l}\text { Appears to be } \\
\text { routine data }\end{array}$ & $\begin{array}{l}\text { USD } 3 \text { (for doc- } \\
\text { tors for referral } \\
\text { of new smear- } \\
\text { positive TB pa- } \\
\text { tient), USD } 8 \\
\text { (for village doc- } \\
\text { tors for DOT } \\
\text { for } 6 \text { months to } \\
\text { new smear-pos- } \\
\text { itive patient), } \\
\text { USD } 1 \text { (village } \\
\text { leaders to dis- } \\
\text { seminate TB } \\
\text { knowledge). }\end{array}$ & Unclear & $\begin{array}{l}\text { Yes (as- } \\
\text { sessed by } \\
\text { reviewers } \\
\text { but not ex- } \\
\text { plicitly stat- } \\
\text { ed) }\end{array}$ \\
\hline & $\begin{array}{l}\text { Pow- } \\
\text { ell-Jackson } \\
2014\end{array}$ & $\begin{array}{l}\text { Payment re- } \\
\text { form: condi- } \\
\text { tional cash } \\
\text { payment } \\
\text { and target } \\
\text { payment }\end{array}$ & $\begin{array}{l}\text { Unclear, however Yip } 2014 \text { suggests that } \\
\text { the health centres are paid and they } \\
\text { then cascade payments to village clinics }\end{array}$ & $\begin{array}{l}\text { Appears } \\
\text { to be re- } \\
\text { searchers } \\
\text { with Ningxia } \\
\text { province de- } \\
\text { cision mak- } \\
\text { ers }\end{array}$ & Unclear & $\begin{array}{l}2 \text { RMB (for vil- } \\
\text { lage doctors } \\
\text { per visit at clin- } \\
\text { ic) or } 4 \text { RMB } \\
\text { (per home vis- } \\
\text { it). Amounts to } \\
\text { average } 12,000 \\
\text { RMB per village } \\
\text { doctor. }\end{array}$ & Unclear & $\begin{array}{l}\text { Yes (as- } \\
\text { sessed by } \\
\text { reviewers } \\
\text { but not ex- } \\
\text { plicitly stat- } \\
\text { ed) }\end{array}$ \\
\hline & Yip 2014 & $\begin{array}{l}\text { Payment re- } \\
\text { form to cap- } \\
\text { itation with } \\
\text { PBF) }\end{array}$ & $\begin{array}{l}\text { Township health centres and village } \\
\text { posts underwent performance assess- } \\
\text { ments at twice yearly - New Coopera- } \\
\text { tive Medical Scheme (NCMS) dispersed } \\
70 \% \text { of budget to health centres based } \\
\text { at the beginning of the year and with- } \\
\text { held the remaining } 30 \% \text { pending the re- } \\
\text { sults of these assessments. Health cen- } \\
\text { tres disbursed a share of this funding } \\
\text { to village posts. Centres obtaining high- } \\
\text { er than average performance scores re- } \\
\text { ceived more than the } 30 \% \text { of the budget }\end{array}$ & $\begin{array}{l}\text { Targets set } \\
\text { by New Co- } \\
\text { operative } \\
\text { Medical } \\
\text { Scheme }\end{array}$ & $\begin{array}{l}\text { Representa- } \\
\text { tives of the } \\
\text { supervising } \\
\text { township } \\
\text { health cen- } \\
\text { tre, the coun- } \\
\text { ty department } \\
\text { of health and } \\
\text { the county } \\
\text { New Cooper- } \\
\text { ative Medical } \\
\text { Scheme office }\end{array}$ & Unclear & Unclear & Yes \\
\hline
\end{tabular}




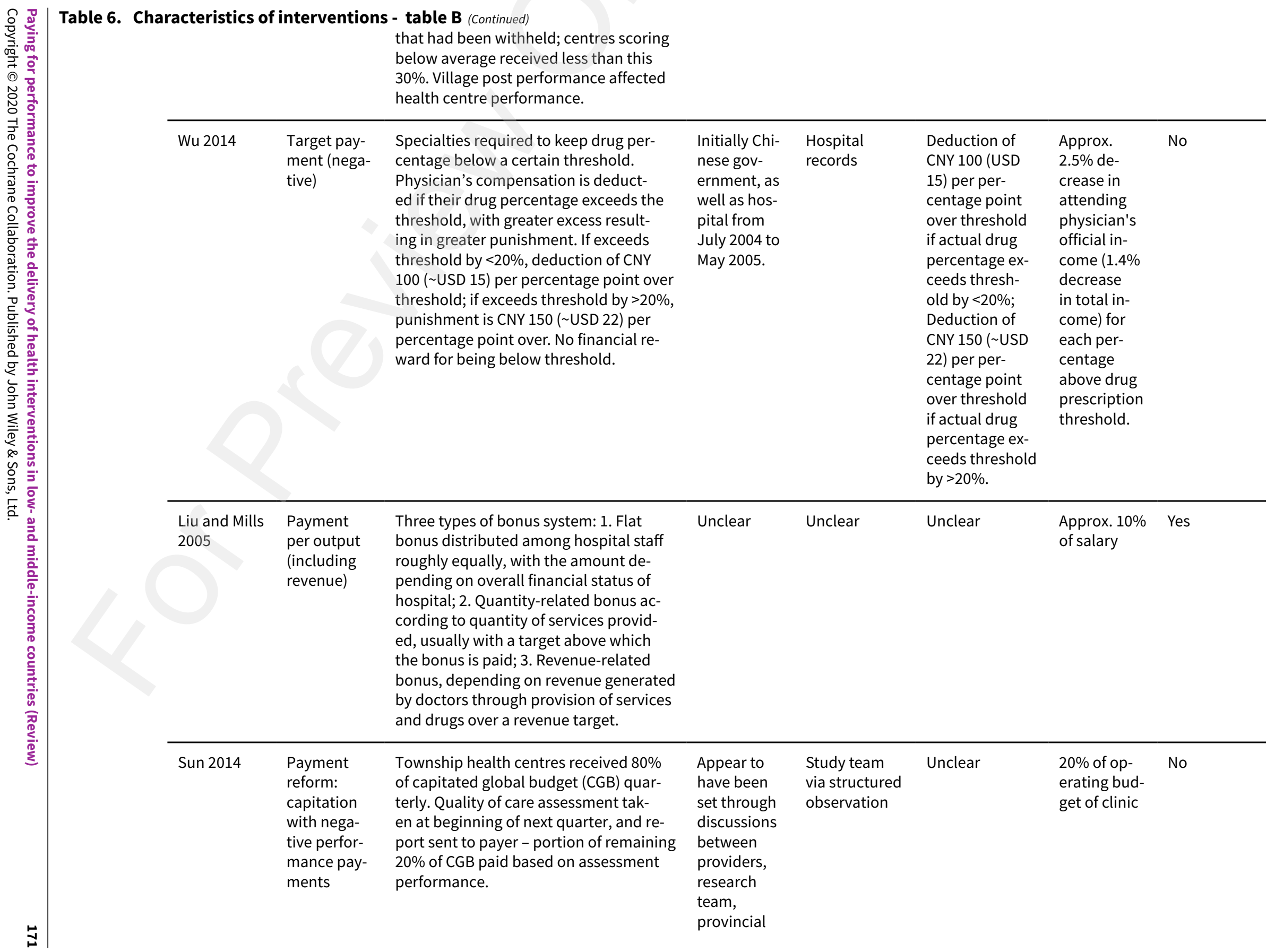




\begin{tabular}{|c|c|c|c|c|c|c|c|c|c|}
\hline & & & & $\begin{array}{l}\text { and coun- } \\
\text { ty officials, } \\
\text { and New } \\
\text { Coopera- } \\
\text { tive Medical } \\
\text { Scheme offi- } \\
\text { cials. }\end{array}$ & & & & & 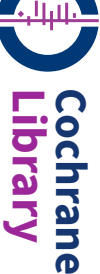 \\
\hline Congo & Zeng 2018a & $\begin{array}{l}\text { Payment } \\
\text { per output } \\
\text { modified } \\
\text { by quality } \\
\text { score }\end{array}$ & Unclear & Unclear & $\begin{array}{l}\text { Facility reg- } \\
\text { isters, with } \\
\text { verification } \\
\text { by CORDAID, } \\
\text { who also car- } \\
\text { ry out quar- } \\
\text { terly quality } \\
\text { checks }\end{array}$ & $\begin{array}{l}\text { From USD } 0.40 \\
\text { (curative visits; } \\
\text { HIV/AIDS cas- } \\
\text { es with oppor- } \\
\text { tunistic infec- } \\
\text { tions treated), } \\
\text { to USD } 60 \text { (tu- } \\
\text { berculosis and } \\
\text { leprosy cases } \\
\text { cured). }\end{array}$ & Unclear & Yes & 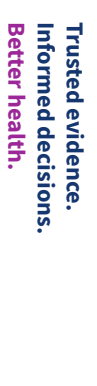 \\
\hline $\begin{array}{l}\text { Democratic } \\
\text { Republic of } \\
\text { the Congo }\end{array}$ & $\begin{array}{l}\text { Huillery } \\
2017\end{array}$ & $\begin{array}{l}\text { Condition- } \\
\text { al cash pay- } \\
\text { ment }\end{array}$ & Unclear & Unclear & $\begin{array}{l}\text { Facility regis- } \\
\text { ters }\end{array}$ & $\begin{array}{l}\text { From USD } 0.6 \\
\text { (curative care } \\
\text { visit) to USD } 5 \\
\text { (complex case } \\
\text { referral) }\end{array}$ & $\begin{array}{l}\text { Total incen- } \\
\text { tives repre- } \\
\text { sent approx. } \\
\text { half of facili- } \\
\text { ties' budget. }\end{array}$ & $\begin{array}{l}\text { Yes (as- } \\
\text { sessed by } \\
\text { reviewers } \\
\text { but not ex- } \\
\text { plicitly stat- } \\
\text { ed) }\end{array}$ & \\
\hline & $\begin{array}{l}\text { Soeters } \\
2011\end{array}$ & $\begin{array}{l}\text { Payment } \\
\text { per output } \\
\text { modified } \\
\text { by quality } \\
\text { score }\end{array}$ & Unclear & $\begin{array}{l}\text { Targets ap- } \\
\text { pear to have } \\
\text { been set } \\
\text { by external } \\
\text { consultants. } \\
\text { Health fa- } \\
\text { cilities sub- } \\
\text { mitted busi- } \\
\text { ness plans } \\
\text { quarterly } \\
\text { outlining } \\
\text { strategies } \\
\text { for deliver- } \\
\text { ing health } \\
\text { packages. }\end{array}$ & Unclear & $\begin{array}{l}\text { USD } 200 \text { to USD } \\
4000 \text { per facil- } \\
\text { ity per month } \\
\text { - variation be- } \\
\text { tween facilities } \\
\text { according to } \\
\text { quality and re- } \\
\text { moteness. }\end{array}$ & Unclear & $\begin{array}{l}\text { Yes (as- } \\
\text { sessed by } \\
\text { reviewers } \\
\text { but not ex- } \\
\text { plicitly stat- } \\
\text { ed) }\end{array}$ & 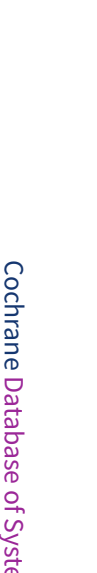 \\
\hline El Salvador & Bernal 2018 & $\begin{array}{l}\text { PBF (fixed } \\
\text { element } \\
\text { alongside a }\end{array}$ & $\begin{array}{l}\text { Specification that } 25 \% \text { bonus received } \\
\text { upon achieving a weighted } 80 \% \text { of tar- } \\
\text { gets is to be spent in the health sector }\end{array}$ & $\begin{array}{l}\text { Targets } \\
\text { agreed be- } \\
\text { tween gov- }\end{array}$ & $\begin{array}{l}\text { Independent } \\
\text { third party }\end{array}$ & $\begin{array}{l}\text { Total incen- } \\
\text { tive trance USD }\end{array}$ & $\begin{array}{l}25 \% \text { of to- } \\
\text { tal value of } \\
\text { funding en- }\end{array}$ & Yes & 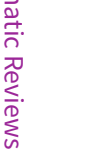 \\
\hline
\end{tabular}




\begin{tabular}{|c|c|c|c|c|c|c|c|c|}
\hline & & $\begin{array}{l}\text { targeted el- } \\
\text { ement) }\end{array}$ & $\frac{2}{4+2}$ & $\begin{array}{l}\text { ernment } \\
\text { and Salud } \\
\text { Mesoamer- } \\
\text { ica Initia- } \\
\text { tive based } \\
\text { on indica- } \\
\text { tors around } \\
\text { inputs and } \\
\text { quality of } \\
\text { care, service } \\
\text { utilization } \\
\text { and health } \\
\text { outcomes. }\end{array}$ & $\begin{array}{l}\text { household } \\
\text { survey }\end{array}$ & $\begin{array}{l}1,625,000 \text { for } \\
\text { first phase. }\end{array}$ & \multicolumn{2}{|l|}{$\begin{array}{l}\text { velope of- } \\
\text { fered to gov- } \\
\text { ernments. }\end{array}$} \\
\hline Haiti & Zeng 2013 & $\begin{array}{l}\text { Perfor- } \\
\text { mance } \\
\text { based con- } \\
\text { tracting, } \\
\text { with indica- } \\
\text { tors for per- } \\
\text { formance } \\
\text { chosen at } \\
\text { year end to } \\
\text { avoid distor- } \\
\text { tion }\end{array}$ & $\begin{array}{l}\text { Facility given autonomy on use of mon- } \\
\text { ey }\end{array}$ & $\begin{array}{l}\text { MSH worked } \\
\text { to set tar- } \\
\text { gets with } \\
\text { NGO each } \\
\text { year based } \\
\text { on histori- } \\
\text { cal perfor- } \\
\text { mance }\end{array}$ & $\begin{array}{l}\text { Monthly re- } \\
\text { ports by } \\
\text { health facility }\end{array}$ & Unclear & $\begin{array}{l}5 \%-10 \% \text { of } \\
\text { budget, de- } \\
\text { pending } \\
\text { on perfor- } \\
\text { mance }\end{array}$ & Yes \\
\hline India & $\begin{array}{l}\text { Mohanan } \\
2017\end{array}$ & $\begin{array}{l}\text { Payment for } \\
\text { health out- } \\
\text { come tar- } \\
\text { gets (com- } \\
\text { bining neg- } \\
\text { ative target } \\
\text { payments } \\
\text { and incre- } \\
\text { mental pay- } \\
\text { ments for } \\
\text { lower lev- } \\
\text { els of mater- } \\
\text { nal mortali- } \\
\text { ty from spe- } \\
\text { cific caus- } \\
\text { es); second } \\
\text { arm tested } \\
\text { payment for } \\
\text { adherence }\end{array}$ & $\begin{array}{l}2 \text { payment mechanisms in intervention } \\
\text { arms: In both arms, providers given in- } \\
\text { centive payment only at end of study } \\
\text { period, with no interim payments. For } \\
\text { output based arm, payment based on } \\
\text { rewards for each of } 4 \text { outcomes. For in- } \\
\text { put based arm, payment based on re- } \\
\text { wards for each of } 5 \text { domains of care. }\end{array}$ & $\begin{array}{l}\text { All incen- } \\
\text { tives and } \\
\text { contracts } \\
\text { are set to al- } \\
\text { low equal } \\
\text { maximum } \\
\text { level of pay- } \\
\text { ment + to } \\
\text { ensure that } \\
\text { the project } \\
\text { could afford } \\
\text { it all. }\end{array}$ & $\begin{array}{l}\text { Experimental } \\
\text { setting; mea- } \\
\text { sured through } \\
\text { household } \\
\text { surveys and } \\
\text { repeated } \\
\text { provider sur- } \\
\text { veys }\end{array}$ & $\begin{array}{l}\text { Maximum of } \\
\text { INR } 150,000 \\
\text { (USD 2,700 at } \\
\text { time of con- } \\
\text { tract) for doc- } \\
\text { tors }\end{array}$ & $\begin{array}{l}\text { Approx. 15\% } \\
\text { of special- } \\
\text { ist doctor } \\
\text { salary }\end{array}$ & Yes \\
\hline
\end{tabular}




\begin{tabular}{|c|c|c|c|c|c|c|c|c|c|}
\hline & & $\begin{array}{l}\text { to WHO pro- } \\
\text { tocols for } \\
\text { maternal } \\
\text { health care } \\
\text { (payment } \\
\text { according } \\
\text { to score } \\
\text { against five } \\
\text { domains of } \\
\text { care) }\end{array}$ & $\sqrt{2}$ & & & & & & 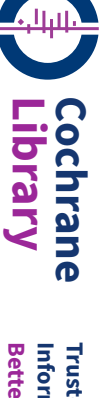 \\
\hline Kenya & Menya 2015 & $\begin{array}{l}\text { Target pay- } \\
\text { ments (pos- } \\
\text { itive and } \\
\text { negative) }\end{array}$ & $\begin{array}{l}\text { Intervention facilities received pay- } \\
\text { ments based on } 7 \text { performance indi- } \\
\text { cators. Incentives had to be used for } \\
\text { equipment, supplies, repairs, and basic } \\
\text { labour, rather than payments to employ- } \\
\text { ees or clinicians. }\end{array}$ & $\begin{array}{l}\text { Study team - } \\
\text { to foster co- } \\
\text { operation } \\
\text { between de- } \\
\text { partments } \\
\text { and harmo- } \\
\text { nize their } \\
\text { working }\end{array}$ & $\begin{array}{l}\text { Appears to } \\
\text { be from facil- } \\
\text { ity registers } \\
\text { during study } \\
\text { team visits }\end{array}$ & $\begin{array}{l}\text { Maximum USD } \\
1,175(100,000 \\
\text { KSh) per quar- } \\
\text { ter per facility. }\end{array}$ & $\begin{array}{l}\text { Approx. } \\
\text { equivalent } \\
\text { to mon- } \\
\text { ey saved if } \\
\text { overuse of } \\
\text { ACT curbed. }\end{array}$ & Yes & 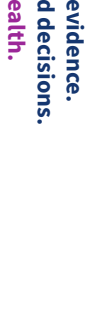 \\
\hline Malawi & $\begin{array}{l}\text { McMahon } \\
2016\end{array}$ & $\begin{array}{l}\text { Payment } \\
\text { per output } \\
\text { modified } \\
\text { by quality } \\
\text { score }\end{array}$ & $\begin{array}{l}\text { Rewards paid to facilities based on } \\
\text { achievement of set targets. Rewards } \\
\text { to be used for facility improvements or } \\
\text { other strategies outlined in annual busi- } \\
\text { ness plans developed by facility staff } \\
\text { and Support for Service Delivery Inte- } \\
\text { gration (SSDI) staff. Rewards cannot be } \\
\text { redistributed to health workers as per- } \\
\text { formance bonuses. }\end{array}$ & Unclear & $\begin{array}{l}\text { Quality is } \\
\text { measured by } \\
\text { communities } \\
\text { and patient } \\
\text { interviews. } \\
\text { Further de- } \\
\text { tails unclear. }\end{array}$ & Unclear & Unclear & Yes & \\
\hline $\begin{array}{l}\text { Multiple - } \\
\text { Burkina Fa- } \\
\text { so, Ghana } \\
\text { and Tanza- } \\
\text { nia }\end{array}$ & $\begin{array}{l}\text { Duysburgh } \\
2015\end{array}$ & $\begin{array}{l}\text { Clinical de- } \\
\text { cision guide } \\
+ \text { PBF (fi- } \\
\text { nancial and } \\
\text { non-finan- } \\
\text { cial incen- } \\
\text { tives) }\end{array}$ & Unclear & $\begin{array}{l}\text { Based on } \\
\text { qualitative } \\
\text { research } \\
\text { with stake- } \\
\text { holders in- } \\
\text { volved, for } \\
\text { instance } \\
\text { health work- } \\
\text { ers and poli- } \\
\text { cy makers. }\end{array}$ & $\begin{array}{l}\text { Emphasis on } \\
\text { routine mea- } \\
\text { surement of } \\
\text { indicators }\end{array}$ & Unclear & Unclear & Unclear & 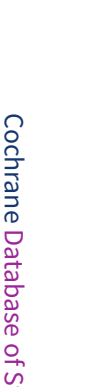 \\
\hline Peru & $\begin{array}{l}\text { Cruzado } \\
\text { de la Vega, } \\
2017\end{array}$ & $\begin{array}{l}\text { Combina- } \\
\text { tions of the } \\
\text { above - ap- } \\
\text { pears to }\end{array}$ & $\begin{array}{l}\text { Agreements used to transfer resources } \\
\text { to the budgets of these regions with the } \\
\text { condition of fulfilling management com- } \\
\text { mitments and coverage goals with a }\end{array}$ & $\begin{array}{l}\text { Programme } \\
\text { is based on } \\
\text { agreement } \\
\text { made be- }\end{array}$ & Unclear & Unclear & Unclear & Unclear & 疍 \\
\hline
\end{tabular}




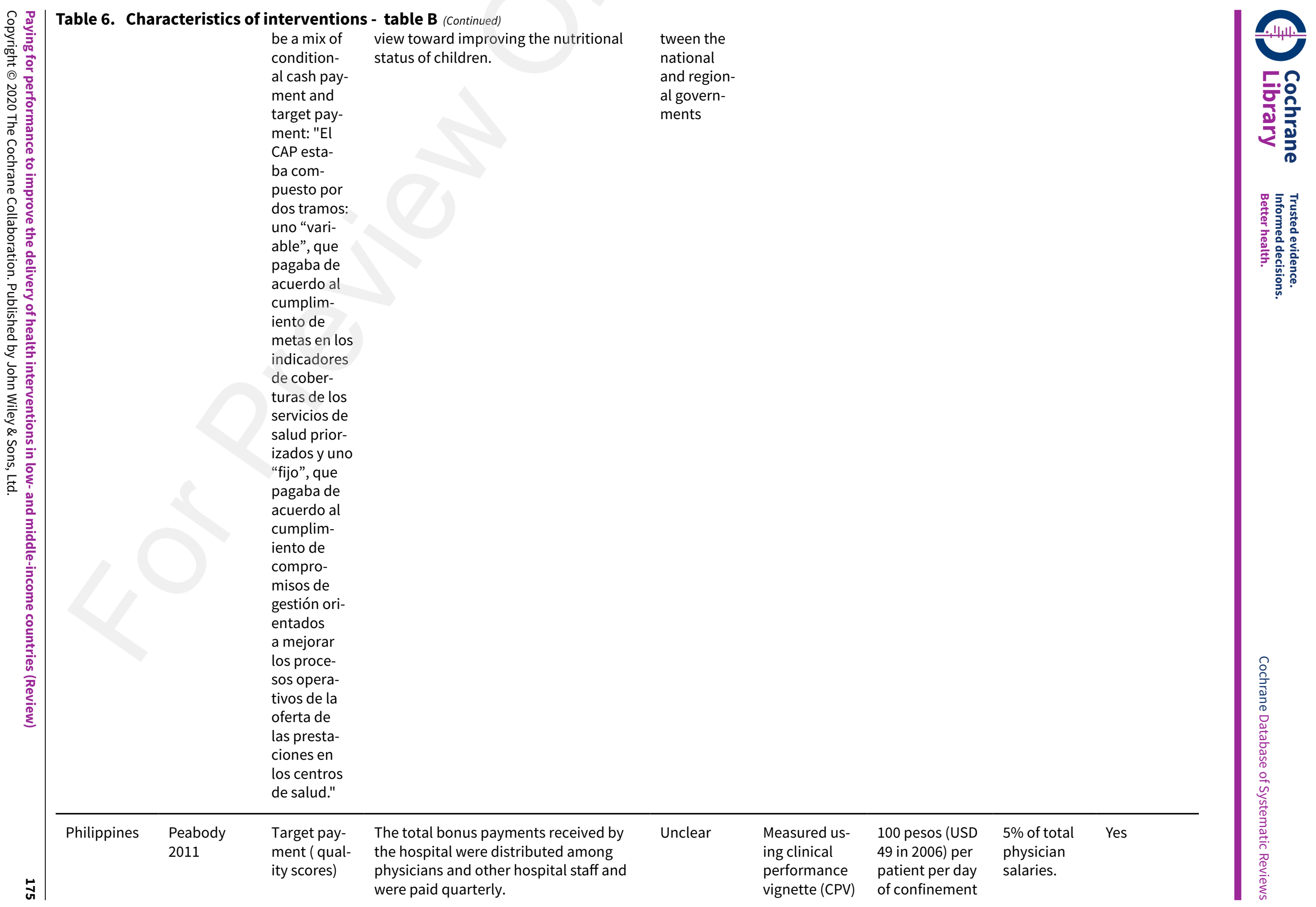




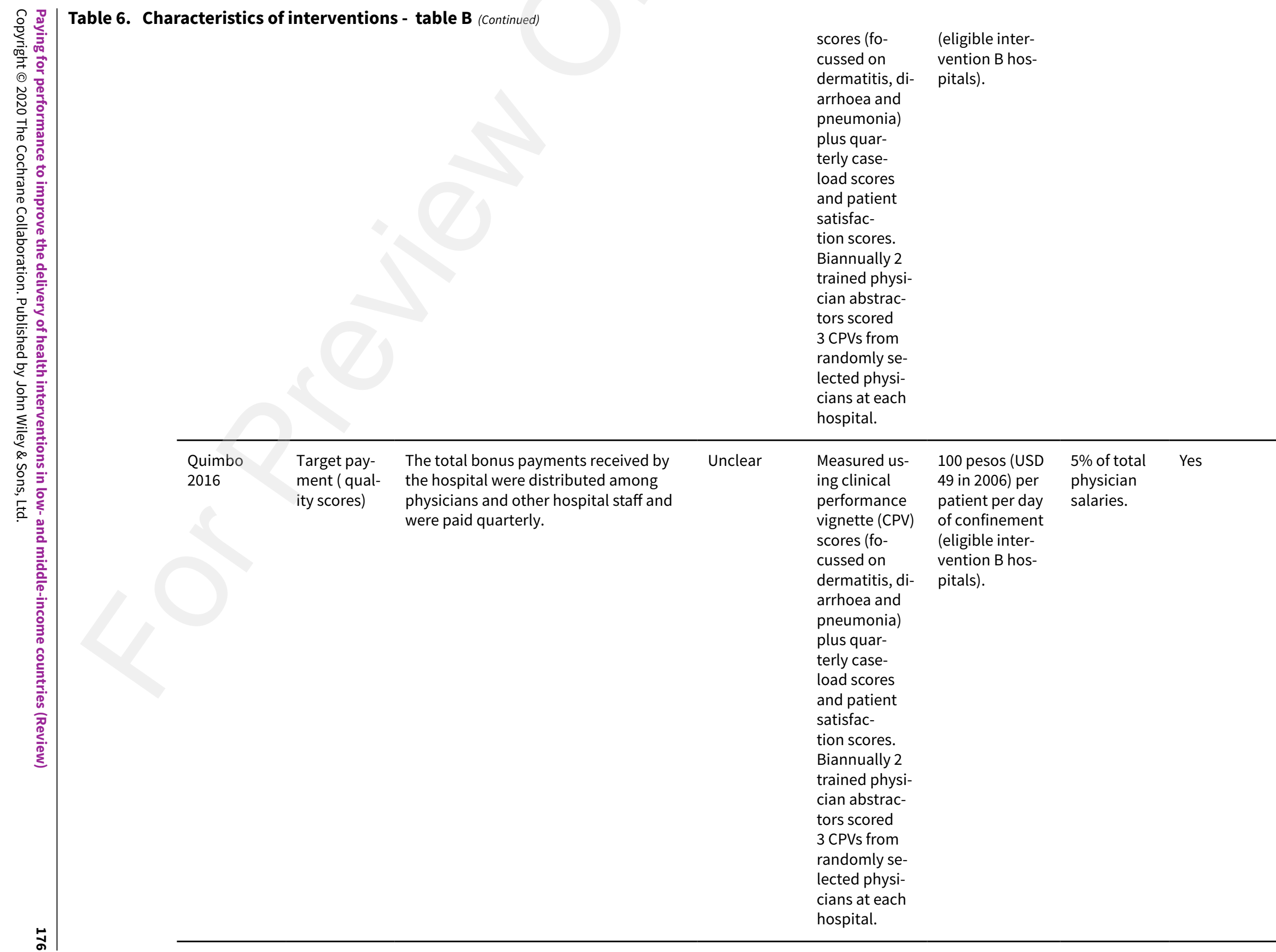




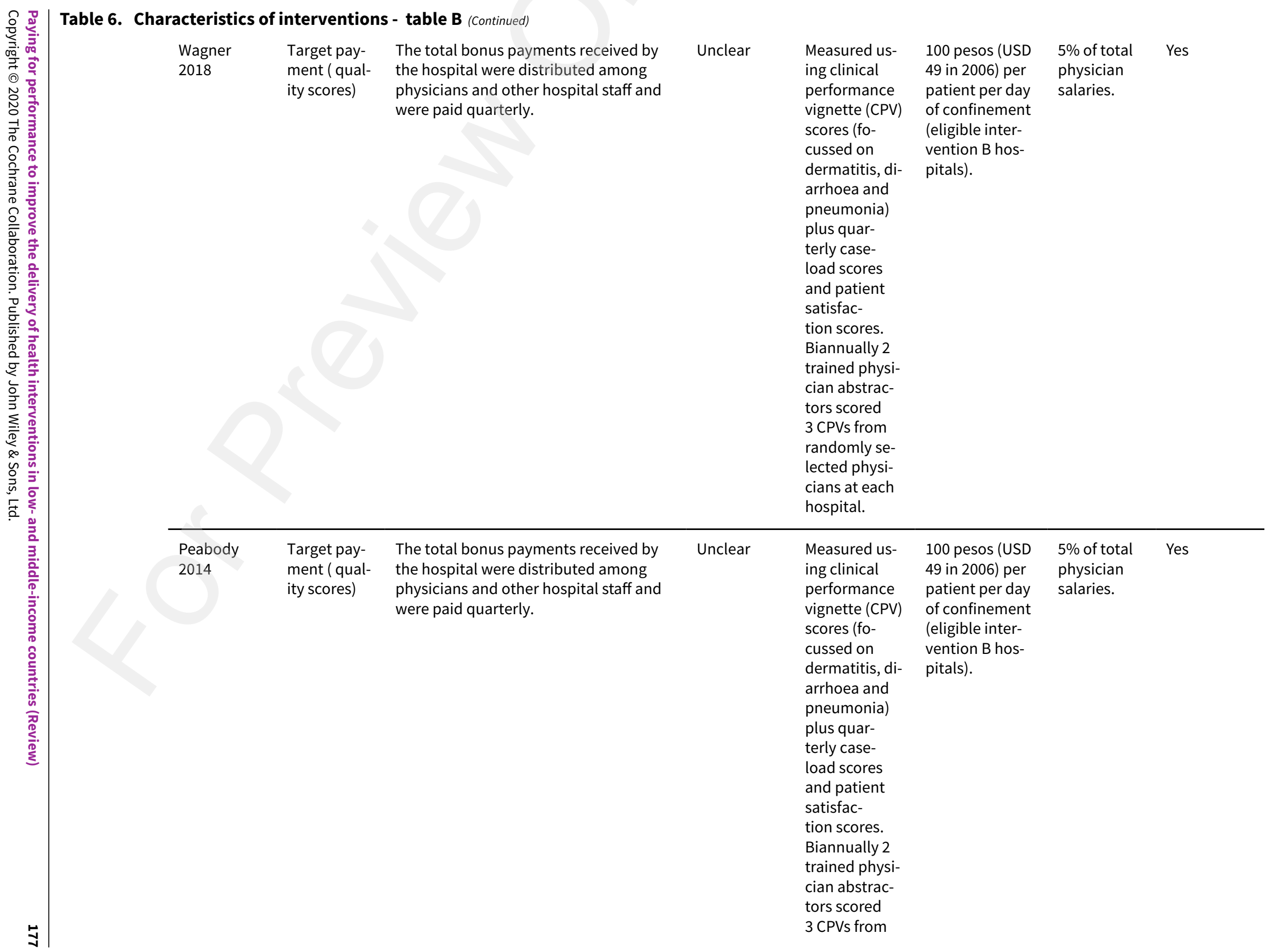




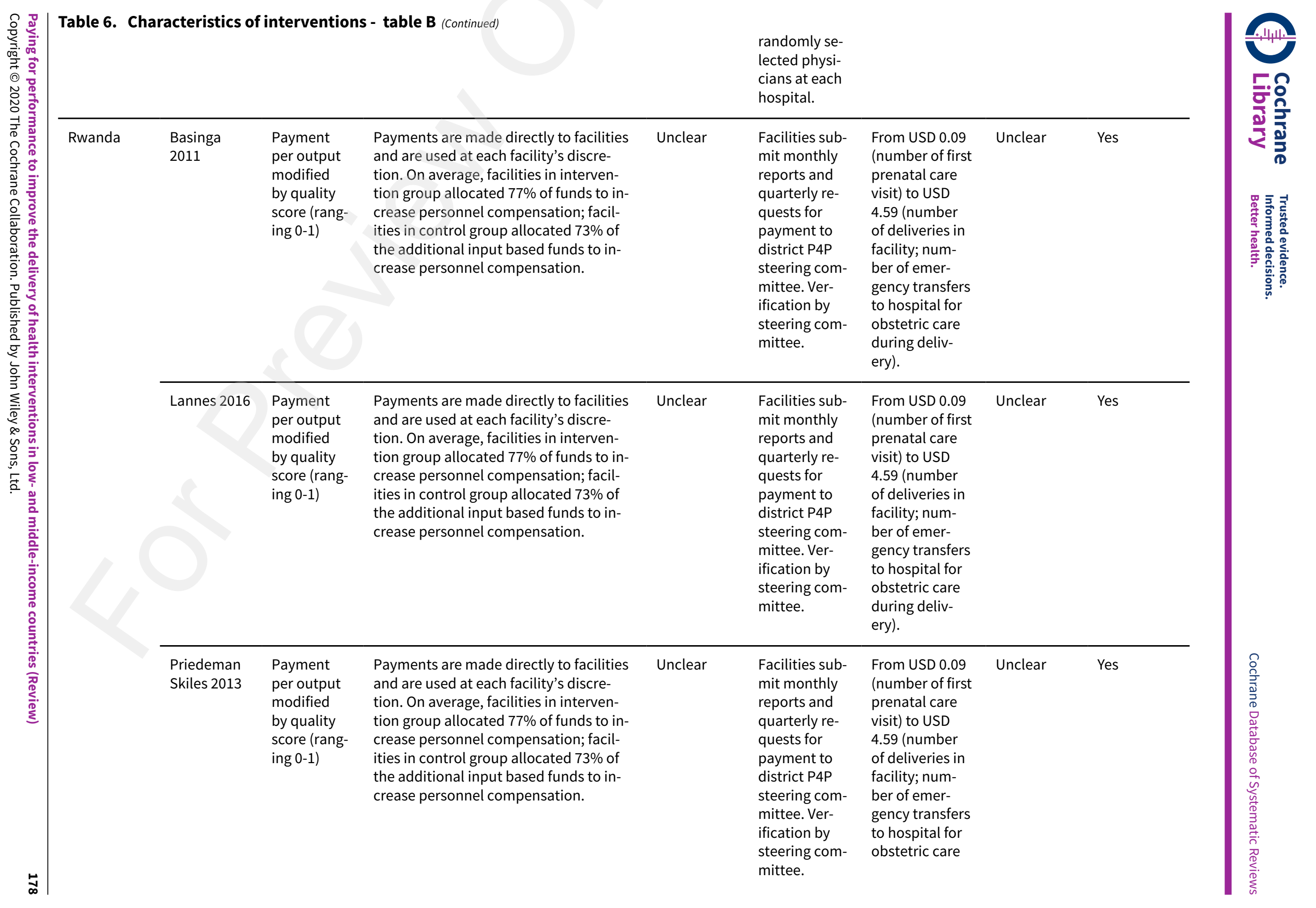




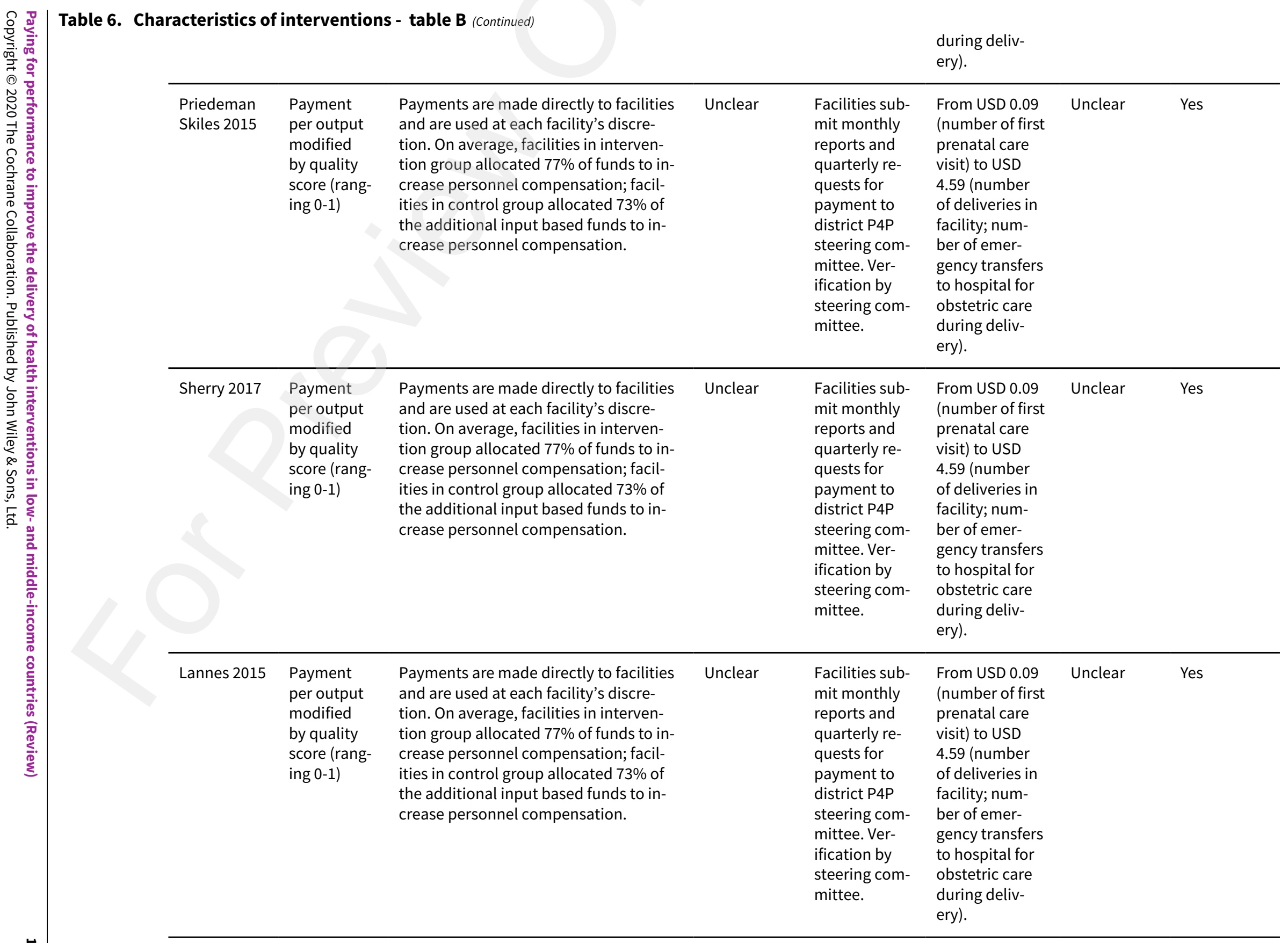




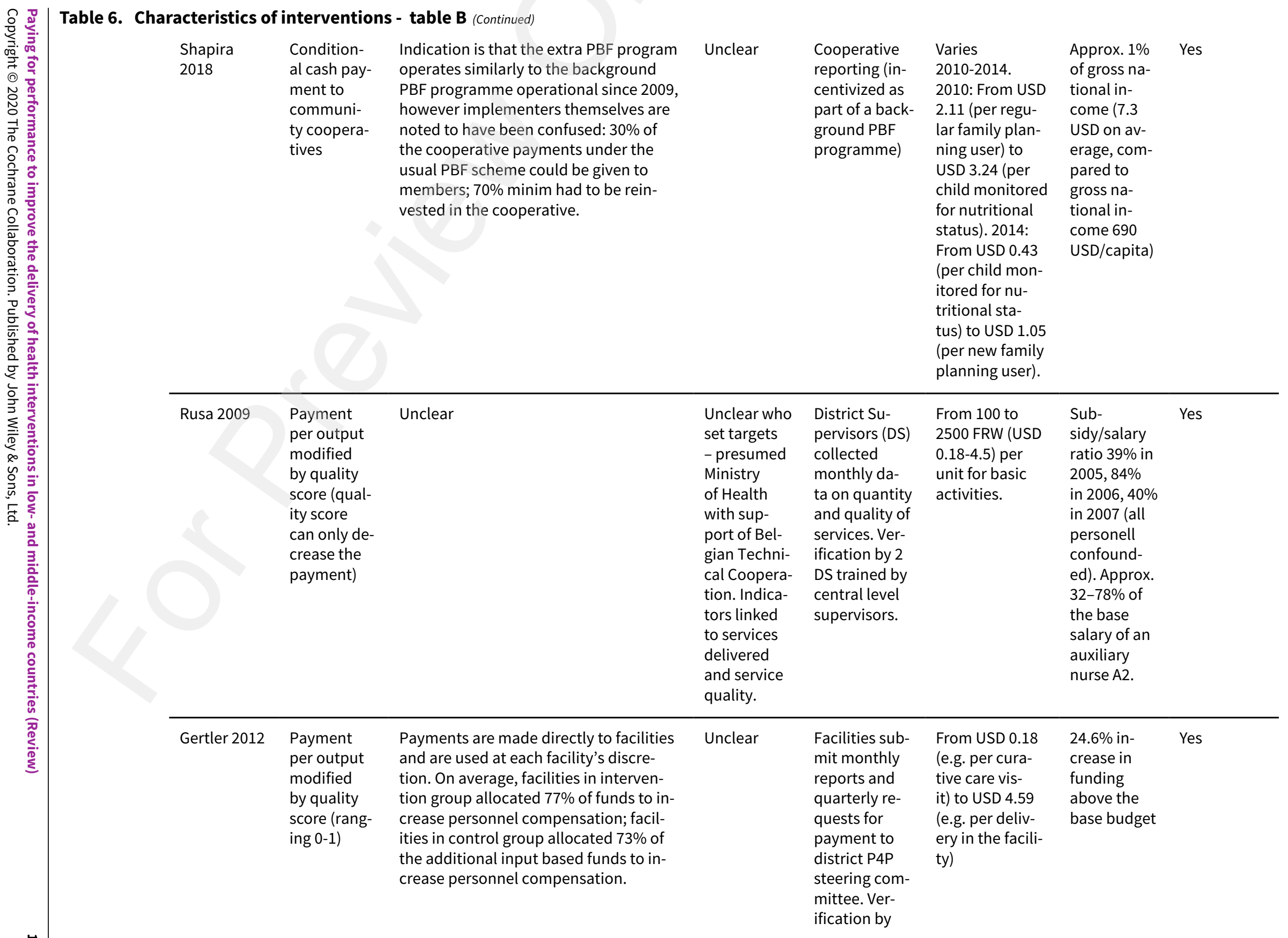




\begin{tabular}{|c|c|c|c|c|c|c|c|c|}
\hline & $\begin{array}{l}\text { de Walque } \\
2015\end{array}$ & $\begin{array}{l}\text { Payment } \\
\text { per output }\end{array}$ & $\begin{array}{l}\text { Payments are made directly to facilities } \\
\text { and are used at each facility's discre- } \\
\text { tion. On average, facilities in interven- } \\
\text { tion group allocated } 60-80 \% \text { of funds to } \\
\text { increase personnel compensation. }\end{array}$ & $\begin{array}{l}\text { The Ministry } \\
\text { of Health }\end{array}$ & $\begin{array}{l}\text { Facilities sub- } \\
\text { mit monthly } \\
\text { reports and } \\
\text { quarterly re- } \\
\text { quests for } \\
\text { payment to } \\
\text { district P4P } \\
\text { steering com- } \\
\text { mittee. Ver- } \\
\text { ification by } \\
\text { steering com- } \\
\text { mittee. }\end{array}$ & $\begin{array}{l}\text { From USD } 0.46 \\
\text { (per HIV+ pa- } \\
\text { tient treated } \\
\text { with co-tri- } \\
\text { moxazole each } \\
\text { month) to USD } \\
9.17 \text { (per infant } \\
\text { born to HIV+ } \\
\text { mothers tested) }\end{array}$ & $\begin{array}{l}\text { 14\% of over- } \\
\text { all expen- } \\
\text { ditures in } \\
2007 .\end{array}$ & Yes \\
\hline Swaziland & Kliner 2015 & $\begin{array}{l}\text { Payment } \\
\text { per output }\end{array}$ & $\begin{array}{l}\text { Community Support Workers (CSWs) } \\
\text { given monthly financial incentives to } \\
\text { cover travel to the clinic with (or on be- } \\
\text { half of) the patient, and cover other sup- } \\
\text { plies for the patient. }\end{array}$ & Unclear & $\begin{array}{l}\text { Appears to be } \\
\text { TB register }\end{array}$ & $\begin{array}{l}\text { USD } 5.75 \text { per } \\
\text { month/per pa- } \\
\text { tient plus USD } \\
34.40 \text { per pa- } \\
\text { tient who com- } \\
\text { pleted treat- } \\
\text { ment or was } \\
\text { cured after } 6 \\
\text { months }\end{array}$ & Unclear & $\begin{array}{l}\text { Yes (as- } \\
\text { sessed by } \\
\text { reviewers } \\
\text { but not ex- } \\
\text { plicitly stat- } \\
\text { ed) }\end{array}$ \\
\hline \multirow[t]{3}{*}{ Tanzania } & Brock 2018 & $\begin{array}{l}\text { PBF (condi- } \\
\text { tional provi- } \\
\text { sion of ma- } \\
\text { terial goods) }\end{array}$ & $\begin{array}{l}\text { NA - this is about receiving gifts both } \\
\text { conditional or not }\end{array}$ & Study team & Study team & Book & $\begin{array}{l}\text { Not applic- } \\
\text { able (incen- } \\
\text { tive a book) }\end{array}$ & Yes \\
\hline & $\begin{array}{l}\text { Binyaruka } \\
2015\end{array}$ & $\begin{array}{l}\text { PBF (target } \\
\text { payment) }\end{array}$ & $\begin{array}{l}\text { Full payment made to facilities if } 100 \% \\
\text { of target achieved. If less than } 100 \% \text { but } \\
\text { at least } 75 \% \text { of targets achieved, } 50 \% \\
\text { of payment is made. } 75 \% \text { of bonus pay- } \\
\text { ments required to be distributed among } \\
\text { health workers. Remaining } 25 \% \text { retained } \\
\text { by facility - used for drugs, supplies, } \\
\text { renovations. }\end{array}$ & Unclear & $\begin{array}{l}\text { National } \\
\text { Health Man- } \\
\text { agement In- } \\
\text { formation } \\
\text { System }\end{array}$ & $\begin{array}{l}\text { Maximum USD } \\
820 \text { for dispen- } \\
\text { saries; USD } \\
\text { 3,220 for health } \\
\text { centres; and } \\
\text { USD 6,790 for } \\
\text { hospitals. }\end{array}$ & $\begin{array}{l}\text { Approx. } 10 \% \\
\text { of health } \\
\text { worker } \\
\text { monthly } \\
\text { salary. }\end{array}$ & Yes \\
\hline & $\begin{array}{l}\text { Binyaruka } \\
2017\end{array}$ & $\begin{array}{l}\text { PBF (target } \\
\text { payment) }\end{array}$ & $\begin{array}{l}\text { Full payment made to facilities if } 100 \% \\
\text { of target achieved. If less than } 100 \% \text { but } \\
\text { at least } 75 \% \text { of targets achieved, } 50 \% \\
\text { of payment is made. } 75 \% \text { of bonus pay- } \\
\text { ments required to be distributed among }\end{array}$ & Unclear & $\begin{array}{l}\text { National } \\
\text { Health Man- } \\
\text { agement In- } \\
\text { formation } \\
\text { System }\end{array}$ & $\begin{array}{l}\text { Maximum USD } \\
820 \text { for dispen- } \\
\text { saries; USD } \\
3,220 \text { for health } \\
\text { centres; and }\end{array}$ & $\begin{array}{l}\text { Approx. } 10 \% \\
\text { of health } \\
\text { worker } \\
\text { monthly } \\
\text { salary. }\end{array}$ & Yes \\
\hline
\end{tabular}


Table 6. Characteristics of interventions - table B (Continued)

health workers. Remaining $25 \%$ retained

USD 6,790 for

by facility - used for drugs, supplies,

hospitals.

renovations.

\begin{tabular}{ll}
\hline Binyaruka & PBF (target \\
2018 & payment)
\end{tabular}

Full payment made to facilities if $100 \%$

of target achieved. If less than $100 \%$ but

Unclear

National

Maximum USD

at least $75 \%$ of targets achieved, $50 \%$

Health Man-

820 for dispen-

Approx. $10 \%$ Yes

of payment is made. $75 \%$ of bonus pay-

agement In-

saries; USD

health

ments required to be distributed among

formation

3,220 for health

worker

health workers. Remaining $25 \%$ retained

System

centres; and

monthly

by facility - used for drugs, supplies,

USD 6,790 for

salary.

renovations.

$\begin{array}{ll}\text { Mayumana } & \text { PBF (target } \\ 2017 & \text { payment) }\end{array}$

Full payment made to facilities if $100 \%$

of target achieved. If less than $100 \%$ but

at least $75 \%$ of targets achieved, $50 \%$

of payment is made. $75 \%$ of bonus pay-

ments required to be distributed among

health workers. Remaining $25 \%$ retained

hospitals.

Und

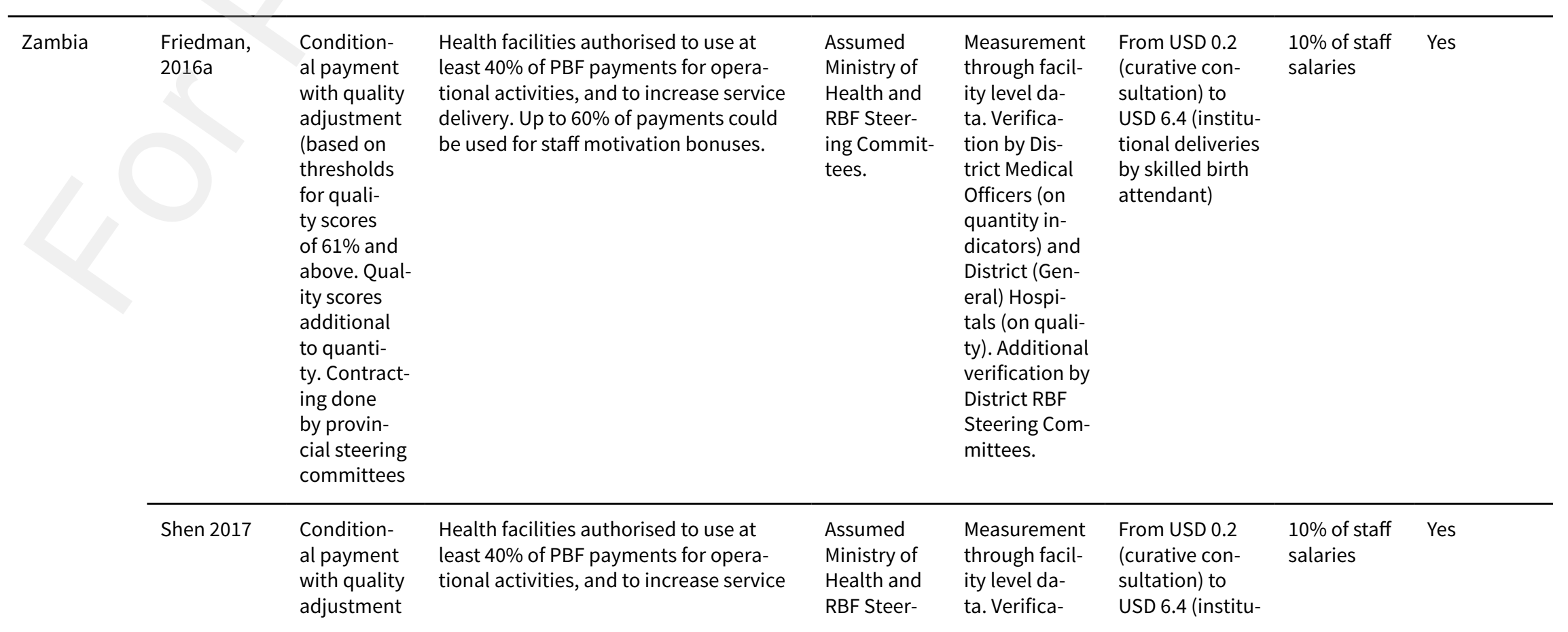

$\begin{array}{lll}\text { National } & \text { Maximum USD } & \text { Approx. 10\% } \\ \text { Health Man- } & \text { 820 for dispen- } & \text { of health } \\ \text { agement In- } & \text { saries; USD } & \text { worker } \\ \text { formation } & 3,220 \text { for health } & \text { monthly } \\ \text { System } & \text { centres; and } & \text { salary. } \\ & \text { USD 6,790 for } & \\ & \text { hospitals. } & \end{array}$

es




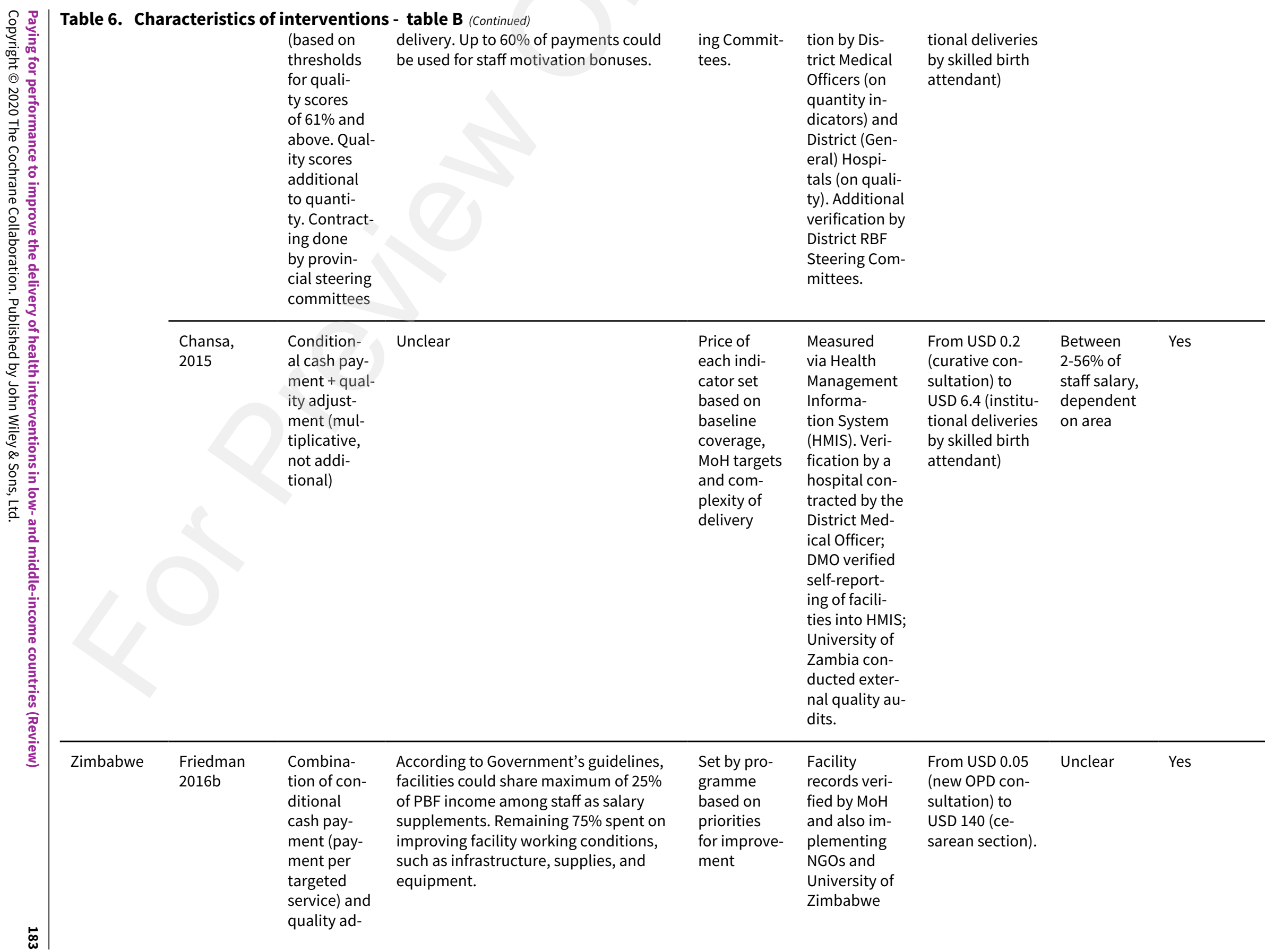




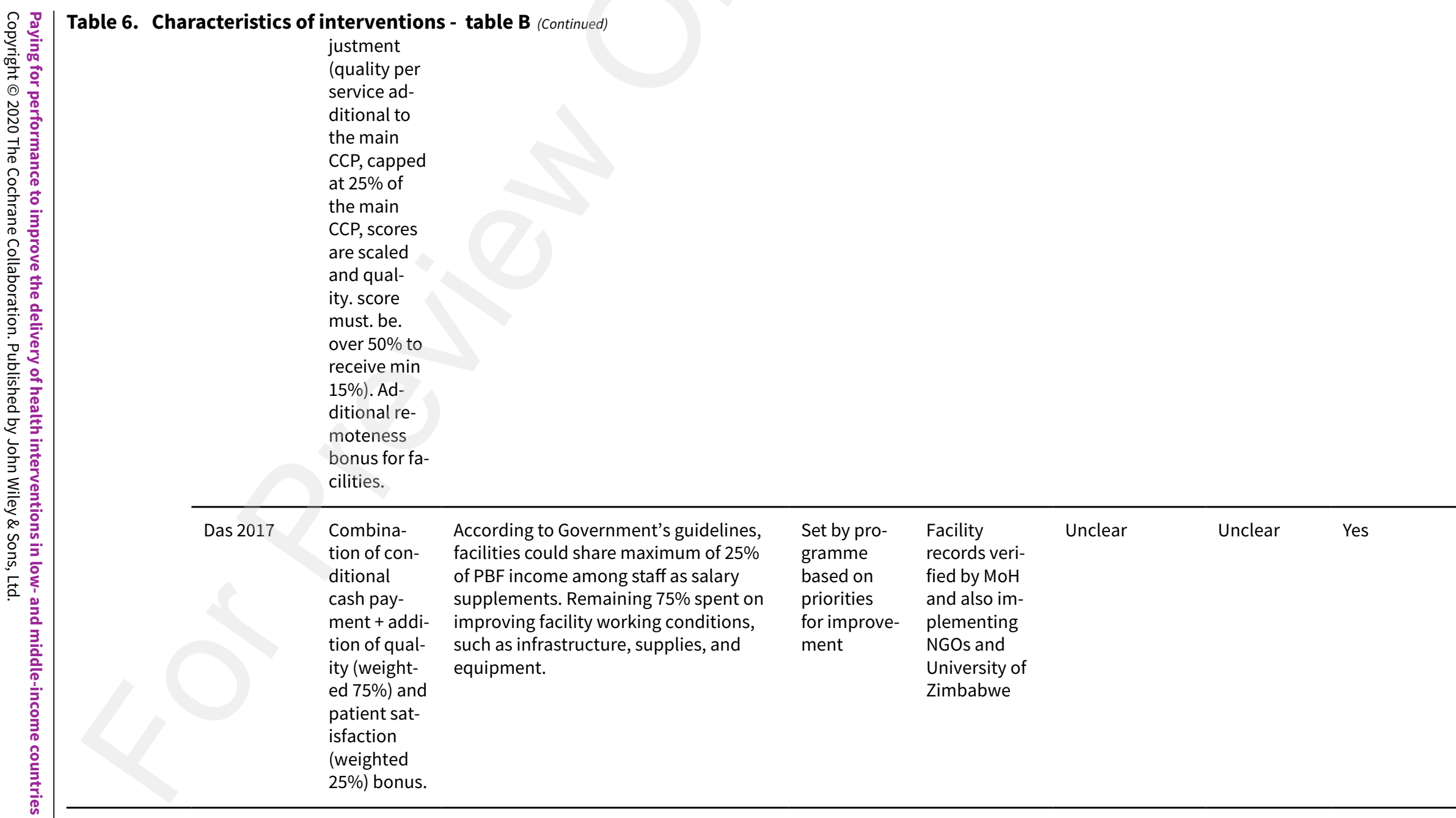


Table 7. Intervention classification - table A

\begin{tabular}{|c|c|c|c|c|c|c|}
\hline $\begin{array}{l}\text { Scheme clas- } \\
\text { sification (as } \\
\text { based on de- } \\
\text { scriptions pro- } \\
\text { vided in re- }\end{array}$ & Details on scheme & $\begin{array}{l}\text { Nr. } \\
\text { Stud- } \\
\text { ies }\end{array}$ & $\begin{array}{l}\text { Stud- } \\
\text { ies re- } \\
\text { port- } \\
\text { ing }\end{array}$ & $\begin{array}{l}\text { Coun- } \\
\text { tries } \\
\text { in- } \\
\text { clud- } \\
\text { ed (n) }\end{array}$ & $\begin{array}{l}\text { Study } \\
\text { types } \\
\text { (n) }\end{array}$ & $\begin{array}{l}\text { Comparators against } \\
\text { which scheme impacts as } \\
\text { sessed }(n)\end{array}$ \\
\hline
\end{tabular}

ments)

\begin{tabular}{|c|c|c|c|c|c|c|}
\hline $\begin{array}{l}\text { Capitation and } \\
\text { PBF }\end{array}$ & $\begin{array}{l}\text { Payment reforms including capitation and } \\
\text { PBF elements }\end{array}$ & 2 & $\begin{array}{l}\text { Yip } \\
2014 \\
\text { and } \\
\text { Sun } \\
2016\end{array}$ & $\begin{array}{l}\text { China } \\
(2)\end{array}$ & $\begin{array}{l}\text { RCT } \\
(1) \\
\text { and } \\
\text { qua- } \\
\text { si-non } \\
\text { ran- } \\
\text { dom- } \\
\text { ized } \\
\text { trial } \\
(1)\end{array}$ & $\begin{array}{l}\text { Fee for service (1) and glob- } \\
\text { al capitated budget only (1) }\end{array}$ \\
\hline $\begin{array}{l}\text { Conditional } \\
\text { provision of } \\
\text { material goods }\end{array}$ & $\begin{array}{l}\text { Conditional provision of material goods } \\
\text { alongside supervision and quality improve- } \\
\text { ment strategies }\end{array}$ & 1 & $\begin{array}{l}\text { Brock } \\
2018\end{array}$ & $\begin{array}{l}\text { Tan- } \\
\text { zania } \\
(1)\end{array}$ & $\begin{array}{l}\text { Qua- } \\
\text { si-non } \\
\text { ran- } \\
\text { dom- } \\
\text { ized } \\
\text { trial } \\
\text { (1) }\end{array}$ & $\begin{array}{l}\text { Unconditional gifts (either } \\
\text { immediate or delayed) as } \\
\text { alternative interventions } \\
\text { and control (all receive a } \\
\text { standard encouragement } \\
\text { intervention) (1) }\end{array}$ \\
\hline $\begin{array}{l}\text { Financial and } \\
\text { non-financial } \\
\text { incentives }+ \\
\text { clinical decision } \\
\text { guide }\end{array}$ & $\begin{array}{l}\text { Mix of financial and non-financial incen- } \\
\text { tives, alongside clinical decision guide and } \\
\text { supervision/technical support }\end{array}$ & 1 & $\begin{array}{l}\text { Duys- } \\
\text { burgh } \\
2016\end{array}$ & $\begin{array}{l}\text { Burki- } \\
\text { na Fa- } \\
\text { so, } \\
\text { Ghana } \\
\text { and } \\
\text { Tan- } \\
\text { zania } \\
\text { (all in } \\
\text { 1) }\end{array}$ & $\begin{array}{l}\text { CBA } \\
(1)\end{array}$ & Control as standard care (1) \\
\hline $\begin{array}{l}\text { Performance } \\
\text { related pay }\end{array}$ & $\begin{array}{l}\text { Performance-related pay (results-based } \\
\text { management) involving different types of } \\
\text { agreement according to province imple- } \\
\text { mented (ranging from multi-level agree- } \\
\text { ments with strategic targets to not speci- } \\
\text { fied) }\end{array}$ & 1 & $\begin{array}{l}\text { Vinuela } \\
2015\end{array}$ & $\begin{array}{l}\text { Brazil } \\
(1)\end{array}$ & ITS (1) & $\begin{array}{l}\text { Comparison of impact } \\
\text { over time in implementing } \\
\text { provinces. (1) }\end{array}$ \\
\hline $\begin{array}{l}\text { Performance } \\
\text { based contract- } \\
\text { ing or service } \\
\text { agreements }\end{array}$ & $\begin{array}{l}\text { Service agreements introduced as part of } \\
\text { reform and in case of contracting, with in- } \\
\text { dicators for performance chosen at year } \\
\text { end to avoid distortion }\end{array}$ & 3 & $\begin{array}{l}\text { Van } \\
\text { den } \\
\text { Poel } \\
2016, \\
\text { Khim } \\
2018 \\
\text { and } \\
\text { Zeng } \\
2013\end{array}$ & $\begin{array}{l}\text { Cam- } \\
\text { bodia } \\
(2) \\
\text { Haiti } \\
(1)\end{array}$ & $\begin{array}{l}\text { CBA } \\
(2) \\
\text { ITS (1) }\end{array}$ & $\begin{array}{l}\text { Routine practice as control } \\
\text { (2) and comparison of indi- } \\
\text { cators over time. (1) }\end{array}$ \\
\hline Hybrid scheme & Payment per output and for target & 2 & $\begin{array}{l}\text { Pow- } \\
\text { ell-Jack- } \\
\text { son } \\
2014\end{array}$ & $\begin{array}{l}\text { Chi- } \\
\text { na }(1) \\
\text { Peru } \\
(1)\end{array}$ & $\begin{array}{l}\text { Qua- } \\
\text { si/non } \\
\text { ran- } \\
\text { dom- }\end{array}$ & Control as standard care (2) \\
\hline
\end{tabular}


Table 7. Intervention classification - table A (Continued)

$\begin{array}{ll}\text { Cruza- } & \text { ized } \\ \text { do de } & \text { trials } \\ \text { la Vega } & (2) \\ 2017 & \end{array}$

2017

$\begin{array}{lllllll}\begin{array}{l}\text { Results based } \\ \text { aid }\end{array} & \begin{array}{l}\text { Fixed element alongside a targeted ele- } \\ \text { ment as part of results based aid }\end{array} & 1 & \begin{array}{l}\text { Bernal } \\ 2018\end{array} & \begin{array}{l}\text { El-Sal- } \\ \text { vador } \\ (1)\end{array} & \begin{array}{l}\text { CBA } \\ (1)\end{array} & \text { Control as status quo (1) }\end{array}$




\begin{tabular}{|c|c|c|c|c|c|c|c|}
\hline \multicolumn{2}{|c|}{$\begin{array}{l}\text { Scheme classification (as } \\
\text { based on descriptions provid- } \\
\text { ed in reviewed documents) }\end{array}$} & \multirow{2}{*}{$\begin{array}{l}\text { Details on scheme } \\
\begin{array}{l}\text { Payment for each out- } \\
\text { put }\end{array}\end{array}$} & \multirow{2}{*}{$\begin{array}{l}\text { Nr. Studies } \\
9\end{array}$} & \multirow{2}{*}{$\begin{array}{l}\text { Studies reporting } \\
\text { Huillery 2017, Shapira 2018, } \\
\text { Witvorapong 2016, Ir 2015, } \\
\text { Matsuoka 2014, Yao 2008, } \\
\text { Kliner 2015, Celhay 2015, } \\
\text { Walque } 2015\end{array}$} & \multirow{2}{*}{$\begin{array}{l}\begin{array}{l}\text { Coun- } \\
\text { tries in- } \\
\text { cluded } \\
\text { (n) }\end{array} \\
\text { Afghanistar } \\
\text { (1), Ar- } \\
\text { gentina } \\
\text { (1), Chi- } \\
\text { na (1), } \\
\text { Cambo- } \\
\text { dia (2), } \\
\text { DRC (1), } \\
\text { Swazi- } \\
\text { land (1), } \\
\text { Rwanda } \\
\text { (2) }\end{array}$} & \multirow{2}{*}{$\begin{array}{l}\text { Study types } \\
\text { (n) } \\
\text { nCT (4), Qua- } \\
\text { si/non-ran- } \\
\text { domized (2), } \\
\text { ITS (2), CBA } \\
\text { (1) }\end{array}$} & \multirow{2}{*}{$\begin{array}{l}\text { Comparators against which } \\
\text { scheme impacts assessed (n) }\end{array}$} \\
\hline $\begin{array}{l}\text { Payment per } \\
\text { output }\end{array}$ & $\begin{array}{l}\text { Payment per } \\
\text { output }\end{array}$ & & & & & & \\
\hline & & $\begin{array}{l}\text { Payment per output } \\
\text { with income potential- } \\
\text { ly withheld }\end{array}$ & 1 & Chang 2017 & China (1) & ITS (1) & $\begin{array}{l}\text { Comparison of impact over } \\
\text { time in implementing hospital. } \\
\text { (1) }\end{array}$ \\
\hline & & $\begin{array}{l}\text { Payment per output } \\
\text { including revenue }\end{array}$ & 1 & Liu and Mills 2009 & China (1) & ITS (1) & $\begin{array}{l}\text { Comparison over time in imple- } \\
\text { menting provinces (1) }\end{array}$ \\
\hline & $\begin{array}{l}\text { Payment per } \\
\text { output modi- } \\
\text { fied by quality } \\
\text { score }\end{array}$ & $\begin{array}{l}\text { Payment per output } \\
\text { with quality as multi- } \\
\text { plicative adjuster (be- } \\
\text { tween } 0-1 \text { ) }\end{array}$ & 11 & $\begin{array}{l}\text { Zeng 2018a, Chansa 2015, } \\
\text { Lagarde 2015, Basinga 2011, } \\
\text { Lannes 2015, Lannes 2016, } \\
\text { Priedeman Skiles 2013, } \\
\text { Priedeman Skiles 2015, } \\
\text { Sherry 2017, Rusa 2009, } \\
\text { Gertler } 2013\end{array}$ & $\begin{array}{l}\text { Congo } \\
\text { (1), Zam- } \\
\text { bia (1), } \\
\text { Benin } \\
\text { (1), } \\
\text { Rwanda } \\
\text { (8) }\end{array}$ & $\begin{array}{l}\text { Quasi/non- } \\
\text { randomized } \\
\text { trial (8), CBA } \\
(1), \text { ITS (2) }\end{array}$ & $\begin{array}{l}\text { Control with standard care (2), } \\
\text { Over time comparison in imple- } \\
\text { mentation areas (2), Compara- } \\
\text { tor of matched funding ( } 7)\end{array}$ \\
\hline & & $\begin{array}{l}\text { Payment per output } \\
\text { with quality bonuses } \\
\text { (quality adjuster an } \\
\text { additional but not de- } \\
\text { tracting component) }\end{array}$ & 7 & $\begin{array}{l}\text { Bonfrer 2014a, Bonfrer } \\
\text { 2014b, Falisse 2015, Rudas- } \\
\text { ingwa 2015, Shen 2017, } \\
\text { Friedman 2016a }\end{array}$ & $\begin{array}{l}\text { Burundi } \\
(4), \text { Zam- } \\
\text { bia (2) }\end{array}$ & $\begin{array}{l}\text { RCT (2) and } \\
\text { CBA (4) }\end{array}$ & $\begin{array}{l}\text { Control as standard care (5), } \\
\text { Comparator of enhanced } \\
\text { matched financing (2) }\end{array}$ \\
\hline & & $\begin{array}{l}\text { No description of pay- } \\
\text { ment equation - quali- } \\
\text { ty adjustment noted }\end{array}$ & 1 & Engineer 2016 & $\begin{array}{l}\text { Afghanistar } \\
\text { (1) }\end{array}$ & $\mathrm{RCT}(1)$ & Control with standard care (1) \\
\hline
\end{tabular}




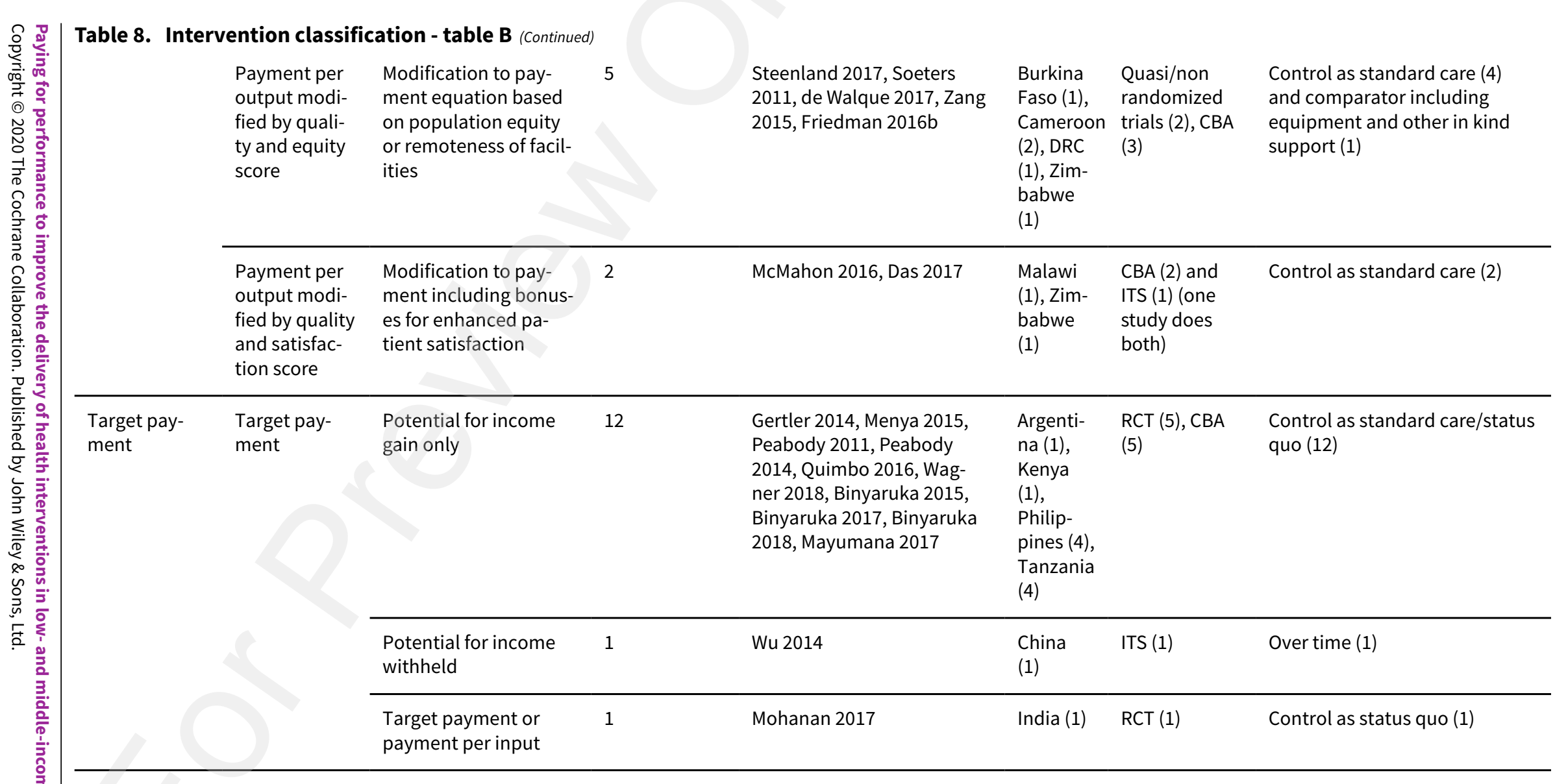


Table 9. Sensitivity analyses against control: Direction of relative effect and GRADE rating for targeted outcomes across RCT studies only

\section{Direction of relative effect and GRADE rating for targeted outcomes across RCT studies only}

\begin{tabular}{|c|c|c|c|c|}
\hline Outcome & $\begin{array}{l}\text { Indicator (if indicator not } \\
\text { named, no RCT evidence avail- } \\
\text { able) }\end{array}$ & $\begin{array}{l}\text { Comment } \\
\text { on ef- } \\
\text { fect (de- } \\
\text { sirable, } \\
\text { undesir- } \\
\text { able, neu- } \\
\text { tral or } \\
\text { uncer- } \\
\text { tain) }\end{array}$ & $\begin{array}{l}\text { Certainty } \\
\text { of the ev- } \\
\text { idence }\end{array}$ & $\begin{array}{l}\text { Commentary on intervention effect } \\
\text { [SIMON: please make it clear below where you are } \\
\text { refering to a range rather than a single result] }\end{array}$ \\
\hline \multirow{15}{*}{$\begin{array}{l}\text { Primary: } \\
\text { Utilization } \\
\text { and deliv- } \\
\text { ery }\end{array}$} & $\begin{array}{l}\text { Child immunization: receiving at } \\
\text { least one vaccine }\end{array}$ & - & $\oplus \oplus \oplus \ominus$ & $\begin{array}{l}\text { P4P probably has no important effect on outcome } \\
(1 \%) \text {. }\end{array}$ \\
\hline & $\begin{array}{l}\text { Child immunization: fully vaccinat- } \\
\text { ed }\end{array}$ & $\boldsymbol{\Delta}$ & $\oplus \oplus \ominus \ominus$ & P4P may lead to higher rate of full vaccination $(16.1 \%)$ \\
\hline & Child immunization: receiving BCG & $\boldsymbol{\Delta}$ & $\oplus \oplus \ominus \ominus$ & P4P may lead to higher rate of BCG vaccination (1-7\%) \\
\hline & Child immunization: receiving DTP & $\boldsymbol{\Delta}$ & $\oplus \oplus \ominus \ominus$ & P4P may lead to higher rate of DTP vaccination (6.1\%) \\
\hline & Child immunization: measles & - & $\oplus \oplus \ominus \ominus$ & $\begin{array}{l}\text { P4P may have little to no important effect on measles } \\
\text { vaccination rates }(-3.6 \%) \text {. }\end{array}$ \\
\hline & Child immunization: polio & $\boldsymbol{\Delta}$ & $\oplus \oplus \ominus \ominus$ & P4P may lead to higher rate of polio vaccination ( $21 \%)$ \\
\hline & Child immunization: pentavalent & $\boldsymbol{\nabla}$ & $\oplus \oplus \oplus \ominus$ & $\begin{array}{l}\text { P4P reduces the pentavalent immunization rate } \\
(-5.7 \%)\end{array}$ \\
\hline & $\begin{array}{l}\text { Probability of any utilization (\% } \\
\text { utilising) }\end{array}$ & $=$ & $\oplus \oplus \ominus \ominus$ & $\begin{array}{l}\text { P4P may have slight positive effects on overall utiliza- } \\
\text { tion of services }(4.2 \%)\end{array}$ \\
\hline & $\begin{array}{l}\text { Antenatal care (delivery and uti- } \\
\text { lization rates overall) }\end{array}$ & - & $\oplus \oplus \ominus \ominus$ & $\begin{array}{l}\text { P4P may have a slight positive effect on the ANC uti- } \\
\text { lization rate (4\%) }\end{array}$ \\
\hline & Total number ANC visits & $\nabla$ & $\oplus \oplus \ominus \ominus$ & $\begin{array}{l}\text { P4P may lead to a decrease in the total number of } \\
\text { ANC visits, estimated at }-35 \% \text { to }-4.60 \% \text {. }\end{array}$ \\
\hline & At least one ANC (utilization rates) & $\boldsymbol{\nabla}$ & $\oplus \oplus \oplus \ominus$ & $\begin{array}{l}\text { P4P probably leads to a reduction in the utilization of } \\
\text { at least } 1 \text { ANC visit (-10\% to }-1.5 \%)\end{array}$ \\
\hline & At least four ANC (utilization rates) & $\nabla$ & $\oplus \oplus \ominus \ominus$ & $\begin{array}{l}\text { P4P may lead to a decrease in rate of women utilizing } \\
4 \text { or more ANC sessions }(-5.4 \%)\end{array}$ \\
\hline & $\begin{array}{l}\text { ANC from qualified provider (\% re- } \\
\text { ceiving) }\end{array}$ & $\mathbf{r}$ & $\oplus \oplus \ominus \ominus$ & $\begin{array}{l}\text { P4P may lead to an increase in the delivery of ANC by } \\
\text { a qualified provider ( } 4.7 \%) \text {. }\end{array}$ \\
\hline & $\begin{array}{l}\text { Family planning (\% using any } \\
\text { method) }\end{array}$ & $\nabla$ & $\oplus \oplus \ominus \ominus$ & $\begin{array}{l}\text { P4P may have slight negative or no impact on family } \\
\text { planning utilization (-6.3\% to null effect). }\end{array}$ \\
\hline & $\begin{array}{l}\text { Family planning (\% using modern } \\
\text { methods) }\end{array}$ & 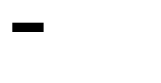 & $\oplus \oplus \ominus \ominus$ & $\begin{array}{l}\text { P4P may have no important effect on utilzation of } \\
\text { modern family planning }(0.2 \%) \text {. }\end{array}$ \\
\hline
\end{tabular}


Table 9. Sensitivity analyses against control: Direction of relative effect and GRADE rating for targeted outcomes across RCT studies only (Continued)

$\begin{array}{ll}\begin{array}{l}\text { Institutional delivery (rates or cov- } \quad \Delta \quad \oplus \oplus \oplus \ominus \\ \text { erage) }\end{array} & \begin{array}{l}\text { P4P probably has positive effects on the rate of insti- } \\ \text { tutional deliveries (effects range from }-3 \% \text { to } 18.1 \%, \\ \text { but are predominantly positive) }\end{array}\end{array}$

\begin{tabular}{llll}
\hline $\begin{array}{l}\text { Institutional delivery: \% using C } \\
\text { section }\end{array}$ & - & $\oplus \oplus \oplus \ominus$ & $\begin{array}{l}\text { P4P probably has limited effect on the rate of C-sec- } \\
\text { tions withing the institutional deliveries (2\%) }\end{array}$ \\
\hline $\begin{array}{l}\text { Institutional delivery: likelihood of } \\
\text { skilled attendance at birth }\end{array}$ & $\boldsymbol{\Delta}$ & $\oplus \oplus \oplus \ominus$ & $\begin{array}{l}\text { P4P probably improves the likelihood of having a } \\
\text { skilled birth attender (4 to 16.2\%). }\end{array}$ \\
\hline $\begin{array}{l}\text { Postnatal care (overall utilization } \\
\text { rate) }\end{array}$ & $\boldsymbol{\Delta}$ & $\oplus \oplus \oplus \ominus$ & $\begin{array}{l}\text { P4P probably has positive impacts on postnatal care } \\
\text { utilization (effects from -2\% to 10.8\%, predominantly } \\
\text { positive). }\end{array}$
\end{tabular}

\begin{tabular}{llll}
\hline $\begin{array}{l}\text { Postnatal care: likelihood of skilled } \\
\text { attendance }\end{array}$ & $\boldsymbol{\Delta}$ & $\oplus \oplus \ominus \ominus$ & $\begin{array}{l}\text { P4P may have a positive effect on skilled attendance } \\
\text { during postnatal care (15.79\%). }\end{array}$ \\
\hline $\begin{array}{l}\text { Postnatal care: \% receiving timely } \\
\text { access }\end{array}$ & - & $\oplus \oplus \oplus \ominus$ & $\begin{array}{l}\text { P4P has no important effect on this outcome (effect } \\
0.8 \%) .\end{array}$ \\
\hline $\begin{array}{l}\text { Curative consultations in children } \\
\text { (rates) }\end{array}$ & $\boldsymbol{\nabla}$ & $\oplus \oplus \ominus \ominus$ & $\begin{array}{l}\text { P4P may reduce the utilization of curative care visits } \\
\text { for children by up to } 10.9 \% .\end{array}$
\end{tabular}

\begin{tabular}{lll}
\hline $\begin{array}{l}\text { Primary: Neonatal mortality } \\
\text { Health } \\
\text { outcomes }\end{array}$ & $\oplus \oplus \oplus \ominus$ & $\begin{array}{l}\text { P4P probably has no significant impact on neonatal } \\
\text { mortality (0.03\%). }\end{array}$ \\
\hline
\end{tabular}

\begin{tabular}{|c|c|c|c|}
\hline $\begin{array}{l}\text { Primary: } \\
\text { Quality of } \\
\text { care }\end{array}$ & $\begin{array}{l}\text { Background and physical assess- } \\
\text { ment (scores general, across ANC, } \\
\text { PNC, child care and for other con- } \\
\text { sultations). }\end{array}$ & $\oplus \oplus \ominus \ominus$ & $\begin{array}{l}\text { P4P may have negative effects on quality of care } \\
\text { scores associated with background and physical as- } \\
\text { sessments (-17\% to } 4 \% \text {, predominantly negative). }\end{array}$ \\
\hline
\end{tabular}

\begin{tabular}{|c|c|c|c|}
\hline $\begin{array}{l}\text { Correct patient management by } \\
\text { health care providers (scores in re- } \\
\text { lation to ANC, child care and PNC) }\end{array}$ & - & $\oplus \oplus \oplus \ominus$ & $\begin{array}{l}\text { P4P probably has no effect on quality of care scores } \\
\text { associated with correct patient management }(0.03 \%)\end{array}$ \\
\hline $\begin{array}{l}\text { Patient counselling (scores on ANC } \\
\text { and PNC related counselling) }\end{array}$ & $\square$ & $\oplus \oplus \ominus \ominus$ & $\begin{array}{l}\text { P4P effects on quality of care scores range between } \\
-37 \% \text { to } 6 \% \text {. }\end{array}$ \\
\hline $\begin{array}{l}\text { Immunizations (score for receiving } \\
\text { any tetanus and nr. of tetanus vac- } \\
\text { cinations) }\end{array}$ & - & $\oplus \oplus \ominus \ominus$ & $\begin{array}{l}\text { P4P may have little to no important effect on quality } \\
\text { of care relating to immunizations ( } 2.25 \%) \text {. }\end{array}$ \\
\hline $\begin{array}{l}\text { Women in ANC being given or pre- } \\
\text { scribed folic acid/iron (\%) }\end{array}$ & $\boldsymbol{\Delta}$ & $\oplus \oplus \ominus \ominus$ & $\begin{array}{l}\text { P4P may improve the likelihood of being prescribed } \\
\text { folic acid/iron during ANC by up to } 5.5 \% \text {. }\end{array}$ \\
\hline Staff knowledge and skills (score) & - & $\oplus \oplus \ominus \ominus$ & $\begin{array}{l}\text { P4P may have little to no effect on staff knowledge } \\
\text { and skills. }\end{array}$ \\
\hline Patient knowledge (score) & $\boldsymbol{\Delta}$ & $\oplus \oplus \ominus \ominus$ & $\begin{array}{l}\text { P4P's may have positive effects on patient knowl- } \\
\text { edge: effects range from }-3 \text { to } 116 \% \text {, overall positive. }\end{array}$ \\
\hline Contact time & - & $\oplus \oplus \oplus \ominus$ & $\begin{array}{l}\text { P4P probably has no significant impact upon contact } \\
\text { time }(2.5 \%) \text {. }\end{array}$ \\
\hline
\end{tabular}


Table 9. Sensitivity analyses against control: Direction of relative effect and GRADE rating for targeted outcomes across RCT studies only (Continued)

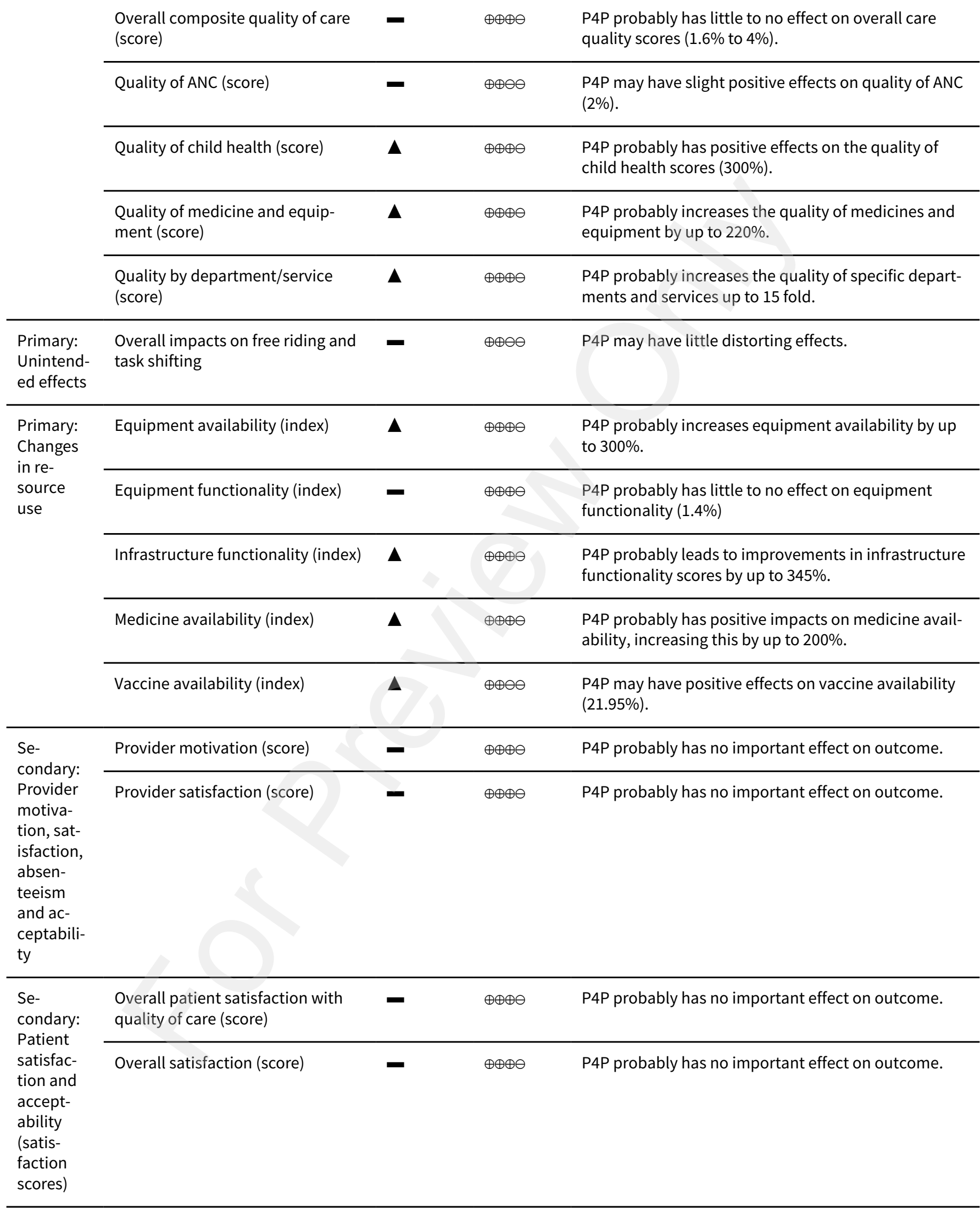


Table 9. Sensitivity analyses against control: Direction of relative effect and GRADE rating for targeted outcomes across RCT studies only (Continued)

\begin{tabular}{|c|c|c|c|c|}
\hline $\begin{array}{l}\text { Se- } \\
\text { condary: }\end{array}$ & $\begin{array}{l}\text { Facility or managerial autonomy } \\
\text { (score) }\end{array}$ & $\boldsymbol{\Delta}$ & $\oplus \oplus \ominus \ominus$ & $\begin{array}{l}\text { P4P may have positive impacts on facility autonomy } \\
\text { (score increases up to } 146 \% \text { ). }\end{array}$ \\
\hline on man- & Facility governance (score) & - & $\oplus \oplus \ominus \ominus$ & P4P may have little to no effect on this outcome. \\
\hline $\begin{array}{l}\text { or infor- } \\
\text { mation } \\
\text { systems } \\
\text { (if not a } \\
\text { targeted } \\
\text { measure } \\
\text { of perfor- } \\
\text { mance) }\end{array}$ & Quality of management (score) & - & $\oplus \oplus \ominus \ominus$ & P4P may have little to no effect on this outcome. \\
\hline
\end{tabular}

\author{
Direction of effect key \\ $\Delta$ Desirable \\ $\boldsymbol{\nabla}$ Non-desirable \\ - Neutral \\ $\square \quad$ Uncertain \\ Certainty in evidence key \\ $\oplus \oplus \oplus \ominus \quad$ Moderate \\ $\oplus \oplus \ominus \ominus \quad$ Low
}

Table 10. Sensitivity analyses against comparator: Direction of relative effect and GRADE rating for targeted outcomes across RCT studies only

Direction of relative effect and GRADE rating for targeted outcomes across RCT studies only

\begin{tabular}{|c|c|c|c|c|}
\hline Outcome & $\begin{array}{l}\text { Indicator (if indicator not } \\
\text { named, no RCT evidence } \\
\text { available) }\end{array}$ & $\begin{array}{l}\text { Comment } \\
\text { on ef- } \\
\text { fect de- } \\
\text { sirable, } \\
\text { undesir- } \\
\text { able, neu- } \\
\text { tral or } \\
\text { uncer- } \\
\text { tain) }\end{array}$ & $\begin{array}{l}\text { Certain- } \\
\text { ty in evi- } \\
\text { dence }\end{array}$ & Commentary on intervention effect \\
\hline \multirow{6}{*}{$\begin{array}{l}\text { Primary: } \\
\text { Utilization } \\
\text { and deliv- } \\
\text { ery }\end{array}$} & Child immunization & $\nabla$ & $\oplus \oplus \ominus \ominus$ & $\begin{array}{l}\text { P4P may decrease the likelihood of children being immu- } \\
\text { nized by up to } 7.4 \% \text {. }\end{array}$ \\
\hline & Child immunization: BCG & - & $\oplus \oplus \ominus \ominus$ & $\begin{array}{l}\text { P4P may have little to no effect on utilization of BCG vacci- } \\
\text { nation }(+3.1 \%) \text {. }\end{array}$ \\
\hline & Child immunization: DTP & - & $\oplus \oplus \ominus \ominus$ & $\begin{array}{l}\text { P4P may have little to no effect on utilization of DTP vacci- } \\
\text { nation }(-1 \%) \text {. }\end{array}$ \\
\hline & $\begin{array}{l}\text { Child immunization: fully } \\
\text { vaccinated }\end{array}$ & $\boldsymbol{\Delta}$ & $\oplus \oplus \ominus \ominus$ & $\begin{array}{l}\text { P4P may have positive effects on the likelihood of children } \\
\text { being fully vaccinated (39.8\%). }\end{array}$ \\
\hline & Probability of any utilization & $\boldsymbol{\Delta}$ & $\oplus \oplus \ominus \ominus$ & $\begin{array}{l}\text { P4P may have slight positive effects on probability of care } \\
\text { seeking }(8.3 \%) \text { but overall other effects are inconsistent. }\end{array}$ \\
\hline & $\begin{array}{l}\text { Family planning (\% utilizing } \\
\text { any) }\end{array}$ & - & $\oplus \oplus \ominus \ominus$ & $\begin{array}{l}\text { P4P may have little to no effect on the utilization of family } \\
\text { planning services. }\end{array}$ \\
\hline
\end{tabular}


Table 10. Sensitivity analyses against comparator: Direction of relative effect and GRADE rating for targeted outcomes across RCT studies only (Continued)

$\begin{array}{ll}\text { Antenatal care: \% utilising at } \quad-\quad & \begin{array}{l}\text { P4P may have little to no effect on utilization of ANC } \\ \text { least one ANC }\end{array}\end{array}$

\begin{tabular}{|c|c|c|}
\hline $\begin{array}{l}\text { Antenatal care: } \% \text { utilising } \\
\text { four or more }\end{array}$ & $\oplus \oplus \ominus \ominus$ & $\begin{array}{l}\text { P4P may have little to no effect on utilization of } 4 \text { or more } \\
\text { ANC appointments }(-0.6 \%) \text {. }\end{array}$ \\
\hline
\end{tabular}

\begin{tabular}{lll}
\hline $\begin{array}{l}\text { Antenatal care: \% accessing } \\
\begin{array}{l}\text { ANC in first trimester } \\
\text { Utilization of curative ser- }\end{array}\end{array}$ & $\begin{array}{l}\text { P4P may have a positive effect on timely care initiation by } \\
\text { women (1-10\% initiating care earlier, approx. 1 month earli- } \\
\text { er) }\end{array}$ \\
\hline $\begin{array}{l}\text { vices in children } \\
\text { Pis }\end{array}$ & $\oplus \oplus \ominus \ominus$ & $\begin{array}{l}\text { P4P may have little to no effect on utilization of curative } \\
\text { visits for children (-3.1\%). }\end{array}$ \\
\hline
\end{tabular}

\begin{tabular}{|c|c|c|}
\hline $\begin{array}{l}\text { Institutional delivery (utiliza- } \\
\text { tion rate) }\end{array}$ & $\oplus \oplus \ominus \ominus$ & $\begin{array}{l}\text { P4P may have negative effects on the utilization of institu- } \\
\text { tional deliveries }(-8.7 \%)\end{array}$ \\
\hline
\end{tabular}

\begin{tabular}{|c|c|c|}
\hline $\begin{array}{l}\text { Postnatal care (utilization } \\
\text { rate) }\end{array}$ & $\oplus \oplus \ominus \ominus$ & $\begin{array}{l}\text { P4P may have negative effects on the utilization of postna- } \\
\text { tal care }(-10 \%)\end{array}$ \\
\hline
\end{tabular}

\begin{tabular}{|c|c|c|c|c|}
\hline \multirow{2}{*}{$\begin{array}{l}\text { Primary: } \\
\text { Changes } \\
\text { in re- } \\
\text { source } \\
\text { use }\end{array}$} & $\begin{array}{l}\text { Equipment availability (com- } \\
\text { posite score) }\end{array}$ & $\boldsymbol{\Delta}$ & $\oplus \oplus \ominus \ominus$ & $\begin{array}{l}\text { P4P may improve equipment availability scores by up to } \\
75 \% \text {. }\end{array}$ \\
\hline & $\begin{array}{l}\text { Medicine availability (com- } \\
\text { posite score) }\end{array}$ & $\nabla$ & $\oplus \oplus \ominus \ominus$ & $\begin{array}{l}\text { P4P may decrease medicine availability scores by up to } \\
160 \% \text {. }\end{array}$ \\
\hline $\begin{array}{l}\text { Primary: } \\
\text { Health } \\
\text { outcomes }\end{array}$ & $\begin{array}{l}\text { Likelihood of women breast- } \\
\text { feeding }\end{array}$ & - & $\oplus \oplus \ominus \ominus$ & $\begin{array}{l}\text { P4P may have little to no effect on the likelihood of women } \\
\text { breastfeeding. }\end{array}$ \\
\hline \multirow{6}{*}{$\begin{array}{l}\text { Primary: } \\
\text { Quality of } \\
\text { care }\end{array}$} & $\begin{array}{l}\text { Background and physical as- } \\
\text { sessment (score) }\end{array}$ & $\boldsymbol{\nabla}$ & $\oplus \oplus \ominus \ominus$ & $\begin{array}{l}\text { P4P may decrease the likelihood of providers conducting } \\
\text { background and physical assessments by up to } 5.4 \% \text {. }\end{array}$ \\
\hline & Counselling (score) & $\boldsymbol{\nabla}$ & $\oplus \oplus \ominus \ominus$ & $\begin{array}{l}\text { P4P may have negative effects on providers counselling pa- } \\
\text { tients appropriately }(-40 \%) \text {. }\end{array}$ \\
\hline & $\begin{array}{l}\text { Immunizations quality } \\
\text { (score) }\end{array}$ & $\mathbf{\Delta}$ & $\oplus \oplus \ominus \ominus$ & $\begin{array}{l}\text { P4P may have slight positive effects on immunization qual- } \\
\text { ity }(5.2 \%) \text {. }\end{array}$ \\
\hline & Knowledge outcomes (score) & $\boldsymbol{\nabla}$ & $\oplus \oplus \oplus \ominus$ & $\begin{array}{l}\text { P4P may have slight negative effects on patient knowledge } \\
\text { outcomes }(-5.4 \% \text { to }-2.4 \%)\end{array}$ \\
\hline & $\begin{array}{l}\text { Total quality family planning } \\
\text { (score) }\end{array}$ & $\boldsymbol{\Delta}$ & $\oplus \oplus \oplus \ominus$ & $\begin{array}{l}\text { P4P probably has positive effects on the quality of family } \\
\text { planning }(500 \%) \text {. }\end{array}$ \\
\hline & $\begin{array}{l}\text { Total quality antenatal care } \\
\text { (score) }\end{array}$ & $\boldsymbol{\Delta}$ & $\oplus \oplus \ominus \ominus$ & P4P may have positive effects on ANC quality scores (40\%). \\
\hline $\begin{array}{l}\text { Se- } \\
\text { condary: } \\
\text { Impacts } \\
\text { on man- } \\
\text { agement } \\
\text { or infor- } \\
\text { mation } \\
\text { systems } \\
\text { (if not a } \\
\text { targeted }\end{array}$ & $\begin{array}{l}\text { Facility and managerial au- } \\
\text { tonomy (score) }\end{array}$ & $\boldsymbol{\Delta}$ & $\oplus \oplus \ominus \ominus$ & $\begin{array}{l}\text { P4P may increase facility and managerial autonomy scores } \\
\text { by up to } 46 \% \text {. }\end{array}$ \\
\hline
\end{tabular}

Paying for performance to improve the delivery of health interventions in low- and middle-income countries (Review) 
Table 10. Sensitivity analyses against comparator: Direction of relative effect and GRADE rating for targeted outcomes across RCT studies only (Continued)

measure

of perfor-

mance)

\author{
$\Delta$ Desirable \\ $\boldsymbol{\nabla}$ Non-desirable \\ - Neutral \\ $\square \quad$ Uncertain \\ Certainty in evidence key \\ $\oplus \oplus \oplus \ominus \quad$ Moderate \\ $\oplus \oplus \ominus \ominus$ Low
}

Table 11. Sub-group analyses - table A

\begin{tabular}{lll}
\hline Type of PBF & Average rank of scheme \\
\cline { 2 - 3 } & Control & Comparator \\
\hline Performance based contracting or service agreements & 1.33 & N/A \\
\hline Results based aid & 1.33 & N/A \\
\hline Payment per output (quality and equity adjustment) & 1.57 & 1.50 \\
\hline Payment per output (quality adjustment) & 1.66 & N/A N/A \\
\hline Payment per output and for target & 1.75 & 1.83 \\
\hline Payment per output (quality and satisfaction adjustment) & 1.92 & N/A \\
\hline Payment per output & 2.17 & N/A \\
\hline Target payment & 2.17 & N/A \\
\hline Capitation and P4P & 2.50 & N/A \\
\hline Financial and non-financial incentives + decision guide & 3.00 & N/A \\
\hline Performance related pay & & \\
\hline
\end{tabular}

Lower rating better 


\begin{tabular}{|c|c|c|c|c|c|c|c|c|c|}
\hline \multicolumn{10}{|c|}{ Findings of sub-group analyses (P4P against control) by outcome - b } \\
\hline \multicolumn{10}{|c|}{ Average rank by outcome } \\
\hline Scheme design & $\begin{array}{l}\text { P: Utiliza- } \\
\text { tion and } \\
\text { delivery }\end{array}$ & $\begin{array}{l}\text { P: Health } \\
\text { outcomes }\end{array}$ & $\begin{array}{l}\text { P: Quality } \\
\text { of care }\end{array}$ & $\begin{array}{l}\text { P: } \\
\text { Changes } \\
\text { in re- } \\
\text { source } \\
\text { use }\end{array}$ & $\begin{array}{l}\text { S: } \\
\text { Provider } \\
\text { moti- } \\
\text { vation, } \\
\text { satis- } \\
\text { faction, } \\
\text { absen- } \\
\text { teeism } \\
\text { and ac- } \\
\text { cept- } \\
\text { ability }\end{array}$ & $\begin{array}{l}\text { S: Pa- } \\
\text { tient } \\
\text { satisfac- } \\
\text { tion and } \\
\text { accept- } \\
\text { ability } \\
\text { (satis- } \\
\text { faction } \\
\text { scores) }\end{array}$ & $\begin{array}{l}\text { S: Im- } \\
\text { pacts on } \\
\text { overall } \\
\text { financ- } \\
\text { ing or re- } \\
\text { source al- } \\
\text { location }\end{array}$ & $\begin{array}{l}\text { S: Impacts } \\
\text { on manage- } \\
\text { ment or in- } \\
\text { formation } \\
\text { systems (if } \\
\text { not a tar- } \\
\text { geted mea- } \\
\text { sure of per- } \\
\text { formance) }\end{array}$ & $\begin{array}{l}\text { S: Equi- } \\
\text { ty-consid- } \\
\text { eration: Ev- } \\
\text { idence of } \\
\text { differential } \\
\text { impact on } \\
\text { different } \\
\text { parts of the } \\
\text { population }\end{array}$ \\
\hline $\begin{array}{l}\text { Performance based contracting or service } \\
\text { agreements }\end{array}$ & 1.33 & $\mathrm{~N} / \mathrm{A}$ & $\mathrm{N} / \mathrm{A}$ & $\mathrm{N} / \mathrm{A}$ & $\mathrm{N} / \mathrm{A}$ & $\mathrm{N} / \mathrm{A}$ & $\mathrm{N} / \mathrm{A}$ & $\mathrm{N} / \mathrm{A}$ & $\mathrm{N} / \mathrm{A}$ \\
\hline Results based aid & 1.33 & $\mathrm{~N} / \mathrm{A}$ & $\mathrm{N} / \mathrm{A}$ & N/A & $\mathrm{N} / \mathrm{A}$ & $\mathrm{N} / \mathrm{A}$ & N/A & $\mathrm{N} / \mathrm{A}$ & $\mathrm{N} / \mathrm{A}$ \\
\hline $\begin{array}{l}\text { Payment per output (quality and equity ad- } \\
\text { justment) }\end{array}$ & 1.47 & 2.00 & 1.55 & 1.67 & 1.00 & 2.00 & 1.50 & 1.67 & 1.00 \\
\hline Payment per output and for target & 1.50 & 2.00 & $\mathrm{~N} / \mathrm{A}$ & 2.00 & N/A & $\mathrm{N} / \mathrm{A}$ & N/A & $\mathrm{N} / \mathrm{A}$ & 2.00 \\
\hline Payment per output (quality adjustment) & 1.65 & 1.00 & 1.64 & 1.40 & 2.00 & 1.78 & 3.00 & 1.33 & 2.00 \\
\hline Payment per output & 2.00 & $\mathrm{~N} / \mathrm{A}$ & 2.60 & $\mathrm{~N} / \mathrm{A}$ & 2.00 & 2.00 & $\mathrm{~N} / \mathrm{A}$ & $\mathrm{N} / \mathrm{A}$ & $\mathrm{N} / \mathrm{A}$ \\
\hline Target payment & 2.50 & 1.00 & 2.20 & 2.33 & 3.00 & $\mathrm{~N} / \mathrm{A}$ & 1.33 & 3.00 & 1.50 \\
\hline Capitation and PBF & $\mathrm{N} / \mathrm{A}$ & N/A & $\mathrm{N} / \mathrm{A}$ & N/A & $\mathrm{N} / \mathrm{A}$ & 3.00 & 2.00 & $\mathrm{~N} / \mathrm{A}$ & $\mathrm{N} / \mathrm{A}$ \\
\hline $\begin{array}{l}\text { Financial and non-financial incentives }+ \text { deci- } \\
\text { sion guide }\end{array}$ & N/A & $\mathrm{N} / \mathrm{A}$ & 3.00 & $\mathrm{~N} / \mathrm{A}$ & $\mathrm{N} / \mathrm{A}$ & $\mathrm{N} / \mathrm{A}$ & N/A & $\mathrm{N} / \mathrm{A}$ & $\mathrm{N} / \mathrm{A}$ \\
\hline Performance related pay & $\mathrm{N} / \mathrm{A}$ & $\mathrm{N} / \mathrm{A}$ & $\mathrm{N} / \mathrm{A}$ & $\mathrm{N} / \mathrm{A}$ & $\mathrm{N} / \mathrm{A}$ & $\mathrm{N} / \mathrm{A}$ & $\mathrm{N} / \mathrm{A}$ & $\mathrm{N} / \mathrm{A}$ & $\mathrm{N} / \mathrm{A}$ \\
\hline $\begin{array}{l}\text { Payment per output (quality and satisfaction } \\
\text { adjustment) }\end{array}$ & $\mathrm{N} / \mathrm{A}$ & N/A & 2.33 & N/A & $\mathrm{N} / \mathrm{A}$ & 1.57 & N/A & $\mathrm{N} / \mathrm{A}$ & $\mathrm{N} / \mathrm{A}$ \\
\hline
\end{tabular}



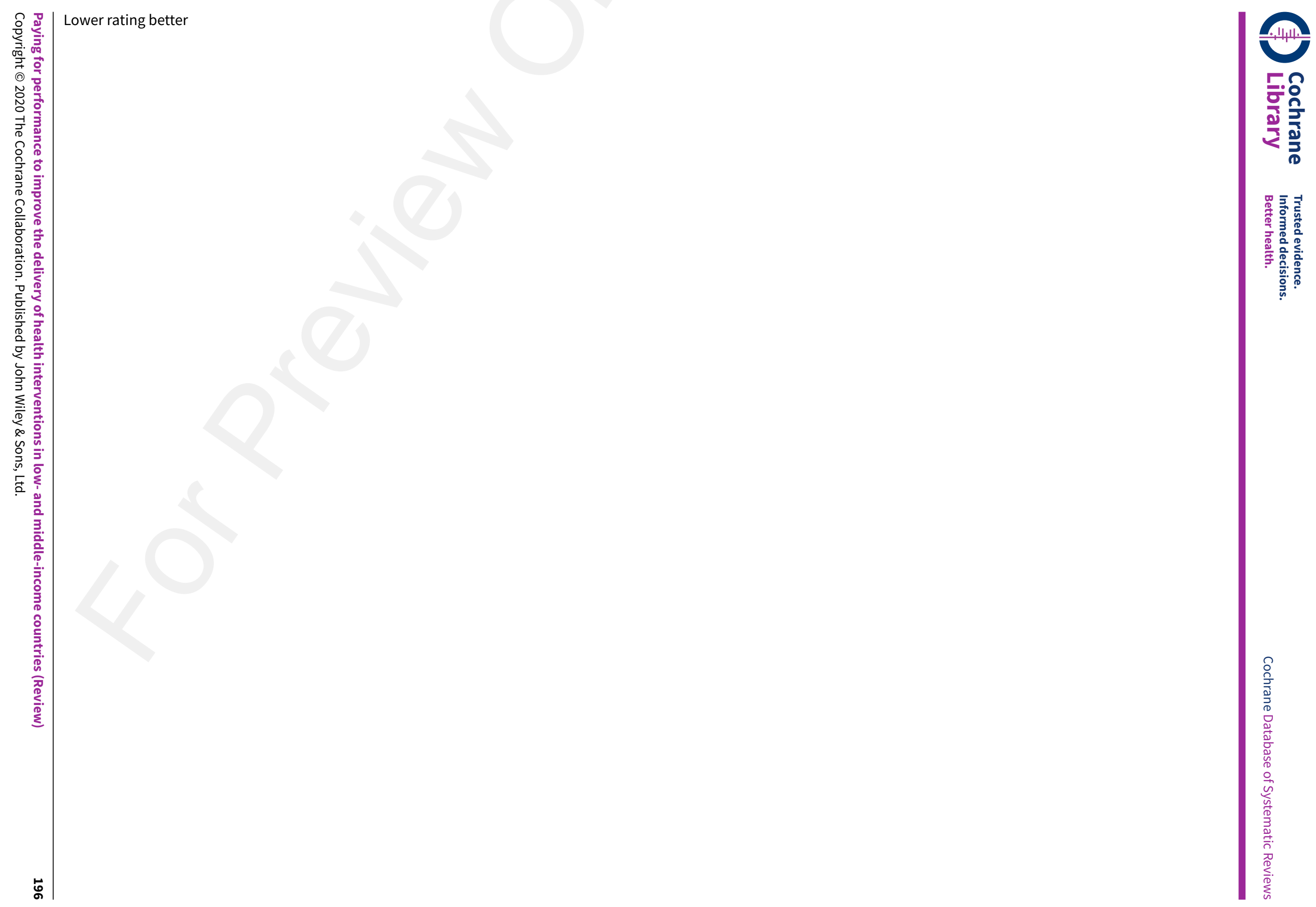


\section{AP PEN DICES}

\section{Appendix 1. Reasons for Exclusion at Full Text Screening}

\section{Exclusions Based on Type of Study}

1. Study not a) RCT, b) Quasi-randomized trial, c) Controlled before and after study (CBA), or d) interrupted time series (ITS)

2. Study is a CBA, but there is only 1 cluster/site in each comparison group

3. Study is a CBA, but the pre- and post- intervention periods for study and control groups are not the same

4. Study is a CBA, but the choice of control site is not appropriate - e.g. different socio-economic characteristics, or major differences in the baseline group

5. Study is an ITS, but does not have clearly defined time of intervention

6. Study is an ITS but not have a) at least 3 data points before or after the intervention, nor is it likely that b) at least 3 data points before and after the intervention could be retrieved from the authors

\section{Exclusions based on study population/participants:}

1. The study population/participants/health care providers are not from Low and Middle Income Countries (as classified by the World Bank)

\section{Exclusions based on intervention components:}

1. Study is not an impact evaluation of P4P schemes (including ancillary components), compared to any alternative (including nonconditional financial incentives and different levels of conditional financial incentives)

2. Study intervention does not cover a) conditional cash payment, b) conditional provision of material goods, c) target payments (payments for reaching a certain level of coverage, which can be defined in absolute terms or relative to a starting point)

3. Study focussed on the demand side of health care only (i.e. payments to consumers, not producers),

4. Study focussed only on payment to health workers or facilities which are not explicitly linked to changing patterns of performance (e.g. for coming to work; salary increases; routine increases in activity-based payments such as DRGs or fees for service)

5. Study focussed only on changes to budget flows which are routine or intended to motivate, but without being conditional on specific activity or output measures

\section{Exclusions based on type of provider:}

1. Study does not include a) Health workers/Providers of health care services, b) Public health facilities, c) Private for profit/not for profit health facilities, d) Non-governmental organizations, e) Sub-national governments (municipalities or provinces), f) National governments (Ministries of Health), or $\mathbf{g}$ ) Multiple levels of health care provision

\section{Exclusions based on primary outcomes of this systematic review:}

1. Study does not report on our major outcome measures of interest: a) Changes in targeted measures of provider performance, the delivery or utilization of healthcare services, or patient outcomes, b) Unintended effects, including motivating unintended behaviours, distortions (ignoring important tasks that are not rewarded with incentives), cherry-picking/cream-skimming (prioritising patients that are most profitable over those who release fewer financial rewards), gaming (improving or cheating on reporting rather than improving performance), increased inequities, and dependency on financial incentives, or c) Changes in resource use, including for incentives, administration and services

\section{Other:}

1. Insufficient detail given in paper to determine inclusion/exclusion. More information needed.

2. Duplicate

3. Ongoing study for which relevant results not yet available

4. Study complementary to, or superseded by, other included studies

\section{Appendix 2. Search strategies}

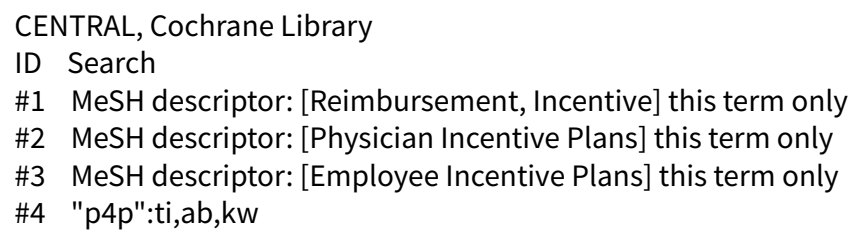


\#5 ((performance or result or results) near/3 (pay* or paid or money or monetary or cash or financ ${ }^{\star}$ or fund ${ }^{\star}$ or econom* or disbursement ${ }^{\star}$ or remunerat ${ }^{\star}$ or reimburs ${ }^{*}$ or compensat $\left.\left.{ }^{\star}\right)\right): t i, a b, k w$

\#6 ((performance or result or results) near/3 (nonmonetary or voucher* or token or tokens or goods)):ti,ab,kw

\#7 ((performance or result or results) near/3 (reward ${ }^{\star}$ or bonus* or initiative* or incentive* ${ }^{\star}$ or contract or contracts)):ti,ab,kw

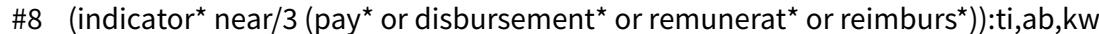

\#9 ((performance or merit) next based):ti,ab,kw

\#10 ((payment or financial or monetary or nonmonetary or economic or disbursement or remuneration or reimbursement or reward ${ }^{\star}$ or bonus) next incentive ${ }^{\star}: \mathrm{ti}, \mathrm{ab}, \mathrm{kw}$

\#11 ((payment or financial or monetary or nonmonetary or economic or disbursement or remuneration or reimbursement) next (reward ${ }^{\star}$ or bonus $\left.)^{\star}\right): \mathrm{ti}, \mathrm{ab}, \mathrm{kw}$

$\# 12$ (pay* near/3 quality):ti,ab,kw

\#13 (bonus next payment $\left.{ }^{\star}\right): t i, a b, k w$

\#14 ((incentive* or compensatory or reimbursement) next (plan or plans)):ti,ab,kw

\#15 ((incentiv* or motivat* or positive* next reinforc ${ }^{\star}$ ) near/3 (quality or output* or outcome* or delivery or utilisation or utilization)):ti,ab,kw

\#16 ((incentiv* or motivat* or positive* next reinforc $\left.{ }^{\star}\right)$ near/3 (target or targets or "health goal" or "health goals" or measurable next action* or behaviour ${ }^{\star}$ or behavior ${ }^{\star}$ or "best practice" or practice next pattern* or standard or standards or recommendation* or guideline $\left.)^{\star}\right): \mathrm{ti}, \mathrm{ab}, \mathrm{kw}$

\#17 (conditional near/3 (pay* or money or monetary or cash or financ* or fund ${ }^{\star}$ or econom* or disbursement* or remunerat* or reimburs $^{\star}$ or nonmonetary or voucher* or token or tokens or goods or reward* or bonus* or incentive* or motivat $\left.\left.{ }^{\star}\right)\right): t i, a b, k w$

\#18 (incentive next payment ${ }^{\star}$ ):ti,ab,kw

\#19 ((target or targets or targeted) near/3 (pay* or reward*)):ti,ab,kw

\#20 ((chang* or enhanc* or improve $\left.{ }^{\star}\right)$ near/6 (provider* or practitioner* or "health personnel" or "health care personnel" or "healthcare personnel" or health next worker* or "health care" next worker* or healthcare next worker* or physician* or doctor or doctors or nurse or nurses or health next facilit* or "health care" next facilit* or healthcare next facilit* or hospital or hospitals or health next service* or "health care" next service* or healthcare next service* or health next sector* or "health care" next sector ${ }^{\star}$ or healthcare next sector* or "health administrations" or government* or nongovernment ${ }^{\star}$ ) near/6 performance):ti,ab,kw

\#21 ("provider recognition" next program*):ti,ab,kw

\#22 "cash on delivery":ti,ab,kw

\#23 ("output based aid" or "result based aid" or "results based aid"):ti,ab,kw

\#24 ("program for result" or "program for results" or "programs for result" or "programs for results" or "programme for result" or "programme for results" or "programmes for result" or "programmes for results"):ti,ab,kw

$\# 25 \# 1$ or \#2 or \#3 or \#4 or \#5 or \#6 or \#7 or \#8 or \#9 or \#10 or \#11 or \#12 or \#13 or \#14 or \#15 or \#16 or \#17 or \#18 or \#19 or \#20 or \#21 or \#22 or \#23 or \#24

\#26 (Africa or Asia or Caribbean or "West Indies" or "South America" or "Latin America" or "Central America"):ti,ab,kw

\#27 Afghanistan or Albania or Algeria or Angola or Antigua or Barbuda or Argentina or Armenia or Armenian or Aruba or Azerbaijan or Bahrain or Bangladesh or Barbados or Benin or Byelarus or Byelorussian or Belarus or Belorussian or Belorussia or Belize or Bhutan or Bolivia or Bosnia or Herzegovina or Hercegovina or Botswana or Brasil or Brazil or Bulgaria or "Burkina Faso" or "Burkina Fasso" or "Upper Volta" or Burundi or Urundi or Cambodia or "Khmer Republic" or Kampuchea or Cameroon or Cameroons or Cameron or Camerons or "Cape Verde" or "Central African Republic" or Chad or Chile or China or Colombia or Comoros or "Comoro Islands" or Comores or Mayotte or Congo or Zaire or "Costa Rica" or "Cote d'Ivoire" or "Ivory Coast" or Croatia or Cuba or Cyprus or Czechoslovakia or "Czech Republic" or Slovakia or "Slovak Republic"):ti,ab,kw

\#28 (Djibouti or "French Somaliland" or Dominica or "Dominican Republic" or "East Timor" or "East Timur" or "Timor Leste" or Ecuador or Egypt or "United Arab Republic" or "El Salvador" or Eritrea or Estonia or Ethiopia or Fiji or Gabon or "Gabonese Republic" or Gambia or Gaza or Georgia or Georgian or Ghana or "Gold Coast" or Greece or Grenada or Guatemala or Guinea or Guam or Guiana or Guyana or Haiti or Honduras or Hungary or India or Maldives or Indonesia or Iran or Iraq or "Isle of Man" or Jamaica or Jordan or Kazakhstan or Kazakh or Kenya or Kiribati or Korea or Kosovo or Kyrgyzstan or Kirghizia or "Kyrgyz Republic" or Kirghiz or Kirgizstan or "Lao PDR" or Laos or Latvia or Lebanon or Lesotho or Basutoland or Liberia or Libya or Lithuania):ti,ab,kw

\#29 (Macedonia or Madagascar or "Malagasy Republic" or Malaysia or Malaya or Malay or Sabah or Sarawak or Malawi or Nyasaland or Mali or Malta or "Marshall Islands" or Mauritania or Mauritius or "Agalega Islands" or Mexico or Micronesia or "Middle East" or Moldova or Moldovia or Moldovian or Mongolia or Montenegro or Morocco or Ifni or Mozambique or Myanmar or Myanma or Burma or Namibia or Nepal or "Netherlands Antilles" or "New Caledonia" or Nicaragua or Niger or Nigeria or "Northern Mariana Islands" or Oman or Muscat or Pakistan or Palau or Palestine or Panama or Paraguay or Peru or Philippines or Philipines or Phillipines or Phillippines or Poland or Portugal or "Puerto Rico"):ti,ab,kw

\#30 (Romania or Rumania or Roumania or Russia or Russian or Rwanda or Ruanda or "Saint Kitts" or "St Kitts" or Nevis or "Saint Lucia" or "St Lucia" or "Saint Vincent" or "St Vincent" or Grenadines or Samoa or "Samoan Islands" or "Navigator Island" or "Navigator Islands" or "Sao Tome" or "Saudi Arabia" or Senegal or Serbia or Montenegro or Seychelles or "Sierra Leone" or Slovenia or "Sri Lanka" or Ceylon or "Solomon Islands" or Somalia or Sudan or Suriname or Surinam or Swaziland or Syria or Tajikistan or Tadzhikistan or Tadjikistan or Tadzhik or Tanzania or Thailand or Togo or "Togolese Republic" or Tonga or Trinidad or Tobago or Tunisia or Turkey or Turkmenistan or Turkmen or Uganda or Ukraine or Uruguay or USSR or "Soviet Union" or "Union of Soviet Socialist Republics" or Uzbekistan or Uzbek or Vanuatu or "New Hebrides" or Venezuela or Vietnam or "Viet Nam" or "West Bank" or Yemen or Yugoslavia or Zambia or Zimbabwe or Rhodesia):ti,ab,kw 
\#31 (developing or less* next developed or "under developed" or underdeveloped or "middle income" or low* next income or underserved or "under served" or deprived or poor ${ }^{\star}$ ) next (countr* or nation* or population* or world):ti,ab,kw

\#32 (developing or less ${ }^{\star}$ next developed or "under developed" or underdeveloped or "middle income" or low* next income) next (economy or economies):ti,ab,kw

\#33 low* next (gdp or gnp or "gross domestic" or "gross national"):ti,ab,kw

\#34 (low near/3 middle near/3 countr ${ }^{\star}$ ):ti,ab,kw

\#35 (Imic or Imics or "third world" or "lami country" or "lami countries"):ti,ab,kw

\#36 ("transitional country" or "transitional countries"):ti,ab,kw

\#37 \#26 or \#27 or \#28 or \#29 or \#30 or \#31 or \#32 or \#33 or \#34 or \#35 or \#36

\#38 \#25 and \#37 in Trials

\#39 \#25 and \#37 with Cochrane Library publication date Between Jan 2018 and Jul 2019, in Trials

\#40 \#25 and \#37 with Publication Year from 2018 to 2019, in Trials

\#41 \#39 or \#40

MEDLINE and Epub Ahead of Print, In-Process \& Other Non-Indexed Citations and Daily 1946 to June 18, 2019, Ovid

ID Search

1 Reimbursement, Incentive/

2 Physician Incentive Plans/

3 Employee Incentive Plans/

4 or/1-3

5 "p4p".ti,ab,kw.

6 ((performance or result? based) adj3 (pay* or paid or money or monetary or cash or financ ${ }^{\star}$ or fund* or econom* or disbursement? or remunerat* or reimburs* or compensat $\left.\left.{ }^{\star}\right)\right)$.ti,ab,kf.

7 ((performance or result? based) adj3 (nonmonetary or voucher? or token? or goods)).ti,ab,kf.

8 ((performance or result? based) adj3 (reward* or bonus? or initiative? or incentive? or contract?)).ti,ab,kf.

9 (indicator? adj3 (pay* or disbursement? or remunerat* or reimburs $\left.{ }^{\star}\right)$ ).ti,ab,kf.

10 ((performance or merit) adj based).ti,ab,kf.

11 ((payment or financial or monetary or nonmonetary or economic or disbursement or remuneration or reimbursement or reward or bonus) adj incentive?).ti,ab,kf.

12 ((payment or financial or monetary or nonmonetary or economic or disbursement or remuneration or reimbursement) adj (reward* or bonus?)).ti,ab,kf.

13 (pay* adj3 quality).ti,ab,kf.

14 bonus payment?.ti,ab,kw.

15 ((incentive or compensatory or reimbursement) adj plan?).ti,ab,kf.

16 ((incentiv ${ }^{\star}$ or motivat ${ }^{\star}$ or positive ${ }^{\star}$ reinforc ${ }^{\star}$ ) adj3 (quality or output? or outcome? or delivery or utilisation or utilization)).ti,ab,kf.

17 ((incentiv ${ }^{\star}$ or motivat* or positive* reinforc ${ }^{\star}$ ) adj3 (target or targets or health goal? or measurable action? or behaviour? or behavior? or best practice or practice pattern? or standard? or recommendation? or guideline?)).ti,ab,kf.

18 (conditional adj3 (pay* or money or monetary or cash or financ ${ }^{\star}$ or fund* or econom ${ }^{\star}$ or disbursement? or remunerat* or reimburs ${ }^{\star}$ or nonmonetary or voucher? or token? or goods or reward? or bonus? or incentive? or motivat $\left.{ }^{\star}\right)$ ).ti,ab,kf.

19 incentive payment?.ti,ab,kw.

20 ((target or targets or targeted) adj3 (pay* or reward*)).ti,ab,kw.

21 ((chang $^{\star}$ or enhanc $^{\star}$ or improve $\left.{ }^{\star}\right)$ adj6 (provider? or practitioner? or health personnel or health care personnel or healthcare personnel or health worker? or health care worker? or healthcare worker? or physician* or doctor? or nurse? or health facilit* or health care facilit* or healthcare facilit* or hospital? or health service? or health care service? or healthcare service? or health sector? or health care sector? or healthcare sector? or health administrations or government ${ }^{\star}$ or nongovernment ${ }^{\star}$ ) adj6 performance).ti,ab,kf.

22 provider recognition program*.ti,ab,kw.

23 cash on delivery.ti,ab,kw.

24 (output based aid or result? based aid).ti,ab,kw.

25 program $^{\star}$ for result?.ti,ab,kw.

26 or $/ 5-25$

274 or 26

28 Developing Countries.sh,kf.

29 (Africa or Asia or Caribbean or West Indies or South America or Latin America or Central America).hw,kf,ti,ab,cp.

30 (Afghanistan or Albania or Algeria or Angola or Antigua or Barbuda or Argentina or Armenia or Armenian or Aruba or Azerbaijan or Bahrain or Bangladesh or Barbados or Benin or Byelarus or Byelorussian or Belarus or Belorussian or Belorussia or Belize or Bhutan or Bolivia or Bosnia or Herzegovina or Hercegovina or Botswana or Brasil or Brazil or Bulgaria or Burkina Faso or Burkina Fasso or Upper Volta or Burundi or Urundi or Cambodia or Khmer Republic or Kampuchea or Cameroon or Cameroons or Cameron or Camerons or Cape Verde or Central African Republic or Chad or Chile or China or Colombia or Comoros or Comoro Islands or Comores or Mayotte or Congo or Zaire or Costa Rica or Cote d'Ivoire or Ivory Coast or Croatia or Cuba or Cyprus or Czechoslovakia or Czech Republic or Slovakia or Slovak Republic or Djibouti or French Somaliland or Dominica or Dominican Republic or East Timor or East Timur or Timor Leste or Ecuador or Egypt or United Arab Republic or El Salvador or Eritrea or Estonia or Ethiopia or Fiji or Gabon or Gabonese Republic or Gambia or Gaza or Georgia Republic or Georgian Republic or Ghana or Gold Coast or Greece or Grenada or Guatemala or Guinea or Guam or Guiana or Guyana

Paying for performance to improve the delivery of health interventions in low- and middle-income countries (Review) 
or Haiti or Honduras or Hungary or India or Maldives or Indonesia or Iran or Iraq or Isle of Man or Jamaica or Jordan or Kazakhstan or Kazakh or Kenya or Kiribati or Korea or Kosovo or Kyrgyzstan or Kirghizia or Kyrgyz Republic or Kirghiz or Kirgizstan or Lao PDR or Laos or Latvia or Lebanon or Lesotho or Basutoland or Liberia or Libya or Lithuania or Macedonia or Madagascar or Malagasy Republic or Malaysia or Malaya or Malay or Sabah or Sarawak or Malawi or Nyasaland or Mali or Malta or Marshall Islands or Mauritania or Mauritius or Agalega Islands or Mexico or Micronesia or Middle East or Moldova or Moldovia or Moldovian or Mongolia or Montenegro or Morocco or Ifni or Mozambique or Myanmar or Myanma or Burma or Namibia or Nepal or Netherlands Antilles or New Caledonia or Nicaragua or Niger or Nigeria or Northern Mariana Islands or Oman or Muscat or Pakistan or Palau or Palestine or Panama or Paraguay or Peru or Philippines or Philipines or Phillipines or Phillippines or Poland or Portugal or Puerto Rico or Romania or Rumania or Roumania or Russia or Russian or Rwanda or Ruanda or Saint Kitts or St Kitts or Nevis or Saint Lucia or St Lucia or Saint Vincent or St Vincent or Grenadines or Samoa or Samoan Islands or Navigator Island or Navigator Islands or Sao Tome or Saudi Arabia or Senegal or Serbia or Montenegro or Seychelles or Sierra Leone or Slovenia or Sri Lanka or Ceylon or Solomon Islands or Somalia or South Africa or Sudan or Suriname or Surinam or Swaziland or Syria or Tajikistan or Tadzhikistan or Tadjikistan or Tadzhik or Tanzania or Thailand or Togo or Togolese Republic or Tonga or Trinidad or Tobago or Tunisia or Turkey or Turkmenistan or Turkmen or Uganda or Ukraine or Uruguay or USSR or Soviet Union or Union of Soviet Socialist Republics or Uzbekistan or Uzbek or Vanuatu or New Hebrides or Venezuela or Vietnam or Viet Nam or West Bank or Yemen or Yugoslavia or Zambia or Zimbabwe or Rhodesia).hw,kf,ti,ab,cp.

31 ((developing or less* developed or under developed or underdeveloped or middle income or low* income or underserved or under served or deprived or poor ${ }^{\star}$ ) adj (countr* or nation? or population? or world)).ti,ab.

32 ((developing or less ${ }^{\star}$ developed or under developed or underdeveloped or middle income or low* income) adj (economy or economies)).ti,ab.

33 (low* adj (gdp or gnp or gross domestic or gross national)).ti,ab.

34 (low adj3 middle adj3 countr ${ }^{\star}$ ).ti,ab.

35 (Imic or Imics or third world or lami countr $\left.{ }^{\star}\right)$.ti,ab.

36 transitional countr*.ti,ab.

37 or/28-36

38 randomized controlled trial.pt.

39 controlled clinical trial.pt.

40 multicenter study.pt.

41 pragmatic clinical trial.pt.

42 non-randomized controlled trials as topic/

43 interrupted time series analysis/

44 controlled before-after studies/

45 (randomis* or randomiz* or randomly or groups or trial or multicenter or multi center or multicentre or multi centre or intervention? or effect? or impact? or controlled or control group? or (before adj5 after) or (pre adj5 post) or ((pretest or pre test) and (posttest or post test)) or quasiexperiment ${ }^{\star}$ or quasi experiment ${ }^{\star}$ or pseudo experiment ${ }^{\star}$ or pseudoexperiment ${ }^{\star}$ or evaluat ${ }^{\star}$ or time series or time point? or time trend? or repeated measur $\left.{ }^{\star}\right) . t i, a b$.

46 or/38-45

47 exp Animals/

48 Humans/

4947 not (47 and 48)

50 review.pt.

51 meta analysis.pt.

52 news.pt.

53 comment.pt.

54 editorial.pt.

55 cochrane database of systematic reviews.jn.

56 comment on.cm.

57 (systematic review or literature review).ti.

58 or/49-57

5946 not 58

6027 and 37 and 59

$61\left(201705^{\star}\right.$ or $201706^{\star}$ or $201707^{\star}$ or $201708^{\star}$ or $201709^{\star}$ or $201710^{\star}$ or $201711^{\star}$ or $201712^{\star}$ or $2018^{\star}$ or $\left.2019^{\star}\right) . d t, d p, e d, e p, y r$.

6260 and 61

Embase 1974 to 2019 June 18, Ovid

ID Search

1 "p4p".ti,ab,kw.

2 ((performance or result? based) adj3 (pay* or paid or money or monetary or cash or financ ${ }^{\star}$ or fund* or econom* or disbursement? or remunerat* ${ }^{\star}$ or reimburs ${ }^{\star}$ or compensat $\left.\left.{ }^{\star}\right)\right) . t i, a b, k w$.

3 ((performance or result? based) adj3 (nonmonetary or voucher? or token? or goods)).ti,ab,kw.

4 ((performance or result? based) adj3 (reward ${ }^{\star}$ or bonus? or initiative? or incentive? or contract?)).ti,ab,kw.

5 (indicator? adj3 (pay* or disbursement? or remunerat* or reimburs*)).ti,ab,kw.

6 ((performance or merit) adj based).ti,ab,kw.

Paying for performance to improve the delivery of health interventions in low- and middle-income countries (Review) 
7 ((payment or financial or monetary or nonmonetary or economic or disbursement or remuneration or reimbursement or reward ${ }^{\star}$ or bonus) adj incentive?).ti,ab,kw.

8 ((payment or financial or monetary or nonmonetary or economic or disbursement or remuneration or reimbursement) adj (reward ${ }^{\star}$ or bonus?)).ti,ab,kw.

9 (pay* adj3 quality).ti,ab,kw.

10 bonus payment?.ti,ab,kw.

11 ((incentive or compensatory or reimbursement) adj plan?).ti,ab,kw.

12 ((incentiv* or motivat $^{\star}$ or positive* reinforc $^{\star}$ ) adj3 (quality or output? or outcome? or delivery or utilisation or utilization)).ti,ab,kw.

13 ((incentiv $^{\star}$ or motivat ${ }^{\star}$ or positive ${ }^{\star}$ reinforc ${ }^{\star}$ ) adj3 (target or targets or health goal? or measurable action? or behaviour? or behavior? or best practice or practice pattern? or standard? or recommendation? or guideline?)).ti,ab,kw.

14 (conditional adj3 (pay $^{\star}$ or money or monetary or cash or financ ${ }^{\star}$ or fund ${ }^{\star}$ or econom ${ }^{\star}$ or disbursement? or remunerat* or reimburs ${ }^{\star}$ or nonmonetary or voucher? or token? or goods or reward? or bonus? or incentive? or motivat $\left.{ }^{\star}\right)$ ).ti,ab,kw.

15 incentive payment?.ti,ab,kw.

16 ((target or targets or targeted) adj3 (pay* or reward*)).ti,ab,kw.

17 ((chang* or enhanc* or improve $\left.{ }^{\star}\right)$ adj6 (provider? or practitioner? or health personnel or health care personnel or healthcare personnel or health worker? or health care worker? or healthcare worker? or physician* or doctor? or nurse? or health facilit* or health care facilit* or healthcare facilit* or hospital? or health service? or health care service? or healthcare service? or health sector? or health care sector? or healthcare sector? or health administrations or government ${ }^{\star}$ or nongovernment ${ }^{\star}$ ) adj6 performance).ti,ab,kw.

18 provider recognition program*.ti,ab,kw.

19 cash on delivery.ti,ab,kw.

20 (output based aid or result? based aid).ti,ab,kw.

21 or $1-20$

22 Developing Country.sh.

23 (Africa or Asia or Caribbean or West Indies or South America or Latin America or Central America).hw,ti,ab,cp.

24 (Afghanistan or Albania or Algeria or Angola or Antigua or Barbuda or Argentina or Armenia or Armenian or Aruba or Azerbaijan or Bahrain or Bangladesh or Barbados or Benin or Byelarus or Byelorussian or Belarus or Belorussian or Belorussia or Belize or Bhutan or Bolivia or Bosnia or Herzegovina or Hercegovina or Botswana or Brasil or Brazil or Bulgaria or Burkina Faso or Burkina Fasso or Upper Volta or Burundi or Urundi or Cambodia or Khmer Republic or Kampuchea or Cameroon or Cameroons or Cameron or Camerons or Cape Verde or Central African Republic or Chad or Chile or China or Colombia or Comoros or Comoro Islands or Comores or Mayotte or Congo or Zaire or Costa Rica or Cote d'Ivoire or Ivory Coast or Croatia or Cuba or Cyprus or Czechoslovakia or Czech Republic or Slovakia or Slovak Republic or Djibouti or French Somaliland or Dominica or Dominican Republic or East Timor or East Timur or Timor Leste or Ecuador or Egypt or United Arab Republic or El Salvador or Eritrea or Estonia or Ethiopia or Fiji or Gabon or Gabonese Republic or Gambia or Gaza or Georgia Republic or Georgian Republic or Ghana or Gold Coast or Greece or Grenada or Guatemala or Guinea or Guam or Guiana or Guyana or Haiti or Honduras or Hungary or India or Maldives or Indonesia or Iran or Iraq or Isle of Man or Jamaica or Jordan or Kazakhstan or Kazakh or Kenya or Kiribati or Korea or Kosovo or Kyrgyzstan or Kirghizia or Kyrgyz Republic or Kirghiz or Kirgizstan or Lao PDR or Laos or Latvia or Lebanon or Lesotho or Basutoland or Liberia or Libya or Lithuania or Macedonia or Madagascar or Malagasy Republic or Malaysia or Malaya or Malay or Sabah or Sarawak or Malawi or Nyasaland or Mali or Malta or Marshall Islands or Mauritania or Mauritius or Agalega Islands or Mexico or Micronesia or Middle East or Moldova or Moldovia or Moldovian or Mongolia or Montenegro or Morocco or Ifni or Mozambique or Myanmar or Myanma or Burma or Namibia or Nepal or Netherlands Antilles or New Caledonia or Nicaragua or Niger or Nigeria or Northern Mariana Islands or Oman or Muscat or Pakistan or Palau or Palestine or Panama or Paraguay or Peru or Philippines or Philipines or Phillipines or Phillippines or Poland or Portugal or Puerto Rico or Romania or Rumania or Roumania or Russia or Russian or Rwanda or Ruanda or Saint Kitts or St Kitts or Nevis or Saint Lucia or St Lucia or Saint Vincent or St Vincent or Grenadines or Samoa or Samoan Islands or Navigator Island or Navigator Islands or Sao Tome or Saudi Arabia or Senegal or Serbia or Montenegro or Seychelles or Sierra Leone or Slovenia or Sri Lanka or Ceylon or Solomon Islands or Somalia or South Africa or Sudan or Suriname or Surinam or Swaziland or Syria or Tajikistan or Tadzhikistan or Tadjikistan or Tadzhik or Tanzania or Thailand or Togo or Togolese Republic or Tonga or Trinidad or Tobago or Tunisia or Turkey or Turkmenistan or Turkmen or Uganda or Ukraine or Uruguay or USSR or Soviet Union or Union of Soviet Socialist Republics or Uzbekistan or Uzbek or Vanuatu or New Hebrides or Venezuela or Vietnam or Viet Nam or West Bank or Yemen or Yugoslavia or Zambia or Zimbabwe or Rhodesia).hw,ti,ab,cp.

25 ((developing or less ${ }^{\star}$ developed or under developed or underdeveloped or middle income or low ${ }^{\star}$ income or underserved or under served or deprived or poor ${ }^{\star}$ ) adj (countr* or nation? or population? or world)).ti,ab.

26 ((developing or less* developed or under developed or underdeveloped or middle income or low* income) adj (economy or economies)).ti,ab.

27 (low* adj (gdp or gnp or gross domestic or gross national)).ti,ab.

28 (low adj3 middle adj3 countr ${ }^{\star}$ ).ti,ab.

29 (Imic or Imics or third world or lami countr $\left.{ }^{\star}\right)$.ti,ab.

30 transitional countr*.ti,ab.

31 or/22-30

32 Randomized Controlled Trial/

33 Controlled Clinical Trial/

34 Quasi Experimental Study/

35 Pretest Posttest Control Group Design/

36 Time Series Analysis/

Paying for performance to improve the delivery of health interventions in low- and middle-income countries (Review) 
37 Experimental Design/

38 Multicenter Study/

39 (randomis* or randomiz* or randomly or groups or trial or multicenter or multi center or multicentre or multi centre or intervention? or effect? or impact? or controlled or control group? or (before adj5 after) or (pre adj5 post) or ((pretest or pre test) and (posttest or post test)) or quasiexperiment ${ }^{\star}$ or quasi experiment ${ }^{\star}$ or pseudo experiment ${ }^{\star}$ or pseudoexperiment ${ }^{\star}$ or evaluat* or time series or time point? or time trend? or repeated measur $\left.{ }^{\star}\right)$.ti,ab.

40 or/32-39

41 exp animals/or exp invertebrate/ or animal experiment/ or animal model/ or animal tissue/ or animal cell/ or nonhuman/

42 human/ or normal human/ or human cell/

$43 \quad 41$ and 42

$44 \quad 41$ not 43

45 (systematic review or literature review).ti.

46 "cochrane database of systematic reviews".jn.

47 or/ $44-46$

$48 \quad 40$ not 47

4921 and 31 and 48

50 limit 49 to embase

$51\left(201705^{\star}\right.$ or $201706^{\star}$ or $201707^{\star}$ or $201708^{\star}$ or $201709^{\star}$ or $201710^{\star}$ or $201711^{\star}$ or $201712^{\star}$ or $2018^{\star}$ or $\left.2019^{\star}\right)$.dd.

52 ("2017" or "2018" or "2019").yr.

5351 or 52

5450 and 53

PsycINFO 1806 to June Week 2 2019, Ovid

ID Search

1 Monetary Incentives/

2 Monetary Rewards/

3 "p4p".ti,ab.

4 ((performance or result? based) adj3 (pay* or paid or money or monetary or cash or financ ${ }^{\star}$ or fund* or econom* or disbursement? or remunerat* ${ }^{\star}$ or reimburs ${ }^{\star}$ or compensat $\left.\left.{ }^{\star}\right)\right) . t i, a b$.

5 ((performance or result? based) adj3 (nonmonetary or voucher? or token? or goods)).ti,ab.

6 ((performance or result? based) adj3 (reward or bonus? or initiative? or incentive? or contract?)).ti,ab.

7 (indicator? adj3 (pay ${ }^{\star}$ or disbursement? or remunerat* ${ }^{\star}$ or reimburs*)).ti,ab.

8 ((performance or merit) adj based).ti,ab.

9 ((payment or financial or monetary or nonmonetary or economic or disbursement or remuneration or reimbursement or reward ${ }^{\star}$ or bonus) adj incentive?).ti,ab.

10 ((payment or financial or monetary or nonmonetary or economic or disbursement or remuneration or reimbursement) adj (reward* or bonus?)).ti,ab.

11 (pay* adj3 quality).ti,ab.

12 bonus payment?.ti,ab.

13 ((incentive or compensatory or reimbursement) adj plan?).ti,ab.

14 ((incentiv* or motivat ${ }^{\star}$ or positive reinforc $^{\star}$ ) adj3 (quality or output? or outcome? or delivery or utilisation or utilization)).ti,ab.

15 ((incentiv $^{\star}$ or motivat* or positive* reinforc ${ }^{\star}$ ) adj3 (target or targets or health goal? or measurable action? or behaviour? or behavior? or best practice or practice pattern? or standard? or recommendation? or guideline?)).ti,ab.

16 (conditional adj3 (pay ${ }^{\star}$ or money or monetary or cash or financ ${ }^{\star}$ or fund ${ }^{\star}$ or econom ${ }^{\star}$ or disbursement? or remunerat* or reimburs ${ }^{\star}$ or nonmonetary or voucher? or token? or goods or reward? or bonus? or incentive? or motivat*)).ti,ab.

17 incentive payment?.ti,ab.

18 ((target or targets or targeted) adj3 (pay* or reward $\left.\left.{ }^{\star}\right)\right) . t i, a b$.

19 ((chang $^{\star}$ or enhanc $^{\star}$ or improve $\left.{ }^{\star}\right)$ adj6 (provider? or practitioner? or health personnel or health care personnel or healthcare personnel or health worker? or health care worker? or healthcare worker? or physician* or doctor? or nurse? or health facilit* or health care facilit* or healthcare facilit* or hospital? or health service? or health care service? or healthcare service? or health sector? or health care sector? or healthcare sector? or health administrations or government* or nongovernment $^{\star}$ ) adj6 performance).ti,ab.

20 provider recognition program*.ti,ab.

21 cash on delivery.ti,ab.

22 (output based aid or result? based aid).ti,ab.

23 or/1-22

24 Developing Countries/

25 (Africa or Asia or Caribbean or West Indies or South America or Latin America or Central America).id,ti,ab,hw.

26 (Afghanistan or Albania or Algeria or Angola or Antigua or Barbuda or Argentina or Armenia or Armenian or Aruba or Azerbaijan or Bahrain or Bangladesh or Barbados or Benin or Byelarus or Byelorussian or Belarus or Belorussian or Belorussia or Belize or Bhutan or Bolivia or Bosnia or Herzegovina or Hercegovina or Botswana or Brasil or Brazil or Bulgaria or Burkina Faso or Burkina Fasso or Upper Volta or Burundi or Urundi or Cambodia or Khmer Republic or Kampuchea or Cameroon or Cameroons or Cameron or Camerons or Cape Verde or Central African Republic or Chad or Chile or China or Colombia or Comoros or Comoro Islands or Comores or Mayotte or Congo or 
Zaire or Costa Rica or Cote d'Ivoire or Ivory Coast or Croatia or Cuba or Cyprus or Czechoslovakia or Czech Republic or Slovakia or Slovak Republic or Djibouti or French Somaliland or Dominica or Dominican Republic or East Timor or East Timur or Timor Leste or Ecuador or Egypt or United Arab Republic or El Salvador or Eritrea or Estonia or Ethiopia or Fiji or Gabon or Gabonese Republic or Gambia or Gaza or Georgia Republic or Georgian Republic or Ghana or Gold Coast or Greece or Grenada or Guatemala or Guinea or Guam or Guiana or Guyana or Haiti or Honduras or Hungary or India or Maldives or Indonesia or Iran or Iraq or Isle of Man or Jamaica or Jordan or Kazakhstan or Kazakh or Kenya or Kiribati or Korea or Kosovo or Kyrgyzstan or Kirghizia or Kyrgyz Republic or Kirghiz or Kirgizstan or Lao PDR or Laos or Latvia or Lebanon or Lesotho or Basutoland or Liberia or Libya or Lithuania or Macedonia or Madagascar or Malagasy Republic or Malaysia or Malaya or Malay or Sabah or Sarawak or Malawi or Nyasaland or Mali or Malta or Marshall Islands or Mauritania or Mauritius or Agalega Islands or Mexico or Micronesia or Middle East or Moldova or Moldovia or Moldovian or Mongolia or Montenegro or Morocco or Ifni or Mozambique or Myanmar or Myanma or Burma or Namibia or Nepal or Netherlands Antilles or New Caledonia or Nicaragua or Niger or Nigeria or Northern Mariana Islands or Oman or Muscat or Pakistan or Palau or Palestine or Panama or Paraguay or Peru or Philippines or Philipines or Phillipines or Phillippines or Poland or Portugal or Puerto Rico or Romania or Rumania or Roumania or Russia or Russian or Rwanda or Ruanda or Saint Kitts or St Kitts or Nevis or Saint Lucia or St Lucia or Saint Vincent or St Vincent or Grenadines or Samoa or Samoan Islands or Navigator Island or Navigator Islands or Sao Tome or Saudi Arabia or Senegal or Serbia or Montenegro or Seychelles or Sierra Leone or Slovenia or Sri Lanka or Ceylon or Solomon Islands or Somalia or South Africa or Sudan or Suriname or Surinam or Swaziland or Syria or Tajikistan or Tadzhikistan or Tadjikistan or Tadzhik or Tanzania or Thailand or Togo or Togolese Republic or Tonga or Trinidad or Tobago or Tunisia or Turkey or Turkmenistan or Turkmen or Uganda or Ukraine or Uruguay or USSR or Soviet Union or Union of Soviet Socialist Republics or Uzbekistan or Uzbek or Vanuatu or New Hebrides or Venezuela or Vietnam or Viet Nam or West Bank or Yemen or Yugoslavia or Zambia or Zimbabwe or Rhodesia).ti,ab,hw.

27 ((developing or less ${ }^{\star}$ developed or under developed or underdeveloped or middle income or low ${ }^{\star}$ income or underserved or under served or deprived or poor ${ }^{\star}$ ) adj (countr* or nation? or population? or world)).ti,ab.

28 ((developing or less ${ }^{\star}$ developed or under developed or underdeveloped or middle income or low income) adj (economy or economies)).ti,ab.

29 (low* adj (gdp or gnp or gross domestic or gross national)).ti,ab.

30 (low adj3 middle adj3 countr ${ }^{\star}$ ).ti,ab.

31 (Imic or Imics or third world or lami countr ${ }^{\star}$ ).ti,ab.

32 transitional countr*.ti,ab.

33 or/24-32

34 Treatment Outcome.md.

35 Empirical Study.md.

36 Prospective Study.md.

37 Quantitative Study.md.

38 experimental design/

39 between groups design/

40 quantitative methods/

41 quasi experimental methods/

42 pretesting/

43 posttesting/

44 repeated measures/

45 time series/

46 (posttest or posttests or post test or post tests or pretest or pretests or pre test or pre tests or "pretest/posttest" or quasi experimental or repeated measure or repeated measurement or repeated measurements or repeated measures or time series).id.

47 (randomis* $^{*}$ or randomiz* or randomly or groups or trial or multicenter or multi center or multicentre or multi centre or intervention? or effect? or impact? or controlled or control group? or (before adj5 after) or (pre adj5 post) or ((pretest or pre test) and (posttest or post test)) or quasiexperiment ${ }^{\star}$ or quasi experiment ${ }^{\star}$ or pseudo experiment ${ }^{\star}$ or pseudoexperiment ${ }^{\star}$ or evaluat ${ }^{\star}$ or time series or time point? or time trend? or repeated measur ${ }^{\star}$.ti,ab.

48 or $/ 34-47$

4923 and 33 and 48

$50\left(201804^{\star}\right.$ or $201805^{\star}$ or $201806^{\star}$ or $201807^{\star}$ or $201808^{\star}$ or $201809^{\star}$ or $201810^{\star}$ or $201811^{\star}$ or $201812^{\star}$ or $\left.2019^{\star}\right)$.up.

51 ("2018" or "2019").yr.

5250 or 51

$53 \quad 49$ and 52

CINAHL 1981 to present, EbscoHost

ID Search

S49 S47 AND S48

S48 EM 201804-

S47 S21 AND S31 AND S45

Limiters - Exclude MEDLINE records

S46 S21 AND S31 AND S45

S45 S32 OR S33 OR S34 OR S35 OR S36 OR S37 OR S38 OR S39 OR S40 OR S41 OR S42 OR S43 OR S44 
S44 TI ( (randomis* or randomiz* or randomly or trial or effect* or impact* or intervention* or before N5 after or pre N5 post or ((pretest or "pre test") and (posttest or "post test")) or quasiexperiment* or quasi W0 experiment* or pseudo experiment* or pseudoexperiment* or evaluat* or "time series" or time W0 point* or repeated W0 measur $\left.{ }^{\star}\right)$ ) OR AB ( (randomis* or randomiz* or randomly or trial or effect* or impact* or intervention* or before N5 after or pre N5 post or ((pretest or "pre test") and (posttest or "post test")) or quasiexperiment*

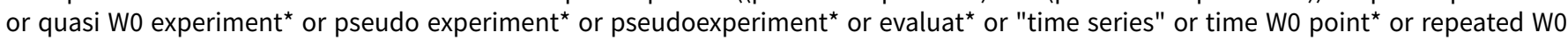
measur*) )

S43 (MH "Health Services Research")

S42 (MH "Multicenter Studies")

S41 (MH "Quasi-Experimental Studies+")

S40 (MH "Pretest-Posttest Design+")

S39 (MH "Experimental Studies")

S38 (MH "Nonrandomized Trials")

S37 (MH "Intervention Trials")

S36 (MH "Clinical Trials")

S35 (MH "Randomized Controlled Trials")

S34 PT research

S33 PT clinical trial

S32 PT randomized controlled trial

S31 S22 OR S23 OR S24 OR S25 OR S26 OR S27 OR S28 OR S29 OR S30

S30 TI transitional NO countr* OR AB transitional NO countr ${ }^{\star}$

S29 TI ( Imic or Imics or "third world" or lami N0 countr") OR AB ( Imic or Imics or "third world" or lami N0 countr")

S28 TI low N3 middle N3 countr* OR AB low N3 middle N3 countr ${ }^{\star}$

S27 TI ( low* N0 (gdp or gnp or "gross domestic" or "gross national")) OR AB ( low* N0 (gdp or gnp or "gross domestic" or "gross national"))

S26 TI ( (developing or less* N0 developed or "under developed" or underdeveloped or "middle income" or low* N3 income) N0 (economy or economies) ) OR AB ( (developing or less* N0 developed or "under developed" or underdeveloped or "middle income" or low* N3 income) NO (economy or economies))

S25 TI (developing or less* N0 developed or "under developed" or underdeveloped or "middle income" or low* N0 income or underserved or "under served" or deprived or poor ${ }^{\star}$ ) NO (countr* or nation* or population* or world) ) OR AB ( developing or less ${ }^{\star}$ NO developed or "under developed" or underdeveloped or "middle income" or low* NO income or underserved or "under served" or deprived or poor ${ }^{\star}$ ) N0 (countr* or nation* or population* or world))

S24 TX Afghanistan or Albania or Algeria or Angola or Antigua or Barbuda or Argentina or Armenia or Armenian or Aruba or Azerbaijan or Bahrain or Bangladesh or Barbados or Benin or Byelarus or Byelorussian or Belarus or Belorussian or Belorussia or Belize or Bhutan or Bolivia or Bosnia or Herzegovina or Hercegovina or Botswana or Brasil or Brazil or Bulgaria or Burkina Faso or Burkina Fasso or Upper Volta or Burundi or Urundi or Cambodia or Khmer Republic or Kampuchea or Cameroon or Cameroons or Cameron or Camerons or Cape Verde or Central African Republic or Chad or Chile or China or Colombia or Comoros or Comoro Islands or Comores or Mayotte or Congo or Zaire or Costa Rica or Cote d'Ivoire or Ivory Coast or Croatia or Cuba or Cyprus or Czechoslovakia or Czech Republic or Slovakia or Slovak Republic or Djibouti or French Somaliland or Dominica or Dominican Republic or East Timor or East Timur or Timor Leste or Ecuador or Egypt or United Arab Republic or El Salvador or Eritrea or Estonia or Ethiopia or Fiji or Gabon or Gabonese Republic or Gambia or Gaza or Georgia Republic or Georgian Republic or Ghana or Gold Coast or Greece or Grenada or Guatemala or Guinea or Guam or Guiana or Guyana or Haiti or Honduras or Hungary or India or Maldives or Indonesia or Iran or Iraq or Isle of Man or Jamaica or Jordan or Kazakhstan or Kazakh or Kenya or Kiribati or Korea or Kosovo or Kyrgyzstan or Kirghizia or Kyrgyz Republic or Kirghiz or Kirgizstan or Lao PDR or Laos or Latvia or Lebanon or Lesotho or Basutoland or Liberia or Libya or Lithuania or Macedonia or Madagascar or Malagasy Republic or Malaysia or Malaya or Malay or Sabah or Sarawak or Malawi or Nyasaland or Mali or Malta or Marshall Islands or Mauritania or Mauritius or Agalega Islands or Mexico or Micronesia or Middle East or Moldova or Moldovia or Moldovian or Mongolia or Montenegro or Morocco or Ifni or Mozambique or Myanmar or Myanma or Burma or Namibia or Nepal or Netherlands Antilles or New Caledonia or Nicaragua or Niger or Nigeria or Northern Mariana Islands or Oman or Muscat or Pakistan or Palau or Palestine or Panama or Paraguay or Peru or Philippines or Philipines or Phillipines or Phillippines or Poland or Portugal or Puerto Rico or Romania or Rumania or Roumania or Russia or Russian or Rwanda or Ruanda or Saint Kitts or St Kitts or Nevis or Saint Lucia or St Lucia or Saint Vincent or St Vincent or Grenadines or Samoa or Samoan Islands or Navigator Island or Navigator Islands or Sao Tome or Saudi Arabia or Senegal or Serbia or Montenegro or Seychelles or Sierra Leone or Slovenia or Sri Lanka or Ceylon or Solomon Islands or Somalia or South Africa or Sudan or Suriname or Surinam or Swaziland or Syria or Tajikistan or Tadzhikistan or Tadjikistan or Tadzhik or Tanzania or Thailand or Togo or Togolese Republic or Tonga or Trinidad or Tobago or Tunisia or Turkey or Turkmenistan or Turkmen or Uganda or Ukraine or Uruguay or USSR or Soviet Union or Union of Soviet Socialist Republics or Uzbekistan or Uzbek or Vanuatu or New Hebrides or Venezuela or Vietnam or Viet Nam or West Bank or Yemen or Yugoslavia or Zambia or Zimbabwe or Rhodesia

S23 TX Africa or Asia or Caribbean or "West Indies" or "South America" or "Latin America" or "Central America"

S22 (MH "Developing Countries")

S21 S1 OR S2 OR S3 OR S4 OR S5 OR S6 OR S7 OR S8 OR S9 OR S10 OR S11 OR S12 OR S13 OR S14 OR S15 OR S16 OR S17 OR S18 OR S19 OR S20

S20 TI ( "output based aid" or "output based aid" or "result based aid" or "results based aid" ) OR AB ( "output based aid" or "output based aid" or "result based aid" or "results based aid" )

S19 TI "cash on delivery" OR AB "cash on delivery"

S18 TI "provider recognition" N0 program* OR AB "provider recognition" N0 program*

Paying for performance to improve the delivery of health interventions in low- and middle-income countries (Review) 
S17 TI ( (chang* or enhanc* or improve*) N6 (provider* or practitioner* or "health personnel" or "health care personnel" or "healthcare personnel" or health N0 worker* or "health care" N0 worker* or healthcare N0 worker* or physician* or doctor or doctors or nurse or nurses or health N0 facilit* or "health care" N0 facilit* or healthcare N0 facilit* or hospital or hospitals or health N0 service* or "health care" N0 service $^{\star}$ or healthcare N0 service* or health N0 sector ${ }^{\star}$ or "health care" N0 sector ${ }^{\star}$ or healthcare N0 sector* or "health administrations" or government* or nongovernment ${ }^{\star}$ ) N6 performance ) OR AB ( (chang* or enhanc* or improve*) N6 (provider* or practitioner* or "health personnel" or "health care personnel" or "healthcare personnel" or health N0 worker* or "health care" N0 worker* or healthcare N0 worker* or physician* or doctor or doctors or nurse or nurses or health N0 facilit* or "health care" N0 facilit* or healthcare N0 facilit* or hospital or hospitals or health N0 service* or "health care" N0 service* or healthcare N0 service* or health N0 sector ${ }^{\star}$ or "health care" N0 sector* or healthcare N0 sector* or "health administrations" or government* or nongovernment* ${ }^{\star}$ N6 performance )

S16 TI (target or targets or targeted) N3 (pay* or reward*) OR AB (target or targets or targeted) N3 (pay ${ }^{\star}$ or reward ${ }^{\star}$ )

S15 TI (incentive No payment*) OR AB (incentive N0 payment*)

S14 TI (conditional N3 (pay ${ }^{\star}$ or money or monetary or cash or financ* or econom* or disbursement* or remunerat ${ }^{\star}$ or reimburs $^{\star}$ or nonmonetary or voucher ${ }^{\star}$ or token or tokens or goods or reward ${ }^{\star}$ or bonus ${ }^{\star}$ or incentive* or motivat ${ }^{\star}$ ) ) OR AB ( conditional N3 (pay ${ }^{\star}$ or money or monetary or cash or financ ${ }^{\star}$ or econom ${ }^{\star}$ or disbursement ${ }^{\star}$ or remunerat* or reimburs ${ }^{\star}$ or nonmonetary or voucher ${ }^{\star}$ or token or

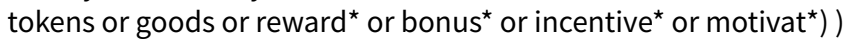

S13 TI ( (incentiv* or motivat* or positive* N0 reinforc*) N3 (target or targets or "health goal" or "health goals" or measurable N0 action* or behaviour ${ }^{\star}$ or behavior* or "best practice" or practice N0 pattern* or standard or standards or recommendation* or guideline*) ) OR AB ( (incentiv* or motivat* or positive* N0 reinforc ${ }^{\star}$ ) N3 (target or targets or "health goal" or "health goals" or measurable N0 action* or behaviour* or behavior* or "best practice" or practice N0 pattern* or standard or standards or recommendation* or guideline*) )

S12 TI ( (incentiv or motivat $^{\star}$ or positive ${ }^{\star}$ N0 reinforc ${ }^{\star}$ ) N3 (quality or output ${ }^{\star}$ or outcome ${ }^{\star}$ or delivery or utilisation or utilization) ) OR $A B$ ( (incentiv ${ }^{\star}$ or motivat ${ }^{\star}$ or positive* N0 reinforc ${ }^{\star}$ ) N3 (quality or output ${ }^{\star}$ or outcome ${ }^{\star}$ or delivery or utilisation or utilization) )

S11 TI ( (incentive ${ }^{\star}$ or compensatory or reimbursement) NO (plan or plans) ) OR AB ( (incentive* or compensatory or reimbursement) N0 (plan or plans))

S10 TI (bonus N0 payment ${ }^{\star}$ ) OR AB (bonus N0 payment*)

S9 TI (pay* N3 quality) OR AB (pay* N3 quality)

S8 $\mathrm{TI}$ ( (payment or financial or monetary or nonmonetary or economic or disbursement or remuneration or reimbursement) N0 (reward ${ }^{\star}$ or bonus $\left.{ }^{\star}\right)$ ) OR AB ( (payment or financial or monetary or nonmonetary or economic or disbursement or remuneration or reimbursement) No (reward* or bonus*))

S7 TI ( (payment or financial or monetary or nonmonetary or economic or disbursement or remuneration or reimbursement or reward ${ }^{\star}$ or bonus) NO incentive* ) OR AB ( (payment or financial or monetary or nonmonetary or economic or disbursement or remuneration or reimbursement or reward* or bonus) N0 incentive* $\left.{ }^{\star}\right)$

S6 TI ( (performance or merit) NO based) OR AB ( (performance or merit) N0 based )

S5 TI ( indicator ${ }^{\star}$ N3 (pay* or disbursement ${ }^{\star}$ or remunerat ${ }^{\star}$ or reimburs ${ }^{\star}$ ) ) OR AB ( indicator ${ }^{\star}$ N3 (pay ${ }^{\star}$ or disbursement $^{\star}$ or remunerat $^{\star}$ or reimburs*) )

S4 TI ( ((performance or "result based" or "results based") N3 (reward* or bonus* or initiative* or incentive* or contract or contracts)) ) OR AB ( ((performance or "result based" or "results based") N3 (reward* or bonus* or initiative* or incentive* or contract or contracts)) )

S3 TI ( (performance or "result based" or "results based") N3 (nonmonetary or voucher* or token or tokens or goods) ) OR AB ( (performance or "result based" or "results based") N3 (nonmonetary or voucher* or token or tokens or goods))

S2 TI ((performance or "result based" or "results based") N3 (pay* or paid or money or monetary or cash or financ* or fund* or econom* or disbursement ${ }^{\star}$ or remunerat* or reimburs ${ }^{\star}$ or compensat $\left.{ }^{\star}\right)$ ) OR AB ((performance or "result based" or "results based") N3 (pay ${ }^{\star}$ or paid or money or monetary or cash or financ ${ }^{\star}$ or fund ${ }^{\star}$ or econom ${ }^{\star}$ or disbursement ${ }^{\star}$ or remunerat $^{\star}$ or reimburs $^{\star}$ or compensat $\left.\left.^{\star}\right)\right)$

S1 (MH "Reimbursement, Incentive")

Global Health Library (WHO)

ID Search

1 "performance based" or "reward based" or "result based" or "results based" or "performance incentive" or "performance incentives"

or "reimbursement incentive" or "reimbursement incentives" or "p4p" or "pay for performance" or "paying for performance" or "payment for performance" or "payments for performance" or "pay by performance" or "paying by performance" or "payment by performance" or "payments by performance" or "performance related payment" or "performance related payments" or "incentive payment" or "incentive payments" or "payment incentive" or "payment incentives" or "financial incentive" or "financial incentives" or "economic incentive" or "economic incentives" or "monetary incentive" or "monetary incentives" or "financial reward" or "financial rewards" or "economic reward" or "economic rewards" or "monetary reward" or "monetary rewards" or "rewarding performance" or "performance reward" or "performance rewards" or "bonus payment" or "bonus payments" or "conditional cash"

AND

"randomised" or "randomized" or "groups" or "trial" or "controlled" or "control group" or "control groups" or" effect" or "effects" or "impact" or "impacts" or "evaluat" or "evaluation" or "time series" or "quasiexperiment" or "quasiexperiments" or "quasi experiment" or "quasi experiments" or "repeated measure" or "repeated measures" or "repeated measurement" or "repeated measurements"

ClinicalTrials.gov, NIH (https://clinicaltrials.gov)

Advanced search in Intervention/treatment (6 individual strategies/searches)

ID Search 
1 "performance based" OR "reward based" OR "result based" OR "results based" OR "performance incentive" OR "performance incentives" OR "reimbursement incentive" OR "reimbursement incentives" OR "p4p"

2 "pay for performance" OR "paying for performance" OR "payment for performance" OR "payments for performance" OR "pay by performance" OR "paying by performance" OR "payment by performance" OR "payments by performance"

3 "performance related payment" OR "performance related payments" OR "incentive payment" OR "incentive payments" OR "payment incentive" OR "payment incentives"

4 "financial incentive" OR "financial incentives" OR "economic incentive" OR "economic incentives" OR "monetary incentive" OR "monetary incentives"

5 "financial reward" OR "financial rewards" OR "economic reward" OR "economic rewards" OR "monetary reward" OR "monetary rewards"

6 "rewarding performance" OR "performance reward" OR "performance rewards" OR "bonus payment" OR "bonus payments" OR "conditional cash"

ICTRP, WHO (http://apps.who.int/trialsearch/AdvSearch.aspx)

Advanced search in the Intervention with Recruitment status: ALL (6 individual strategies/searches)

ID Search

1 performance based OR reward based OR result based OR results based OR performance incentive OR performance incentives OR reimbursement incentive OR reimbursement incentives OR $p 4 p$

2 pay for performance OR paying for performance OR payment for performance OR payments for performance OR pay by performance OR paying by performance OR payment by performance OR payments by performance

3 performance related payment OR performance related payments OR incentive payment OR incentive payments OR payment incentive OR payment incentives

4 financial incentive OR financial incentives OR economic incentive OR economic incentives OR monetary incentive OR monetary incentives

5 financial reward OR financial rewards OR economic reward OR economic rewards OR monetary reward OR monetary rewards

6 rewarding performance OR performance reward OR performance rewards OR bonus payment OR bonus payments OR conditional cash

Global Health 1973 to 2019 Week 43, Ovid

ID Search

1 "p4p".af.

2 ((result based or results based) adj (pay* or fund* or reward*)).af.

3 (pay* adj3 perform $\left.^{\star}\right)$.af.

4 ((performance or merit) adj based).af.

5 ((performance or payment or financial or monetary or nonmonetary or economic or disbursement or remuneration or reimbursement or reward* or bonus) adj incentive?).af.

6 incentive payment?.af.

7 ((performance or payment or financial or monetary or nonmonetary or economic or disbursement or remuneration or reimbursement) $\operatorname{adj}($ reward* or bonus?)).af.

8 (pay* adj3 quality).af.

9 ((incentive or compensatory or reimbursement) adj plan?).af.

10 (conditional adj3 (pay* or money or monetary or cash or financ ${ }^{\star}$ or fund ${ }^{\star}$ or econom ${ }^{\star}$ or disbursement? or remunerat* or reimburs ${ }^{\star}$ or nonmonetary or voucher? or token? or goods or reward? or bonus? or incentive? or motivat*)).af.

11 ((target or targets or targeted) adj3 (pay* or reward*)).af.

12 ((chang* or enhanc $^{\star}$ or improve $\left.{ }^{\star}\right)$ adj6 (provider? or practitioner? or health personnel or health care personnel or healthcare personnel or health worker? or health care worker? or healthcare worker? or physician ${ }^{\star}$ or doctor? or nurse? or health facilit ${ }^{\star}$ or health care facilit ${ }^{\star}$ or healthcare facilit* or hospital? or health service? or health care service? or healthcare service? or health sector? or health care sector? or healthcare sector? or health administrations or government* or nongovernment $^{\star}$ ) adj6 performance).af.

13 or $/ 1-12$

14 (random* $^{\star}$ or intervention? or control* or evaluat* or (before adj5 after) or (pre adj5 post) or ((pretest or pre test) and (posttest or post test)) or quasiexperiment ${ }^{\star}$ or quasi experiment* or time series or time point? or time trend? or repeated measur $\left.{ }^{\star}\right)$.ti,ab.

15 (trial or effect? or impact?).ti.

16 or/14-15

$17 \quad 13$ and 16

EconLit 1886 to present, EBSCOhost

ID Search

S27 S15 AND S16 AND S25 AND S26

S26 TI (randomis* OR randomiz* OR randomly OR groups OR trial OR multicenter OR "multi center" OR multicentre OR "multi centre" OR intervention* OR effect* OR impact* OR controlled OR "control group" OR "before and after" OR quasiexperiment* OR quasi WO experiment* OR pseudo W0 experiment* OR pseudoexperiment* OR evaluat* OR "time series" OR time W0 point ${ }^{\star}$ OR time W0 trend* OR repeated WO measur ${ }^{\star}$ ) OR AB (randomis ${ }^{\star}$ OR randomiz* OR randomly OR groups OR trial OR multicenter OR "multi center" OR multicentre OR "multi centre" OR intervention* OR effect* OR impact* OR controlled OR "control group" OR "before and after" OR quasiexperiment* 
OR quasi W0 experiment* OR pseudo W0 experiment* OR pseudoexperiment* OR evaluat* OR "time series" OR time W0 point* OR time W0 trend* OR repeated WO measur $\left.{ }^{\star}\right)$

S25 S17 OR S18 OR S19 OR S20 OR S21 OR S22 OR S23 OR S24

S24 TI ("transitional country" or "transitional countries")) OR AB ("transitional country" or "transitional countries"))

S23 TI (Imic or Imics or "third world" or "lami country" or "lami countries") OR AB (Imic or Imics or "third world" or "lami country" or "lami countries")

S22 TI (low N3 middle N3 countr*) OR AB (low N3 middle N3 countr*)

S21 TI (low* W0 (gdp or gnp or "gross domestic" or "gross national")) OR AB (low* W0 (gdp or gnp or "gross domestic" or "gross national")) S20 TI ((developing or "less developed" or "lesser developed" or "under developed" or underdeveloped or "middle income" or "low income" or "lower income") WO (economy or economies)) OR AB ((developing or "less developed" or "lesser developed" or "under developed" or underdeveloped or "middle income" or "low income" or "lower income") W0 (economy or economies))

S19 TI ((developing or "less developed" or "lesser developed" or "under developed" or underdeveloped or "middle income" or "low income" or "lower income" or underserved or "under served" or deprived or poor ${ }^{\star}$ ) W0 (countr* or nation* or population* or world)) OR $\mathrm{AB}$ ((developing or "less developed" or "lesser developed" or "under developed" or underdeveloped or "middle income" or "low income" or "lower income" or underserved or "under served" or deprived or poor*) W0 (countr* or nation* or population* or world))

S18 TX (Afghanistan OR Albania OR Algeria OR Angola OR Antigua OR Barbuda OR Argentina OR Armenia OR Armenian OR Aruba OR Azerbaijan OR Bahrain OR Bangladesh OR Barbados OR Benin OR Byelarus OR Byelorussian OR Belarus OR Belorussian OR Belorussia OR Belize OR Bhutan OR Bolivia OR Bosnia OR Herzegovina OR Hercegovina OR Botswana OR Brasil OR Brazil OR Bulgaria OR "Burkina Faso" OR "Burkina Fasso" OR "Upper Volta" OR Burundi OR Urundi OR Cambodia OR "Khmer Republic" OR Kampuchea OR Cameroon OR Cameroons OR Cameron OR Camerons OR "Cape Verde" OR "Central African Republic" OR Chad OR Chile OR China OR Colombia OR Comoros OR "Comoro Islands" OR Comores OR Mayotte OR Congo OR Zaire OR "Costa Rica" OR "Cote d'Ivoire" OR "Ivory Coast" OR Croatia OR Cuba OR Cyprus OR Czechoslovakia OR "Czech Republic" OR Slovakia OR "Slovak Republic" OR Djibouti OR "French Somaliland" OR Dominica OR "Dominican Republic" OR "East Timor" OR "East Timur" OR "Timor Leste" OR Ecuador OR Egypt OR "United Arab Republic" OR "El Salvador" OR Eritrea OR Estonia OR Ethiopia OR Fiji OR Gabon OR "Gabonese Republic" OR Gambia OR Gaza OR Georgia OR Georgian OR Ghana OR "Gold Coast" OR Greece OR Grenada OR Guatemala OR Guinea OR Guam OR Guiana OR Guyana OR Haiti OR Honduras OR Hungary OR India OR Maldives OR Indonesia OR Iran OR Iraq OR "Isle of Man" OR Jamaica OR Jordan OR Kazakhstan OR Kazakh OR Kenya OR Kiribati OR Korea OR Kosovo OR Kyrgyzstan OR Kirghizia OR "Kyrgyz Republic" OR Kirghiz OR Kirgizstan OR "Lao PDR" OR Laos OR Latvia OR Lebanon OR Lesotho OR Basutoland OR Liberia OR Libya OR Lithuania OR Macedonia OR Madagascar OR "Malagasy Republic" OR Malaysia OR Malaya OR Malay OR Sabah OR Sarawak OR Malawi OR Nyasaland OR Mali OR Malta OR "Marshall Islands" OR Mauritania OR Mauritius OR "Agalega Islands" OR Mexico OR Micronesia OR "Middle East" OR Moldova OR Moldovia OR Moldovian OR Mongolia OR Montenegro OR Morocco OR Ifni OR Mozambique OR Myanmar OR Myanma OR Burma OR Namibia OR Nepal OR "Netherlands Antilles" OR "New Caledonia" OR Nicaragua OR Niger OR Nigeria OR "Northern Mariana Islands" OR Oman OR Muscat OR Pakistan OR Palau OR Palestine OR Panama OR Paraguay OR Peru OR Philippines OR Philipines OR Phillipines OR Phillippines OR Poland OR Portugal OR "Puerto Rico" OR Romania OR Rumania OR Roumania OR Russia OR Russian OR Rwanda OR Ruanda OR "Saint Kitts" OR "St Kitts" OR Nevis OR "Saint Lucia" OR "St Lucia" OR "Saint Vincent" OR "St Vincent" OR Grenadines OR Samoa OR "Samoan Islands" OR "Navigator Island" OR "Navigator Islands" OR "Sao Tome" OR "Saudi Arabia" OR Senegal OR Serbia OR Montenegro OR Seychelles OR "Sierra Leone" OR Slovenia OR "Sri Lanka" OR Ceylon OR "Solomon Islands" OR Somalia OR Sudan OR Suriname OR Surinam OR Swaziland OR Syria OR Tajikistan OR Tadzhikistan OR Tadjikistan OR Tadzhik OR Tanzania OR Thailand OR Togo OR "Togolese Republic" OR Tonga OR Trinidad OR Tobago OR Tunisia OR Turkey OR Turkmenistan OR Turkmen OR Uganda OR Ukraine OR Uruguay OR USSR OR "Soviet Union" OR "Union of Soviet Socialist Republics" OR Uzbekistan OR Uzbek OR Vanuatu OR "New Hebrides" OR Venezuela OR Vietnam OR "Viet Nam" OR "West Bank" OR Yemen OR Yugoslavia OR Zambia OR Zimbabwe OR Rhodesia)

S17 TX (Africa OR Asia OR Caribbean OR "West Indies" OR "South America" OR "Latin America" OR "Central America")

S16 TI (health* OR medical OR practitioner* OR physician* OR doctor OR doctors OR nurse OR nurses OR hospital OR hospitals) OR $A B$ (health* OR medical OR practitioner* OR physician* OR doctor OR doctors OR nurse OR nurses OR hospital OR hospitals)

S15 S1 OR S2 OR S3 OR S4 OR S5 OR S6 OR S7 OR S8 OR S9 OR S10 OR S11 OR S12 OR S13 OR S14

S14 TI ((chang* OR enhanc* OR improve*) N6 (provider* OR practitioner* OR "health personnel" OR "health care personnel" OR "healthcare personnel" OR "health worker" OR "health workers" OR "health care worker" OR "health care workers" OR "healthcare worker" OR "healthcare workers" OR physician* OR doctor OR doctors OR nurse OR nurses OR "health facility" OR "health facilities" OR "health care facility" OR "health care facilities" OR "healthcare facility" OR "healthcare facilities" OR hospital OR hospitals OR "health service" OR "health services" OR "health care service" OR "health care services" OR "healthcare service" OR "healthcare services" OR "health sector" OR "health sectors" OR "health care sector" OR "health care sectors" OR "healthcare sector" OR "healthcare sectors" OR "health administrations" OR government* OR nongovernment $\left.{ }^{\star}\right)$ N6 performance) OR AB ((chang* OR enhanc* OR improve*) N6 (provider OR practitioner ${ }^{\star}$ OR "health personnel" OR "health care personnel" OR "healthcare personnel" OR "health worker" OR "health workers" OR "health care worker" OR "health care workers" OR "healthcare worker" OR "healthcare workers" OR physician* OR doctor OR doctors OR nurse OR nurses OR "health facility" OR "health facilities" OR "health care facility" OR "health care facilities" OR "healthcare facility" OR "healthcare facilities" OR hospital OR hospitals OR "health service" OR "health services" OR "health care service" OR "health care services" OR "healthcare service" OR "healthcare services" OR "health sector" OR "health sectors" OR "health care sector" OR "health care sectors" OR "healthcare sector" OR "healthcare sectors" OR "health administrations" OR government* OR nongovernment*) N6 performance)

S13 TI ((target OR targets OR targeted) N3 (pay* OR reward*)) OR AB ((target OR targets OR targeted) N3 (pay ${ }^{\star}$ OR reward $\left.^{\star}\right)$ )

S12 TI (conditional N3 (pay* OR money OR monetary OR cash OR financ* OR fund ${ }^{\star}$ OR econom* OR disbursement* OR remunerat* OR reimburs* OR nonmonetary OR voucher ${ }^{\star}$ OR token OR tokens OR goods OR reward* OR bonus* OR incentive* OR motivat*)) OR AB 
(conditional N3 (pay* OR money OR monetary OR cash OR financ ${ }^{\star}$ OR fund ${ }^{\star}$ OR econom ${ }^{\star}$ OR disbursement ${ }^{\star}$ OR remunerat $^{\star}$ OR reimburs ${ }^{\star}$ OR nonmonetary OR voucher ${ }^{\star}$ OR token OR tokens OR goods OR reward ${ }^{\star}$ OR bonus $^{\star}$ OR incentive ${\left.\left.\text { OR } \text { motivat }^{\star}\right)\right)}^{\star}$

S11 TI ((incentive* OR compensatory OR reimbursement) W0 (plan OR plans)) OR AB ((incentive* OR compensatory OR reimbursement) WO (plan OR plans))

S10 TI (pay* W3 quality) OR AB (pay* W3 quality)

S9 TI ((payment OR financial OR monetary OR nonmonetary OR economic OR disbursement OR remuneration OR reimbursement) W0 (reward* OR bonus*)) OR AB ((payment OR financial OR monetary OR nonmonetary OR economic OR disbursement OR remuneration OR reimbursement) WO (reward* OR bonus $\left.\left.{ }^{\star}\right)\right)$

S8 TI (incentive W0 payment ${ }^{\star}$ ) OR AB (incentive W0 payment ${ }^{\star}$ )

S7 TI ((payment OR financial OR monetary OR nonmonetary OR economic OR disbursement OR remuneration OR reimbursement OR reward* OR bonus) WO incentive ${ }^{\star}$ ) OR AB ((payment OR financial OR monetary OR nonmonetary OR economic OR disbursement OR remuneration $O R$ reimbursement $O R$ reward ${ }^{\star} O R$ bonus) $W 0$ incentive*)

S6 TI ((performance OR merit) WO based) OR AB ((performance OR merit) WO based)

S5 TI (("result based" OR "results based") WO (pay ${ }^{\star}$ OR fund* OR reward*)) OR AB (("result based" OR "results based") W0 (pay ${ }^{\star}$ OR fund ${ }^{\star}$ OR reward*))

S4 TI ("p4p" OR (pay* N3 perform*)) OR AB ("p4p" OR (pay* N3 perform*))

S3 (SU(Compensation) AND SU(Incentives))

S2 SU ("Personnel Economics: Compensation and Compensation Methods and Their Effects")

S1 SU ("Compensation Packages; Payment Methods")

The Grey Literature Report (http://www.greylit.org/) (individual strategies/searches)

ID Search

1 "pay for performance"

2 "p4p"

3 "reimbursement incentive"

4 "payment incentive"

5 "payment reward"

6 "performance incentive"

7 "performance reward"

8 "performance payment"

9 "performance based financing"

10 "result based payment"

11 "result based funding"

12 "result based financing"

BLDS British Library for Development Studies (http://blds.ids.ac.uk) (individual strategies/searches)

ID Search

1 pay for performance

2 paying for performance

3 p4p

4 reimbursement incentive

5 reimbursement incentives

6 payment incentive

7 payment incentives

8 payment reward

9 payment rewards

10 performance incentive

11 performance incentives

12 performance reward

13 performance rewards

14 performance payment

15 performance payments

16 performance based financing

17 result based payment

18 results based payment

19 result based payments

20 results based payments

21 result based funding

22 results based funding

23 result based financing

24 results based financing 
OpenGrey (http://www.opengrey.eu/)

ID Search

1 "pay for performance" OR "paying for performance" OR "p4p" OR "reimbursement incentive" OR "reimbursement incentives" OR "payment incentive" OR "payment incentives" OR "payment reward" OR "payment rewards" OR "performance incentive" OR "performance incentives" OR "performance reward" OR "performance rewards" OR "performance payment" OR "performance payments" OR "performance based financing" OR "result based payment" OR "results based payment" OR "result based payments" OR "results based payments" OR "result based funding" OR "results based funding" OR "result based financing" OR "results based financing"

3ie Database of Impact Evaluations (http://www.3ieimpact.org/en/)(individual strategies/searches)

ID Search

1 "pay for performance" OR "paying for performance" OR "p4p" OR "reimbursement incentive" OR "reimbursement incentives"

2 "payment incentive" OR "payment incentives" OR "payment reward" OR "payment rewards" OR "performance incentive" OR "performance incentives" OR "performance reward" OR "performance rewards" OR "performance payment" OR "performance payments" 3 "performance based financing"

4 "result based payment" OR "results based payment" OR "result based payments" OR "results based payments" OR "result based funding" OR "results based funding" OR "result based financing" OR "results based financing"

African Development Bank (https://www.afdb.org/en/) (individual strategies/searches)

ID Search

1 "pay for performance"

2 "p4p"

3 "reimbursement incentive"

4 "payment incentive"

5 "payment reward"

6 "performance incentive"

7 "performance reward"

8 "performance payment"

9 "performance based financing"

10 "result based payment"

11 "result based funding"

12 "result based financing"

USAID (https://www.usaid.gov/) (individual strategies/searches)

ID Search

1 "pay for performance"

2 "paying for performance"

3 "p4p"

4 "reimbursement incentive"

5 "reimbursement incentives"

6 "payment incentive"

7 "payment incentives"

8 "payment reward"

9 "payment rewards"

10 "performance incentive"

11 "performance incentives"

12 "performance reward"

13 "performance rewards"

14 "performance payment"

15 "performance payments"

16 "performance based financing"

17 "result based payment"

18 "results based payment"

19 "result based payments"

20 "results based payments"

21 "result based funding"

22 "results based funding"

23 "result based financing"

24 "results based financing"

Cordaid (https://www.cordaid.org/en/) (individual strategies/searches)

ID Search

1 pay for performance

2 paying for performance

Paying for performance to improve the delivery of health interventions in low- and middle-income countries (Review) 
$3 \mathrm{p} 4 \mathrm{p}$

4 reimbursement incentive

5 reimbursement incentives

6 payment incentive

7 payment incentives

8 payment reward

9 payment rewards

10 performance incentive

11 performance incentives

12 performance reward

13 performance rewards

14 performance payment

15 performance payments

16 performance based financing

17 result based payment

18 results based payment

19 result based payments

20 results based payments

21 result based funding

22 results based funding

23 result based financing

24 results based financing

Management Sciences for Health (https://www.msh.org/) (individual strategies/searches)

ID Search

1 "pay for performance"

2 "p4p"

3 "reimbursement incentive"

4 "payment incentive"

5 "payment reward"

6 "performance incentive"

7 "performance reward"

8 "performance payment"

9 "performance based financing"

10 "result based payment"

11 "result based funding"

12 "result based financing"

Centre for Global Development (https://www.cgdev.org/) (individual strategies/searches)

ID Search

1 "pay for performance"

2 "p4p"

3 "reimbursement incentive"

4 "payment incentive"

5 "payment reward"

6 "performance incentive"

7 "performance reward"

8 "performance payment"

9 "performance based financing"

10 "result based payment"

11 "result based funding"

12 "result based financing"

Deutsche Gesellschaft für Technische Zusammenarbeit (GTZ) (https://www.giz.de/de/html/index.html) (individual strategies/searches)

ID Search

1 "pay for performance"

2 "paying for performance"

3 "p4p"

4 "reimbursement incentive"

5 "reimbursement incentives"

6 "payment incentive"

7 "payment incentives" 
8 "payment reward"

9 "payment rewards"

10 "performance incentive"

11 "performance incentives"

12 "performance reward"

13 "performance rewards"

14 "performance payment"

15 "performance payments"

16 "performance based financing"

17 "result based payment"

18 "results based payment"

19 "result based payments"

20 "results based payments"

21 "result based funding"

22 "results based funding"

23 "result based financing"

24 "results based financing"

KfW Entwicklungsbank (https://www.kfw-entwicklungsbank.de/International-financing/KfW-Entwicklungsbank/) (individual strategies/ searches)

ID Search

1 pay-for-performance

2 paying-for-performance

3 p4p

4 reimbursement-incentive

5 reimbursement-incentives

6 payment-incentive

7 payment-incentives

8 payment-reward

9 payment-rewards

10 performance-incentive

11 performance-incentives

12 performance-reward

13 performance-rewards

14 performance-payment

15 performance-payments

16 performance-based-financing

17 result-based-payment

18 results-based-payment

19 result-based-payments

20 results-based-payments

21 result-based-funding

22 results-based-funding

23 result-based-financing

24 results-based-financing

Department for International Development (https://www.gov.uk/government/organisations/department-for-international-development) (individual strategies/searches)

ID Search

1 "pay for performance"

2 "p4p"

3 "reimbursement incentive"

4 "payment incentive"

5 "payment reward"

6 "performance incentive"

7 "performance reward"

8 "performance payment"

9 "performance based financing"

10 "result based payment"

11 "result based funding"

12 "result based financing" 
Global Fund to Fight AIDS (https://www.theglobalfund.org/en/) (individual strategies/searches)

ID Search

1 "pay for performance"

2 "paying for performance"

3 "p4p"

4 "reimbursement incentive"

5 "reimbursement incentives"

6 "payment incentive"

7 "payment incentives"

8 "payment reward"

9 "payment rewards"

10 "performance incentive"

11 "performance incentives"

12 "performance reward"

13 "performance rewards"

14 "performance payment"

15 "performance payments"

16 "performance based financing"

17 "result based payment"

18 "results based payment"

19 "result based payments"

20 "results based payments"

21 "result based funding"

22 "results based funding"

23 "result based financing"

24 "results based financing"

University of Cape Town (https://www.uct.ac.za/search/) (individual strategies/searches)

ID Search

1 "pay for performance"

2 "paying for performance"

3 "p4p"

4 "reimbursement incentive"

5 "reimbursement incentives"

6 "payment incentive"

7 "payment incentives"

8 "payment reward"

9 "payment rewards"

10 "performance incentive"

11 "performance incentives"

12 "performance reward"

13 "performance rewards"

14 "performance payment"

15 "performance payments"

16 "performance based financing"

17 "result based payment"

18 "results based payment"

19 "result based payments"

20 "results based payments"

21 "result based funding"

22 "results based funding"

23 "result based financing"

24 "results based financing"

Kenya Institute of Policy Analysis and Research (IPAR) (http://iparkenya.blogspot.co.uk/) (individual strategies/searches)

ID Search

1 "pay for performance"

2 "paying for performance"

3 "p4p"

4 "reimbursement incentive"

5 "reimbursement incentives"

6 "payment incentive"

Paying for performance to improve the delivery of health interventions in low- and middle-income countries (Review) 
7 "payment incentives"

8 "payment reward"

9 "payment rewards"

10 "performance incentive"

11 "performance incentives"

12 "performance reward"

13 "performance rewards"

14 "performance payment"

15 "performance payments"

16 "performance based financing"

17 "result based payment"

18 "results based payment"

19 "result based payments"

20 "results based payments"

21 "result based funding"

22 "results based funding"

23 "result based financing"

24 "results based financing"

Institute of Tropical Medicine Belgium (http://www.itg.be/E) (individual strategies/searches)

ID Search

1 pay for performance

2 paying for performance

3 p4p

4 reimbursement incentive

5 reimbursement incentives

6 payment incentive

7 payment incentives

8 payment reward

9 payment rewards

10 performance incentive

11 performance incentives

12 performance reward

13 performance rewards

14 performance payment

15 performance payments

16 performance based financing

17 result based payment

18 results based payment

19 result based payments

20 results based payments

21 result based funding

22 results based funding

23 result based financing

24 results based financing

Appendix 3. Data extraction template

\begin{tabular}{llll}
\hline Category & $\begin{array}{l}\text { Extracted } \\
\text { data }\end{array}$ & $\begin{array}{l}\text { Page/Fig- } \\
\text { ure /Lo- } \\
\text { cation in } \\
\text { Text }\end{array}$ \\
& notes \\
& \\
\hline
\end{tabular}

Doubts over inclusion?

Comment on any inclusion criteria you think this paper may

If you have serious doubts, discuss before proceeding! violate 
(Continued)

\section{General descriptors}

Name of reviewer

\begin{tabular}{ll}
\hline Date & dd/mm/yyyy \\
\hline Study ID & $\begin{array}{l}\text { surname of first author and year first full report of study } \\
\text { was published e.g. Smith 2001 }\end{array}$ \\
\hline $\begin{array}{l}\text { Other reports of this study (en- } \\
\text { tire reference) }\end{array}$ & Surname, Initial \\
\hline First author & yyyy \\
\hline Year of publication & Name; Email; Phone; Address \\
\hline Publication type &
\end{tabular}

Data repository

Funders of study

\section{Setting}

Country

Free text

\section{PBF scheme}

Exact data or NR or unclear (specify page)

Level at which PBF incentive is paid?

\begin{tabular}{|c|c|}
\hline $\begin{array}{l}\text { How are the PBF incentives } \\
\text { used and cascaded? }\end{array}$ & Describe the mechanism of payment to everyone involv \\
\hline $\begin{array}{l}\text { Scale of PBF intervention }+ \text { ra- } \\
\text { tionale }\end{array}$ & Descriptive: e.g. national to $X$ districts, or populations \\
\hline Context & E.g. urban and rural, poverty levels, etc \\
\hline Sector & E.g. public, private, mixes, faith based organizations \\
\hline $\begin{array}{l}\text { Clinical or population group } \\
\text { targeted }\end{array}$ & $\begin{array}{l}\text { E.g. MCH or TB patients or mothers attending with chil- } \\
\text { dren under } 5\end{array}$ \\
\hline \multicolumn{2}{|l|}{ Type of PBF } \\
\hline $\begin{array}{l}\text { Who set the targets/how were } \\
\text { the targets set? }\end{array}$ & $\begin{array}{l}\text { E.g. Who made the decisions re: targets and based on } \\
\text { what? }\end{array}$ \\
\hline
\end{tabular}


(Continued)

Payment frequency

\section{Payment formula}

Measurement of targets: how

and where from?

Verification mechanisms

Magnitude of incentives

Relative size of incentive

Are incentives additional to normal wage/funding?
E.g. Data source for measurement

E.g. how is the data verified, by whom?

E.g price per indicator (if table then copy in separate sheet and link)

E.g. compared to health worker salary, overall funding of health facility

Extract data on the whole scheme budget + the facility/health worker incentive elements

\begin{tabular}{l}
\hline Ancillary components: \\
\hline Increased funding \\
\hline $\begin{array}{l}\text { Increased health facility au- } \\
\text { tonomy }\end{array}$
\end{tabular}

Yes if done

\section{Training}

\section{Supervision}

\section{Supplies}

\section{Technical support}

\section{Management support}

\section{Other quality improvement} strategies

\section{Increasing salaries}

\section{Construction of new facilities}

\section{Improvements in information} systems

\section{Changes in governance, priori- \\ ty setting or rationing}

\section{Processes to involve stake- holders}

\section{Complementary demand-side incentives}

\section{Other (specify)}

\section{Overall cost}


(Continued)

Source of funding

More details

Optional to fill in

\section{Impact evaluation: Participants, meth- \\ ods, data and analysis}

\section{Type of study}

\begin{tabular}{ll}
\hline Aim of study $\quad$ Describe aim
\end{tabular}

Location of care

Sector

Urban or rural areas?

Choice of study setting selection

Describe why the study settings were chosen

\section{Data}

\section{Data collection methods}

$\begin{array}{ll}\text { Data source } & \text { E.g. house hold surveys, DHS }\end{array}$

\section{Who collected data?}

Time of baseline data collec-

tion

Time of endline data collec-

tion

Follow-up of the PBF scheme

\section{Participants}

Level at which outcomes are assessed

Description of patient-group(s)

affected by the intervention

Inclusion/exclusion criteria relating to participants

Total sample

Number of providers

Specify number of health care workers

Number of patients 
(Continued)

Number of episodes of care

Clustering level (overall)

Copy rows as much as needed to capture all clustering

Level 1

From the most macro to micro

Units per level 1

e.g. 17 households

Level 2

Units per level 2

Level 3

Units per level 3

Proportion of eligible

providers (or allocation units)

who participated in evaluation

Other setting-specific factors

that may be of relevance when

assessing external validity

\section{Analytic methods}

Unit of allocation (EPOC item:

6.1)

Unit of analysis (EPOC item:

6.2)

Power calculation (EPOC item:

6.3)

Score done if the study is powered; not done if underpow-

ered; unclear if calculation missing + COPY calculation

Type of statistical analysis

\section{Equations}

Copy it here!

\begin{tabular}{ll}
\hline Group descriptions & COPY \\
& OVER \\
& FOR EACH \\
& GROUP \\
& \\
\hline Study arm/group & Interven- \\
& tion group \\
& 1
\end{tabular}

Description of study arm/

group intervention

E.g. scheme detailed above + payments to demand side

OR control description

\section{Participant characteristics in group}


(Continued)

\section{Baseline}

Number of providers

Number of patients

Number of episodes of care

$\begin{array}{ll}\text { Notes } & \begin{array}{l}\text { Any notes on participant groups that may affect generaliz- } \\ \text { ability }\end{array}\end{array}$
ability

Clustering level (overall)

Copy rows as much as needed to capture all clustering

Level 1

e.g. households

Units per level 1

e.g. 17 households

Level 2

Units per level 2

\section{Endline (+ copy if needed for} follow up)

Number of providers

Number of patients

Number of episodes of care \begin{tabular}{ll}
\hline Notes & $\begin{array}{l}\text { Any notes on participant groups that may affect generaliz- } \\
\text { ability }\end{array}$
\end{tabular}

Clustering level (overall)

Copy rows as much as needed to capture all clustering

Level 1

e.g. households

Units per level 1

e.g. 17 households

Level 2

Units per level 2 More detail about interven-
tion

If it deviates from the normal scheme then add in more info here

\begin{tabular}{ll}
\hline Results & COPY \\
& OVER \\
& FOR EACH \\
& OUT- \\
COME
\end{tabular}

Type of outcome 
(Continued)
Specific indicator
List the exact indicator assessed

Summative findings

Interpretation of findings (direction, magnitude)

Explanatory notes

Comments from authors

E.g. what to keep in mind when interpreting

Comments from us

\section{COPY THE}

RESULTS

\section{Overall interpretation/ impli- cations}

Comments from authors

Comments from us

\section{QUALITY CRITERIA: RISK OF BIAS (Cochrane EPOC, 'Suggested risk of bias criteria for EPOC reviews', 2017)}

Risk of bias for studies with a separate control group (randomised trials; non-randomised trials; controlled before-after studies)

\section{Random sequence genera- \\ tion}

Score "Low risk" if a random component in the sequence generation process is described (e.g. Referring to a random number table). Score "High risk" when a nonrandom method is used (e.g. performed by date of admission). Non-randomised trials and controlled before-after studies should be scored "High risk". Score "Unclear risk" if not specified in the paper.

\section{Allocation concealment}

Score "Low risk" if the unit of allocation was by institution, team or professional and allocation was performed on all units at the start of the study; or if the unit of allocation was by patient or episode of care and there was some form of centralised randomisation scheme, an onsite computer system or sealed opaque envelopes were used. Controlled before-after studies should be scored "High risk". Score "Unclear risk" if not specified in the paper.

\section{Baseline outcome measure- ment similar}


(Continued)

\author{
Baseline characteristics sim- \\ ilar
}

Score "Low risk" if baseline characteristics of the study and control providers are reported and similar. Score "Unclear risk" if it is not clear in the paper (e.g. characteristics are mentioned in text but no data were presented). Score "High risk" if there is no report of characteristics in text or tables or if there are differences between control and intervention providers. Note that in some cases imbalance in patient characteristics may be due to recruitment bias whereby the provider was responsible for recruiting patients into the trial.

\section{Incomplete outcome data}

Score "Low risk" if missing outcome measures were unlikely to bias the results (e.g. the proportion of missing data was similar in the intervention and control groups or the proportion of missing data was less than the effect size i.e. unlikely to overturn the study result). Score "High risk" if missing outcome data was likely to bias the results. Score "Unclear risk" if not specified in the paper (Do not assume $100 \%$ follow up unless stated explicitly).

Score "Low risk" if the authors state explicitly that the primary outcome variables were assessed blindly, or the outcomes are objective, e.g. length of hospital stay. Primary outcomes are those variables that correspond to the primary hypothesis or question as defined by the authors. Score "High risk" if the outcomes were not assessed blindly. Score "Unclear risk" if not specified in the paper.

\author{
Protection against contami- \\ nation
}

Score "Low risk" if allocation was by community, institution or practice and it is unlikely that the control group received the intervention. Score "High risk" if it is likely that the control group received the intervention (e.g. if patients rather than professionals were randomised). Score "Unclear risk" if professionals were allocated within a clinic or practice and it is possible that communication between intervention and control professionals could have occurred (e.g. physicians within practices were allocated to intervention or control)

\begin{tabular}{ll}
\hline Selective outcome reporting & $\begin{array}{l}\text { Score "Low risk" if there is no evidence that outcomes } \\
\text { were selectively reported (e.g. all relevant outcomes in } \\
\text { the methods section are reported in the results section). } \\
\text { Score "High risk" if some important outcomes are subse- } \\
\text { quently omitted from the results. Score "Unclear risk" if } \\
\text { not specified in the paper. }\end{array}$ \\
\hline Other risks of bias & $\begin{array}{l}\text { Score "Low risk" if there is no evidence of other risk of bi- } \\
\text { ases. }\end{array}$ \\
\hline
\end{tabular}

Risk of bias for interrupted time series studies

\section{Intervention independent of other changes}

Score "Low risk" if there are compelling arguments that the intervention occurred independently of other changes over time and the outcome was not influenced by other confounding variables/historic events during study period. If Events/variables identified, note what they are. 
Shape of the intervention effect pre-specified
Score "Low risk" if point of analysis is the point of intervention OR a rational explanation for the shape of intervention effect was given by the author(s). Where appropriate, this should include an explanation if the point of analysis is NOT the point of intervention. Score "High risk" if it is clear that the condition above is not met.

\author{
Intervention unlikely to af- \\ fect data collection
}

Score "Low risk" if reported that intervention itself was unlikely to affect data collection (for example, sources and methods of data collection were the same before and after the intervention); Score "High risk" if the intervention itself was likely to affect data collection (for example, any change in source or method of data collection reported).

\section{Knowledge of the allocat- ed interventions adequately prevented during the study}

Score "Low risk" if the authors state explicitly that the primary outcome variables were assessed blindly, or the outcomes are objective, e.g. length of hospital stay. Primary outcomes are those variables that correspond to the primary hypothesis or question as defined by the authors. Score "High risk" if the outcomes were not assessed blindly. Score "Unclear risk" if not specified in the paper.

\section{Incomplete outcome data \\ adequately addressed}

Score "Low risk" if missing outcome measures were unlikely to bias the results (e.g. the proportion of missing data was similar in the pre- and post-intervention periods or the proportion of missing data was less than the effect size i.e. unlikely to overturn the study result). Score "High risk" if missing outcome data was likely to bias the results. Score "Unclear risk" if not specified in the paper (Do not assume $100 \%$ follow up unless stated explicitly).

Score "Low risk" if there is no evidence that outcomes were selectively reported (e.g. all relevant outcomes in the methods section are reported in the results section). Score "High risk" if some important outcomes are subsequently omitted from the results. Score "Unclear risk" if not specified in the paper.

Other risks of bias

Score "Low risk" if there is no evidence of other risk of biases. E.g. should consider if seasonality is an issue (i.e. if January to June comprises the pre-intervention period and July to December the post, could the "seasons' have caused a spurious effect).

Appendix 4. Comparison 1: Summary of findings tables 1-45

\section{1. Targeted measures of provider performance}

\section{1. 1. Delivery and utilization}

Table 1: Delivery and utilization of HIV-AIDS, malaria and TB services

\section{Outcome Utilization and delivery: HIV-AIDS, malaria and TB}


(Continued)

Patient Households and patients exposed to HIV/TB/malaria and seeking care at health facilities
group

Compari- Pure control group (standard practice, status quo, no additional financing)

son

Interven- Any type of paying for performance (P4P)
tion

Settings Burundi, Cameroon, China, Congo, Swaziland, Tanzania

Impact summary

$\begin{array}{ll}\begin{array}{l}\text { Nr of } \\ \text { studies }\end{array} & \begin{array}{l}\text { Certain- } \\ \text { ty of the } \\ \text { evidence } \\ \end{array} \\ & \text { (GRADE) }\end{array}$

\begin{tabular}{lll}
\hline $\begin{array}{l}\text { Provision } \\
\text { of HIV }\end{array}$ & P4P may have a desirable effect on the & 3 (Zeng \\
testing & increases in testing rates ranging from & Walque \\
(\% of per- & $6-600 \%$. & 2017, \\
sons test- & & McMahon \\
ed) & & 2016)
\end{tabular}

Low $^{1}$

Indicators assessed differently and over the course of different time points: de Walque provision of HIV testing from facility registers, Zeng \% of patients receiving test when offered and McMahon considers different populations (males, females - both pregnant and not); effects consistent at end-points of studies.

No RCT reported this outcome for this comparison.

\begin{tabular}{|c|c|c|c|c|}
\hline $\begin{array}{l}\text { Provision } \\
\text { of ART ( } \% \\
\text { of per- } \\
\text { sons re- } \\
\text { ceiving) }\end{array}$ & $\begin{array}{l}\text { P4P may have undesirable effects: ART } \\
\text { provision in the general population is not- } \\
\text { ed to decline by } 121 \% \text {; in pregnant women, } \\
\text { effects on utilization and delivery of ART at } \\
\text { health centres estimated at } 0 \text {, at hospitals }\end{array}$ & $\begin{array}{l}2 \text { (de } \\
\text { Walque } \\
2017 \\
\text { McMahon } \\
2016 \text { ) }\end{array}$ & Low $^{2}$ & $\begin{array}{l}\text { Indicators differ, and there is inconsistency } \\
\text { over time in impacts. } \\
\text { No RCT reported this outcome for this com- } \\
\text { parison. }\end{array}$ \\
\hline
\end{tabular}
$-13 \%$.

\begin{tabular}{|c|c|c|c|c|}
\hline $\begin{array}{l}\text { Provision } \\
\text { of PMTCT } \\
\text { (\% of } \\
\text { women } \\
\text { receiv- } \\
\text { ing) }\end{array}$ & $\begin{array}{l}\text { P4P may have desirable effects: the } \% \text { of } \\
\text { women receiving PMTCT ranges from }-3.8 \% \\
\text { to } 21 \% \text {. }\end{array}$ & $\begin{array}{l}2 \text { (Bin- } \\
\text { yaruka } \\
2015, \text { de } \\
\text { Walque } \\
2017)\end{array}$ & Low $^{3}$ & $\begin{array}{l}\text { Indicators differ: Binyaruka assesses PMTCT } \\
\text { in ANC clients only, de Walque at facility lev- } \\
\text { els. } \\
\text { No RCT reported this outcome for this com- } \\
\text { parison. }\end{array}$ \\
\hline
\end{tabular}

\begin{tabular}{|c|c|c|c|c|}
\hline $\begin{array}{l}\text { Bed- } \\
\text { net use } \\
\text { (\% chil- } \\
\text { dren and } \\
\text { house- } \\
\text { holds us- } \\
\text { ing bed- } \\
\text { nets) }\end{array}$ & $\begin{array}{l}\text { P4P may have undesirable effects: the ef- } \\
\text { fect of P4P on the } \% \text { of children or house- } \\
\text { holds using bednets (ranges from } 0 \text { to neg- } \\
\text { ative } 7.3 \%) \text {. }\end{array}$ & $\begin{array}{l}2 \text { (Zeng } \\
2018 a, \\
\text { Bonfrer } \\
2014 a)\end{array}$ & Low $^{4}$ & $\begin{array}{l}\text { Two distinct criteria, though targeting same } \\
\text { concept so no indirectness suspected. Au- } \\
\text { thors of one paper note ceiling effects. } \\
\text { No RCT reported this outcome for this com- } \\
\text { parison. }\end{array}$ \\
\hline $\begin{array}{l}\text { TB adher- } \\
\text { ence rate } \\
(\%)\end{array}$ & $\begin{array}{l}\text { The effects of the intervention on TB ad- } \\
\text { herence are uncertain: we note inconsis- } \\
\text { tent effects, ranging from a positive effect } \\
\text { (-2 \% reduction in loss to follow-up com- } \\
\text { pared to control) in all patients; to } 62 \% \text { in- } \\
\text { crease in loss to follow-up in smear posi- } \\
\text { tive patients. }\end{array}$ & $\begin{array}{l}2 \text { (Kliner } \\
\text { 2015, Yao } \\
2008 \text { ) }\end{array}$ & Very low 5 & $\begin{array}{l}\text { Indicators differ: one assesses defaulting in } \\
\text { general and the other in smear+ patients. } \\
\text { No RCT reported this outcome for this com- } \\
\text { parison. }\end{array}$ \\
\hline
\end{tabular}


(Continued)

Summary: Overall certainty in evidence is low; P4P may have desirable effects on the proportion of persons undergoing HIV testing, as well as PMTCT. However, it may worsen ART delivery.

1 Majority of studies with limitations for 1 or more criteria in RoB and indirectness

2Limitations for 1 or more criteria in RoB and inconsistency of indicators

3 Limitations for 1 or more criteria in RoB and indirectness

${ }^{4}$ Critical limitations for 1 or more criteria in RoB

${ }^{5}$ Critical limitations for 1 or more criteria RoB and indirectness

Table 2: Delivery and utilization of immunizations

\begin{tabular}{ll}
\hline Outcome & Utilization and delivery: Immunizations \\
\hline $\begin{array}{l}\text { Patient } \\
\text { group }\end{array}$ & Children and mothers undergoing vaccinations, reports for different age-groups \\
\hline
\end{tabular}

Compari- Pure control group (standard practice, status quo, no additional financing)

son

Interven- Any type of paying for performance (P4P)

tion

Settings Afghanistan, Argentina, Burundi, Cambodia, Cameroon, Congo, DRC, Malawi, Peru, Zambia, Zimbabwe

\begin{tabular}{|c|c|c|c|c|}
\hline & Impact summary & Nr of studies & $\begin{array}{l}\text { Certain- } \\
\text { ty of the } \\
\text { evidence } \\
\text { (GRADE) }\end{array}$ & Comments \\
\hline $\begin{array}{l}\text { Child im- } \\
\text { muniza- } \\
\text { tion: \% re- } \\
\text { ceiving at } \\
\text { least one } \\
\text { vaccine }\end{array}$ & $\begin{array}{l}\text { P4P may make little } \\
\text { to no difference to } \\
\text { outcome: effects in- } \\
\text { consistent of small } \\
\text { magnitude, ranging } \\
\text { between }-1 \text { to } 1 \% \text {. }\end{array}$ & $\begin{array}{l}2 \text { (Bonfrer 2014a, } \\
\text { Huillery 2017) }\end{array}$ & Low $^{1}$ & $\begin{array}{l}\text { Indicators assessed across different age groups, one } \\
\text { in children and one in infants. } \\
\text { Sensitivity analysis: One RCT reports positive effect } \\
1 \% \text {, moderate certainty in evidence (one study only). }\end{array}$ \\
\hline $\begin{array}{l}\text { Children } \\
\text { fully vac- } \\
\text { cinated } \\
(\%)\end{array}$ & $\begin{array}{l}\text { Effects of the inter- } \\
\text { vention are uncer- } \\
\text { tain: literature notes } \\
\text { effect sizes ranging } \\
\text { from }-18 \% \text { to } 38.9 \%\end{array}$ & $\begin{array}{l}8 \text { (Bonfrer 2014b, de } \\
\text { Walque 2017, Zeng } \\
\text { 2018a, McMahon 2016, } \\
\text { Cruzado de la Vega } \\
\text { 2017, Friedman 2016a } \\
\text { and Friedman 2016b, } \\
\text { Chansa 2015) }\end{array}$ & Low $^{2}$ & $\begin{array}{l}\text { Exact indicators differ across population groups as- } \\
\text { sessed (age groups) and ITS slope and level change } \\
\text { captured within range. } \\
\text { Sensitivity analysis: One RCT estimate at } 16.1 \% \text {, cer- } \\
\text { tainty in evidence is low (serious concerns over two or } \\
\text { more RoB criteria, one study only) }\end{array}$ \\
\hline $\begin{array}{l}\text { Children } \\
\text { receiving } \\
\text { BCG (\%) }\end{array}$ & $\begin{array}{l}\text { P4P may have small } \\
\text { desirable effects: } \\
\text { effects range from } \\
\text { small negative ef- } \\
\text { fects }(-3.4 \%) \text { to posi- } \\
\text { tive }(7 \%) \text {. }\end{array}$ & $\begin{array}{l}8 \text { (Bonfrer 2014a, Bonfr- } \\
\text { er 2014b, Falisse 2015, } \\
\text { Huillery 2017, Zeng } \\
\text { 2018a, Friedman 2016a } \\
\text { and Friedman 2016b) }\end{array}$ & Low 1 & $\begin{array}{l}\text { Exact indicators differ, summary over indicators in } \\
\text { coverage, children } 12-24 \text { months, and different time } \\
\text { points. } \\
\text { Sensitivity analysis: RCT evidence ranges between } \\
1-7 \% \text { (two studies); certainty in evidence is low (criti- } \\
\text { cal limitations RoB and indirectness.) }\end{array}$ \\
\hline
\end{tabular}


(Continued)

\begin{tabular}{|c|c|c|c|c|}
\hline $\begin{array}{l}\text { Children } \\
\text { receiving } \\
\text { DTP (\%) }\end{array}$ & $\begin{array}{l}\text { P4P may have unde- } \\
\text { sirable effects, rang- } \\
\text { ing from }-19.7 \% \text { to } \\
+9 \% \text {. }\end{array}$ & $\begin{array}{l}6 \text { (Bonfrer 2014b, } \\
\text { Falisse 2015, Zeng } \\
\text { 2018a, Friedman 2016a, } \\
\text { Matsuoka 2014) }\end{array}$ & Low $^{3}$ & $\begin{array}{l}\text { Exact indicators differ, summary draws on data across } \\
\text { coverage and } \% \text { indicators for children of different } \\
\text { age groups receiving DTP } 1,2,3 \text { and ITS slope and lev- } \\
\text { el change captured within range. }\end{array}$ \\
\hline
\end{tabular}

Sensitivity analysis: RCT effect is $6.1 \%$; certainty in evidence is low (one study, concerns over RoB)

\begin{tabular}{|c|c|c|c|c|}
\hline $\begin{array}{l}\text { Children } \\
\text { receiving } \\
\text { measles } \\
\text { vaccina- } \\
\text { tion }(\%)\end{array}$ & $\begin{array}{l}\text { P4P may have desir- } \\
\text { able effects, ranging } \\
\text { from }-5 \% \text { to } 18.7 \%\end{array}$ & $\begin{array}{l}6 \text { (Bonfrer 2014b, de } \\
\text { Walque 2017, Binyaruka } \\
\text { 2015, Friedman 2016a, } \\
\text { Friedman 2016b, Mat- } \\
\text { suoka 2014) }\end{array}$ & Low $^{3}$ & $\begin{array}{l}\text { Indirectness likely as indicators assessed across dif- } \\
\text { ferent populations and and ITS slope and level change } \\
\text { captured within range. } \\
\text { Sensitivity analysis: RCT effect is - } 3.6 \% \text {; certainty in } \\
\text { evidence is low (one study, RoB concerns). }\end{array}$ \\
\hline $\begin{array}{l}\text { Children } \\
\text { receiving } \\
\text { polio vac- } \\
\text { cination } \\
(\%)\end{array}$ & $\begin{array}{l}\text { P4P may have desir- } \\
\text { able effects, ranging } \\
\text { from }-7.1 \% \text { to }+23 \%\end{array}$ & $\begin{array}{l}7 \text { (Bonfrer 2014b, } \\
\text { Falisse 2015, McMahon } \\
\text { 2016, Binyaruka 2015, } \\
\text { de Walque 2017, Fried- } \\
\text { man 2016a and Fried- } \\
\text { man 2016b) }\end{array}$ & Low 1 & $\begin{array}{l}\text { Indicators different, ranging from coverage to \% re- } \\
\text { ceiving specified number of doses. } \\
\text { Sensitivity analysis: RCT effect is } 21 \% \text { (low certainty } \\
\text { evidence - concerns over } 1 \text { criteria among RoB and } \\
\text { one study only) }\end{array}$ \\
\hline $\begin{array}{l}\text { Children } \\
\text { receiving } \\
\text { pentava- } \\
\text { lent vacci- } \\
\text { nation }(\%)\end{array}$ & $\begin{array}{l}\text { P4P may make little } \\
\text { to no difference to } \\
\text { the outcome, with } \\
\text { effects ranging from } \\
-5.7 \% \text { to } 3.1 \%\end{array}$ & $\begin{array}{l}3 \text { (Engineer 2016, Bin- } \\
\text { yaruka 2015, McMahon } \\
\text { 2016) }\end{array}$ & Low $^{1}$ & $\begin{array}{l}\text { Sensitivity analysis: RCT effect is }-5.7 \% \text {; certainty in } \\
\text { evidence is moderate (downgraded, as one study on- } \\
\text { ly). }\end{array}$ \\
\hline $\begin{array}{l}\text { Mothers } \\
\text { receiv- } \\
\text { ing immu- } \\
\text { nizations } \\
(\%)\end{array}$ & $\begin{array}{l}\text { P4P may have desir- } \\
\text { able effects, ranging } \\
\text { from }-2.2 \% \text { to } 65.5 \%\end{array}$ & $\begin{array}{l}9 \text { (Gertler 2014, Bonfrer } \\
\text { 2014a, Bonfrer 2014b, } \\
\text { Falisse 2015, de Walque } \\
\text { 2017, Zang 2015, Zeng } \\
\text { 2018a, McMahon 2016, } \\
\text { Binyaruka 2015) }\end{array}$ & Low 4 & $\begin{array}{l}\text { Indicators are substantively different, ranging from } \\
\text { coverage rates, to \% of women vaccinated at facilities, } \\
\text { to \% of women giving birth who had received vaccine. } \\
\text { No RCT reported this outcome for this comparison. }\end{array}$ \\
\hline
\end{tabular}

Summary: Effects on overarching likelihood of children being vaccinated appear inconsistent; some vaccinations such as polio, measles, BCG may be positively affected, while others such as DTP may be negatively affected. Certainty in evidence is low.

1Limitations for 1 or more criteria in RoB and indirectness

2Limitations for 1 or more criteria in RoB and indirectness, upgraded for appreciable benefit

3Limitations for 1 or more criteria in RoB and indirectness, one study re-analysed)

${ }^{4}$ Critical limitations for 1 or more criteria in RoB and noted indirectness, +1 for potential of large effect,-1 for suspected publication bias)

Table 3: General service utilization and delivery (any, curative, outpatient)

\begin{tabular}{ll}
\hline Outcome & Utilization and delivery: general \\
\hline Patient group & Overall patients utilizing clinics \\
\hline Comparison & Pure control group (standard practice, status quo, no additional financing) \\
\hline Intervention & Any type of paying for performance (P4P)
\end{tabular}


(Continued)

Settings Burundi, Cameroon, China, Congo, Zambia

\begin{tabular}{|c|c|c|c|c|}
\hline & Impact summary & Nr of studies & $\begin{array}{l}\text { Certain- } \\
\text { ty of the } \\
\text { evidence } \\
\text { (GRADE) }\end{array}$ & Comments \\
\hline $\begin{array}{l}\text { Probability of } \\
\text { any utilization } \\
\text { (\% rate) }\end{array}$ & $\begin{array}{l}\text { P4P may make little to no difference to } \\
\text { the outcome, effects noted are consis- } \\
\text { tently positive ranging from } 2-4.2 \% \text {. }\end{array}$ & $\begin{array}{l}2 \text { (Bonfrer 2014a, } \\
\text { Friedman 2016a) }\end{array}$ & Low $^{1}$ & $\begin{array}{l}\text { Sensitivity analysis: RCT suggests } \\
\text { impacts around } 4.2 \% \text {; certainty in } \\
\text { evidence is low (concerns over RoB } \\
\text { criteria, one study only) }\end{array}$ \\
\hline $\begin{array}{l}\text { Frequency of cu- } \\
\text { rative utilization } \\
\text { (\% rate) }\end{array}$ & $\begin{array}{l}\text { P4P may have desirable effects: litera- } \\
\text { ture notes } 83 \% \text { increase in utilization. }\end{array}$ & 1 (Zeng 2018a) & Low $^{2}$ & $\begin{array}{l}\text { No RCT reported this outcome for } \\
\text { this comparison. }\end{array}$ \\
\hline $\begin{array}{l}\text { Frequency of } \\
\text { outpatient uti- } \\
\text { lization ( } \% \text { rate) }\end{array}$ & $\begin{array}{l}\text { P4P may have desirable effects, rang- } \\
\text { ing from }-3 \% \text { to up to } 15 \%\end{array}$ & $\begin{array}{l}3 \text { (Falisse 2015, } \\
\text { Zang 2015, } \\
\text { Chansa 2015) }\end{array}$ & Low $^{1}$ & $\begin{array}{l}\text { ITS slope and level change captured } \\
\text { within range. No RCT reported this } \\
\text { outcome for this comparison. }\end{array}$ \\
\hline $\begin{array}{l}\text { Frequency of all } \\
\text { visits (number of } \\
\text { visits) }\end{array}$ & $\begin{array}{l}\text { P4P may have little to no impact on } \\
\text { the outcome of interest, with effects } \\
\text { in number of total visits in range of } \\
0.8-3.6 \%\end{array}$ & $\begin{array}{l}1 \text { (Powell-Jack- } \\
\text { son 2014) }\end{array}$ & Low $^{3}$ & $\begin{array}{l}\text { No RCT reported this outcome for } \\
\text { this comparison. }\end{array}$ \\
\hline Summary: & \multicolumn{4}{|c|}{$\begin{array}{l}\text { P4P may have desirable effects of curative and outpatient utilization, however appears to make little to no differ- } \\
\text { ent to utilization or frequency of visits overall. Certainty in evidence is low. }\end{array}$} \\
\hline
\end{tabular}

${ }^{1}$ Critical limitations for 2 RoB criteria

${ }^{2}$ Concerns over 2 or more RoB criteria and suspected publication bias, one study only, upgraded for large effect

${ }^{3}$ Critical concerns over 1 RoB criterion, one study only

Table 4: Delivery and Utilization of Family Planning services

\begin{tabular}{|c|c|c|c|}
\hline Outcome & \multicolumn{3}{|l|}{ Utilization and delivery: RMNCH - family planning } \\
\hline $\begin{array}{l}\text { Patient } \\
\text { group }\end{array}$ & \multicolumn{3}{|l|}{ Women of reproductive age (15-49) in study districts. } \\
\hline $\begin{array}{l}\text { Compari- } \\
\text { son }\end{array}$ & \multicolumn{3}{|c|}{ Pure control group (standard practice, status quo, no additional financing) } \\
\hline $\begin{array}{l}\text { Interven- } \\
\text { tion }\end{array}$ & \multicolumn{3}{|l|}{ Any type of paying for performance (P4P) } \\
\hline Settings & \multicolumn{3}{|l|}{ Burundi, Cameroon, Congo, DRC, Zambia, Zimbabwe } \\
\hline & Impact summary & $\begin{array}{l}\text { Certainty } \\
\text { of the ev- } \\
\text { idence }\end{array}$ & Comments \\
\hline
\end{tabular}


(Continued)

\begin{tabular}{|c|c|c|c|c|}
\hline $\begin{array}{l}\text { Any fami- } \\
\text { ly planning } \\
\text { (\% persons } \\
\text { using any } \\
\text { method) }\end{array}$ & $\begin{array}{l}\text { Effects of the intervention are uncertain: In- } \\
\text { consistent effects on the utilization rate of } \\
\text { any contraceptives, ranging from }-6.37 \text { to } \\
6.7 \% \text { overall. }\end{array}$ & $\begin{array}{l}5 \text { (Zeng 2018a, Bin- } \\
\text { yaruka 2015, Fried- } \\
\text { man 2016a, Fried- } \\
\text { man 2016b, Huillery } \\
\text { 2017) }\end{array}$ & Low $^{1}$ & $\begin{array}{l}\text { Sensitivity analysis: Two RCT } \\
\text { report estimates suggestive of } \\
\text { no or negative impacts rang- } \\
\text { ing from }-6.3 \% \text { to } 0 \% \text {; certain- } \\
\text { ty in evidence is low (concerns } \\
\text { over RoB, two studies) }\end{array}$ \\
\hline
\end{tabular}

\begin{tabular}{|c|c|c|c|c|}
\hline $\begin{array}{l}\text { Modern } \\
\text { family plan- } \\
\text { ning uti- } \\
\text { lization (\% } \\
\text { women uti- } \\
\text { lizing mod- } \\
\text { ern meth- } \\
\text { ods) }\end{array}$ & $\begin{array}{l}\text { Overarchingly, effects of the intervention are } \\
\text { uncertain. P4P may have positive effects on } \\
\text { the coverage of modern family planning ser- } \\
\text { vices, with effects ranging from } 3.6 \text { to } 19.5 \% \text {. } \\
\text { However, effects of the intervention on facili- } \\
\text { ty utilization rates are uncertain: effects range } \\
\text { from }-20.5 \% \text { to } 36 \% \text {. }\end{array}$ & $\begin{array}{l}7 \text { (de Walque 2017, } \\
\text { Zang 2015, Fried- } \\
\text { man 2016a, Fried- } \\
\text { man 2016b, Bonfrer } \\
\text { 2014a, Falisse 2015, } \\
\text { Zeng 2018a) }\end{array}$ & Low $^{1}$ & $\begin{array}{l}\text { Sensitivity analysis: RCT esti- } \\
\text { mates relative effect of } 0.2 \% \\
\text { in household survey; certainty } \\
\text { in evidence is low (one study, } \\
\text { RoB concerns) }\end{array}$ \\
\hline $\begin{array}{l}\text { Family } \\
\text { planning } \\
\text { (\% of ser- } \\
\text { vices deliv- } \\
\text { ered) }\end{array}$ & $\begin{array}{l}\text { P4P probably improves the delivery of family } \\
\text { planning services, with effects ranging from } \\
10 \% \text { to } 300 \% \text { increase in delivery of family } \\
\text { planning services at health facility. }\end{array}$ & $\begin{array}{l}2 \text { (Friedman 2016b, } \\
\text { de Walque 2017) }\end{array}$ & $\begin{array}{l}\text { Moder- } \\
\text { ate }^{2}\end{array}$ & $\begin{array}{l}\text { No RCT reported this outcome } \\
\text { for this comparison. }\end{array}$ \\
\hline
\end{tabular}

Summary: Moderate certainty that delivery of family planning services is increasing, consistent with the positive effects noted in relation to utilization of modern family planning methods among women (low certainty). Low certainty on the use of any family planning method, however.

${ }^{1}$ Critical limitations over 2 or more RoB criteria

${ }^{2}$ Critical RoB limitation on one criterion, study design + large effect in large sample size

Table 5: Delivery and utilization of antenatal care

\begin{tabular}{|c|c|c|c|c|}
\hline Outcome & \multicolumn{4}{|c|}{ Utilization and delivery: RMNCH - antenatal care } \\
\hline $\begin{array}{l}\text { Patient } \\
\text { group }\end{array}$ & \multicolumn{4}{|c|}{ Pregnant women enrolled in study within specified time frames. } \\
\hline $\begin{array}{l}\text { Compari- } \\
\text { son }\end{array}$ & \multicolumn{4}{|c|}{ Pure control group (standard practice, status quo, no additional financing) } \\
\hline $\begin{array}{l}\text { Interven- } \\
\text { tion }\end{array}$ & \multicolumn{4}{|c|}{ Any type of paying for performance (P4P) } \\
\hline Settings & \multicolumn{4}{|c|}{$\begin{array}{l}\text { Afghanistan, Benin, Burkina Faso, Burundi, Cambodia, Cameroon, DRC, El-Salvador, India, Malawi, Peru, Rwanda, } \\
\text { Zambia, Zimbabwe }\end{array}$} \\
\hline & Impact summary & Nr of studies & $\begin{array}{l}\text { Certainty } \\
\text { of the ev- } \\
\text { idence } \\
\text { (GRADE) }\end{array}$ & Comments \\
\hline $\begin{array}{l}\text { Antenatal } \\
\text { care (\% of } \\
\text { women uti- } \\
\text { lizing ANC) }\end{array}$ & $\begin{array}{l}\mathrm{P} 4 \mathrm{P} \text { may have desirable effects, } \\
\text { ranging from }-4.9 \% \text { to } 15 \% \text {. }\end{array}$ & $\begin{array}{l}5 \text { (de Walque 2017, } \\
\text { Mohanan 2017, } \\
\text { Chansa 2015, Fried- }\end{array}$ & Low $^{1}$ & $\begin{array}{l}\text { Indicators overall consistent. ITS slope and } \\
\text { level change captured within range. } \\
\text { Sensitivity analysis: RCT estimates } 4 \% \text {, cer- } \\
\text { tainty in evidence is low (concerns over }\end{array}$ \\
\hline
\end{tabular}


(Continued)

man 2016b, Zeng

2018a)
RoB limited information and one study only).

$\begin{array}{ll}\text { Total num- } & \text { Effects of the intervention are } \\ \text { ber of ANC } & \text { uncertain: relative effects range } \\ \text { visits } & \text { from }-16.4 \% \text { to } 37.6 \% .\end{array}$

visits

\author{
7 (Gertler 2014, La- \\ garde 2015, Huillery \\ 2017, Bernal 2018, \\ Friedman 2016a, \\ Friedman 2016b, Mat- \\ suoka 2014)
}

Low $^{1}$

Some differences in indicator specifications and populations data collected in. ITS slope and level change captured within range

Sensitivity analysis: RCT estimates range from $-35 \%$ to $-4.6 \%$; certainty in evidence is low (critical limitations RoB criteria for one study, two studies overall)

\begin{tabular}{|c|c|c|c|c|}
\hline $\begin{array}{l}\text { At least one } \\
\text { ANC (uti- } \\
\text { lization } \\
\text { rates) }\end{array}$ & $\begin{array}{l}\mathrm{P} 4 \mathrm{P} \text { may have desirable effects, } \\
\text { ranging from }-1.5 \% \text { to } 26.9 \% \\
\text { (median is } 1.1 \% \text { (IQR } 3) \text { ). }\end{array}$ & $\begin{array}{l}10 \text { (Engineer 2016, } \\
\text { Bonfrer 2014a, Bonfr- } \\
\text { er 2014b, Falisse 2015, } \\
\text { Huillery 2017, Bernal } \\
\text { 2018, Friedman 2016a, } \\
\text { Friedman 2016b, Mat- } \\
\text { suoka 2014) }\end{array}$ & Low2 & $\begin{array}{l}\text { Differences in specification of indicators, } \\
\text { though not substantive. ITS slope and level } \\
\text { change captured within range. } \\
\text { Sensitivity analysis: Three RCTs suggest ef- } \\
\text { fects ranging from - } 10 \text { to }-1.5 \% \text {; certainty in } \\
\text { evidence is moderate (limitations for RoB } \\
\text { criteria) }\end{array}$ \\
\hline $\begin{array}{l}\text { At least two } \\
\text { ANC (uti- } \\
\text { lization } \\
\text { rates) }\end{array}$ & $\begin{array}{l}\text { P4P may make little to no dif- } \\
\text { ference on utilization of two or } \\
\text { more ANC visits (effects ranging } \\
\text { from }-1.1 \text { to } 1.1 \%) \text {. }\end{array}$ & $\begin{array}{l}3 \text { (de Walque 2017, } \\
\text { Zang 2015, Matsuoka } \\
\text { 2014) }\end{array}$ & Low $^{3}$ & $\begin{array}{l}\text { No RCT reported this outcome for this } \\
\text { comparison. }\end{array}$ \\
\hline $\begin{array}{l}\text { At least four } \\
\text { ANC (uti- } \\
\text { lization } \\
\text { rates) }\end{array}$ & $\begin{array}{l}\text { P4P may have desirable effects, } \\
\text { ranging from from }-5.4 \% \text { to } 27 \% \\
\text { overall (though short term im- } \\
\text { pacts estimated to be higher in } \\
\text { some cases). }\end{array}$ & $\begin{array}{l}4 \text { (Steenland 2017, } \\
\text { McMahon 2016, Fried- } \\
\text { man 2016a,Matsuoka } \\
\text { 2014) }\end{array}$ & Low $^{1}$ & $\begin{array}{l}\text { ITS slope and level change captured within } \\
\text { range. } \\
\text { Sensitivity analysis: RCT estimate is -5.4\%; } \\
\text { certainty in evidence is low (concerns over } \\
\text { RoB, } 1 \text { study only) }\end{array}$ \\
\hline $\begin{array}{l}\text { ANC from } \\
\text { qualified } \\
\text { provider } \\
\text { (utilization } \\
\text { rates) }\end{array}$ & $\begin{array}{l}\text { P4P may make little to no dif- } \\
\text { ference on utilization of ANC } \\
\text { from a qualified provider, ef- } \\
\text { fects ranging from } 2.5 \text { to } 4.7 \% \text {. }\end{array}$ & $\begin{array}{l}2 \text { (Friedman 2016a, } \\
\text { Friedman 2016b) }\end{array}$ & Low $^{1}$ & $\begin{array}{l}\text { Sensitivity analysis: RCT estimate is } 4.7 \% \text {; } \\
\text { certainty in evidence is low (concerns over } \\
\text { RoB, } 1 \text { study only) }\end{array}$ \\
\hline $\begin{array}{l}\text { Delivery of } \\
\text { iron sup- } \\
\text { plementa- } \\
\text { tion dur- } \\
\text { ing ANC (\% } \\
\text { women re- } \\
\text { ceiving) }\end{array}$ & $\begin{array}{l}\text { P4P may have undesirable ef- } \\
\text { fects, differing over the time- } \\
\text { span of assessment and also by } \\
\text { facility type; effects range be- } \\
\text { tween }-109 \% \text { to } 6 \% \text {. }\end{array}$ & $\begin{array}{l}2 \text { (McMahon 2016, } \\
\text { Cruzado de la Vega } \\
\text { 2017) }\end{array}$ & Low2 & $\begin{array}{l}\text { No RCT reported this outcome for this } \\
\text { comparison. }\end{array}$ \\
\hline $\begin{array}{l}\text { Women } \\
\text { accessing } \\
\text { care in first } \\
\text { trimester } \\
\text { (\% women } \\
\text { receiving) }\end{array}$ & $\begin{array}{l}\mathrm{P} 4 \mathrm{P} \text { may have desirable effects, } \\
\text { ranging from }-0.1 \% \text { to } 37.7 \% \text {; }\end{array}$ & $\begin{array}{l}4 \text { (Steenland 2017, } \\
\text { Bernal 2018, McMa- } \\
\text { hon 2016, Friedman } \\
\text { 2016b) }\end{array}$ & Low $^{1}$ & $\begin{array}{l}\text { No RCT reported this outcome for this } \\
\text { comparison. }\end{array}$ \\
\hline
\end{tabular}

Summary: Certainty in evidence is low overall, however it appears P4P may have positive effects on accessing ANC in general. 
${ }^{2}$ Critical limitations over 2 or more RoB criteria and indirectness

${ }^{3}$ Serious limitations over 1 criteria and lack of information in ITS

Table 6: Delivery and utilization of institutional deliveries

\begin{tabular}{ll}
\hline Outcome & Utilization and delivery: RMNCH - institutional deliveries \\
\hline $\begin{array}{l}\text { Patient } \\
\text { group }\end{array}$ & Women giving birth in study periods. \\
\hline $\begin{array}{l}\text { Compari- } \\
\text { son }\end{array}$ & Pure control group (standard practice, status quo, no additional financing) \\
\hline $\begin{array}{l}\text { Interven- } \\
\text { tion }\end{array}$ & Any type of paying for performance (P4P) \\
\hline
\end{tabular}

Settings Afghanistan, Burkina Faso, Burundi, Cambodia, Cameroon, DRC, India, Malawi, Tanzania, Zambia, Zimbabwe

\begin{tabular}{|c|c|c|c|c|}
\hline & Impact summary & Nr of studies & $\begin{array}{l}\text { Certainty } \\
\text { of the ev- } \\
\text { idence }\end{array}$ & Comments \\
\hline $\begin{array}{l}\text { Institution- } \\
\text { al delivery } \\
\text { utilization } \\
\text { (utilization } \\
\text { rate) }\end{array}$ & $\begin{array}{l}\text { Effects of the intervention } \\
\text { are uncertain, and range } \\
\text { from -3\% to } 27 \% \text { (median } \\
9.45, \text { IQR } 17.5 \text { ); majority of } \\
\text { studies reporting positive } \\
\text { effects on utilization or cov- } \\
\text { erage rates overall. }\end{array}$ & $\begin{array}{l}13 \text { (Steenland 2017, Ir 2015, } \\
\text { Huillery 2017, Friedman } \\
\text { 2016a, Friedman 2016b, } \\
\text { Bonfrer 2014a, Bonfrer } \\
\text { 2014b, Falisse 2015, Zang } \\
\text { 2015, Zeng 2018a, Mo- } \\
\text { hanan 2017, Binyaruka } \\
\text { 2015, Chansa 2015) }\end{array}$ & Very low ${ }^{1}$ & $\begin{array}{l}\text { Indicators specified differently, which in- } \\
\text { troduces issues with interpretation. ITS } \\
\text { slope and level change captured within } \\
\text { range. } \\
\text { Sensitivity analysis: Three RCTs provide } \\
\text { estimates that are inconsistent but P4P } \\
\text { may have desirable effects, range from -3 } \\
\text { to } 18.1 \% \text {; certainty in evidence is moder- } \\
\text { ate (concerns over RoB) }\end{array}$ \\
\hline $\begin{array}{l}\text { Institution- } \\
\text { al delivery: } \\
\text { C section } \\
\text { (utilization } \\
\text { rate) }\end{array}$ & $\begin{array}{l}\text { P4P may have desirable ef- } \\
\text { fects, ranging from } 2 \% \text { to } \\
146 \% \text {. }\end{array}$ & $\begin{array}{l}2 \text { (Huillery 2017, Friedman } \\
\text { 2016b) }\end{array}$ & Low2 & $\begin{array}{l}\text { Sensitivity analysis: RCT estimate is } 2 \% \text {; } \\
\text { certainty in evidence is moderate (one } \\
\text { study only) }\end{array}$ \\
\hline $\begin{array}{l}\text { Institution- } \\
\text { al delivery: } \\
\text { skilled at- } \\
\text { tendance } \\
\text { (utilization } \\
\text { rate) }\end{array}$ & $\begin{array}{l}\text { P4P may have desirable ef- } \\
\text { fects, ranging from }-5 \% \text { to } \\
42 \% \text {. }\end{array}$ & $\begin{array}{l}6 \text { (Engineer 2016, de Walque } \\
\text { 2017, McMahon 2016, Fried- } \\
\text { man 2016a, Friedman } \\
\text { 2016b, Zeng 2018a) }\end{array}$ & Low $^{3}$ & $\begin{array}{l}\text { Sensitivity analysis: Effects positive } \\
\text { across the two RCTs ( } 4 \% \text { to } 16.2 \% \text { ); cer- } \\
\text { tainty in evidence is low (RoB concerns) }\end{array}$ \\
\hline Summary: & \multicolumn{4}{|c|}{$\begin{array}{l}\text { Very low to low certainty in results surrounding overall utilization of institutional deliveries and skilled attendance at } \\
\text { these, suggestive of potential desirable effects on C-section delivery and skilled attendance at deliveries. }\end{array}$} \\
\hline
\end{tabular}

1Serious concerns over RoB, indirectness and suspected publication bias

2 Serious concerns over RoB criteria

${ }^{3}$ Concerns over more than 2 RoB criteria 
Table 7: Delivery and utilization of postnatal care

\begin{tabular}{|c|c|c|c|c|}
\hline Outcome & \multicolumn{4}{|c|}{ Utilization and delivery: RMNCH - postnatal care } \\
\hline Patient group & \multicolumn{4}{|c|}{ Women who have given birth in enrolled facilities. } \\
\hline Comparison & \multicolumn{4}{|c|}{ Pure control group (standard practice, status quo, no additional financing) } \\
\hline Intervention & \multicolumn{4}{|c|}{ Any type of paying for performance (P4P) } \\
\hline \multirow[t]{2}{*}{ Settings } & \multicolumn{4}{|c|}{ Afghanistan, Burkina Faso, DRC, India, Malawi, Tanzania, Zambia, Zimbabwe } \\
\hline & Impact summary & Nr of studies & $\begin{array}{l}\text { Certainty } \\
\text { of the ev- } \\
\text { idence }\end{array}$ & Comments \\
\hline $\begin{array}{l}\text { Postnatal care: } \\
\text { overall utiliza- } \\
\text { tion rate }\end{array}$ & $\begin{array}{l}\text { P4P may have desir- } \\
\text { able effects, ranging } \\
\text { from }-2.88 \% \text { to } 25 \% \\
\text { overall. }\end{array}$ & $\begin{array}{l}5 \text { (Steenland 2017, Mo- } \\
\text { hanan 2017, Huillery } \\
\text { 2017, Friedman 2016a, } \\
\text { Friedman 2016b) }\end{array}$ & Low $^{2}$ & $\begin{array}{l}\text { Sensitivity analysis: Three studies are RCT and } \\
\text { estimates range from - } 2 \% \text { to } 10.8 \% \text {; moderate } \\
\text { certainty in evidence (serious concerns over } 2 \\
\text { RoB criteria in one of the studies) }\end{array}$ \\
\hline $\begin{array}{l}\text { Postnatal care: } \\
\text { proportion of } \\
\text { women receiv- } \\
\text { ing skilled at- } \\
\text { tendance }\end{array}$ & $\begin{array}{l}\text { P4P may have desir- } \\
\text { able effects, ranging } \\
\text { from } 15.79 \% \text { to } 26.4 \% \text {. }\end{array}$ & $\begin{array}{l}2 \text { (Friedman 2016a, } \\
\text { Friedman 2016b) }\end{array}$ & Low $^{2}$ & $\begin{array}{l}\text { Sensitivity analysis: RCT estimate is } 15.79 \% \text {; low } \\
\text { certainty in evidence (RoB concerns and one } \\
\text { study only) }\end{array}$ \\
\hline $\begin{array}{l}\text { Postnatal care: } \\
\text { proportion of } \\
\text { women with } \\
\text { timely access }\end{array}$ & $\begin{array}{l}\text { P4P may have desir- } \\
\text { able effects, ranging } \\
\text { from }-3 \% \text { to } 25 \% \text {. }\end{array}$ & $\begin{array}{l}4 \text { (Engineer 2016, } \\
\text { McMahon 2016, Bin- } \\
\text { yaruka 2015, Fried- } \\
\text { man 2016b) }\end{array}$ & Low $^{3}$ & $\begin{array}{l}\text { Comparability of indicators compromised; some } \\
\text { estimate at facility level and other household } \\
\text { and for different time frames. } \\
\text { Sensitivity analysis: RCT result suggestive of no } \\
\text { impact (- } 0.8 \%) \text {; moderate certainty evidence } \\
\text { (one study only). }\end{array}$ \\
\hline Summary: & \multicolumn{4}{|c|}{ Low certainty in evidence overall, however indicative of potential positive effects of P4P on postnatal care. } \\
\hline
\end{tabular}

1Based on RCT - Friedman 2016b, downgraded - one study only, RoB

2Serious concerns over RoB criteria

${ }^{3}$ Serious concerns over RoB criteria and indirectness

Table 8: Delivery and utilization of child care

\begin{tabular}{ll}
\hline Outcome & Utilization and delivery: Child care \\
\hline Patient group & Households with children in study catchment areas. \\
\hline Comparison & Pure control group (standard practice, status quo, no additional financing) \\
\hline Intervention & Any type of paying for performance (P4P) \\
\hline Settings & Congo, Haiti, Malawi, Zambia \\
\hline
\end{tabular}


(Continued)

\begin{tabular}{|c|c|c|c|c|}
\hline & Impact summary & Nr of studies & $\begin{array}{l}\text { Certainty } \\
\text { of the evi- } \\
\text { dence }\end{array}$ & Comments \\
\hline $\begin{array}{l}\text { Utilization rate of } \\
\text { consultations in } \\
\text { children }\end{array}$ & $\begin{array}{l}\text { Effects of the intervention are uncertain: con- } \\
\text { sultation rates for children under } 1 \text { increasing } \\
\text { by } 9.4 \% \text {, and for those between } 1-4 \text { by } 5.7 \% \text {. }\end{array}$ & 1 (Zeng 2013) & Very low ${ }^{1}$ & $\begin{array}{l}\text { No RCT reported this out- } \\
\text { come for this comparison. }\end{array}$ \\
\hline $\begin{array}{l}\text { Utilization rate } \\
\text { of curative con- } \\
\text { sultations in chil- } \\
\text { dren }\end{array}$ & $\begin{array}{l}\text { P4P may have slight undesirable effects: esti- } \\
\text { mated at } 10.9 \% \text { reduction in utilization. }\end{array}$ & $\begin{array}{l}1 \text { (Friedman } \\
\text { 2016a) }\end{array}$ & Low $^{2}$ & Study is an RCT. \\
\hline $\begin{array}{l}\text { Vitamin A sup- } \\
\text { plementation in } \\
\text { children(rate) }\end{array}$ & $\begin{array}{l}\text { P4P may have desirable effects: consistently } \\
\text { positive impacts on children receiving vitamin } \\
\text { A supplementation; impact on rates ranging } \\
\text { between } 50 \text { to } 155 \% \text {. }\end{array}$ & $\begin{array}{l}2 \text { (Zeng 2018a, } \\
\text { McMahon } \\
\text { 2016) }\end{array}$ & Low $^{2}$ & $\begin{array}{l}\text { Indicators not directly com- } \\
\text { parable, given different esti- } \\
\text { mation (by facility or popula- } \\
\text { tion). } \\
\text { No RCT reported this out- } \\
\text { come for this comparison. }\end{array}$ \\
\hline Summary: & $\begin{array}{l}\text { Overall inconsistent effects: evidence of desirak } \\
\text { and undesirable effects for utilization of child c }\end{array}$ & $\begin{array}{l}\text { impacts for Vit } \\
\text { ultations. }\end{array}$ & A suppl & ntation, however uncertain \\
\hline
\end{tabular}

1Serious concerns over 2 or more RoB criteria, one study only

2 Serious concerns over 2 or more RoB criteria

\section{1. 2. Quality of care}

Table 9: Adherence to procedures and guidelines and adverse drug reaction management

\begin{tabular}{|c|c|c|c|c|}
\hline Outcome & \multicolumn{4}{|c|}{ Quality of care: adherence to procedures and guidelines and adverse drug reaction management } \\
\hline Patient group & \multicolumn{4}{|c|}{ Predominantly mothers and children seeking care or living in the districts where assessments occurred. } \\
\hline Comparison & \multicolumn{4}{|c|}{ Pure control group (standard practice, status quo, no additional financing) } \\
\hline Intervention & \multicolumn{4}{|c|}{ Any type of paying for performance (P4P) } \\
\hline \multirow[t]{2}{*}{ Settings } & \multicolumn{4}{|c|}{ Afghanistan, Benin, Burundi, Zambia, Zimbabwe, Multiple } \\
\hline & Impact summary & Nr of studies & $\begin{array}{l}\text { Certainty } \\
\text { of the ev- } \\
\text { idence }\end{array}$ & Comments \\
\hline $\begin{array}{l}\text { Background and } \\
\text { physical assess- } \\
\text { ment (scores } \\
\text { general, across } \\
\text { ANC, PNC, child } \\
\text { care and for oth- } \\
\text { er consultations) }\end{array}$ & $\begin{array}{l}\text { Effects of the intervention are un- } \\
\text { certain, ranging from - } 17 \% \text { to } 23 \% \\
\text { change in scores. }\end{array}$ & $\begin{array}{l}7 \text { (Friedman } \\
2016 a, \text { Fried- } \\
\text { man 2016b, En- } \\
\text { gineer 2016, La- } \\
\text { garde 2015, Bon- } \\
\text { frer 2014b, Duys- } \\
\text { burgh 2016, Das } \\
\text { 2017) }\end{array}$ & Very low 1 & $\begin{array}{l}\text { Substantial variation in specified in- } \\
\text { dicators, calculated averages across } \\
\text { a range of measures, which may not } \\
\text { be directly comparable but speak to } \\
\text { same underlying concept. } \\
\text { Sensitivity analysis: Two RCT suggest } \\
\text { impacts range from - } 17 \% \text { to } 4 \% \text {, low } \\
\text { certainty in evidence(serious con- } \\
\text { cerns over RoB). }\end{array}$ \\
\hline
\end{tabular}


(Continued)

Correct patient management by health care providers (scores in relation to ANC, child care and PNC)
Effects of the intervention are uncertain: Engineer estimates difference to be minor at $0.8 \%$, Friedman observes differences across diverse items ranging from $-75 \%$ (for management of children with anaemia) up to $225 \%$ for management of a child with HIV; Duysburgh notes similar differences from -12 to $26 \%$ change in scores.
3 (Engineer 2016, Very low 1 Sensitivity analysis: RCT estimates Friedman 2016b, impact at $0.6 \%$, moderate certainty Duysburgh 2016) evidence (one study only, no other concerns)

\begin{tabular}{|c|c|c|c|c|}
\hline $\begin{array}{l}\text { Patient coun- } \\
\text { selling (scores } \\
\text { on ANC and PNC } \\
\text { related coun- } \\
\text { selling) }\end{array}$ & $\begin{array}{l}\text { Effects of the intervention are uncer- } \\
\text { tain, ranging from - } 37 \% \text { to } 17.25 \% \\
\text { change in scores, depending on the } \\
\text { service and type of patient coun- } \\
\text { selling conducted, however high lev- } \\
\text { els of heterogeneity in the way indi- } \\
\text { cators are specified. }\end{array}$ & $\begin{array}{l}6 \text { (Friedman } \\
\text { 2016a, Friedman } \\
\text { 2016b, Engineer } \\
\text { 2016, Lagarde } \\
\text { 2015, Das 2017, } \\
\text { Duysburgh 2016) }\end{array}$ & Very low 1 & $\begin{array}{l}\text { Sensitivity analysis: RCT estimates } \\
\text { suggest impacts between }-37 \text { to } 6 \% \text {, } \\
\text { low certainty in evidence (serious } \\
\text { concerns over RoB, indirectness). }\end{array}$ \\
\hline $\begin{array}{l}\text { Quality of care } \\
\text { in delivery of im- } \\
\text { munizations in } \\
\text { ANC (\%) }\end{array}$ & $\begin{array}{l}\text { P4P may have desirable effects, rang- } \\
\text { ing from } 2.25 \% \text { to } 14 \% \text { change in } \\
\text { scores overall. }\end{array}$ & $\begin{array}{l}2 \text { (Friedman } \\
2016 a, \text { Friedman } \\
2016 b)\end{array}$ & Low 2 & $\begin{array}{l}\text { Sensitivity analysis: RCT estimates } \\
2.25 \% \text { on average; low certainty in } \\
\text { evidence (serious RoB concerns, one } \\
\text { study only) }\end{array}$ \\
\hline $\begin{array}{l}\text { Women in ANC } \\
\text { given or pre- } \\
\text { scribed folic } \\
\text { acid/iron or both } \\
(\%)\end{array}$ & $\begin{array}{l}\text { P4P may have desirable effects, rang- } \\
\text { ing from } 5.5 \% \text { to } 19.2 \% \text { change in } \\
\text { scores. }\end{array}$ & $\begin{array}{l}2 \text { (Friedman } \\
2016 a, \text { Friedman } \\
2016 b)\end{array}$ & Low $^{2}$ & $\begin{array}{l}\text { Sensitivity analysis: RCT estimates } \\
5.5 \% \text {, low certainty in evidence (seri- } \\
\text { ous RoB concerns, one study only). }\end{array}$ \\
\hline $\begin{array}{l}\text { Prescription } \\
\text { quality of care } \\
\text { (index score) }\end{array}$ & $\begin{array}{l}\text { P4P may have desirable effects, ef- } \\
\text { fects on scores in PBF groups esti- } \\
\text { mated at } 7 \% \text { change in score com- } \\
\text { pared to control. }\end{array}$ & 1 (Das 2017) & Low $^{2}$ & $\begin{array}{l}\text { No RCT reported this outcome for this } \\
\text { comparison. }\end{array}$ \\
\hline Summary: & $\begin{array}{l}\text { Very low to limited certainty in results } \\
\text { sponding positively, across three othe } \\
\text { directness. }\end{array}$ & $\begin{array}{l}\text { ss this area - } \\
\text { as effects are }\end{array}$ & $\begin{array}{l}\text { rs on } \\
\text { to be ir }\end{array}$ & $\begin{array}{l}\text { of care for ANC and prescriptions re- } \\
\text { stent though to be expected given in- }\end{array}$ \\
\hline
\end{tabular}

1Serious concerns over the RoB and indirectness

${ }^{2}$ Concerns over RoB criteria

Table 10: Human resource skills and responsiveness

\begin{tabular}{ll}
\hline Outcome & Quality of care: human resource inputs \\
\hline Patient group & Predominantly patients using RMCH and curative care services at targeted health facilities \\
\hline Comparison & Pure control group (standard practice, status quo, no additional financing) \\
\hline Intervention & Any type of paying for performance (P4P) \\
\hline Settings & Afghanistan, Benin, Burundi \\
\hline
\end{tabular}


(Continued)

\begin{tabular}{|c|c|c|c|c|}
\hline & Impact summary & Nr of studies & $\begin{array}{l}\text { Certainty of the } \\
\text { evidence }\end{array}$ & Comments \\
\hline $\begin{array}{l}\text { Staff knowl- } \\
\text { edge and skills } \\
\text { (score) }\end{array}$ & $\begin{array}{l}\text { P4P may make little to no difference, } \\
\text { effect estimated at } 0.2 \% \text { difference in } \\
\text { knowledge scores. }\end{array}$ & 1 (Engineer 2016) & Low $^{1}$ & Study is an RCT. \\
\hline $\begin{array}{l}\text { Staff respon- } \\
\text { siveness (score) }\end{array}$ & $\begin{array}{l}\text { P4P may have desirable effects, rang- } \\
\text { ing from }-2 \text { to } 49 \%\end{array}$ & $\begin{array}{l}2 \text { (Bonfrer 2014a, La- } \\
\text { garde 2015) }\end{array}$ & Very low 2 & $\begin{array}{l}\text { No RCT reported this } \\
\text { outcome for this com- } \\
\text { parison. }\end{array}$ \\
\hline Summary: & \multicolumn{4}{|c|}{$\begin{array}{l}\text { Overall very low to low certainty in evidence, however suggestive of desirable effects in relation to staff respon- } \\
\text { siveness. }\end{array}$} \\
\hline
\end{tabular}

${ }^{1}$ No concerns over RoB but imprecision likely, one study only

2 Serious concerns over RoB criteria and indirectness

Table 11: Patient knowledge outcomes and perceptions

\begin{tabular}{|c|c|c|c|c|}
\hline Outcome & \multicolumn{4}{|c|}{ Quality of care: patient outcomes and perceptions and contact and waiting time } \\
\hline $\begin{array}{l}\text { Patient } \\
\text { group }\end{array}$ & \multicolumn{4}{|c|}{ Predominantly women and households accessing care in facilities included in studies } \\
\hline $\begin{array}{l}\text { Compari- } \\
\text { son }\end{array}$ & \multicolumn{4}{|c|}{ Pure control group (standard practice, status quo, no additional financing) } \\
\hline $\begin{array}{l}\text { Interven- } \\
\text { tion }\end{array}$ & \multicolumn{4}{|l|}{ Any type of paying for performance (P4P) } \\
\hline Settings & \multicolumn{4}{|l|}{ Afghanistan, Benin, Burundi, Tanzania, Zambia } \\
\hline & Impact summary & Nr of studies & $\begin{array}{l}\text { Certainty of } \\
\text { the evidence }\end{array}$ & Comments \\
\hline $\begin{array}{l}\text { Patient } \\
\text { knowl- } \\
\text { edge } \\
\text { (score) }\end{array}$ & $\begin{array}{l}\text { P4P may have desirable effects, ranging } \\
\text { from - } 3 \% \text { to } 116 \% \text {, however majority is posi- } \\
\text { tive. Average across area is } 37 \% \text {. }\end{array}$ & 1 (Friedman 2016a) & Low $^{1}$ & Study is an RCT. \\
\hline $\begin{array}{l}\text { Contact } \\
\text { time }\end{array}$ & $\begin{array}{l}\text { P4P may make little to no difference to indi- } \\
\text { cator, effects ranging from }-5.1 \% \text { to } 5.9 \% \text {. }\end{array}$ & $\begin{array}{l}3 \text { (Engineer 2016, La- } \\
\text { garde 2015, Binyaruka } \\
2015 \text { ) }\end{array}$ & Low $^{2}$ & $\begin{array}{l}\text { Sensitivity analysis: RCT es- } \\
\text { timates at } 2.5 \% \text {; certainty } \\
\text { in evidence moderate (one } \\
\text { study only) }\end{array}$ \\
\hline $\begin{array}{l}\text { Waiting } \\
\text { time }\end{array}$ & $\begin{array}{l}\mathrm{P} 4 \mathrm{P} \text { may have undesirable effects, as in- } \\
\text { creases in dissatisfaction with waiting times } \\
\text { range from } 10.8 \text { to } 12 \% \text {. }\end{array}$ & $\begin{array}{l}2 \text { (Bonfrer 2014a, Bin- } \\
\text { yaruka 2015) }\end{array}$ & Low $^{3}$ & $\begin{array}{l}\text { No RCT reported this out- } \\
\text { come for this comparison. }\end{array}$ \\
\hline Summary: & $\begin{array}{l}\text { Low certainty in evidence overall, however in } \\
\text { fects on contact and waiting time. }\end{array}$ & cative of desirable effec & on patient kno & edge, limited to negative ef- \\
\hline
\end{tabular}


${ }^{1}$ Concerns over RoB criteria, one study only

2 Serious concerns over RoB and indirectness

3Serious concerns over RoB

Table 12: Quality scores

\begin{tabular}{|c|c|c|c|c|}
\hline Outcome & \multicolumn{4}{|c|}{ Quality of care: Quality composite scores (assessed via a mix of direct observation and patient exit interviews) } \\
\hline $\begin{array}{l}\text { Patient } \\
\text { group }\end{array}$ & \multicolumn{4}{|c|}{ Mixed groups - varies according to study and scheme. } \\
\hline $\begin{array}{l}\text { Compari- } \\
\text { son }\end{array}$ & \multicolumn{4}{|c|}{ Pure control group (standard practice, status quo, no additional financing) } \\
\hline $\begin{array}{l}\text { Interven- } \\
\text { tion }\end{array}$ & \multicolumn{4}{|l|}{ Any type of paying for performance (P4P) } \\
\hline Settings & \multicolumn{4}{|c|}{ Afghanistan, Burundi, Cameroon, Philippines, Tanzania, Zambia, Zimbabwe, Multiple } \\
\hline & Impact summary & Nr of studies & $\begin{array}{l}\text { Certainty } \\
\text { of the ev- } \\
\text { idence }\end{array}$ & Comments \\
\hline $\begin{array}{l}\text { Overall } \\
\text { composite } \\
\text { quality of } \\
\text { care score }\end{array}$ & $\begin{array}{l}\text { P4P may have desirable effects, rang- } \\
\text { ing from }-4 \% \text { to } 20 \% \text { change in scores in } \\
\text { majority of studies, one study notes out- } \\
\text { lier of } 15 \text { times increase. }\end{array}$ & $\begin{array}{l}8 \text { (Engineer 2016, } \\
\text { Bonfrer 2014a, Das } \\
\text { 2017, de Walque 2017, } \\
\text { Peabody 2011, Quim- } \\
\text { bo 2016, Friedman } \\
\text { 2016b, Zang 2015) }\end{array}$ & Low $^{1}$ & $\begin{array}{l}\text { Sensitivity analysis: Two RCTs sug- } \\
\text { gest impacts between } 1.6 \% \text { to } \\
4 \% \text {; moderate certainty evidence } \\
\text { (some concerns over RoB) }\end{array}$ \\
\hline $\begin{array}{l}\text { Quality } \\
\text { family plan- } \\
\text { ning (score) }\end{array}$ & $\begin{array}{l}\text { P4P may improve the quality of family } \\
\text { planning services (range: } 9-32 \% \text { change } \\
\text { in score increases in quality of family } \\
\text { planning scores). }\end{array}$ & $\begin{array}{l}3 \text { (Rudasingwa 2014, } \\
\text { Zang 2015) }\end{array}$ & Low $^{2}$ & $\begin{array}{l}\text { No RCT reported this outcome for } \\
\text { this comparison. }\end{array}$ \\
\hline $\begin{array}{l}\text { Quality of } \\
\text { ANC (score) }\end{array}$ & $\begin{array}{l}\text { Effects of the intervention are uncertain, } \\
\text { ranging from }-11.3 \% \text { to } 27.3 \% \text { change in } \\
\text { scores. }\end{array}$ & $\begin{array}{l}7 \text { (Friedman 2016a, } \\
\text { Friedman 2016b, de } \\
\text { Walque 2017, Zang } \\
\text { 2015, Binyaruka 2015, } \\
\text { Duysburgh 2016) }\end{array}$ & Low $^{3}$ & $\begin{array}{l}\text { Sensitivity analysis: RCT estimates } \\
\text { increase of } 4 \% \text {; low certainty in ev- } \\
\text { idence (one study, concerns over } \\
\text { RoB). }\end{array}$ \\
\hline $\begin{array}{l}\text { Quality ma- } \\
\text { ternity care } \\
\text { (score) }\end{array}$ & $\begin{array}{l}\text { P4P may have desirable effects, ranging } \\
\text { from } 6.4 \% \text { to } 31 \% \text { change in scores. }\end{array}$ & $\begin{array}{l}2 \text { (Zang 2015, Fried- } \\
\text { man 2016b) }\end{array}$ & Low2 & $\begin{array}{l}\text { No RCT reported this outcome for } \\
\text { this comparison. }\end{array}$ \\
\hline $\begin{array}{l}\text { Quality of } \\
\text { child health } \\
\text { care (score) }\end{array}$ & $\begin{array}{l}\text { P4P probably improves quality of child } \\
\text { health care scores, relative impact } \\
\text { on scores ranging from } 6.1 \% \text { to } 300 \% \\
\text { change in scores. }\end{array}$ & $\begin{array}{l}3 \text { (Friedman 2016a, } \\
\text { Friedman 2016b, } \\
\text { Duysburgh 2016) }\end{array}$ & $\begin{array}{l}\text { Moder- } \\
\text { ate }^{4}\end{array}$ & $\begin{array}{l}\text { Sensitivity analysis: RCT suggests } \\
300 \% \text {; moderate certainty evi- } \\
\text { dence (downgraded } 2 \text { - RoB con- } \\
\text { cerns, one study + upgraded for ef- } \\
\text { fect) }\end{array}$ \\
\hline $\begin{array}{l}\text { Quality of } \\
\text { outpatient } \\
\text { services } \\
\text { (score) }\end{array}$ & $\begin{array}{l}\text { Effects of the intervention are uncertain, } \\
\text { relative effect is } 23 \% \text { change in score. }\end{array}$ & 1 (Zang 2015) & Very low 5 & $\begin{array}{l}\text { No RCT reported this outcome for } \\
\text { this comparison. }\end{array}$ \\
\hline
\end{tabular}


(Continued)

\begin{tabular}{|c|c|c|c|c|}
\hline $\begin{array}{l}\text { Quality } \\
\text { of medi- } \\
\text { cine and } \\
\text { equipment } \\
\text { (score) }\end{array}$ & $\begin{array}{l}\text { P4P probably improves quality of med- } \\
\text { icine and equipment scores, effects } \\
\text { ranging from } 2.7-220 \% \text { change in scores } \\
\text { overall. }\end{array}$ & $\begin{array}{l}5 \text { (Bonfrer 2014a, } \\
\text { Friedman 2016a, } \\
\text { Friedman 2016b, } \\
\text { Duysburgh 2016, Das } \\
2017 \text { ) }\end{array}$ & $\begin{array}{l}\text { Moder- } \\
\text { ate }^{6}\end{array}$ & $\begin{array}{l}\text { Sensitivity analysis: RCT suggests } \\
220 \% \text {; moderate certainty evi- } \\
\text { dence (downgraded } 2 \text { - RoB con- } \\
\text { cerns, one study + } 1 \text { effect) }\end{array}$ \\
\hline $\begin{array}{l}\text { Quality by } \\
\text { depart- } \\
\text { ment and/ } \\
\text { or service } \\
\text { (score) }\end{array}$ & $\begin{array}{l}\text { P4P probably improves quality of care } \\
\text { scores by department, relative effects } \\
\text { vary from increases of } 39 \% \text { to } 15 \text {-fold- } \\
\text { change in score increases in the indices } \\
\text { across outpatient care, delivery room, } \\
\text { referral services, IPC and waste manage- } \\
\text { ment. }\end{array}$ & $\begin{array}{l}3 \text { (Friedman 2016a, } \\
\text { Friedman 2016b, Das } \\
2017 \text { ) }\end{array}$ & $\begin{array}{l}\text { Moder- } \\
\text { ate }^{6}\end{array}$ & $\begin{array}{l}\text { Sensitivity analysis: RCT impact } \\
\text { suggests } 15 \text { fold increase; moder- } \\
\text { ate certainty evidence (downgrad- } \\
\text { ed } 2 \text { - RoB concerns, one study }+1 \\
\text { effect) }\end{array}$ \\
\hline
\end{tabular}

Summary Family planning, maternal and child health, medicine and equipment and department quality appear to respond positively, however ANC effects are mixed. Overall certainty is moderate for few indicators only.

1Serious concerns over RoB, indirectness and potential publication bias, upgraded for large effect

2Serious concerns over RoB criteria

3Serious concerns over RoB criteria and indirectness

${ }^{4}$ Serious concerns over RoB but upgraded for large effect

5 Serious concerns over RoB criteria, one study only

${ }^{6}$ Serious concerns over RoB and indirectness, but upgraded for large effect

\section{2. Health outcomes}

Table 13: Burden of disease measures

\begin{tabular}{|c|c|c|c|c|}
\hline Outcome & \multicolumn{4}{|c|}{ Health outcomes: burden of disease measures } \\
\hline Patient group & \multicolumn{4}{|l|}{ Mothers and children. } \\
\hline Comparison & \multicolumn{4}{|c|}{ Pure control group (standard practice, status quo, no additional financing) } \\
\hline Intervention & \multicolumn{4}{|l|}{ Any type of paying for performance (P4P) } \\
\hline \multirow[t]{2}{*}{ Settings } & \multicolumn{4}{|l|}{ Argentina, Philippines } \\
\hline & Impact summary & Nr of studies & $\begin{array}{l}\text { Certainty of } \\
\text { the evidence }\end{array}$ & Comments \\
\hline $\begin{array}{l}\text { Disability adjusted } \\
\text { life-years }\end{array}$ & $\begin{array}{l}\text { P4P may avert } 25401 \text { ( } 4064-46738) \\
\text { (due to a mix of neonatal mortality and } \\
\text { low-birth weight reduction) }\end{array}$ & 1 (Gertler 2014) & Low $^{1}$ & $\begin{array}{l}\text { No RCT reported this out- } \\
\text { come for this compari- } \\
\text { son. }\end{array}$ \\
\hline
\end{tabular}

${ }^{1}$ Critical concerns over 3 RoB criteria

Table 14: Mortality and incidence of sickness 


\begin{tabular}{|c|c|c|c|c|}
\hline Outcome & \multicolumn{4}{|c|}{ Health outcomes: mortality and incidence of sickness } \\
\hline $\begin{array}{l}\text { Patient } \\
\text { group }\end{array}$ & \multicolumn{4}{|l|}{ Mothers and children } \\
\hline Comparison & \multicolumn{4}{|c|}{ Pure control group (standard practice, status quo, no additional financing) } \\
\hline $\begin{array}{l}\text { Interven- } \\
\text { tion }\end{array}$ & \multicolumn{4}{|l|}{ Any type of paying for performance (P4P) } \\
\hline Settings & \multicolumn{4}{|l|}{ Argentina, Brazil, India } \\
\hline & Impact summary & $\begin{array}{l}\text { Nr of stud- } \\
\text { ies }\end{array}$ & $\begin{array}{l}\text { Certainty } \\
\text { of the ev- } \\
\text { idence }\end{array}$ & Comments \\
\hline $\begin{array}{l}\text { Child mor- } \\
\text { tality (per } \\
1000 \text { chil- } \\
\text { dren born } \\
\text { alive) }\end{array}$ & $\begin{array}{l}\mathrm{P} 4 \mathrm{P} \text { may have desirable effects; reduction in } \\
\text { mortality ranging from } 0.2-6.5 \% \text {. }\end{array}$ & $\begin{array}{l}1 \text { (Viñuela } \\
2015)\end{array}$ & Low $^{1}$ & Study is an ITS. \\
\hline $\begin{array}{l}\text { Neonatal } \\
\text { mortality } \\
\text { (see text) }\end{array}$ & $\begin{array}{l}\text { P4P effects are inconsistent: P4P may have de- } \\
\text { sirable effects and ensure reduction in neona- } \\
\text { tal mortality in implementing clinics by up to } \\
22 \% \text {. However, another study identified in- } \\
\text { crease in region of } 6.5 \% \text { across catchment ar- } \\
\text { eas of P4P incentivized providers. }\end{array}$ & $\begin{array}{l}2 \text { (Gertler } \\
\text { 2014, Mo- } \\
\text { hanan 2017) }\end{array}$ & Low $^{2}$ & $\begin{array}{l}\text { Sensitivity analysis: RCT shows } \\
\text { slight increase in neonatal mortali- } \\
\text { ty estimated beta of } 0.0079 \text { increase } \\
\text { (standard error, } 0.0067 \text {, re-caculat- } \\
\text { ed effect } 6.5 \%) \text {, moderate certainty } \\
\text { in evidence(one study only, no sub- } \\
\text { stantive concerns). }\end{array}$ \\
\hline
\end{tabular}

Summary: Low certainty evidence, suggestive of desirable effects.

${ }^{1}$ Concerns over RoB, one study only

${ }^{2}$ Concerns over RoB

Table 15: Reproductive maternal and child health outcomes

\begin{tabular}{|c|c|c|c|c|}
\hline Outcome & \multicolumn{4}{|l|}{ Health outcomes: RMNCH outcomes } \\
\hline Patient group & \multicolumn{4}{|l|}{ Mothers and children } \\
\hline Comparison & \multicolumn{4}{|c|}{ Pure control group (standard practice, status quo, no additional financing) } \\
\hline Intervention & \multicolumn{4}{|l|}{ Any type of paying for performance (P4P) } \\
\hline Settings & \multicolumn{4}{|l|}{ Cameroon, Peru } \\
\hline & Impact summary & Nr of studies & $\begin{array}{l}\text { Certainty of the } \\
\text { evidence }\end{array}$ & Comments \\
\hline $\begin{array}{l}\text { Unwanted } \\
\text { pregnancy } \\
\text { (rate) }\end{array}$ & $\begin{array}{l}\text { Effects of the intervention are uncertain. } \\
\text { An increase of } 1 \% \text { in unwanted preg- } \\
\text { nancies noted. }\end{array}$ & 1 (Zang 2015) & Very low ${ }^{1}$ & $\begin{array}{l}\text { No RCT reported this out- } \\
\text { come for this comparison. }\end{array}$ \\
\hline
\end{tabular}


(Continued)
Reported
P4P may have desirable effects, rang-
1 (Cruzado de la Ve- Low 2
No RCT reported this out- anaemia in ing from $2-3 \%$ reduction in children with ga 2017) come for this comparison.
children $(\%)$ anaemia.

Summary:

Overall, inconsistent impacts - relatively small increase in unwanted pregnancies (very low certainty in estimate) but positive impacts on reported anaemia in children (reduction of $2-3 \%$ with low certainty).

1Serious concerns over the RoB criteria, one study only)

${ }^{2}$ Concerns over RoB, one study only)

Table 16: Tuberculosis treatment success

\begin{tabular}{llll}
\hline Primary outcome & Health outcomes: Tuberculosis treatment success & \\
\hline Patient group & Tuberculosis patients & & \\
\hline Comparison & Pure control group (standard practice, status quo, no additional financing) & Comments \\
\hline Intervention & Any type of paying for performance (P4P) & Certainty of \\
Settings & China, Swaziland & Nr of studies evidence & No RCT reported this \\
\hline & Impact summary & Lutcome for this com- \\
parison.
\end{tabular}

${ }^{1}$ Serious concerns over the RoB criteria

Table 17: Human resource inputs

\begin{tabular}{|c|c|c|c|}
\hline Outcome & \multicolumn{3}{|l|}{ Changes in resource use: human resources } \\
\hline Patient group & \multicolumn{3}{|l|}{ Schemes targeting maternal and child health. } \\
\hline Comparison & \multicolumn{3}{|c|}{ Pure control group (standard practice, status quo, no additional financing) } \\
\hline Intervention & \multicolumn{3}{|l|}{ Any type of paying for performance (P4P) } \\
\hline Settings & \multicolumn{3}{|l|}{ Cameroon, El Salvador } \\
\hline & Impact summary & $\begin{array}{l}\text { Certainty of } \\
\text { the evidence }\end{array}$ & Comments \\
\hline
\end{tabular}


(Continued)

\begin{tabular}{lllll}
$\begin{array}{l}\text { Human re- } \\
\text { source avail- } \\
\text { ability }\end{array}$ & $\begin{array}{l}\text { P4P probably has desirable effects on nurse } \\
\text { availability, approx. 1-2 extra nurses in ab- } \\
\text { solute numbers, increasing proportion of } \\
\text { qualified staff by 19-44\%. }\end{array}$ & $\begin{array}{l}\text { 2 (de Walque } \\
2017, \text { Zang 2015) }\end{array}$ & Moderate ${ }^{1}$ & $\begin{array}{l}\text { No RCT reported this out- } \\
\text { come for this compari- } \\
\text { son. }\end{array}$ \\
\hline $\begin{array}{l}\text { Curative health } \\
\text { visits per health } \\
\text { care profes- } \\
\text { sional }\end{array}$ & $\begin{array}{l}\text { Effects of the intervention are uncertain, } \\
\text { there is an estimated decrease of 66\%. }\end{array}$ & 1 (Bernal 2018) & Very low 2 & $\begin{array}{l}\text { No RCT reported this out- } \\
\text { come for this compari- } \\
\text { son. }\end{array}$ \\
\hline
\end{tabular}
Summary: $\quad$ HR availability appears to increase if targeted (moderate certainty); limited certainty in estimates on curative health visits/health professional ratio.

1Some limitations for RoB across half the studies and imprecision

2Serious limitations for RoB and for imprecision, one study only

Table 18: Medicine and equipment availability

\begin{tabular}{|c|c|c|c|c|}
\hline Outcome & \multicolumn{4}{|c|}{ Changes in resource use: Medicine and equipment } \\
\hline $\begin{array}{l}\text { Patient } \\
\text { group }\end{array}$ & \multicolumn{4}{|c|}{ Schemes targeting maternal and child health predominantly. } \\
\hline Comparison & \multicolumn{4}{|c|}{ Pure control group (standard practice, status quo, no additional financing) } \\
\hline $\begin{array}{l}\text { Interven- } \\
\text { tion }\end{array}$ & \multicolumn{4}{|c|}{ Any type of paying for performance (P4P) } \\
\hline Settings & \multicolumn{4}{|c|}{ Afghanistan, Cameroon, Tanzania, Zambia, Zimbabwe } \\
\hline & Impact summary & Nr of studies & $\begin{array}{l}\text { Certainty } \\
\text { of the ev- } \\
\text { idence }\end{array}$ & Comments \\
\hline $\begin{array}{l}\text { Equipment } \\
\text { availability } \\
\text { (index) }\end{array}$ & $\begin{array}{l}\mathrm{P} 4 \mathrm{P} \text { may have desirable effects, } \\
\text { ranging in magnitude from approx. } \\
3-308 \% \text {. }\end{array}$ & $\begin{array}{l}4 \text { (de Walque 2017, Bin- } \\
\text { yaruka 2017, Friedman } \\
\text { 2016a, Friedman 2016b) }\end{array}$ & Low $^{1}$ & $\begin{array}{l}\text { Sensitivity analysis: RCT estimate } \\
\text { is } 308 \% \text {; low certainty evidence } \\
\text { (downgraded } 2 \text { - RoB concerns) }\end{array}$ \\
\hline $\begin{array}{l}\text { Equipment } \\
\text { functionality } \\
\text { (index) }\end{array}$ & $\begin{array}{l}\text { P4P may have little to no impact on } \\
\text { the indicator, slight positive effect } \\
\text { (range } 1.4 \% \text { ) difference in equip- } \\
\text { ment functionality compared to } \\
\text { control. }\end{array}$ & 1 (Engineer 2016) & Low $^{2}$ & Study is an RCT. \\
\hline $\begin{array}{l}\text { Infrastruc- } \\
\text { ture func- } \\
\text { tionality (in- } \\
\text { dex) }\end{array}$ & $\begin{array}{l}\mathrm{P} 4 \mathrm{P} \text { may have desirable effects, } \\
\text { ranging from } 4.5 \% \text { to } 345 \% \text {. }\end{array}$ & $\begin{array}{l}3 \text { (Engineer 2016, Fried- } \\
\text { man 2016a and Fried- } \\
\text { man 2016b) }\end{array}$ & Low $^{1}$ & $\begin{array}{l}\text { Sensitivity analysis: Two RCTs sug- } \\
\text { gest impacts between } 4.5 \% \text { to } \\
345 \% \text {; low certainty in evidence } \\
\text { (downgraded due to RoB) }\end{array}$ \\
\hline $\begin{array}{l}\text { Medicine } \\
\text { availability } \\
\text { (index) }\end{array}$ & $\begin{array}{l}\mathrm{P} 4 \mathrm{P} \text { may have desirable effects, } \\
\text { ranging from } 4.3 \text { to } 977 \% \text {. }\end{array}$ & $\begin{array}{l}4 \text { (Engineer 2016, de } \\
\text { Walque 2017, Zang } \\
\text { 2015, Friedman 2016a } \\
\text { and Friedman 2016b) }\end{array}$ & Low $^{1}$ & $\begin{array}{l}\text { Sensitivity analysis: Two RCT pro- } \\
\text { vide estimates from } 0.6 \% \text { to } 200 \% \text {; } \\
\text { low certainty in evidence (down- } \\
\text { graded due to RoB). }\end{array}$ \\
\hline
\end{tabular}


(Continued)

\begin{tabular}{|c|c|c|c|c|}
\hline $\begin{array}{l}\text { Vaccine } \\
\text { availability } \\
\text { (index) }\end{array}$ & $\begin{array}{l}\text { Effects of the intervention are } \\
\text { uncertain, ranging from }-89 \% \text { to } \\
24.7 \% \text {. }\end{array}$ & $\begin{array}{l}4 \text { (de Walque 2017, Bin- } \\
\text { yaruka 2017, Friedman } \\
\text { 2016a, Friedman 2016b) }\end{array}$ & Low $^{3}$ & $\begin{array}{l}\text { Sensitivity analysis: RCT estimate is } \\
21.95 \% \text {; low certainty in evidence } \\
\text { (RoB concerns, one study) }\end{array}$ \\
\hline $\begin{array}{l}\text { Stock out } \\
\text { equipment }\end{array}$ & $\begin{array}{l}\text { P4P may have desirable effects, re- } \\
\text { duction of stock-out estimated at } \\
33 \%\end{array}$ & 1 (Binyaruka 2017) & Low 4 & $\begin{array}{l}\text { No RCT reported this outcome for } \\
\text { this comparison. }\end{array}$ \\
\hline $\begin{array}{l}\text { Stock out } \\
\text { vaccines }\end{array}$ & $\begin{array}{l}\text { P4P may have desirable effects, re- } \\
\text { duction of stock-outs estimated at } \\
47.4 \% \text {. }\end{array}$ & 1 (Binyaruka 2017) & Low 4 & $\begin{array}{l}\text { No RCT reported this outcome for } \\
\text { this comparison. }\end{array}$ \\
\hline Summary: & ainty in evidence, howev & rally suggestive of $\mathrm{de}$ & le effects. & \\
\hline
\end{tabular}

1Serious concerns over RoB and imprecision

${ }^{2}$ Concern over imprecision, one study only

3Serious concerns over RoB and imprecision, indirectness

${ }^{4}$ Serious concerns over RoB and imprecision, indirectness, one study only

\section{4. Secondary outcomes}

Table 19: Provider motivation, satisfaction, absenteeism and acceptability

\begin{tabular}{|c|c|c|c|c|}
\hline Outcome & \multicolumn{4}{|c|}{ Provider motivation, satisfaction, absenteeism and acceptability } \\
\hline Participants & \multicolumn{4}{|c|}{ Health care workers at the facilities where studies conducted. } \\
\hline Comparison & \multicolumn{4}{|c|}{ Pure control group (standard practice, status quo, no additional financing) } \\
\hline Intervention & \multicolumn{4}{|l|}{ Any type of paying for performance (P4P) } \\
\hline Settings & \multicolumn{4}{|l|}{ Afghanistan, Benin } \\
\hline & Impact summary & Nr of studies & $\begin{array}{l}\text { Certainty of } \\
\text { the evidence }\end{array}$ & Comments \\
\hline $\begin{array}{l}\text { Provider absen- } \\
\text { teeism (\%) }\end{array}$ & $\begin{array}{l}\mathrm{P} 4 \mathrm{P} \text { may have little to no effect on indica- } \\
\text { tor, estimated to range between } 0.7-2 \% \text { in- } \\
\text { creases in absenteeism rate. }\end{array}$ & 1 (Lagarde 2015) & Low $^{1}$ & $\begin{array}{l}\text { No RCT reported this } \\
\text { outcome for this com- } \\
\text { parison. }\end{array}$ \\
\hline $\begin{array}{l}\text { Provider motiva- } \\
\text { tion (score) }\end{array}$ & $\begin{array}{l}\text { P4P probably has little to no effect on indi- } \\
\text { cator. }\end{array}$ & 1 (Engineer 2016) & Moderate ${ }^{2}$ & Study is an RCT. \\
\hline $\begin{array}{l}\text { Provider satisfac- } \\
\text { tion (score) }\end{array}$ & $\begin{array}{l}\text { P4P probably has little to no effect on indi- } \\
\text { cator. }\end{array}$ & 1 (Engineer 2016) & Moderate ${ }^{2}$ & Study is an RCT. \\
\hline Summary & \multicolumn{4}{|c|}{ Certainty in evidence is low to moderate, relative effects suggestive of neutral effects overall. } \\
\hline
\end{tabular}

1 Serious concerns over RoB and imprecision, one study only

2One study only, no other concerns

Paying for performance to improve the delivery of health interventions in low- and middle-income countries (Review) 
Table 20: Patient satisfaction and acceptability

\begin{tabular}{|c|c|c|c|c|}
\hline Outcome & \multicolumn{4}{|c|}{ Patient satisfaction and acceptability (satisfaction scores) } \\
\hline Patient group & \multicolumn{4}{|c|}{ Patients that had accessed ANC, child or curative care at study facilities. } \\
\hline Comparison & \multicolumn{4}{|c|}{ Pure control group (standard practice, status quo, no additional financing) } \\
\hline Intervention & \multicolumn{4}{|l|}{ Any type of paying for performance (P4P) } \\
\hline Settings & \multicolumn{4}{|c|}{ Afghanistan, Benin, Cameroon, China, Tanzania, Zimbabwe } \\
\hline & Impact summary & $\begin{array}{l}\text { Nr of stud- } \\
\text { ies }\end{array}$ & $\begin{array}{l}\text { Certainty } \\
\text { of the ev- } \\
\text { idence }\end{array}$ & Comments \\
\hline $\begin{array}{l}\text { Patient satisfaction } \\
\text { with facility cleanli- } \\
\text { ness (score) }\end{array}$ & $\begin{array}{l}\text { P4P may have desirable effects, ranging } \\
\text { from } 19.5 \% \text { to } 30 \% \text {. }\end{array}$ & $\begin{array}{l}2 \text { (de Walque } \\
2017, \text { Das } \\
2017 \text { ) }\end{array}$ & Low $^{1}$ & $\begin{array}{l}\text { No RCT reported this out- } \\
\text { come for this comparison. }\end{array}$ \\
\hline $\begin{array}{l}\text { Patient satisfaction } \\
\text { with contact time } \\
\text { (score) }\end{array}$ & $\begin{array}{l}\text { Effects of the intervention are uncertain: } \\
\text { positive impacts (approx. } 2.25 \% \text { ) in satisfac- } \\
\text { tion score with consultation times. }\end{array}$ & 1 (Das 2017) & Very low2 2 & $\begin{array}{l}\text { No RCT reported this out- } \\
\text { come for this comparison. }\end{array}$ \\
\hline $\begin{array}{l}\text { Patient satisfaction } \\
\text { with opening hours } \\
\text { (score) }\end{array}$ & $\begin{array}{l}\text { P4P may have desirable effects, ranging } \\
\text { from under } 1 \%-17.11 \% \text { (for the opening } \\
\text { hours for ANC consultations) }\end{array}$ & $\begin{array}{l}2 \text { (de Walque } \\
2017, \text { Das } \\
2017 \text { ) }\end{array}$ & Low $^{1}$ & $\begin{array}{l}\text { No RCT reported this out- } \\
\text { come for this comparison. }\end{array}$ \\
\hline $\begin{array}{l}\text { Patient satisfaction } \\
\text { with waiting time } \\
\text { (score) }\end{array}$ & $\begin{array}{l}\text { Effects of the intervention are uncertain, } \\
\text { positive effect estimated at } 32 \% \text {. }\end{array}$ & 1 (Das 2017) & Very low ${ }^{2}$ & $\begin{array}{l}\text { No RCT reported this out- } \\
\text { come for this comparison. }\end{array}$ \\
\hline $\begin{array}{l}\text { Patient satisfaction } \\
\text { with privacy (score) }\end{array}$ & $\begin{array}{l}\text { P4P may have desirable effects, ranging } \\
\text { from } 4.6 \% \text { to } 44.6 \% \text {. }\end{array}$ & $\begin{array}{l}2 \text { (de Walque } \\
2017, \text { Das } \\
2017 \text { ) }\end{array}$ & Low $^{1}$ & $\begin{array}{l}\text { No RCT reported this out- } \\
\text { come for this comparison. }\end{array}$ \\
\hline $\begin{array}{l}\text { Overall patient satis- } \\
\text { faction with quality of } \\
\text { care (score) }\end{array}$ & $\begin{array}{l}\text { P4P may have little to no effect: slight posi- } \\
\text { tive effect reported in range of } 0.4 \% \text {. }\end{array}$ & $\begin{array}{l}1 \text { (Engineer } \\
2016)\end{array}$ & Low $^{2}$ & Study is RCT \\
\hline $\begin{array}{l}\text { Patient satisfaction } \\
\text { with staff: Communi- } \\
\text { cation (score) }\end{array}$ & $\begin{array}{l}\text { P4P may have little to no effect on the indi- } \\
\text { cator: average effects ranging from } 0.2 \% \text { to } \\
5.3 \% \text { in comparison to control (politeness of } \\
\text { staff during ANC and childcare and commu- } \\
\text { nication during delivery). }\end{array}$ & $\begin{array}{l}2 \text { (Lagarde } \\
\text { 2015, Bin- } \\
\text { yaruka 2015) }\end{array}$ & Low $^{1}$ & $\begin{array}{l}\text { No RCT reported this out- } \\
\text { come for this comparison. }\end{array}$ \\
\hline $\begin{array}{l}\text { Patient satisfaction } \\
\text { with staff: Attitude } \\
\text { (score) }\end{array}$ & $\begin{array}{l}\text { P4P may have desirable effects, ranging } \\
\text { from } 3.3 \% \text { to } 13.3 \% \text { (for ANC and curative } \\
\text { care). }\end{array}$ & $\begin{array}{l}2 \text { (Das 2017, } \\
\text { Lagarde } \\
2015)\end{array}$ & Low $^{1}$ & $\begin{array}{l}\text { No RCT reported this out- } \\
\text { come for this comparison. }\end{array}$ \\
\hline $\begin{array}{l}\text { Overall satisfaction } \\
\text { (score) }\end{array}$ & $\begin{array}{l}\text { P4P may have desirable effects, ranging } \\
\text { from }-0.05 \text { to absolute increase in scores in } \\
\text { range of } 0.6 \text { standard deviations. }\end{array}$ & $\begin{array}{l}2 \text { (Yip 2014, } \\
\text { Das 2017) }\end{array}$ & Low $^{1}$ & $\begin{array}{l}\text { Sensitivity analysis: RCT es- } \\
\text { timate between negative } \\
0.03 \% \text { and } 0.1 \% \text {, both cross- } \\
\text { ing no effect line; GRADE } \\
\text { moderate (one study only, no } \\
\text { other concerns) }\end{array}$ \\
\hline
\end{tabular}


(Continued)

${ }^{1}$ Concerns over RoB criteria

${ }^{2}$ Concerns over RoB criteria, one study only

Table 21: Impacts on overall financing and resource allocation

\begin{tabular}{|c|c|c|c|c|}
\hline Outcome & \multicolumn{4}{|c|}{ Impacts on overall financing or resource allocation } \\
\hline Patient group & \multicolumn{4}{|c|}{ Households accessing care (except for remuneration, for which health care workers are reporting) } \\
\hline Comparison & \multicolumn{4}{|c|}{ Pure control group (standard practice, status quo, no additional financing) } \\
\hline Intervention & \multicolumn{4}{|l|}{ Any type of PBF } \\
\hline Settings & \multicolumn{4}{|l|}{ China } \\
\hline & Impact summary & Nr of studies & $\begin{array}{l}\text { Certainty in evi- } \\
\text { dence }\end{array}$ & Comments \\
\hline $\begin{array}{l}\text { Expenditure on } \\
\text { medicine and } \\
\text { equipment }\end{array}$ & $\begin{array}{l}\text { P4P may have little to no effect on drug } \\
\text { expenditures for insured patients ris- } \\
\text { ing by } 2.5 \% \text {, dropping for uninsured by } \\
0.9 \% \text {. }\end{array}$ & 1 (Wu 2014) & Low $^{1}$ & $\begin{array}{l}\text { Study is an ITS. No RCT re- } \\
\text { ported this outcome for this } \\
\text { comparison. }\end{array}$ \\
\hline Summary: & \multicolumn{4}{|c|}{ Low certainty in evidence, however suggestive of slight desirable effects. } \\
\hline
\end{tabular}

1Some limited concerns over generalizability and RoB, one study only

Table 22: Management or information systems

\begin{tabular}{|c|c|c|c|c|}
\hline Outcome & Impacts on management or information systems & & & \\
\hline Patient group & Health care workers and management staff in PBF anc & control facilities & & \\
\hline Comparison & Pure control group (standard practice, status quo, no & dditional financing) & & \\
\hline Intervention & Any type of PBF & & & \\
\hline \multirow[t]{2}{*}{ Settings } & Afghanistan, Zambia & & & \\
\hline & Impact summary & Nr of studies & $\begin{array}{l}\text { Certainty in } \\
\text { evidence }\end{array}$ & Comments \\
\hline $\begin{array}{l}\text { Facility or man- } \\
\text { agerial autono- } \\
\text { my (index) }\end{array}$ & $\begin{array}{l}\text { P4P may have desirable effects, estimate on autono- } \\
\text { my index } 136 \% \text {. }\end{array}$ & $\begin{array}{l}1 \text { (Friedman } \\
2016 a)\end{array}$ & Low $^{1}$ & Study is an RCT. \\
\hline
\end{tabular}


(Continued)

Facility governance (index)
P4P may have little to no effect on the indicator, intervention group has lower mean than controls, dif-

Study is an RCT.

\begin{tabular}{|c|c|c|c|c|}
\hline $\begin{array}{l}\text { Quality of man- } \\
\text { agement (index) }\end{array}$ & $\begin{array}{l}\text { P4P may have little to no effect on the indicator, im- } \\
\text { pacts on management functionality index is posi- } \\
\text { tive, around } 0.6 \% \text {. }\end{array}$ & 1 (Engineer 2016) & Low $^{2}$ & Study is an RCT. \\
\hline Summary: & $\begin{array}{l}\text { Low certainty evidence, however suggestive of desir } \\
\text { governance and quality of management. }\end{array}$ & effects on man & au & to no effect on \\
\hline
\end{tabular}

1Downgraded for RoB, imprecision, one study only, upgraded for large effects

2Downgraded for imprecision, one study only

Table 23: Equity impacts

\begin{tabular}{|c|c|c|c|c|}
\hline Outcome & \multicolumn{4}{|c|}{ Equity-consideration: Evidence of differential impact on different parts of the population } \\
\hline Patient group & \multicolumn{4}{|c|}{ Same as for main utilization outcomes; primarily mothers and children in PBF and control districts. } \\
\hline Comparison & \multicolumn{4}{|c|}{ Pure control group (standard practice, status quo, no additional financing) } \\
\hline Intervention & \multicolumn{4}{|l|}{ Any type of PBF } \\
\hline \multirow[t]{2}{*}{ Settings } & \multicolumn{4}{|l|}{ Peru, Zimbabwe } \\
\hline & Impact summary & Nr of studies & $\begin{array}{l}\text { Certain- } \\
\text { ty in evi- } \\
\text { dence }\end{array}$ & Comments \\
\hline $\begin{array}{l}\text { Equity of child im- } \\
\text { munization deliv- } \\
\text { ery (wealth relat- } \\
\text { ed) }\end{array}$ & $\begin{array}{l}\text { P4P may have desirable effects that are pro poor, rang- } \\
\text { ing from increasing utilization of immunizations by } \\
4.5 \% \text { to } 42 \% \text { among the poorest groups in comparison } \\
\text { to wealthiest. }\end{array}$ & $\begin{array}{l}2 \text { (Cruzado } \\
\text { de la Vega } \\
2017, \text { Fried- } \\
\text { man 2016b) }\end{array}$ & Low $^{1}$ & $\begin{array}{l}\text { No RCT reported } \\
\text { this outcome for this } \\
\text { comparison. }\end{array}$ \\
\hline $\begin{array}{l}\text { Equity in ANC de- } \\
\text { livery (wealth re- } \\
\text { lated) }\end{array}$ & $\begin{array}{l}\text { P4P may have undesirable effects: impacts suggest } \\
\text { households below median wealth/poorest households } \\
\text { benefit less in ANC utilization compared to those of me- } \\
\text { dian wealth. }\end{array}$ & $\begin{array}{l}\text { 2, Friedman } \\
2016 b)\end{array}$ & Low $^{1}$ & $\begin{array}{l}\text { No RCT reported } \\
\text { this outcome for this } \\
\text { comparison. }\end{array}$ \\
\hline $\begin{array}{l}\text { Equity in institu- } \\
\text { tional delivery } \\
\text { (wealth related) }\end{array}$ & $\begin{array}{l}\text { P4P may have little to no effect, estimate suggestive } \\
\text { of slight pro-poor effect (under } 2 \% \text { compared to above } \\
\text { median wealth group). }\end{array}$ & $\begin{array}{l}1 \text { (Friedman } \\
2016 b)\end{array}$ & Low $^{2}$ & $\begin{array}{l}\text { No RCT reported } \\
\text { this outcome for this } \\
\text { comparison. }\end{array}$ \\
\hline $\begin{array}{l}\text { Equity in institu- } \\
\text { tional delivery (by } \\
\text { educational status } \\
\text { of mother) }\end{array}$ & $\begin{array}{l}\text { P4P may have little to no effect: } 0.3 \% \text { more institution- } \\
\text { al deliveries among mothers with primary education or } \\
\text { less compared to mothers with secondary education or } \\
\text { above. }\end{array}$ & $\begin{array}{l}1 \text { (Friedman } \\
2016 b)\end{array}$ & Low $^{2}$ & $\begin{array}{l}\text { No RCT reported } \\
\text { this outcome for this } \\
\text { comparison. }\end{array}$ \\
\hline Summary: & \multicolumn{4}{|c|}{$\begin{array}{l}\text { Mixed picture in relation to equity effects overall, however some desirable effects in relation to child immuniza- } \\
\text { tion, undesirable in relation to ANC. }\end{array}$} \\
\hline
\end{tabular}


1Concerns over consistent RoB and imprecision

${ }^{2}$ Concerns over RoB, one study only

\section{5. Changes in untargeted measures of provider performance}

\subsubsection{Untargeted delivery and utilization}

Table 24: Delivery and utilization of HIV-AIDS, malaria and TB services

\begin{tabular}{|c|c|c|c|c|}
\hline Outcome & \multicolumn{4}{|c|}{ Utilization and delivery: HIV-AIDS, malaria and TB } \\
\hline $\begin{array}{l}\text { Patient } \\
\text { group }\end{array}$ & \multicolumn{4}{|c|}{ Households and patients exposed to HIV/TB/malaria and seeking care at health facilities } \\
\hline Comparison & \multicolumn{4}{|c|}{ Pure control group (standard practice, status quo, no additional financing) } \\
\hline $\begin{array}{l}\text { Interven- } \\
\text { tion }\end{array}$ & \multicolumn{4}{|l|}{ Any type of PBF } \\
\hline Settings & \multicolumn{4}{|l|}{ Cameroon, Malawi } \\
\hline & Impact summary & Nr of studies & $\begin{array}{l}\text { Certainty in } \\
\text { evidence }\end{array}$ & Comments \\
\hline $\begin{array}{l}\text { Provision of } \\
\text { HIV testing } \\
\text { (\%) }\end{array}$ & $\begin{array}{l}\text { P4P may have desirable effects, rang- } \\
\text { ing from long term (-2 to } 15 \%) \text {, though } \\
\text { consistently positive at hospital levels } \\
\text { in the range of } 12-15 \% \text {. }\end{array}$ & $\begin{array}{l}1 \text { (McMahon } \\
2016)\end{array}$ & Low $^{1}$ & $\begin{array}{l}\text { Indicators assessed at different time } \\
\text { points and different health facility types. } \\
\text { No RCT reported this outcome for this } \\
\text { comparison. }\end{array}$ \\
\hline $\begin{array}{l}\text { Bednet use } \\
\text { (\%children } \\
\text { and house- } \\
\text { holds) }\end{array}$ & $\begin{array}{l}\text { P4P probably has little to no impact on } \\
\text { the outcome, effect } \\
\text { estimated at } 0.12 \% \text {. }\end{array}$ & $\begin{array}{l}1 \text { (de Walque } \\
2017)\end{array}$ & Moderate 2 & $\begin{array}{l}\text { Indicator concerns children sleeping un- } \\
\text { der a bed net. } \\
\text { No RCT reported this outcome for this } \\
\text { comparison. }\end{array}$ \\
\hline
\end{tabular}

Summary: $\quad$ Limited influence on bednet use, however may have desirable effects on provision of HIV testing.

${ }^{1}$ Non-critical limitations for 1 or more criteria in RoB, one study only

2No substantive concerns, one study only

Table 25: Untargeted delivery of services (generic)

\begin{tabular}{ll}
\hline $\begin{array}{l}\text { Primary out- } \\
\text { come }\end{array}$ & Utilization and delivery: general \\
\hline Patient group & Overall patients utilizing clinics \\
\hline Comparison & Pure control group (standard practice, status quo, no additional financing) \\
\hline Intervention & Any type of PBF \\
\hline Settings & Cambodia, China, DRC, El-Salvador, Haiti, Tanzania \\
\hline
\end{tabular}


(Continued)

\begin{tabular}{|c|c|c|c|c|}
\hline & Impact summary & $\begin{array}{l}\text { Nr of stud- } \\
\text { ies }\end{array}$ & $\begin{array}{l}\text { Certain- } \\
\text { ty in evi- } \\
\text { dence }\end{array}$ & Comments \\
\hline $\begin{array}{l}\text { Probability of } \\
\text { any utilization } \\
(\%)\end{array}$ & $\begin{array}{l}\text { P4P may have little to no effect, impacts in- } \\
\text { consistent across studies, ranging from - } 6 \\
\text { to } 2.4 \% \text { overall. }\end{array}$ & $\begin{array}{l}2 \text { (Pow- } \\
\text { ell-Jack- } \\
\text { son 2014, } \\
\text { Huillery } \\
2017 \text { ) }\end{array}$ & Low $^{1}$ & $\begin{array}{l}\text { Sensitivity analysis: RCT estimate is - } 6 \% \text {; } \\
\text { moderate certainty in evidence (one } \\
\text { study only, no further concerns). }\end{array}$ \\
\hline $\begin{array}{l}\text { Frequency of } \\
\text { curative uti- } \\
\text { lization (\%) }\end{array}$ & $\begin{array}{l}\text { Effects of the intervention are uncertain: } \\
\text { decrease overall (range of } 2 \%) \text { and in } \\
\text { women } 15-49(0.2 \%) \text {; non-significant in- } \\
\text { crease in children }<5(0.06 \%)\end{array}$ & $\begin{array}{l}1 \text { (Bernal } \\
2018)\end{array}$ & Very low 2 & $\begin{array}{l}\text { No RCT reported this outcome for this } \\
\text { comparison. }\end{array}$ \\
\hline $\begin{array}{l}\text { Frequency of } \\
\text { outpatient uti- } \\
\text { lization (\%) }\end{array}$ & $\begin{array}{l}\text { P4P may have little to no effect, range ap- } \\
\text { pears }-4 \% \text { to } 6.7 \% \text { overall, but likely small } \\
\text { effects over longer time periods. }\end{array}$ & $\begin{array}{l}4 \text { (Khim } \\
2018, \\
\text { Yip 2014, } \\
\text { Bernal } \\
2018, \text { Bin- } \\
\text { yaruka } \\
2015)\end{array}$ & Low $^{3}$ & $\begin{array}{l}\text { Differences exist in indicator specifica- } \\
\text { tion - e.g. visits per day/month. } \\
\text { Sensitivity analysis: RCT evaluation sug- } \\
\text { gests negative effects, reduction in ab- } \\
\text { solute number of patients per day range } \\
\text { of } 1 \% \text {; moderate certainty in evidence } \\
\text { (one study only, no further concerns) }\end{array}$ \\
\hline $\begin{array}{l}\text { Frequency - } \\
\text { all visits (num- } \\
\text { ber of visits) }\end{array}$ & $\begin{array}{l}\mathrm{P} 4 \mathrm{P} \text { may have little to no effect, } 2.7 \% \text { in- } \\
\text { crease in consultations for non-incen- } \\
\text { tivized services noted. }\end{array}$ & $\begin{array}{l}1 \text { (Zeng } \\
2013)\end{array}$ & Low $^{3}$ & $\begin{array}{l}\text { No RCT reported this outcome for this } \\
\text { comparison. }\end{array}$ \\
\hline $\begin{array}{l}\text { Frequency - } \\
\text { elderly visit- } \\
\mathrm{s} \text { (number of } \\
\text { visits) }\end{array}$ & $\begin{array}{l}\text { P4P may have little to no effect, increases } \\
\text { in visits in range of } 2.8-5.7 \% \text { noted. }\end{array}$ & $\begin{array}{l}2 \text { (Bernal } \\
2018 \text {, Zeng } \\
2013)\end{array}$ & Low $^{3}$ & $\begin{array}{l}\text { No RCT reported this outcome for this } \\
\text { comparison. }\end{array}$ \\
\hline Summary: & \multicolumn{4}{|c|}{ If not targeted, impacts as to be expected, P4P may have little to no effect. } \\
\hline
\end{tabular}

${ }^{1}$ Concerns over lack of comparability between indicators and RoB criteria

${ }^{2}$ Concerns over RoB criteria and potential for imprecision, one study only

${ }^{3}$ Concerns over RoB criteria

Table 26: Untargeted delivery of reproductive maternal and child health

\begin{tabular}{|c|c|c|c|}
\hline Outcome & \multicolumn{3}{|l|}{ Utilization and delivery: RMNCH - family planning } \\
\hline Patient group & \multicolumn{3}{|l|}{ Women of reproductive age (15-49) in study districts. } \\
\hline Comparison & \multicolumn{3}{|c|}{ Pure control group (standard practice, status quo, no additional financing) } \\
\hline Intervention & \multicolumn{3}{|l|}{ Any type of PBF } \\
\hline \multirow[t]{2}{*}{ Settings } & \multicolumn{3}{|l|}{ Afghanistan, Zambia } \\
\hline & Impact summary & $\begin{array}{l}\text { Certainty in } \\
\text { evidence }\end{array}$ & Comments \\
\hline
\end{tabular}

Paying for performance to improve the delivery of health interventions in low- and middle-income countries (Review) 
(Continued)

\begin{tabular}{llll}
$\begin{array}{l}\text { Family planning (\% } \\
\text { women utilizing mod- } \\
\text { ern methods) }\end{array}$ & $\begin{array}{l}\text { P4P probably has little to no effect on the } \\
\text { outcome, Negative effect, estimated at } \\
-0.1 \%\end{array}$ & 1 (Engineer 2016) & Moderate 1 \\
\hline $\begin{array}{l}\text { Family planning (\% ser- } \\
\text { vices delivered) }\end{array}$ & $\begin{array}{l}\text { P4P may have desirable effects, a 9.7\% in- } \\
\text { crease in the range of services delivered was } \\
\text { noted. }\end{array}$ & $\begin{array}{l}1 \text { (Friedman } \\
\text { 2016a) }\end{array} \quad$ Low 2
\end{tabular}

Summary: $\quad$ Non-targeted effects largely consistent with ones noted as when targeted.

$1^{1}$ o serious limitations, one study only

2Limitations noted in RoB, one study only

Table 27: Untargeted delivery and utilization of antenatal care

\begin{tabular}{|c|c|c|c|c|}
\hline Outcome & \multicolumn{4}{|c|}{ Utilization and delivery: RMNCH - antenatal care } \\
\hline Patient group & \multicolumn{4}{|c|}{ Pregnant women enrolled in study within specified time frames. } \\
\hline Comparison & \multicolumn{4}{|c|}{ Pure control group (standard practice, status quo, no additional financing) } \\
\hline Intervention & \multicolumn{4}{|l|}{ Any type of PBF } \\
\hline Settings & \multicolumn{4}{|l|}{ Burundi, Cameroon, India, Tanzania, Zambia } \\
\hline & Impact summary & $\begin{array}{l}\text { Nr of stud- } \\
\text { ies }\end{array}$ & $\begin{array}{l}\text { Certain- } \\
\text { ty in evi- } \\
\text { dence }\end{array}$ & Comments \\
\hline $\begin{array}{l}\text { Antenatal care } \\
\text { (utilization rate) }\end{array}$ & $\begin{array}{l}\text { P4P may make little to no difference to } \\
\text { the outcome: small, but not significant, } \\
\text { reduction in P4P group compared to con- } \\
\text { trol (range of } 5 \% \text { ) }\end{array}$ & $\begin{array}{l}1 \text { (Mohanan } \\
\text { 2017) }\end{array}$ & Low 1 & Study is an RCT. \\
\hline $\begin{array}{l}\text { At least one ANC } \\
\text { (utilization rates) }\end{array}$ & $\begin{array}{l}\text { Effects of the intervention are uncertain: } \\
\text { positive impact, estimated at 3.4\%. }\end{array}$ & $\begin{array}{l}1 \text { (Binyaruka } \\
2015)\end{array}$ & Very low ${ }^{2}$ & $\begin{array}{l}\text { No RCT reported this outcome for } \\
\text { this comparison. }\end{array}$ \\
\hline $\begin{array}{l}\text { At least two ANC } \\
\text { (utilization rates) }\end{array}$ & $\begin{array}{l}\text { Effects of the intervention are uncertain: } \\
\text { both substantial level and trend increases } \\
\text { and decreases noted across different dis- } \\
\text { tricts. }\end{array}$ & $\begin{array}{l}1 \text { (Khim } \\
2018)\end{array}$ & Very low ${ }^{2}$ & $\begin{array}{l}\text { Authors attribute changes more } \\
\text { to increased financing availability } \\
\text { throughout country. } \\
\text { No RCT reported this outcome for } \\
\text { this comparison. }\end{array}$ \\
\hline $\begin{array}{l}\text { At least four ANC } \\
\text { (utilization rates) }\end{array}$ & $\begin{array}{l}\text { Effects of the intervention are uncertain: } \\
\text { effect estimated at } 6 \% \text {. }\end{array}$ & $\begin{array}{l}1 \text { (Binyaruka } \\
2015)\end{array}$ & Very low ${ }^{2}$ & $\begin{array}{l}\text { No RCT reported this outcome for } \\
\text { this comparison. }\end{array}$ \\
\hline $\begin{array}{l}\text { Women access- } \\
\text { ing care in first } \\
\text { trimester (\% } \\
\text { women receiving) }\end{array}$ & $\begin{array}{l}\text { P4P may have desirable effects, ranging } \\
\text { between } 1.4 \% \text { and } 12 \% \text {. }\end{array}$ & $\begin{array}{l}2 \text { (Bonfrer } \\
2014 b, \text { Fried- } \\
\text { man 2016a) }\end{array}$ & Low $^{3}$ & $\begin{array}{l}\text { Sensitivity analysis: RCT estimate at } \\
12 \% \text { reduction in time of first ANC } \\
\text { visit; GRADE at } 2 \text { (concerns over } 2 \\
\text { RoB criteria, one study only) }\end{array}$ \\
\hline
\end{tabular}


${ }^{1}$ Concerns over RoB, one study only

${ }^{2}$ Critical concerns over more than 2 criteria, one study only

3 Critical concerns over more than 2 criteria

Table 28: Untargeted delivery of institutional deliveries

\begin{tabular}{|c|c|c|c|c|}
\hline Outcome & \multicolumn{4}{|c|}{ Utilization and delivery: RMNCH - institutional deliveries } \\
\hline Patient group & \multicolumn{4}{|l|}{ Women giving birth in study periods. } \\
\hline Comparison & \multicolumn{4}{|c|}{ Pure control group (standard practice, status quo, no additional financing) } \\
\hline Intervention & \multicolumn{4}{|l|}{ Any type of PBF } \\
\hline \multirow[t]{2}{*}{ Settings } & India, Rwanda & & & \\
\hline & Impact summary & Nr of studies & $\begin{array}{l}\text { Certainty in evi- } \\
\text { dence }\end{array}$ & Comments \\
\hline $\begin{array}{l}\text { Institutional deliv- } \\
\text { ery utilization or } \\
\text { coverage rates }\end{array}$ & $\begin{array}{l}\text { P4P may make little to no difference to } \\
\text { the outcome of interest, impact }(-2 \%) \\
\text { overall. }\end{array}$ & 1 (Mohanan 2017) & Low $^{1}$ & Study is an RCT. \\
\hline $\begin{array}{l}\text { Institutional deliv- } \\
\text { ery: C section (\%) }\end{array}$ & $\begin{array}{l}\text { Effects of the intervention are uncertain; } \\
\text { utilization of } C \text { sections decreasing by } \\
21 \% \text {. }\end{array}$ & 1 (Gertler 2014) & Very low ${ }^{2}$ & $\begin{array}{l}\text { No RCT reported this } \\
\text { outcome for this com- } \\
\text { parison. }\end{array}$ \\
\hline Summary: & \multicolumn{4}{|c|}{$\begin{array}{l}\text { Very low certainty in the impacts on institutional delivery utilization (consistent with when outcome is target- } \\
\text { ed), utilization of C-sections noted to be decreasing from an average of } 26 \% \text { to } 5 \% \text {, though unclear if impacts } \\
\text { positive. }\end{array}$} \\
\hline
\end{tabular}

1Minor RoB concerns across 2 or more criteria, one study

2 Serious concerns over 2 or more criteria, one study only

Table 29: Untargeted delivery of postnatal care

\begin{tabular}{|c|c|c|c|c|}
\hline Outcome & \multicolumn{4}{|c|}{ Utilization and delivery: RMNCH - postnatal care } \\
\hline Patient group & \multicolumn{4}{|c|}{ Women who have given birth in enrolled facilities. } \\
\hline Comparison & \multicolumn{4}{|c|}{ Pure control group (standard practice, status quo, no additional financing) } \\
\hline Intervention & \multicolumn{4}{|l|}{ Any type of PBF } \\
\hline \multirow[t]{2}{*}{ Settings } & \multicolumn{4}{|c|}{ Burundi, Cameroon, Congo, DRC, El-Salvador, India, Tanzania } \\
\hline & Impact summary & Nr of studies & $\begin{array}{l}\text { Certainty in } \\
\text { evidence }\end{array}$ & Comments \\
\hline
\end{tabular}


(Continued)

\begin{tabular}{|c|c|c|c|c|}
\hline $\begin{array}{l}\text { Delivery and cov- } \\
\text { erage of postnatal }\end{array}$ & $\begin{array}{l}\text { P4P may have desirable ef- } \\
\text { fects, ranging from } 7.2 \text { to } 85 \% \text {. }\end{array}$ & $\begin{array}{l}3 \text { (de Walque 2017, Zeng } \\
\text { 2018a, Falisse 2015) }\end{array}$ & Low $^{1}$ & $\begin{array}{l}\text { No RCT reported this outcome for } \\
\text { this comparison. }\end{array}$ \\
\hline
\end{tabular}
care

\begin{tabular}{|c|c|c|c|c|}
\hline $\begin{array}{l}\text { Postnatal care } \\
\text { (overall utilization } \\
\text { rate) }\end{array}$ & $\begin{array}{l}\text { P4P probably has undesirable } \\
\text { effects, ranging from }-8.9 \text { to } \\
-0.02 \% \text {. }\end{array}$ & $\begin{array}{l}3 \text { (Huillery 2017, de } \\
\text { Walque 2017, Mohanan } \\
\text { 2017) }\end{array}$ & Moderate 2 & $\begin{array}{l}\text { Sensitivity analysis: Two RCTs es- } \\
\text { timate impact between - } 2 \% \text { to } \\
\text {-1.4\%; moderate certainty evi- } \\
\text { dence (some concerns over RoB) }\end{array}$ \\
\hline $\begin{array}{l}\text { Postnatal care: } \\
\text { timely access ( } \% \\
\text { women receiving) }\end{array}$ & $\begin{array}{l}\text { P4P may have desirable ef- } \\
\text { fects, ranging from }-5.8 \text { to } \\
49.45 \% \text {. }\end{array}$ & $\begin{array}{l}2 \text { (Bernal 2018, Binyaru- } \\
\text { ka 2015) }\end{array}$ & Low $^{3}$ & $\begin{array}{l}\text { No RCT reported this outcome for } \\
\text { this comparison. }\end{array}$ \\
\hline
\end{tabular}

Summary: Inconsistent effects noted across this area, with limited to moderate certainty in evidence.

${ }^{1}$ Concerns over more than 2 criteria in RoB and imprecision, 2 of 3 studies non-RCT, upgraded due to large effect

2Downgraded for indirectness

${ }^{3}$ Concerns over RoB and indirectness

Table 30: Untargeted delivery of child care

\begin{tabular}{lll}
\hline Outcome & Utilization and delivery: Child care & \\
\hline Patient group & Households with children in study catchment areas. & \\
\hline Comparison & Pure control group (standard practice, status quo, no additional financing) & \\
\hline Intervention & Any type of PBF & Comments \\
\hline Settings & Tanzania & Nence \\
\hline & Impact summary in evi- & Cory low1 \\
\hline $\begin{array}{l}\text { Utilization rate of } \\
\text { consultations in } \\
\text { children }\end{array}$ & $\begin{array}{l}\text { Effects of the intervention are uncer- } \\
\text { tain: Impacts on child consultations } \\
\text { (under 5s) -18.4\% in Tanzania. }\end{array}$ & $\begin{array}{l}\text { 1 (Binyaruka 2015) } \\
\text { come for this compari- } \\
\text { son. }\end{array}$ \\
\hline $\begin{array}{l}\text { Summary: } \\
\text { Negative impacts on overall utilization of child consultations, suggesting outcome must be targeted to achieve } \\
\text { impacts; very low certainty in evidence. }\end{array}$
\end{tabular}

1Serious concerns over 2 or more RoB criteria, one study only

\section{5. 2. Untargeted quality of care}

Table 31: Adherence to procedures and guidelines and adverse drug reaction management 
(Continued)

\begin{tabular}{|c|c|c|c|c|}
\hline Patient group & \multicolumn{4}{|c|}{$\begin{array}{l}\text { Predominantly mothers and children seeking care or living in the districts where assessments oc- } \\
\text { curred. }\end{array}$} \\
\hline Comparison & \multicolumn{4}{|c|}{ Pure control group (standard practice, status quo, no additional financing) } \\
\hline Intervention & Any type of PBF & & & \\
\hline \multirow[t]{2}{*}{ Settings } & Congo, DRC & & & \\
\hline & Impact summary & Nr of studies & $\begin{array}{l}\text { Certainty in } \\
\text { evidence }\end{array}$ & Comments \\
\hline $\begin{array}{l}\text { Correct patient man- } \\
\text { agement by health care } \\
\text { providers (scores in relation } \\
\text { to ANC, child care and PNC) }\end{array}$ & $\begin{array}{l}\text { P4P probably makes little to no } \\
\text { difference to the outcome, effects } \\
\text { ranging from - } 1 \% \text { to } 4 \% \text { on items } \\
\text { assessing compliance with desired } \\
\text { postnatal care procedures. }\end{array}$ & 1 (Huillery 2017) & Moderate 1 & Study is an RCT \\
\hline $\begin{array}{l}\text { Prescription quality of care: } \\
\text { Women receiving medica- } \\
\text { tion via prescription in case } \\
\text { of illness }(\%)\end{array}$ & $\begin{array}{l}\mathrm{P} 4 \mathrm{P} \text { may have desirable effects, } \\
\text { ranging from }-8 \text { to } 20 \%\end{array}$ & $\begin{array}{l}2 \text { (Zeng 2018a, } \\
\text { Huillery 2017) }\end{array}$ & Low $^{2}$ & $\begin{array}{l}\text { Sensitivity analysis: RCT } \\
\text { suggests negative effect } \\
\text { (-8\%), moderate certain- } \\
\text { ty evidence (one study } \\
\text { only). }\end{array}$ \\
\hline
\end{tabular}

Summary:

Probably little to no effect on correct patient management, may have desirable effects on prescription quality of care.

${ }^{1}$ No serious concerns, 1 study only

${ }^{2}$ Concerns over RoB

Table 32: Human resource inputs

\begin{tabular}{|c|c|c|c|c|}
\hline Outcome & \multicolumn{4}{|l|}{ Quality of care: human resource inputs } \\
\hline Patient group & \multicolumn{4}{|c|}{ Predominantly patients using $\mathrm{RMCH}$ and curative care services at targeted health facilities } \\
\hline Comparison & \multicolumn{4}{|c|}{ Pure control group (standard practice, status quo, no additional financing) } \\
\hline Intervention & \multicolumn{4}{|l|}{ Any type of PBF } \\
\hline Settings & \multicolumn{4}{|l|}{ Benin } \\
\hline & Impact summary & Nr of studies & $\begin{array}{l}\text { Certainty in evi- } \\
\text { dence }\end{array}$ & Comments \\
\hline $\begin{array}{l}\text { Staff knowl- } \\
\text { edge and skills } \\
\text { (score) }\end{array}$ & $\begin{array}{l}\text { P4P may have little to no effect: positive on } \\
\text { clinical knowledge of staff but unclear if clin- } \\
\text { ically relevant }(2.3 \% \text { increase in vignette test } \\
\text { scores) }\end{array}$ & 1 (Lagarde 2015) & Low $^{1}$ & $\begin{array}{l}\text { No RCT reported this } \\
\text { outcome for this com- } \\
\text { parison. }\end{array}$ \\
\hline Summary: & \multicolumn{4}{|c|}{ Effects on staff knowledge consistent with when outcomes are targeted, but limited certainty. } \\
\hline
\end{tabular}


1Serious concerns over RoB

Table 33: Patient outcomes and perceptions

\begin{tabular}{llll}
\hline Outcome & Quality of care: patient outcomes and perceptions & \\
\hline Patient group & Predominantly pregnant women & & \\
\hline Comparison & Pure control group (standard practice, status quo, no additional financing) & \\
\hline Intervention & Any type of PBF & Nr of studies & Certainty in \\
\hline Settings & DRC & Commentence \\
\hline & Impact summary & Moderate1 \\
\hline $\begin{array}{l}\text { Patient knowl- } \\
\text { edge (scores) }\end{array}$ & $\begin{array}{l}\text { P4P probably has little to no effect on patient knowledge } \\
\text { tors on patient knowledge of diagnosis, danger signs and } \\
\end{array}$ & medication adherence. & 2017) \\
\hline Summary: & Consistent with impacts on the targeted outcomes. & & \\
\hline
\end{tabular}

${ }^{1}$ No serious concerns, 1 study only

Table 34: Contact and waiting time

\begin{tabular}{|c|c|c|c|c|}
\hline Outcome & \multicolumn{4}{|l|}{ Quality of care: Contact and waiting time } \\
\hline $\begin{array}{l}\text { Patient } \\
\text { group }\end{array}$ & \multicolumn{4}{|c|}{ Predominantly women and children using $\mathrm{RMCH}$ services at facilities. } \\
\hline $\begin{array}{l}\text { Compari- } \\
\text { son }\end{array}$ & \multicolumn{4}{|c|}{ Pure control group (standard practice, status quo, no additional financing) } \\
\hline $\begin{array}{l}\text { Interven- } \\
\text { tion }\end{array}$ & \multicolumn{4}{|l|}{ Any type of PBF } \\
\hline Settings & \multicolumn{4}{|l|}{ China, DRC, Tanzania } \\
\hline & Impact summary & Nr of studies & $\begin{array}{l}\text { Certain- } \\
\text { ty in evi- } \\
\text { dence }\end{array}$ & Comments \\
\hline $\begin{array}{l}\text { Contact } \\
\text { time }(\% \\
\text { change) }\end{array}$ & $\begin{array}{l}\text { P4P may have little to no effect on the } \\
\text { outcome: effects ranging from }-2.2 \% \text { to } \\
\text { positive } 1.79 \%\end{array}$ & $\begin{array}{l}2 \text { (Huillery } \\
2017 \text {, Binyaru- } \\
\text { ka 2015) }\end{array}$ & Low $^{1}$ & $\begin{array}{l}\text { Sensitivity analysis: RCT suggest positive } \\
\text { effects only, ranging from } 1.03 \text { to } 2.55 \text {; } \\
\text { moderate certainty evidence (no serious } \\
\text { concerns, one study only) }\end{array}$ \\
\hline $\begin{array}{l}\text { Waiting } \\
\text { time ( } \% \\
\text { change) }\end{array}$ & $\begin{array}{l}\text { Effects of the intervention are uncertain: } \\
20 \% \text { reduction in waiting time of untar- } \\
\text { geted services. }\end{array}$ & $\begin{array}{l}1 \text { (Binyaruka } \\
2015)\end{array}$ & Very low ${ }^{2}$ & $\begin{array}{l}\text { No RCT reported this outcome for this } \\
\text { comparison. }\end{array}$ \\
\hline
\end{tabular}


(Continued)

\begin{tabular}{|c|c|c|c|c|}
\hline $\begin{array}{l}\text { Length of } \\
\text { stay ( } \% \\
\text { change) }\end{array}$ & $\begin{array}{l}\text { P4P may have undesirable effects, ex- } \\
\text { tending length of stay relatively by } 0.05 \\
\text { to } 0.7-16 \% \text { (depending on insurance sta- } \\
\text { tus of population) }\end{array}$ & $\begin{array}{l}2 \text { (Wu 2014, } \\
\text { Huillery 2017) }\end{array}$ & Low $^{3}$ & $\begin{array}{l}\text { Sensitivity analysis: RCT estimates } 5 \% \text { in- } \\
\text { crease in length of stay; low certainty evi- } \\
\text { dence (no serious concerns, but likely im- } \\
\text { precision and one study only) }\end{array}$ \\
\hline
\end{tabular}

Summary: Similarly inconsistent effects on contact times as when indicators are targeted, however suggestive of positive effects on waiting time (i.e. waiting time is reduced) and negative effects on length of stay (i.e. this increases).

${ }^{1}$ Serious concerns over RoB and indirectness

2Serious concerns over RoB criteria, one study only

3Some concerns over several RoB criteria

Table 35: Composite quality of care scores

\begin{tabular}{|c|c|c|c|c|}
\hline Outcome & \multicolumn{4}{|l|}{ Quality of care: Quality composite scores } \\
\hline Patient group & \multicolumn{4}{|l|}{ Mixed groups - varies according to study and scheme. } \\
\hline Comparison & \multicolumn{4}{|c|}{ Pure control group (standard practice, status quo, no additional financing) } \\
\hline Intervention & \multicolumn{4}{|l|}{ Any type of PBF } \\
\hline \multirow[t]{2}{*}{ Settings } & \multicolumn{4}{|l|}{ Burundi, DRC } \\
\hline & Impact summary & Nr of studies & $\begin{array}{l}\text { Certain- } \\
\text { ty in evi- } \\
\text { dence }\end{array}$ & Comments \\
\hline $\begin{array}{l}\text { Overall composite } \\
\text { quality of care score }\end{array}$ & $\begin{array}{l}\text { P4P probably has undesirable effects, range of } \\
52 \% \text {. }\end{array}$ & $\begin{array}{l}1 \text { (Huillery } \\
2017 \text { ) }\end{array}$ & Moderate ${ }^{1}$ & Study is an RCT. \\
\hline $\begin{array}{l}\text { Quality maternity } \\
\text { care (score) }\end{array}$ & $\begin{array}{l}\text { Effects of the intervention are uncertain: } 45.6 \% \\
\text { increase in score, statistically significant. }\end{array}$ & $\begin{array}{l}1 \text { (Rudasingwa } \\
2014 \text { ) }\end{array}$ & Very low 2 & $\begin{array}{l}\text { No RCT reported this out- } \\
\text { come for this compari- } \\
\text { son. }\end{array}$ \\
\hline $\begin{array}{l}\text { Quality of out- } \\
\text { patient services } \\
\text { (score) }\end{array}$ & $\begin{array}{l}\text { Effects of the intervention are uncertain: im- } \\
\text { pact indicated at } 38 \% \text {. }\end{array}$ & $\begin{array}{l}1 \text { (Rudasingwa } \\
2014 \text { ) }\end{array}$ & Very low ${ }^{2}$ & $\begin{array}{l}\text { No RCT reported this out- } \\
\text { come for this compari- } \\
\text { son. }\end{array}$ \\
\hline $\begin{array}{l}\text { Quality of medi- } \\
\text { cine and equipment } \\
\text { (score) }\end{array}$ & $\begin{array}{l}\text { Effects of the intervention are uncertain: } \\
\text { ranges from }-14 \% \text { (material management) to } \\
8.8 \% \text { (laboratory care) impacts on scores. }\end{array}$ & $\begin{array}{l}1 \text { (Rudasingwa } \\
2014)\end{array}$ & Very low 2 & $\begin{array}{l}\text { No RCT reported this out- } \\
\text { come for this compari- } \\
\text { son. }\end{array}$ \\
\hline Summary: & $\begin{array}{l}\text { Overall, composite score is negative, suggestin } \\
\text { uncertain. }\end{array}$ & ality must be & ed to ach & impacts. Other effects are \\
\hline
\end{tabular}

${ }^{1}$ Concerns over imprecision of estimate, one study only, however magnitude high so upgraded

2Serious concerns over RoB and generalizability, one study only 
1. 6. Untargeted health outcomes

Table 36: Mortality and incidence of sickness

\begin{tabular}{|c|c|c|c|c|}
\hline Outcome & \multicolumn{4}{|c|}{ Health outcomes: mortality and incidence of sickness } \\
\hline Patient group & \multicolumn{4}{|l|}{ Mothers and children } \\
\hline Comparison & \multicolumn{4}{|c|}{ Pure control group (standard practice, status quo, no additional financing) } \\
\hline Intervention & \multicolumn{4}{|l|}{ Any type of PBF } \\
\hline Settings & \multicolumn{4}{|l|}{ DRC, India, Zambia, Zimbabwe } \\
\hline & Impact summary & Nr of studies & $\begin{array}{l}\text { Certain- } \\
\text { ty in evi- } \\
\text { dence }\end{array}$ & Comments \\
\hline $\begin{array}{l}\text { Child mortality (\% } \\
\text { of children alive still } \\
\text { from mothers giv- } \\
\text { ing birth in study } \\
\text { period) }\end{array}$ & $\begin{array}{l}\text { P4P probably has a desirable effect, achieving a } \\
\text { reduction of approx. } 1 \% \text {. }\end{array}$ & $\begin{array}{l}1 \text { (Huillery } \\
2017 \text { ) }\end{array}$ & Moderate ${ }^{1}$ & Study is an RCT. \\
\hline $\begin{array}{l}\text { Neonatal mortality } \\
\text { rate }\end{array}$ & $\begin{array}{l}\text { P4P probably has little to no effect: Small reduc- } \\
\text { tion in neonatal mortality } 0.07 \% \text {, however mod- } \\
\text { el with controls suggest possible increase } 0.3 \% \text {. }\end{array}$ & $\begin{array}{l}1 \text { (Mohanan } \\
\text { 2017) }\end{array}$ & Moderate 1 & Study is an RCT. \\
\hline $\begin{array}{l}\text { Incidence of sick- } \\
\text { ness }\end{array}$ & $\begin{array}{l}\text { P4P may have desirable effects: consistent re- } \\
\text { duction in incidence of sickness, range of }-4 \% \text { to } \\
-29 \% \text { on average. }\end{array}$ & $\begin{array}{l}2 \text { (Friedman } \\
2016 a, \text { Fried- } \\
\text { man 2016b) }\end{array}$ & Low $^{2}$ & $\begin{array}{l}\text { Sensitivity analysis: RCT } \\
\text { estimates } 4 \% \text { reduc- } \\
\text { tion, low certainty ev- } \\
\text { idence. (RoB criteria, } \\
\text { one study only) }\end{array}$ \\
\hline
\end{tabular}

Summary:

Moderate certainty evidence suggestive of reductions in child mortality, and low certainty in reduction of incidence of sickness.

1 No serious concerns, one study only

2Serious concerns over 3 RoB criteria

Table 37: Reproductive maternal and child health outcomes

\begin{tabular}{ll}
\hline Outcome & Health outcomes: RMNCH outcomes \\
\hline Patient group & Mothers and children \\
\hline Comparison & Pure control group (standard practice, status quo, no additional financing) \\
\hline Intervention & Any type of PBF \\
\hline Settings & Cameroon, DRC, Philippines \\
\hline
\end{tabular}


(Continued)

\begin{tabular}{|c|c|c|c|c|}
\hline & Impact summary & Nr of studies & $\begin{array}{l}\text { Certainty in } \\
\text { evidence }\end{array}$ & Comments \\
\hline $\begin{array}{l}\text { Child wasting } \\
(\%)\end{array}$ & $\begin{array}{l}\text { P4P probably has a desirable effect, sig- } \\
\text { nalling a reduction in wasting from } 5.9 \% \\
\text { to } 9.25 \% \text {. }\end{array}$ & $\begin{array}{l}2 \text { (de Walque } \\
2017, \text { Peabody } \\
\text { 2014) }\end{array}$ & Moderate 1 & $\begin{array}{l}\text { Sensitivity analysis: RCT estimates } \\
\text { a } 9.25 \% \text { increase in likelihood of } \\
\text { children not wasting; low certainty } \\
\text { evidence (one study only, RoB sig- } \\
\text { nificant concerns around this out- } \\
\text { come) }\end{array}$ \\
\hline $\begin{array}{l}\text { Incidence of } \\
\text { pregnancy (\%) }\end{array}$ & $\begin{array}{l}\text { P4P probably has little to no effect: } \\
\text { small reduction (1\%) in pregnancies. }\end{array}$ & 1 (Huillery 2017) & Moderate $^{2}$ & Study is an RCT. \\
\hline $\begin{array}{l}\text { Reported } \\
\text { anaemia in } \\
\text { children (\%) }\end{array}$ & $\begin{array}{l}\text { P4P probably has a desirable effect, ap- } \\
\text { prox. } 5 \% \text { reduction in anaemic children. }\end{array}$ & 1 (Peabody 2014) & Moderate $^{2}$ & Study is an RCT. \\
\hline Summary: & Moderate certainty evidence suggestive o & lesirable effects & ealth outco & , despite not being targeted. \\
\hline
\end{tabular}

${ }^{1}$ Critical concerns over 1 RoB criterion

${ }^{2}$ No serious concerns, one study only

1.7. Unintended effects

Table 38: Unintended effects

\begin{tabular}{llll}
\hline Outcome & Unintended effects & \\
\hline Patient group & Differs by study & & \\
\hline Comparison & Pure control group (standard practice, status quo, no additional financing) & & Comments \\
\hline Intervention & Any type of PBF & Nr of studies & Certainty in \\
evidence & Low1 & $\begin{array}{l}\text { Both are RCT in different popu- } \\
\text { lations: women and children vs. } \\
\text { all patients requiring antibiotic } \\
\text { based care }\end{array}$ \\
\hline $\begin{array}{l}\text { Overall impacts } \\
\text { on free riding and } \\
\text { task shifting }\end{array}$ & $\begin{array}{l}\text { P4P may make little to no differ- } \\
\text { ence to the outcome: No effects } \\
\text { or differences noted between PBF } \\
\text { groups and control. }\end{array}$ & $\begin{array}{l}\text { Y (Hip 2014) } \\
\text { Impact summary }\end{array}$ & $\begin{array}{l}\text { Certain that no unintended effects such as free-riding or task-shifting take place; consistent with findings when } \\
\text { targeted. }\end{array}$ \\
\hline \begin{tabular}{l} 
Summary: \\
\hline
\end{tabular}
\end{tabular}

${ }^{1}$ Concerns over imprecision and limited comparability of indicators

\section{8. Untargeted resource use}

Table 39: Human resources 


\begin{tabular}{|c|c|c|c|c|}
\hline Outcome & \multicolumn{4}{|l|}{ Changes in resource use: human resources } \\
\hline Patient group & \multicolumn{4}{|l|}{ Schemes targeting maternal and child health. } \\
\hline Comparison & \multicolumn{4}{|c|}{ Pure control group (standard practice, status quo, no additional financing) } \\
\hline Intervention & \multicolumn{4}{|l|}{ Any type of PBF } \\
\hline \multirow[t]{2}{*}{ Settings } & \multicolumn{4}{|l|}{ Benin } \\
\hline & Impact summary & Nr of studies & $\begin{array}{l}\text { Certainty in } \\
\text { evidence }\end{array}$ & Comments \\
\hline $\begin{array}{l}\text { Human resource avail- } \\
\text { ability (persons avail- } \\
\text { able) }\end{array}$ & $\begin{array}{l}\text { Effects of the intervention are uncertain: } \\
\text { No increase in number of qualified staff } \\
\text { available per facility is noted. }\end{array}$ & $\begin{array}{l}1 \text { (Lagarde } \\
2015)\end{array}$ & Very low ${ }^{1}$ & $\begin{array}{l}\text { No RCT reported this out- } \\
\text { come for this compari- } \\
\text { son. }\end{array}$ \\
\hline $\begin{array}{l}\text { Curative health visits } \\
\text { per health care profes- } \\
\text { sional }\end{array}$ & $\begin{array}{l}\text { Effects of the intervention are uncertain: } \\
\text { estimated increase of } 52 \% \text {. }\end{array}$ & $\begin{array}{l}1 \text { (Lagarde } \\
2015)\end{array}$ & Very low2 2 & $\begin{array}{l}\text { No RCT reported this out- } \\
\text { come for this compari- } \\
\text { son. }\end{array}$ \\
\hline Summary: & Effects of the intervention are uncertain. & & & \\
\hline
\end{tabular}

1 (serious limitations for RoB, one study only)

2(serious limitations for RoB and for imprecision)

Table 40: Medicine and equipment availability and functionality

\begin{tabular}{|c|c|c|c|c|}
\hline Outcome & \multicolumn{4}{|c|}{ Changes in resource use: Medicine and equipment } \\
\hline Patient group & \multicolumn{4}{|l|}{ Predominantly across RMNCH schemes. } \\
\hline Comparison & \multicolumn{4}{|c|}{ Pure control group (standard practice, status quo, no additional financing) } \\
\hline Intervention & \multicolumn{4}{|l|}{ Any type of PBF } \\
\hline Settings & \multicolumn{4}{|l|}{ Benin, DRC, Tanzania } \\
\hline & Impact summary & Nr of studies & $\begin{array}{l}\text { Certain- } \\
\text { ty in evi- } \\
\text { dence }\end{array}$ & Comments \\
\hline $\begin{array}{l}\text { Equipment } \\
\text { availability } \\
\text { (index) }\end{array}$ & $\begin{array}{l}\text { Effects of the intervention are uncertain: rang- } \\
\text { ing from negative }-6.4 \% \text { to positive } 6.9 \% \text {. }\end{array}$ & $\begin{array}{l}3 \text { (Lagarde 2015, } \\
\text { Huillery 2017, } \\
\text { Binyaruka 2017) }\end{array}$ & Very low ${ }^{1}$ & $\begin{array}{l}\text { Sensitivity analysis: RCT sug- } \\
\text { gests - } 64 \% \text {; low certainty ev- } \\
\text { idence (some concerns over } \\
\text { RoB and imprecision, one } \\
\text { study only) }\end{array}$ \\
\hline $\begin{array}{l}\text { Equipment } \\
\text { functionality } \\
\text { (index) }\end{array}$ & $\begin{array}{l}\text { Effects of the intervention are uncertain: small } \\
(3 \%) \text { positive effect. }\end{array}$ & $\begin{array}{l}1 \text { (Mayumana } \\
2017 \text { ) }\end{array}$ & Very low ${ }^{1}$ & $\begin{array}{l}\text { No RCT reported this outcome } \\
\text { for this comparison. }\end{array}$ \\
\hline
\end{tabular}


(Continued)

$\begin{array}{lllll}\text { Infrastructure } & \text { P4P may have little to no effect: small increase } & 1 \text { (Huillery 2017) } & \text { Low } 2 & \text { Study is an RCT. } \\ \begin{array}{ll}\text { functionality } & \text { in infrastructure functionality (magnitude not } \\ \text { (index) } & \begin{array}{l}\text { interpretable), but authors note no relevant } \\ \text { difference to control. }\end{array}\end{array}\end{array}$

\begin{tabular}{|c|c|c|c|c|}
\hline $\begin{array}{l}\text { Medicine } \\
\text { availability } \\
\text { (index) }\end{array}$ & $\begin{array}{l}\text { P4P may have desirable effects: ranging from } \\
0.6-13.8 \% \text { increases in comparison to control. }\end{array}$ & $\begin{array}{l}2 \text { (Lagarde 2015, } \\
\text { Binyaruka 2017) }\end{array}$ & Low $^{1}$ & $\begin{array}{l}\text { No RCT reported this outcome } \\
\text { for this comparison. }\end{array}$ \\
\hline $\begin{array}{l}\text { Vaccine avail- } \\
\text { ability (\%) }\end{array}$ & $\begin{array}{l}\text { Effects of the intervention are uncertain: esti- } \\
\text { mated at } 5.6 \%\end{array}$ & $\begin{array}{l}1 \text { (Binyaruka } \\
2017)\end{array}$ & Very low ${ }^{1}$ & $\begin{array}{l}\text { No RCT reported this outcome } \\
\text { for this comparison. }\end{array}$ \\
\hline $\begin{array}{l}\text { Stockout } \\
\text { equipment }\end{array}$ & $\begin{array}{l}\text { Effects of the intervention are uncertain: posi- } \\
\text { tive effect in reducing stock-outs (15\%). }\end{array}$ & $\begin{array}{l}1 \text { (Mayumana } \\
2017 \text { ) }\end{array}$ & Very low 1 & $\begin{array}{l}\text { No RCT reported this outcome } \\
\text { for this comparison. }\end{array}$ \\
\hline $\begin{array}{l}\text { Stockout } \\
\text { medicines }\end{array}$ & $\begin{array}{l}\text { Effects of the intervention are uncertain: posi- } \\
\text { tive effect in reducing stockouts (16-30\%) }\end{array}$ & $\begin{array}{l}2 \text { (Mayumana } \\
\text { 2017, Binyaruka } \\
2017 \text { ) }\end{array}$ & Very low 1 & $\begin{array}{l}\text { No RCT reported this outcome } \\
\text { for this comparison. }\end{array}$ \\
\hline $\begin{array}{l}\text { Stockout vac- } \\
\text { cines }\end{array}$ & $\begin{array}{l}\text { P4P may have desirable effects: reducing } \\
\text { stockouts (10-60\%). }\end{array}$ & $\begin{array}{l}2 \text { (Mayumana } \\
\text { 2017, Binyaruka } \\
2017 \text { ) }\end{array}$ & Low $^{3}$ & $\begin{array}{l}\text { No RCT reported this outcome } \\
\text { for this comparison. }\end{array}$ \\
\hline Summary: & $\begin{array}{l}\text { Evidence largely consistent with when indicat } \\
\text { dence base. }\end{array}$ & are targeted, tho & naller & tude and overall weaker evi- \\
\hline
\end{tabular}

1 Serious concerns over RoB and imprecision

2Concerns over imprecision, one study only

3Serious concerns over RoB and imprecision, upgrade for effect

\section{9. Untargeted secondary outcomes}

Table 41: Provider motivation, satisfaction, absenteeism and acceptability

\begin{tabular}{|c|c|c|c|c|}
\hline Outcome & \multicolumn{4}{|c|}{ Provider motivation, satisfaction, absenteeism and acceptability } \\
\hline $\begin{array}{l}\text { Partici- } \\
\text { pants }\end{array}$ & \multicolumn{4}{|c|}{ Health care workers at the facilities where studies conducted. } \\
\hline $\begin{array}{l}\text { Compari- } \\
\text { son }\end{array}$ & \multicolumn{4}{|c|}{ Pure control group (standard practice, status quo, no additional financing) } \\
\hline $\begin{array}{l}\text { Interven- } \\
\text { tion }\end{array}$ & \multicolumn{4}{|l|}{ Any type of PBF } \\
\hline \multirow[t]{2}{*}{ Settings } & \multicolumn{4}{|c|}{ Benin, Cameroon, DRC, Zambia, Zimbabwe } \\
\hline & Impact summary & Nr of studies & $\begin{array}{l}\text { Certain- } \\
\text { ty in evi- } \\
\text { dence }\end{array}$ & Comments \\
\hline
\end{tabular}


(Continued)

\begin{tabular}{|c|c|c|c|c|}
\hline $\begin{array}{l}\text { Provider at- } \\
\text { tendance }\end{array}$ & $\begin{array}{l}\text { P4P probably has a desirable effect, } \\
\text { estimated at } 7 \% \text {, though not differ- }\end{array}$ & 1 (Huillery 2017) & $\begin{array}{l}\text { Moder- } \\
\text { ate } 1\end{array}$ & Study is RCT \\
\hline
\end{tabular}

(\%) ent from the control sites.

\begin{tabular}{|c|c|c|c|c|}
\hline $\begin{array}{l}\text { Provider } \\
\text { motivation } \\
\text { (score) }\end{array}$ & $\begin{array}{l}\text { P4P may have a desirable effect, es- } \\
\text { timate at } 0.7 \text { to } 8 \% \text {, however not- } \\
\text { ed to be largely similar to controls } \\
\text { across studies. }\end{array}$ & $\begin{array}{l}5 \text { (Huillery 2017, Lagarde } \\
\text { 2015, Shen 2017, Fried- } \\
\text { man 2016a) }\end{array}$ & Low $^{2}$ & $\begin{array}{l}\text { Sensitivity analysis: RCT estimates } \\
\text { range between } 1 \text { and } 6.9 \% \text {; low cer- } \\
\text { tainty of evidence (concerns over } \\
\text { RoB) }\end{array}$ \\
\hline $\begin{array}{l}\text { Provider } \\
\text { satisfaction } \\
\text { (score) }\end{array}$ & $\begin{array}{l}\text { Effects are uncertain and range from } \\
-81 \% \text { to } 31 \% \text {. }\end{array}$ & $\begin{array}{l}7 \text { (Friedman 2016a, Fried- } \\
\text { man 2016b, Lagarde } \\
\text { 2015, de Walque 2017, } \\
\text { Huillery 2017, Shen 2017) }\end{array}$ & Low $^{2}$ & $\begin{array}{l}\text { Sensitivity analysis: Two study RCT } \\
\text { estimates are inconsistent overall, } \\
\text { ranging from - } 81 \% \text { to } 5 \% \text {; low cer- } \\
\text { tainty of evidence (concerns over } \\
\text { RoB and imprecision) }\end{array}$ \\
\hline
\end{tabular}

Summary If not targeted, provider attendance appears to increase.

1 No serious concerns, one study only

${ }^{2}$ Serious concerns over RoB and indirectness

Table 42: Patient satisfaction and acceptability (satisfaction scores)

\begin{tabular}{|c|c|c|c|c|}
\hline Outcome & \multicolumn{4}{|c|}{ Patient satisfaction and acceptability (satisfaction scores) } \\
\hline Patient group & \multicolumn{4}{|c|}{ Patients that had accessed ANC, child or curative care at study facilities. } \\
\hline Comparison & \multicolumn{4}{|c|}{ Pure control group (standard practice, status quo, no additional financing) } \\
\hline Intervention & \multicolumn{4}{|l|}{ Any type of PBF } \\
\hline Settings & \multicolumn{4}{|l|}{ Cameroon, Congo, DRC, Zambia, Zimbabwe } \\
\hline & Impact summary & $\begin{array}{l}\text { Nr of stud- } \\
\text { ies }\end{array}$ & $\begin{array}{l}\text { Certain- } \\
\text { ty in evi- } \\
\text { dence }\end{array}$ & Comments \\
\hline $\begin{array}{l}\text { Patient satis- } \\
\text { faction with } \\
\text { facility cleanli- } \\
\text { ness (scores) }\end{array}$ & $\begin{array}{l}\text { Effects of the intervention are uncertain: im- } \\
\text { pacts on satisfaction scores range from }-21.9 \% \text { to } \\
12.5 \% \text {. }\end{array}$ & $\begin{array}{l}3 \text { (Zeng } \\
2018 a \text {, Fried- } \\
\text { man 2016a, } \\
\text { Friedman } \\
\text { 2016b) }\end{array}$ & Low $^{1}$ & $\begin{array}{l}\text { Sensitivity analysis: RCT esti- } \\
\text { mate at - } 22 \% \text {; low certainty evi- } \\
\text { dence ( } 1 \text { study, RoB concerns) }\end{array}$ \\
\hline $\begin{array}{l}\text { Patient satis- } \\
\text { faction with } \\
\text { contact time } \\
\text { (score) }\end{array}$ & $\begin{array}{l}\text { P4P may have undesirable effects: impacts on sat- } \\
\text { isfaction relating to the time health care work- } \\
\text { ers spend on ANC consults, ranges from }-5 \% \text { to } \\
0.3 \% \text {; for child care consults ranging from }-11.3 \% \\
\text { to } 4.7 \% \text {. }\end{array}$ & $\begin{array}{l}2 \text { (Friedman } \\
2016 a, \text { Fried- } \\
\text { man 2016b) }\end{array}$ & Low $^{1}$ & $\begin{array}{l}\text { Sensitivity analysis: RCT esti- } \\
\text { mate ranges } 1.2 \% \text {; low certain- } \\
\text { ty evidence ( } 1 \text { study, RoB con- } \\
\text { cerns) }\end{array}$ \\
\hline $\begin{array}{l}\text { Patient satis- } \\
\text { faction with } \\
\text { opening hours } \\
\text { (score) }\end{array}$ & $\begin{array}{l}\text { P4P may have undesirable effects: impacts on sat- } \\
\text { isfaction scores associated with facility opening } \\
\text { hours for ANC care ranging from - } 11 \% \text { to } 9 \% \text {; for } \\
\text { child care ranging from }-19.3 \% \text { to } 1.2 \% \text {. }\end{array}$ & $\begin{array}{l}2 \text { (Friedman } \\
2016 a, \text { Fried- } \\
\text { man 2016b) }\end{array}$ & Low $^{1}$ & $\begin{array}{l}\text { Sensitivity analysis: RCT esti- } \\
\text { mate at }-15 \% \text {; low certainty evi- } \\
\text { dence ( } 1 \text { study, RoB concerns) }\end{array}$ \\
\hline
\end{tabular}


(Continued)

Patient satisfaction with waiting time (score)
Effects of the intervention are uncertain: Impacts on the acceptability of waiting times for ANC appointments are consistently positive and higher in the PBF group, ranging from $10.5 \%$ to $21.8 \%$; for child health consultations they range from $-8.3 \%$ to $11.6 \%$

\begin{tabular}{|c|c|c|}
\hline $\begin{array}{l}3 \text { (de Walque } \\
2017, \text { Fried- } \\
\text { man 2016a, } \\
\text { Friedman }\end{array}$ & Low $^{1}$ & $\begin{array}{l}\text { Sensitivity analysis: RCT esti- } \\
\text { mate ranges } 1.9 \% \text {; low certain- } \\
\text { ty evidence ( } 1 \text { study, RoB con- } \\
\text { cerns) }\end{array}$ \\
\hline
\end{tabular}

2016b)

\begin{tabular}{|c|c|c|c|c|}
\hline $\begin{array}{l}\text { Overall pa- } \\
\text { tient satis- } \\
\text { faction with } \\
\text { quality of care } \\
\text { (score) }\end{array}$ & $\begin{array}{l}\text { P4P may have desirable effects in relation to pa- } \\
\text { tients' satisfaction with quality of care, ranging } \\
\text { from } 0 \% \text { to } 7.4 \% \text {. }\end{array}$ & $\begin{array}{l}2 \text { (Zeng } \\
2018 a, \\
\text { Huillery } \\
\text { 2017) }\end{array}$ & Low2 & $\begin{array}{l}\text { Sensitivity analysis: RCT esti- } \\
\text { mate }-1 \% \text {, low certainty evi- } \\
\text { dence (concerns over indirect- } \\
\text { ness and precision, one study } \\
\text { only) }\end{array}$ \\
\hline $\begin{array}{l}\text { Overall pa- } \\
\text { tient satisfac- } \\
\text { tion with wel- } \\
\text { come and re- } \\
\text { ception at fa- } \\
\text { cility (score) }\end{array}$ & $\begin{array}{l}\text { P4P may have desirable effects ranging from }-3 \% \\
\text { to } 11.7 \% \text { satisfaction with welcome quality at } \\
\text { health facilities. }\end{array}$ & $\begin{array}{l}2 \text { (Zeng } \\
2018 a \\
\text { Huillery } \\
\text { 2017) }\end{array}$ & Low 2 & $\begin{array}{l}\text { Sensitivity analysis: RCT esti- } \\
\text { mates are - } 3 \% \text { or } 0 \text {; low certain- } \\
\text { ty evidence (concerns over in- } \\
\text { directness and precision, one } \\
\text { study only) }\end{array}$ \\
\hline $\begin{array}{l}\text { Patient satis- } \\
\text { faction with } \\
\text { staff: Com- } \\
\text { munication } \\
\text { (score) }\end{array}$ & $\begin{array}{l}\text { P4P may have desirable effects, ranging between } \\
-2.2 \text { to } 7.45 \% \text { on average in relation to commu- } \\
\text { nication satisfaction for ANC; largely positive for } \\
\text { childcare, ranging from } 1.85 \text { to } 7.1 \% \text { on average. }\end{array}$ & $\begin{array}{l}3 \text { (de Walque } \\
2017, \text { Fried- } \\
\text { man 2016a, } \\
\text { Friedman } \\
\text { 2016b) }\end{array}$ & Low 1 & $\begin{array}{l}\text { Sensitivity analysis: RCT esti- } \\
\text { mate } 2.45 \% \text {; low certainty evi- } \\
\text { dence ( } 1 \text { study, RoB concerns) }\end{array}$ \\
\hline $\begin{array}{l}\text { Patient satis- } \\
\text { faction with } \\
\text { staff: Trust } \\
\text { (score) }\end{array}$ & $\begin{array}{l}\text { P4P may have desirable effects, ranging from } \\
-0.25 \% \text { to } 23.75 \% \text { on average for scores reflecting } \\
\text { trust in the skills of health care providers. }\end{array}$ & $\begin{array}{l}2 \text { (Friedman } \\
2016 a, \text { Fried- } \\
\text { man 2016b) }\end{array}$ & Low 1 & $\begin{array}{l}\text { Sensitivity analysis: RCT esti- } \\
\text { mate } 24 \% \text {; low certainty evi- } \\
\text { dence ( } 1 \text { study RoB concerns) }\end{array}$ \\
\hline $\begin{array}{l}\text { Overall satis- } \\
\text { faction (score) }\end{array}$ & $\begin{array}{l}\text { P4P probably has desirable effects: impacts on } \\
\text { overall patient satisfaction scores ranging from } 1 \\
\text { to } 88.5 \% \text { on average across ANC and child health } \\
\text { care. }\end{array}$ & $\begin{array}{l}4 \text { (de Walque } \\
2017, \\
\text { Huillery } \\
\text { 2017, Fried- } \\
\text { man 2016a, } \\
\text { Friedman } \\
\text { 2016b) }\end{array}$ & $\begin{array}{l}\text { Moder- } \\
\text { ate }^{3}\end{array}$ & $\begin{array}{l}\text { Sensitivity analysis: Two RCTs } \\
\text { estimate between } 1 \text { and } 88 \% \text {; } \\
\text { low certainty evidence (RoB } \\
\text { concerns) }\end{array}$ \\
\hline
\end{tabular}
When indicators not targeted, very inconsistent impacts across most indicators in area. Low certainty in evidence overall.

${ }^{1}$ Concerns over RoB criteria

2Serious concerns over RoB

3Some concerns over RoB and large effect

Table 43: Impacts on overall financing or resource allocation

\section{Outcome Impacts on overall financing or resource allocation}

Patient Households accessing care (except for remuneration, for which health care workers are reporting) group 
(Continued)

Compari- Pure control group (standard practice, status quo, no additional financing) son

Interven- Any type of PBF

tion

Settings Benin, Cameroon, Tanzania, Zimbabwe

\begin{tabular}{|c|c|c|c|c|}
\hline & Impact summary & Nr of studies & $\begin{array}{l}\text { Certain- } \\
\text { ty in evi- } \\
\text { dence }\end{array}$ & Comments \\
\hline $\begin{array}{l}\text { Out of } \\
\text { pocket } \\
\text { payments } \\
\text { - user } \\
\text { fees }\end{array}$ & $\begin{array}{l}\text { P4P may have undesirable effects: impacts on user fees for con- } \\
\text { sultations range from }-15 \% \text { to } 63 \% \text {; the majority of impacts were } \\
\text { negative (i.e. user fees increased). }\end{array}$ & $\begin{array}{l}4 \text { (de Walque } \\
\text { 2017, Binyaru- } \\
\text { ka 2015, Lagarde } \\
\text { 2015, Friedman } \\
\text { 2016b) }\end{array}$ & Low $^{1}$ & $\begin{array}{l}\text { No RCT reported } \\
\text { this outcome for } \\
\text { this comparison. }\end{array}$ \\
\hline $\begin{array}{l}\text { Expen- } \\
\text { diture } \\
\text { on medi- } \\
\text { cine and } \\
\text { equip- } \\
\text { ment }\end{array}$ & $\begin{array}{l}\text { P4P probably has little to no effect on the outcome: impacts on } \\
\text { drug expenditure at township health centres and health centres } \\
\text { ranging from }-2.1 \text { to }-4.7 \% \text {. }\end{array}$ & 1 (Yip 2014) & $\begin{array}{l}\text { Moder- } \\
\text { ate }^{2}\end{array}$ & Study is a RCT. \\
\hline $\begin{array}{l}\text { Probabil- } \\
\text { ity of pay- } \\
\text { ment for } \\
\text { users }\end{array}$ & $\begin{array}{l}\text { Effects of the intervention are uncertain. Probability of paying for } \\
\text { antenatal care decreased, range } 15.28 \text { to } 33.3 \% \text {; effect on deliv- } \\
\text { ery payments are inconsistent though likely largely positive, re- } \\
\text { ported to range between a } 30.3 \% \text { reduction and } 1.5 \% \text { increase } \\
\text { in probability of payment. Probability of payment for postnatal } \\
\text { care appears to have increased consistently ranging from } 35 \% \text { to } \\
61 \% \text {. }\end{array}$ & $\begin{array}{l}2 \text { (Binyaruka } \\
\text { 2015, Friedman } \\
\text { 2016b) }\end{array}$ & Low $^{1}$ & $\begin{array}{l}\text { No RCT reported } \\
\text { this outcome for } \\
\text { this comparison. }\end{array}$ \\
\hline
\end{tabular}

Summary: Inconsistent impacts on user fees and expenditures on medicine and equipment, suggesting these need to be targeted to be influenced; probability of payments for users decreases for some services on outpatient basis but not for PNC, which may require inpatient care.

1 Concerns over RoB criteria

2No serious concerns, one study only

Table 44: Impacts on management or information systems

\begin{tabular}{ll}
\hline Outcome & Impacts on management or information systems \\
\hline Patient group & Health care workers and management staff in PBF and control facilities \\
\hline Comparison & Pure control group (standard practice, status quo, no additional financing) \\
\hline Intervention & Any type of PBF \\
\hline Settings & Benin, Cameroon, Tanzania, Zambia, Zimbabwe \\
\hline
\end{tabular}


(Continued)

$\begin{array}{lll}\text { Impact summary } & \text { Nr of studies } & \begin{array}{l}\text { Certain- } \\ \text { ty in evi- } \\ \text { dence }\end{array}\end{array} \quad$ Comments

\begin{tabular}{|c|c|c|c|c|}
\hline $\begin{array}{l}\text { Facility or } \\
\text { managerial } \\
\text { autonomy } \\
\text { (score) }\end{array}$ & $\begin{array}{l}\text { P4P may have desirable effects, ranging } \\
\text { from } 144 \text { to } 188 \% \text { overall. }\end{array}$ & $\begin{array}{l}2 \text { (Lagarde 2015, } \\
\text { Friedman 2016b) }\end{array}$ & Low $^{1}$ & $\begin{array}{l}\text { No RCT reported this out- } \\
\text { come for this comparison. }\end{array}$ \\
\hline $\begin{array}{l}\text { Facility gover- } \\
\text { nance (score) }\end{array}$ & $\begin{array}{l}\text { P4P may have undesirable effects, in rela- } \\
\text { tion to the number of governance meetings } \\
\text { held at facility in last } 90 \text { days, ranging from } \\
-10.2 \% \text { to }-5.5 \% \text {. }\end{array}$ & $\begin{array}{l}2 \text { (Mayumana 2017, } \\
\text { Friedman 2016a, } \\
\text { Friedman 2016b) }\end{array}$ & Low $^{2}$ & $\begin{array}{l}\text { Sensitivity analysis: RCT esti- } \\
\text { mates }-10.2 \% \text {; GRADE } 2 \text { (one } \\
\text { study only, RoB concerns) }\end{array}$ \\
\hline $\begin{array}{l}\text { Quality of } \\
\text { management } \\
\text { (score) }\end{array}$ & $\begin{array}{l}\text { P4P may have undesirable effects, staff rat- } \\
\text { ing of management quality in facility is neg- } \\
\text { atively impacted (-15\%). }\end{array}$ & 1 (de Walque 2017) & Low $^{3}$ & $\begin{array}{l}\text { No RCT reported this out- } \\
\text { come for this comparison. }\end{array}$ \\
\hline
\end{tabular}

Summary: Overall effects on autonomy are sustained as when indicator is targeted, governance is not responsive, however quality of management is negatively affected.

1 Downgraded for RoB, imprecision, upgraded for large effects

2Downgraded for RoB and imprecision

3Downgraded for imprecision, one study only

Table 45: Equity-consideration: Evidence of differential impact on different parts of the population

\begin{tabular}{|c|c|c|c|c|}
\hline Outcome & \multicolumn{4}{|c|}{ Equity-consideration: Evidence of differential impact on different parts of the population } \\
\hline Patient group & \multicolumn{4}{|c|}{ Same as for main utilization outcomes; primarily mothers and children in PBF and control districts. } \\
\hline Comparison & \multicolumn{4}{|c|}{ Pure control group (standard practice, status quo, no additional financing) } \\
\hline Intervention & \multicolumn{4}{|l|}{ Any type of PBF } \\
\hline Settings & \multicolumn{4}{|l|}{ Afghanistan, Tanzania } \\
\hline & Impact summary & $\begin{array}{l}\text { Nr of stud- } \\
\text { ies }\end{array}$ & $\begin{array}{l}\text { Certain- } \\
\text { ty in evi- } \\
\text { dence }\end{array}$ & Comments \\
\hline $\begin{array}{l}\text { Equity of child } \\
\text { immunization } \\
\text { delivery (wealth } \\
\text { related) }\end{array}$ & $\begin{array}{l}\text { Effects of the intervention are uncertain: Ef- } \\
\text { fects towards poorest, approximately } 0.4 \% \text { in } \\
\text { comparison to less poor. }\end{array}$ & $\begin{array}{l}1 \text { (Binyaruka } \\
2015)\end{array}$ & Very low ${ }^{1}$ & $\begin{array}{l}\text { No RCT reported this outcome } \\
\text { for this comparison. }\end{array}$ \\
\hline $\begin{array}{l}\text { Equity in institu- } \\
\text { tional delivery } \\
\text { (wealth related) }\end{array}$ & $\begin{array}{l}\text { P4P may have undesirable effects: Studies } \\
\text { suggest increased inequality among patients } \\
\text { among PBF facilities; impacts on patients are } \\
\text { higher in mid-wealth quintiles. }\end{array}$ & $\begin{array}{l}2 \text { (Engineer } \\
\text { 2016, Bin- } \\
\text { yaruka 2015) }\end{array}$ & Low $^{2}$ & $\begin{array}{l}\text { Sensitivity analysis: RCT esti- } \\
\text { mate also supports that wealth- } \\
\text { ier women were likelier to re- } \\
\text { ceive institutional deliveries; } \\
\text { moderate certainty evidence } \\
\text { (one study only, no substantial } \\
\text { concerns) }\end{array}$ \\
\hline
\end{tabular}


(Continued)

Equity in institutional delivery (by educational status of mother)
Effects of the intervention are uncertain: More institutional deliveries recorded among mothers with basic education rather than none/illiterate; differential effect range of $3 \%$.

\section{1 (Binyaruka Very low ${ }^{1} \quad$ No RCT reported this outcome 2018) for this comparison.}

Summary:

Overall estimates supportive of effects as when targeted, except for institutional deliveries where negative effect is observed if not targeted.

1 Concerns over RoB and imprecision, one study only

${ }^{2}$ Concerns over RoB and imprecision

Appendix 5. Comparison 2: Summary of Findings tables 46-66

\subsection{Targeted Measures of provider performance}

\subsubsection{Delivery and utilization}

Table 46: Utilization of mother and child immunization

\begin{tabular}{|c|c|c|c|c|}
\hline Outcome & \multicolumn{4}{|c|}{ Utilization: mother and child immunization } \\
\hline Patient group & \multicolumn{4}{|c|}{ Mother and children accessing health services } \\
\hline Comparison & \multicolumn{4}{|c|}{ Comparator groups (matched financing or inputs) } \\
\hline Intervention & \multicolumn{4}{|l|}{ Any type of paying for performance (P4P) } \\
\hline \multirow[t]{2}{*}{ Settings } & \multicolumn{4}{|l|}{ Cambodia, DRC, Rwanda, Zambia } \\
\hline & Impact summary & Nr of studies & $\begin{array}{l}\text { Certainty } \\
\text { of the ev- } \\
\text { idence }\end{array}$ & Comments \\
\hline $\begin{array}{l}\text { Child immuniza- } \\
\text { tion (likelihood of } \\
\text { being vaccinated) }\end{array}$ & $\begin{array}{l}\text { Effects of } \mathrm{P} 4 \mathrm{P} \text { are uncertain, with im- } \\
\text { pact on the likelihood of any vaccina- } \\
\text { tion ranging from }-7.4 \text { to } 19 \% \text {. }\end{array}$ & $\begin{array}{l}3 \text { (Van de Poel } \\
\text { 2016, Soeters } \\
\text { 2011, Friedman } \\
\text { 2016a) }\end{array}$ & Low $^{1}$ & $\begin{array}{l}\text { Some indirectness observed across } \\
\text { studies. } \\
\text { Sensitivity analysis: RCT estimate } \\
\text { suggests P4P may have undesirable } \\
\text { effects (-7.4\%); certainty in evidence } \\
\text { is low (down-graded: RoB criteria, } \\
\text { one study). }\end{array}$ \\
\hline $\begin{array}{l}\text { Child immuniza- } \\
\text { tion: \% receiving } \\
\text { BCG }\end{array}$ & $\begin{array}{l}\text { P4P may lead to little or no differ- } \\
\text { ence: impacts on coverage of BCG } \\
\text { vaccination, estimated at } 3.1 \% \text {. }\end{array}$ & $\begin{array}{l}1 \text { (Friedman } \\
2016 a)\end{array}$ & Low 1 & Study is an RCT. \\
\hline $\begin{array}{l}\text { Child immuniza- } \\
\text { tion: \% receiving } \\
\text { DTP }\end{array}$ & $\begin{array}{l}\text { P4P may lead to little or no differ- } \\
\text { ence: effect estimated at }-1 \% \text {. }\end{array}$ & $\begin{array}{l}1 \text { (Friedman } \\
2016 a)\end{array}$ & Low $^{1}$ & Study is an RCT. \\
\hline $\begin{array}{l}\text { Child immuniza- } \\
\text { tion: } \% \text { fully vacci- } \\
\text { nated }\end{array}$ & $\begin{array}{l}\text { Effects of } P 4 P \text { are uncertain, impacts } \\
\text { on coverage of immunization (full im- } \\
\text { munization at } 12-23 \text { months), ranges } \\
\text { from }-8.1 \% \text { to } 39.8 \%\end{array}$ & $\begin{array}{l}3 \text { (Basinga } \\
\text { 2011, Sherry } \\
\text { 2017, Friedman } \\
\text { 2016a) }\end{array}$ & Low $^{1}$ & $\begin{array}{l}\text { Sensitivity analysis: P4P may have } \\
\text { desirable effects: RCT estimates posi- } \\
\text { tive impact at } 39.8 \% \text {; low certainty in } \\
\text { evidence (RoB criteria, one study). }\end{array}$ \\
\hline
\end{tabular}


(Continued)

\begin{tabular}{|c|c|c|c|c|}
\hline $\begin{array}{l}\text { Immunization } \\
\text { during ANC - \% re- } \\
\text { ceiving tetanus in- }\end{array}$ & $\begin{array}{l}\text { P4P may have desirable effects on- } \\
\text { immunization rates, effect estimated } \\
\text { at } 6.84 \% \text {. }\end{array}$ & 1 (Sherry 2017) & Low $^{2}$ & $\begin{array}{l}\text { No RCT reported this outcome for this } \\
\text { comparison. }\end{array}$ \\
\hline
\end{tabular}
ceiving tetanus inat $6.84 \%$.

jection

Summary:

Overall inconsistent effects across this area, limited certainty in estimates.

1Concerns over RoB criteria

2Some concerns over RoB and other concurrent campaigns, one study only

Table 47: Utilization of family planning

\begin{tabular}{|c|c|c|c|c|}
\hline Outcome & Utilization of family planning & & & \\
\hline Patient group & Women and households enrolled in studies. & & & \\
\hline Comparison & Comparator groups (matched financing or inputs) & & & \\
\hline Intervention & Any type of paying for performance (P4P) & & & \\
\hline \multirow[t]{2}{*}{ Settings } & DRC, Rwanda, Zambia & & & \\
\hline & Impact summary & Nr of studies & $\begin{array}{l}\text { Certainty } \\
\text { of the evi- } \\
\text { dence }\end{array}$ & Comments \\
\hline $\begin{array}{l}\text { Family plan- } \\
\text { ning: \% using } \\
\text { any method }\end{array}$ & $\begin{array}{l}\text { P4P may make little or no difference, effects on } \\
\text { the current use of contraceptives among house- } \\
\text { holds in study (recent birth households or other- } \\
\text { wise) estimated between }-4.28 \text { and } 2.8 \% \text {. }\end{array}$ & $\begin{array}{l}2 \text { (Shapira 2017, Fried- } \\
\text { man 2016a) }\end{array}$ & Low $^{1}$ & All studies are RCTs. \\
\hline $\begin{array}{l}\text { Family plan- } \\
\text { ning: \% using } \\
\text { modern meth- } \\
\text { ods }\end{array}$ & $\begin{array}{l}\text { P4P may have little to no effect on utilization of } \\
\text { modern family planning methods. }\end{array}$ & $\begin{array}{l}3 \text { (Sherry 2017, Priede- } \\
\text { man Skiles 2013, } \\
\text { Soeters 2011) }\end{array}$ & Low $^{2}$ & $\begin{array}{l}\text { No RCT reported } \\
\text { this outcome for } \\
\text { this comparison. }\end{array}$ \\
\hline Summary: & \multicolumn{4}{|c|}{$\begin{array}{l}\text { Inconsistent effects overall on family planning, however consistent positive effects on utilization of modern family } \\
\text { planning. }\end{array}$} \\
\hline
\end{tabular}

1Some concerns over RoB criteria)

2Some concerns over multiple RoB criteria

Table 48: Utilization of antenatal care

\begin{tabular}{ll} 
Outcome & Utilization of antenatal care \\
\hline $\begin{array}{l}\text { Patient } \\
\text { group }\end{array}$ & Pregnant women seeking antenatal care in enrolled facilities.
\end{tabular}

Paying for performance to improve the delivery of health interventions in low- and middle-income countries (Review) 
(Continued)

Compari- Comparator groups (matched financing or inputs)

son

Interven- $\quad$ Any type of paying for performance (P4P)

tion

\begin{tabular}{|c|c|c|c|c|}
\hline Settings & Argentina, Cambodia, Rwanda, Zambia & & & \\
\hline & Impact summary & Nr of studies & $\begin{array}{l}\text { Certainty } \\
\text { of the ev- } \\
\text { idence }\end{array}$ & Comments \\
\hline $\begin{array}{l}\text { Antenatal } \\
\text { care: \% re- } \\
\text { ceiving at } \\
\text { least one } \\
\text { ANC }\end{array}$ & $\begin{array}{l}\text { P4P may have little to no effect on the out- } \\
\text { come: likelihood of any ANC being utilized } \\
\text { among populations in the sites ranging from } \\
-1.5 \% \text { to } 3.2 \% \text {. }\end{array}$ & $\begin{array}{l}3 \text { (Van de Poel } \\
2016, \text { Basinga 2011, } \\
\text { Friedman 2016a) }\end{array}$ & Low $^{1}$ & $\begin{array}{l}\text { Sensitivity analysis: RCT esti- } \\
\text { mate is }-1.5 \% \text {; low certainty in ev- } \\
\text { ifence (RoB criteria, one study on- } \\
\text { ly). }\end{array}$ \\
\hline $\begin{array}{l}\text { Antenatal } \\
\text { care: \% re- } \\
\text { ceiving four } \\
\text { or more } \\
\text { ANC }\end{array}$ & $\begin{array}{l}\text { P4P may have little to no effect on the out- } \\
\text { come: the use of four or more ANC visits by } \\
\text { women in the study sites ranging from }-5.3 \\
\text { to } 4.4 \% \text {. }\end{array}$ & $\begin{array}{l}5 \text { (Basinga 2011, } \\
\text { Priedeman Skiles } \\
\text { 2013, Sherry 2017, } \\
\text { Shapira 2017, Fried- } \\
\text { man 2016a) }\end{array}$ & Low $^{2}$ & $\begin{array}{l}\text { Sensitivity analysis: RCT esti- } \\
\text { mate is - } 0.6 \% \text {; low certainty in ev- } \\
\text { idence (RoB criteria, one study } \\
\text { only) }\end{array}$ \\
\hline $\begin{array}{l}\text { Antena- } \\
\text { tal care: \% } \\
\text { receiving } \\
\text { ANC in first } \\
\text { trimester }\end{array}$ & $\begin{array}{l}\text { P4P may have desirable effects: Likelihood } \\
\text { of ANC utilization being in the first trimester } \\
\text { increases in PBF facilities by } 1.3 \text { to } 10 \% \text {; } \\
\text { studies note that RBF facilities see women } \\
\text { initiating antenatal care approximately } 1 \\
\text { month earlier compared to other facilities. }\end{array}$ & $\begin{array}{l}4 \text { (Celhay 2015, } \\
\text { Priedeman Skiles } \\
\text { 2013, Shapira 2017, } \\
\text { Friedman 2016a) }\end{array}$ & Low $^{3}$ & $\begin{array}{l}\text { Sensitivity analysis: Two stud- } \\
\text { ies, RCT estimates suggest be- } \\
\text { tween } 1.3 \text { to } 10 \% \text { of women initi- } \\
\text { ate care earlier, approximately by } \\
1 \text { month; GRADE } 3 \text { (RoB criteria } \\
\text { and indirectness). }\end{array}$ \\
\hline
\end{tabular}

Summary: Potential desirable effects on timely utilization of ANC, however little to no effect on ANC utilization overall.

${ }^{1}$ Critical concerns over Low or more RoB criteria

2Some concerns over RoB

${ }^{3}$ Concerns over RoB criteria

Table 49: Utilization of institutional delivery, postnatal care and child curative care

\begin{tabular}{ll}
\hline Outcome & Utilization: institutional delivery, postnatal care and child curative care \\
\hline $\begin{array}{l}\text { Patient } \\
\text { group }\end{array}$ & Pregnant women in households in facility catchment areas and children under 5. \\
\hline
\end{tabular}

Compari- Comparator groups (matched financing or inputs)

son

Interven- $\quad$ Any type of paying for performance (P4P)

tion

Settings Cambodia, DRC, Rwanda, Zambia 
(Continued)

$\begin{array}{lll}\text { Impact summary } & \text { Nr of studies } & \begin{array}{l}\text { Certainty } \\ \text { of the ev- } \\ \text { idence }\end{array}\end{array}$

Institution- Effects of the intervention are unceral deliver- tain: Inconsistent effects on in faciliies (rates ty delivery rates ranging from $-8.7 \%$ to and cover- $\quad 23.2 \%$; one study estimates effects on age)

\author{
7 (Van de Poel \\ 2016, Soeters 2011, \\ Basinga 2011, \\ Priedeman Skiles \\ 2013, Sherry 2017, \\ Shapira 2017, Fried- \\ man 2016a)
}

Low ${ }^{1} \quad$ Overall impacts noted are largely positive, only Zambia studies suggest negative impacts, suggestive of potential publication bias.

Sensitivity analysis: Two studies, but evidence inconsistent, between -8.7 to $1.9 \%$; low certainty in evidence (RoB criteria).

Study is an RCT.

\begin{tabular}{lllll}
\hline $\begin{array}{l}\text { Postnatal } \\
\text { care (rates } \\
\text { and cover- } \\
\text { age) }\end{array}$ & $\begin{array}{l}\text { P4P may have undesirable effects: im- } \\
\text { pacts on any PNC being utilized, ap- } \\
\text { proximately -10\%. }\end{array}$ & 1(Friedman 2016a) & Low1 & Study is an RCT. \\
\hline $\begin{array}{l}\text { Child } \\
\begin{array}{l}(<5) \text { cura- } \\
\text { tive visits } \\
\text { (rates) }\end{array}\end{array}$ & $\begin{array}{l}\text { P4P may have little to no effect on } \\
\text { the outcome, ranging from -5.76\% to }\end{array}$ & $\begin{array}{l}\text { 2(Sherry 2017, } \\
\text { Friedman 2016a) }\end{array}$ & Low ${ }^{1}$ & $\begin{array}{l}\text { Sensitivity analysis: RCT estimate is } \\
-3.1 \% \text {; low certainty in evidence (RoB } \\
\text { criteria, one study only) }\end{array}$ \\
\hline Summary: & Inconsistent effects overall in this area, low certainty in evidence. & \\
\hline
\end{tabular}

1Concerns over RoB criteria

Table 50: Utilization of services (general)

\begin{tabular}{|c|c|c|c|c|}
\hline Outcome & \multicolumn{4}{|c|}{ Probability of any utilization and total utilization } \\
\hline Patient group & \multicolumn{4}{|l|}{ All patients accessing } \\
\hline Comparison & \multicolumn{4}{|c|}{ Comparator groups (matched financing or inputs) } \\
\hline Intervention & \multicolumn{4}{|l|}{ Any type of paying for performance (P4P) } \\
\hline Settings & \multicolumn{4}{|l|}{ DRC and Zambia } \\
\hline & Impact summary & Nr of studies & $\begin{array}{l}\text { Certainty } \\
\text { of the evi- } \\
\text { dence }\end{array}$ & Comments \\
\hline $\begin{array}{l}\text { Probability of } \\
\text { any utilization } \\
\text { (generic) }\end{array}$ & $\begin{array}{l}\text { P4P may have desirable effects, esti- } \\
\text { mated to range between } 1.5 \text { to } 10 \% \text {, } \\
\text { however may differ according to type } \\
\text { of health provider or facility visited. }\end{array}$ & $\begin{array}{l}2 \text { (Soeters } \\
2011 \text {, Fried- } \\
\text { man 2016a) }\end{array}$ & Low $^{1}$ & $\begin{array}{l}\text { Sensitivity analysis: RCT estimate is } 1.5 \\
\text { overall, however ranges from - } 6 \% \text { to } 9 \% \\
\text { depending on the type of facility or health } \\
\text { care worker visited; low certainty in evi- } \\
\text { dence (one study). }\end{array}$ \\
\hline
\end{tabular}

1Serious concerns over RoB 


\subsubsection{Quality of care}

Table 51: Adherence to procedure and guidelines

\begin{tabular}{|c|c|c|c|c|}
\hline Outcome & \multicolumn{4}{|c|}{ Quality of care: Adherence to procedure and guidelines } \\
\hline $\begin{array}{l}\text { Patient } \\
\text { group }\end{array}$ & \multicolumn{4}{|c|}{ Dependent on indicator. Largely those accessing RMNCH services. Additionally those accessing curative services. } \\
\hline $\begin{array}{l}\text { Compari- } \\
\text { son }\end{array}$ & \multicolumn{4}{|l|}{ Comparator groups (matched financing or inputs) } \\
\hline $\begin{array}{l}\text { Interven- } \\
\text { tion }\end{array}$ & \multicolumn{4}{|l|}{ Any type of paying for performance (P4P) } \\
\hline Settings & \multicolumn{4}{|l|}{ Benin, Rwanda, Zambia } \\
\hline & Impact summary & Nr of studies & $\begin{array}{l}\text { Certainty } \\
\text { of the ev- } \\
\text { idence }\end{array}$ & Comments \\
\hline $\begin{array}{l}\text { Back- } \\
\text { ground } \\
\text { and phys- } \\
\text { ical as- } \\
\text { sessment } \\
\text { (score) }\end{array}$ & $\begin{array}{l}\text { P4P may have desirable effects: Ranging } \\
\text { from }-5.93 \% \text { to } 10.62 \% \text { overall on diverse set } \\
\text { of measures reflective of ANC, child health } \\
\text { and adult curative consultations. }\end{array}$ & $\begin{array}{l}3 \text { (Lagarde 2015, } \\
\text { Sherry 2017, } \\
\text { Friedman 2016a) }\end{array}$ & Low $^{1}$ & $\begin{array}{l}\text { Sensitivity analysis: RCT estimate is } \\
-5.4 \% \text { on average; low certainty evi- } \\
\text { dence (RoB criteria, one study). }\end{array}$ \\
\hline $\begin{array}{l}\text { Coun- } \\
\text { selling } \\
\text { (score) }\end{array}$ & $\begin{array}{l}\text { Effects are uncertain: Effects ranging from } \\
-37 \% \text { to } 26.12 \% \text { overall. }\end{array}$ & $\begin{array}{l}3 \text { (Lagarde 2015, } \\
\text { Sherry } 2017, \\
\text { Friedman 2016a) }\end{array}$ & Low 1 & $\begin{array}{l}\text { Sensitivity analysis: RCT estimate is } \\
-40 \% \text { on average; low certainty evi- } \\
\text { dence (RoB criteria, one study). }\end{array}$ \\
\hline $\begin{array}{l}\text { Immu- } \\
\text { nization } \\
\text { quality } \\
\text { (score) }\end{array}$ & $\begin{array}{l}\text { P4P may have desirable effects: Quality in- } \\
\text { dex of vaccinations increasing in PBF facili- } \\
\text { ties by } 3.2 \% \text {; overall effects on likelihood of } \\
\text { receiving a tetanus vaccine during ANC esti- } \\
\text { mated at } 7.2 \% \text {. }\end{array}$ & $\begin{array}{l}2 \text { (Basinga 2011, } \\
\text { Friedman 2016a) }\end{array}$ & Low 1 & $\begin{array}{l}\text { Sensitivity analysis: RCT estimate is } \\
5.2 \% \text { on average; low certainty evi- } \\
\text { dence (RoB criteria, one study). }\end{array}$ \\
\hline
\end{tabular}

Summary: Overall low certainty in evidence, some desirable effects noted.

1Serious concerns over RoB criteria

Table 52: Human resource knowledge and skills

\begin{tabular}{ll} 
Outcome & Quality of care: Human resource knowledge and skills, health literacy \\
\hline $\begin{array}{l}\text { Patient } \\
\text { group }\end{array}$ & Mainly from studies focused on $\mathrm{RMNCH}$. \\
\hline
\end{tabular}

Compari- Comparator groups (matched financing or inputs)

son

Interven- Any type of paying for performance (P4P)

tion

Paying for performance to improve the delivery of health interventions in low- and middle-income countries (Review) 
(Continued)

\begin{tabular}{|c|c|c|c|c|}
\hline Settings & DRC, Rwanda & & & \\
\hline & Impact summary & Nr of studies & $\begin{array}{l}\text { Certainty } \\
\text { of the ev- } \\
\text { idence }\end{array}$ & Comments \\
\hline $\begin{array}{l}\text { Staff } \\
\text { knowl- } \\
\text { edge and } \\
\text { skills } \\
\text { (scores) }\end{array}$ & $\begin{array}{l}\text { P4P may have desirable effects on provider knowledge } \\
\text { (or availability of knowledgeable staff in facility), rang- } \\
\text { ing from an absolute increase in knowledge scores of } \\
0.4 \text { SD, to relative impacts on availability of skilled per- } \\
\text { sonnel between } 0.06 \text { to } 15 \% \text { change in scores. }\end{array}$ & $\begin{array}{l}3 \text { (Soeters } \\
\text { 2011, Sherry } \\
\text { 2017, Gertler } \\
\text { 2012) }\end{array}$ & Low $^{1}$ & $\begin{array}{l}\text { No RCT reported this out- } \\
\text { come for this comparison. }\end{array}$ \\
\hline $\begin{array}{l}\text { Knowl- } \\
\text { edge Out- } \\
\text { comes (in- } \\
\text { dex) }\end{array}$ & $\begin{array}{l}\text { P4P may have desirable effects on health literacy out- } \\
\text { comes (though these are diverse, e.g. having heard } \\
\text { about family planning vs. HIV/AIDS) ranging from }-5.4 \% \\
\text { to } 10 \% \text { change in scores. }\end{array}$ & $\begin{array}{l}2 \text { (Soeters } \\
2011 \text {, Shapira } \\
2017 \text { ) }\end{array}$ & Low $^{2}$ & $\begin{array}{l}\text { Sensitivity analysis: RCT } \\
\text { suggests impacts are con- } \\
\text { sistently negative, ranging } \\
\text { from }-5.4 \% \text { to }-2.4 \% \text {, moder- } \\
\text { ate certainty evidence (data } \\
\text { sources and one study) }\end{array}$ \\
\hline
\end{tabular}

Summary: Overarchingly desirable effects, low certainty evidence.

1Serious concerns over RoB criteria and imprecision

${ }^{2}$ Concerns over RoB criteria

Table 53: Total quality scores

\begin{tabular}{|c|c|c|c|c|}
\hline Outcome & Quality of care: Total quality scores & & & \\
\hline Patient group & Principally mothers and children. & & & \\
\hline Comparison & Comparator groups (matched financing & rinputs) & & \\
\hline Intervention & Any type of paying for performance (P4P & & & \\
\hline \multirow[t]{2}{*}{ Settings } & DRC, Rwanda, Zambia & & & \\
\hline & Impact summary & Nr of studies & $\begin{array}{l}\text { Certainty } \\
\text { of the ev- } \\
\text { idence }\end{array}$ & Comments \\
\hline $\begin{array}{l}\text { Total quality } \\
\text { family planning } \\
\text { (scores) }\end{array}$ & $\begin{array}{l}\text { P4P may have desirable effects, rang- } \\
\text { ing from } 1.34 \% \text { to } 500 \% \text { change in } \\
\text { scores increases in quality of family } \\
\text { planning in PBF facilities. }\end{array}$ & $\begin{array}{l}2 \text { (Sherry 2017, } \\
\text { Friedman 2016a) }\end{array}$ & Low $^{1}$ & $\begin{array}{l}\text { Sensitivity analysis: RCT estimate } \\
500 \% \text {; low certainty in evidence (-2 } \\
\text { for RoB and one study) }\end{array}$ \\
\hline $\begin{array}{l}\text { Total quality } \\
\text { antenatal care } \\
\text { (scores) }\end{array}$ & $\begin{array}{l}\text { P4P may have desirable effects on pre- } \\
\text { natal care scores, ranging from } 3.56 \text { to } \\
40 \% \text {. }\end{array}$ & $\begin{array}{l}3 \text { (Friedman } \\
\text { 2016a, Basinga } \\
\text { 2011, Sherry 2017) }\end{array}$ & Low $^{1}$ & $\begin{array}{l}\text { Sensitivity analysis: RCT estimate } \\
40 \% \text { increase in ANC quality of care; } \\
\text { low certainty in evidence ( } 2 \text { for RoB } \\
\text { and one study only). }\end{array}$ \\
\hline $\begin{array}{l}\text { Total quali- } \\
\text { ty composite } \\
\text { (score) }\end{array}$ & $\begin{array}{l}\text { P4P may have desirable effects, rang- } \\
\text { ing from } 25 \% \text { to } 0.13 S D \text { changes in } \\
\text { composite scores. }\end{array}$ & $\begin{array}{l}2 \text { (Soeters 2011, } \\
\text { Gertler 2012) }\end{array}$ & Low $^{1}$ & $\begin{array}{l}\text { No RCT reported this outcome for } \\
\text { this comparison. }\end{array}$ \\
\hline
\end{tabular}


(Continued)

Summary: $\quad$ Moderate certainty in the consistently positive results across this area.

${ }^{1}$ Serious concerns over RoB

\subsection{Health Outcomes}

Table 54: Reproductive maternal and child health outcomes

\begin{tabular}{llll}
\hline Outcome & Health Outcomes: RMNCH Outcomes & \\
\hline Patient group & Pregnant women and children & \\
\hline Comparison & Comparator groups (matched financing or inputs) & \\
\hline Intervention & Any type of paying for performance (P4P) & Certainty of the evi- & Comments \\
\hline Settings & Zambia & Nr of studies & Lowce 1 \\
\hline & Impact summary & Study is an RCT. \\
\hline $\begin{array}{l}\text { Proportion of women } \\
\text { breastfeeding }\end{array}$ & P4P may have little to no effect, & no impacts noted. & \\
\hline $\begin{array}{l}\text { Summary: } \\
\text { P4P may have no effect. }\end{array}$ & \\
\hline
\end{tabular}

${ }^{1}$ Concerns over RoB criteria, one study only

\subsection{Resource use}

Table 55: Changes in medicine and equipment use

\begin{tabular}{|c|c|c|c|c|}
\hline Outcome & \multicolumn{4}{|c|}{ Changes in Resource Use: Medicine and Equipment } \\
\hline Patient group & \multicolumn{4}{|c|}{ Primarily mothers and children, and patients using other curative services } \\
\hline Comparison & \multicolumn{4}{|c|}{ Comparator groups (matched financing or inputs) } \\
\hline Intervention & \multicolumn{4}{|l|}{ Any type of paying for performance (P4P) } \\
\hline \multirow[t]{2}{*}{ Settings } & Zambia & & & \\
\hline & Impact summary & Nr of studies & $\begin{array}{l}\text { Certainty of } \\
\text { the evidence }\end{array}$ & Comments \\
\hline $\begin{array}{l}\text { Equipment avail- } \\
\text { ability (composite } \\
\text { score) }\end{array}$ & $\begin{array}{l}\text { P4P may have desirable effects, estimated } \\
\text { at } 75 \% \text { increase, however non significant in } \\
\text { comparison to comparator. }\end{array}$ & 1 (Friedman 2016a) & Low $^{1}$ & Study is an RCT. \\
\hline
\end{tabular}


(Continued)

Medicine availability (composite score)

Summary:
P4P may have undesirable effects, estimated at $-160 \%$ decrease in composite score.
Study is an RCT.

\title{
Study is an RCT.
}

(n)

Inconsistent effects in relation to medicines vs. equipment, equipment availability appears to be increased; that of medicine decreased.

\author{
that of medicine decreased.
}

${ }^{1}$ Concerns over RoB, imprecision, one study only but upgraded for substantive effect

\subsection{Secondary outcomes}

Table 56: Impacts on management or information systems

\begin{tabular}{|c|c|c|c|c|}
\hline Outcome & \multicolumn{4}{|c|}{ Impacts on management or information systems } \\
\hline Patient group & \multicolumn{4}{|c|}{ Health care workers in PBF and comparator facilities } \\
\hline Comparison & \multicolumn{4}{|c|}{ Comparator groups (matched financing or inputs) } \\
\hline Intervention & \multicolumn{4}{|l|}{ Any type of paying for performance (P4P) } \\
\hline \multirow[t]{2}{*}{ Settings } & Zambia & & & \\
\hline & Impact summary & Nr of studies & $\begin{array}{l}\text { Certainty of the evi- } \\
\text { dence }\end{array}$ & Comments \\
\hline $\begin{array}{l}\text { Facility and man- } \\
\text { agerial autonomy } \\
\text { (score) }\end{array}$ & $\begin{array}{l}\text { P4P may have desirable effects: Esti- } \\
\text { mated impact on autonomy index in } \\
\text { range of } 46 \% \text {. }\end{array}$ & 1 (Friedman 2016a) & Low $^{1}$ & Study is an RCT. \\
\hline Summary: & \multicolumn{4}{|c|}{ Consistently positive effects on facility and managerial autonomy, though larger when targeted. } \\
\hline
\end{tabular}

${ }^{1}$ Concerns over RoB and imprecision, one study only

Table 57: Patient satisfaction and acceptability

\begin{tabular}{|c|c|c|c|c|}
\hline Outcome & \multicolumn{4}{|l|}{ S: Patient satisfaction and acceptability } \\
\hline Patient group & \multicolumn{4}{|c|}{ Patients attending antenatal, child care or curative adult care in facilities. } \\
\hline Comparison & \multicolumn{4}{|c|}{ Comparator groups (matched financing or inputs) } \\
\hline Intervention & \multicolumn{4}{|l|}{ Any type of paying for performance (P4P) } \\
\hline Settings & \multicolumn{4}{|l|}{ Benin, DRC } \\
\hline & Impact summary & Nr of studies & $\begin{array}{l}\text { Certainty of } \\
\text { the evidence }\end{array}$ & Comments \\
\hline Waiting time & $\begin{array}{l}\text { Effects of the intervention are uncertain: } \\
\text { Impact in the range of } 7 \% \text {. }\end{array}$ & 1 (Soeters 2011) & Very low ${ }^{1}$ & $\begin{array}{l}\text { No RCT reported this out- } \\
\text { come for this comparison. }\end{array}$ \\
\hline
\end{tabular}

Paying for performance to improve the delivery of health interventions in low- and middle-income countries (Review) 
(Continued)

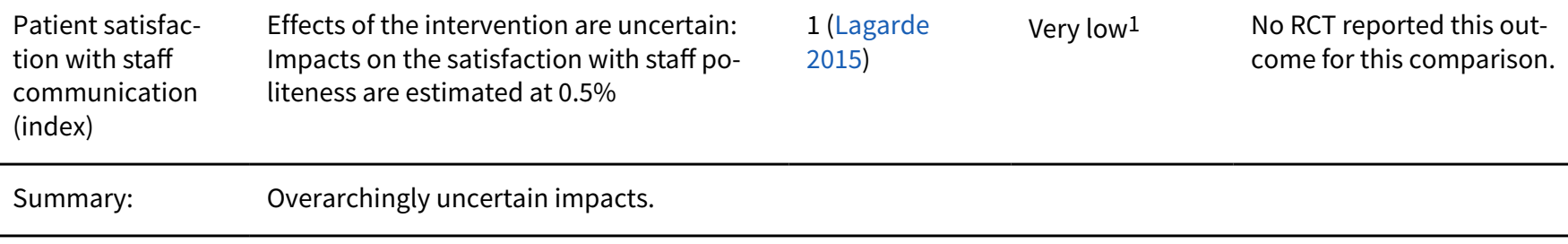

1Serious concerns over RoB, one study only

Table 58: Equity-consideration: Evidence of differential impact on different parts of the population

\begin{tabular}{|c|c|c|c|c|}
\hline Outcome & \multicolumn{4}{|c|}{ Equity-consideration: Evidence of differential impact on different parts of the population } \\
\hline Patient group & \multicolumn{4}{|c|}{ Women and households utilizing family planning, antenatal, delivery and child care. } \\
\hline Comparison & \multicolumn{4}{|l|}{ Comparator groups (matched financing or inputs) } \\
\hline Intervention & \multicolumn{4}{|l|}{ Any type of paying for performance (P4P) } \\
\hline Settings & \multicolumn{4}{|l|}{ Cambodia, Rwanda } \\
\hline Patient group & \multicolumn{4}{|l|}{$\begin{array}{l}\text { Women and households utilizing family planning, } \\
\text { antenatal, delivery and child care. }\end{array}$} \\
\hline & Impact summary & Nr of studies & $\begin{array}{l}\text { Certainty } \\
\text { of the ev- } \\
\text { idence }\end{array}$ & Comments \\
\hline $\begin{array}{l}\text { Wealth related: } \\
\text { Antenatal care } \\
\text { (utilization) }\end{array}$ & $\begin{array}{l}\text { P4P may have little to no effect: Inconsistent im- } \\
\text { pacts regarding } 4 \text { or more ANC visits in relation to } \\
\text { pro-poor effects (estimated at under } 10 \% \text { in compar- } \\
\text { ison to least poor); similar in relation to utilization of } \\
\text { ANC in first trimester. }\end{array}$ & $\begin{array}{l}2 \text { (Lannes 2016, } \\
\text { Priedeman Skiles } \\
\text { 2013) }\end{array}$ & Low $^{1}$ & $\begin{array}{l}\text { No RCT reported } \\
\text { this outcome for } \\
\text { this comparison }\end{array}$ \\
\hline $\begin{array}{l}\text { Wealth related: } \\
\text { Curative visits (uti- } \\
\text { lization) }\end{array}$ & $\begin{array}{l}\text { P4P may have little to no effect: utilization among } \\
\text { lower socio-economic groups increased between } \\
3.5 \% \text { and } 10 \% \text {. }\end{array}$ & $\begin{array}{l}2 \text { (Lannes 2016, } \\
\text { Priedeman Skiles } \\
\text { 2015) }\end{array}$ & Low $^{1}$ & $\begin{array}{l}\text { No RCT reported } \\
\text { this outcome for } \\
\text { this comparison }\end{array}$ \\
\hline $\begin{array}{l}\text { Wealth related: } \\
\text { Family planning } \\
\text { (utilization) }\end{array}$ & $\begin{array}{l}\text { P4P may have undesirable effects, less poor and } \\
\text { mid-status groups appear to benefit more. }\end{array}$ & $\begin{array}{l}2 \text { (Lannes 2016, } \\
\text { Priedeman Skiles } \\
\text { 2015) }\end{array}$ & Low $^{1}$ & $\begin{array}{l}\text { No RCT reported } \\
\text { this outcome for } \\
\text { this comparison }\end{array}$ \\
\hline $\begin{array}{l}\text { Wealth related: In- } \\
\text { stitutional deliv- } \\
\text { ery (utilization) }\end{array}$ & $\begin{array}{l}\text { P4P may have undesirable effects: middle-income } \\
\text { groups (or mid-poverty) groups benefit more than } \\
\text { poorest. }\end{array}$ & $\begin{array}{l}3 \text { (Van de Poel } \\
\text { 2016, Lannes } \\
\text { 2016, Priedeman } \\
\text { Skiles 2015) }\end{array}$ & Low $^{1}$ & $\begin{array}{l}\text { No RCT reported } \\
\text { this outcome for } \\
\text { this comparison }\end{array}$ \\
\hline Summary: & Low certainty overall, suggestive of limited to negati & effects. & & \\
\hline
\end{tabular}

1Some concern over RoB 


\subsection{Changes in untargeted measures of provider performance}

\subsubsection{Untargeted delivery and utilization}

Table 59: Utilization of mother and child immunization

\begin{tabular}{lll}
\hline Outcome & Utilization: mother and child immunization & \\
\hline Patient group & Mother and children accessing health services & \\
\hline Comparison & Comparator groups (matched financing or inputs) & \\
\hline Intervention & Any type of paying for performance (P4P) & Certainty of the evi- \\
\hline Settings & Argentina & dence \\
\hline & Impact summary & Moderate 1 \\
\hline $\begin{array}{l}\text { Cross-price spillover ef- } \\
\text { fect on mothers receiving } \\
\text { tetanus vaccination }\end{array}$ & $\begin{array}{l}\text { P4P probably has little to no } \\
\text { effect, impact estimated 2\%. }\end{array}$ & S (Celhay 2015) \\
\hline \begin{tabular}{l} 
Summary: \\
\hline
\end{tabular}
\end{tabular}

1 One study only

Table 60: Utilization of institutional delivery, postnatal care and child curative care

\begin{tabular}{|c|c|c|c|c|}
\hline Outcome & \multicolumn{4}{|c|}{ Utilization: institutional delivery, postnatal care and child curative care } \\
\hline Patient group & \multicolumn{4}{|c|}{ Pregnant women in households in facility catchment areas and children under 5.} \\
\hline Comparison & \multicolumn{4}{|c|}{ Comparator groups (matched financing or inputs) } \\
\hline Intervention & \multicolumn{4}{|l|}{ Any type of paying for performance (P4P) } \\
\hline \multirow[t]{2}{*}{ Settings } & Rwanda & & & \\
\hline & Impact summary & Nr of studies & $\begin{array}{l}\text { Certainty of the evi- } \\
\text { dence }\end{array}$ & Comments \\
\hline $\begin{array}{l}\text { Postnatal care } \\
\text { (rates and cover- } \\
\text { age) }\end{array}$ & $\begin{array}{l}\text { P4P may make little to no difference to } \\
\text { the outcome, effects on any PNC being } \\
\text { utilized estimated at }-0.5 \% \text {. }\end{array}$ & 1 (Shapira 2017) & Low 1 & Study is an RCT. \\
\hline Summary: & \multicolumn{4}{|c|}{ Consistent with when indicator targeted, negative effects on the utilization on post-natal care noted. } \\
\hline
\end{tabular}

1Serious RoB concerns, one study only 


\subsubsection{Untargeted quality of care}

Table 61: Human resource inputs

\begin{tabular}{|c|c|c|c|c|}
\hline Outcome & \multicolumn{4}{|c|}{ Quality of care: Human resource inputs } \\
\hline Patient group & \multicolumn{4}{|c|}{ Mainly from studies focused on $\mathrm{RMNCH}$. } \\
\hline Comparison & \multicolumn{4}{|c|}{ Comparator groups (matched financing or inputs) } \\
\hline Intervention & \multicolumn{4}{|c|}{ Any type of paying for performance (P4P) } \\
\hline \multirow[t]{2}{*}{ Settings } & \multicolumn{4}{|l|}{ Benin } \\
\hline & Impact summary & Nr of studies & $\begin{array}{l}\text { Certainty of the evi- } \\
\text { dence }\end{array}$ & Comments \\
\hline $\begin{array}{l}\text { Staff knowledge } \\
\text { and skills (score) }\end{array}$ & $\begin{array}{l}\text { Effects are uncertain: esti- } \\
\text { mated at } 5.6 \% \text {. }\end{array}$ & 1 (Lagarde 2015) & Very low 1 & $\begin{array}{l}\text { No RCT reported this out- } \\
\text { come for this comparison. }\end{array}$ \\
\hline Summary: & \multicolumn{4}{|c|}{ Consistent with when indicator is targeted, impacts are positive but limited certainty in estimate. } \\
\hline
\end{tabular}

1Serious concerns over RoB criteria and imprecision, one study only

\section{6. Untargeted health outcomes}

Table 62: Reproductive maternal and child health outcomes

\begin{tabular}{|c|c|c|c|c|}
\hline Primary outcome & \multicolumn{4}{|c|}{ Health Outcomes: RMNCH Outcomes } \\
\hline Patient group & \multicolumn{4}{|c|}{ Women with pregnancies in study periods } \\
\hline Comparison & \multicolumn{4}{|c|}{ Comparator groups (matched financing or inputs) } \\
\hline Intervention & \multicolumn{4}{|c|}{ Any type of paying for performance (P4P) } \\
\hline \multirow[t]{2}{*}{ Settings } & \multicolumn{4}{|l|}{ Rwanda, Zambia } \\
\hline & Impact summary & Nr of studies & $\begin{array}{l}\text { Certainty of } \\
\text { the evidence }\end{array}$ & Comments \\
\hline $\begin{array}{l}\text { Proportion of women } \\
\text { breastfeeding }\end{array}$ & $\begin{array}{l}\text { P4P may have little to no effect, } \\
\text { impact estimated at } 0.29 \% \text {. }\end{array}$ & 1 ( Sherry 2017) & Low 1 & Study is an RCT. \\
\hline $\begin{array}{l}\text { Reported illness in } \\
\text { children }(\%)\end{array}$ & $\begin{array}{l}\mathrm{P} 4 \mathrm{P} \text { may have desirable effects, } \\
\text { ranging from }-5 \% \text { to } 10.5 \% \text {. }\end{array}$ & $\begin{array}{l}2 \text { (Priedeman Sk- } \\
\text { iles 2015, Friedman } \\
\text { 2016a) }\end{array}$ & Low $^{2}$ & $\begin{array}{l}\text { Sensitivity analysis: } R C T \text { re- } \\
\text { ports }+10.5 \% \text {; low certainty ev- } \\
\text { idence (RoB criteria, } 1 \text { study } \\
\text { only). }\end{array}$ \\
\hline Summary: & \multicolumn{4}{|l|}{ Overall inconsistent effects. } \\
\hline
\end{tabular}

1Some concerns over RoB, one study only 
${ }^{2}$ Concerns over RoB criteria

\section{7. Untargeted resource use}

Table 63: Medicine and equipment availability

\begin{tabular}{|c|c|c|c|c|}
\hline Primary outcome & \multicolumn{4}{|c|}{ Changes in Resource Use: Medicine and Equipment } \\
\hline Patient group & \multicolumn{4}{|c|}{ Primarily mothers and children, and patients using other curative services } \\
\hline Comparison & \multicolumn{4}{|c|}{ Comparator groups (matched financing or inputs) } \\
\hline Intervention & \multicolumn{4}{|l|}{ Any type of paying for performance (P4P) } \\
\hline \multirow[t]{2}{*}{ Settings } & Benin & & & \\
\hline & Impact summary & Nr of studies & $\begin{array}{l}\text { Certainty of } \\
\text { the evidence }\end{array}$ & Comments \\
\hline $\begin{array}{l}\text { Equipment avail- } \\
\text { ability (composite } \\
\text { score) }\end{array}$ & $\begin{array}{l}\text { Effects of the intervention are uncer- } \\
\text { tain: Negative effect in the range of } \\
-2.5 \% \text {. }\end{array}$ & 1 (Lagarde 2015) & Very low ${ }^{1}$ & $\begin{array}{l}\text { No RCT reported this out- } \\
\text { come for this comparison. }\end{array}$ \\
\hline $\begin{array}{l}\text { Medicine avail- } \\
\text { ability (composite } \\
\text { score) }\end{array}$ & $\begin{array}{l}\text { Effects of the intervention are uncer- } \\
\text { tain: Positive effect in the range of } \\
4.8 \% \text {. }\end{array}$ & 1 (Lagarde 2015) & Very low ${ }^{1}$ & $\begin{array}{l}\text { No RCT reported this out- } \\
\text { come for this comparison. }\end{array}$ \\
\hline Summary: & \multicolumn{4}{|c|}{$\begin{array}{l}\text { Opposite impacts to when indicators are targeted: medicine availability appears to be increasing and that of } \\
\text { equipment decreasing. }\end{array}$} \\
\hline
\end{tabular}

1Serious concerns over RoB and imprecision

\section{8. Untargeted secondary outcomes}

Table 64: Impacts on management or information systems

\begin{tabular}{|c|c|c|c|c|}
\hline Outcome & \multicolumn{4}{|c|}{ Impacts on management or information systems } \\
\hline Patient group & \multicolumn{4}{|c|}{ Health care workers in PBF and comparator facilities } \\
\hline Comparison & \multicolumn{4}{|c|}{ Comparator groups (matched financing or inputs) } \\
\hline Intervention & \multicolumn{4}{|l|}{ Any type of paying for performance (P4P) } \\
\hline \multirow[t]{2}{*}{ Settings } & \multicolumn{4}{|l|}{ Benin } \\
\hline & Impact summary & Nr of studies & $\begin{array}{l}\text { Certainty of the } \\
\text { evidence }\end{array}$ & Comments \\
\hline $\begin{array}{l}\text { Facility and manage- } \\
\text { rial autonomy (score) }\end{array}$ & $\begin{array}{l}\text { Effect of the intervention is uncertain: } \\
\text { impact estimated at } 0.3 \% \text { difference } \\
\text { compared to comparator. }\end{array}$ & 1 (Lagarde 2015) & Very low 1 & $\begin{array}{l}\text { No RCT reported this } \\
\text { outcome for this com- } \\
\text { parison. }\end{array}$ \\
\hline Summary: & Effects uncertain. & & & \\
\hline
\end{tabular}


${ }^{1}$ Concerns over RoB and imprecision, one study only

Table 65: Patient satisfaction and acceptability

\begin{tabular}{|c|c|c|c|c|}
\hline Outcome & \multicolumn{4}{|l|}{ Patient satisfaction and acceptability } \\
\hline $\begin{array}{l}\text { Patient } \\
\text { group }\end{array}$ & \multicolumn{4}{|c|}{ Patients attending antenatal, childcare or curative adult care in facilities. } \\
\hline $\begin{array}{l}\text { Compari- } \\
\text { son }\end{array}$ & \multicolumn{4}{|l|}{ Comparator groups (matched financing or inputs) } \\
\hline $\begin{array}{l}\text { Interven- } \\
\text { tion }\end{array}$ & \multicolumn{4}{|l|}{ Any type of paying for performance (P4P) } \\
\hline Settings & \multicolumn{4}{|l|}{ Rwanda, Zambia } \\
\hline & Impact summary & $\begin{array}{l}\text { Nr of stud- } \\
\text { ies }\end{array}$ & $\begin{array}{l}\text { Certainty } \\
\text { of the ev- } \\
\text { idence }\end{array}$ & Comments \\
\hline $\begin{array}{l}\text { Cleanli- } \\
\text { ness }\end{array}$ & $\begin{array}{l}\text { P4P may have a desirable effect: Impacts on satis- } \\
\text { faction scores for antenatal, child and adult curative } \\
\text { care are consistently positive and range from } 2.45 \% \\
\text { to } 11.90 \% \text {. }\end{array}$ & $\begin{array}{l}2 \text { (Lannes } \\
\text { 2015, Fried- } \\
\text { man 2016a) }\end{array}$ & Low $^{1}$ & $\begin{array}{l}\text { Sensitivity analysis: RCT estimate } \\
2.45 \% \text {; low certainty in evidence } \\
\text { (RoB criteria, one study only). }\end{array}$ \\
\hline $\begin{array}{l}\text { Contact } \\
\text { time }\end{array}$ & $\begin{array}{l}\text { P4P may have a desirable effect: Impacts on client } \\
\text { satisfaction with contact time range from } 2.1 \text { to } \\
7.8 \% \text {, though impacts are not consistently positive } \\
\text { within studies. }\end{array}$ & $\begin{array}{l}2 \text { (Lannes } \\
2015, \text { Fried- } \\
\text { man 2016a) }\end{array}$ & Low $^{1}$ & $\begin{array}{l}\text { Sensitivity analysis: RCT estimate } \\
7.8 \% \text {; low certainty in evidence } \\
\text { (RoB criteria, one study only). }\end{array}$ \\
\hline $\begin{array}{l}\text { Waiting } \\
\text { time }\end{array}$ & $\begin{array}{l}\text { P4P may have a desirable effect: Impacts on client } \\
\text { satisfaction with waiting times range from } 0.05 \% \\
\text { to } 6 \% \text {, though at times negative (e.g. for childcare } \\
\text { from }-0.07 \text { to }-2.6 \% \text { ) }\end{array}$ & $\begin{array}{l}2 \text { (Lannes } \\
2015, \text { Fried- } \\
\text { man 2016a) }\end{array}$ & Low $^{1}$ & $\begin{array}{l}\text { Sensitivity analysis: RCT estimate } \\
0.05 \% \text {; low certainty in evidence } \\
\text { (RoB criteria, one study only). }\end{array}$ \\
\hline $\begin{array}{l}\text { Patient } \\
\text { satisfac- } \\
\text { tion with } \\
\text { staff com- } \\
\text { munica- } \\
\text { tion (in- } \\
\text { dex) }\end{array}$ & $\begin{array}{l}\text { P4P may have little to no effect: Impacts on client } \\
\text { satisfaction with staff courteousness estimated at } \\
3.35 \%\end{array}$ & $\begin{array}{l}1 \text { (Fried- } \\
\text { man 2016a) }\end{array}$ & Low $^{2}$ & $\begin{array}{l}\text { Sensitivity analysis: RCT estimate } \\
2.35 \% \text {; low certainty in evidence } \\
\text { (RoB criteria, one study only). }\end{array}$ \\
\hline
\end{tabular}

Summary: Low certainty in evidence, overarchingly desirable effects.

${ }^{1}$ Serious concerns over RoB

2 Serious concerns over RoB, one study only

Table 66: Provider motivation, satisfaction, absenteeism and acceptability

\section{Outcome Provider motivation, satisfaction, absenteeism and acceptability}


(Continued)

Partic- Health care workers in PBF and comparator facilities

ipant

group

Compari- Comparator groups (matched financing or inputs)

son

\begin{tabular}{|c|c|c|c|c|}
\hline Interven- & Any type of paying for perfo & nance (P4P) & & \\
\hline \multirow[t]{2}{*}{ Settings } & \multicolumn{4}{|l|}{ Benin and Zambia } \\
\hline & Impact summary & Nr of studies & $\begin{array}{l}\text { Certainty } \\
\text { of the ev- } \\
\text { idence }\end{array}$ & Comments \\
\hline $\begin{array}{l}\text { Moti- } \\
\text { vation } \\
\text { (score) }\end{array}$ & $\begin{array}{l}\text { P4P may have little to no } \\
\text { effect, impacts range from } \\
-3.8 \% \text { to } 2.4 \%\end{array}$ & $\begin{array}{l}3 \text { (Lagarde 2015, } \\
\text { Shen 2017, Fried- } \\
\text { man 2016a) }\end{array}$ & Low $^{1}$ & $\begin{array}{l}\text { Sensitivity analysis: RCT estimates inconsistent } \\
\text { overall, ranging from }-3.8 \text { to. } 2.4 \% \text { depending on } \\
\text { item; low certainty evidence (indirectness, RoB, one } \\
\text { sudy) }\end{array}$ \\
\hline $\begin{array}{l}\text { Satis- } \\
\text { faction } \\
\text { (score) }\end{array}$ & $\begin{array}{l}\text { P4P may have little to no } \\
\text { effect, impacts ranging } \\
\text { from }-4.6 \text { to } 4.3 \% \text {. }\end{array}$ & $\begin{array}{l}3 \text { (Lagarde 2015, } \\
\text { Shen 2017, Fried- } \\
\text { man 2016a) }\end{array}$ & Low $^{1}$ & $\begin{array}{l}\text { Sensitivity analysis: RCT estimates inconsistent } \\
\text { overall, ranging from }-4.6 \% \text { to } 4.3 \% \text { depending on } \\
\text { item; low certainty evidence (indirectness, RoB, one } \\
\text { study) }\end{array}$ \\
\hline
\end{tabular}

Summary: Overall little to no effect, low certainty evidence.

${ }^{1}$ Concerns over RoB, indirectness and imprecision

Appendix 6. Risk of Bias Supporting Judgments

Table 1: Risk of Bias - studies with a control group 


\begin{tabular}{lll}
\hline Country Study ID $\quad$ Study design & $\begin{array}{l}\text { Random } \\
\text { sequence } \\
\text { generation } \\
\text { (low=ran- } \\
\text { dom, }\end{array}$ \\
& high=not \\
& random, \\
unclear if \\
not speci- \\
fied)
\end{tabular}

\section{Allocation}

Baseline outcome mea-

Baseline characteristics similar

Incomplete outconcealment surement similar

come data

\begin{tabular}{|c|c|c|c|c|c|c|c|}
\hline Argentina & Gertler 2014 & CBA & $\begin{array}{l}\text { High - as per } \\
\text { guidance. }\end{array}$ & $\begin{array}{l}\text { High - as per } \\
\text { guidance. }\end{array}$ & $\begin{array}{l}\text { Low - analyses methods } \\
\text { adjust for differences }\end{array}$ & $\begin{array}{l}\text { Low except high for neonatal mor- } \\
\text { tality (noted imbalance only for this } \\
\text { outcome). }\end{array}$ & $\begin{array}{l}\text { Low: paper men- } \\
\text { tions missing- } \\
\text { ness of } 3 \% \text {, simi- } \\
\text { lar across groups. } \\
\text { Complete case } \\
\text { analyses are con- } \\
\text { ducted which } \\
\text { may compromise } \\
\text { results but no re- } \\
\text { porting of miss- } \\
\text { ingness by out- } \\
\text { come. }\end{array}$ \\
\hline Burkina Faso & $\begin{array}{l}\text { Steenland } \\
2017\end{array}$ & CBA & $\begin{array}{l}\text { High - as per } \\
\text { guidance. }\end{array}$ & $\begin{array}{l}\text { High - as per } \\
\text { guidance. }\end{array}$ & $\begin{array}{l}\text { Low - analyses methods } \\
\text { adjust for differences }\end{array}$ & $\begin{array}{l}\text { High - Table } 1 \text { suggests differences } \\
\text { between comparison and interven- } \\
\text { tion exist - e.g. number of health fa- } \\
\text { cilities } / 100,000 \text { people consistently } \\
\text { higher in intervention than in com- } \\
\text { parator. }\end{array}$ & $\begin{array}{l}\text { Low - see Appen- } \\
\text { dix Table } 4 .\end{array}$ \\
\hline Burundi & Bonfrer 2014a & CBA & $\begin{array}{l}\text { High - as per } \\
\text { guidance. }\end{array}$ & $\begin{array}{l}\text { High - as per } \\
\text { guidance. }\end{array}$ & $\begin{array}{l}\text { Low - analyses methods } \\
\text { adjust for differences }\end{array}$ & $\begin{array}{l}\text { High - Appendix Table } 6 \text { suggests dif- } \\
\text { ferences exist between the different } \\
\text { districts, e.g. population characteris- } \\
\text { tics (poverty) varies between } 28.7 \% \\
\text { and } 82.3 \% \text {. }\end{array}$ & $\begin{array}{l}\text { Unclear: not } \\
\text { specified. }\end{array}$ \\
\hline Burundi & Bonfrer 2014b & CBA & $\begin{array}{l}\text { High - as per } \\
\text { guidance. }\end{array}$ & $\begin{array}{l}\text { High - as per } \\
\text { guidance. }\end{array}$ & $\begin{array}{l}\text { Low - analyses methods } \\
\text { adjust for differences }\end{array}$ & Low - comparable. & $\begin{array}{l}\text { Unclear: not } \\
\text { specified. }\end{array}$ \\
\hline Burundi & Falisse 2015 & CBA & $\begin{array}{l}\text { High - as per } \\
\text { guidance. }\end{array}$ & $\begin{array}{l}\text { High - as per } \\
\text { guidance. }\end{array}$ & $\begin{array}{l}\text { Low - analyses methods } \\
\text { adjust for differences }\end{array}$ & High - data not presented. & $\begin{array}{l}\text { Low - authors } \\
\text { note outcomes to } \\
\text { focus on chosen } \\
\text { based on com- }\end{array}$ \\
\hline
\end{tabular}




\begin{tabular}{|c|c|c|c|c|c|c|c|}
\hline \multicolumn{7}{|l|}{ (Continued) } & \multirow{2}{*}{$\begin{array}{l}\begin{array}{l}\text { pleteness and } \\
\text { sensitivity analy- } \\
\text { ses conducted. }\end{array} \\
\text { Low - authors } \\
\text { note outcomes to } \\
\text { focus on chosen } \\
\text { based on com- } \\
\text { pleteness. }\end{array}$} \\
\hline 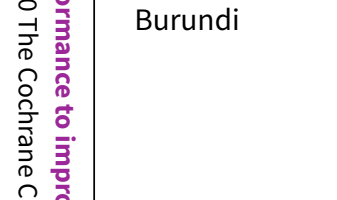 & $\begin{array}{l}\text { Rudasingwa } \\
2015\end{array}$ & CBA & $\begin{array}{l}\text { High - as per } \\
\text { guidance. }\end{array}$ & $\begin{array}{l}\text { High - as per } \\
\text { guidance. }\end{array}$ & $\begin{array}{l}\text { Low - analyses methods } \\
\text { adjust for differences }\end{array}$ & High - data not presented. & \\
\hline Cambodia & $\begin{array}{l}\text { Van de Poel } \\
2015\end{array}$ & CBA & $\begin{array}{l}\text { High - as per } \\
\text { guidance. }\end{array}$ & $\begin{array}{l}\text { High - as per } \\
\text { guidance. }\end{array}$ & $\begin{array}{l}\text { Low - analyses methods } \\
\text { adjust for differences }\end{array}$ & Low - comparable. & $\begin{array}{l}\text { Unclear: not } \\
\text { specified. }\end{array}$ \\
\hline Cameroon & Zang 2015 & $\mathrm{CBA}$ & $\begin{array}{l}\text { High - as per } \\
\text { guidance. }\end{array}$ & $\begin{array}{l}\text { High - as per } \\
\text { guidance. }\end{array}$ & $\begin{array}{l}\text { Low - analyses methods } \\
\text { adjust for differences }\end{array}$ & Low - comparable. & $\begin{array}{l}\text { Unclear: not } \\
\text { specified. }\end{array}$ \\
\hline 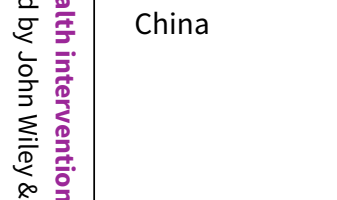 & Yao 2008 & CBA & $\begin{array}{l}\text { High - as per } \\
\text { guidance. }\end{array}$ & $\begin{array}{l}\text { High - as per } \\
\text { guidance. }\end{array}$ & $\begin{array}{l}\text { Paper re-analysed; re- } \\
\text { analysed results noted } \\
\text { as low (analyses meth- } \\
\text { ods adjust for differ- } \\
\text { ences) }\end{array}$ & $\begin{array}{l}\text { High - Table } 1 \text { suggests the interven- } \\
\text { tion is done in areas that are more } \\
\text { populated and poorer compared to } \\
\text { control. }\end{array}$ & $\begin{array}{l}\text { Unclear: not } \\
\text { specified. }\end{array}$ \\
\hline $\begin{array}{l}\text { Congo - Re- } \\
\text { public of }\end{array}$ & Zeng 2018 & $\mathrm{CBA}$ & $\begin{array}{l}\text { High - as per } \\
\text { guidance. }\end{array}$ & $\begin{array}{l}\text { High - as per } \\
\text { guidance. }\end{array}$ & $\begin{array}{l}\text { Low - analyses methods } \\
\text { adjust for differences }\end{array}$ & $\begin{array}{l}\text { High - Table } 3 \text { suggests significant } \\
\text { differences, e.g. in household size, } \\
\text { daily spending and age of mother }\end{array}$ & $\begin{array}{l}\text { Unclear: not } \\
\text { specified. }\end{array}$ \\
\hline $\begin{array}{l}\text { Democratic } \\
\text { Republic of } \\
\text { the Congo }\end{array}$ & Soeters 2011 & $\mathrm{CBA}$ & $\begin{array}{l}\text { High - as per } \\
\text { guidance. }\end{array}$ & $\begin{array}{l}\text { High - as per } \\
\text { guidance. }\end{array}$ & $\begin{array}{l}\text { Low - analyses methods } \\
\text { adjust for differences }\end{array}$ & High - not specified. & $\begin{array}{l}\text { Unclear: not } \\
\text { specified. }\end{array}$ \\
\hline El Salvador & Bernal 2018 & $\mathrm{CBA}$ & $\begin{array}{l}\text { High - as per } \\
\text { guidance. }\end{array}$ & $\begin{array}{l}\text { High - as per } \\
\text { guidance. }\end{array}$ & $\begin{array}{l}\text { Low - analyses methods } \\
\text { adjust for differences }\end{array}$ & $\begin{array}{l}\text { High - Table } 2 \text { and page } 9 \text { highlight } \\
\text { the differences between results } \\
\text { based aid provinces and those with } \\
\text { national funding. }\end{array}$ & $\begin{array}{l}\text { Unclear: not } \\
\text { specified. }\end{array}$ \\
\hline Haiti & Zeng 2013 & $\mathrm{CBA}$ & $\begin{array}{l}\text { High - as per } \\
\text { guidance. }\end{array}$ & $\begin{array}{l}\text { High - as per } \\
\text { guidance. }\end{array}$ & $\begin{array}{l}\text { Low - analyses methods } \\
\text { adjust for differences }\end{array}$ & High - data not presented. & $\begin{array}{l}\text { Unclear: not } \\
\text { specified. }\end{array}$ \\
\hline $\begin{array}{l}\text { Multiple - } \\
\text { Burkina Fa- } \\
\text { so, Ghana and } \\
\text { Tanzania }\end{array}$ & $\begin{array}{l}\text { Duysburgh } \\
2015\end{array}$ & CBA & $\begin{array}{l}\text { High - as per } \\
\text { guidance. }\end{array}$ & $\begin{array}{l}\text { High - as per } \\
\text { guidance. }\end{array}$ & $\begin{array}{l}\text { Paper re-analysed; re- } \\
\text { analysed results noted } \\
\text { as low (analyses meth- } \\
\text { ods adjust for differ- } \\
\text { ences) }\end{array}$ & $\begin{array}{l}\text { High - Appendix Table } \mathrm{S} 1 \text { suggests } \\
\text { differences between intervention } \\
\text { and control sites but unclear what } \\
\text { effect this would have on outcomes. }\end{array}$ & $\begin{array}{l}\text { Unclear: not } \\
\text { specified. }\end{array}$ \\
\hline
\end{tabular}




\begin{tabular}{|c|c|c|c|c|c|c|c|}
\hline 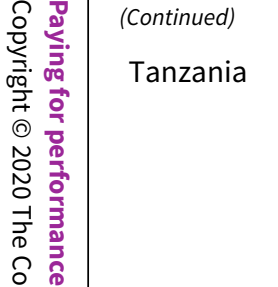 & $\begin{array}{l}\text { Binyaruka } \\
2015\end{array}$ & CBA & $\begin{array}{l}\text { High - as per } \\
\text { guidance. }\end{array}$ & $\begin{array}{l}\text { High - as per } \\
\text { guidance. }\end{array}$ & $\begin{array}{l}\text { Low - analyses methods } \\
\text { adjust for differences }\end{array}$ & $\begin{array}{l}\text { Low except for: ANC visits and IPT } \\
\text { during ANC, outpatient visits per } \\
\text { month under/over } 5 \text {, patient assess- } \\
\text { ments of staff kindness, probability } \\
\text { of payment for delivery care, satis- } \\
\text { faction with interpersonal care }\end{array}$ & $\begin{array}{l}\text { High: authors } \\
\text { note that this } \\
\text { may have biased } \\
\text { results. }\end{array}$ \\
\hline 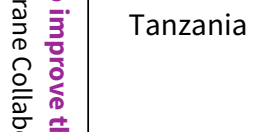 & $\begin{array}{l}\text { Binyaruka } \\
2017\end{array}$ & CBA & $\begin{array}{l}\text { High - as per } \\
\text { guidance. }\end{array}$ & $\begin{array}{l}\text { High - as per } \\
\text { guidance. }\end{array}$ & $\begin{array}{l}\text { Low - analyses methods } \\
\text { adjust for differences }\end{array}$ & $\begin{array}{l}\text { Low except for: availability and } \\
\text { stockouts of medicines and medical } \\
\text { supplies }\end{array}$ & $\begin{array}{l}\text { Unclear: not } \\
\text { specified. }\end{array}$ \\
\hline 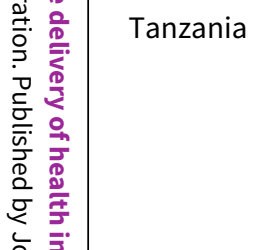 & $\begin{array}{l}\text { Binyaruka } \\
2018\end{array}$ & CBA & $\begin{array}{l}\text { High - as per } \\
\text { guidance. }\end{array}$ & $\begin{array}{l}\text { High - as per } \\
\text { guidance. }\end{array}$ & $\begin{array}{l}\text { Low - analyses methods } \\
\text { adjust for differences }\end{array}$ & $\begin{array}{l}\text { Low except for: ANC visits and IPT } \\
\text { during ANC, outpatient visits per } \\
\text { month under/over 5, patient assess- } \\
\text { ments of staff kindness, probability } \\
\text { of payment for delivery care, satis- } \\
\text { faction with interpersonal care }\end{array}$ & $\begin{array}{l}\text { High: authors } \\
\text { note that this } \\
\text { may have biased } \\
\text { results. }\end{array}$ \\
\hline 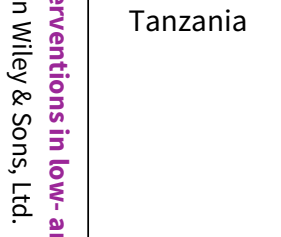 & $\begin{array}{l}\text { Mayumana } \\
2017\end{array}$ & CBA & $\begin{array}{l}\text { High - as per } \\
\text { guidance. }\end{array}$ & $\begin{array}{l}\text { High - as per } \\
\text { guidance. }\end{array}$ & $\begin{array}{l}\text { Low - analyses methods } \\
\text { adjust for differences }\end{array}$ & $\begin{array}{l}\text { Low except for: medical supply } \\
\text { stockouts, disruptions due to broken } \\
\text { equipment, governance outcomes } \\
\text { (committee meetings, content of su- } \\
\text { pervision, existence of community } \\
\text { health fund) }\end{array}$ & $\begin{array}{l}\text { High: authors } \\
\text { note that this } \\
\text { may have biased } \\
\text { results. }\end{array}$ \\
\hline 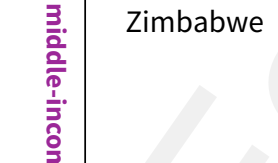 & Das, 2017 & CBA & $\begin{array}{l}\text { High - as per } \\
\text { guidance. }\end{array}$ & $\begin{array}{l}\text { High - as per } \\
\text { guidance. }\end{array}$ & $\begin{array}{l}\text { Low - analyses methods } \\
\text { adjust for differences }\end{array}$ & Low - comparable. & $\begin{array}{l}\text { High: sub-set } \\
\text { analyses with } \\
\text { particularly small } \\
\text { samples }\end{array}$ \\
\hline 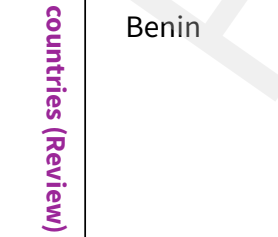 & Lagarde 2015 & $\begin{array}{l}\text { Quasi/non- } \\
\text { randomized } \\
\text { trial }\end{array}$ & $\begin{array}{l}\text { Unclear: not } \\
\text { specified. }\end{array}$ & $\begin{array}{l}\text { Unclear: not } \\
\text { specified. }\end{array}$ & $\begin{array}{l}\text { High - analyses methods } \\
\text { do not adjust for base- } \\
\text { line differences in out- } \\
\text { comes, but do adjust for } \\
\text { facility and health work- } \\
\text { er differences }\end{array}$ & $\begin{array}{l}\text { High - Appendix Table } 6 \text { suggests dif- } \\
\text { ferences exist between the different } \\
\text { districts, e.g. population characteris- } \\
\text { tics (poverty) varies between } 28.7 \% \\
\text { and } 82.3 \% \text {. }\end{array}$ & $\begin{array}{l}\text { Unclear: not } \\
\text { specified. }\end{array}$ \\
\hline Cameroon & $\begin{array}{l}\text { De Walque } \\
2017\end{array}$ & $\begin{array}{l}\text { Quasi/non- } \\
\text { randomized } \\
\text { trial }\end{array}$ & $\begin{array}{l}\text { Low - se- } \\
\text { quence de- } \\
\text { scribed in } \\
\text { enough de- } \\
\text { tail. }\end{array}$ & $\begin{array}{l}\text { Low - as- } \\
\text { signment by } \\
\text { province/dis- } \\
\text { trict/cluster. }\end{array}$ & $\begin{array}{l}\text { Low - analyses methods } \\
\text { adjust for differences }\end{array}$ & Low - comparable. & $\begin{array}{l}\text { Unclear: not } \\
\text { specified. }\end{array}$ \\
\hline
\end{tabular}




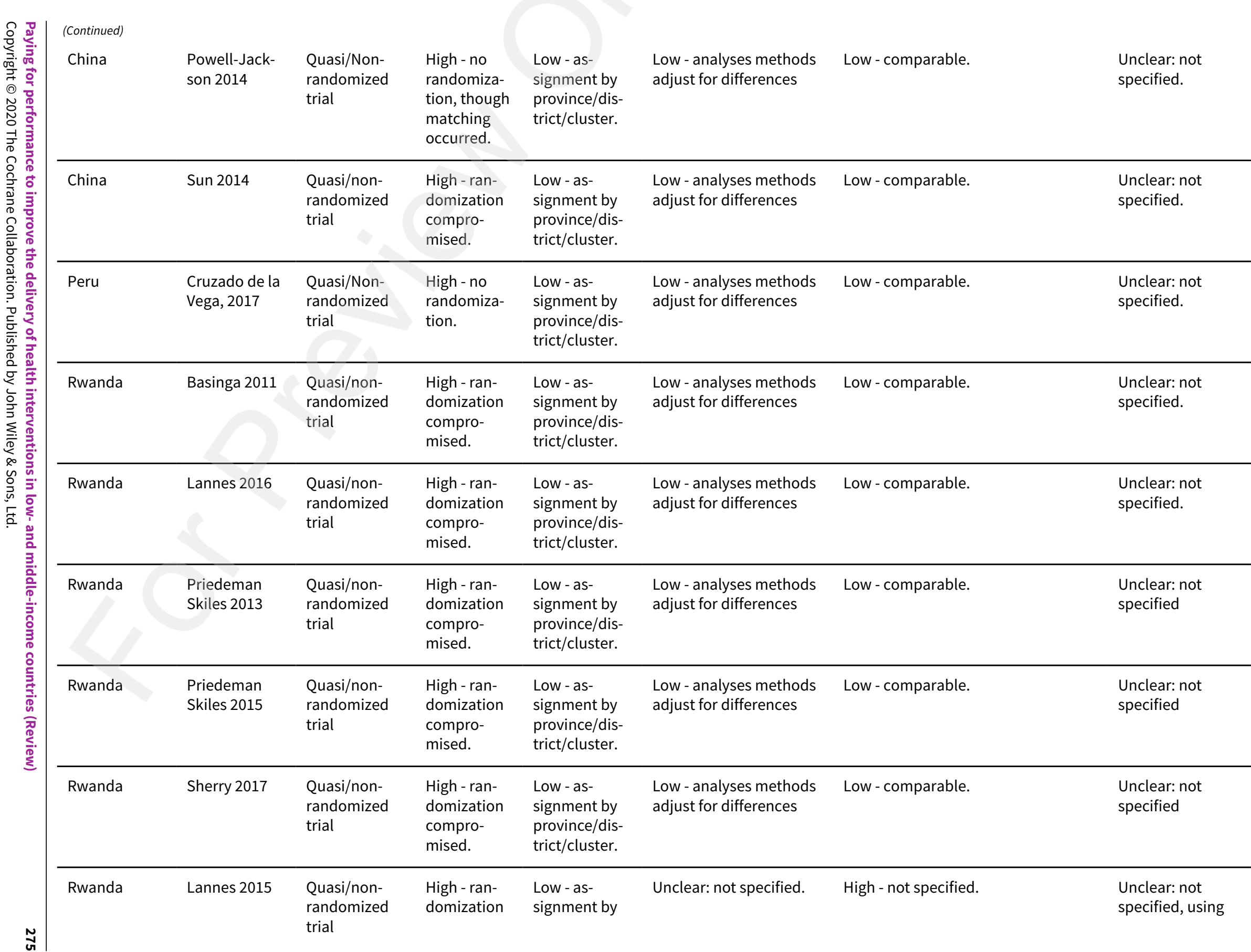




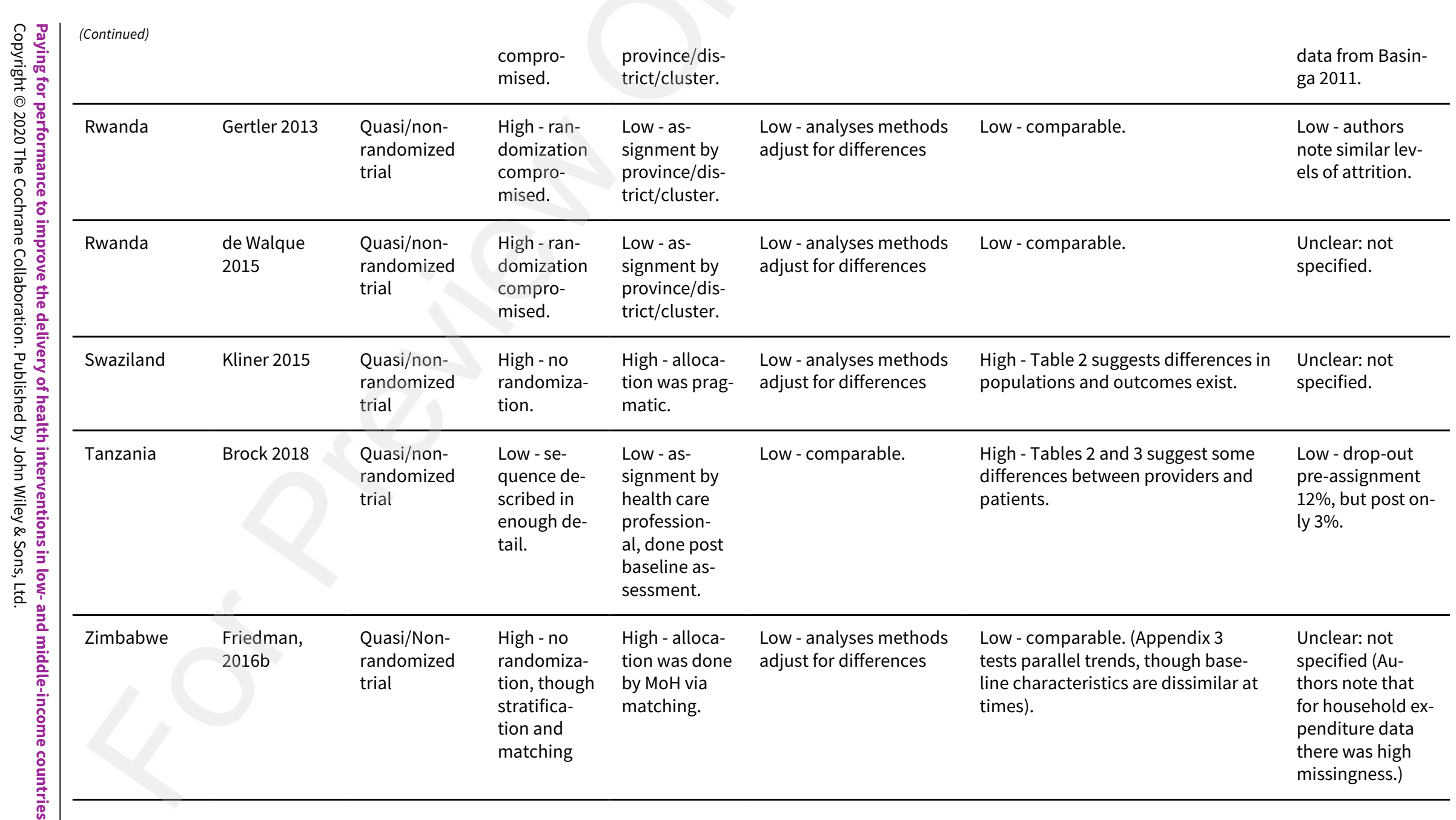


Table 2: Risk of Bias - interrupted time series studies 


\begin{tabular}{|c|c|c|c|c|c|c|c|c|c|}
\hline Country & Study ID & $\begin{array}{l}\text { Study de- } \\
\text { sign }\end{array}$ & $\begin{array}{l}\text { Intervention inde- } \\
\text { pendent of other } \\
\text { changes }\end{array}$ & $\begin{array}{l}\text { Shape of } \\
\text { the inter- } \\
\text { vention ef- } \\
\text { fect pre- } \\
\text { specified }\end{array}$ & $\begin{array}{l}\text { Intervention unlikely to } \\
\text { affect data collection }\end{array}$ & $\begin{array}{l}\text { Knowledge of } \\
\text { the allocated in- } \\
\text { terventions ade- } \\
\text { quately prevent- } \\
\text { ed during the } \\
\text { study }\end{array}$ & $\begin{array}{l}\text { Incom- } \\
\text { plete } \\
\text { out- } \\
\text { come } \\
\text { data } \\
\text { ade- } \\
\text { quate- } \\
\text { ly ad- } \\
\text { dressed }\end{array}$ & $\begin{array}{l}\text { Selective } \\
\text { outcome } \\
\text { reporting }\end{array}$ & $\begin{array}{l}\text { Other risks } \\
\text { of bias }\end{array}$ \\
\hline Brazil & $\begin{array}{l}\text { Viñuela } \\
2015\end{array}$ & ITS & $\begin{array}{l}\text { Unclear: other reforms } \\
\text { were happening in the } \\
\text { education and justice } \\
\text { sectors which could } \\
\text { contribute as well. }\end{array}$ & $\begin{array}{l}\text { Low - spec- } \\
\text { ified as per } \\
\text { guidance. }\end{array}$ & $\begin{array}{l}\text { Unclear: intervention may } \\
\text { have affected data collec- } \\
\text { tion. }\end{array}$ & $\begin{array}{l}\text { Low: unlikely al- } \\
\text { location affects } \\
\text { data collection. }\end{array}$ & $\begin{array}{l}\text { Un- } \\
\text { clear: } \\
\text { not } \\
\text { speci- } \\
\text { fied. }\end{array}$ & Low & $\begin{array}{l}\text { Note: data } \\
\text { is aggregat- } \\
\text { ed at high } \\
\text { level - this } \\
\text { may impact } \\
\text { analyses } \\
\text { and find- } \\
\text { ings. }\end{array}$ \\
\hline Cambodia & Ir 2015 & ITS & $\begin{array}{l}\text { High: multiple PBF } \\
\text { reforms introduced } \\
\text { alongside voucher } \\
\text { schemes, changes to } \\
\text { health service delivery } \\
\text { (more trained profes- } \\
\text { sionals) also occurred. }\end{array}$ & $\begin{array}{l}\text { High - as per } \\
\text { guidance, } \\
\text { effect shape } \\
\text { not speci- } \\
\text { fied. }\end{array}$ & $\begin{array}{l}\text { Unclear: intervention may } \\
\text { have affected data collect- } \\
\text { ed as same source was } \\
\text { used for payments and for } \\
\text { outcome assessment. }\end{array}$ & $\begin{array}{l}\text { Unclear: health } \\
\text { workers them- } \\
\text { selves appear to } \\
\text { be reporting. }\end{array}$ & $\begin{array}{l}\text { Un- } \\
\text { clear: } \\
\text { not } \\
\text { speci- } \\
\text { fied. }\end{array}$ & Low & Low \\
\hline Cambodia & Khim 2018 & ITS & Unclear: not specified. & $\begin{array}{l}\text { Low - spec- } \\
\text { ified as per } \\
\text { guidance. }\end{array}$ & $\begin{array}{l}\text { Unclear: intervention may } \\
\text { have affected data collec- } \\
\text { tion. }\end{array}$ & $\begin{array}{l}\text { Low: unlikely al- } \\
\text { location affects } \\
\text { data collection. }\end{array}$ & $\begin{array}{l}\text { Un- } \\
\text { clear: } \\
\text { not } \\
\text { speci- } \\
\text { fied. }\end{array}$ & Low & $\begin{array}{l}\text { Note: sev- } \\
\text { eral other } \\
\text { schemes } \\
\text { were imple- } \\
\text { mented at } \\
\text { the same } \\
\text { time and } \\
\text { high vari- } \\
\text { ability in im- } \\
\text { plementa- } \\
\text { tion of this } \\
\text { scheme not- } \\
\text { ed. }\end{array}$ \\
\hline Cambodia & $\begin{array}{l}\text { Matsuoka } \\
2014\end{array}$ & ITS & Unclear: not specified. & $\begin{array}{l}\text { Low - spec- } \\
\text { ified as per } \\
\text { guidance. }\end{array}$ & $\begin{array}{l}\text { Unclear: intervention may } \\
\text { have affected data collec- } \\
\text { tion. }\end{array}$ & $\begin{array}{l}\text { Unclear: not } \\
\text { specified. }\end{array}$ & $\begin{array}{l}\text { Un- } \\
\text { clear: } \\
\text { not }\end{array}$ & Low & $\begin{array}{l}\text { Note: data } \\
\text { re-analysed. }\end{array}$ \\
\hline
\end{tabular}




\begin{tabular}{|c|c|c|c|c|c|c|c|c|c|}
\hline 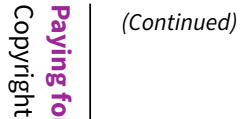 & & & & & & & $\begin{array}{l}\text { speci- } \\
\text { fied. }\end{array}$ & & \\
\hline 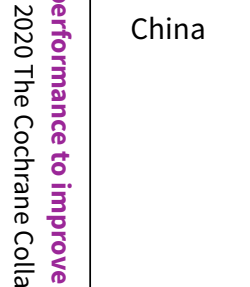 & $\begin{array}{l}\text { Chang } \\
2017\end{array}$ & ITS & $\begin{array}{l}\text { High: other interven- } \\
\text { tions concurrent (in- } \\
\text { cluding further PBF + } \\
\text { introduction of data- } \\
\text { base). }\end{array}$ & $\begin{array}{l}\text { Low - spec- } \\
\text { ified as per } \\
\text { guidance. }\end{array}$ & $\begin{array}{l}\text { High: intervention intro- } \\
\text { duced alongside an HMIS } \\
\text { intervention. }\end{array}$ & $\begin{array}{l}\text { Unclear: not } \\
\text { specified. }\end{array}$ & $\begin{array}{l}\text { Un- } \\
\text { clear: } \\
\text { not } \\
\text { speci- } \\
\text { fied. }\end{array}$ & Low & $\begin{array}{l}\text { Note: } \\
\text { three PBF } \\
\text { schemes } \\
\text { were imple- } \\
\text { mented, on- } \\
\text { ly one as- } \\
\text { sessed. }\end{array}$ \\
\hline 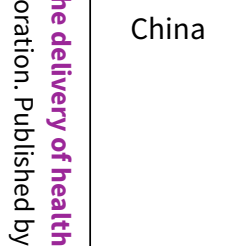 & Wu 2014 & ITS & $\begin{array}{l}\text { Unclear: other reforms } \\
\text { happening but robust- } \\
\text { ness checks performed } \\
\text { to ascertain impacts } \\
\text { and effects are consis- } \\
\text { tent. }\end{array}$ & $\begin{array}{l}\text { Low - spec- } \\
\text { ified as per } \\
\text { guidance. }\end{array}$ & $\begin{array}{l}\text { Low: no effects on data } \\
\text { collection. }\end{array}$ & $\begin{array}{l}\text { Low: unlikely al- } \\
\text { location affects } \\
\text { data collection. }\end{array}$ & $\begin{array}{l}\text { Un- } \\
\text { clear: } \\
\text { not } \\
\text { speci- } \\
\text { fied. }\end{array}$ & Low & $\begin{array}{l}\text { Note: not } \\
\text { generaliz- } \\
\text { able, study } \\
\text { conducted } \\
\text { in one set- } \\
\text { ting. }\end{array}$ \\
\hline 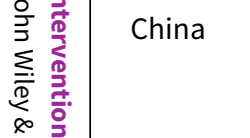 & $\begin{array}{l}\text { Liu and } \\
\text { Mills } 2005\end{array}$ & ITS & $\begin{array}{l}\text { High: other changes in } \\
\text { the country likely to af- } \\
\text { fect trends. }\end{array}$ & $\begin{array}{l}\text { Low - spec- } \\
\text { ified as per } \\
\text { guidance. }\end{array}$ & $\begin{array}{l}\text { Low: no effects on data } \\
\text { collection. }\end{array}$ & $\begin{array}{l}\text { Low: blinded and } \\
\text { random assess- } \\
\text { ments. }\end{array}$ & $\begin{array}{l}\text { Low: } \\
\text { panel } \\
\text { dataset. }\end{array}$ & Low & Low \\
\hline 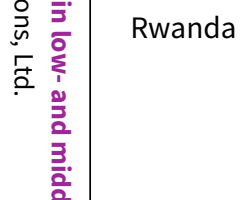 & Rusa 2009 & ITS & $\begin{array}{l}\text { High: other changes in } \\
\text { the country (user fee } \\
\text { removal) likely to af- } \\
\text { fect trends. }\end{array}$ & $\begin{array}{l}\text { Low - spec- } \\
\text { ified as per } \\
\text { guidance. }\end{array}$ & $\begin{array}{l}\text { Unclear: intervention may } \\
\text { have affected data collec- } \\
\text { tion. }\end{array}$ & $\begin{array}{l}\text { Unclear: not } \\
\text { specified. }\end{array}$ & $\begin{array}{l}\text { Un- } \\
\text { clear: } \\
\text { not } \\
\text { speci- } \\
\text { fied. }\end{array}$ & Low & Low \\
\hline $\begin{array}{l}\frac{1}{\bar{\Xi}} \\
\hat{0} \\
\overline{3} \\
0 \\
0\end{array}$ & $\begin{array}{l}\text { Chansa, } \\
2015\end{array}$ & ITS & Unclear: not specified. & $\begin{array}{l}\text { Low - spec- } \\
\text { ified as per } \\
\text { guidance. }\end{array}$ & $\begin{array}{l}\text { High: intervention intro- } \\
\text { duced alongside audits. }\end{array}$ & $\begin{array}{l}\text { Low: unlikely al- } \\
\text { location affects } \\
\text { data collection. }\end{array}$ & $\begin{array}{l}\text { Low: } \\
\text { HMIS } \\
\text { data. }\end{array}$ & Low & Low \\
\hline 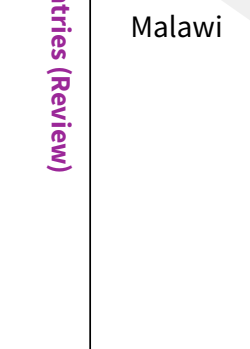 & $\begin{array}{l}\text { McMahon } \\
2016\end{array}$ & $\begin{array}{l}\text { CBA and } \\
\text { ITS }\end{array}$ & Unclear: not specified. & $\begin{array}{l}\text { Low - spec- } \\
\text { ified as per } \\
\text { guidance. }\end{array}$ & $\begin{array}{l}\text { High: intervention directly } \\
\text { targets improvements in } \\
\text { data. }\end{array}$ & $\begin{array}{l}\text { Unclear: not } \\
\text { specified. }\end{array}$ & $\begin{array}{l}\text { High: } \\
\text { several } \\
\text { indica- } \\
\text { tors ex- } \\
\text { cluded } \\
\text { due to } \\
\text { miss- } \\
\text { ing- } \\
\text { ness. }\end{array}$ & Low & Low \\
\hline
\end{tabular}




\section{Appendix 7. Full list of studies for which no full text could be obtained}

Being compiled

\section{FEE D B A C K}

Update on grey literature searches, June 2020

\section{Summary}

The grey literature searches are still going on and we can update these post review process.

\section{WHAT'S NEW}

\begin{tabular}{lll}
\hline Date & Event & Description \\
\hline 16 December 2020 & Feedback has been incorporated & Addressed reviewer comments. \\
\hline
\end{tabular}

$\begin{array}{ll}12 \text { March } 2020 & \text { New citation required and conclusions } \\ \text { have changed }\end{array}$

This update includes 62 new studies. Previous study inclusion criteria has changed and we have excluded from this update 9 studies previously included in the review; Changes to results and conclusions, summary of findings tables, GRADE. New review authors have contributed to this update.

12 March $2020 \quad$ New search has been performed

This is the first update of the Cochrane review published in 2012. We have conducted a new search and have updated other content.

\section{HISTORY}

Protocol first published: Issue 3, 2009

Review first published: Issue 2, 2012

\begin{tabular}{lll}
\hline Date & Event & Description \\
\hline 13 February 2012 & Amended & Minor edits \\
\hline
\end{tabular}

\section{CONTRIBUTIONS OF AUTHORS}

All authors reviewed and updated the protocol. Marit Johanson and JF developed the search strategy. KD, AV and JF selected the studies and undertook data extraction. KD led in the drafting of the review, with the support of SW and AF. All authors have reviewed and commented on the final draft.

\section{DECLARATIONS OF INTEREST}

No conflicts of interest apply.

\section{SOURCES OF SUPPORT}

\section{Internal sources}

- Norwegian Knowledge Centre for the Health Services, Norway

\section{External sources}

- Institute of Global Health and Development, Queen Margaret University, UK, UK

The Institute offered necessary infrastructure and staff time for undertaking the review. 


\section{DIFFERENCES BETWEEN PROTOCOLAND REVIEW}

The following represent deviations from the protocol (Witter 2009) and original review (Witter 2012):

- Search strategies have been altered to include further up to date terms referring to paying for performance (see Appendix 2); -Additional databases were added to the search strategy; however, no search of DARE or IPA was conducted;

- Given the volume of data retrieved, we restricted our analyses and synthesis to those indicators which were comparable (i.e. indicators similarly formulated, calculated and which could speak to similar underlying populations so as to minimize indirectness) and discussed across two or more studies;

-Sub-group analyses: given inconsistencies in reporting of characteristics intended to be used for sub-group analyses, we used scheme design as the primary criterion by which to conduct sub-group analyses.

- Given the volume of impact evaluations, the findings of health economic evaluations or qualitative studies conducted alongside impact evaluations have not been included. We will attempt to include these studies in further work exploring the mechanisms behind P4P impacts. 